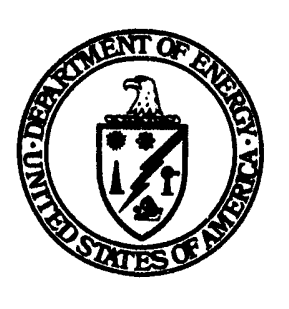

\title{
Mined Geologic Disposal System Requirements Document Revision 1
}

(B00000000-00811-1708-00002) 


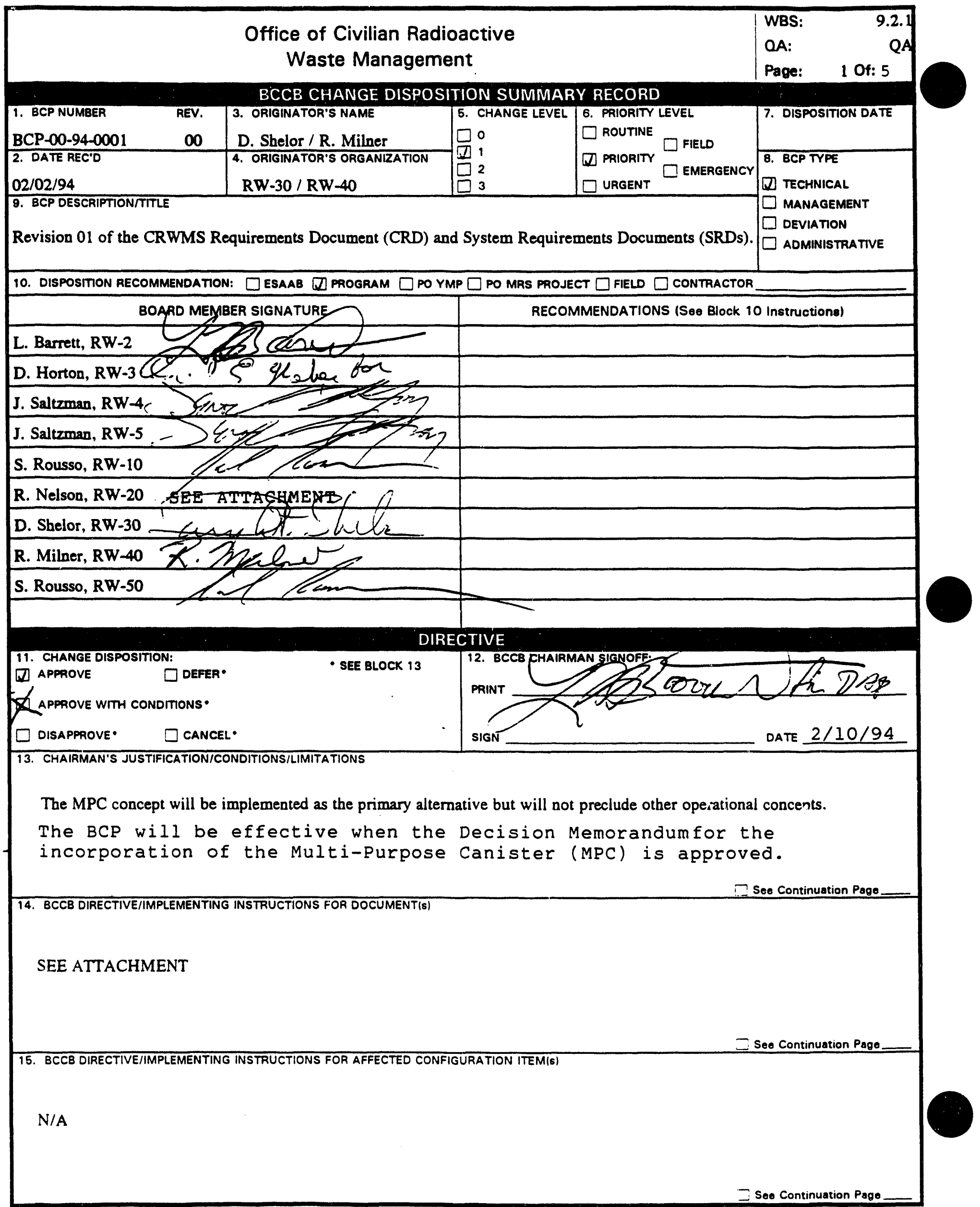




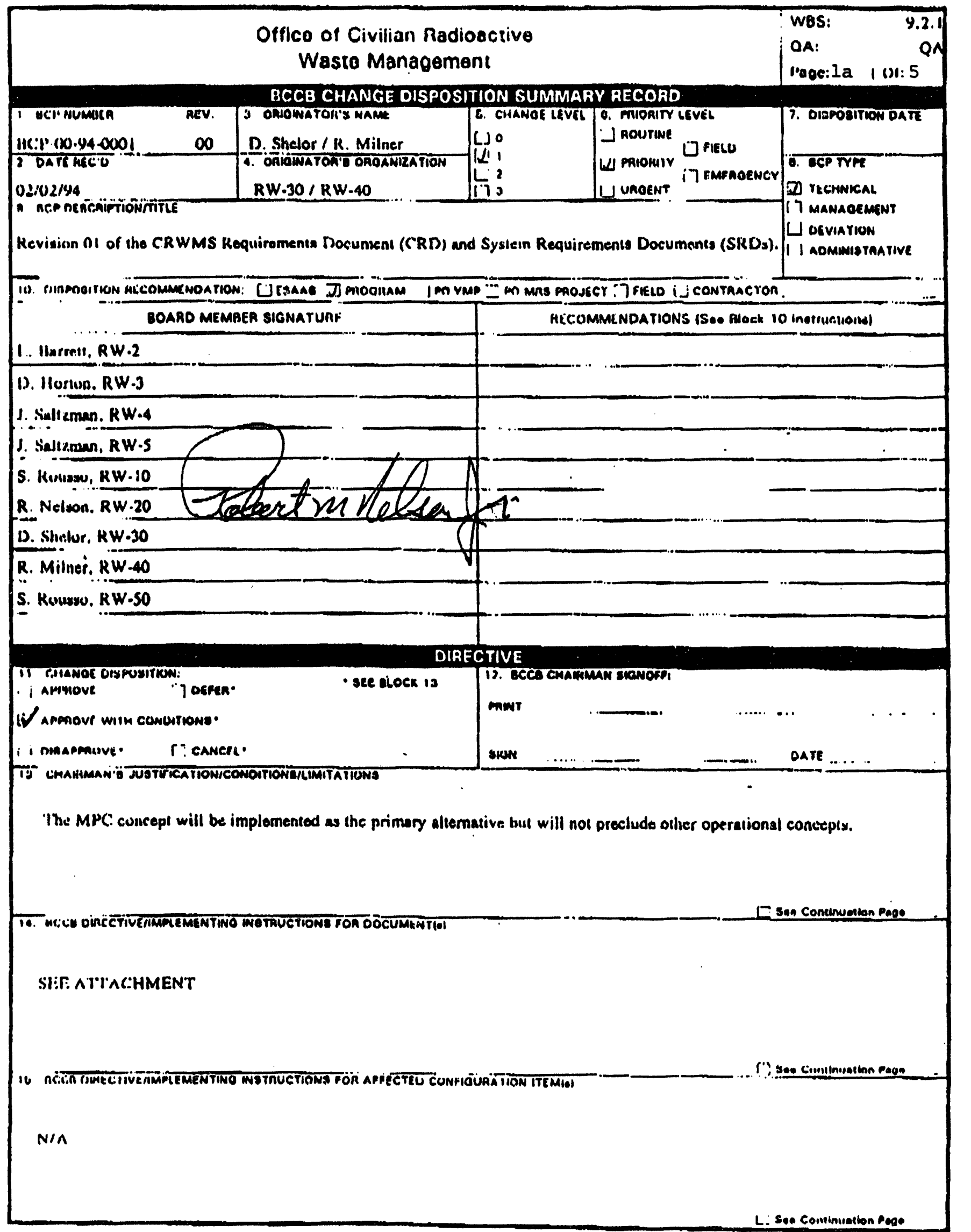


Directive (continued)

BCP-00-94-0001, Rev. 00

14. The following documents shall be transmitted by the PBCCB Executive secretary in accordance with applicable approved procedures for controlled distribution in a timely manner:

(1) A00000000-00811-1708-00003, Rev. 1, DOE/RW-0406P, Civilian Radioactive Waste Management System Requirements Document (CRD);

(2) E00000000-00811-1708-00001, Rev. 1, DOE/RW-0351P, Waste Acceptance System Requirements Document (WA-SRD);

(3) D00000000-00811-1708-00002, Rev. 1, DOE/RW-0425, Transportation System Requirements Document (TransSRD) :

(4) C00000000-00811-1708-00002, Rev. 1, DOE/RW-0420, Monitored Retrievable Storage System Requirements Document (MRS-SRD); and

(5) B00000000-00811-1708-00002, Rev. 1, DOE/RW-0404P, Mined Geologic Disposal System Requirements Document (MGDSRD) •

Documents contained in the following actions are affected by incorporation of the MPC system into the CRD and the SRDs (1 through 5 above). The scheduling of subsequent changes to the following documents shall be implemented either by including change(s) into the next planned document revision (per document), or changing the document(s) through the Document Change Notice (DCN) process. These changes shall be coordinated with current FY94 budget availability and document revision schedules. The decision as to which process is used (Revision vice $\mathrm{nCN}$ ) will depend on extent of change and timing as it pertains to effective change implementation. It shall be left to the discretion of the PBCCB Executive secretary in coordination with document authors and cognizant $A D / O D s$ as to which change process to employ.

All actions shall be assigned an action item identifier and shall be forwarded to each $A D / O D$ for implementation. A formal transmittal of action item assignments will be transmitted by the PBCCB secretary within 1C working days of approval of BCP-00-940001 .

Action Items shall be tracked through closure by the PBCCB Secretariat Administrator. 
Page 3 of 5

\section{Directive (continued) \\ BCP-00-94-0001, Rev. 00}

(A) RW-30 is responsible for the following actions:

(1) Review the Program Management system Manual, DOE/RW0043, Rev. 5 Program structure to determine necessary changes appropriate for the MPC. Incorporate identified changes into the next planned revision (Rev. 6) of the document. If changes are not extensive, a DCN shall be distributed to effect the change(s);

(2) Review DOE/RW-0051P, Rev. 2, OCRWM Systems Engineering Management Plan. The section titled "The Application of Systems Engineering to CRWMS Development" shall be revised to reflect development of the MPC - related systems. Also review the balance of the document for other changes resulting from the approval of BCP-0094-0001. Incorporate necessary changes into the next planned revision (Rev. 3) of the document. If changes are not extensive, a DCN shall be distributed to effect the change(s); and

(3) Update the CRWMS Interface Specification, A0000000000811-6300-00001, to incorporate descriptions of interfaces that will change because of incorporation of the MPC system into the CRWMS technical baseline. Incorporate changes into the next planned revision of the document. If changes are not extensive, a DCN shall be distributed to effect the change(s).

(4) Prepare record packages for this BCP and collect all documentation that supports the MPC decision including the Decision Memoranda and all significant conceptual studies and analyses to provide to $\mathrm{RW}-20$. 


\section{DIRECTIVE (continued) \\ BCP-00-94-0001. Rev. 00}

(B) RW-20 is responsible for the following actions:

(1) Review DOE/ RW-0223, Rev. 3, Program Cost and Schedule Baseline, for changes to scope with respect to establishment of the MPC - based technical baseline and its impact to the YMSC MSA. Provide necessary changes to $\mathrm{RW}-10$ for incorporation into the next planned revision (Rev. 4) of the document. If changes are not extensive, a DCN shall be distributed to effect the change(s). RW-20 shall contact the PBCCB Executive secretary when this action is completed.

(2) RW-20 shall re-evaluate its cost and schedule milestones at the Project level and incorporate changes as necessary resulting from changes to the Program cost and Schedule Baseline and approval of BCP-00-94-0001.

(3) Review DOE/RW-0313P, Yucca Mountain site Characterization Project Plan, for necessary changes to site characterization resulting from approval of this $\mathrm{BCP}$. Incorporate changes into the next planned revision of the document. If changes are not extensive, a $D C N$ shall be distributed to effect the change (s).

(4) Ensure compliance with 10CFR60.21c and submit supporting record package for inclusion in the YMPO local records center to support future LA activities.

(C) $\mathrm{RW}-40$ is responsible for the following actions:

(1) Review DOE/ RW-0223, Rev. 3, Program cost and Schedule Baseline, for changes to scope with respect to establishment of the MPC - based technical baseline and its impact to the MRS MSA. Provide necessary changes to $\mathrm{RW}-10$ for incorporation into the next planned revision of the document. If changes are not extensive, a DCN shall be distributed to effect the change (s). 
Page 5 of 5

\author{
DIRECTIVE (continued) \\ BCP-00-94-0001. Rev. 00
}

(2) Review C00000000-00811-4600-00004, MRS Project Plan dated 10/02/92. Change the cost, schedule and scope baselines for Key Decision (KD) \# 1 to reflect the MPC system. The MRS mission described in KD \# 0 may need to be re-defined. Incorporate required changes into the next planned revision of the document. If changes are not extensive, a DCN shall be distributed to effect the change(s).

(3) $\mathrm{RW}-40$ shall re-evaluate its cost and schedule milestones at the Project level and incorporate changes as necessary resulting from changes to the program cost and Schedule Baseline and approval of BCP-00-94-0001.

(D) RW-10 is responsible for the following action(s):

(1) Modify DOE/RW-0325P, Program WBS Dictionary to incorporate the MPC system.

(2) Coordinate with $\mathrm{RW}-20$ to complete actions prescribed in section (B) (1) and (B) (2) above.

(3) Coordinate with $\mathrm{RW}-40$ to complete actions prescribed in section (C) (1), (C) (2), and (C) (3) above.

\title{
Project Level MPC System Incorporation Actions
}

(E) RW-40 shall perform the following actions:

RW-40 shall review baseline documentation and ensure that documents reflect changes resulting from BCP-00-94-0001 approval. RW-40 shall ensure that project level technical baseline documentation reflects changes in the Program level CRD and SRDs.

(F) The Yucca Mountain Site Characterization Project office shall perform the following actions:

The YMP Project office shall review baseline documentation and ensure that documents reflect changes resulting from BCP-00-94-0001 approval. The YMP Project office shall ensure that Project level technical baseline documentation reflects changes in the Program level CRD and SRDs. 


\section{OFFICE OF CIVILIAN RADIOACTIVE WASTE MANAGEMENT \\ I ROGRAM CHANGE CONTROL BOARD REVISION/CHANGE RECORD}

(1) DOCUMENT NUMBER: DOE/RW-0404P/B00000000-0081:1-1708-00002

(2) DOCUMENT TITLE: Mined Geologic Disposal System Requirements Document

\begin{tabular}{|c|l|l|l|}
\hline $\begin{array}{c}\text { (3) } \\
\text { REVISION } \\
\text { DATE } \\
\text { NUMBER }\end{array}$ & $\begin{array}{c}\text { BCP } \\
\text { NUMBER }\end{array}$ & $(5)$ & (0) \\
\hline $\begin{array}{c}\text { Rev. } 1 \\
\text { March } 1994\end{array}$ & $\begin{array}{c}\text { BCP-00- } \\
94-0001\end{array}$ & $\begin{array}{l}\text { Incorporate the Multi-Purpose Canister (MCP) concept } \\
\text { into the CRWMS technical baseline. }\end{array}$ & Al1
\end{tabular}

(ด)

PAGES AFTECTED 
Title: Mined Geologic Disposal System Requirements Document

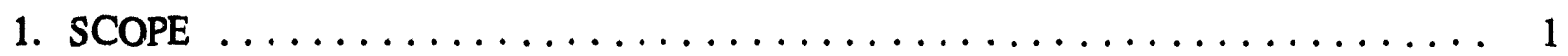

1.1 IDENTIFICATION $\ldots \ldots \ldots \ldots \ldots \ldots \ldots \ldots \ldots \ldots \ldots \ldots \ldots$

1.2 PURPOSE OF CRWMS REQUIREMENTS DOCUMENTS $\ldots \ldots \ldots \ldots, 1$

1.2.1 CRWMS Requirements Hierarchy $\ldots \ldots \ldots \ldots \ldots \ldots \ldots \ldots 1$

1.2.2 Purpose of MGDS-RD $\ldots \ldots \ldots \ldots \ldots \ldots \ldots \ldots \ldots, 3$

1.3 CRWMS/MGDS OVERVIEW $\ldots \ldots \ldots \ldots \ldots \ldots \ldots \ldots \ldots \ldots$

1.3.1 MGDS Mission $\ldots \ldots \ldots \ldots \ldots \ldots \ldots \ldots \ldots \ldots, \ldots \ldots$

1.3.2 MGDS Background $\ldots \ldots \ldots \ldots \ldots \ldots \ldots \ldots \ldots, 3$

1.3.3 MGDS Functions $\ldots \ldots \ldots \ldots \ldots \ldots \ldots \ldots \ldots \ldots, \ldots \ldots$

1.3.4 System Concept ..................... 4

1.3.5 MGDS Period of Performance $\ldots \ldots \ldots \ldots \ldots \ldots \ldots, 6$

1.4 DOCUMENT ORGANIZATION AND DESCRIPTION $\ldots \ldots \ldots \ldots \ldots 7$

1.4.1 Document Organization $\ldots \ldots \ldots \ldots \ldots \ldots \ldots \ldots \ldots$

1.4.2 Description ....................... 7

2. APPLICABLE DOCUMENTS $\ldots \ldots \ldots \ldots \ldots \ldots \ldots \ldots \ldots \ldots$

2.1 FEDERAL LAWS AND DOCUMENTS $\ldots \ldots \ldots \ldots \ldots \ldots \ldots$

2.1.1 Laws, Statutes, U.S. Codes, and Treaties ............ 9

2.1.2 Code of Federal Regulations and Executive Orders $\ldots \ldots \ldots \ldots 10$

2.1.3 Other Documents, Orders, and Directives ............ 11

2.2 STATE LAWS AND TRIBAL LAWS $\ldots \ldots \ldots \ldots \ldots \ldots \ldots \ldots \ldots$

2.3 LOCAL ORDINANCES $\ldots \ldots \ldots \ldots \ldots \ldots \ldots \ldots \ldots \ldots \ldots \ldots$

2.4 NON-GOVERNMENT DOCUMENTS $\ldots \ldots \ldots \ldots \ldots \ldots \ldots \ldots \ldots$

2.4.1 National and International Standards . . . . . . . . . . . 13

2.4.2 Other Publications . . . . . . . . . . . . . . . . 13

2.5 OTHER REFERENCES $\ldots \ldots \ldots \ldots \ldots \ldots \ldots \ldots \ldots \ldots \ldots \ldots$ 
Title: Mined Geologic Disposal System Requirements Document

TABLE OF CONTENTS (Continued)

Page

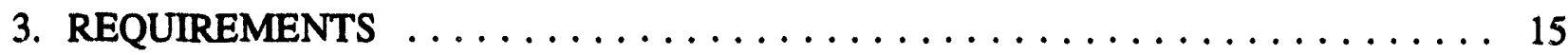

3.1 SYSTEM DEFINITION $\ldots \ldots \ldots \ldots \ldots \ldots \ldots \ldots \ldots \ldots \ldots \ldots$

3.1.1 MGDS Functions - Dispose of Waste - Function $1.4 \ldots \ldots \ldots 15$

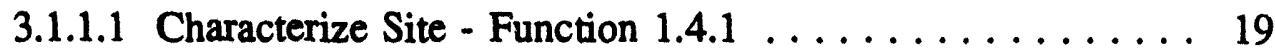

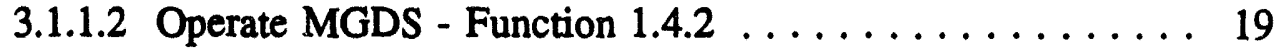

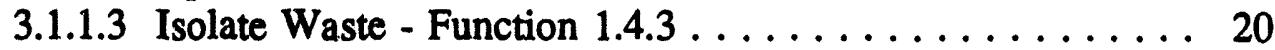

3.1.1.4 Evaluate System Performance - Function 1.4.4 . . . . . 20

3.1.1.5 Close MGDS - Function 1.4.5 . . . . . . . . . 20

3.1.2 MGDS Functional Relationships $\ldots \ldots \ldots \ldots \ldots \ldots \ldots \ldots 20$

3.1.3 MGDS Architecture Description ................ 21

3.1.4 Function to Architecture Cross-Reference . . . . . . . . . 26

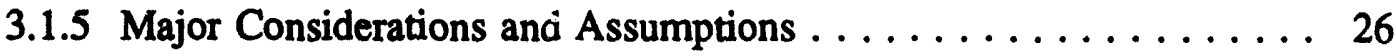

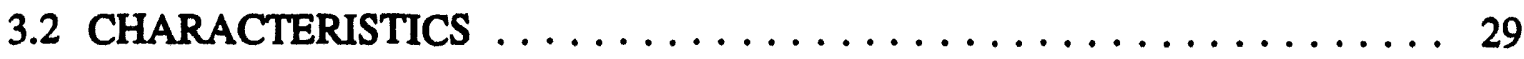

3.2.1 Performance Characteristics . . . . . . . . . . . . . . 29

3.2.1.1 Site Characterization Mode Requirements . . . . . . . . 31

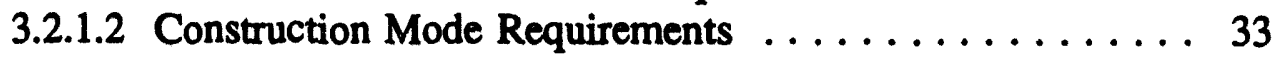

3.2.1.3 Emplacement Mode Requirements ............. 33

3.2.1.4 Caretaker Mode Requirements ............... 35

3.2.1.5 Retrieval Mode Requirements ............... 35

3.2.1.6 Closure and Decommissioning Mode Requirements ...... 35

3.2.1.7 Post-closure Mode Requirements .............. 36

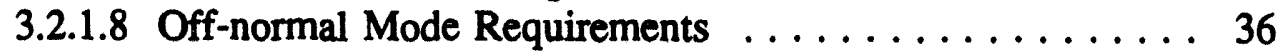

3.2.2 Radiological Protection $\ldots \ldots \ldots \ldots \ldots \ldots \ldots \ldots \ldots \ldots$

3.2.2. General Requirements . . . . . . . . . . . . 36

3.2.2.2 Reserved ...................... 37

3.2.2.3 Public Protection .................... 38

3.2.2.4 Airborne Radioactive Material Control . . . . . . . . . 38

3.2.2.5 Radiation Monitoring . . . . . . . . . . . . . 38 
3.2.2.6 Criticality Protection . . . . . . . . . . . . . . . 39

3.2.2.7 Low Level Waste Disposal . . . . . . . . . . . . . . . . 39

3.2.2.8 Transportation Protection ............... 40

3.2.3 Interface Requirements $\ldots \ldots \ldots \ldots \ldots \ldots \ldots \ldots \ldots \ldots 40$

3.2.3.1 MGDS Local Interfaces ................... 40

3.2.3.2 Interfaces with Other CRWMS Elements . . . . . . 40

3.2.4 Physical Characteristics $\ldots \ldots \ldots \ldots \ldots \ldots \ldots \ldots \ldots \ldots 47$

3.2.4.1 Protective Coatings and Materials $\ldots \ldots \ldots \ldots \ldots \ldots 48$

3.2.4.2 Habitability . . . . . . . . . . . . . . . 48

3.2.4.3 Security $\ldots \ldots \ldots \ldots \ldots \ldots \ldots \ldots \ldots \ldots . \ldots 49$

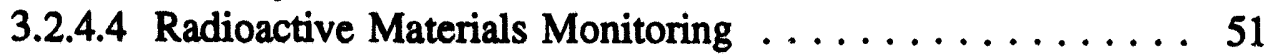

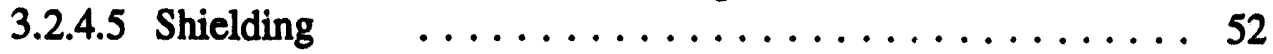

3.2.4.6 Design Basis Events ................. 52

3.2.5 System Quality Factors $\ldots \ldots \ldots \ldots \ldots \ldots \ldots \ldots \ldots$

3.2.5.1 Reliability ..................... 53

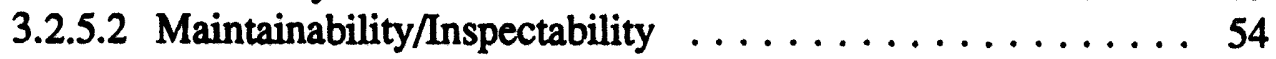

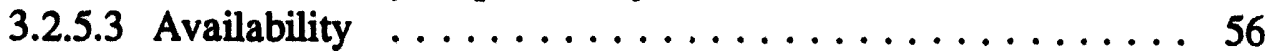

3.2.5.4 Service Life ................... 57

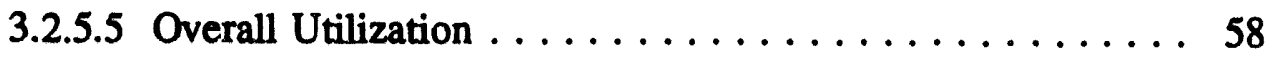

3.2.6 Environmental Requirements ................. 58

3.2.6.1 Natural Environment . . . . . . . . . . . . 58

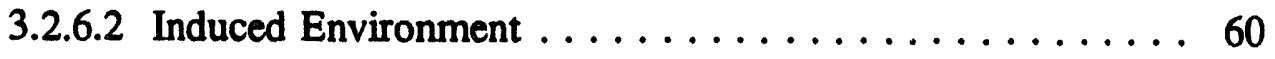

3.2.7 Transportability/Modularity .................. 61

3.2.8 Flexibility, Expansion, and Integration $\ldots \ldots \ldots \ldots \ldots \ldots 61$

3.2.9 Portability and Load Carrying $\ldots \ldots \ldots \ldots \ldots \ldots \ldots \ldots$

3.3 DESIGN AND CONSTRUCTION $\ldots \ldots \ldots \ldots \ldots \ldots \ldots \ldots \ldots \ldots$

3.3.1 General Design Criteria $\ldots \ldots \ldots \ldots \ldots \ldots \ldots \ldots \ldots 6$ 


\section{TABLE OF CONTENTS (Continued)}

3.3.2 Electromagnetic Radiation . . . . . . . . . . . . . . . . 63

3.3.3 Nameplates and Markings $\ldots \ldots \ldots \ldots \ldots \ldots \ldots \ldots 66 \ldots$

3.3.4 Workmanship ......................... 64

3.3.5 Interchangeability $\ldots \ldots \ldots \ldots \ldots \ldots \ldots \ldots \ldots \ldots 6, \ldots \ldots \ldots$

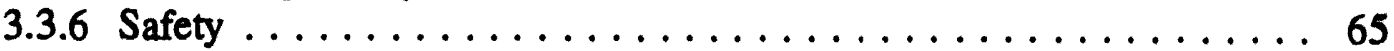

3.3.6.1 General Requirements . . . . . . . . . . . . . 65

3.3.6.2 System Safety Precedence $\ldots \ldots \ldots \ldots \ldots \ldots \ldots \ldots 65$

3.3.6.3 Facilities, Equipment, and Materials Protective Measures .. 66

3.3.6.4 Personnel Protective Equipment . . . . . . . . . . . 67

3.3.6.5 Subsurface Protective Measures . . . . . . . . . . . . 67

3.3.6.6 Safety Labels an ! Placards . . . . . . . . . . . . . . . . 68

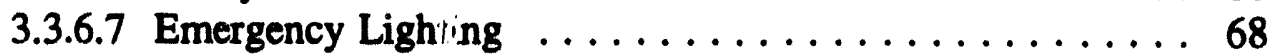

3.3.6.8 Equipment Related Hazards $\ldots \ldots \ldots \ldots \ldots \ldots \ldots 68$

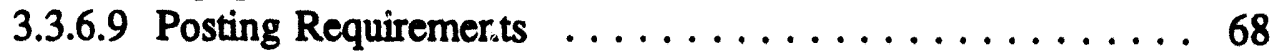

3.3.6.10 Work Platforms . . . . . . . . . . . . . . . 69

3.3.6.11 Electrical Safety $\ldots \ldots \ldots \ldots \ldots \ldots \ldots \ldots . \ldots 69$

3.3.7 Human Factors Engineering $\ldots \ldots \ldots \ldots \ldots \ldots \ldots \ldots$

3.3.7.1 Workstations and Control Rooms . . . . . . . . . 70

3.3.7.2 Voice Communications Equipment ........... 70

3.3.7.3 Alarms and Warning Systems . . . . . . . . . . . . . . 70

3.3.7.4 Controls . ....................... 70

3.3.7.5 Visual Displays ................... 70

3.3.7.6 Control Panel Layout . . . . . . . . . . . . . . . . . . . . 70

3.3.7.7 Control Display Integration . . . . . . . . . . 71

3.3.7.8 Labeling, Markings, and Signs ............. 71

3.3.7.9 Visual Display Terminal Workstation . . . . . . . 71

3.3.7.10 Anthropometry ................. 71

3.3.7.11 Remote Handling and Operation . . . . . . . . . . 71

3.3.7.12 Vehicles and Material Handling ............. 71

3.3.7.13 Accessibility and Useability by the Physically

Handicapped .................... 71

3.3.7.14 User-Computer Software Interface . . . . . . . . . 72

3.3.8 Methods and Controls ..................... 72

3.3.8.1 Material Management $\ldots \ldots \ldots \ldots \ldots \ldots \ldots \ldots \ldots 72$

3.3.8.2 Inventory Control $\ldots \ldots \ldots \ldots \ldots \ldots \ldots \ldots \ldots 72$ 
Title: Mined Geologic Disposal System Requirements Document

\section{TABLE OF CONTENTS (Continued)}

3.3.9 Government Furnished Property . . . . . . . . . . . 73

3.3.10 Computer Resources $\ldots \ldots \ldots \ldots \ldots \ldots \ldots \ldots \ldots \ldots . \ldots 73$

3.3.11 Environmental Protection Requirements $\ldots \ldots \ldots \ldots \ldots \ldots 73$

3.3.11.1 Reserved .................... 73

3.3.11.2 Air Pollution Control .................. 73

3.3.11.3 Water Pollution Control .................. 74

3.3.11.4 Drinking Water .................. 74

3.3.11.5 Toxic Substances Control . . . . . . . . . . 75

3.3.11.6 Pesticide Control .................... 75

3.3.11.7 Solid Waste Control . . . . . . . . . . . . . 75

3.3.11.8 Noise Control . .................... 75

3.3.11.9 Endangered Species ................ 75

3.4 DOCUMENTATION $\ldots \ldots \ldots \ldots \ldots \ldots \ldots \ldots \ldots \ldots \ldots \ldots$

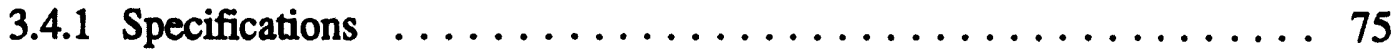

3.4.2 Drawings ........................ 76

3.4.3 Maintenance, Operators, and Technical Manuals ......... 76

3.4.4 Test Plans and Procedures ................... 76

3.4.5 Quality Assurance Documentation $\ldots \ldots \ldots \ldots \ldots \ldots \ldots 76$

3.4.6 Construction Records .................... 76

3.4.7 Computer Documentation ................... 77

3.4.8 Records Management ..................... 77

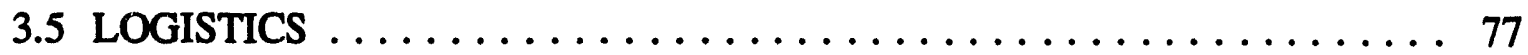

3.5.1 Maintenance $\ldots \ldots \ldots \ldots \ldots \ldots \ldots \ldots \ldots \ldots \ldots \ldots .77$

3.5.1.1 Equipment Maintenance $\ldots \ldots \ldots \ldots \ldots \ldots \ldots 77$

3.5.1.2 Calibration Maintenance ................ 78

3.5.1.3 Cask Maintenance . . . . . . . . . . . . . . . . 78

3.5.1.4 Standardization .................... 79

3.5.1.5 Security Equipment Maintenance ............. 79

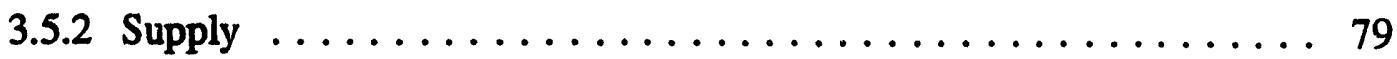

3.5.3 Facilities $\ldots \ldots \ldots \ldots \ldots \ldots \ldots \ldots \ldots \ldots \ldots \ldots . \ldots . \ldots$ 


\section{TABLE OF CONTENTS (Continued)}

3.5.3.1 Warehouse Requirements . . . . . . . . . . . . 79

3.5.3.2 Receiving and Shipping Facilities $\ldots \ldots \ldots \ldots \ldots \ldots 80$

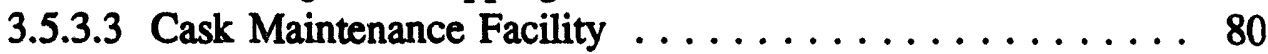

3.5.3.4 Licensing Support System Facility . . . . . . . . . . . . . 80

3.5.3.5 Other Facilities $\ldots \ldots \ldots \ldots \ldots \ldots \ldots \ldots \ldots$. . . . 80

3.5.4 Support \& Test Equipment $\ldots \ldots \ldots \ldots \ldots \ldots \ldots \ldots \ldots$

3.6 PERSONNEL AND TRAINING $\ldots \ldots \ldots \ldots \ldots \ldots \ldots \ldots \ldots \ldots$

3.6.1 Personnel $\ldots \ldots \ldots \ldots \ldots \ldots \ldots \ldots \ldots \ldots \ldots \ldots \ldots$

3.6.2 Training $\ldots \ldots \ldots \ldots \ldots \ldots \ldots \ldots \ldots \ldots \ldots \ldots, 81$

3.6.2.1 General Requirements . . . . . . . . . . . 81

3.6.2.2 Health Physics Training ............... 82

3.7 MGDS SEGMENT CHARACTERISTICS/REQUIREMENTS $\ldots \ldots \ldots .82$

3.7.1 MGDS Site Segment $\ldots \ldots \ldots \ldots \ldots \ldots \ldots \ldots \ldots \ldots$

3.7.1.1 Site Segment Description ............... 82

3.7.1.2 Site Segment Interface Requirements . . . . . . . . 82

3.7.1.3 Site Characterization Requirements ........... 83

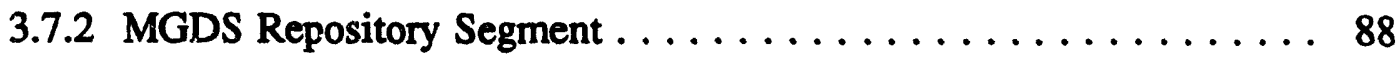

3.7.2.1 Repository Segment Description . . . . . . . . . 88

3.7.2.2 Geologic Setting Requirements . . . . . . . . . . . . 89

3.7.2.3 Repository Site Development Requirements ... . . . . . . 90

3.7.2.4 Repository Utilities and Services Requirements . . . . . . . . 91

3.7.2.5 Repository Surface Facility Requirements . . . . . . . . . . . . 94

3.7.2.6 Repository Underground Requirements ............ 99

3.7.2.7 Performance Confirmation Requirements . . . . . . . 102

3.7.2.8 Radiological Protection ... . . . . . . . . . . . . . . . 104

3.7.3 Engineered Barrier System Segment . . . . . . . . . . . 105

3.7.3.1 Engineered Barrier System Segment Description ... . . . . 105

3.7.3.2 Engineered Barrier System General Requirements . . . . . . 105

3.7.3.3 Waste Package Requirements . . . . . . . . . . . . . . . . 107 
Title: Mined Geologic Disposal System Requirements Document

TABLE OF CONTENTS (Continued)

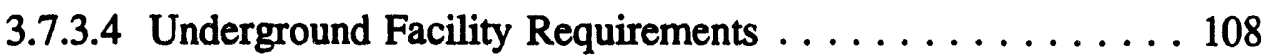

3.8 PRECEDENCE . . . . . . . . . . . . . . . . . . . . . . . . 109

3.9 QUALIFICATION/QUALITY ASSURANCE $\ldots \ldots \ldots \ldots \ldots \ldots$

4. CONFORMANCE VERIFICATION $\ldots \ldots \ldots \ldots \ldots \ldots \ldots \ldots \ldots \ldots \ldots \ldots \ldots \ldots$

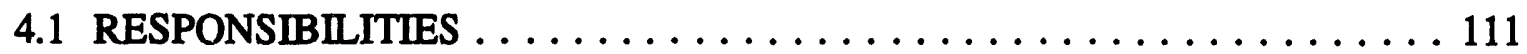

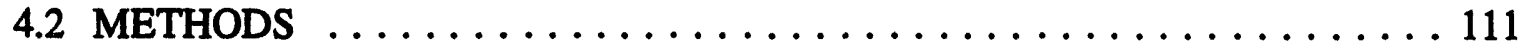

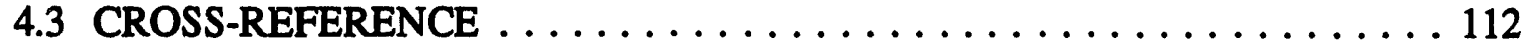

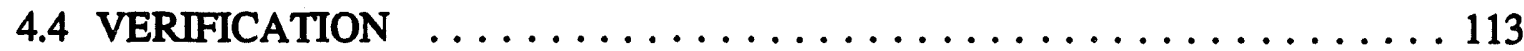

5. PREPARATION FOR OPERATIONS $\ldots \ldots \ldots \ldots \ldots \ldots \ldots \ldots \ldots \ldots \ldots \ldots \ldots$

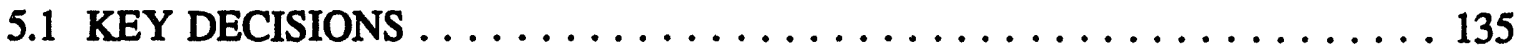

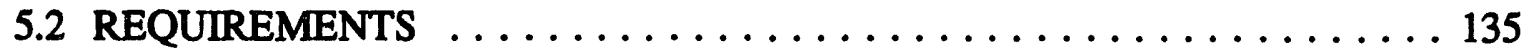

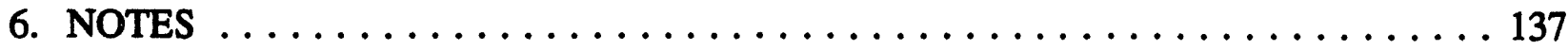

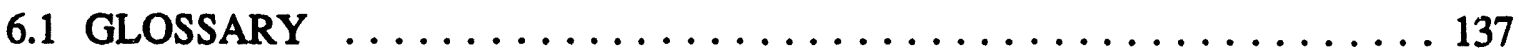

6.2 ACRONYMS AND ABBREVIATIONS $\ldots \ldots \ldots \ldots \ldots \ldots \ldots \ldots . \ldots \ldots$

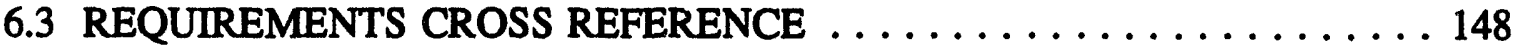

6.4 SOURCE DOCUMENT CROSS REFERENCE $\ldots \ldots \ldots \ldots \ldots \ldots \ldots 165$

6.5 CRD RROSS REFERENCE $\ldots \ldots \ldots \ldots \ldots \ldots \ldots \ldots \ldots \ldots \ldots$

Appendix A Site Characterization System Requirements $\ldots \ldots \ldots \ldots \ldots \ldots \ldots$ A-1

Appendix B Site Suitability Evaluation Criteria $\ldots \ldots \ldots \ldots \ldots \ldots \ldots \ldots$ B-1

Appendix C Mined Geologic Disposal System Requirements Function Descriptions ... C C-1 
Title: Mined Geologic Disposal System Requirements Document Revision: 1

Page: viii

\section{LIST OF FIGURES}

$\underline{\text { Page }}$

1-1. Program-Level System Requirements Documents $\ldots \ldots \ldots \ldots \ldots \ldots \ldots \ldots$

| 1-2. Civilian Radioactive Waste Management System Waste Flow ........... 5

3-1. Manage Waste Disposal Function Flow Diagram $\ldots \ldots \ldots \ldots \ldots \ldots \ldots$

3-2. Dispose of Waste (1.4) Function Flow Diagram $\ldots \ldots \ldots \ldots \ldots \ldots \ldots$

3-3. N-Square Chart for 1. Manage Waste Disposal $\ldots \ldots \ldots \ldots \ldots \ldots \ldots \ldots 22$

3-4. N-Square Chart for 1.4 Dispose of Waste $\ldots \ldots \ldots \ldots \ldots \ldots \ldots \ldots \ldots \ldots$

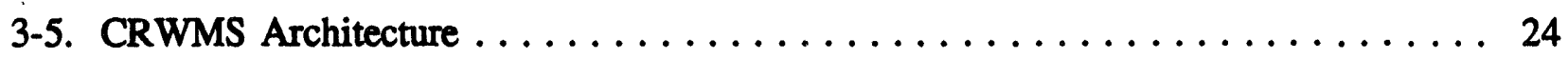

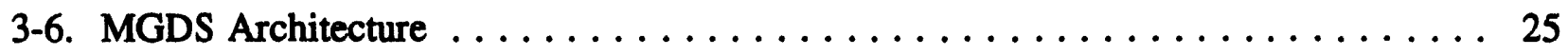

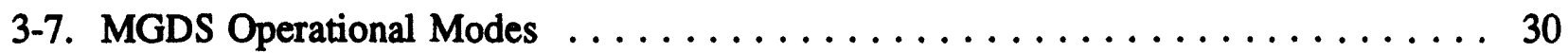


Title: Mined Geologic Disposal System Requirements Document

\section{LIST OF TABLES}

Page

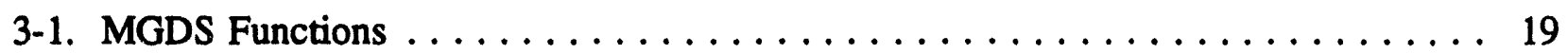

3-2. MGDS Functions Allocated to Segments $\ldots \ldots \ldots \ldots \ldots \ldots \ldots \ldots \ldots \ldots$

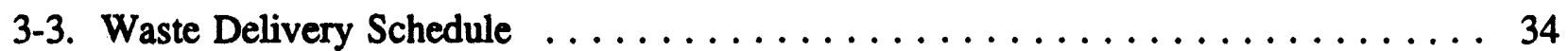

3-4. MGDS Queuing Space for Transportation Cask Subsystems $\ldots \ldots \ldots \ldots \ldots 43$

3-5. Types of Transportation Cask Subsystems $\ldots \ldots \ldots \ldots \ldots \ldots \ldots \ldots \ldots$

3-6. MGDS Segment-to-Transportation Segment Interfaces $\ldots \ldots \ldots \ldots \ldots \ldots \ldots$

3-7. Mandatory 10CFR60 Requirements for Site Characterization Facilities . . . . . . 84

3-8. 10CFR60 Site Characterization Facility Requirements To Be Considered ...... 85

3-9. Additional Site Characterization Facilities Requirements $\ldots \ldots \ldots \ldots 6$

3-10. Functions Assigned To Repository Segment $\ldots \ldots \ldots \ldots \ldots \ldots$

4-1. Conformance Verification Matrix $\ldots \ldots \ldots \ldots \ldots \ldots \ldots \ldots \ldots \ldots \ldots \ldots \ldots$

6-1. Requirements Cross-Reference . . . . . . . . . . . . . . . . . . . . . . 148

6-2. Source Document Cross-Reference . . . . . . . . . . . . . . . . 165

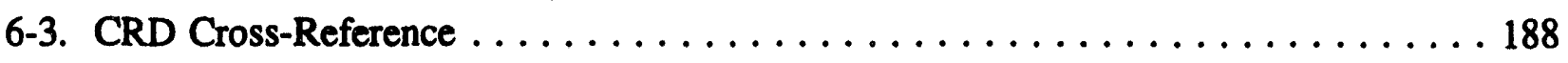


Title: Mined Geologic Disposal System Requirements Document Revision: 1

Page: $x$ 
Title: Mined Geologic Disposal System Requirements Document

Revision: 1

Page: 1

\section{SCOPE}

\subsection{IDENTIFICATION}

This Mined Geologic Disposal System Requirements Document (MGDS-RD) describes the functions to be performed by, and the requirements for, a Mined Geologic Disposal System (MGDS) for the permanent disposal of spent nuclear fuel (SNF) (including SNF loaded in multipurpose canisters (MPCs)) and commercial and defense high-level radioactive waste (HLW) in support of the Civilian Radioactive Waste Management System (CRWMS).

The development and control of the MGDS-RD is subject to the Department of Energy (DOE) Office of Civilian Radioactive Waste Management (OCRWM) Quality Assurance Requirements and Description Document (QARD) (DOE/RW-0333P). As part of the technical requirements baseline, it is also subject to Baseline Management Plan (DOE/RW-0381P) controls. The MGDS-RD has been revised in accordance with the CRWMS M\&O Technical Document Preparation Plan (TDPP) for the Revision of System Requirements Documents.

\subsection{PURPOSE OF CRWMS REQUIREMENTS DOCUMENTS}

A description of the place of this requirements document within the OCRWM document hierarchy and of the detailed purpose is provided in the following paragraphs.

\subsubsection{CRWMS Requirements Hierarchy}

The OCRWM Program Management System Manual (DOE/RW-0043) and Systems Engineering Management Plan (DOE/RW-0051P) establish the technical document hierarchy (hierarchy of technical requirements and configuration baseline documents) for the CRWMS program. Figure 1-1 illustrates the program-level requirements documents in this hierarchy. This set of documents establishes the system requirements to be addressed by the design of the system elements, including the MGDS.

Many of the technical requirements for the CRWMS are documented in a variety of Federal regulations, DOE directives and orders, and other Government documents. The CRWMS Requirements Document (CRD) (Reference 2.4.2.B) establishes the technical requirements for the entire program by summarizing the source documentation that must be addressed and by deriving requirements not covered in the regulations, but necessary to accomplish the CRWMS mission. The CRD also defines the CRWMS by identifying top-level functions for each element, defining the top-level system architecture of the CRWMS, and by allocating the functions and requirements to the architectural elements of the system, including the MGDS. In doing so, the CRD establishes the basis for the requirements to be addressed and expanded in this document and the requirements documents for the other elements. 
Title: Mined Geologic Disposal System Requirements Document

Page: 2

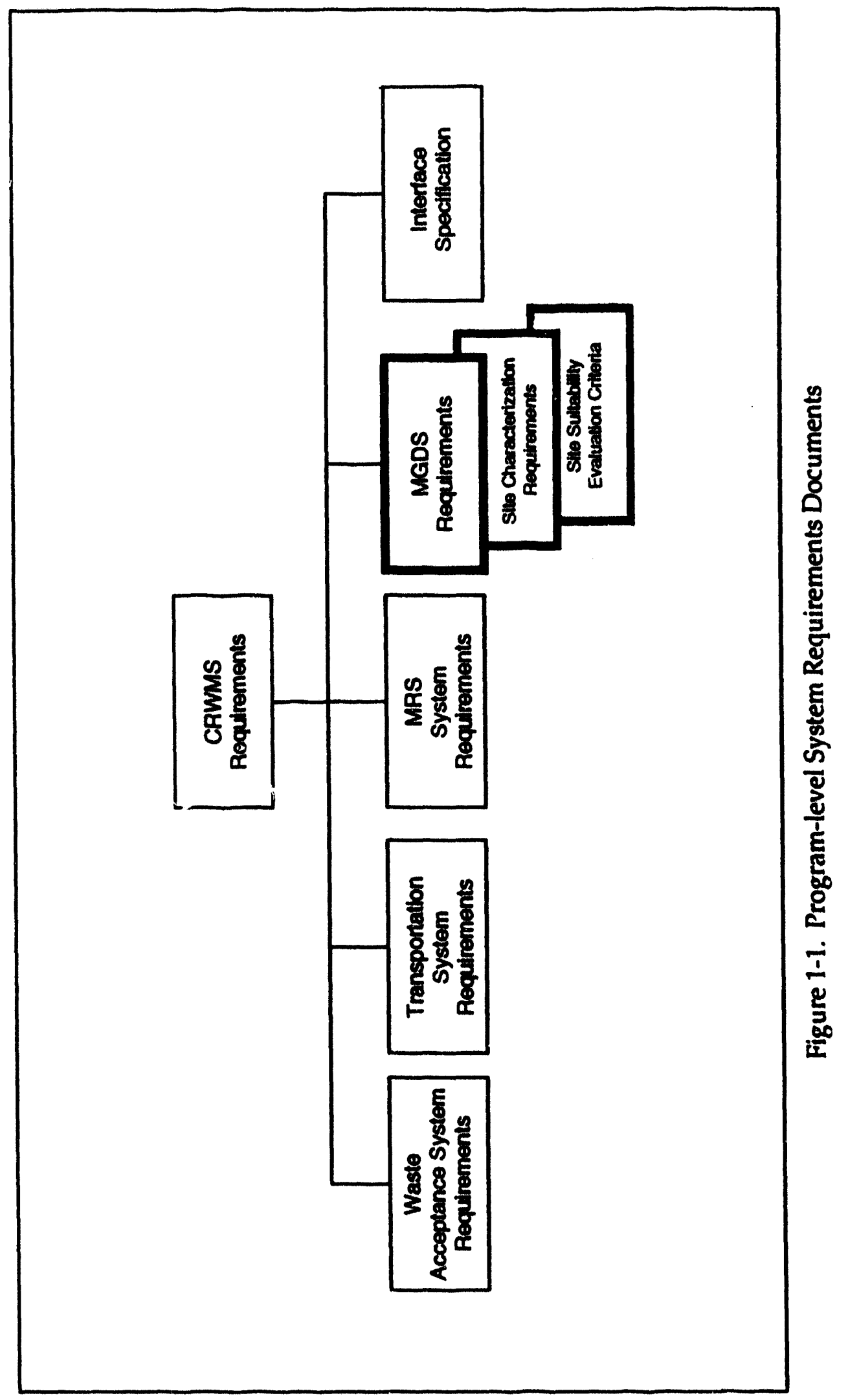


Title: Mined Geologic Disposal System Requirements Document

Revision: 1

Page: 3

\subsubsection{Purpose of MGDS-RD}

The purpose of the MGDS-RD is to define the program-level requirements for the design of the Repository, the Exploratory Studies Facility (ESF), and Surface Based Testing Facilities (SBTF) consistent with the CRD. These requirements include design, operation, and decommissioning requirements to the extent they impact on the physical development of the MGDS. The document also presents an overall description of the MGDS, its functions (derived using the functional analysis documented by the Physical System Requirements (PSR) documents as a starting point), its segments as described in Section 3.1.3, and the requirements allocated to the segments. In addition, the program-level interfaces of the MGDS are identified. As such, the MGDS-RD provides the technical baseline for the design of the MGDS.

Design of the MGDS must be consistent with the requirements of the MGDS-RD. While the MGDS may evolve and change through the design process, changes must occur in a controlled manner that ensures the CRWMS remains integrated. In doing this, the CRD and MGDS-RD will be revised to capture the changes.

\subsection{CRWMS/MGDS OVERVIEW}

The CRWMS is composed of four system elements. These elements, as identified in the CRD, are Waste Acceptance, Transportation, Monitored Retrievable Storage (MRS), and MGDS. Separate program-level requirements documents are written for each system element.

\subsubsection{MGDS Mission}

The mission of the MGDS is to emplace SNF and HLW in a Nuclear Regulatory Commission (NRC) licensed geologic repository, that has been determined to be suitable in accordance with the Nuclear Waste Policy Act of 1982 (NWPA) as amended, in a timely manner that protects the health and safety of the public and workers, and maintains the quality of the environment.

\subsubsection{MGDS Background}

In the Nuclear Waste Policy Amendments Act of 1987 (NWPAA), the Yucca Mountain site was designated by Congress as the single site for characterization as a geologic repository. The process and the schedule for this program were specified initially in the NWPA. The act further states that Yucca Mountain will be selected only if suitable and the President recommends it, and, if the state objects, Congress approves it.

This MGDS-RD has been written to support the design of a repository in support of the potential license application should DOE determine that Yucca Mountain, Nevada is a suitable repository site. Technical efforts are inherently and unavoidably site-specific. It is fully recognized that Yucca Mountain may be found to be unsuitable for a repository, or the CRWMS could be directed to another site. If that is the case, this document will become invalid and a new document will be written to support the revision of the design for whatever alternative site is specified for the repository by programmatic or policy decisions. 
Title: Mined Geologic Disposal System Requirements Document

This document contains appendices, including the Site Characterization System Requirements and the Site Suitability Evaluation Criteria, which document the requirements for site characterization and site suitability, respectively.

The NWPA defines SNF as the fuel that has been withdrawn from a nuclear reactor following irradiation, the constituent elements of which have not been separated by reprocessing. As used in this document, SNF is defined to include the nonfuel components and hardware as identified in 10CFR961. HLW is defined as: (1) the highly radioactive material resulting from the reprocessing of SNF, including liquid waste that contains fission products in sufficient concentrations, and (2) other highly radioactive material that has been determined by the NRC, consistent with the law, to require permanent isolation [NWPA Sec 2 (23) and (12)]. Note that the CRWMS will accept both SNF and solidified HLW which are referred to herein as waste. By a 1985 Presidential Memorandum, the DOE was instructed to proceed with plans and actions to dispose of defense waste in the MGDS.

\subsubsection{MGDS Functions}

The following list represents the top-level functions of the MGDS. These functions are further decomposed in Section 3.1 and are described in Appendix C.
A. Characterize Site
B. Operate MGDS
C. Isolate Waste
D. Evaluate System Performance
E. Close MGDS

\subsubsection{System Concept}

The CRWMS function, "Manage Waste Disposal", means to direct or control any physical activity, operation, or process conducted to accept, transport, store, or dispose of SNF or HLW. For planning, systems analysis, and conceptual design purposes, Manage Waste Disposal is divided into four subfunctions that the CRWMS must perform. These are Accept Waste, Transport Waste, Store Waste, and Dispose of Waste. The four corresponding physical system elements of the CRWMS that have been identified to implement these functions are Waste Acceptance, Transportation, MRS, and MGDS.

I Figure 1-2 is a pictorial description of the CRWMS waste flow. This document addresses the fourth element, the MGDS.

I The waste will be delivered to the MGDS by the CRWMS Transportation system element. SNF from the MRS facility will be loaded in multi-purpose canisters (MPCs) as described in Section 3.1.5.J of this MGDS-RD.

\footnotetext{
1 Includes waste retrieval
} 
Title: Mined Geologic Disposal System Requirements Document

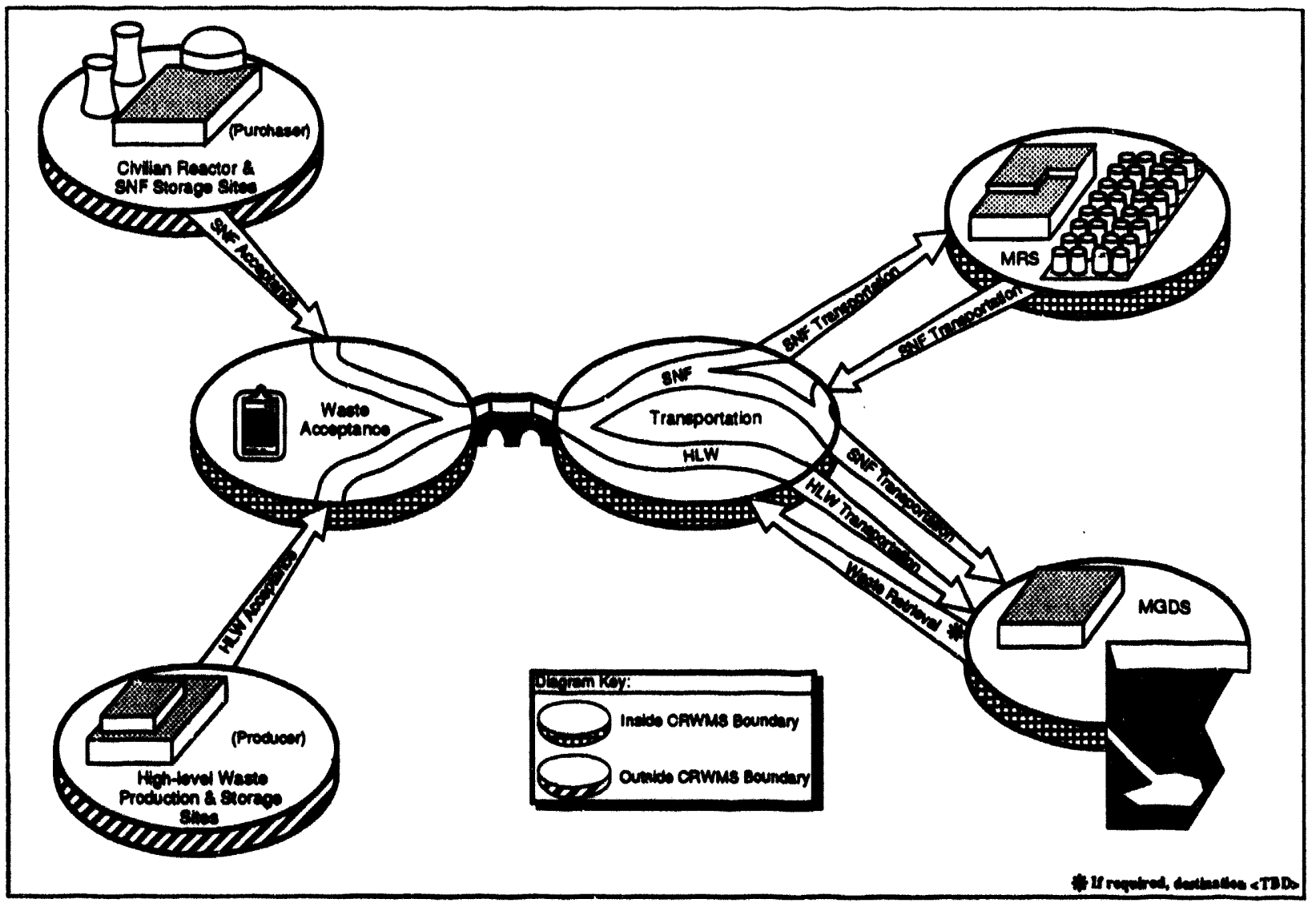

Figure 1-2. Civilian Radioactive Waste Management System Waste Flow

The MGDS will emplace waste in an isolated geologic medium with no fureseeable intent of recovery, although the option to retrieve emplaced wastes will be preserved until the NRC amends the repository license for permanent closure.

Prior to construction of the MGDS, the potential site at Yucca Mountain is being characterized to determine its suitability to host a repository and to obtain design and performance data. The data will be used to support repository and waste package design and to predict the performance of the geologic setting in isolating the waste from the accessible environment. The facilities supporting site characterization, the ESF and SBTF, are related to the MGDS. If the site is found to be suitable, parts of the ESF may be incorporated into the MGDS design. The ESF will include roads, utilities, and other non-geologic repository operations area (GROA) features that could be retained in the non-GROA part of the MGDS. Additionally, the ramps, hoists, and some drifts will likely be a part of the planned GROA. Site characterization activities including the ESF and SBTF construction and operation shall not compromise the ability of the MGDS to isolate waste.

The MGDS architecture, as defined in this document, consists of the Site Segment, the Repository Segment, and the Engineered Barrier System (EBS) Segment.

The Site Segment is defined as the facilities provided at the potential site to support site characterization. These include the ESF and SBTF. While not a physical system, the Test 
Title: Mined Geologic Disposal System Requirements Document

Revision: 1

Page: 6

Program is included in the Site Segment. The Site Segment is temporary, and will not exist when the repository begins operations.

The primary (but nut only) source of requirements for the MGDS, 10CFR60, defines the repository as the GROA and the portion of the geologic setting that provides isolation of radioactive wastes. The MGDS-RD, however, requires and specifies additional facilities not covered by 10CFR60 and allocates them to the Repository Segment. These additional facilities include non-waste-handling facilities provided to house support functions such as administration, maintenance, personnel support, visitor's center, security, safety, health physics, medical aid station, offices, and support for underground construction.

The EBS Segment is defined in Section 3.7.3 as the waste package and the underground facility.

The surface facilities will be clustered in two main sites, collocated with the portals to the ramps that provide access to the subsurface facilities. There will be auxiliary sites for special purposes such as storage of explosives. The facilities at the portal of one of the ramps is the location for receiving radioactive wastes in transportation casks by truck or rail. The waste will be removed from the transportation casks and placed into waste packages that will then be transported to the undergrourd emplacement location. Surface facilities will also house support and performance confirmation functions as well as provide a place at the other portal to store excavated rock. The underground repository will provide space for waste emplacement in vertical or horizontal boreholes or in the drifts, depending upon the technologies now under study. The underground facility will also house support systems, including ventilation systems, equipment to monitor for radioactivity, and mine rescue equipment.

The support functions performed at the MGDS include administrative, safety, security, logistics, and performance confirmation functions.

\subsubsection{MGDS Period of Performance}

This MGDS-RD addresses data- and design-related requirements that apply to all operational phases of the MGDS project - from site characterization through post-closure. Site characterization activities are essential to developing a site suitability determination and to the design and licensing process. The site characterization activities require construction of test facilities that are subsystems of the temporary Site Segment and that may, in part, be incorporated into the disposal system.

The time period for Site Segment operations began when surface-based testing began and will continue until the license to commence repository operations is issued.

Once a site has been found suitable and a license issued, the repository will be constructed. The time period for Repository Segment and EBS Segment performance begins with the initial delivery of waste to the MGDS and continues through at least 10,000 years following permanent closure of the MGDS facility. 
Title: Mined Geologic Disposal System Requirements Document

Revision: 1

Page: 7

\subsection{DOCUMENT ORGANIZATION AND DESCRIPTION}

\subsubsection{Document Organization}

This MGDS-RD is organized as follows:

A. Section 1: Scope. This section presents the system overview including the MGDS mission and system concept.

B. Section 2: Applicable Documents. This section identifies documents that are specifically related to various requirements ot the MGDS. The documents are listed to provide requirement traceability to the source documents and are not to be incorporated as requirements themselves.

C. Section 3: Requirements. Except for the preparation for operation requirements in section 5 and the requirements in Appendices A and B, this section contains all requirements of the MGDS at the program-level and begins with a system definition. Performance characteristics and design and construction criteria are presented. Specialty engineering and logistics requirements are addressed along with requirements for documentation, personnel, and training. Section 3 containing a breakout of requirements for each segment follows those requirements. Qualification requirements, including requirements for quality assurance (QA), are also provided.

D. Section 4: Conformance Verification. This section addresses conformance verification and includes a cross-reference matrix to define how each requirement of sections 3 and 5 is to be verified.

E. Section 5: Preparation for Operations. This section contains requirements for preparation of the system for acceptance and operations.

F. Section 6: Notes. This section contains material that is explanatory in nature. There are no binding requirements in this section.

G. Appendices: Data included in the appendices are binding with regard to MGDS requirements and may be changed only through the formal document change procedures. This document includes three appendices:

Appendix A Site Characterization System Requirements

Appendix B Site Suitability Evaluation Criteria

Appendix C MGDS Function Descriptions

\subsubsection{Description}

The central purpose of the MGDS-RD is to define the program-level requirements for the design of the repository, the ESF, and the SBTF. As indicated in the outline of section 1.4.1, section 3 of this document is the primary source of the requirements, although some appear in section 
5 and the appendices. The requirements and source documents allocated to the MGDS by the CRD are addressed in expanded form. Requirements are included that have been derived to meet the system mission. In some cases, to provide consistent requirements throughout CRWMS, the CRD has applied the relevant technical content of regulatory requirements for another element (the MRS, for example) to the MGDS. These derived requirements are based on the judgment of the document preparation team and are documented and justified in the CRD QA file on Issue Clarification and Derived Requirements Documentation Forms.

Section 3.1 establishes the description of the system in terms of functions and physical segments and the relationship between the two. Sections 3.2 to 3.6 address requirements important to the design of the MGDS in terms of interfaces, specialty engineering disciplines (e.g., system safety, integrated logistics support, human factors, reliability/availability/maintainability, safeguards and security), and construction standards. Section 3.7 contains requirements associated with the MGDS segments, with one subsection for each segment.

The statement of a requirement is followed by a reference to the original source document reference to which the requirement is traced, in square brackets (e.g., [10CFR60.112] or [CRD]). When no source document is identified, "[Derived]" will follow the requirement and the approved MGDS-RD is the authority for the requirement. The identification and determination of the requirement are documented on Issue Clarification and Derived Requirements Documentation Forms included in the QA records for the MGDS-RD.

The verb "shall" is used to specify mandatory requirements, while "will" is used to show intent or simple future tense.

A fundamental approach of the MGDS-RD is to reword the requirements as necessary into statements of clear engineering direction that are verifiable and do not depend upon the context in which they were originally presented. In other words, they are stated in such a manner that the success or failure of the design and development process in achieving the required capability can be measured and verified by some engineering technique (analysis, examination, test, or demonstration). At times this may involve interpretation of requirements. It may also involve establishing measures for performance. Inasmuch as the MGDS project is evolving, some of this can only be done on an iterative basis. Sites have to be approved, studies and analyses have to be completed, decisions must be made, and issues have to be resolved with the NRC. As a result, some requirements in early versions of requirements documents contain specifics that are still to be determined and are labeled "TBD." In other instances, engineering judgment may permit a tentative statement as to values to be used for initial design work. In these instances, the requirement is labeled "TBR" (to be resolved). These requirements are being coordinated with the MGDS design organization to provide agreement with the conceptual design. Recognizing the risk associated with developing a design based on uncertainties associated with these requirements, the document includes requirements to develop a design that can be modified to address potential changes.

Some requirements from regulations which specify procedural items have been restated to include or derive requirements on the physical system. The procedural (non-physical) aspect of these requirements is beyond the scope of this document. 
Title: Mined Geologic Disposal System Requirements Document

Revision: 1

Page: 9

\section{APPLICABLE DOCUMENTS}

This section, specifically Section 2.1 through 2.4, identifies documents which have been referenced as sources of requirements for the MGDS-RD. The documents are listed to provide traceability to the source documents and are not to be incorporated as requirements themselves.

For each document, the issue in effect on the date of the approval of the MGDS-RD, forms a part of the MGDS requirements to the degree specified herein. Each project-level DRD is to use revisions and issues of source documents in effect on the date of approval of that DRD.

Section 2.5 identifies reference materials that have not been used as sources of requirements, but are provided here for reference.

\subsection{FEDERAL LAWS AND DOCUMENTS}

In this category, the following are used as sources of requirements in the MGDS-RD.

\subsubsection{Laws, Statutes, U.S. Codes, and Treaties ${ }^{2}$}

Identifier

A. 7 USC136 et seq. $\quad$ Federal Insecticide, Fungicide, and Rodenticide Act of 1988

B. 15USC2601 et seq. Toxic Substances Control Act

C. 29USC651 et seq. Occupational Safety and Health Act

D. 33USC1251 et seq. Clean Water Act of 1977

E. 42USC300f ei seq. Safe Drinking Water Act

F. $\quad$ 42USC4901 et seq. Noise Control Act of 1972

G. 42USC7401 et seq. Clean Air Act

H. 42USC10101 et seq. Nuclear Waste Policy Act of 1982 (NWPA, Public Law 97 425) and Nuclear Waste Policy Amendments Act of 1987 (NWPAA, Public Law 100-203) 
Title: Mined Gèologic Disposal System Requirements Document

\subsubsection{Code of Federal Regulations and Executive Orders}

Identifier

A. $10 \mathrm{CFR} 2$

B. 10CFR20

C. 10CFR60

D. 10CFR71

E. 10CFR75

F. 10CFR960

G. 10CFR961

H. 27CFR55

I. 29CFR 1910

J. 29CFR 1926

K. 30CFR57

L. 33CFR323

M. $40 \mathrm{CFR} 50$

N. 40 CFR60

O. 40 CFR61

P. $40 \mathrm{CFR} 122$

Q. 40CFR 141

\section{Title or Description}

Rules of Practice For Domestic Licensing Proceedings and Issuance of Orders

Standards for Protection Against Radiation

Disposal of High-Level Radioactive Wastes in Geologic Repositories

Packaging and Transportation of Radioactive Material

Safeguards on Nuclear Material - Implementation of US/LAEA Agreement

General Guidelines for the Recommendation of Sites for Nuclear Waste Repositories

Standard Contract for Disposal of Spent Nuclear Fuel and/or HighLevel Radioactive Waste

Commerce in Explosives

Occupational Safety and Health Standards

Safety and Health Regulations for Construction

Safety and Health Standards - Underground Metal and Non-Metal Mines

Permits for Discharges of Dredged or Fill Material into Waters of the United States

National Primary and Secondary Ambient Air Quality Standards

Standards of Performance for New Stationary Sources

National Emission Standards for Hazardous Air Pollutants

EPA Administered Permit Programs: the National Pollutant Discharge Elimination System

National Primary Drinking Water Regulations 
Title: Mined Geologic Disposal System Requirements Document

R. 40CFR143 National Secondary Drinking Water Regulations

S. 40CFR165 Regulations for the Acceptance of Certain Pesticides and Recommended Procedures for the Disposal and Storage of Pesticides and Pesticide Containers

T. 40CFR191 Environmental Radiation Protection Standards for Management and Disposal of Spent Nuclear Fuel, High-Level and Transuranic Radioactive Wastes $<\mathrm{TBR}$ - pending new standards $>^{3}$

U. 40CFR204 Noise Emission Standards for Construction Equipment

V. 40CFR205 Transportation Equipment Noise Emission Control

W. 40CFR261 Identification and Listing of Hazardous Waste

X. 40CFR262 Standards Applicable to Generators of Hazardous Waste

Y. 40CFR270 EPA Administered Permit Programs: the Hazardous Waste Permit Program

Z. 41CFR101 Federal Property Management and Regulations

AA. 49CFR177 Carriage by Public Highway

BB. 50CFR 17 Endangered and Threatened Wildlife and Plants

CC. Exec Order Executive Order: Floodplain Management 11988

DD. Presidential Dispose of Defense Waste in a Commercial Repository Memorandum (April 30, 1985)

\subsubsection{Other Documents, Orders, and Directives}

Identifier

A. DOE Order 3790.1A $\mathrm{A}^{* 4} \begin{aligned} & \text { Federal Employees' Occupational Safety and Health } \\ & \text { Program }\end{aligned}$

B. DOE Order 4330.4A Real Property Maintenance Management

\section{Title or Description}

Real Property Maintenance Management

See Section 3.1.5.D of this document.

4 "The noted DOE Orders apply only to the extent they do not conflict with NRC direction. 
Title: Mined Geologic Disposal System Requirements Document

C. DOE Order 4700.1 Project Management System

D. DOE Order 5480.4" Environmental Protection, Safety, and Health Protection Standards

E. DOE Order 5480.7A* Fire Protection

F. DOE Order $6430.1 A^{*}$ General Design Criteria

G. DOE/RW-0194P

Records Management Policies and Requirements

H. DOE/RW-0199*5

Site Characterization Plan

I. DOE/RW-0316P

Draft Mission Plan Amendment

J. DOE/RW-0333P

OCRWM Quality Assurance Requirements and Description (QARD)

K. BLM Manual

Bureau of Land Management Manual, Section 9113 Road Standards

L. NUREG 0700

Guidelines for Control Room Design Reviews

M. DOE Letter, $2 / 27 / 90$

Appel, (OCRWM) to Linehan, (NRC), the enclosure to which is entitled "Applicability of 10CFR60 Requirements to the Exploratory Shaft Facility, U.S. DOE."

N. MOA RW/NS

Nuclear Safety Requirements, dated April 16, 1992

O. MOU, DOE/DOL

Memo of Understanding Between the U.S. Department of Energy and the U.S. Department of Labor, December 23, 1986

\subsection{STATE LAWS AND TRIBAL LAWS}

In this category, the following are used as sources of requirements in the CRD. None were used for this document. Documents will be included in this section, if and when applicable.

\subsection{LOCAL ORDINANCES}

In this category, the following are used as sources of requirements in the CRD. None were used for this document. Documents will be included in this section, if and when applicable.

Documents marked with an asterisk are "unqualified sources" as described in quality assurance procedures. 
Title: Mined Geologic Disposal System Requirements Document

\subsection{NON-GOVERNMENT DOCUMENTS}

In this category, the following are used as sources of requirements in the MGDS-RD.

\subsubsection{National and International Standards}

\section{$\underline{\text { Identifier }}$}

A. ANSI C2

B. ANSINFPA 70

\subsubsection{Other Publications}

Identifier
A. UCRL 15673
B. DOE/RW-0406P
C. $*$

\section{Title or Description}

National Electric Safety Code

National Electric Code

\section{Title or Description}

Human Factors Design Guidelines for Maintainability of Department of Energy Nuclear Facilities

CRWMS Requirements Document (CRD) (A0000000000811-1708-0003)

MPC-MGDS Thermal Requirements, December 10, 1993, R.H. Bahney, M\&O

\subsection{OTHER REFERENCES}

This section identifies documents that have not been used as sources of requirements, but are provided here for reference.

Identifier

A. DOE/RW-0334P

B. DOE/RW-DRAFT

C. DOE/RW-DRAFT

D. DOE/RW-0264

\section{Title or Description}

Physical Systems Requirements - Overall System, Rev. 0, January 1992

Physical Systems Requirements - Dispose of Waste (Draft, June 21, 1991)

Physical System Requirements - Exploratory Studies Facility (Draft, July 1991)

Waste Management System Requirements (WMSR) Document, Volume I, General System Requirements, Rev. 2, February 1992 
Title: Mined Geologic Disposal System Requirements Document

E. DOE/RW-0268P

Waste Management System Requirements (WMSR) Document, Volume IV, MGDS, Rev. 2, February 1992

F. DOE/RW-0270P

Waste Management System Description Document (WMSD) Rev. 1, February 1992

G. A00000000-01717- Concept of Operations for the MPC System, Rev. 0 6700-00001

H. A00000000-01717- Technical Document Preparation Plan for the Revision of 4600-00009 System Requirement Documents, Rev. 2

I. DOE/RW-0351P

Waste Acceptance System Requirements Document (WASRD), Rev. 1, (E00000000-00811-1708-00001)

J. DOE/RW-0420

Monitored Retrievable Storage System Requirements Document (MRS-SRD), Rev. 1, (C00000000-00811-170800002)

K. DOE/RW-0425

Transportation System Requirements Document (Trans SRD), Rev. 1, (D00000000-00811-1708-00002) 
Title: Mined Geologic Disposal System Requirements Document

\section{REQUIREMENTS}

This section, in 3.2 to 3.9, specifies the requirements which are mandatory for the siting, design, construction, and closure of the MGDS. Section 3.1 defines the system, while the balance of the sections state requirements. Those measures for performance which are specifically assigned to architectural segments that are designed to accomplish MGDS functions are allocated to those segments in section 3.7. The MGDS design requirements documents (DRDs), to be published separately at the project level, will specify design-related requirements for each segment as well as the interfaces particular to that segment.

\subsection{SYSTEM DEFINITION}

This section defines the MGDS by identifying and defining the functions the MGDS will perform, providing information on the interrelationships of the functions, defining the top-level architecture of the MGDS, and allocating the identified functions to the architecture. It also describes the major considerations and assumptions used in specifying the requirements contained in subsequent sections. This section additionally provides a summary of the assumptions and considerations that are fundamental to development of this document and, thus to the design of the CRWMS physical system.

\subsubsection{MGDS Functions - Dispose of Waste - Function 1.4}

The top-level function of the MGDS, Dispose of Waste, is shown in context with the other CRWMS functions in Figure 3-1. The Dispose of Waste function includes, as subfunctions, Characterize Site, Operate MGDS, Isolate Waste, Evaluate System Performance, and Close MGDS. These functions are depicted in the Functional Flow Block Diagram in Figure 3-2. There is no significance to the sequence of numbers assigned to the functions.

As shown in Figure 3-2, site characterization precedes the operation of the MGDS. Although it is not an operational function, it requires design and construction activities which are subject to the applicable requirements of this document (see section 3.7.1.3.B). Also, between the functions Characterize Site and Operate MGDS, a number of programmatic (or administrative) functions assigned to the DOE, NRC, the President, Congress, and possibly the courts are necessary. These are represented by the "ghost" function, Construct MGDS, and include, but are not limited to:

- DOE recommendation and Presidential approval of site selection

- MGDS design

- License application and approval

- MGDS construction (including the surface facilities and the initial portion of the underground emplacement areas)

- Key Decision 4 - Approval to commence operations

Procedure-related requirements for these programmatic functions are not within the scope of this document. (The MGDS-RD addresses the functions to be performed by the MGDS facilities and 


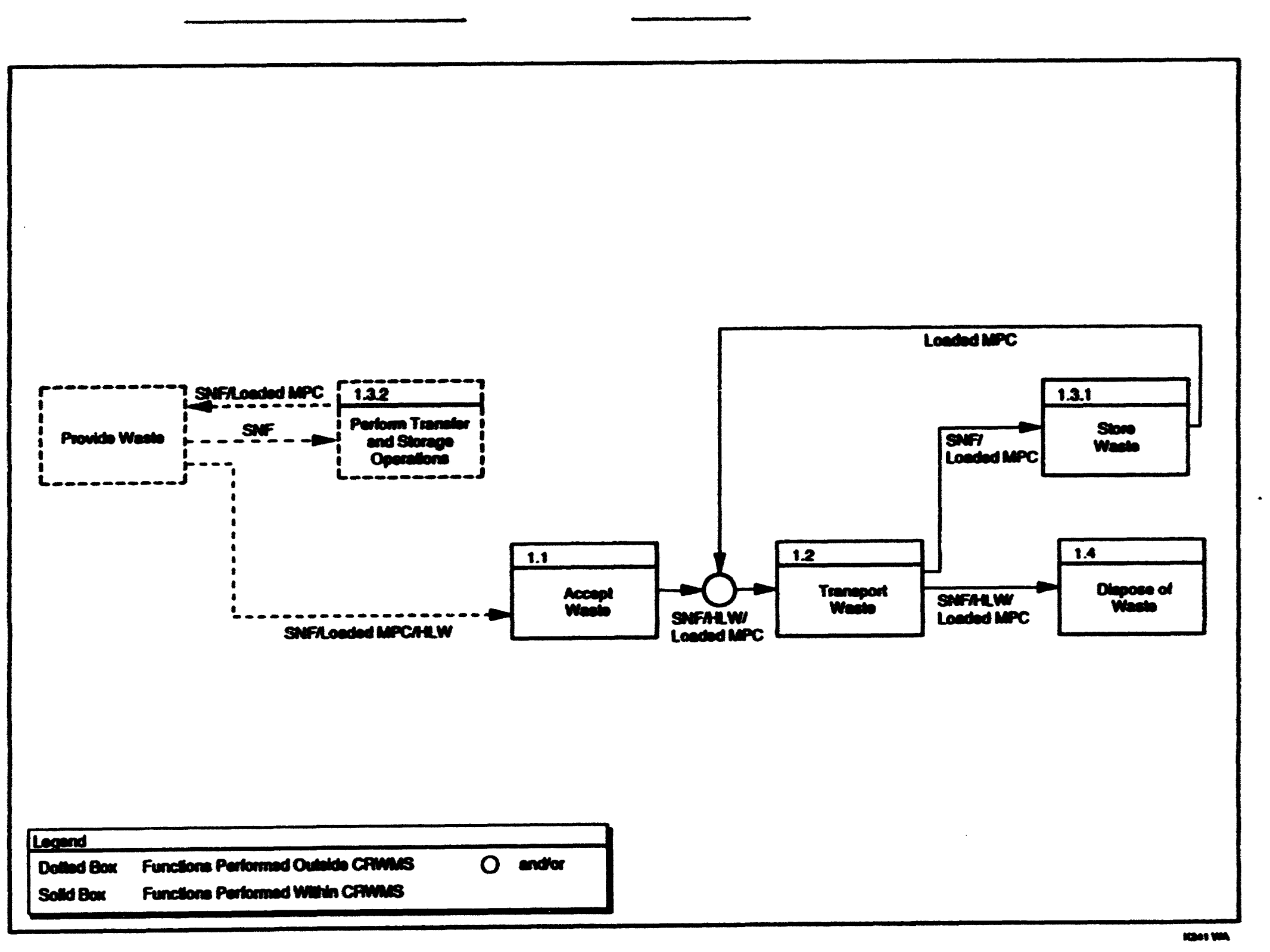

Figure 3-1. Manage Waste Disposal Function Flow Diagram 


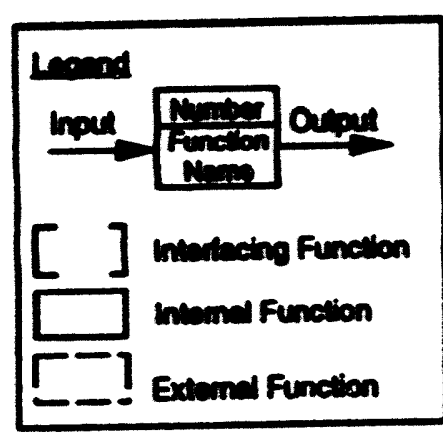

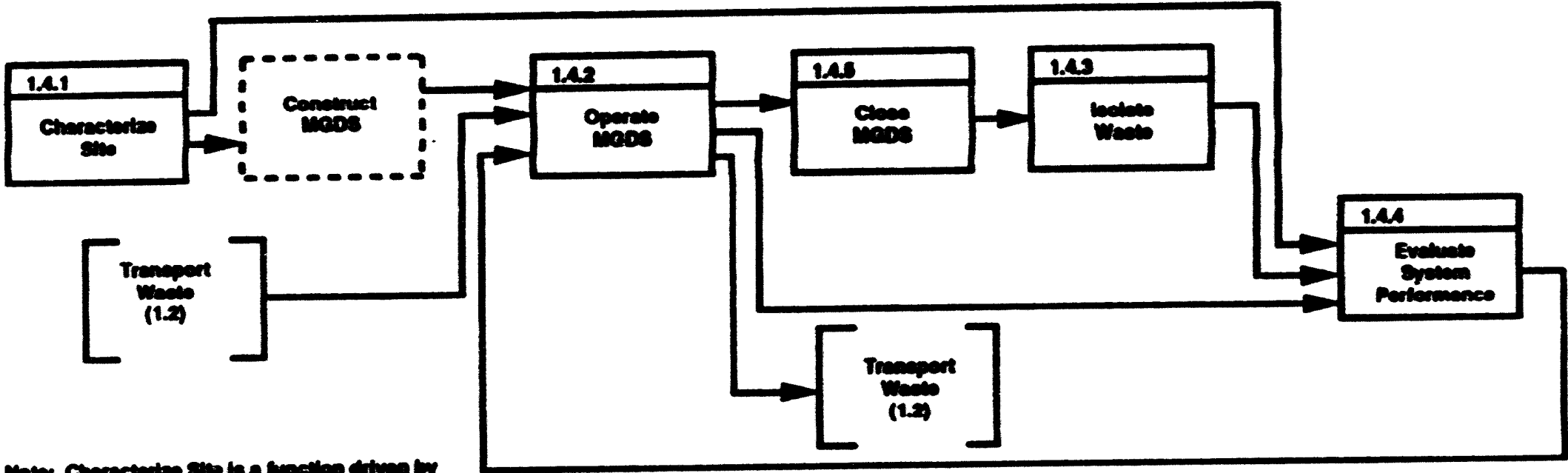

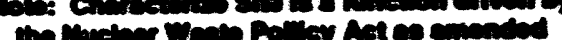


hardware as a means to determine the facilities that are the end-products of design and construction. Design and construction requirements important to these facilities are included in section 3.3 of this MGDS-RD).

Dispose of Waste includes functions and activities required to emplace spent fuel and high-level radioactive waste in a geologic medium (while preserving an option for retrievability) and to isolate such wastes from the accessible environment.

The Characterize Site function precedes the operation of the MGDS and includes performing a coordinated series of in-situ and surface-based tests, investigations and analyses. The tests establish the geologic conditions and the ranges of the parameters of the site relevant to evaluation of site suitability and the design of a repository.

A site at Yucca Mountain in the State of Nevada was designated as the potential location for the MGDS. In order to determine whether the potential site is suitable for recommendation as a repository, the Secretary of Energy is directed by the NWPAA to "carry out ... appropriate site characterization activities at the Yucca Mountain site." Such investigations, also required by 10CFR60, consist primarily of surface-based field studies, the construction of an ESF, and the tests conducted in that facility.

The term "disposal" is defined in the law as the emplacement in a repository of high-level radioactive waste, spent nuclear fuel, or other highly radioactive material with no foreseeable intent of recovery, whether or not such emplacement permits the recovery of such waste. [NWPA, 2 (9) $]^{6}$

This "disposal" isolates the radioactive wastes from the accessible environment. [10CFR60.2] This isolation is accomplished by a "Disposal System" - any combination of engineered and natural barriers that isolate spent nuclear fuel or radioactive waste after disposal. [40CFR191.12(a)]

Table 3-1 provides a list of Dispose of Waste subfunctions. A more detailed description of these subfunctions, along with an indentured list, is contained in the Appendix $C$ to this document. The following sections define the major subfunctions of Dispose of Waste.

- Entries in square brackets refer to the source documents from which the noted text was derived. 
Title: Mined Geologic Disposal System Requirements Document

Table 3-1. MGDS Functions

\begin{tabular}{|l|l|}
\hline \multicolumn{1}{|c|}{ Function Title } & \multicolumn{1}{|c|}{ Number } \\
\hline Dispose of Waste & 1.4 \\
\hline Characterize Site & 1.4 .1 \\
\hline Conduct Surface Investigations & 1.4 .1 .1 \\
\hline Conduct Subsurface Investigations & 1.4 .1 .2 \\
\hline Assess Data & 1.4 .1 .3 \\
\hline Close ESF & 1.4 .1 .4 \\
\hline Operate MGDS & 1.4 .2 \\
\hline Handle Waste & 1.4 .2 .1 \\
\hline Support MGDS Operations & 1.4 .2 .2 \\
\hline Isolate Waste & 1.4 .3 \\
\hline Contain Waste & 1.4 .3 .1 \\
\hline Limit Release of Radionuclides & 1.4 .3 .2 \\
\hline Evaluate System Performance & 1.4 .4 \\
\hline Close MGDS & 1.4 .5 \\
\hline Close Underground Openings & 1.4 .5 .1 \\
\hline Decommission Surface Facilities & 1.4 .5 .2 \\
\hline Establish Institutional Barriers & 1.4 .5 .3 \\
\hline Reclaim Site & 1.4 .5 .4 \\
\hline
\end{tabular}

\subsubsection{Characterize Site - Function 1.4.1}

This function includes determining the suitability of the potential site for a licensed repository. This includes providing and supporting an ESF and SBTF, and performing a coordinated series of surface and subsurface based tests and genscientific investigations. Site characterization means the program of exploration and research, both in the laboratory and in the field, undertaken to establish the geologic conditions and the ranges of those parameters of a particular site relevant to the procedures under 10CFR60. Site characterization includes borings, surface excavations, excavation of exploratory shafts, limited subsurface lateral excavations and borings, and in situ testing at depth needed to determine the suitability of the site for a geologic repository, but does not include preliminary borings and geophysical testing needed to decide whether site characterization should be undertaken. It also includes either closing the ESF or preparing to incorporate it into the MGDS.

\subsubsection{Operate MGDS - Function 1.4.2}

This function includes operating surface and underground facilities to handle radioactive wastes (including receiving, preparing, transferring, emplacing and retrieving (if required) radioactive 
wastes), and supporting MGDS operations (including, but not limited to, development of underground openings, and supplying utilities, services, QA, and administration). This function begins at the time the waste is received at the repository and ends at permanent closure.

\subsubsection{Inolate Waste - Function 1.4.3}

This function includes inhibiting the transport of radionuclides so that amounts and concentrations entering the accessible environment are kept within prescribed limits. It includes initial containment of waste within a waste package, and then, by means of the other engineered and natural barriers, retardation of the movement of any uncontained radionuclides within the geologic setting.

\subsubsection{Evaluate System Performance - Function 1.4.4}

This function includes: estimating the ability of the repository system to comply with regulations governing its pre-closure and post-closure performance objectives and its effects on the environment; using the estimates in updates to compliance documents and in support of the continuing development of the system; conducting the performance confirmation and environmental monitoring programs needed to supply data for the estimates; and planning for post-closure monitoring of the system. The function starts during site characterization and continues until permanent closure. [10CFR60.140(b)] Provision may be added for post-closure monitoring.

\subsubsection{Close MGDS - Function 1.4.5}

This function includes permanent closure of the MGDS to human access. This may include final backfilling of all or part of the undergmund facility (if deemed necessary by analysis and authorized by the license), closing and sealing openings (ramps, shafts, and boreholes), decommissioning surface facilities, reclaiming the site, and establishing institutional barriers. This does not preclude partial backfilling before permanent closure. This function begins upon approval of the license amendment for permanent closure and continues until the last institutional barrier is established and the license is terminated. Provisions may be added for post-permanent closure monitoring.

\subsubsection{MGDS Functional Relationships}

Figure 3-1 shows the functional relationships between CRWMS functions. The relationships shown between the functions in Figure 3-1 illustrute the major functional flow of CRWMS - i.e., the flow of spent nuclear fuel and high-level waste from Purchaser/Producer to repository. The path through Store Waste is for a portion of the spent nuclear fuel only. [DOE/RW-0239]

Figure 3-2 shows the relationships between Dispose of Waste functions.

The functions that are addressed in this document are those that are to be performed by the facilities, geologic setting, hardware, and software that make up the MGDS. There are numerous other interfaces between the functions, e.g., movement of unloaded casks, reports, etc., which are 
secondary to the major functional flow and create additional feedback loops. These interchanges between the functions are shown in the N-Square diagrams of Figures 3-3 and 3-4. Here the functions are shown in the diagonal array of boxes running from the top left corner to the bottom right corner of the figure. The outputs of a function are shown in the boxes in the same row with the function. The inputs to a function are shown in the boxes in the same column with the function. For example, outputs from Operate MGDS that are inputs to Close MGDS are shown in the box in the same row as Operate MGDS and in the same column as Close MGDS.

\subsubsection{MGDS Architecture Description}

Figure 3-5 shows the MGDS in context with the other CRWMS elements. The MGDS consists of the physical segments that will be developed to accomplish the five top-level MGDS functions just discussed. These functions will be implemented by the Site Segment, the Repository Segment, and the EBS Segment, as shown in the MGDS conceptual architecture in Figure 3-6. The ESF, the SBTF, and the site characterization test program are components of the Site Segment.

These Site, Repository, and EBS Segments will provide the primary facilities, hardware, software, and processes that comprise the physical means, together with the natural systems of the site, to accomplish all MGDS functions. The structure and components of the MGDS segments and of the ESF and SBTF will be specified in detail in project-level DRDs to be published separately. A description of the three MGDS segments with their major measures for performance is provided in Section 3.7. The composition of the segments will be established in the project-level MGDS DRDs. The primary linkages that involve significant material, equipment, data or information flows between segments will be defined and specified in project-level DRDs. 


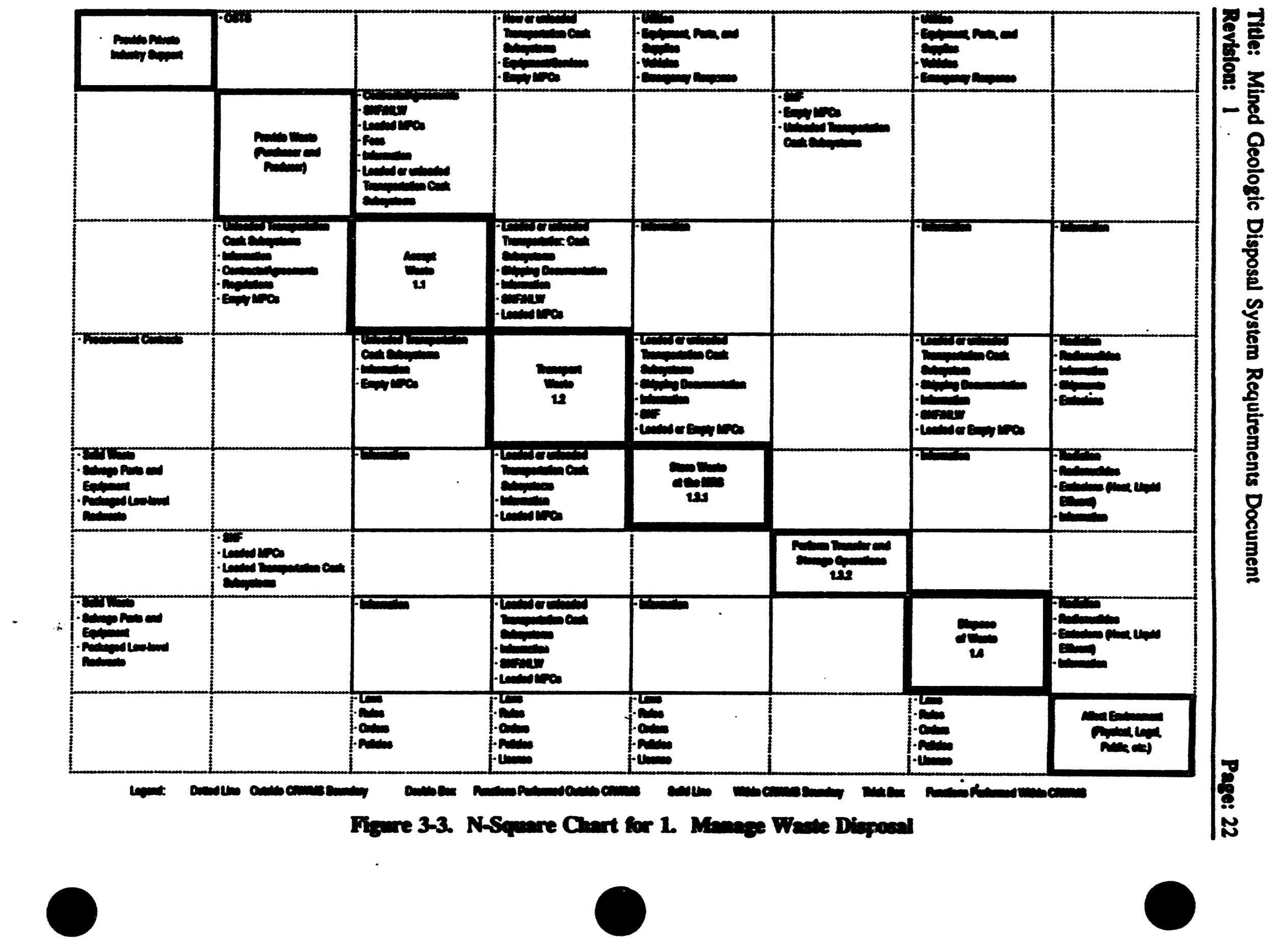


Title: Mined Geologic Disposal System Requirements Document Revision: 1

Page: 23

\begin{tabular}{|c|c|c|c|c|c|c|}
\hline $\begin{array}{l}\text { Outside } \\
\text { CRWMS }\end{array}$ & & 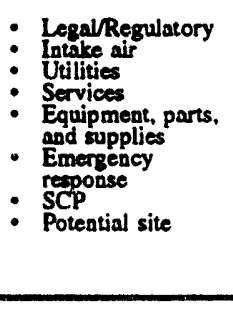 & $\begin{array}{l}\text { - Legal/Regulatory } \\
\text { Documentation } \\
\text { - Erocedures, and data } \\
\text { Equipment, parts, } \\
\text { and supplies } \\
\text { Utilitites } \\
\text { : Services } \\
\text { : Emergency response } \\
\text { Vechicles } \\
\text { - lntake air } \\
\text { License amendments } \\
\text { to construct and } \\
\text { operate }\end{array}$ & $\begin{array}{l}\text { - Human } \\
\text { - Nativity } \\
\text { Natural } \\
\text { transport } \\
\text { media }\end{array}$ & & $\begin{array}{l}\text { - Legal/ } \\
\text { Regulatory } \\
\text { - Utilities } \\
\text { - Services } \\
\text { - License } \\
\text { amendment to } \\
\text { terminate }\end{array}$ \\
\hline & $\begin{array}{c}\text { Outside of } \\
1.4\end{array}$ & - Models & $\begin{array}{l}\text { - Loaded or unloaded } \\
\text { Transportation Cask } \\
\text { Subsytems } \\
\text { SNFhiLW } \\
\text { Shipping Documents } \\
\text { - Lopded or empty } \\
\text { MPCs } \\
\text { Waste containers } \\
\text { - Information }\end{array}$ & & - Models & \\
\hline 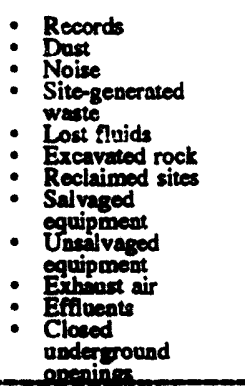 & 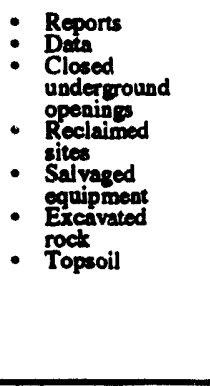 & $\begin{array}{c}1.4 .1 \\
\text { Chargcterize } \\
\text { Site }\end{array}$ & $\begin{array}{l}\text { - Characterized Sire } \\
\text { - Site data }\end{array}$ & & $\begin{array}{l}\text { - Data } \\
\text { - Samples }\end{array}$ & - Excavated rock \\
\hline 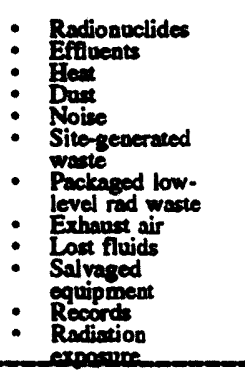 & 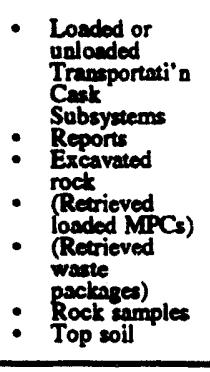 & & $\begin{array}{l}1.4 .2 \\
\text { Qperate }\end{array}$ & $\begin{array}{l}\text { - Guidance } \\
\text { Emplacement } \\
\text { - locations } \\
\text { Waste } \\
\text { - Eackiges } \\
\text { - Engineered } \\
\text { baniers } \\
\text { - Sealed } \\
\text { sccesses and } \\
\text { boreholes } \\
\text { - Institutional } \\
\text { barriers }\end{array}$ & 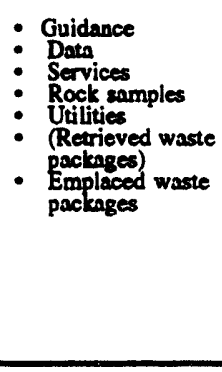 & $\begin{array}{l}\text { - Guidance } \\
\text { Support } \\
\text { - Contaminated } \\
\text { Gacilities } \\
\text { - Excavated rock }\end{array}$ \\
\hline $\begin{array}{l}\text { : Radionuclides } \\
\text { - Rediation }\end{array}$ & & & & $\begin{array}{l}1.4 .3 \\
\text { Isolate }\end{array}$ & - Data & \\
\hline - Records & $\begin{array}{l}\text { - Reports } \\
\text { - Cigration data } \\
\text { - Containment } \\
\text { - Updated } \\
\text { models }\end{array}$ & - Reports & $\begin{array}{l}\text { : Reports } \\
\text { Corroctive action } \\
\text { - guidance } \\
\text { (Retrieved waste } \\
\text { pactages) }\end{array}$ & & $\begin{array}{c}\text { 1.4.4 } \\
\text { Evaluate } \\
\text { System } \\
\text { Performance }\end{array}$ & - Reports \\
\hline 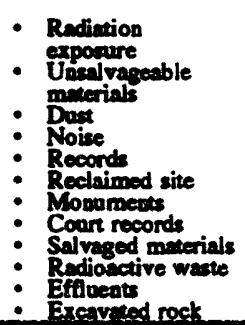 & - Reports & & & & & $\begin{array}{l}1.4 .5 \\
\text { Close } \\
\text { MGDS }\end{array}$ \\
\hline
\end{tabular}

$$
\text { ( ) }=\text { if required }
$$

Figure 3-4. N-Square Chart for 1.4 Dispose of Waste 


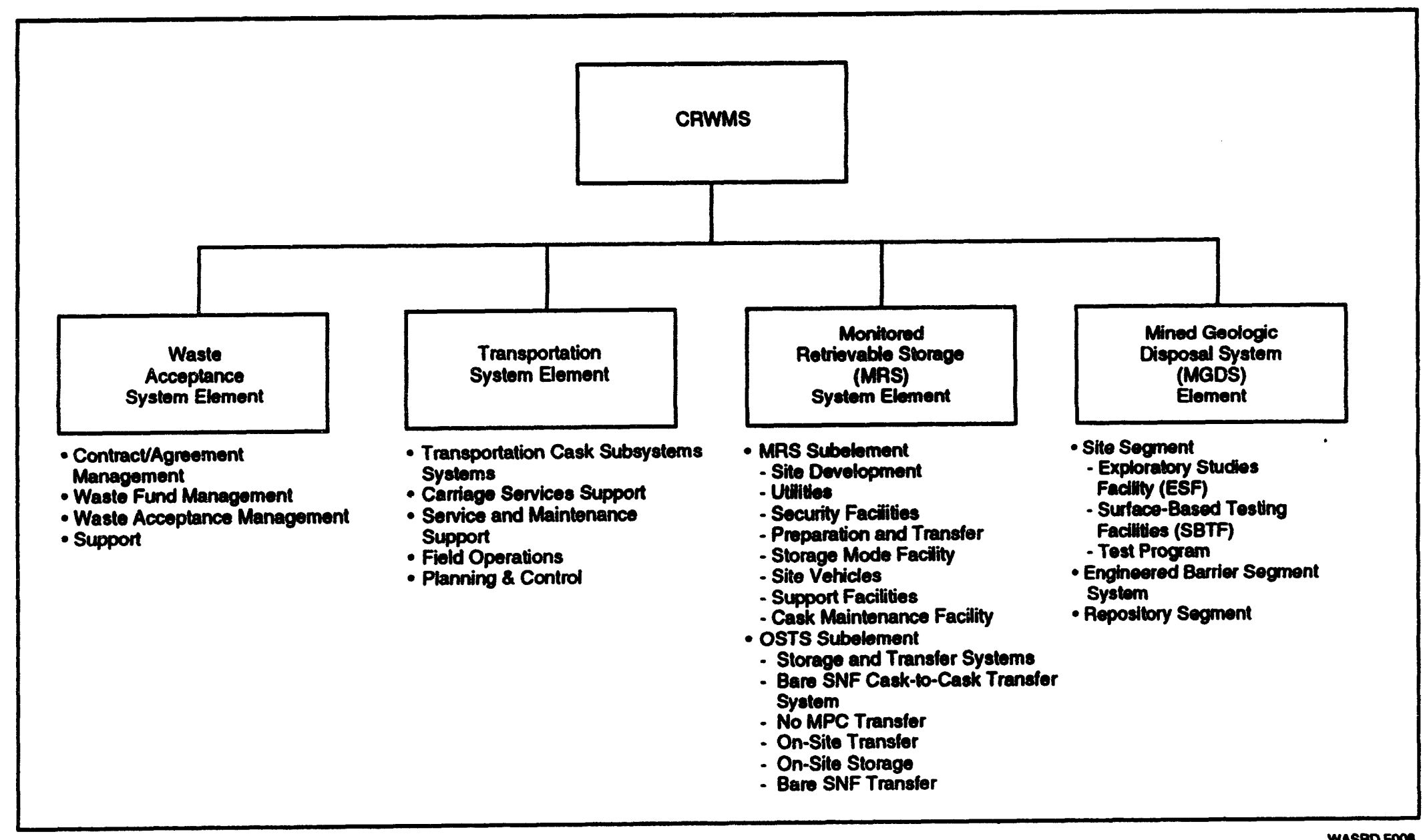

WASRD.FO00

Figure 3-5. CRWMS Architecture 


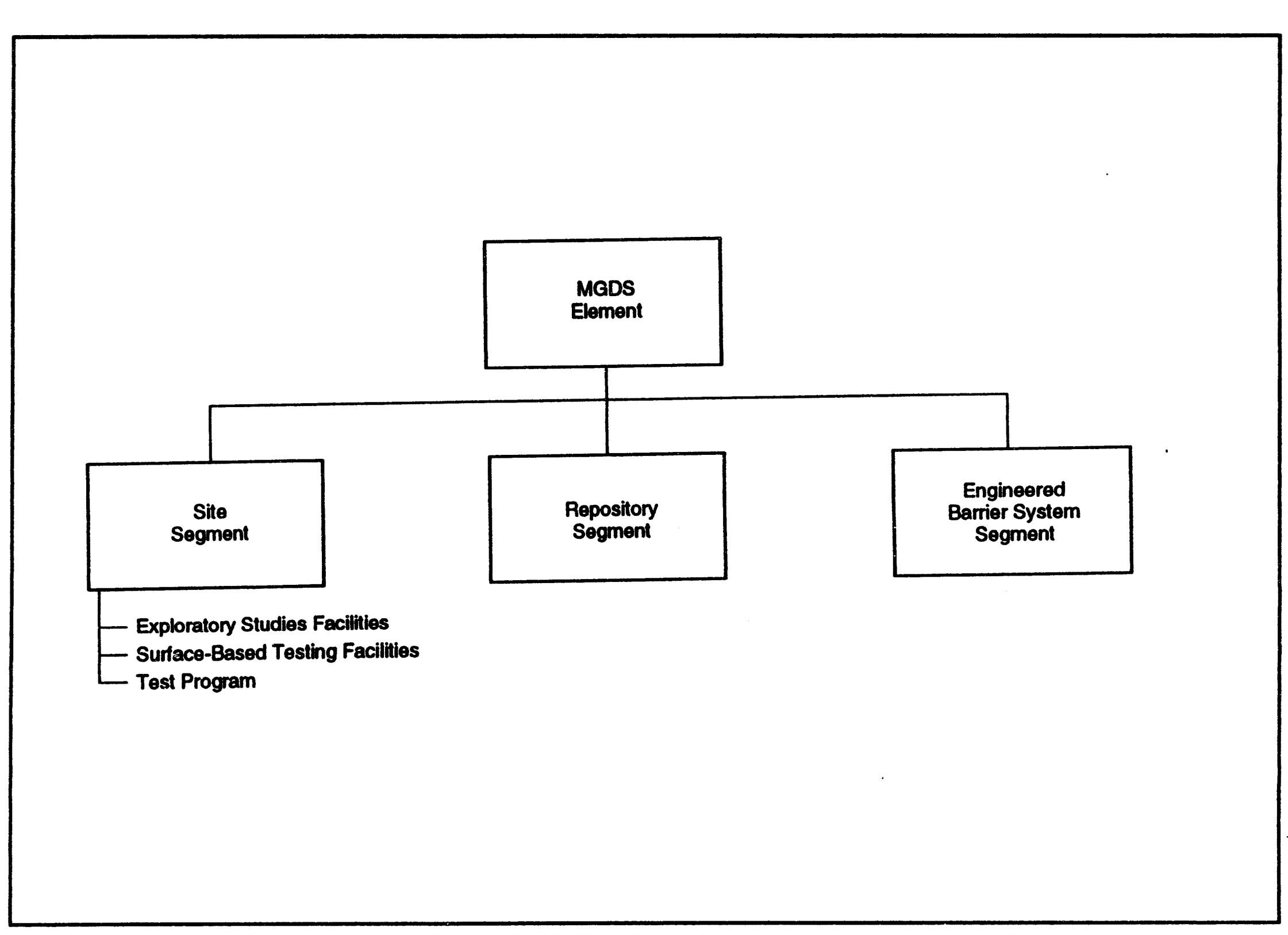

Figure 3-6. MGDS Architecture 
Title: Mined Gèologic Disposal System Requirements Document

\subsubsection{Function to Architecture Cross-Reference}

The allocation of functions to the MGDS segments is shown in Table 3-2.

Table 3-2. MGDS Functions Allocated to Segments

\begin{tabular}{|c|l|c|c|c|}
\hline Function Title & $\begin{array}{c}\text { MGDS } \\
\text { Function } \\
\text { Number }\end{array}$ & $\begin{array}{c}\text { SITE } \\
\text { SEGMENT }\end{array}$ & $\begin{array}{c}\text { REPOSITORY } \\
\text { SEGMENT }\end{array}$ & $\begin{array}{c}\text { EBS } \\
\text { SEGMENT }\end{array}$ \\
\hline Dispose of Waste & 1.4 & $\mathrm{X}$ & $\mathrm{X}$ & $\mathrm{X}$ \\
\hline Characterize Site & 1.4 .1 & $\mathrm{X}$ & & \\
\hline Conduct Surface Investigations & 1.4 .1 .1 & $\mathrm{X}$ & & \\
\hline Conduct Subsurface Investigations & 1.4 .1 .2 & $\mathrm{X}$ & & \\
\hline Assess Data & 1.4 .1 .3 & $\mathrm{X}$ & & \\
\hline Close ESF & 1.4 .1 .4 & $\mathrm{X}$ & & \\
\hline Operate MGDS & 1.4 .2 & & $\mathrm{X}$ & \\
\hline Handle Waste & 1.4 .2 .1 & & $\mathrm{X}$ & \\
\hline Support MGDS Operations & 1.4 .2 .2 & & $\mathrm{X}$ & $\mathrm{X}$ \\
\hline Isolate Waste & 1.4 .3 & & $\mathrm{X}$ & $\mathrm{X}$ \\
\hline Contain Waste & 1.4 .3 .1 & & & $\mathrm{X}$ \\
\hline Limit Release of Radionuclides & 1.4 .3 .2 & & $\mathrm{X}$ & $\mathrm{X}$ \\
\hline Evaluate System Performance & 1.4 .4 & $\mathrm{X}$ & $\mathrm{X}$ & \\
\hline Close MGDS & 1.4 .5 & & $\mathrm{X}$ & \\
\hline Close Underground Openings & 1.4 .5 .1 & & $\mathrm{X}$ & \\
\hline Decommission Surface Facilities & 1.4 .5 .2 & & $\mathrm{X}$ & \\
\hline Establish Institutional Barriers & 1.4 .5 .3 & & $\mathrm{X}$ & \\
\hline Reclaim Site & 1.4 .5 .4 & & $\mathrm{X}$ & \\
\hline
\end{tabular}

\subsubsection{Major Considerations and Assumptions}

I The considerations and assumptions provided in this section may not be explicitly addressed in I a requirement statement. However, this background information is important to understanding I the development of the MGDS. This information includes general conditions, stipulations, or I assertions that provide a basic premise used to structure the requirements documents and to I develop requirement statements. Considerations or assumptions may represent DOE policy or I management decisions. They also may form a basis for functional analysis and requirements I development, where regulations and written policy do not provide needed definitive direction to I system design and development.

I Assumptions related to specific requirements or technical issues may be the subject of program

I technical direction or system analyses. These assumptions will be annotated $\langle$ TBD $>$ or $\langle$ TBR $\rangle$, $I$ and when the assumption is validated the $\langle$ TBD $>$ or $\langle$ TBR $>$ will be removed from the related 
Title: Mined Geologic Disposal System Requirements Document

Revision: 1

Page: 27

requirement(s). Additionally, the assumption will be removed, restated as a consideration, or incorporated in a requirement statement(s).

A. Reserved.

B. A Cask Maintenance Facility, to be collocated with the MGDS <TBR>, will be designed, constructed and integrated by the MGDS to meet the requirements of the Transportation System element. [CRD]

C. For activities and facilities over which the NRC has regulatory authority, the NRC requirements are the controlling "nuclear safety" requirements. This means that portions of DOE CFR requirements and DOE Orders that address topics covered by CFR requirements issued by the NRC are not applicable to the CRWMS. Specifically, there are no nuclear safety design-related requirements in DOE Order 5480.11 applicable to the MGDS-RD.

D. The MGDS design will be based on the technical requirements contained in the 1985 issue of 40CFR 191 until it is replaced by a standard applicable to Yucca Mountain. EPA revised 40CFR191 on December 20, 1993. As provided in the Waste Isolation Pilot Plant (WIPP) Land Withdrawal Act, this revised standard applies only to the WIPP and specifically not to the site at Yucca Mountain. Standards applicable to Yucca Mountain are being developed by the EPA per the Energy Act of 1992. The requirements based on 40CFR 191 are marked <TBR> to indicate they are subject to review until the standard is replaced.

E. The continuing heat generation of waste packages after emplacement requires management. The heat must be removed from the waste to avoid temperatures that may lead to structural failure within the waste form. The thermal load on the geologic setting may require management to avoid adverse effects on its waste isolation capability. There are several possible ways to manage these thermal loads. These include: blending the waste (i.e., mixing SNF or HLW of different thermal outputs in MPCs and waste packages); partially filling MPCs and waste packages; selecting the age (or thermal characteristics) of waste to be accepted for emplacement; and varying the spacing of waste packages within the underground facility; or some combination of these.

The assumption used in developing this MGDS-RD regarding the extent of any blending of SNF or HLW that may be required for thermal load modulation is limited to blending that can be accomplished by the waste acceptance process.

Thermal loading studies will, among other things, determine the extent of blending that may be required, if any. If significant blending is required, this could have a major impact on the MRS facility and/or MGDS design and operations; as well as the use of MPCs in the system; or may require negotiations with Purchasers, should blending of wastes loaded into MPCs at utility reactor sites be recommended. These issues will be the subject of system studies. If these studies show that changes in system design requirements are necessary, the requirements documents will be revised. 
F. The MGDS requirements are driven by 10CFR60. 10CFR60 is directed at "the licensing of DOE to receive and possess source, special nuclear, and by-product material at a geologic repository operations area." As such, it does not provide all (i.e., the nonlicensed) requirements needed for the MGDS (i.e., the system). As the GROA and other areas become better defined, MGDS requirements will be modified.

G. The term "controlled area" is used in this document in three different ways, depending upon the language in the source document. In each case, the applicable definition is provided in a footnote.

H. It is the position of DOE that the Federal Mine Safety and Health Act of 1977 (30USC801 et seq.) does not apply to the MGDS project because neither the geologic repository nor the ESF will be mines as defined in the Act. DOE's policy, however, is further stated in memorandum of understanding (MOU) with the Department of Labor, December 23, 1986. The MOU states DOE's "policy of compliance with MSHA [Mine Safety and Health Administration] standards as though repositories were commercial mines by taking necessary actions with the DOE contractors to assure prompt and effective correction of any deficiencies and to otherwise ensure general compliance with MSHA's mining health and safety requirements." Specifically, the MOU declares 30 CFR Parts 31, 32, 36, 48, 49, and 57 are relevant to OCRWM underground operations. These parts are consistent with 10CFR60.131(b)(9). Further, DOE Order 5480.4, with change 3, imposes (by policy) Tunnel Safety Orders, Administrative Code, Title 8, Chapter 4, Subchapter 20, State of California. The California Mine Safety Orders are not considered applicable because there is no mine involved. This MGDS-RD is based on these policies.

I. The need to build a second repository to dispose of remaining inventories of waste will be submitted to and reviewed by Congress on or after January 1, 2007, but not later than January 1, 2010.

J. SNF will be received from the MRS and directly from Purchaser sites loaded in Transportation Cask Subsystems. Most, but not all, transportation cask subsystems will incorporate a multi-purpose canister (MPC) with a transportation overpack. All shipments from the MRS will be in MPCs. The MPC serves as a canister (basket) for the SNF for such purposes as confining the waste during transportation and storage and maintaining criticality control during transportation, storage, emplacement, and disposal. It also aids in removing heat from the SNF.

Depending on material selection and performance, credit may or may not be taken for any waste containment capability contributed by the MPC toward meeting waste package requirements.

The Repository Segment will remove the loaded MPC from the transportation cask and transfer it to a disposal container (which with the MPC and possibly other overpacks will constitute a waste package) for disposal and long-term containment. 
The requirements for MPCs and transportation cask subsystems are documented in the Transportation SRD (Reference 2.5.J) and its derivative design requirements documents. Requirements for the waste package are included in this MGDS-RD. Program-level requirements for the interface between the MPC and the waste package are addressed in both documents.

K. It is assumed that the MPC will remain sealed through the expected life cycle and will not be opened at the MGDS unless addition of filler material at the MGDS may be required as part of preparation for disposal. An inert gas or other filler material $\langle\mathrm{TBD}>$ may be added to enhance heat transfer or to control criticality and corrosion. The filler, if required, may be added through a port that will then be sealed or the addition of filler may require the MPC to be opened.

Other potential reasons for opening an MPC include, but may not be limited to: inspections to verify its contents; repacking the waste if the MPC is later found to be incompatible with the waste package and performance confirmation testing.

L. The MGDS license will include the MPC for those waste package configurations that include an MPC.

M. It is assumed that loaded MPCs emplaced for disposal will have a maximum thermal output of 14.2 kilowatts. Accommodation of this condition will require management of the waste delivery schedule or storage of loaded MPCs with a higher thermal output until the thermal output has decreased to 14.2 kilowatts. This 14.2 kilowatts is equivalent to the thermal output of 21 PWR assemblies with $40 \mathrm{GWd} / \mathrm{MTU}$ burmup and $3.75 \%$ initial enrichment 10 years after discharge from a reactor. (Twenty-one assemblies represents the capacity of one of several potential MPC configurations.)

\subsection{CHARACTERISTICS}

\subsubsection{Performance Characteristics}

Performance characteristics are the system's capabilities specified in terms of states, phases, or modes of operation in which the system can exist.

A. Mission Requirement. The design of the MGDS shall provide for the disposal of SNF and civilian and defense HLW such that the public health and safety and the environment are protected. [NWPA 111(a)(4)] [Presidential Memo, 1985]

B. Modes. The MGDS will operate in the following eight modes as depicted in Figure 3-7, related to the five operational phases described in the CRD.

1. Site characterization

2. Construction

3. Emplacement

4. Caretaker

5. Retrieval 


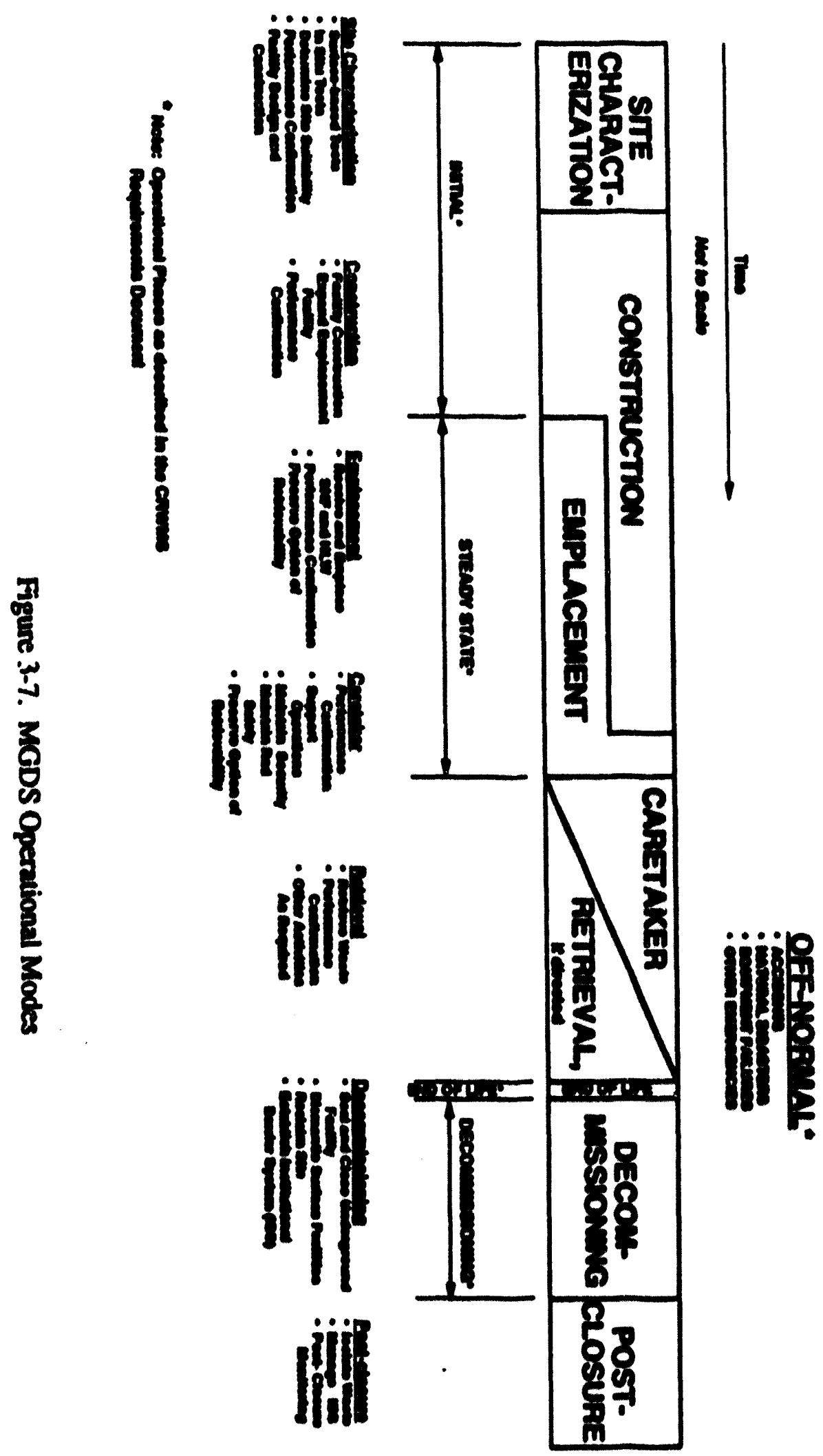

$O E: 085 \mathrm{~d}$ 
6. Decommissioning and closure

7. Post-closure

8. Off-normal

Typical activities for the MGDS during each operational phase are shown in Figure 3-7.

As shown in Figure 3-7, the MGDS can operate in more than one mode at a time. For example, the construction mode will begin after NRC issuance of the repository construction license. According to the current concept, only a portion of the emplacement locations will have been finished when the MGDS begins emplacement operations (again, after NRC approval). The MGDS will continue to expand the underground facility in parallel with waste emplacement operations. This is a unique program aspect in that construction becomes part of the operation of the system.

When the MGDS has reached its legislated or physical capacity for waste disposal, it will be in the caretaker mode. The option to retrieve any and all emplaced waste will be preserved from the time of emplacement until permanent closure is authorized. Performance confirmation continues during this mode.

When the NRC amends the repository license to authorize permanent closure, the underground facility will be backfilled (if required and authorized) and sealed; the surface facilities will be decontaminated and dismantled or converted to other uses; and an institutional barrier system will be established to preclude human activities that could compromise waste isolation for thousands of years.

The off-normal mode involves accident, natural disaster, and other unexpected scenarios and can occur during any of the other modes.

The requirements cited in the following subsections (3.2.1.1 through 3.2.1.8) are descriptive of the modes but may not be unique to the modes with which they are identified. For example, a performance confirmation program is required in all of the modes.

\subsubsection{Site Characterization Mode Requirements}

A. Yucca Mountain site characterization activities (including but not limited to design, development, ESF construction, and site investigations) shall be limited to those necessary to provide the data required for evaluation of the suitability of the site for an application for construction authorization?. [NWPA, 113(c)(1)]

7 Section $113(\mathrm{c})(1)$ of the NWPA also allows activities necessary to provide data required for compliance with the National Environmental Policy Act of 1969 (421 JSC4321 et seq) (activities which are not considered part of site characterization). 
B. Investigations to obtain the required information shall be conducted in such a manner as to limit adverse effects on the long-term performance of the geologic repository to the extent practical. [10CFR60.15(c)(1)]

C. The number of exploratory boreholes, ramps, and shafts shall be limited to the extent practical, consistent with obtaining the information needed for site characterization. [10CFR60.15(c)(2)]

D. To the extent practical, exploratory shafts and ramps shall be located where shafts and ramps are planned for the GROA and exploratory boreholes shall be located where large unexcavated pillars are planned. [10CFR60.15(c)(3)]

E. Subsurface exploratory drilling, excavation, and in situ testing before and during construction shall be planned and coordinated with GROA design and construction. [10CFR60.15(c)(4)]

F. Environmental impact requirements:

1. Site Characterization activities shall be conducted in a manner that minimizes any significant adverse environmental impact. [NWPAA Sect. 112 (b)(1)(D)(iii), NWPA Sect. 113(a)] [10CFR960.3-4]

2. If found to be unsuitable, the candidate site shall be decontaminated and decommissioned and any significant adverse environmental impacts shall be mitigated in accordance with plans in an approved Site Characterization Plan (SCP). [10CFR960.3-4] [NWPA, 113(b)(1)(A)(iii)] [10CFR60.17(a)(3)]

G. Reserved.

H. The site characterization program shall provide the data needs required by 10CFR60 and 10CFR960, and for 10CFR20 and 40CFR191<TBR>, as invoked by 10CFR60. The applicable requirements from these references, which originate the need for site data, are identified in Appendix A to this MGDS-RD. [CRD]

1. Radioactive material may be used for site characterization, but its use shall have the concurrence of the NRC, shall not exceed the curie equivalent of 10 metric tons of SNF, and it shall remain fully retrievable. [NWPA 113(c)(2)]

J. Alternative designs shall be prepared for major engineering features important to waste isolation, with particular attention to the alternatives that would provide longer radionuclide containment and isolation. These alternative designs are for use in the analysis required by 10CFR60.21(c)(1)(ii)(D). [10CFR60.21(c)(1)(ii)(D)] 


\subsubsection{Construction Mode Requirements}

A. During the early or developmental stages of construction, a program for in situ testing of such features as borehole and shaft seals, backfill, and the thermal interaction effects of the waste packages, backfill, rock, and groundwater shall be conducted. [10CFR60.142(a)]

B. A program of in situ testing shall begin as early as practicable after construction authorization to meet the requirements of 10CFR60.142 (section 3.7.2.7 in this document). [10CFR60.142(b)]

C. Subsurface construction, excavation, alteration, and repairs shall be governed by California Tunnel Safety Orders. [DOE Order 5480.4, Att. 2, 2.e.(8)(a)]

D. Because subsurface construction will continue after emplacement operations begin, radiological protection is required. The GROA shall be designed so that until permanent closure has been completed, radiation exposures, radiation levels, and releases of radioactive materials to unrestricted areas will at all times be maintained within the limits specified in 10CFR20 and applicable environmental standards for radioactivity established by the Environmental Protection Agency (EPA), as listed in section 3.2.2. [10CFR60.111(a)]

\subsubsection{Emplacement Mode Requirements}

A. Assuming the MRS facility is located more than 50 miles from the repository, no quantity of SNF and solidified HLW resulting from the reprocessing of such a quantity of spent fuel containing in excess of 70,000 metric tons of heavy metal shall be emplaced in the repository until such time as a second repository is in operation. (See 3.2.3.2.1.A) [NWPA, 114(d)]

B. Reserved.

C. The MGDS shall be capable of loading SNF assemblies into MPCs in a configuration that conforms with written procedures and, for any required off-site shipment, that complies with the transportation cask certificate of compliance. <TBR> [10CFR71.87(f)] [CRD 3.2.1.1.C]

D. Reserved.

E. Reserved.

F. Reserved.

G. Reserved.

H. Reserved. 


\section{Reserved.}

J. The MODS shall be capable of receiving waste according to the schedule shown in Table 3-3 of this document. [CRD]

Table 3-3. Waste Delivery Schedule (In Metric Tons of Initial Uranium or Equivalent) <TBR>

\begin{tabular}{|c|c|c|c|c|c|}
\hline \multirow{2}{*}{ Year } & \multicolumn{2}{|c|}{ Spent Nuclear Fuel } & \multicolumn{2}{c|}{ High-Level Waste } & Cumulative \\
\cline { 2 - 5 } & $\begin{array}{c}\text { Prom } \\
\text { MRS }\end{array}$ & Cumulative & Annual & Cumulative & SNF and HLW \\
\hline 2010 & 300 & 300 & 0 & 0 & 300 \\
\hline 2011 & 600 & 900 & 0 & 0 & 900 \\
\hline 2012 & 1,200 & 2,100 & 0 & 0 & 2,100 \\
\hline 2013 & 2,000 & 4,100 & 0 & 0 & 4,100 \\
\hline 2014 & 3,000 & 7,100 & 0 & 0 & 7,100 \\
\hline 2015 & 3,000 & 10,100 & 400 & 400 & 10,500 \\
\hline 2016 & 3,000 & 13,100 & 400 & 800 & 13,900 \\
\hline 2017 & 3,000 & 16,100 & 400 & 1,200 & 17,300 \\
\hline 2018 & 3,000 & 19,100 & 400 & 1,600 & 20,700 \\
\hline 2019 & 3,000 & 22,100 & 400 & 2,000 & 24,100 \\
\hline 2020 & 3,000 & 25,100 & 400 & 2,400 & 27,500 \\
\hline 2021 & 3,000 & 28,100 & 400 & 2,800 & 30,900 \\
\hline 2022 & 3,000 & 31,100 & 400 & 3,200 & 34,300 \\
\hline 2023 & 3,000 & 34,100 & 400 & 3,600 & 37,700 \\
\hline 2024 & 3,000 & 37,100 & 400 & 4,000 & 41,100 \\
\hline 2025 & 3,000 & 40,100 & 400 & 4,400 & 44,500 \\
\hline 2026 & 3,000 & 43,100 & 400 & 4,800 & 47,900 \\
\hline 2027 & 3,000 & 46,100 & 400 & 5,200 & 51,300 \\
\hline 2028 & 3,000 & 49,100 & 400 & 5,600 & 55,700 \\
\hline 2029 & 3,000 & 52,100 & 400 & 6,000 & 58,100 \\
\hline 2030 & 3,000 & 55,100 & 400 & 6,400 & 61,500 \\
\hline 2031 & 3,000 & 58,100 & 400 & 6,800 & 64,900 \\
\hline 2032 & 3,000 & 61,100 & 200 & 7,000 & 68,100 \\
\hline 2033 & 1,900 & 63,000 & 0 & 7,000 & 70,000 \\
\hline 2034 & 0 & 63,000 & 0 & 7,000 & 70,000 \\
\hline & & & & & \\
\hline
\end{tabular}

- Notes: In years when SNF is shipped directly from the Purchasers to the MODS, the sum of the waste received at the MODS and the waste shipped trom the MRS will be as stated in this column.

This schedule applies to the first repository only. The disposal function will continue until all waste is disposed of (conceptually, in a second repository). [CRD] 
K. The GROA shall be designed so that until permanent closure has been completed, radiation exposures, radiation levels, and releases of radioactive materials to unrestricted areas will at all times be maintained within the limits specified in 10CFR20 and applicable environmental standards for radioactivity established by the EPA, as listed in section 3.2.2. [10CFR60.111(a)]

\subsubsection{Caretaker Mode Requirements}

The GROA shall be designed so that until permanent closure has been completed, radiation exposures, radiation levels, and releases of radioactive materials to unrestricted areas will at all times be maintained within the limits specified in 10CFR20 and applicable environmental standards for radioactivity established by the EPA a listed in section 3.2.2. [10CFR60.111(a)]

\subsubsection{Retrieval Mode Requirements}

A. The repository shall be designed and constructed to permit the retrieval of any SNF and HLW emplaced in the repository, during an appropriate period of operation of the facility, as specified by the Secretary of Energy. [NWPA, 122]

B. The GROA shall be designed to preserve the option of waste retrieval throughout the period during which wastes are being emplaced and, thereafter until the completion of a performance confirmation program and NRC review of the information obtained from such a program. To satisfy this objective, the geologic repository shall be designed so that any or all of the emplaced waste could be retrieved on a reasonable schedule starting at any time up to 50 years after waste emplacement operations are initiated, unless a different time period is approved or specified by the NRC. 10CFR60.111(b)(3) gives guidance for developing the schedule. [10CFR60.111(b)(1)]

C. The GROA shall be designed so that until permanent closure has been completed, radiation exposures, radiation levels, and releases of radioactive materials to unrestricted areas will at all times be maintained within the limits specified in 10CFR20 and applicable environmental standards for radioactivity established by the EPA, as listed in section 3.2.2. [10CFR60.111(a)]

\subsubsection{Closure and Decommissioning Mode Requirements}

The final state of the GROA shall conform to plans approved as part of the license for permanent closure and decontamination and dismantlement of surface facilities. [10CFR60.52(c)(2)] 


\subsubsection{Post-closure Mode Requirements}

A. The MODS shall include facilities with the capability of implementing a post-permanent closure monitoring program in accordance with the application to amend the license for permanent closure. [10CFR60.51(a)(1)]

B. The MGDS shall identify the controlled areas and the GROA by monuments that are designed, fabricated, and emplaced to be as permanent as practicable. [10CFR60.51(a)(2)(i)]

C. The disposal system shall be designed to provide a reasonable expectation, based upon performance assessments, that the cumulative releases of radionuclides to the accessible environment for 10,000 years after disposal from all significant processes and events that may affect the disposal system shall have a likelihood of less than one chance in 10 of exceeding the quantities calculated according to Table 1 of Appendix A of 40CFR 191; and have a likelihood of less than one chance in 1,000 of exceeding ten times the quantities calculated according to Table 1 of Appendix A of 40CFR191. <TBR> [40CFR191.13(a) <TBR>]

\subsubsection{Off-normal Mode Requirements}

A. The GROA design shall include explosion and fire detection alarm systems and appropriate suppression systems with sufficient capacity and capability to reduce the adverse effects of fires and explosions on structures, systems, and components important to safety. [10CFR60.131(b)(3)(iii)]

B. The structures, systems, and components important to safety shall be designed to maintain control of radioactive waste and radioactive effluents, and permit prompt termination of operations and evacuation of personnel during an emergency. [10CFR60.131(b)(4)(i)]

C. The structures, systems, and components important to safety shall be designed to perform their safety functions during and after credible fires or explosions in the GROA. [10CFR60.131(b)(3)(i)]

\subsubsection{Radiological Protection}

\subsubsection{General Requirements}

A. Reserved.

8 Controlled area, in this case, means a surface location, to be marked by suitable monuments, extending horizontally no more than 10 bilometers in any direction from the outer boundary of the underground facility, and the underlying subsurface, which area has been committed to use as a geologic repository and from which incompatible activities would be restricted following permanent closure. [10CFR60.2] 
B. The MGDS shall, to the extent practicable, be designed and constructed to use procedures and engineering controls based upon sound radiation protection principles to achieve occupational doses and doses to members of the public that are as low as is reasonably achievable (ALARA). NRC Regulatory Guides 8.8 and 8.10 provide guidance for the implementation of ALARA principles. [10CFR20.1101(b)]

C. The MGDS design and operations shall include provisions for controlling doses such that, when approved operational procedures are followed, the exposure dose limits specified in 10CFR20.1201 for occupational doses, and 10CFR20.1301 for individual members of the public, are not exceeded. [10CFR20]

D. The GROA shall be designed so that, until permanent closure has been completed, radiation exposures and radiation levels and releases of radioactive materials to unrestricted areas, will at all times be maintained within the limits specified in 10CFR20 and environmental standards for radioactivity as established by the EPA and specified in this document. [10CFR60.111(a)]

E. Reserved.

F. The MGDS shall provide means to limit the levels of radioactive materials in effluents, during normal operations, anticipated occurrences, and under accident conditions. [10CFR60.131(b)(4)(i)] Releases shall be limited as follows:

1. Under normal operations and anticipated occurrences, the annual dose equivalent to any real individual who is located beyond the controlled area must not exceed 25 mrem to the whole body, 75 mrem to the thyroid, and 25 mrem to any other organ as a result of exposure: to planned discharges of radioactive materials, radon and its decay products excepted, to the general environment; direct radiation from MGDS operations; and any other radiation from uranium fuel cycle operations within the region. $<$ TBR $>$ [40CFR 191.03(a)(1)<TBR>]

\section{Reserved.}

G. The disposal system shall be designed to meet the individual protection requirements specified by 40CFR191.15 <TBR>. [40CFR191.15 <TBR>]

\subsubsection{Reserved}

9 Controlled area, in this case, means: (1) A surface location, to be identified by passive institutional controls, that encompasses no more than 100 square kilometers and extends horizontally no more than five kilometers in any direction from the outer boundary of the original location of the radioactive wastes in a disposal system; and (2) the subsurface underlying such a surface location. 


\subsubsection{Public Protection}

A. Repository facilities shall be designed to operate so that the total effective dose equivalent to individual members of the public from the licensed operation does not exceed $0.1 \mathrm{rem}$ $(1 \mathrm{mSv})$ in a year, exclusive of the dose contribution from the facility's disposal of radioactive material into sanitary sewerage in accordance with 10CFR20.2003. However, the facility may apply for prior NRC authorization to operate up to an annual dose limit for an individual member of the public of $0.5 \mathrm{rem}(5 \mathrm{Msv})$ in accordance with 10CFR20.1301(c). [10CFR20.1301(a),(c)]

B. If members of the public have access to controlled areas ${ }^{10}$, the limits for members of the public shall continue to be applicable to those individuals. [10CFR20.1301(b)]

C. Repository facilities shall be designed to operate so that the dose in any unrestricted area from external sources does not exceed $0.002 \mathrm{rem}(0.02 \mathrm{mSv})$ in any one hour. [10CFR20.1301(a)(2)]

\subsubsection{Airborne Radioactive Material Control}

A. Concentrations of radioactive material in air shall to the extent practicable be controlled through the use of process or other engineering controls (e.g. containment or ventilation). [10CFR20.1701]

B. When it is not practicable to apply process or other engineering controls in restricted areas to control the concentrations of radioactive material in air to values below those that define an airborne radioactivity area, the MGDS shall, consistent with maintaining the total effective dose equivalent ALARA, have the capability to increase monitoring and limit intakes by one or more of the following: control of access, limitation of exposure times, use of respiratory protection equipment, or other controls. [10CFR20.1702]

C. The MGDS shall be capable of implementing and maintaining air sampling sufficient to identify potential hazards, to permit proper protective equipment selection, and to estimate exposures. [10CFR20.1703(a)(3)(i)]

\subsubsection{Radiation Monitoring}

Waste handling facilities shall be equipped to monitor occupational exposures to radiation at levels sufficient to demonstrate compliance with the occupational dose limits of 10CFR20, including:

A. Individual monitoring devices required for use by:

10 Controlled area, in this case, means an area, outside of a restricted area but inside the site boundary, access to which can be limited by the licensee for any reason. 
Title: Mined Geologic Disposal System Requirements Document

1. Adults likely to receive, in 1 year from sources external to the body, a dose in excess of $10 \%$ of the limits in 10CFR20.1201(a). [10CFR20.1502(a)(1)]

2. Minors and declared pregnant women likely to receive, in 1 year from sources external to the body, a dose in excess of $10 \%$ of any of the applicable limits in 10CFR20.1207 or 10CFR20.1208. [10CFR20.1502(a)(2)]

3. Individuals entering a high or very high radiation area. [10CFR20.1502(a)(3)]

B. Equipment to monitor, as specified in 10CFR20.1204, the occupational intake of radioactive material by and assess the committed effective dose equivalent to:

1. Adults likely to receive, in 1 year, an intake in excess of $10 \%$ of the applicable annual limit on intake in table 1, Columns 1 and 2, of appendix B to 10CFR20.1001 10CFR20.2401. [10CFR20.1502(b)(1)]

2. Minors and declared pregnant women likely to receive, in 1 year, a committed effective dose equivalent in excess of $0.05 \mathrm{rem}(0.5 \mathrm{mSv})$. [10CFR20.1502(b)(2)]

\subsubsection{Criticality Protection}

A. All systems for processing, transporting, handling, storing, retrieving, emplacing, and isolating radioactive waste shall be designed to ensure that a nuclear criticality accident is not possible unless at least two unlikely, independent, and concurrent or sequential changes have occurred in the conditions essential to nuclear criticality safety. Each system shall be designed for criticality safety under normal and accident conditions. The calculated effective multiplication factor $\left(k_{\text {eff }}\right)$ must be sufficiently below unity to show at least a 5\% margin, after allowance for the bias in the method of calculation and the uncertainty in the experiments used to validate the method of calculation. [10CFR60.131(b)(7)]

B. If an assessment of the MGDS design indicates a potential for nuclear criticality, the MGDS shall be designed and constructed to comply with the nuclear criticality requirements specified by DOE Order 6430.1A, 1300-4. [DOE Order 6430.1A, 1300-4]

C. Facilities used to process radioactive wastes shall be designed and constructed to comply with the nuclear criticality criteria specified in DOE Order 6430.1A, 1324-3. [DOE Order 6430.1A, 1324-3]

\subsubsection{Low Level Waste Disposal}

A. If the design of the MGDS provides for disposal of licensed low-level waste material into sanitary sewerage, the requirements of 10CFR20.2003 shall be met. [10CFR20.2003]

B. If the design of the MGDS provides for treatment or disposal of licensed low-level waste material by incineration, only the amounts and forms specified in 10CFR20.2005, or 
specifically approved by the NRC pursuant to 10CFR20.2002, shall be allowed. [10CFR20.2004]

\subsubsection{Transportation Protection}

The MGDS shall be provided with the capability to comply with the requirements for the packaging and transporting of radioactive materials contained in 10CFR71 and 49CFR 173 when transporting licensed radioactive material between the MGDS and other CRWMS elements. [CRD]

\subsubsection{Interface Requirements}

\subsubsection{MGDS Local Interfaces}

A. Requirements for external interfaces that affect design, e.g. those with local governments, local utilities, and others, shall be addressed within the design requirements documents. No separate interface specifications will be developed for these interfaces. [CRD]

B. The DRDs shall identify and describe interfaces between MGDS segments. [CRD]

\subsubsection{Interfaces with Other CRWMS Elements}

The interface requirements between the MGDS and the other elements of the CRWMS are included in this section.

In the following sections, requirements on the system element that interfaces with the MGDS are specified in the corresponding System Requirements Document. Those that relate to MPCs are repeated here for information and symmetry. The phrase "is responsible for" is used to indicate that, although the capability is mandatory, it is provided by another system element and is not a requirement on the MGDS.

\subsection{MGDS-MRS Interface Requirements}

I The MGDS and the MRS system elements have an interface through the combined waste capacity limits in effect when the two facilities are less than 50 miles apart; through the licensing linkage mandated by law; during operation when SNF is unloaded from the transportation cask subsystems and its identity is verified. The administrative interface between the two elements, which includes the communication of plans, schedules, and reports, is not addressed in this technical MGDS-RD.

A. In the event that the MRS is located, or planned to be located within 50 miles of the first repository, the combined quantity of waste in both the MRS and the first repository shall not exceed 70,000 metric tons of heavy metal until a second repository is in operation. [NWPA Section 114(d)]

1 B. Reserved. 


\subsection{MGDS-Waste Acceptance Interface Requirements}

The MGDS and Waste Acceptance system elements have interfaces when SNF and HLW are unloaded from the transportation casks arriving from Purchasers and Producers and its identity and characteristics are verified.

A. The MGDS shall be capable of receiving and handling standard, failed, and nonstandard SNF described in paragraphs 1,2 , and 3 below, respectively.

1. Standard SNF meeting the criteria specified in 10CFR961.11 Appendix E, Sections B.1 through B. ${ }^{11}$

2 Failed SNF meeting the criteria specified in 10CFR961.11 Appendix E, Section B.6

3. Nonstandard SNF, which is any SNF that does not fall within the standard or failed SNF description in paragraphs 1 or 2 above [10CFR961.11 Article VI.A.1]

B. The MGDS shall be capable of receiving and handling standard and nonstandard HLW described in paragraphs 1 and 2 below, respectively.

1. Standard canistered HLW, which is borosilicate glass sealed inside an austenitic stainless steel canister that has a concentric neck and lifting flange and meets the following criteria:

a. Total length will be 3.000 meters $(+0.005,-0.020 \mathrm{~m})$.

b. Diameter will be 61.0 centimeters $(+1.5,-1.0 \mathrm{~cm})$.

c. Weight will not exceed 2500 kilograms.

d. Fill height will be equivalent to at least $80 \%$ of the volume of the empty canister.

e. Total heat generation rate will not exceed 1500 watts per canister at the year of shipment.

f. Waste temperature will not have exceeded $400^{\circ} \mathrm{C}$ during transit to ensure that the glass transition temperature was not exceeded.

2. Nonstandard canistered HLW, which is any HLW that does not fall within the standard canistered HLW description in paragraph 1. [10CFR961.11 Article VI.A.1] 
C. The MGDS shall be capable of handling standard canistered HLW using a grapple provided by the waste producer. The grapple will have the following capabilities.

1. The grapple, when attached to the hoist and engaged with the flange, will be capable of moving the canistered waste form in the vertical direction.

2. The grapple will be capable of being remotely engaged with and remotely disengaged from the HLW canister flange.

3. The grapple will be capable of being engaged or disengaged while remaining within the projected diameter of the waste form canister.

4. The grapple will include features that prevent inadvertent release of a suspended canistered waste form. [Derived]

D. The MGDS shall be capable of handling standard, failed, and nonstandard SNF, and nonstandard canistered HLW using grapples of its own design. [Derived]

E. The MGDS shall have the capability to open MPCs and to inspect and verify the description and characteristics of:

1. SNF prior to loading into a waste package, MPC, or transportation cask

2. HLW prior to loading into a waste package or transportation cask

3. Loaded MPCs prior to loading into a waste package or transportation cask.

If the SNF or HLW is improperly described, the MGDS will notify Waste Acceptance for resolution of the waste description. <TBR> [10CFR961.11 Art VI B.2, B.3(b)] [CRD 3.2.1.1.A]

\subsection{MGDS-Transportation Interface Requirements}

I The MGDS and Transportation system elements have interfaces when SNF and HLW loaded in I transportation cask subsystems are received for disposal at the MGDS and when unloaded casks I are returned to the system. It is recognized that the MPC and transportation cask designs will I be required years before a final MGDS design is available. The required interface coordination I will be done on an iterative basis.

A. The Transportation motive support equipment and the MGDS shall be equipped with compatible communication equipment to allow truck drivers and rail engineers operating in the immediate vicinity of the MGDS to provide advance notice of their arrival. [Derived]

B. Access points for vehicles carrying transportation casks shall have an area for detaching and removing the Transportation motive support equipment from the site and attaching an on-site vehicle to the transporter. [Derived]

C. Provision shall be made for inspection of transportation cask subsystems upon receipt. This inspection includes measurement of radiation levels external to the transportation 
casks, levels of rontamination on the transportation cask surface, and the surface temperatures of the transportation casks. [Derived]

D. Area shall be provided for queuing transportation casks/transporter systems awaiting access to the MGDS cask handling facility as designated in Table 3-4. [Derived]

Table 3-4. MGDS Queuing Space for Transportation Cask Subsystems <TBR>

\begin{tabular}{|l|c|c|}
\hline $\begin{array}{l}\text { Transportation } \\
\text { Cask/Transporter Type }\end{array}$ & $\begin{array}{l}\text { Number of } \\
\text { Truck Casks }\end{array}$ & $\begin{array}{c}\text { Number of } \\
\text { Rail Casks }\end{array}$ \\
\hline Loaded 'From-Reactor' & $<$ TBD $>$ & $\langle$ TBD $\rangle$ \\
\hline Unloaded 'From-Reactor' & SBD $>$ & $\langle$ TBD $\rangle$ \\
\hline Loaded MPC & N/A & 8 \\
\hline Unloaded MPC & N/A & 10 \\
\hline
\end{tabular}

E. The MGDS shall provide queuing space sufficient to allow 20 feet separation between loaded transportation casks awaiting access to the cask handling facility. [49CFR177.842(f)]

F. The MGDS shall be capable of receiving and handling transportation casks subsystems which include casks and may be loaded with MPCs, as provided by Transportation. The types of transportation cask subsystems presently available or anticipated to be available are shown in Table 3-5. [10CFR961.11 Article IV.B.2] <TBR>

Transportation will deliver NRC-certified casks, which may include MPCs, to the MGDS for loading and/or unloading operations.

Table 3-5. Types of Transportation Cask Subsystems <TBR>

\begin{tabular}{|c|c|c|c|c|c|c|c|}
\hline \multirow[b]{2}{*}{ Category } & \multirow{2}{*}{$\begin{array}{c}\text { NRC } \\
\text { Docket } \\
\text { No. }\end{array}$} & \multirow[b]{2}{*}{ Type } & \multicolumn{2}{|c|}{ Capacity } & \multirow{2}{*}{$\begin{array}{l}\text { Loaded } \\
\text { Weight } \\
\text { (lbs) }\end{array}$} & \multicolumn{2}{|c|}{ Overall Dimensions } \\
\hline & & & PWR & BWR' $^{\prime}$ & & $\begin{array}{l}\text { Length } \\
\text { (in.) }\end{array}$ & $\begin{array}{l}\text { Diameter } \\
\text { (in.) }\end{array}$ \\
\hline 'From-Reactor: & Exioting C & & & & & & \\
\hline NLI $1 / 2$ & $71-9010$ & LWT & 1 & 2 & 49,500 & 195.2 & 47.125 \\
\hline NAC-LWT & $71-9225$ & LWT & 1 & 2 & 49,000 & 214 & 50 \\
\hline TN-8 & $71-9015$ & OWT & 3 & - & 79,400 & 218 & 68 \\
\hline TN-9 & $71-9016$ & OWT & - & 7 & 79,400 & 227 & 68 \\
\hline IF-300 & $71-9001$ & Rail & 7 & 17 & 140,000 & 210 & 64 \\
\hline
\end{tabular}


Title: Mined Geologic Disposal System Requirements Document

\begin{tabular}{|c|c|c|c|c|c|c|c|}
\hline \multirow[b]{2}{*}{ Category } & \multirow{2}{*}{$\begin{array}{c}\text { NRC } \\
\text { Docket } \\
\text { No. }\end{array}$} & \multirow[b]{2}{*}{ Type } & \multicolumn{2}{|c|}{ Capacity } & \multirow{2}{*}{$\begin{array}{l}\text { Loaded } \\
\text { Weight } \\
\text { (lbs) }\end{array}$} & \multicolumn{2}{|c|}{ Overall Dimeasions } \\
\hline & & & PWR & BWR' & & $\begin{array}{l}\text { Length } \\
\text { (in.) }\end{array}$ & $\begin{array}{l}\text { Diameter } \\
\text { (in.) }\end{array}$ \\
\hline \multicolumn{8}{|c|}{$\begin{array}{l}\text { From-Reactor: } \\
\text { Imnovativo Technolory }\end{array}$} \\
\hline OA-4 & 71.9226 & LWT & 4 & . & 52,600 & 187.5 & 48 \\
\hline OA-9 & 71.9227 & LWT & - & 9 & 52,900 & 198.0 & 47.73 \\
\hline Extra Long & $\langle\mathrm{TBD}\rangle$ & $\langle\mathrm{TBD}\rangle$ & $\langle\mathrm{TBD}\rangle$ & $\langle T B D\rangle$ & $\langle\mathrm{TBD}\rangle$ & $\langle\mathrm{TBD}\rangle$ & $\langle\mathrm{TBD}\rangle$ \\
\hline \multicolumn{8}{|c|}{ Traopportable Storage Cacks } \\
\hline$\langle$ TBD $\rangle$ & $\langle\mathrm{TBD}\rangle$ & Rail & 26 & 52 & 200,000 & 202 & 102 \\
\hline \multicolumn{8}{|l|}{ HIW Cak } \\
\hline$\angle \mathrm{TBD}\rangle$ & $\langle\mathrm{TBD}\rangle$ & $\langle\mathrm{TBD}\rangle$ & $\angle T B D\rangle$ & $\langle\mathrm{TBD}\rangle$ & $\langle\mathrm{TBD}\rangle$ & $\langle\mathrm{TBD}\rangle$ & $\langle\mathrm{TBD}\rangle$ \\
\hline \multicolumn{8}{|c|}{ Mula-Purpoes Canbars ' } \\
\hline $\begin{array}{l}\text { MPC for 75-Ton } \\
\text { Cack Subsyztem }\end{array}$ & N/A & N/A & 12 & 24 & $<\mathrm{TBD}\rangle$ & 195 & 50 \\
\hline $\begin{array}{l}\text { 75-Ton MPC Cask } \\
\text { Subsyatem }{ }^{3}\end{array}$ & $\langle$ TBD $\rangle$ & Rail & 12 & 24 & 150,000 & 205 & 70 \\
\hline $\begin{array}{l}\text { MPC for 125-Ton } \\
\text { Caak Subsyztem }\end{array}$ & N/A & N/A & 21 & 40 & $\langle\mathrm{TBD}\rangle$ & 195 & 60 \\
\hline $\begin{array}{l}\text { 125-Ton MPC } \\
\text { Cask Subsystem }\end{array}$ & $\langle\mathrm{TBD}\rangle$ & Rail & 21 & 40 & 250,000 & 210 & 90 \\
\hline
\end{tabular}

Capacity of BWR fuel assembly with channols

The requirement to bandle existing casks at the MODS is <TBR>

Nominal values, for planning purposes only, based on the MPC Conceptual Design Report

G. The MGDS shall have facilities to clean the interiors of unloaded casks to satisfy the requirements of Transportation and any existing agreements for cleanliness with the waste Purchasers/Producers or the MRS. [Derived]

H. The MGDS shall provide facilities to support Transportation emergency operations. [Derived]

1. The MGDS shall provide a queuing area sufficient to accommodate loaded cask storage for waiting times of 24 hours. [Derived]

J. The MGDS shall provide an emplacement environment (e.g., waste package design, underground facility design, emplacement mode or orientation, spacing between waste packages, etc.) for the MPC with disposal container, such that an emplaced waste package with a thermal output of $14.2 \mathrm{~kW}$ will not result in an MPC surface temperature higher than $225^{\circ} \mathrm{C}<\mathrm{TBR}>$. [Ref 2.4.2.C] [RW-0199] [10CFR60.135(a)(2)] [Derived by 3.2.1.1.H] 
The MPC design is responsible for maintaining the peak SNF cladding temperature below the maximum temperature designated for disposal. To meet this requirement, the peak cladding temperature in a loaded MPC with a thermal output of $14.2 \mathrm{~kW}$ may not exceed $350^{\circ} \mathrm{C}$ when subjected to an MPC external wall temperature of $225^{\circ} \mathrm{C}$.

K. Any MODS facilities provided for waste storage shall be designed to provide an environment capable of maintaining an ambient temperature not to exceed the ambient temperature designated (in the MPC design) for storage. [10CFR60.135(a)(2)] [Derived by CRD 3.2.1.1.H]

The MPC design is responsible for maintaining the peak SNF cladding temperature below the maximum cladding temperature designated for storage, in the storage environment provided at the MGDS.

L. The waste package design shall interface with the MPC design to ensure compliance with the requirements specified in Section 3.7.3.3.G of this MGDS-RD. [CRD 3.2.3.2.B] [DOE 4700.1 Ch II B.2.c(2)(c)]

The MPC design is responsible for meeting applicable requirements imposed on waste forms in 10CFR60.135(c) and Section 3.7.3.3.0 of this MGDS-RD.

M. The waste package design shall interface with the MPC design to ensure compliance with the nuclear criticality requirements specified in Section 3.2.2.6 of this MGDS-RD. [10CFR60.131(b)(7)] [CRD 3.2.2.5]

The MPC design is responsible for maintaining the SNF subcritical under normal and off-normal conditions.

N. Design of the waste package shall not preclude removal of the MPC without damage to the MPC.[10CFR60.131(b)] [CRD 3.2.1.3]

The MPC design is responsible for not precluding removal of the SNF intact.

O. The waste package design shall be coordinated with the MPC design to ensure structural, metallurgical, thermal, radiological, and dimensional compatibility.

[DOE 4700.1 Ch III B.2.c(2)(c)][CRD 3.2.3.2.B]

The MPC design is responsible for coordinating with the waste package design to ensure that MPC weight, dimensional envelope, and configuration do not exceed MGDS capabilities to transfer underground, emplace, and retrieve the loaded waste package. 
P. Repository Segment waste handling equipment and facilities shall be physically compatble with waste forms and MPCs as received from Transportation. [DOE 4700.1 Ch III B.2.c(2)(c)][CRD 3.2.3.2.B]

The MPC design is responsible for coordinating with the waste package design to ensure that MPC weight, dimensional envelope, and configuration do not exceed MODS capabilities to transfer underground, emplace, and retrieve the loaded waste package.

Q. The waste package container(s) shall provide structural integrity for the loaded MPC to withstand the loads induced in waste-handling operations, including retrieval. [NWPA 122] [10CFR60.135(b)(3)] [Derived by CRD 3.2.1.1.H, CRD 3.2.1.1.J, CRD 3.2.5.1.C]

The MPC design is responsible for:

1. the structural and confinement integrity of the loaded MPC outside of any overpacks under loads imposed by repository waste transfer operations (including transfer operations following retrieval).

2. the structural integrity of the MPC and SNF assemblies while loaded in the waste package under loads imposed by repository handling operations. This includes the requirement that structural integrity be preserved for 100 years following emplacement to allow intact unloading after retrieval of the waste package.

R. The waste package container(s) shall provide structural integrity for the waste form (whether or not loaded in an MPC) to withstand the loads induced in off-normal occurrences. [10CFR60.135(b)(3)] [CRD 3.2.5.1.C]

The MPC design is responsible for:

1. the structural and confinement integrity of the loaded MPC outside of any overpacks under loads imposed by ... . off-normal occurrences.

2. the structural integrity of the MPC and SNF assemblies while loaded in the waste package under loads imposed by ... off-normal occurrences.

S. The MODS shall have the capability to cut open an MPC, remove and replace SNF without damage to the SNF, and re-seal the MPC for disposal. [10CFR60.131(b)] [CRD 3.2.1.3]

The MPC design is responsible for providing the capability to be cut open and re-sealed for disposal at the MGDS. 
T. The MGDS shall be capable of adding filler <TBD> material to the MPC. <TBR> [10CFR60.131(b)(7), 10CFR60.135(a)(2)] [CRD 3.2.3.2.B]

The MPC design is responsible for providing for the addition of filler material at the MGDS.

U. The MGDS shall be capable of receiving waste shipments by rail and truck. [RW-0316P $p$ 101] [CRD 3.2.1.1.1]

All shipments from the MRS facility to the MODS will be made by rail in dedicated trains.

Shipments from Producer facilities will be by rail in dedicated trains.

Shipments from Purchaser facilities will be made by truck or rail.

\subsection{Segment Interface Summary}

The MODS design shall address requirements for the MODS segment interfaces with Transportation segments identified in Table 3-6. The ' $X$ ' in the table indicates that there is a functional interface between the segments involving Function 1.2 Transport Waste. An entry of "None" in the table indicates that no interface has been identified between the segments. [DOE 4700.1 Ch III B.2.c(2)(c)][CRD 3.2.3.2.B]

Transportation is responsible for ensuring that the Transportation Segment interfaces to Function 1.4 Dispose of Waste at the MGDS are addressed.

Table 3-6. MGDS Segment-to-Transportation Segment Interfaces

\begin{tabular}{|c|c|c|c|c|}
\hline $\begin{array}{c}\text { Trans } \rightarrow \\
\text { SEGMIENTS } \\
\text { MODS } \downarrow\end{array}$ & $\begin{array}{c}\text { TRANS CASK } \\
\text { SUBSYSTEMS } \\
\text { SEGMENT }\end{array}$ & $\begin{array}{c}\text { TRANS SERVICE AND } \\
\text { MANTENANCE } \\
\text { SUPPORT SEOMENT }\end{array}$ & $\begin{array}{c}\text { TRANS FLED } \\
\text { OPERATIONS } \\
\text { SEGMENT }\end{array}$ & $\begin{array}{c}\text { TRANS PLANINING } \\
\text { AND CONTROL } \\
\text { SEGMENT }\end{array}$ \\
\hline SITE SEGMENT & NONE & NONE & NONE & NONE \\
\hline $\begin{array}{c}\text { REPOSITORY } \\
\text { SEGMENT }\end{array}$ & $\mathrm{X}$ & $\mathrm{X}$ & $\mathrm{X}$ & $\mathrm{X}$ \\
\hline EBS SEGMENT & $\mathrm{X}$ & NONE & NONE & NONE \\
\hline
\end{tabular}




\subsubsection{Phyaical Characteriatics}

Selection of standards to meet the requirements specified in this section shall be by engineering analysis and shall be documented in accordance with appropriate QA procedures. [CRD]

\subsubsection{Protective Coatings and Materials}

Facilities and equipment that require coating to enhance decontamination of surfaces or because of environmental requirements shall be coated in accordance with ASTM D4256, or other DOEapproved guideline, e. g. DOE Order 6430.1A, 0900-99.0. [CRD]

\subsubsection{Habitability}

Some of the following statements refer to two or more documents which are acceptable references, the choice of which is left to design analysis.

\subsection{Environmontal Controls}

Environmental controls shall be capable of maintaining an environment that provides comfortable and appropriate workspace temperature, humidity, and personal storage, lavatory, and toilet facilities as required by 29CFR1910.141. NUREO 0700 Section 6.1 .5 may be used for reference. [29CFR1910.141]

\subsection{Heating, Ventilation, and Air Conditioning}

Heating, ventilation, and air conditioning equipment in surface facilities shall be sized to conform with the guidelines in NUREG 0700 Section 6.1.5. MIL-STD-1472D Section 5.8.1 and the applicable ASHRAE standard may be used for reference. [CRD]

\subsection{Ilumination}

Lighting in working areas and other enclosures shall conform to the applicable Recommended Practice of the Illuminating Engineering Society. NUREG 0700 Section 6.1.5 may be used for reference. [CRD]

\subsection{Acoustical Noise}

Work spaces shall be provided an acoustical environment that conforms to the requirements of 29CFR1910.95. NUREG 0700 Section 6.1.5 and MIL-STD-1472D Section 5.8.3 may be used for reference. [29CFR1910.95]

\subsection{Vibration}

Facilities, buildings, personnel enclosures, and vehicles shall be designed, located, or modified for vibration control (to be determined at the design level). ANSI Standard S-3.18 or MIL-STD1472D Section 5.8.4 may be used for reference. [CRD] 


\subsection{Underground Personnel Enclosures}

Unless otherwise specified, underground personnel enclosures, including but not limited to those provided for offices, laboratories, break rooms and the like, shall, to the extent practicable as determined by design analysis, conform to the environmental and habitability requirements specified above for surface personnel enclosures. This requirement does not apply to areas where active construction is underway and areas where deemed unnecessary by project-level design analysis. [CRD]

\subsubsection{Security}

\subsection{Physical Security ${ }^{12}$}

\subsection{Physical Protection}

The physical security system and access controls shall be designed and constructed to satisfy the applicable security requirements of DOE Order 6430.1A, 1300-10, tailored to the application and focused on the threat of sabotage to special nuclear material facilities and theft of high-value equipment and supplies. [CRD]

\subsection{Physical Barriers}

A. Vital equipment shall be located within a vital area, which, in turn, shall be located within a protected area such that access to vital equipment requires passage through at least two physical barriers. More than one vital area may be within a single protected area. See section 6.1 for definition of vital area, vital equipment, protected area, and physical barrier. [Derived]

B. Material access areas shall be located within protected areas such that access to the material access area requires passage through at least two physical barriers. More than one material access area may be within a single protected area. [Derived]

C. The physical barrier at the perimeter of the protected area shall be separated from any other barrier designated as a physical barrier within the protected area, and the intervening space monitored or periodically checked to detect the presence of persons or vehicles so that the facility security organization can respond to suspicious activity or to the breaching of any physical barrier. [Derived]

D. An isolation zone shall be established around the physical barrier at the perimeter of the protected area and any part of a building used as part of that physical barrier. [Derived]

\footnotetext{
${ }^{12}$ The applicability of 10CFR73 to the MODS is <TBD>.
} 
E. There shall be monitors in the isolation zone to detect the presence of individuals or vehicles within the zone so as to allow response by armed members of the MGDS security organization to be initiated at the time of penetration of the protected area. [Derived]

F. Parking facilities, both for employees and visitors, shall be located outside the isolation zone. [Derived]

\subsection{Access Control}

A. The MODS shall provide control for all points of personnel and vehicle access into a protected area, including shipping or receiving areas, and into each vital area. [Derived]

B. Provisions shall be made to allow identification and validation of access authorization for personnel and vehicles at such points. [Derived]

C. At the point of personnel and vehicle access into a protected area, the MODS shall provide equipment and space necessary for a search of individuals and hand-carried packages for devices such as firearms, explosives, and incendiary devices, or other items which could be used for radiological sabotage. The search may be conducted either by a physical search or by the use of equipment capable of detecting such devices. [Derived]

D. The MGDS shall be designed to provide for identification and authorization checks and for a random search of all packages being delivered into the protected area. [Derived]

E. The MODS shall have a system to control keys, locks, combinations, and related equipment to minimize the possibility of compromise of the securit;' of nuclear material. [Derived]

\subsection{Security of Licensed Material}

The MGDS shall provide the capability to control and maintain constant surveillance over licensed material that is in a controlled or unrestricted area and that is not in storage. [10CFR20.1802]

\subsection{High Radiation Area Access Control}

A. Access to high and very high radiation areas shall be controlled in accordance with the requirements specified by 10CFR20.1601 and 20.1602. [10CFR20.1601] [10CFR20.1602] 
B. The MGDS design shall provide at each entrance or access point to a high radiation area:

1. One or more of the following features:

a. A control device that, upon entry into the area, causes the level of radiation to be reduced below that level at which an individual might receive a deep-dose equivalent of $0.1 \mathrm{rem}(1 \mathrm{mSv})$ in 1 hour at 30 centimeters from the radiation source or from any surface that the radiation penetrates [10CFR20.1601(a)(1)]

b. A control device that energizes a conspicuous visible or audible alarm signal so that the individual entering the high radiation area and the supervisor of the activity are made aware of the entry [10CFR20.1601(a)(2)]

c. Entryways that are locked, except during periods when access to the areas is required, with positive control over each individual entry [10CFR20.1601(a)(3)]

2. Or, in place of the controls required by 3.2.4.3.2.B.1 above, continuous direct or electronic surveillance that is capable of preventing unauthorized entry [10CFR20.1601(b)]

3. Or an alternative method for controlling access to high radiation areas approved in advance by the NRC. [10CFR20.1601(c)]

4. The controls required by subparagraphs 1 and 3 above shall not prevent individuals from leaving a high radiation area. [10CFR20.1601(d)]

5. Control shall not be required for each entrance or access point to a room or other area that is a high radiation area solely because of the presence of radioactive materials prepared for transport and packaged and labeled in accordance with the regulations of the Department of Transportation provided that the packages do not remain in the area longer than 3 days and the dose rate at 1 meter from the external surface of any package does not exceed $0.01 \mathrm{rem}(0.1 \mathrm{mSv})$ per hour. [10CFR20.1601(e)]

\subsection{Underground Access Controls}

A system shall be provided to control access to the underground as required by 30CFR57.11058 and 29CFR1926.800(c). [30CFR57.11058][29CFR1926.800(c)]

\subsubsection{Radioactive Materials Monitoring}

The MGDS shall be equipped to monitor the exposed external surfaces of packages, Transportation casks, and MPCs known to contain radioactive material for radioactive contaminativi and radiation levels in compliance with 10CFR20.1906. [10CFR20.1906] 


\subsubsection{Shielding}

\subsection{Shielding Design}

A. Normally Occupied Areas. The shielding design basis shall limit the maximum exposure to an individual worker to one-fifth of the annual occupational external exposure limits. Within this design basis, personnel exposures must be maintained ALARA. Specifically, the shielding should be designed with the goal of limiting the total Effective Dose Equivalent to less than one rem per year to workers, based on their predicted exposure time in the normally occupied area. The Effective Dose Equivalent is the sum of all contributing external penetrating radiation (gamma and neutron). In addition, appropriate shielding must be installed, if necessary, to minimize non-penetrating external radiation exposures to the skin and lens of the eye of the worker. In most cases, the confinement barrier or process equipment provides this shielding. [DOE Order 6430.1A, $1300-6.2]$

B. Intermittently Occupied Areas. Shielding and other radiation protection measures shall be provided for areas requiring intermittent access, such as for preventive maintenance, component changes, adjustment of systems and equipment, and so forth, with the goal of limiting dose rates based on occupancy, time, and frequency of exposure to one rem per year. [DOE Order 6430.1A, 1300-6.2]

C. Concrete. Concrete radiation shielding design shall comply with ANSI/ANS 6.4 and ACI 349 and shall consider the material specifications of ANSI/ANS 6.4.2 where it provides a critical confinement or structural function. For other shields, ACI 318 is appropriate and provides adequate strength for design earthquake (DE) loads. [DOE Order 6430.1A, 1300-6.2]

D. Penetrations. Design of shield walls shall avoid straight-line penetrations to prevent radiation streaming. [DOE Order 6430.1A, 1300-6.2]

\subsection{Remote Shielded Operation}

Remote shielded operation (i.e., with remote handling equipment such as remote manipulators) shall be considered where it is anticipated that exposures to hands and forearms would otherwise approach the dose requirements in section 3.2.2 or where contaminated puncture wounds could occur. [DOE Order 6430.1A, 1300-6.3]

\subsubsection{Design Basis Events and Accidents}

A. Design Objective. A design objective shall be to ensure that conservatively estimated consequences of normal operations and credible accidents are limited in accordance with requirements contained in DOE Order 6430.1A, Section 1300-1.4, Guidance on Limiting Exposure of the Public. The MGDS DRDs will develop events based on site function and licensing requirements. [DOE Order 6430.1A, 1324-2.1] 
B. Aircraft. Unless the safety analysis can demonstrate that the risk from an aircraft crashing into the facility is acceptable, potential aircraft crashes shall be considered among the spectrum of man-made missiles that confinement structures must be designed to withstand or against which they must be protected. [DOE Order 6430.1A, 0111-99.0]

C. External Blasts and Missiles. The potential effects of a major explosion at a nearby facility or transportation route shall be considered among the spectrum of external blast effects and missiles that confinement structures must be designed to withstand or against which they must be protected. [DOE Order 6430.1A, 0111-99.0]

D. Internal Blasts and Missiles. The probable consequence of design basis accidents involving internally generated missiles or blast effects shall be considered. Such design basis accidents typically involve failure of high-speed rotating machinery, cranes, experimental facilities, high-energy fluid system components, or explosives. Structures required to function following such accidents must be designed to withstand these design basis accidents. [DOE Order 6430.1A, 0111-99.0]

\subsubsection{System Quality Factors}

The quality factors for the MGDS are described in this section. These factors include Reliability, Maintainability, Inspectability, Availability, and Service Life.

\subsubsection{Reliability}

The MGDS shall be designed and constructed to provide a fault-tolerant (or fail-safe) system that allows for the continued management, handling, transfer, storage, emplacement, retrieval, and isolation of SNF and HLW in a safe manner that optimally protects health, safety, and the environment under all operational conditions. Nothing in this section shall be construed to indicate that NRC-mandated redundancy of systems may be neglected. [CRD]

\subsection{Reliability Program Requirements}

The MGDS design organizations shall establish and execute a reliability, availability, and maintainability (RAM) program to support Integrated Logistics Support and the general engineering program for the CRWMS. Reliability shall be addressed as an element of design reviews. [CRD]

\subsection{Reliability of Equipment ${ }^{13}$}

A failure modes and effects analysis shall be performed for all major equipment whose failure can result in personnel injury or illness. Based on this analysis, designs shall be developed to ensure reliability which minimizes safety hazards to the extent possible. Under such design conditions, failures shall not result in personal injury or occupational illness. If designs cannot

\footnotetext{
${ }^{13}$ This requirement is applicable to the MGDS only during preclosure.
} 
be developed to these requirements, then the reliability of systems will be shown by analysis to be such as to minimize the probability of injury or illness to personnel. In demonstrating system reliability, MIL-STD-882B shall be considered in the design, where applicable. (These requirements differ from "items important to safety" and "items important to waste isolation", both of which have very specific meanings for meeting NRC requirements. Further, these criteria do not supplant radiological standards contained in NRC or EPA requirements; e.g., the radiological standards of 10CFR20. They also do not address reliability of the engineered barrier system.) [CRD]

\subsection{Structure, System and Component Reliability}

Structures, systems, and components that are important to safety shall be designed and located so that they continue to perform their safety functions effectively during and after credible fire and explosion conditions in the GROA. [10CFR60.131(b)(3)]

\subsection{Utilities Reliability}

A. Each utility service system that is important to safety shall be designed so that essential safety functions can be performed under both normal and accident conditions. [10CFR60.131(b)(5)(i)]

B. The design of utility services and distribution systems that are important to safety shall include redundant systems to the extent necessary to maintain, with adequate capacity, the ability to perform safety functions. [10CFR60.131(b)(5)(ii)]

\subsection{System Throughput}

All equipment shall be shown by analysis to have adequate reliability to allow the MGDS to meet the throughput requirements identified in Table 3-3 and its mission. [CRD]

\subsubsection{Maintainability/Inspectability}

\subsection{Testing and Maintenance}

Systems, structures, and components that are important to safety shall be designed to permit periodic inspection, maintenance, and testing as necessary to ensure their continued functioning and readiness. [10CFR60.131(b)(6)]

\subsection{Physical Clearance}

A. Corridors. The size and arrangement of interior corridors shall accommodate the movement of equipment including initial equipment installation, facility operations, and possible future removal or replacement of equipment. [DOE Order 6430.1A, 0110-99.0.4]

B. Maintenance Accessibility. Facility design shall provide access for routine maintenance, repair, or replacement of equipment subject to failure. Accessibility includes proper 
lighting and utility hookups and acceptable levels of radiological exposure. [DOE Order 6430.1A, 1300-3.5]

\subsection{Mean Time to Repair}

The mean time to repair each piece of installed equipment shall be identified in design calculations. Sufficient parts must be maintained in inventory for items to be repaired in place and qualified repair personnel available to ensure the mean time to repair can be achieved. [Derived]

\subsection{Replacement Equipment}

A. Replacement equipment shall be provided as necessary for equipment which must be removed to be repaired to support the mean time to repair. Such equipment must be accessible and transportable. [Derived]

B. A lifting device having capability to remove and install equipment shall be provided for equipment that weighs more than the limits for human portability. [Derived]

C. Replaceability shall be addressed during design for all equipment. [Derived]

\subsection{Fault Isolation}

When fault isolation is important in addressing mean times to repair, fault detection shall be built into the system in terms of electronic detection, measurement points, etc., to the extent practicable. [Derived]

\subsection{Maintenance in Radioactive Environments}

Equipment which normally operates in a radioactive environment or in the vicinity of radioactive components shall be designed to be moved to a non-radioactive environment for maintenance or repair, whenever possible. When that is not possible, the design shall allow for installation of temporary shielding, permit minimizing radiation exposure times, and provide sufficient space for ease of operation, maintenance, and repair. [10CFR60.131(a)(2)]

\subsection{Important to Safety Equipment}

Equipment which could fail during an operation important to safety shall be designed to permit recovery of the operation without compromising the health and safety of the public or the MGDS employees. [Derived] 


\subsection{Design for Maintainability}

A. The MGDS shall be designed and constructed so that facilities are easily and economically maintained. Maintainability considerations include:

1. Use of easily maintained features and durable materials

2. Ease of replacement of installed equipment (i.e., without structure modification)

3. Accessibility of installed equipment and building systems for performance of maintenance

4. Life cycle costs in selection of features, systems, and finishes

5. Provisions of maintenance instructions and as-built drawings, especially the location of underground and otherwise concealed utility lines, process chemical and coolant piping. [DOE Order 4700.1, p. V-17, q]

B. Engineered hardware shall be designed to meet the maintainability requirements as specified in UCRL 15673, Human Factors Guidelines for Maintainability of Department of Energy Nuclear Facilities, Section 1. Should hardware require movement by personnel in order to provide accessibility for maintenance, requirements for portability (Section 3.2.9 of this document) shall be included in the design. [UCRL 15673, Section 1]

C. Facility support equipment shall conform to the requirements for maintainability specified in UCRL 15673, Section 2. [UCRL 15673, Section 2]

D. The design of equipment, facilities and systems shall conform to the maintainability requirements specified in UCRL 15673, Section 3. [UCRL 15673, Section 3]

E. The time required to perform work in the vicinity of radioactive components shall be kept to an absolute minimum; for example, by providing sufficient space for ease of operation and designing equipment for ease of repair and replacement. [10CFR60.131(a)(2)]

\subsection{Mean Downtime}

Facilities, subsystems, and equipment of the MGDS shall be designed with a mean downtime that is consistent with the availability requirements specified in section 3.2.5.3 of this document. The mean downtime shall include mean time to repair, disruptive preventive maintenance time, logistics delay time, administrative delay time, and safety delay time. [Derived]

\subsubsection{Availability}

A. The MGDS design shall address availability as a factor in determining the operational capacity of its subsystems. [CRD] 
B. Reserved.

\subsubsection{Service Life}

A. The Repository Segment shall be designed for a maintainable service life of at least 100 years <TBR> or the period of time authorized by the license granted by the NRC in accordance with the provisions of 10CFR60.3. [Derived]

B. The service life requirements of structures, systems, and components shall be specified in the DRDs and derivative specifications. Service life values will normally be determined by the logistic support analysis specified in Section 3.5.2, and other engineering and cost studies with appropriate consideration to the terms of the license or certificate. [CRD]

\subsubsection{Overall Utilization}

Overall utilization is the product of scheduled utilization, availability, and worker productivity, where scheduled utilization is the ratio of scheduled operating hours per year to total hours per year. Availability is the system element availability as required in section 3.2.5.3. Worker productivity is the average fraction of a work period that workers perform required work; time waiting for resources, break time, dress out time, and other non-productive time is not included. [CRD]

A. Overall utilization shall be a subject addressed at design reviews. [CRD]

B. Reserved.

\subsubsection{Environmental Requirements}

\subsubsection{Natural Environment}

GROA structures, systems, and components important to safety shall be designed so that the effects of anticipated natural phenomena and environmental conditions will not interfere with necessary safety functions. [10CFR60.131(b)(1), (2)]

A. Natural Conditions. Natural phenomena and environmental conditions at the GROA considered in the design shall include events and conditions such as earthquakes, tornados, wind, lightning, floods, precipitation, humidity, temperature, sand and dust, and fungus, bacteria, and algae. [CRD]

B. Combinations. The design bases shall reflect appropriate consideration of the most severe conditions reported for the site and surrounding area and appropriate combinations of the normal and accidental conditions and the effects of natural phenomena, with appropriate margins to take into account the limitations of the data and the period of time in which the data have accumulated. [CRD] 
C. Adverse Interaction. All structures, systems, and components shall be designed so that their failure does not lead to loss of safety function of structures, systems and components that are important to safety. [Derived]

D. Design Earthquake. Design earthquake parameters for surface facilities that house waste handling functions shall be calculated in accordance with UCRL 15910. [Derived]

E. Tornado and Extreme Wind

1. Regulatory Guidance. The guidance in NRC Regulatory Guide 1.76, Design Basis Tornado for Nuclear Power Plants, applies to the geologic repository design. [Derived]

2. Determination of Design Basis Tornado. DOE site-specific hazard model studies summarized in UCRL 53526 shall be used to select the design basis tornado and extreme wind characteristics for the design of structures important to safety. If sitespecific hazard model studies are not available, a hazard model shall be developed consistent with the approach used in UCRL 15910. In applying UCRL 53526, specific information on relating frequency of occurrence to facility hazard levels may be obtained from UCRL 15910. [DOE Order 6430.1A, 0111-99.0.2]

3. Tornado Analysis. In designing for tornado or extreme wind resistance:

a. The tornado rotational speed shall be appropriately combined with the translational speed. [DOE Order 6430.1A, 0111-99.0.2]

b. Resulting loads from the rate of pressure drop, taking into consideration any pressure equalization due to permissible venting, shall be combined with velocityinduced pressure loads as stipulated in UCRL 15910. [DOE Order 6430.1A, 0111-99.0.2]

c. UCRL 53526 provides the characteristics of typical potential tornado-generated missiles. Additional missiles may be identified from review of on-site sources and possible missiles that could be borne to the site by tomado. Both small highvelocity missiles and massive low-velocity missiles shall be considered separately in terms of penetration, perforation, or crushing effects. The horizontal and vertical velocities of the missiles shall be combined in the design. [DOE Order 6430.1A, 0111-99.0.2]

4. Load Combination. Loads resulting from the design basis tornado shall be assumed capable of occurring at any time. However, for design purposes, design basis tornado loads need not be assumed to occur simultaneously with other severe site-related events such as earthquake, fire, or flood, except where the simultaneous occurrence is related (e.g., fire from lightning or other wind-related causes). [DOE Order 6430.1A, 0111-99.0.2] 
F. Floods. The design loads on GROA facilities from flooding shall comply with UCRL 15910. In calculating design loads from flooding, a conservative approach must be taken to ensure that the loads used in the design are greater than the maximum historic levels recorded for the site and no less than the probable maximum flood. [DOE Order 6430.1A, 0111-99.0.3]

G. Flood Protection. If, after compliance with the requirements of the Executive Order 11988, new construction of structures or facilities are to be located in a flood plain, then:

1. Accepted flood-proofing and other flood protection measures shall be applied by the MGDS design to new construction or rehabilitation. [Executive Order 11988, Section 2(b)]

2. To achieve flood protection, the MGDS design shall, wherever practicable, elevate structures above the base flood level rather than filling in land. [Executive Order 11988, Section 2(b)]

\section{H. Earth and Groundwater}

1. Ever', foundation wall or other wall serving as a retaining structure shall be designed to resist, in addition to the vertical loads acting on it, the incident lateral earth pressures and surcharges, plus hydrostatic pressures corresponding to the maximum probable groundwater level. [DOE Order 6430.1A, 0111-2.8.2]

2. Retaining walls shall be designed for earth pressures and potential groundwater levels producing the highest stresses and overturning moments. When a water-pressure-relief system is incorporated into the design, only earth pressures need to be considered. In cohesive soils, the long-term consolidation effects on the stability of the walls must be considered. Lateral earth pressures must be determined in accordance with accepted structural and geotechnical engineering practice. [DOE Order 6430.1A, 0111-2.8.2]

I. Thermal Analysis. The design of structures shall include the effects of stresses and movements resulting from variations in temperature, including the effect of emplaced waste packages. The rise and fall in the temperature must be determined for the localities in which the structures are to be built. Structures must be designed for movements resulting from the maximum seasonal temperature change. The design must provide for the lags between air temperatures and the interior temperatures of massive concrete members or structures. In cable-supported structures, changes in cable sag and tension must be considered. [DOE Order 6430.1A, 0111-2.8.4]

J. Rain and Snow Loads. Live loads on roofs shall be as stipulated in ANSI/ASCE 7-88 which include the minimum roof live loads or the snow loads and snow drifts or possible rain loads stipulated therein, whichever produces the more severe effect. [DOE Order 6430.1A, 0111-2.3.2] 


\subsubsection{Induced Environment}

\subsection{Fire, Explosion, and Other Disaster Protection}

A. GROA structures, systems, and components important to safety shall be designed to perform their safety functions during and after credible fire or explosion conditions at the GROA. [10CFR60.131(b)(3)(i)]

B. The GROA shall be designed to include means to protect systems, structures, and components important to safety against the adverse effects of either the operation or failure of the fire suppression system. [10CFR60.131(b)(3)(iv)]

C. GROA structures, systems, and components important to safety shall be designed to withstand dynamic effects, such as missile impacts, that could result from equipment failure, and similar events and conditions that could lead to loss of their safety functions. [10CFR60.131(b)(2)]

\subsection{Fire Resistance}

A. For GROA facilities, development of the design basis fire shall include consideration of conditions that may exist during normal operations and special situations (e.g., during periods of decontamination, renovation, modification, repair, and maintenance). [DOE Order 6430.1A, 0110-99.0.6]

B. For GROA facilities, the structural shell surrounding the critical areas and their supporting members shall remain standing and continue to act as a confinement structure during the design basis fire under conditions of failure of any fire suppression system not designed as a safety class item. Fire resistance of this shell must be attained by an integral part of the structure (concrete slabs, walls, beams, and columns) and not by a composite assembly (membrane fire-proofing). Penetrations in this shell must incorporate, as a minimum, protection against design basis fire exposures. [DOE Order 6430.1A, 011099.0.6]

C. For GROA facilities, in no event shall the fire resistance rating be less than two hours under conditions of failure of any fire suppression system not designed as a safety class item. [DOE Order 6430.1A, 0110-99.0.6]

D. To the extent practicable, the GROA facilities shall be designed to incorporate the use of noncombustible and heat resistant materials. [10CFR60.131(b)(3)(ii)]

\subsection{Vibration}

Equipment supports shall be designed to avoid resonance resulting from the harmony between the natural frequency of the structure and the operating frequency of reciprocating or rotating equipment supported on the structure. The operating frequency of supported equipment must be determined from manufacturers' data prior to completion of structural design. Resonance must 
be prevented by designing equipment isolation supports to reduce the dynamic transmission of the applied load to as low a level as can be economically achieved in the design. [DOE Order 6430.1A, 0111-2.8.1]

\subsection{Creep and Shrinkage}

Concrete and masonry structures used to house waste handling facilities shall be investigated for stresses and deformations induced by creep and shrinkage. For concrete and masonry structures, the minimum linear coefficient of shrinkage must be assumed to be 0.0002 inch/inch, unless a detailed analysis is undertaken. The theoretical shrinkage displacement shall be computed as the product of the linear coefficient and the length of the member. [DOE Order 6430.1A, 01112.8.5]

\subsection{Underground Openings}

Underground openings shall be designed and constructed to provide suitable ground control in compliance with 30CFR57 Subpart B. [30CFR57 Subpart B]

\subsubsection{Transportability/Modularity}

To the extent practical, all temporary facilities shall be of either transportable or modular design. Specific requirements for temporary/modular facilities shall be addressed in DRDs as appropriate. [CRD]

\subsubsection{Flexibility, Expansion, and Integration}

MGDS facilities shall be designed and constructed so as not to preclude the later addition, where appropriate, of facilities for offices and laboratories or expansion of its basic mission, e.g. increased storage area or increased disposal capacity. [CRD]

\subsubsection{Portability and Load Carrying}

Equipment and components that are developed for the MODS and that must be moved over short distances for maintenance or other purposes shall be designed to facilitate movement by taking into consideration such things as weight, hand grips, lifting aids, etc. [CRD]

\subsection{DESIGN AND CONSTRUCTION}

\subsubsection{General Design Criteria}

A. All site survey, planning and design activities shall consider the criteria of DOE Order 6430.1A which do not pertain to areas under NRC jurisdiction. [CRD]

B. Unless specifically waived in writing by OCRWM, design and construction of wll MGDS facilities and equipment shall be accomplished using the criteria specifies in the 
appropriate section of DOE Order 6430.1A, unless those requirements pertain to areas under NRC jurisdiction. The following components are addressed in DOE Order 6430.1A:

1. General Requirements

2. Site and Civil Engineering

3. Concrete

4. Masonry

5. Metals

6. Woods and Plastics

7. Thermal and Moisture Protection

8. Doors and Windows

9. Finishes

10. Specialties

11. Equipment

12. Fumishings

13. Special Facilities

14. Conveying Systems

15. Mochanical

16. Electrical

[CRD]

C. State, county, municipal, and other local regulations, building and zoning codes, and ordinances shall be reviewed and incorporated, as appropriate, in the MGDS designs whenever those practices are not in conflict with the requirements of DOE Order 6430.1A. [Derived]

D. Should conflicts exist between DOE Order 6430.1A and state, county, municipal, or local codes or regulations, a deviation shall be requested in accordance with Section 0101-2, Criteria Deviations, of DOE Order 6430.1A. All deviations from DOE Order 6430.1A to meet NRC requirements or current engineering practices must be documented. [DOE Order 6430.1A, 0101-2]

E. All design bases shall be consistent with the results of site characterization. [10CFR60.130]

F. The MODS facilities licensed by the NRC shall meet all requirements indicated by the rules governing the license and specified by the MGDS-RD. [CRD]

G. Standards or other DOE-accepted documents, identified as sufficient or more appropriate for the support of design, shall be used at the discretion of the designers, provided there are no conflicts with the identified requirements of the MGDS. Examples of this type of documentation are NUREGs, Regulatory Guides and other similar types of guidance provided by the NRC. [CRD] 


\subsubsection{Electromagnetic Radiation}

A. Critical communications and data circuits shall be protected or shielded from electromagnetic interference from sources within the MGDS and from external sources to the extent specified by manufacturers of sensitive data processing and communications equipment used in the system. [DOE Order 6430.1A, 0200-99.8.1]

B. Lighting fixture types and locations shall be coordinated with the equipment and functions of telecommunication, alarm, and automatic data processing centers to provide the required illumination without creating electrical or electromagnetic interference detrimental to proper operation of equipment. [DOE Order 6430.1A 1655-99.8]

C. Shielding shall be provided to protect magnetic recording equipment, magnetic tapes, and disk packs where electromagnetic field of 10 microvolts or 50 Oersteds or greater can be expected. [DOE Order 6430.1A 0110-99.8.3]

D. Provisions shall be made to minimize the possibility of electromagnetic transmitters inadvertently detonating blasting caps. [Derived]

\subsubsection{Nameplates and Markings}

A. Equipment and any parts of that equipment to be used by personnel shall be identified with appropriate labels. Equipment and equipment parts include, but are not limited to, system and subsystem component groupings, individual components, control positions or modes, display markings, instructions, procedure manuals, storage spaces, access panels, and tools. [DOE Order 6430.1A, 1300-12.4.11]

B. The label shall indicate clearly and concisely the function and purpose of the item being labeled. Unnecessary information (e.g., information used only for manufacturing purposes) must not be included. Hierarchial labeling should be used to facilitate component location on control panels. [DOE Order 6430.1A, 1300-12.4.11]

C. The label information shall be easy to understand. Words, symbols, and other markings in a label or instruction shall be unambiguous and accurate. The terminology used shall have commonly accepted meaning for all users. [DOE Order 6430.1A, 1300-12.4.11]

D. Label design shall be consistent with use of abbreviations and acronyms minimized. Various equipment labels placed on the same or similar pieces of equipment and serving similar functions must use the same material, color, font type, relative location to component general format, and other configuration features to promote simplicity and avoid clutter. The terminology used for equipment, procedures, and training materials mus! be the same for each case. [DOE Order 6430.1A, 1300-12.4.11]

E. Permanent labels shall be attached to the specific component or equipment in such a manner that environmental conditions or usage by personnel will not remove or destroy the label. [DOE Order 6430.1A, 1300-12.4.11] 
F. The identification markings and identification plates, tags, or labels, when used on equipment, systems, subsystems, assemblies, subassemblies, components and piece parts if necessary, shall be permanent for the (pre-closure, in the case of waste packages) life of the item including withstanding environmental conditions and cleaning requirements. These markings shall be accomplished using methods that shall not impact the life and use of the item. [CRD]

(See Sections 3.3.6.6 and 3.3.7.8 for other Labeling and Marking requirements).

\subsubsection{Workmanship}

A. Special processes, including welding, heat treating, and nondestructive testing, shall be controlled and accomplished by qualified personnel using qualified procedures in accordance with applicable codes, standards, specifications, criteria, and other special requirements. [QARD]

B. The workmanship criteria shall reflect the currently applicable codes, standards, regulations, architectural, engineering principles and practices specified in DOE Order 6430.1A (General Design Criteria) - 0109 Reference Standards and Guides, including:
AASHTO
American Association of State Highway and Transportation Officials
ACI American Concrete Institute
AISC
American Institute of Steel Construction
AISI
American Iron and Steel Institute
ANS
American Nuclear Society
ANS1
American National Standards Institute
AREA
American Railway Engineering Association
ARI
Air Conditioning and Refrigeration Institute
ASCE
American Society of Civil Engineers
ASHRAE
American Society of Heating; Refrigerating, and Air-Conditioning Engineers
ASME
American Society of Mechanical Engineers
AWS
American Welding Society
ASTM
American Society for Testing and Materials
IBEE
MBMA
Institute of Blectrical and Electronics Engineers
NAAMM
Metal Building Manufachurers Association
NAPHCC
National Association of Architectural Metal Manufacturers
NCMA
National Association of Plumbing-Heating-Cooling Contractors
NEMA
National Concrete Masonry Association
NFPA
National Electrical Manufacturers Association
NIST
National Fire Protection Association
National Institute of Standards and Technology (formerly National Bureau of Standards)
PCA Portland Cement Association
PCI Prestressed Concrete Insattute

[DOE Order 6430.1A - 0109] 


\subsubsection{Interchangeability}

To the extent practicable, components such as pumps, motors, fans, transformers, etc. used for similar functions in various parts of the system shall be of identical manufacture and model. The objective is to simplify logistical support such as repair parts supply, training, and documentation.

[CRD]

\subsubsection{Safety}

This section addresses the occupational safety requirements for the MGDS. The safety of workers and members of the public is paramount at the MGDS and is addressed throughout this document.

\subsubsection{General Requirements}

A. All MGDS work places shall be designed to be free from recognized hazards that are causing or likely to cause death or serious physical harm to employees. [29USC651 et seq., (654 (a), (b))]

B. All MGDS work places shall be designed to comply with occupational safety and health standards promulgated under 29CFR1910, 29CFR1926, and 30CFR57. [Derived]

\subsubsection{System Safety Precedence}

The order of precedence for satisfying system safety requirements and resolving identified hazards shall be as follows ${ }^{14}$ :

A. The first priority of design shall be to eliminate hazards. If an identified hazard cannot be eliminated, the associated risk shall be reduced to an acceptable level through design selection. [CRD]

B. If identified hazards cannot be eliminated or their associated risk adequately reduced through design selection, that risk shall be reduced through the use of fixed, automatic, or other protective safety design features or devices. Provisions shall be made for periodic functional checks of safety devices when applicable. [CRD]

C. When neither design nor safety devices can effectively eliminate identified hazards or adequately reduce associated risk, devices shall be used to detect the condition and to produce an adequate warning signal to alert personnel of the hazard. Warning signals and their application shall be designed to minimize the probability of incorrect personnel reaction to the signal and shall be standardized within like types of systems. (See Section 3.3.7.3) [CRD]

${ }^{14}$ Useful guidelines for use by design organizations in analyzing safety hazards are available in MIL-STD-882B. 
D. Only where it is impractical to eliminate residual hazards through design selection or adequately reduce the associated risk with safety and warning devices, may procedures and training be used as the only protection. [CRD]

E. This section (3.3.6) imposes requirements from 29CFR1910, 29CFR1926 and 30CFR57.

1. 30CFR57 shall apply only to subsurface facilities and equipment and to those miningrelated surface facilities and equipment specifically addressed in 30CFR57. [CRD]

2. 29CFR1910 and 29CFR1926 shall apply to all other surface facilities and equipment. 29CFR1910 and 29CFR1926 shall also be applied to subsurface facilities and equipment not addressed by 30CFR57 and where safety hazard analysis following the precedence in 3.3.6.2.A-D deems it necessary. [CRD]

\subsubsection{Facilities, Equipment, and Materials Protective Measures}

A. Surface facilities shall be constructed to meet the applicable requirements specified in 29CFR1910, subparts -

1. D - Walking Surfaces

2. E - Means of Egress

3. G - Occupational Health and Environmental Control

4. J - General Environmental Controls. [29CFR1910, Subparts D, E, G, J]

B. Fire protection systems shall be designed in accordance with DOE Order 6430.1A, Divisions 1, 10, 11, 15, and 16. [DOE 6430.1A]

C. Ventilation shall be provided to meet the standards of 29CFR1910.94, as applicable, in surface facilities where hazardous atmospheres are generated. [29CFR1910.94]

D. Facilities for storing and handling hazardous gases and combustible and flammable liquids shall be designed and installed to meet the requirements of 29CFR1910, Subpart H. [29CFR1910, H]

E. Protection against mechanical, fluid, and toxic hazards shall be in accordance with the requirements of 29CFR1910, Subparts H, J, Z and O. MIL-STD-1472D Section 5.13.7 may be used for reference. [29CFR1910: H, O]

F. Instrumentation and control systems shall include provisions to monitor and control the behavior of utility systems important to safety (e.g., power, ventilation, fire alarms, waste water, air quality, etc.) over anticipated ranges for normal operation and for off-normal conditions. [10CFR60.131(b)(8)] 
Title: Mined Geologic Disposal System Requirements Document

G. Ventilation meeting the standards of 30CFR57, subpart D, shall be provided as applicable, in subsurface facilities. [30CFR57, subpart D]

\subsubsection{Personnel Protective Equipment}

A. Protective equipment such as helmets, face shields, safety shoes, and respiratory protectors shall be selected in accordance with the applicable requirements of 29CFR 1910 Subpart I, 29CFR1926 Subpart E, NUREG-0700 Section 6.1.4, 30CFR57 Subpart N, and DOE Order 6430.1A Section 1300-12.4.5. [29CFR1910, I; 29CFR1926, E] [ NUREG-0700 Section 6.1.4] [30CFR57, N] [DOE Order 6430.1A, 1300-12.4.5]

B. Hearing protection devices shall be provided as required by 29CFR1910.95. [29CFR1910.95(a), (b)]

C. In addition to the engineering controls which are the primary method for providing healthful air, and which appear elsewhere in this MGDS-RD, respiratory equipment approved by the Mine Safety and Health Administration (MSHA) shall be provided to persons exposed for short periods to inhalation hazards from gas, dusts, fumes, or mist. [30CFR57.5005(a)]

D. Respiratory protection equipment shall be provided and shall be in compliance with the requirements specified by 10CFR20.1703(a). [10CFR20.1703(a)]

E. Appropriate facilities that provide convenient storage and emergency issue shall be provided for personal protective equipment. [29CFR1910.132(a)]

\subsubsection{Subsurface Protective Measures}

Safety and health protection systems shall be provided in subsurface spaces as required by 30CFR57, 29CFR1910, and 29CFR1926, as applicable to afford the greatest protection (see 3.3.6.2.E above). [CRD]

\subsubsection{Safety Labels and Placards}

A. Safety labels and placards shall be designed and displayed as required in 29CFR1910 Subpart J. MIL-STD-1472D Section 5.13.1 may be used for reference. [29CFR1910, J]

B. Pipe, hose, and tube-line identification for liquids, gas, and steam shall be clearly and unambiguously labeled or coded as to contents, pressure, heat, cold, direction of flow, or other specific hazard information. [CRD]

C. Alerting devices, emergency doors and exits, and equipment provided for use in hazard areas and the environment around surface workspaces shall be designed in accordance with the requirements of 29CFR1910 Subpart E. MIL-STD-1472D Section 5.13.4. may be used for reference. [29CFR 1910, E] 


\subsubsection{Emergency Lighting}

A. Failure of the normal lighting systems shall not inhibit or degrade the operation of emergency lighting. [CRD]

B. The emergency lighting system shall be designed to automatically actuate and shall be powered by batteries that are continuously charged. [CRD]

C. Lighting levels shall comply with the requirements of NUREG-0700 Section 6.1.5.4.c and the recommended practices of the Illuminating Engineering Society. [Derived]

\subsubsection{Equipment Related Hazards}

A. Interlocks, alarms, access, hazard access, and edge rounding shall be provided and designed in accordance with the applicable requirements of 29CFR1910(c)-(f) for surface equipment or 30CFR57 for subsurface equipment. MIL-STD-1472D Section 5.13.5 may be used for reference. [29CFR1910(c)-(f), 30CFR57]

B. To protect servicing and maintenance personnel, tag-out and lock out fixtures shall be provided as required by 29 CFR 1910.147 for surface machines and equipment or 30CFR57.12016 for subsurface machines and equipment. [29CFR1910.147, 30CFR57.12016]

C. Fixed machinery tools shall be selected, installed, and guarded as required by 29CFR1910, Subpart $O$ for surface machinery or 30CFR57, Subpart M for underground machinery. [29CFR1910 Subpart O, 30CFR57 Subpart M]

D. Hand and portable power tools shall meet the applicable requirements specified by 29CFR1910, Subpart P. [29CFR1910, P]

E. Welding equipment and areas where welding operations will be performed shall meet the requirements specified by 29CFR1910, Subpart Q. [29CFR1910, Q]

F. Where the possibility exists for the eyes or body of any person to be exposed to injurious corrosive materials, suitable facilities for quick drenching or flushing of the eyes and body shall be provided within the immediate work area for emergency use. [29CFR1910.151(c)]

\subsubsection{Posting Requirements}

A. Posting of Radiation Areas. Each radiation area shall be posted with a conspicuous sign or signs bearing the radiation symbol and the words "CAUTION, RADIATION AREA." [10CFR20.1902(a)] 
B. Posting of High Radiation Areas. Each high radiation area shall be posted with a conspicuous sign or signs bearing the radiation symbol and the words "CAUTION, HIGH RADIATION AREA" or "DANGER, HIGH RADIATION AREA." [10CFR20.1902(b)]

C. Posting of Very High Radiation Areas. Each very high radiation area shall be posted with a conspicuous sign or signs bearing the radiation symbol and words "GRAVE DANGER, VERY HIGH RADIATION AREA." [10CFR20.1902(c)]

D. Posting of Airborne Radioactivity Areas. Each area with a potential airborne radioactivity hazard shall be posted with a conspicuous sign or signs bearing the radiation symbol and the words "CAUTION, AIRBORNE RADIOACTIVITY AREA" or "DANGER, AIRBORNE RADIOACTIVITY AREA." [10CFR20.1902(d)]

E. Posting of Areas or Rooms in Which Licensed Material is Used or Stored. Each area or room in which there is used or stored an amount of licensed material exceeding 10 times the quantity of such material specified in appendix $C$ to 10CFR20.1001-10CFR20.2401 shall be posted with a conspicuous sign or signs bearing the radiation symbol and the words "CAUTION, RADIOACTIVE MATERIAL(S)" or "DANGER, RADIOACTIVE MATERIAL(S)." [10CFR20.1902(e)]

\subsubsection{Work Platforms}

A. Any powered platforms, manlifts, and vehicle-mounted work platforms shall be designed and constructed to comply with 29CFR1910, Subpart F. [29CFR1910, F]

B. Scaffolds, ladders, work platforms, stands, and bridges shall be provided with safety devices in accordance with the requirements of 29CFR 1910 Subparts D and F. MILSTD-1472D Section 5.13.6 may be used for reference. [29CFR1910, D and F]

\subsubsection{Electrical Safety}

A. Electrical syst by 29CFR19!0, Subpart S. [29CFR1910, S]

B. Provisions shall be made to make reliable and timely emergency power immediately available to instruments, utility service systems, central security systems and operating systems, including alarm systems, important to safety, in the event of a loss of the primary electric power source or circuit. (Backup power requirements for items not identified as important to safety are treated by analysis during design development process). [10CFR60.131(b)(5)(iii)]

C. Protection against electrical hazards shall also conform to the National Electrical Code (ANSINFPA 70), the National Electrical Safety Code (ANSI Standard C2), and, for underground applications, 30CFR57 Subpart K. [ANSI/NFPA 70][ANSI C2][30CFR57, K] 


\subsubsection{Human Factors Engineering}

\subsubsection{Workstations and Control Rooms}

Control rooms include rooms, areas, and personnel enclosures for personnel who operate equipment or monitor the operations of MGDS. Workstations contain workspace and associated equipment for performing those functions. Design and layout of control rooms and workstations shall be performed using NUREG 0700 , Section 6.1 as a reference. [CRD]

\subsubsection{Voice Communications Equipment}

Requirements for human factors engineering and man-machine interfaces with voice communications equipment influence the design and selection of telephones, intercoms, radios, and other voice communication equipment. Design and selection of voice communications equipment shall use NUREG-0700 Section 6.2.1 for general requirements, conventional-powered telephone systems, sound powered telephone systems, hand-portable radio transceivers, fixed-base radio transceivers, announcing systems, point-to-point communication systems, and emergency communications, and MIL-STD-1472D Section 5.3.10 for operating controls for voice communications equipment as references. [CRD]

\subsubsection{Alarms and Warning Systems}

Auditory and visual alarm systems alert personnel to out of tolerance conditions that, if overlooked, may lead to personnel injury, equipment damage, or loss of system capability. Alarms and warning systems shall use NUREG-0700 Section 6.2 for alarms and operator response systems and Section 6.3 for audio displays and alerts as references. [CRD]

\subsubsection{Controls}

Controls include operator activated switches, valves, and similar mechanisms or devices used to regulate or guide operations of a machine, apparatus, or system. Human factors engineering design of controls shall use NUREG-0700 Section 6.4 for selection of and design principles for controls as a reference. [CRD]

\subsubsection{Visual i. Tisplays}

Visual displays include meters, colored lights, graphic devices, and numerical readouts. Design or acquisition of visual displays shall use NUREG-0700 Section 6.5 as a reference. [CRD]

\subsubsection{Control Panel Layout}

The consideration of human engineering aspects of control contributes to operator proficiency, lessens operator fatigue, decreases training requirements, and contributes to safety. Design and layout of control panels shall use NUREG-0700 Section 6.8 as a reference. [CRD] 


\subsubsection{Control Display Integration}

Design and integration of controls with associated displays shall use NUREG-0700 Section 6.9 as a reference. [CRD]

\subsubsection{Labeling, Markings, and Signs}

Labeling and marking equipment and providing signs and location aids shall use NUREG-0700 Section 6.6.1 as a reference. [CRD]

\subsubsection{Visual Display Terminal Workstation}

Human factors engineering of computer terminals, visual displays, and visual display terminal workstations contributes to operator proficiency and lessens operator fatigue. Design, selection, and integration of visual display terminal workstations shall use ANSI/HFS Standard. No. 1001988 Section 5 as a reference. [CRD]

\subsubsection{Anthropometry}

Sizing and layout dimensions for equipment, facilities, and the selection of personnel equipment and clothing to provide compatibility with using personnel shall use MIL-STD-1472D Section 5.6.3.2 as a reference. See DOD-HDBK-743A for special populations. [CRD]

\subsubsection{Remote Handling and Operation}

The design, selection, and integration of equipment, controls, and indicators for remotely operated systems, if used, shall use MIL-STD-1472D Section 5.10 or applicable industry standards as references ${ }^{15}$. [CRD]

\subsubsection{Vehicles and Material Handling}

The human factors engineering, design, selection, and acquisition of operational and transportation vehicles and material handling equipment shall use MIL-STD-1472D Section 5.12 as a reference. [CRD]

\subsubsection{Accessibility and Useability by the Physically Handicapped}

A. All buildings at the MGDS shall be designed and constructed to accommodate the physically handicapped as required by General Services Administration (GSA) Uniform Federal Accessibility Standards. [41CFR101-19.603]

B. The design, selection, and construction of all MGDS facilities shall consider accessibility and useability of facilities and equipment by physically handicapped personnel, both

\footnotetext{
15 For example; the Mining Equipment Manufacturer's Group of the American Mining Congress.
} 
visitors and employees. As a minimum, the criteria and requirements specified in DOE Order 6430.1A Section 1300-13 shall be considered for all facility and equipment designs. [CRD]

\subsubsection{User-Computer Software Interface}

Design of computer software and firmware that provides an interface between users and computers shall use Guidelines for Designing User Interface Software (MTR 10090) as a reference for data entry and user inputs, data display, sequence control, user guidance and prompts, data transmission, and data protection. [CRD]

\subsubsection{Methods and Controls}

\subsubsection{Material Management}

A. The MGDS shall include systems (preferably automated) to provide identification and control of materials, parts, and components, including the use of heat numbers, part numbers, serial numbers, or other means, either on the item or on records traceable to the item as required, throughout fabrication, installation, and use of the item. The identification and control shall be designated to prevent the use of incorrect or defective materials, parts, and components. The material management system shall enable location and removal such items. [QARD]

B. Materials, parts, or components that do not conform to requirements shall not be used or installed. Controls shall include procedures for identification, documentation, segregation, disposition, and notification to affected organizations. Nonconforming items shall be reviewed and accepted, rejected, repaired, or reworked in accordance with documented procedures. [CRD]

C. Measures shall be established to ensure that purchased material, equipment, and services conform to procurement documents. [CRD]

D. Current and projected requirements and capabilities in support of the proposed system/equipment design shall make maximum use of standardization in order to ensure reliability and supportability. [CRD]

\subsubsection{Inventory Control}

A. The MGDS shall use compatible hardware and software systems for maintaining a physical inventory of all SNF and HLW in storage at the MGDS and emplaced underground. These systems shall meet the applicable requirements of this MGDS-RD as appropriate. [CRD]

B. An inventory management system shall be implemented for the MGDS for control of supplies and spare parts. [CRD] 
C. Inventory accounting and control systems for nuclear material shall comply with the safeguard requirements of 10CFR75, in compliance with the US/International Atomic Energy Agency (IAEA) agreement. [10CFR75.1]

\subsubsection{Government Furnished Property}

The site for the MGDS will be provided by the U. S. Government, in accordance with the criteria specified in Appendix B to this MGDS RD. MGDS DRDs will identify, as appropriate, any property to be furnished by the U.S. Government.

A. Reserved.

B. Reserved.

C. Requirements pertaining to the receipt, maintenance, operation, and disposition of Government furnished property shall be specified in DRDs as appropriate. [CRD]

\subsubsection{Computer Resources}

A. Computer resources shall be addressed in MGDS DRDs, as applicable. [CRD]

B. The design of MGDS computer systems shall provide for the intercompatibility of resources, including hardware and software. The design goal is to allow for the common use of databases and information with other CRWMS elements. [CRD]

\subsubsection{Environmental Protection Requirements}

This section identifies and imposes requirements on the MGDS to comply with Federal and state laws and regulations to protect the environment.

A. MGDS-level DRDs shall include these requirements as a minimum and shall add any applicable state and local environmental requirements on the design and construction of the MGDS. [CRD]

B. Significant adverse environmental impacts shall be mitigated, to the extent practicable, during site characterization and repository construction, operation, closure, and decommissioning. [10CFR960.3-4]

\subsubsection{Reserved}

\subsubsection{Air Pollution Control}

A. Point Sources. Stationary sources of air emissions shall comply with the provisions of the Clean Air Act as amended (42USC7401). Federal regulations pertaining to compliance with the Clean Air Act include 40CFR50, 40CFR60, and 40CFR61. [40CFR50, 40CFR60, and 40CFR61] 
B. Non-point Sources. Fugitive air emissions shall be controlled in accordance with the provisions of the Clean Air Act as amended. [42USC7401]

\subsubsection{Water Pollution Control}

A. Point Sources. Point source discharges of treated waste waters into surface water systems shall comply with the provisions of the Clean Water Act as amended (33USC1251), as implemented through the National Pollutant Discharge Elimination System permit process (Section 402 of the Clean Water Act). [33USC1251] [40CFR122.41]

1. If a reservoir is used to regulate the flow in a stream, water releases from the reservoir shall not be used as a substitute for adequate treatment of a waste source which is being discharged into the stream. [33USC1251 et seq. Section 1252(b)(1)]

2. The ultimate disposal of sludge from wastewater treatment facilities shall be performed in accordance with the requirements of Section 405 of the Clean Water Act in addition to any permit requirements. [33USC1251 et seq. Section 1345]

3. A wastewater treatment system shall be provided to comply with $33 \mathrm{USC} 1251$ et seq. [33USC1251 et seq. Section 1311 (a)]

4. The wastewater treatment system shall have means to monitor effluents in compliance with the requirements specified in 33USC1251 et seq. Section 1318. [33USC1251 et seq. Section $1318(a)(1)(A)]$

5. Provision shall be made to limit the discharge of effluents in accordance with 33USC1251 et seq., 1311. [33USC1251 et seq., Section 1311]

B. Fill or Dredged Materials. Placement of fill or dredged material into waters of the United States shall be performed in accordance with the requirements of Section 404 of the Clean Water Act (33USC1251). Federal regulations regarding this permit are contained in 33CFR323. [33CFR323]

\subsubsection{Drinking Water Protection}

A. General. Any MGDS activity which may impact a drinking water source shall meet the requirements of the Safe Drinking Water Act as amended (42USC300f et seq.). [42USC300f et seq.]

B. Underground Injections. Any activity involving underground injections (i.e. of nonradioactive material) shall comply with the provisions of the Safe Drinking Water Act as amended (42USC300f et seq.) which could require an Underground Injection Control permit under 40CFR144.31. [42USC300j] 


\subsubsection{Toxic Substances Control}

The handling, use, and disposal of any toxic substances shall comply with the requirements of the Toxic Substances Control Act, as amended (15USC2601 et seq.) and 29CFR1910 Subpart Z. Federal regulations implementing the Act are coded in 40 CFR, Chapter I, Subchapter R. [15USC2601 et seq., 29CFR1910 Subpart Z]

\subsubsection{Pesticide Control}

The use of pesticides shall comply with the requirements of the Federal Insecticide, Fungicide, and Rodenticide Act as amended (7USC136 et seq.) and its implementing regulations which include 40CFR165. [7USC136, 40CFR165]

\subsubsection{Solid Waste Control}

The management and disposal of any solid and hazardous wastes shall be conducted in accordance with the requirements of the Resource Conservation and Recovery Act, as amended (42USC6901 et seq.) which include permitting for the hazardous wastes. The federal regulations that impact the design of the MGDS are included in 40CFR261, 40CFR262, and 40CFR270. [40CFR261, 40CFR262, 40CFR270]

\subsubsection{Noise Control}

Provisions shall be made to control and monitor noise levels in accordance with the requirements of the Noise Control Act of 1972 (42USC4901 et seq.) as amended, and shall adhere to applicable Federal regulations for the selection of portable air compressors and medium and heavy trucks. [42USC4901 et seq.] [40CFR204, 40CFR205]

\subsubsection{Endangered Species}

All site development shall be designed and constructed with due regard for protection of endangered species of natural life and their habitats. [50CFR17]

\subsection{DOCUMENTATION}

\subsubsection{Specifications}

A. Reserved.

B. All specifications for MGDS facility construction and for equipment development and procuremerit shall be prepared in accordance with the standards of the Construction Specification iristitute format, tailored for the application. [CRD]

C. Measures and procedures shall be established to ensure that applicable requirements as specified herein are correctly translated into specifications. These measures and procedures must ensure that appropriate quality standards are specified and included in 
design documents and that deviations from these standards are properly controlled. [QARD]

\subsubsection{Drawings}

Measures and procedures shall be established to ensure that applicable regulatory requirements, design basis requirements, and other requirements as specified herein are correctly translated into drawings. These measures and procedures shall ensure that appropriate quality standards are specified and included in design documents and that deviations from these standards are properly controlled. [QARD]

\subsubsection{Maintenance, Operators, and Technical Manuals}

Measures and procedures shall be established to ensure that applicable requirements as specified herein are correctly translated into procedures and instructions, including training, operator's, maintenance, and other technical manuals. [QARD]

\subsubsection{Teat Plans and Procedures}

The MGDS project shall establish a test and evaluation program to demonstrate the conformance of the design to the system requirements as required in the verification cross reference table of Section 4.3. [CRD]

\subsubsection{Quality Assurance Documentation}

Quality Assurance documents shall be prepared, maintained and stored in accordance with the requirements specified in the OCRWM QARD, or an equivalent OCRWM-approved QA program. [QARD]

\subsubsection{Construction Records}

A. Construction records requirements for the MGDS, including as-built documentation, shall be specified in the DRDs. [CRD]

B. At a minimum, construction records for the GROA shall be prepared and maintained in accordance with 10CFR60.72(b) to ensure useability for future generations. The required records include as a minimum, the following:

1. Surveys of the underground facility excavations, shafts, ramps, and boreholes referenced to readily identifiable features or monuments

2. A description of the materials encountered

3. Geologic maps and geologic cross-sections

4. Locations and amount of seepage

5. Details of equipment, methods, progress, and sequence of work.

6. Construction problems

7. Anomalous conditions enrountered 
8. Instrument locations, readings, and analysis

9. Location and description of structural support systems

10. Location and description of dewatering systems

11. Details, methods of emplacement, and location of seals used

[10CFR60.72(a) and (b)]

\subsubsection{Computer Documentation}

Analytical models, computational models, and software user documentation developed for the MODS that are considered to be quality affecting shall be prepared in accordance with the OCRWM QARD. [QARD]

\subsubsection{Records Management}

MGDS-level DRDs shall address records management requirements. [10CFR60.71(a), (b)]

\subsection{LOGISTICS}

Logistics requirements are established in this section to provide a disciplined, unified, and iterative approach to development of the support requirements for CRWMS sites, facilities, systems, and equipment. The systems, procedures, and measures developed to achieve these requirements will, in turn, ensure the design, readiness, and operational objectives of the MODS.

\subsubsection{Maintenance}

The basic premise of the program maintenance concept is to minimize the likelihood of, and mitigate the effects of, structure, system, and component failures using preventive maintenance and inspections. When failures do occur, the goal is to provide a capability to restore full operational capability as quickly as possible through a proactive corrective maintenance program. Therefore, structures, systems, and components important to safety shall be designed to permit periodic inspection, testing, and maintenance, as necessary, to ensure their continued functioning and readiness. [10CFR60.131(b)(6)]

\subsubsection{Equipment Maintenance}

\subsection{On-line Maintenance}

A. The performance of on-line maintenance shall be limited to those actions necessary for safety, to prevent system degradation, and to restore security monitoring. It consists of remove and replace actions, minor servicing, minor repairs, or repair to items which cannot easily be removed from service for maintenance. [Derived]

B. The maintenance system shall be equipment intensive, rather than personnel intensive, and shall rely on technology to reduce maintenance requirements. [CRD] 
C. Built-in-test equipment (BITE) and automatic-test-equipment (ATE) shall be used where it is already incorporated into the design of a system or equipment, but existing equipment should not be redesigned to accommodate BITE or ATE without specific authorization. Newly designed equipment or systems shall incorporate BITE and/or ATE only where it can be demonstrated to significantly reduce the on-site maintenance workload. [CRD]

D. Maintenance facilities, equipment, and tools shall be provided based on the criteria specified by DOE Order 4330.4A, I, 3.5. [DOE Order 4330.4A, I, 3.5]

B. Provisions shall be made for maintenance of underground equipment as required by 30CFR57 Subpart M. [30CFR57 Subpart M]

\subsection{Intermediate Maintenance}

A. Intermediate maintenance shall provide failure detection, isolation, and replacement of units which are shop-repairable or vendor-repairable. [Derived]

B. Facilities, tools, and parts for shop repairable items shall be provided at the MGDS. [Derived]

\subsection{Salvaging, Off-site Repair, and Vendor Repair}

Items which cannot be repaired at the MODS shall be salvaged or returned to an off-site shop or the vendor for repair. Because of the long life of the MGDS, vendor supportability must be addressed in procurement and maintenance agreements. [Derived]

\subsubsection{Calibration Maintenance}

A. Radiation and other alarm systems, as appropriate, shall be desirned with provisions for calibration and for testing their operability. [10CFR60.131(a)(0;]

B. The MGDS shall have provisions to ensure that instruments and equipment used for quantitative radiation measurements (e.g., dose rate and effluent monitoring) are calibrated periodically for the radiation measured. [10CFR20.1501(b)]

\subsubsection{Cask Maintenance}

The MODS waste handling facilities shall be capable, as a minimum, of supporting the following maintenance tasks for all transportation casks.

A. Testing the surfaces of incoming casks for contamination and radiation.

B. Decontaminating cask surfaces if required prior to admission into processing and transfer facilities.

C. Cleaning the interior of the casks following unloading. 
D. If necessary, decontaminating to saisfy the cleanliness requirements for transportation and any agreements which may exist with the waste producers as identified in the Waste Acceptance System Requirements Documer.t.

E. Providing technical information, special tools, equipment, lifting trunnions, spare parts and consumables needed to perform incidental maintenance on the cask.

[10CFR961.11, IV, B, (2)(c)]

\subsubsection{Standardization}

A. The design of the MGDS shall allow maintenance to be performed, to the extent practical, using standard tools, lubricants, cleaners, test equipment, etc. [Derived]

B. The use of special tools and the number of standard tools required shall be minimized by selection of common fasteners, clamps, adapters, and connectors. [Derived]

\subsubsection{Security Equipment Maintenance}

The MGDS shall be designed to include means to test and maintain intrusion alarms, emergency alarms, communications equipment, physical barriers, and other security related devices or equipment. ${ }^{16}$ [Derived]

\subsubsection{Supply}

As the maintenance concept influences the design it also affects the type and quantity of supply support that will be required to support the system. Based on projected logistics support requirements for design considerations, an analysis shall be conducted to assess the capability of support available to the system. This Logistic Support Analysis shall be conducted iteratively through all phases of the system or equipment life cycle to satisfy supportability objectives. The level of detail of the analyses and the timing of the task performance shall be tailored to each system and equipment item and shall be responsive to program schedules and milestones. A Logistic Support Analysis program in accordance with the MIL-STD-1388-series or the equivalent shall be established for the MGDS. [CRD]

\subsubsection{Facilities}

\subsubsection{Warehouse Requirements}

Warehouse space shall be provided for the storage of all spare parts, consumable equipment and replaceable equipment in an environment conducive to their safe-keeping and protection. [CRD]

16 The applicability of 10CFR73 to the MGDS is <TBD>. 


\subsubsection{Receiving and Shipping Facilities}

A. A facility shall be provided for receipt of maintenance and repair materials and tools, and shipment and return receipt of items shipped off-site for repair. [Derived]

B. The facility shall be designed with door openings, halls, and aisles adequate for movement of items to be shipped into and out of the facility. [Derived]

\subsubsection{Cask Maintenance Facility}

A cask maintenance facility shall be collocated with the MGDS $<$ TBR> to meet the following | requirements $\langle\mathrm{TBD}>$ : [Derived]

\subsubsection{Licensing Support System Facility}

The MGDS design shall include facilities and equipment to support the Licensing Support System as described in 10CFR2.1101(b)(1). [10CFR2.1011(b)(1)]

\subsubsection{Other Facilities}

Facilities and equipment shall be provided to implement support functions, such as administration (security, visitor center, etc.) and logistics (maintenance, utilities, etc.) not specified above. [CRD]

\subsubsection{Support \& Test Equipment}

Requirements for support and test equipment shall be determined through the logistic support analysis process. Multiple requirements for the same or similar support and test equipment shall be consolidated to the extent that performance of maintenance actions is not adversely impacted. Support and test equipment requirements are determined for each level of maintenance. [CRD]

\subsection{PERSONNEL AND TRAINING}

\subsubsection{Personnel}

System effectiveness (readiness) is bounded by the availability and capabilities of personnel who must operate and maintain the MGDS in an operational mode. Operational requirements shall be derived through human factors analysis, particularly through generation of operational sequencing diagrams and detailed operator task analysis. Maintenance requirements evolve from the maintainability analysis, the Logistics Support Analysis, and detailed maintenance task analysis. These requirements are included for their impacts on the physical requirements of the MGDS.

A. Operations of systems and components that have been identified as important to safety in the Safety Analysis Report and in the license shall be performed only by trained and 
certified personnel or by personnel under the direct visual supervision of an individual with training and certification in such operation. [10CFR60.160]

B. Reserved.

C. The physical condition and general health of personnel certified in the operation of equipment and controls that are important to safety must not be such as might cause operational errors that could endanger other in-plant personnel or the public health and safety. Any condition that might cause impaired judgement or motor coordination shall be considered in the selection of personnel for activities that are important to safety. [10CFR60.162]

\subsubsection{Training}

Training may be accomplished through a combination of formal structured programs and on-thejob training. Training requirements include both the training of personnel initially assigned to the MGDS and the training of replacement personnel throughout the system life cycle as required due to attrition. Training shall cover both operator and maintenance tasks. These requirements are included for the impacts on the physical system (facilities and equipment) of the MGDS. [CRD]

\subsubsection{General Requirements}

A. MGDS equipment maintenance training shall be provided based on the criteria specified by DOE Order 4330.4A, I, 3.1.4. [DOE Order 4330.4A, I, 3.1.4]

B. A training requirements document shall be provided to identify requirements for operator and maintenance training for facilities, hardware and software procured or constructed for the MGDS. The document shall address the following subjects:

1. The contractor and government responsibility for training shall be defined. This will include the concept of how training will be accomplished (e.g., school, contractor training).

2. Equipment required for training purposes shall be identified.

3. Training devices to be developed, characteristics of the training devices, and training and skills to be developed through the use of training devices shall be identified.

4. Training time and locations available for training shall be identified. [CRD]

5. Source material and training aids to support the specified training shall be identified.

C. A program for training, proficiency testing, and certification of personnel shall be established for personnel at the MGDS. [10CFR60.161] 
Title: Mined Geologic Disposal System Requirements Document

\subsubsection{Health Physics Training}

A. The MGDS project shall have facilities, equipment, manuals, and training aids to support a program for training, proficiency testing, and certification of personnel in radiation protection (health physics), and ALARA. [CRD]

B. Reserved.

\subsection{MGDS SEGMENT CHARACTERISTICS/REQUIREMENTS}

This section addresses requirements allocated to each MGDS segment. The MGDS consists of three segments: Site, Repository, and EBS Segment.

\subsubsection{MGDS Site Segment}

\subsubsection{Site Segment Description}

The Site Segment is a temporary segment that exists only before the Repository and EBS Segments are constructed. Physically, the Site Segment consists of the ESF and the SBTF. It also includes the site characterization test program.

A site at Yucca Mountain in Nevada has been designated as the potential site for the MGDS, subject to site characterization and evaluation of site suitability.

A. Appendix A to this MGDS-RD specifies requirements that shall be met in characterizing the potential site in accordance with 10CFR60.15, to evaluate its suitability, and to obtain information needed for design, construction, and license application. [Derived]

B. Appendix B to this MGDS-RD specifies the evaluation criteria that shall be used to determine the suitability of the potential site to host the repository. [Derived]

C. The Site Segment shall provide subsystems and facilities capable of performing its assigned function, Characterize Site (1.4.1). The description for this function is listed in Appendix $\mathrm{C}$ to this MGDS-RD. [CRD 3.7.4.1.1.B]

\subsubsection{Site Segment Interface Requirements}

The Site Design and Test Requirements Document describes and specifies requirements for interfaces between the Site Segment and the Repository Segment and between the Site Segment and the EBS Segment.

| The Site Segment will cease to exist as a segment when the Repository Segment is initiated. Major underground portions of the ESF will be incorporated into the Repository Segment design or closed and sealed. The Site Segment remnants (shafts and boreholes) may intersect the underground facility. The requirements in Sections 3.7.1.3.B and $\mathrm{C}$ below are imposed on the Site Segment to ensure that the Site Segment design, construction, operation, and 
decommissioning do not adversely affect the waste isolation capabilities of the Repository or the geologic setting.

\subsubsection{Site Characterization Requirements}

Execution of the site characterization and site suitability activities requires facilities to support the subsurface- and surface-based studies and to collect the data specified in Appendix A. These facilities have been designated as the ESF and the SBTF respectively.

Conceptually, the ESF is envisioned to include: a subsurface facility; site civil improvements; surface support facilities on two main sites that contain entrances to the underground and on various auxiliary sites for storage and other uses; test support subsystems; and subsystems to supply, distribute, and controi various utilities such as electrical power, water, and communications.

The SBTF is envisioned to include small, distributed test sites designated for a variety of activities including, but not limited to, drilling and trenching; roads and trails; and a pool of transportable support equipment such as generators, fuel and water tanks, chemical latrines; and the like.

A. Limitations. Site characterization activities (including but not limited to design, development, ESF construction, and site investigations) at Yucca Mountain shall be limited to those necessary to provide the data required for evaluation of the suitability of the site for an application for construction authorization ${ }^{17}$. [NWPA, 113(c)(1), as amended]

B. Requirements. DRDs shall apply the requirements listed below in the design of site characterization systems and facilities, as appropriate (some are not applicable to the SBTF). [Derived]

1. Mandatory Design Requirements. The Site characterization facilities and systems shall be designed and constructed in accordance with the applicable ${ }^{18}$ design requirements derived from the regulations, included in, but not limited to, those listed in Table 3-7 such that they do not preclude the ability of the Repository and EBS Segments to meet the requirements in this MGDS-RD.

[DOE Letter 2/27/90]

17 Section 113(c)(1) of the NWPA also allnws activities necessary to provide data required for compliance with the National Environmental Policy Act of 1969 (42USC4321 et seq) (activities that are not considered part of site characterization).

18 This recognizes that not all of the regulations are applicable to the facility design. 
Title: Mined Geologic Disposal System Requirements Document

Table 3-7. Mandatory 10CFR 60 Requirements for Site Characterization Facilities

\begin{tabular}{|c|c|}
\hline $\begin{array}{c}\text { 10CFR60 } \\
\text { REQUIREMENT }\end{array}$ & SUBJECT \\
\hline 10CFR60.4(b) & Communications and records \\
\hline 10CFR60.15(b) & In situ exploration \\
\hline 10CFR60.15(c)(1) & Limit adverse effects on repository \\
\hline 10CFR60.15(c)(2) & Limit borings \\
\hline 10CFR60.15(c)(3) & Boring locations \\
\hline 10CFR60.15(c)(4) & Coordinate with repository design \\
\hline 10 CFR 60.16 & SCP required \\
\hline 10CFR60.21(c)(1)(ii)(D) & SAR: effectiveness of barriers \\
\hline 10CFR60.21(c)(1)(ii)(E) & SAR: analysis of SSC important to safety \\
\hline 10CFR60.21(c)(11) & SAR: Close and Decommission \\
\hline 10CFR60.72(a) & Construction records \\
\hline 10CFR60.72(b) & Construction records \\
\hline 10CFR60.74 & Tests \\
\hline 10CFR60.111(a) & Protection against rad exposures \\
\hline 10CFR60.111(b)(1) & Retrievability \\
\hline 10CFR60.111(b)(3) & Retrievability: schedule \\
\hline 10CFR60.112 & Overall system performance \\
\hline 10CFR60.113(a)(1)(i) & Engineered Barrier System (EBS) \\
\hline 10CFR60.113(a)(1)(ii)(A) & Waste package \\
\hline 10CFR60.113(a)(1)(ii)(B) & EBS \\
\hline 10CFR60.130 & Scope of design criteria \\
\hline 10CFR60.131(b)(1) & Natural phenomena/environmental conditions \\
\hline 10CFR60.131(b)(2) & Equipment failure \\
\hline 10CFR60.131(b)(3) & Fire and explosions \\
\hline 10CFR60.131(b)(4)(i) & Control of radioactive materials \\
\hline 10CFR60.131(b)(6) & Maintainability \\
\hline 10CFR60.131(b)(9) & MSHA regulations \\
\hline 10CFR60.133(a)(1) & Configuration of underground facility \\
\hline 10CFR60.133(a)(2) & Disruptive events \\
\hline 10CFR60.133(b) & Flexibility \\
\hline 10CFR60.133(c) & Retrievability \\
\hline 10CFR60.133(d) & Control of water/gas \\
\hline 10CFR60.133(e)(1) & Underground openings: safe operations \\
\hline 10CFR60.133(e)(2) & Underground openings: stability \\
\hline 10CFR60.133(f) & Rock excavation \\
\hline 10CFR60.133(g) & Ventilation \\
\hline 10CFR60.133(h) & EBS \\
\hline
\end{tabular}


Title: Mined Geologic Disposal System Requirements Document

Revision: 1

Page: 85

\begin{tabular}{|l|l|}
\hline \multicolumn{1}{|c|}{ 10CFR60 } & \multicolumn{1}{c|}{ SUBJECT } \\
\hline 10CFR60.133(i) & Thermal loads \\
\hline 10CFR60.137 & $\begin{array}{l}\text { Performance confirmation: Comply with following } \\
\text { paragraphs }\end{array}$ \\
\hline 10CFR60.140(b) & $\begin{array}{l}\text { Performance confirmation: Start ASAP [Performance } \\
\text { confirmation program is defined in 10CFR60.140(a)] }\end{array}$ \\
\hline 10CFR60.140(c) & Performance confirmation: field tests \\
\hline 10CFR60.140(d)(1) & Performance confirmation: Don't compromise repository \\
\hline 10CFR60.141(a) & Confirmation of parameters \\
\hline 10CFR60.141(b) & Evaluate conditions against assumptions \\
\hline 10CFR60.141(c) & Measure rock parameters \\
\hline 10CFR60.141(d) & Evaluate observations against assumptions \\
\hline 10CFR60.141(e) & Monitor until permanent closure \\
\hline 10CFR60.142(a) & Seal, backfill tests and thermal interaction \\
\hline 10CFR60.142(b) & Early testing \\
\hline 10CFR60.142(c) & Backfill tests \\
\hline 10CFR60.142(d) & Seal tests \\
\hline 10CFR60.151 & QA \\
\hline 10CFR60.152 & QA \\
\hline
\end{tabular}

2. NRC Requirements to be Considered. Requirements from the 10 CFR 60 sections listed in Table 3-8 shall be considered to the extent that they actually impact design, construction, or operation of site characterization facilities and systems. [DOE Letter $2 / 27 / 90]$

Table 3-8. 10CFR60 Site Characterization Facility Requirements To Be Considered ${ }^{19}$

\begin{tabular}{|l|l|}
\hline \multicolumn{1}{|c|}{$\begin{array}{c}\text { 10CFR60 } \\
\text { REQUIREMENT }\end{array}$} & \multicolumn{1}{c|}{ SUBJECT } \\
\hline 10CFR60.17 & Contents of SCP \\
\hline 10CFR60.24(a) & Completeness of EIS \\
\hline 10CFR60.113(a)(2) & Geologic setting: GWTT \\
\hline 10CFR60.113(b)(2) & Radionuclide release rate: thermal pulse \\
\hline 10CFR60.113(b)(3) & Radionuclide release rate: geochemical characteristics \\
\hline 10CFR60.113(b)(4) & Radionuclide release rate: uncertainty \\
\hline 10CFR60.122 & Siting criteria \\
\hline 10CFR60.131(a) & Radiological protection \\
\hline
\end{tabular}

19 to the extent that they actually impact on design, construction or operations as deternined in project-level design analysis 
Title: Mined Geologic Disposal System Requirements Document

Revision: 1

Page: 86

\begin{tabular}{|c|c|}
\hline $\begin{array}{c}\text { 10CFR60 } \\
\text { REQUIREMENT }\end{array}$ & $\overline{\text { SUBJECT }}$ \\
\hline 10CFR60.131(b)(4)(ii) & Emergency response capability \\
\hline 10CFR60.131(b)(8) & Instrumentation \\
\hline 10CFR60.131(b)(10) & Shaft conveyances \\
\hline 10CFR60.134 & Design of seals \\
\hline 10CFR60.143 & Monitor/test waste package \\
\hline
\end{tabular}

3. Additional Requirements. Requirements from the various sources listed in Table 3-9 shall be imposed, only to the extent that they actually impact the design, construction, or operation of site characterization facilities and systems. [Derived]

Table 3-9. Additional Site Characterization Facilities Requirements ${ }^{20}$

\begin{tabular}{|l|l|}
\hline \multicolumn{1}{|c|}{ SOURCE } & \multicolumn{1}{|c|}{ SUBJECT } \\
\hline 7USC136 et seq. & Federal Insecticide, Fungicide, and Rodenticide Act \\
\hline 15USC2601 et seq. & Toxic Substances Control Act \\
\hline 29USC651 et seq. & Occupational Safety and Health Act \\
\hline 33USC1251 et seq. & Clean Water Act of 1977 \\
\hline 42USC300f et seq. & Safe Drinking Water Act \\
\hline 42USC4901 et seq. & Noise Control Act \\
\hline 42USC6901 et seq. & Resource Conservation and Recovery Act \\
\hline 42USC7401 et seq. & Clean Air Act \\
\hline 42USC10101 et & Nuclear Waste Policy Act as Amended \\
seq. & Commerce in Explosives \\
\hline 27CFR55 & Occupational Safety and Health Standards \\
\hline 29CFR1910 & Safety and Health Regulations for Construction \\
\hline 29CFR1926 & Basic Program Elements for Federal Employee Occupational \\
\hline 29CFR1960 & Safety and Health Programs and Related Matters \\
\hline 30CFR31 & Diesel Mine Locomotives \\
\hline 30CFR32 & Mobile Diesel-powered Equipment for Noncoal Mines \\
\hline 30CFR36 & Mobile Diesel-powered Transportation Equipment for Gassy \\
\hline 30CFR48 & Soncoal Mines and Tunnels \\
\hline 30CFR57 & Training and Retraining Miners \\
\hline 33CFR323 & Petal Mines \\
\hline
\end{tabular}

20 to the extent that they actually impact on design, construction or operations as determined in project-level design analysis 
Title: Mined Geologic Disposal System Requirements Document

Revision: 1

Page: 87

\begin{tabular}{|c|c|}
\hline SOURCE & SUBJECT \\
\hline 40CFR50 & $\begin{array}{l}\text { National Primary and Secondary Ambient Air Quality } \\
\text { Standards }\end{array}$ \\
\hline 40 CFR60 & Standards of Performance for New Stationary Sources \\
\hline 40CFR61 & National Emission Standards for Hazardous Air Pollutants \\
\hline 40CFR122 & $\begin{array}{l}\text { EPA Administered Permit Programs: the National Pollutant } \\
\text { Discharge Elimination System }\end{array}$ \\
\hline 40CFR141 & National Primary Drinking Water Regulations \\
\hline 40CFR143 & National Secondary Drinking Water Regulations \\
\hline 40CFR144 & Underground Injection Control \\
\hline 40CFR165 & $\begin{array}{l}\text { Regulations for the Acceptance of Certain Pesticides and } \\
\text { Recommended Procedures for the Disposal and Storage of } \\
\text { Pesticides and Pesticide Containers }\end{array}$ \\
\hline 40CFR204 & Noise Emission Standards for Construction Equipment \\
\hline 40CFR205 & Transportation Equipment Noise Emission Control \\
\hline 40CFR261 & Identification and Listing of Hazardous Waste \\
\hline 40CFR262 & Standards Applicable to Generators of Hazardous Waste \\
\hline 40CFR270 & EPA Hazardous Waste Permit Program \\
\hline 41CFR101 & Federal Property Management Regulations \\
\hline 49CFR177 & Carriage by Public Highway \\
\hline 50CFR17 & Endangered and Threatened Wildlife and Plants \\
\hline Exec Order 11988 & Executive Order: Floodplain Management \\
\hline DOE 3790.1A & Federal Employees' Occupational Safety and Health Program \\
\hline DOE 4330.4A & Real Property Maintenance Management \\
\hline DOE 4700.1 & Project Management System \\
\hline DOE 5480.4 & $\begin{array}{l}\text { Environmental Protection, Safety, and Health Protection } \\
\text { Standards }\end{array}$ \\
\hline$\overline{\text { DOE } 5480.7 \mathrm{~A}}$ & Fire Protection \\
\hline DOE 6430.1A & General Design Criteria \\
\hline DOE/RW-0194 & Records Management Policies and Requirements \\
\hline DOE/RW-0198 & Site Characterization Plan \\
\hline DOE/RW-0214 & DCRWM QARD \\
\hline$\overline{\text { BLM Manual, } 9113}$ & Bureau of Land Management Manual, Road Standards \\
\hline NUREG 0700 & Guidelines for Control Room Design Reviews \\
\hline MOU DOE/DOL & $\begin{array}{l}\text { Memorandum of Understanding: DOE and Department of } \\
\text { Labor }\end{array}$ \\
\hline $\begin{array}{l}\text { ANSI/HFS100- } \\
1988\end{array}$ & $\begin{array}{l}\text { American National Standard for Human Factors Engineering of } \\
\text { Visual Display Terminal Workstations }\end{array}$ \\
\hline$\overline{\text { ANSI R15.16 }}$ & Human Engineering Criteria for Hand-Held Robotics Control \\
\hline ANSI C2 & National Electric Safety Code \\
\hline ANSI S3.18 & Evaluation of Human Exposures to Whole Body Vibration \\
\hline
\end{tabular}


Title: Mined Geologic Disposal System Requirements Document

\begin{tabular}{|l|l|}
\hline \multicolumn{1}{|c|}{ SOURCE } & \multicolumn{1}{c|}{ SUBJECT } \\
\hline ACI 318 & Building Code Requirements for Reinforced Concrete Code \\
\hline ACI 349 & Requirements for Nuclear Safety Related Concrete Structures \\
\hline ASCE 7-88 & Minimum Design Loads for Buildings and Other Structures \\
\hline ANSI/NFPA 70 & National Electric Code \\
\hline MTR 10090 & $\begin{array}{l}\text { Guidelines for Designing User Interface Software (ESD-TR-86- } \\
\text { 278) }\end{array}$ \\
\hline UCRL 15910 & $\begin{array}{l}\text { Design and Evaluation Guidelines for Department of Energy } \\
\text { Facilities Subjected to Natural Phenomena Hazards }\end{array}$ \\
\hline UCRL 53526 & $\begin{array}{l}\text { Natural Phenomena Hazards Modeling Project: Seismic Hazard } \\
\text { Models for Department of Energy }\end{array}$ \\
\hline CMAA 70 & $\begin{array}{l}\text { Crane Manufacturers' Association of America Specification for } \\
\text { Electric Overhead Traveling Cranes }\end{array}$ \\
\hline DOE Letter, & Appel, OCRWM to Linehan (NRC) \\
2/27/90 & \\
\hline
\end{tabular}

C. Where possible, a common service support facility shall provide support for both subsurface and surface-based testing. [CRD]

\subsubsection{MGDS Repository Segment}

While all known requirements imposed by Government regulations for the GROA design are included in this document, these requirements are not exhaustive. Omissions in this document do not provide relief from any obligation to provide such safety features in a specific facility needed to achieve the performance objectives of 10CFR60.111,60.112, and 60.113. Detailed GROA design shall include additional safety features developed in design analysis. [10CFR60.130]

\subsubsection{Repository Segment Description}

The Repository Segment will be used to dispose of radioactive wastes. It includes facilities and surface and subsurface areas where waste handling and support activities are conducted. The Repository Segment includes the GROA, the portion of the geologic setting (geologic, hydrologic, ard geochemical systems) that provides isolation of the radioactive wastes, and other facilities noi directly subject to NRC licensing requirements.

Conceptually, the Repository Segment is envisioned to include an underground facility, site civil improvements, waste handling facilities, surface support facilities on sites that contain entrances to the underground, piles of rock excavated from the underground, and various auxiliary sites for storage and other uses, and subsystems to supply, distribute, and control various utilities and services such as electrical power, water, and communications. Other facilities will be provided to house support functions such as administration, maintenance, personnel support, visitors center, security, safety, health physics, and offices for NRC, MSHA, and other oversight organizations. 
Title: Mined Geologic Disposal System Requirements Document

A. The Repository Segment shall provide subsystems and facilities capable of performing all functions assigned to it in Table 3-10. Descriptions for these functions are listed in Appendix C to this MGDS-RD. [CRD]

Table 3-10. Functions Assigned To Repository Segment

\begin{tabular}{|l|l|}
\hline 1.4 .2 & Operate MGDS \\
\hline 1.4 .2 .1 & Handle Waste \\
\hline 1.4 .2 .2 & Support MGDS \\
\hline 1.4 .3 & $\begin{array}{l}\text { Isolate Waste } \\
\text { (shared with EBS Segment) }\end{array}$ \\
\hline 1.4 .3 .2 & Limit Release of Radionuclides \\
\hline 1.4 .4 & Evaluate System Performance \\
\hline 1.4 .5 & Close MGDS \\
\hline 1.4 .5 .1 & Close Underground Openings \\
\hline 1.4 .5 .2 & Decommission Surface Facilities \\
\hline 1.4 .5 .3 & Establish Institutional Barriers \\
\hline 1.4 .5 .4 & Reclaim Site \\
\hline
\end{tabular}

B. DRDs shall identify and specify requirements for the subsystems and facilities that address the assigned functions. [Derived]

C. The Repository DRD describes and specifies requirements for interfaces between the Repository Segment and the Site and EBS Segments.

1. The Repository Segment interfaces with the Site Segment in that the underground portions of the former ESF will be incorporated into the underground facility.

2. The Repository Segment interfaces with the EBS Segment by providing waste handling functions, waste emplacement locations, ventilation, utilities, logistics, security, fire protection and other safety services as needed, etc.

\subsubsection{Geologic Setting Requirements}

A. Geologic setting. The geologic setting shall be selected ... ${ }^{21}$ to assure that releases of radioactive materials to the accessible environment following permanent closure conform to applicable environmental standards for radioactivity established by the EPA with respect to both anticipated processes and events and unanticipated processes and events. [10CFR60.112]

21 The requirements for the EBS and accesses, boreholes and their seals are addressed in 3.7.2.6 and 3.7.3.2 
B. Ground Water Travel Time. The geologic repository shall be located so that the pre-waste-emplacement groundwater travel time along the fastest path of likely radionuclide travel from the disturbed zone to the accessible environment shall be at least 1,000 years, or such other travel time as may be approved or specified by the NRC. [10CFR60.113 (a)(2)]

C. Ground Water. If any of the average annual radionuclide concentrations existing in a special source of ground water, if one exists, before construction of the disposal system already exceed the limits in 40CFR191.16 (a), the disposal system shall be designed to provide a reasonable expectation that, for 1,000 years after disposal, undisturbed performance of the disposal system shall not increase the existing average annual radionuclide concentrations in water withdrawn from the special source of ground water by more than the limits established in 40CFR191.16(a). 〈TBR> [40CFR191.16 (b) $<$ TBR>]

D. Adverse Effects. Assuming the site has been found suitable and to meet the requirements specified in 10CFR60.122(a), the repository design organization shall account for the effects of any of the potentially adverse conditions listed in 10CFR60.122(c) if they are found to be characteristic of the planned controlled area. ${ }^{22} 10$ CFR60.122(a) specifies that the effects of the potentially adverse conditions can be addressed by analysis, by compensation by favorable conditions (10CFR60.122(b)), or remedied [by engineering design]. [10CFR60.122]

E. Land Ownership. The GROA and the controlled area shall be sited on land for which the DOE exercises the controls specified by 10CFR60.121. [10CFR60.121]

\subsubsection{Repository Site Development Requirements}

A. Site Surveys. Construction, control, property and topographic surveys shall be conducted in accordance with the standards specified in DOE Order 6430.1A, Section 0202, "Surveying". The appropriate class shall be selected from the Survey Suggested Standards and Specifications for Local Surveys (Table 0202-3.1) for each application. The appropriate order for level closure shall be selected from the Accuracy Standards for Level Closures (Table 0202-3.3) for each application. [DOE Order 6430.1A, 0202]

\section{B. Site Grading}

1. In compliance with DOE Order 6430.1A, Section 0150-1, disturbance of the natural terrain shall be minimized during site grading. Where feasible, natural flora on or adjacent to the construction site shall be preserved and protected from vehicular and pedestrian traffic. Topsoil within the area of disturbance shall be stockpiled for later use in landscaping and reclamation efforts. [DOE Order 6430.1A, Section 0150-1]

22 10CFR60.2 definition of controlled area. 
2. Site grading shall be designed and constructed in accordance with DOE Order 6430.1A, Section 0220, "Earthwork." [DOE Order 6430.1A, Section 0220]

3. Parking areas shall be designed and constructed in accordance with DOE Order 6430.1A, Section 0250-4,"Parking Areas." [DOE Order 6430.1A, 0250-4]

\section{Roads}

1. Off-site roads traversing Bureau of Land Management (BLM) property shall be designed and constructed in compliance with BLM Manual, Section 9113. [BLM Manual, Section 9113]

2. Site roads shall be designed and constructed in accordance with DOE Order 6430.1A, Section 0250-3, "Roads," and Section 0250-5, "Pavements." [DOE. Order 6430.1A, 0250-3, -5]

\section{Fencing}

1. Construction area and temporary security fences shall be designed and constructed in accordance with the requirements of DOE Order 6430.1A, Section 0150-5 "Temporary Security Fencing". [DOE Order 6430.1A, 0150-5]

2. Permanent security fences shall be designed and constructed in accordance with the requirements of DOE Order 6430.1A, Section 0280-1 "Fencing". [DOE Order 6430.1A, 0280-1]

E. Environment. Significant adverse environmental impacts shall be mitigated, to the extent practicable, during site characterization and repository construction, operation, closure, and decommissioning. [NWPAA, 112(b)(1)(E)(iii)][NWPA, 113(a)][10CFR960.3-4]

F. Storm Water. The storm water control and site drainage systems shall be designed and constructed in accordance with DOE Order 6430.1A Section 0270-2, Storm Water Management Systems. [DOE Order 6430.1A, 0270-2]

\subsubsection{Repository Utilities and Services Requirements}

Each utility service system that is important to safety shall be designed so that essential safety functions can be performed under both normal and accident conditions. [10CFR60.131(b)(5)(i)]

\subsection{Electric Power}

A. Emergency Power. Provisions shall be made to make reliable and timely emergency power immediately available to instruments, utility service systems, central security systems, and operating systems, including alarm systems important to safety, in the event of loss of the primary electric power source or circuit. (Backup power requirements for 
Title: Mined Geologic Disposal System Requirements Document

items not identified as important to safety are treated by analysis during design development process). $\quad$ [10CFR60.131(b)(5)(iii)]

B. Electric Power. The electric power system shall be designed in accordance with DOE Order 6430.1A, Division 16, "Electrical," and applicable state laws. [DOE Order 6430.1A]

C. Uninterruptible Power. An uninterruptible power supply system shall be provided and shall be designed in accordance with DOE Order 6430.1A, Division 16 Electrical. [DOE Order 6430.1A]

D. Standby Electrical Power. The emergency electrical power supply system shall be provided and shall be designed in accordance with DOE Order 6430.1A, Division 16 Electrical and applicable state law. [DOE Order 6430.1A]

\subsection{Supply and Control Water}

A. Plumbing. Plumbing providing water for human consumption shall be lead-free in compliance with 42USC300g-6. [42USC300g-6]

B. Potable Water. The potable water system shall be designed and installed to comply with all Federal, State, and local requirements, administrative authorities, and process and sanctions regarding the provisions of safe drinking water. [42USC300f et seq., Section 300g-3] [40CFR141 and 40CFR143]

C. Water Supply. The water system shall be designed in accordance with DOE Order 6430.1A, Division 2 Site and Civil Engineering, and Division 15 Mechanical and applicable state laws. [DOE Order 6430.1A]

\subsection{Communications}

A. Communication Systems. Communication systems shall be designed in accordance with the applicable sections of DOE Order 6430.1A, Division 1, Division 2, Division 10, Division 13, Division 15 and Division 16. [DOE Order 6430.1A]

B. Communications Facilities. Communications facilities shall be designed in accordance with the applicable sections of DOE Order 6430.1A Section 1630-99.8 (Telecommunications, Alarms, and Automated Data Processing (ADP) Centers and Radio Repeater Stations). [DOE Order 6430.1A, 1630-99.8]

C. Guard Communication. Each guard or watchman on duty shall be provided continuous communication with a central alarm station within the protected area. This station shall be capable of communication with other guards and watchmen and local law enforcement authorities. [Derived]

D. Telephone Communication. The required security alarm stations shall have conventional telephone service for communication with law enforcement authorities. [Derived] 
E. Reserved

F. Radio Communication. To provide the capability of continuous communication, two-way radio voice communication shall be established in addition to conventional telephone service between local law enforcement authorities and the facility and shall terminate at the facility in a central alarm station within the protected area. [Derived]

G. Communications Power Supply. All communications equipment required for security, including off-site equipment, shall remain operable from independent power sources in the event of loss of primary power. [Derived]

CMOCC Communications. Communication with program operations and management at the Central Management and Operations Control Center (CMOCC) will be by the commercial telephone system.

\subsection{Ilumination System}

A. Lighting. Lighting shall be designed in accordance with DOE Order 6430.1A, Division 16, Electrical. [DOE Order 6430.1A]

B. Security Lighting. Security lighting shall be designed to comply with the DOE Order 5632 series. [DOE Order 6430.1A, 0278]

\subsection{Transportation}

Vehicle and pedestrian transportation facilities and systems at the MGDS shall be designed and constructed to comply with DOE Order 6430.1A Section 0281, Vehicular and Pedestrian Circulation. [DOE Order 6430.1A, 0281]

\subsection{Monitoring}

\section{A. Reserved}

B. Instrumentation and control systems shall include provisions to monitor and control the behavior of systems important to safety over anticipated ranges for normal operation and for accident conditions. [10CFR60.131(b)(8)]

C. Control systems and instrumentation shall be designed in accordance with the applicable sections of DOE Order 6430.1A, Division 15 "Mechanical," and Division 16, "Electrical." [DOE Order 6430.1A]

\subsection{Sanitary Sewerage}

A. The design, construction and operation of sanitary sewage handling and disposal systems shall be as permitted in accordance with the Clean Water Act, 33USC1251 et seq. Section 1345, and applicable state laws. [33USC1251 et seq. Section 1345a] 
B. The sewerage system shall be designed in accordance with DOE Order 6430.1A, Division 2, Site and Civil Engineering and applicable state laws. [DOE Order 6430.1A]

\subsection{Site-Generated Waste Treatment}

A. Radioactive waste treatment facilities shall be designed to process any radioactive waste generated at the GROA into a form suitable to permit safe disposal at the GROA or to permit safe transportation and conversion to a form suitable for disposal at an alternative site in accordance with any regulations that are applicable. [10CFR60.132(d)]

B. Facilities shall be provided to manage and dispose of site-generated solid and hazardous wastes (excluding radioactive wastes) in accordance with requirements of the Clean Water Act, unless arrangements are made for off-site disposal. [33USC1251 et seq.]

\subsubsection{Repository Surface Facility Requirements}

\subsection{Waste Handling Requirements}

\section{A. Waste Handling}

1. Surface facilities in the GROA shall be designed to allow safe handling and lag storage (if needed) of wastes at the GROA, whether these wastes are temporarily on the surface before emplacement or as a result of retrieval from the underground facility. [10CFR60.132(a)]

2. Cranes and similar handling equipment shall be capable of meeting the requirements specified by DOE Order 6430.1A, Section 1460 and the Crane Manufacturers Association of America Standard (CMAA 70). [DOE Order 6430.1A, 1460]

B. Delivery Modes. The Repository Segment shall be capable of receiving shipments of spent fuel and commercial and defense high-level waste delivered by truck or rail. [DOE/RW-0316, p 101]

C. Surface Facility Ventilation. Surface facility ventilation systems supporting waste transfer, inspection, decontamination, processing, or packaging shall be designed to provide protection against radiation exposures and off-site releases as provided in 10CFR60.111(a). [10CFR60.132(b)]

D. Handling systems for SNF, HLW, waste packages, and transportation cask subsystems (including MPCs) shall be designed to provide the capability to minimize the generation of mixed wastes. [Derived by CRD 3.2.2.8] 


\subsection{Alarm Systems}

A. The GROA shall include fire and explosion detection and alarm systems in structures systems and components important to saft(ty. [10CFR60.131 (b)(3)(iii)]

B. All required security alarms shall annunciate in a central security alarm station located within the protected area and in at least one other security station, not necessarily within the protected area, such that a single act cannot remove the capability of calling for assistance or otherwise responding to an alarm.

1. All alarms shall be self-checking and tamper indicating.

2. The annunciation of an alarm at the on-site central security alarm station shall indicate the type of alarm (e.g. intrusion alarm, emergency exit alarm, etc.) and location.

3. All intrusion alarms, emergency exit alarms, alarm systems, and line supervision systems shall, at minimum, meet the performance and reliability levels indicated by GSA Interim Federal Specification W-A- 450/1-17 (GSA-FSS). [Derived]

C. All emergency exits in each protected area and each vital area shall be alarmed. [Derived]

D. The repository design shall include air monitoring and alarm systems designed and installed in compliance with DOE Order 6430.1A, 1300-6.5. [DOE Order 6430.1A, 1300-6.5]

E. At least two security alarm stations, including at least one inside the protected area, shall be provided with the following capabilities:

1. Support continuous manning,

2. Monitor all security alarms initiated on the repository site,

3. Communicate with emergency response agencies and facilities on and off the repository site. [Derived]

F. Unoccupied vital areas and special material access areas shall be protected by an active intrusion alarm system. [Derived]

\subsection{Reserved}

\subsection{Fire Protection Requirements}

Fire protection standards for the Repository Segment are imposed by various authoritative sources. In the event of conflict, the requirements affording greater protection (as determined by design analysis) prevail.

A. The GROA shall be designed to include appropriate suppression systems with sufficient capacity and capability to reduce the adverse effects of fires and explosions on structures, systems, and components important to safety. [10CFR60.131(b)(3)(iii)] 
B. The fire protection shall be designed in accordance with DOE Order 6430.1A, 0110-6. [DOE Order 6430.1A, 0110-6]

C. Detection equipment for fires and explosions shall meet the requirements of DOE Order 5480.7A; DOE Order 6430.1A, Division 15 and Division 16; and any applicable local, State and Federal regulations. [DOE Order 5480.7A, DOE Order 6430.1A]

D. The Repository Segment is to be designed and constructed to achieve the improved risk objectives prescribed by DOE Order 5480.7A, paragraph 4 . To this end the design shall include the compliance features and essential elements specified by DOE Order 5480.7A, paragraphs 9 and 10. [DOE Order 5480.7A]

\subsection{Reserved}

\subsection{Other Surface Facilities}

A. Change Rooms. Change facilities shall be provided to comply with DOE Order 6430.1A, 1300-6.8. [DOE Order 6430.1A, 1300-6.8]

B. Industrial Health and Safety. The Repository Segment shall have the capability of sampling work environments where there is reason to suspect that work processes may create health hazards. [DOE Order 3790.1A, I.3.a.(5)]

C. Training Facility Requirements. The Repository Segment design shall provide facilities, equipment, manuals, and training aids to support training programs required by 10CFR60.161; 29CFR1910; 29CFR1926; 29CFR1960, Subpart H; 30CFR48; 30CFR57; 49CFR172, Subpart H; the QARD; and DOE Orders 3790.1A, 4330.4A and 5000.3A. [Derived]

D. Medical Facility Requirements. The Repository Segment shall include facilities to support the medical services required by DOE Order 3790.1A, Chapter VIII. [DOE Order 3790.1A, Chapter VIII]

\section{E. Office Requirements}

1. Office spaces shall be based on a minimum of 100 square feet per office and a maximum per the Federal Property Management Regulations. [41CFR101-17.3]

2. Reserved

3. The Repository Segment shall include, within the GROA, unfurnished office space dedicated for the use of NRC inspection personnel. The office space shall be equipped with heating, ventilation and air-conditioning, lighting, electrical outlets, visual and acoustic privacy provisions, full access to the repository, and a minimum of 250 square feet of floor area. The office space that is provided will be subject to 
the approval of the Director, Office of Nuclear Material Safety and Safeguards. [10CFR60.75(c)]

4. Office space including a clearly marked mining office shall be provided as necessary to support the management and operation of the MGDS, and to support MSHA, Occupational Safety and Health Administration (OSHA), and other oversight agencies. [Derived]

\section{F. Records Management Requirements}

1. Facilities and equipment shall be provided to preserve and maintain accident records in accordance with 29USC651. [29USC651 et seq., Section 657]

2. Facilities and equipment shall be provided to preserve and maintain the records as required by DOE Order 1324.2A, Records Disposition. [DOE Order 3790.1A, page VII-8, (5)(b)(2)(g)(3)]

3. If a local records center is required and authorized, it shall be designed and outfitted to meet the requirements specified by DOE/RW-0194. [DOE/RW-0194]

4. Facilities and equipment shall be provided to collect, store, and maintain QA records in accordance with the requirements of the QARD. [QARD]

5. Additional record storage facilities shall be provided as necessary to support the operation and management of the MGDS. [Derived]

G. Maintenance Facility Requirements. Maintenance facilities, equipment, and tools shall be provided to support the maintenance concept of the MGDS to be developed based on the policy, and criteria specified by DOE Order 4330.4A. [DOE Order 4330.4A]

H. Test and Maintenance Facility Requirements. The Repository Segment shall include facilities to test and maintain intrusion alarms, emergency alarms, communications equipment, physical barriers, and other security-related devices or equipment utilized pursuant to 10CFR60. [Derived]

\section{Emergency Response Requirements}

1. The Repository Segment shall include a medical emergency response capability including: (1) The ability to treat the initial consequences of potential medical emergencies that might occur on the site and, if necessary, the ability to process injured or sick personnel for transfer to off-site medical emergency facilities; and (2) The capacity to treat the number of patients and types of illnesses or injuries that are likely to occur on the site. [DOE Order 3790.1A, VIII.5(l)(m)]

2. The GROA shall be designed to include on-site facilities and services that ensure a safe and timely response to emergency conditions and that facilitate the use of 
available off-site services (such as fire, police, medical and ambulance service) that may aid in recovery from emergencies. [10CFR60.131(b)(4)(ii)]

3. Space for storage of emergency equipment shall be provided. [DOE Order 6430.1A, 0110-1.3]

\section{J. Explosives Storage.}

1. Storage magazines for explosives and caps shall meet the most stringent of the requirements of 29CFR1910.109, 27CFR55.201-211, and applicable State or local regulations and DOE Orders 5480.4 and 6430.1A. [29CFR1910.109, 27CFR55.201211 and DOE Orders 5480.4 and 6430.1A]

2. Facilities for the storage of explosive materials shall be located in compliance with the regulations in 27CFR55.206.

a. Outdoor magazines in which high explosives are stored shall be located no closer to inhabited buildings, passenger railways, public highways, or other magazines in which high explosives are stored, than the minimum distances specified in the table of distances for storage of explosive materials in 27CFR55.218. [27CFR55.206]

b. Ammonium nitrate and magazines in which blasting agents are stored shall be located no closer to magazines in which high explosives or other blasting agents are stored than the minimum distances specified in the table of distances for the separation of ammonium nitrate and blasting agents in 27CFR55.220. However, the minimum distances for magazines in which explosives and blasting agents are stored from inhabited buildings, etc., may not be less than the distances specified in the table of distances for storage of explosives materials in 27CFR55.218. [27CFR55.206]

K. Personnel Support. Facilities shall be provided to support the working staff at the MGDS to include vehicle access, parking, food service, restrooms, sleeping accommodations as required, and others as determined by analysis of the concept of operations. [Derived]

\section{Decontamination and Dismantlement.}

1. Surface facilities shall be designed to facilitate decontamination or dismantlement to the same extent as would be required, under other parts of NRC regulations, with respect to equivalent activities licensed thereunder. [10CFR60.132(e)]

2. The structures, systems, and components shall include features that will facilitate decontamination for future decommissioning, increase the potential for other uses, or both. [DOE Order 6430.1A, 1300-11.2] 


\subsubsection{Repository Underground Requirements}

A. Shaft conveyances. Shaft conveyances, if used for handling radioactive waste, shall meet the following requirements:

1. Hoists important to safety shall be designed to preclude cage free-fall. [10CFR60.131(b)(10)(i)]

2. Hoists important to safety shall be designed with a reliable cage location system. [10CFR60.131(b)(10)(ii)]

3. Loading and unloading systems for hoists important to safety shall be designed with a reliable system of interlocks that will fail safely upon malfunction. [10CFR60.131(b)(10)(iii)]

4. Hoists important to safety shall be designed to include two independent indicators to indicate when waste packages are in place and ready for transfer. [10CFR60.131(b)(10)(iv)]

B. Underground Facility Ventilation. The underground facility ventilation system shall be designed to:

1. Control the transport of radioactive particulates and gases within and releases from the underground facility in accordance with the performance objectives of 10CFR60.111(a) (Sections 3.2.1.4 and 3.2.2.1.D of this document). [10CFR60.133(g)(1)]

2. Assure continued function during normal operations and under accident conditions. [10CFR60.133(g)(2)]

3. Separate the ventilation of excavation and waste emplacement areas. [10CFR60.133(g)(3)]

C. Diesel Exhaust Ventilation ${ }^{23}$. The underground facility shall be ventilated to comply with the following requirements:

1. 30CFR31.9(a) for diesel locomotives, if used. [10CFR60.131(b)(9) as correlated with revised 30CFR Chapter I] [MOU DOE/DOL]

2. 30CFR32.9(a) for other diesel-powered equipment, if used, in a non-gassy environment. [10CFR60.131(b)(9) as correlated with revised 30CFR Chapter I] [MOU DOE/DOL]

23 The components of diesel exhaust may accelerate corrosion of waste packages in addition to the health hazand. (This is an explanatory note.) 
3. 30CFR36.45 for other diesel-powered equipment, if used, in a gassy environment. [10CFR60.131(b)(9) as correlated with revised 30CFR Chapter I] [MOU DOE/DOL]

D. Retrieval of Waste. The underground facility shall be designed to permit retrieval of waste in accordance with the performance objectives of 10CFR60.111. (Section 3.2.1.5.B of this document) [10CFR60.133(c)]

\section{E. Underground Openings}

1. Openings in the underground facility shall be designed so that operations can be carried out safely and the retrievability option maintained. [10CFR60.133(e)(1)]

2. Openings in the underground facility shall be designed to reduce the potential for deleterious rock movement or fracturing of overlying or surrounding rock. [10CFR60.133(e)(2)]

\section{F. Subsurface Facilities and Systems}

1. The design, construction and operation of subsurface facilities and systems shall be in accordance with the applicable health and safety requirements of 30CFR57. [CRD]

2. The subsurface facility shall be designed so that the effects of credible disruptive events during the period of operations, such as flooding, fires, and explosions, will not spread through the facility. [10CFR60.133 (a)(2)]

3. Subsurface explosives and cap storage facilities shall meet the requirements of 30CFR57 Subpart E. [30CFR57, Subpart E]

4. The GROA shall be designed to include explosion and fire detection alarm systems and appropriate suppression systems with sufficient capacity and capability to reduce the adverse effects of fires and explosions on structures, systems, and components important to safety. [10CFR60.131(b)(3)(iii)]

5. The design of the GROA shall include such provisions for worker protection as may be necessary to provide reasonable assurance that all structures, systems, and components important to safety can perform their intended functions. Any deviation from relevant design requirements in 30CFR57 will give rise to a rebuttable presumption that this requirement has not been met and shall be justified in writing. [10CFR60.131(b)(9), correlated with the revised 30CFR Chapter I]

6. The Repository Segment design shall include air monitoring and alarm systems designed and installed in compliance with DOE Order 6430.1A, 1300-6.5. [DOE Order 6430.1A, 1300-6.5]

7. Space for storage of emergency equipment shall be provided. [DOE Order 6430.1A, 0110-1.3] 


\section{G. Rock Excavation}

1. Provisions shall be made to control dust due to drilling in rock, by the use of dust collectors, or by water or water with a wetting agent (water is the least preferred means), or by ventilation, or by any other approved method or device that is at least as effective in controlling dust. [30CFR57.5003]

2. The design of the underground facility shall incorporate excavation methods that will limit the potential for creating a preferential pathway for groundwater to contact the waste packages or radionuclide migration to the accessible environment. [10CFR60.133(f)]

H. Flexibility. The underground facility shall be designed to allow adjustments to accommodate specific site conditions identified through in-situ monitoring, testing, or excavations. [10CFR60.133(b)]

I. Water and Gas. The underground facility shall be designed to control water and gas intrusion. [10CFR60.133 (d)]

J. Seals

1. Seals for accesses and boreholes shall be designed so that following permanent closure they do not become pathways that compromise the geologic repository's ability to meet the performance objectives for the period following permanent closure. [10CFR60.134(a)]

2. Materials and placement methods for seals shall be selected to reduce, to the extent practicable, (a) the potential for creating a preferential pathway for groundwater to contact the waste packages; or (b) for radionuclide migration through existing pathways. [10CFR60.134(b)(1) and (2)]

3. The ... ${ }^{24}$ seals for accesses and boreholes shall be designed to assure that releases of radioactive materials to the accessible environment following permanent closure conform to applicable environmental standards for radioactivity established by the Environmental Protection Agency with respect to both anticipated processes and events and unanticipated processes and events. [10CFR60.112]

K. Control of Fluids in Construction. All fluids used in the construction and operation of the repository shall be strictly controlled to avoid introduction of products that could accelerate waste package corrosion or transport of radionuclides. [Derived]

24 The requirements for the geologic setting and the EBS, accesses, and boreholes are addressed in 3.7.2.2 and 3.7.3.2 
L. Fire Protection. Fire protection standards for the Repository Segment are imposed by various authoritative sources. In the event of conflict, the requirements affording greater protection (as determined by design analysis) prevail.

1. The GROA shall be designed to include appropriate suppression systems with sufficient capacity and capability to reduce the adverse effects of fires and explosions on structures, systems, and components important to safety. [10CFR60.131(b)(3)(iii)]

2. The fire protection shall be designed in accordance with DOE Order 6430.1A, 0110-6. [DOE Order 6430.1A, 0110-6]

3. Detection equipment for fires and explosions shall meet the requirements of DOE Order 5480.7A; DOE Order 6430.1A, Division 15 and Division 16; and any applicable local, State and Federal regulations. [DOE Order 5480.7A, DOE Order 6430.1A]

4. The Repository Segment is to be designed and constructed to achieve the improved risk objectives prescribed by DOE Order 5480.7A, paragraph 4 . To this end the design shall include the compliance features and essential elements specified by DOE Order 5480.7A, paragraphs 9 and 10. [DOE Order 5480.7A]

M. Industrial Health and Safety. The repository shall have the capability of sampling work environments where there is reason to suspect that work processes may create health hazards. [DOE Order 3790.1A, 1.3.a.(5)]

\subsubsection{Performance Confirmation Requirements}

\section{A. General Requirements}

1. The GROA shall be designed to include the capability to support tests appropriate or necessary (as determined by the NRC) for the administration of the regulations of 10CFR60. These tests may include tests of (1) radioactive waste, (2) the geologic repository including its structures, systems, and components, (3) radiation detection and monitoring instruments, and (4) other equipment and devices used in connection with the receipt, handling, or storage of radioactive waste. [10CFR60.74(a)]

2. The tests required in section 3.7.2.7.A.1 shall include a performance confirmation program carried out in accordance with Subpart F of 10CFR60. [10CFR60.74(b), 60.137]

3. The performance confirmation program shall provide data that indicates, where practical, whether: (1) Actual underground conditions encountered and changes in those conditions during construction and waste emplacement operations are within limits assumed in the licensing review; and (2) Natural and engineered systems and components required for repository operation, or that are designed or assumed to operate as barriers after permanent closure, are functioning as intended and anticipated. [10CFR60.140(a)] 
4. The program shall include in situ monitoring, laboratory and field testing, and in situ experiments, as appropriate, to accomplish the objectives stated in Subpart F of 10CFR60 (3.7.2.7.A.2) above. [10CFR60.140(c)]

5. The program shall:

a. Not adversely affect the ability of the natural and engineered elements of the geologic repository to meet the performance objectives

b. Provide baseline information and analysis of that information on those parameters and natural processes pertaining to the geologic setting that may be changed by site characterization, construction, and operational activities

c. Monitor and analyze changes from the baseline condition of performance of the geologic repository

d. Provide an established plan for feedback and analysis of data, and implementation of appropriate action. [10CFR60.140(d)]

6. The repository shall be capable of monitoring underground conditions and evaluating them against design assumptions. [10CFR60.141(b)]

B. Testing. During the early developmental stages of construction, the Repository Segment shall be capable of supporting in situ testing of such features as borehole and access seals, backfill, and the thermal interaction effects of the waste packages, backfill, rock, and groundwater. [10CFR60.142(a)]

C. Rock Measurements. The Repository Segment shall be capable of measuring, as a minimum, rock deformations and displacement, changes in rock stress and strain, rate and location of water inflow into underground areas, changes in groundwater conditions, rock pore water pressures, including those along fractures and joints, and the thermal and thermomechanical response of the rock mass as a result of development and operations of the geologic repository. [10CFR60.141(c)]

D. Thermomechanical Response. The Repository Segment shall be capable of in situ monitoring of the thermomechanical response of the underground facility until permanent closure to ensure that the performance of the natural and engineering features are within design limits. [10CFR60.141(e)]

E. Laboratory Experiments. To support the waste package monitoring program required by 10CFR60.143(a) and (b), the GROA shall be designed to include facilities (to the extent appropriate for on-site work) capable of supporting laboratory experiments that focus on the internal condition of the waste packages. To the extent practical, the environment experienced by the emplaced waste packages within the underground facility during the waste package monitoring program shall be duplicated in the laboratory experiments. [10CFR60.143(c)] 
F. Backfill Test. A backfill test section shall be constructed to test the effectiveness of backfill placement and compaction procedures against design requirements before permanent backfill placement is begun. [10CFR60.142(c)]

G. Borehole and Access Seal Tests. Test sections shall be established to test the effectiveness of borehole and access seals before full-scale operation proceeds to seal boreholes and accesses. [10CFR60.142(d)]

\subsubsection{Radiological Protection}

A. The GROA shall be designed to maintain radiation doses, levels, and concentrations of radioactive material in air in restricted areas within the limits specified in 10CFR20. Design shall include:

1. Means to limit concentrations of radioactive material in air. [10CFR60.131(a)(1)]

2. Means to limit the time required to perform work in the vicinity of radioactive materials, including, as appropriate, designing equipment for ease of repair and replacement and providing adequate space for ease of operation. [10CFR60.131(a)(2)]

3. Suitable shielding. [10CFR60.131(a)(3)]

4. Means to monitor and control the dispersal of radioactive contamination. [10CFR60.131(a)(4)]

5. Means to control access to high radiation areas or airborne radioactivity areas. [10CFR60.131(a)(5)]

6. A radiation alarm system to wam of significant increases in radiation levels, concentrations of radioactive material in air, and of increased radioactivity released in effluent. The alarm system shall be designed with provisions for calibration and for testing its operability. [10CFR60.131(a)(6)]

B. Occupational health facilities shall be designed in accordance with DOE Order 6430.1A, Division 1. [DOE Order 6430.1A]

C. The repository shall provide a reasonable assurance that the public and the environment will be adequately protected from the hazards posed by radioactive wastes emplaced therein. [NWPA 111(b)(1)]

D. Personnel decontamination facilities shall be provided close to areas that are potential sources of contamination in accordance with DOE Order 6430.1A, 1300-6.6. [DOE Order 6430.1A, 1300-6.6]

E. The Repository Segment shall be equipped with instrumentation capable of suitable and timely measurement and indication of, at least the following: (a) Concentrations of 
radioactive materials in air in the work areas, (b) Quantities of radionuclides in the body, and (c) Quantities of radionuclides excreted from the body. [10CFR20.1204]

F. Surface facilities shall be designed to control the release of radioactive materials in effluents during normal operations so as to meet the performance objectives of 10CFR60.111(a). [10CFR60.132(c)(1)]

G. The effluent monitoring systems shall be designed to measure the amount and concentration of radionuclides in any effluent with sufficient precision to determine whether releases conform to the design requirement for effluent control. The monitoring systems shall be designed to include alarms that can be periodically tested. [10CFR60.132(c)(2)]

\subsubsection{Engineered Barrier System Segment}

\subsubsection{Engineered Barrier System Segment Description}

The EBS Segment means the waste package (the waste form (including MPCs) and any containers, shielding, packing and other absorbent materials immediately surrounding an individual waste container) and the underground facility.

A. The EBS Segment shall provide components capable of contributing to the assigned function, Isolate Waste (1.4.3). The description for this function is listed in Appendix C to this MGDS-RD. [CRD]

B. DRDs shall identify and specify requirements for the components that address the assigned function. [Derived]

C. The Engineered Barrier DRD describes and specifies requirements for interfaces between the EBS Segment and Repository Segment.

The EBS Segment interfaces with the Repository Segment. The outputs from the EBS Segment include radionuclides, radiation, and heat. The major component of the EBS Segment is the waste package, which has interfaces with the Repository Segment wastehandling facilities, with the vehicle that transfers waste packages from the surface to the emplacement locations underground, and with the emplacement location itself. The requirements in Sections 3.7.3.2 through 3.7.3.4 address the additional interface between the EBS Segment and the geologic setting. The EBS Segment does not have an interface with the Site Segment.

\subsubsection{Engineered Barrier System General Requirements}

A. Engineered barriers shall be designed to assist the geologic setting in meeting the performance objectives for the period following permanent closure. [10CFR60.133(h)] 
B. The..${ }^{25}$ EBS shall be designed to assure that releases of radioactive materials to the accessible environment following permanent closure conform to applicable environmental standards for radioactivity established by the EPA with respect to both anticipated processes and events and unanticipated processes and events. [10CFR60.112]

C. The EBS shall be designed, assuming anticipated processes and events, so that containment of radioactive material within the waste packages will be substantially complete for a period to be determined by the NRC, but not less than $300^{26}$ years nor more than 1,000 years after permanent closure of the geologic repository ${ }^{27}$. [10CFR60.113(a)(1)(ii)(A)]

D. The EBS shall be designed, assuming anticipated processes and events, so that the release rate of any radionuclide from the EBS following the containment period shall not exceed one part in 100,000 per year of the inventory of that radionuclide calculated to be present at 1,000 years following permanent closure, or such other fraction of the inventory as may be approved or specified by the NRC; provided, that this requirement does not apply to any radionuclide that is released at a rate less than $0.1 \%$ of the calculated total release rate limit. The calculated total release rate limit shall be taken to be one part in 100,000 per year of the inventory of radioactive waste, originally emplaced in the underground facility, that remains after 1,000 years of radioactive decay. [10CFR60.113(a)(1)(ii)(B)]

\section{E. Seals}

1. Seals for accesses and boreholes shall be designed so that following permanent closure they do not become pathways that compromise the geologic repository's ability to meet the performance objectives for the period following permanent closure. [10CFR60.134(a)]

2. Materials and placement methods for seals shall be selected to reduce, to the extent practicable: (a) the potential for creating a preferential pathway for groundwater to contact the waste packages, or (b) for radionuclide migration through existing pathways. [10CFR60.134(b)(1) and (2)]

3. The.. $.28^{28}$ seals for accesses and boreholes shall be designed to assure that releases of radioactive materials to the accessible environment following permanent closure

25 The requirements for the geologic setting and the accesses, boreholes, and their seals are addressed in 3.7.2.2, and 3.7.2.6 and 3.7.3.2.E.

26

NRC Staff Position 60-001 indicates that this is a minimum performance requirement, and credit can be taken in performance assessments for containment in excess of 1000 years.

27

10CFR60.113(B) says the NRC may later revise this requirement on a case-by-case basis.

32 The requirements for the geologic setting and the EBS, accesses, and boreholes are addressed in 3.7.2.2 and 3.7.3.2 
conform to applicable environmental standards for radioactivity established by the EPA with respect to both anticipated processes and events and unanticipated processes and events. [10CFR60.112]

\subsubsection{Waste Package Requirements}

A. General. Packages for SNF and HLW shall be designed so that the in situ chemical, physical, and nuclear properties of the waste package and its interactions with the emplacement environment do not compromise the function of the waste packages or the performance of the underground facility or the geologic setting. [10CFR60.135(a)(1)] [Derived by CRD 3.2.1.1.H]

B. Integrity.

1. The design of waste packages shall include but not be limited to consideration of the following factors: solubility, oxidation/reduction reactions, corrosion, hydriding, gas generation, thermal effects, mechanical strength, mechanical stress, radiolysis, radiation damage, radionuclide retardation, leaching, fire and explosion hazards, thermal loads, and synergistic interactions. [10CFR60.135(a)(2)] [Derived by CRD 3.2.1.1.H]

2. Waste packages shall be emplaced in an environment (e.g., waste package design, underground facility design, emplacement mode or orientation, spacing between waste packages, etc.), such that SNF cladding temperatures in an emplaced waste package do not exceed $350^{\circ} \mathrm{C}<\mathrm{TBR}>$. [10CFR60.135(a)(2)] [Derived by CRD 3.2.1.1.H]

3. The waste package design shall ensure loaded wastes are maintained subcritical in compliance with the nuclear criticality requirements specified in Section 3.2.2.6 of this MGDS-RD. [10CFR60.131(b)(7)] [CRD 3.2.2.5]

4. The waste package container(s) shall provide structural integrity for the loaded wastes to withstand the loads induced in waste-handling operations, including retrieval. [NWPA 122] [10CFR60.135(b)(3)] [Derived by CRD 3.2.1.1.H, CRD 3.2.1.1.J, CRD 3.2.5.1.C]

C. Package Contents. The waste packages shall not contain explosive or pyrophoric materials or chemically reactive materials in an amount that could compromise the ability of the underground facility to contribute to waste isolation or the ability of the geologic repository to satisfy the performance objectives. [10CFR60.135(b)(1)]

D. Free Liquids. The waste package shall not contain free liquids in an amount that could compromise the ability of the waste packages to achieve the performance objectives relating to containment of radioactive waste (because of chemical interactions or formation of pressurized vapor) or result in spillage and spread of contamination in the event of waste package perforation during the period through permanent closure. [10CFR60.135(b)(2)] 
E. Durability. Waste packages shall be designed to maintain waste containment during transportation within the MGDS, emplacement, and retrieval. [10CFR60.135(b)(3)]

F. Label. A label or other means of identification shall be provided for each waste package. The identification shall not impair the integrity of the waste package and shall be applied in such a way that the information shall be legible at least to the end of the period of retrievability. Each waste package identification shall be consistent with the waste package's permanent written records. [10CFR60.135(b)(4)]

G. Waste Form Requirements. SNF and HLW that is emplaced in the underground facility shall be designed to meet the following criteria:

1. Solidification. All such radioactive wastes shall be in solid form. [10CFR60.135(c)(1)]

2. Sealed Containers. Radioactive waste shall be placed in sealed containers. [10CFR60.135(c)(1)]

3. Consolidation. Particulate waste forms shall be consolidated (for example, by incorporation into an encapsulated matrix) to limit the availability and generation of particulates. [10CFR60.135(c)(2)]

4. Combustibles. All combustible radioactive wastes shall be reduced to a noncombustible form unless it can be demonstrated that a fire involving the waste packages containing combustibles will not compromise the integrity of other waste packages, adversely affect any structures, systems, or components important to safety, or compromise the ability of the underground facility to contribute to waste isolation. [10CFR60.135(c)(3)]

\subsubsection{Underground Facility Requirements}

A. General Criteria. The orientation, geometry, layout, and depth of the underground facility, and the design of any engineered barriers that are part of the underground facility shall contribute to the containment and isolation of radionuclides. [10CFR60.133(a)(1)]

B. Reserved

C. Thermal Loads. The underground facility shall be designed so that the performance objectives will be met taking into account the predicted thermal and thermomechanical response of the host rock, and surrounding strata, and groundwater system. [10CFR60. 133(i)]

D. Control of Fluids in Construction. All fluids used in the construction and operation of the EBS shall be strictly controlled to avoid introduction of products that could accelerate waste package corrosion or transport of radionuclides. [Derived] 


\subsection{PRECEDENCE}

A. The general order of precedence for MGDS requirements is:

1. Federal Law

a. Statutes and Treaties

b. Regulations and Executive Orders

c. Other (e.g., DOE Orders)

2. State Law and Tribal Law

3. Local Ordinances

4. National and International Standards [CRD]

B. In resolving questions of precedence involving DOE Orders or parts of the CFR issued by DOE that address nuclear safety requirements covered by the CFR parts issued by the NRC, the NRC requirements shall take precedence ${ }^{29}$. (See also 3.1.5.C) [MOA, RW/NS, 04/16/92]

C. Precedence between 29CFR1910 (OSHA) and 30CFR57 (MSHA) shall be as described in 3.3.6.2.E. [CRD]

\subsection{QUALIFICATION/QUALITY ASSURANCE}

MGDS shall have a quality assurance program approved by the NRC as satisfying tile provisions of Subpart G of 10CFR60. [10CFR60 Subpart G, QARD]

29 However, DOE Orders, or CFRs, or other standards may be used as a reference in meeting NRC requirements. 
Title: Mined Geologic Disposal System Requirements Document

Revision: 1

Page: 110

INTENTIONALLY LEFT BLANK 
Title: Mined Geologic Disposal System Requirements Document

Revision: 1

Page: 111

\section{CONFORMANCE VERIFICATION}

\subsection{RESPONSIBILITIES}

This section relates the requirements of this document to the compliance methods of Section 4.2 that will be used to verify compliance with the requirements.

The test and evaluation program and the conformance verification activities are not intended to replace activities associated with NRC license application or the satisfaction of that license.

\subsection{METHODS}

The methods of compliance to be used are:

A. Analysis. Analysis is the process needed to verify a requirement by rational thinking, tradeoff studies, modeling, and processing test data and accumulated results to reach a conclusion. Analysis involves the processing of accumulated results and conclusions, intended to provide proof that verification of a requirement has been accomplished. The analytical results may be comprised of a compilation or interpretation of existing information or derived from lower level examinations, tests, demonstrations, or analyses.

Example: Verifying compliance with the Ground Water Travel Time requirement will require integration of the results of multiple studies involving models, test data, and other information.

B. Examination. Examination is the process of investigating a product to verify that required features are incorporated. Examination consists of investigation, without the use of special laboratory appliances, procedures, supplies, or services, to determine conformance to those specified requirements that can be determined by such investigations. Examination is generally nondestructive and includes, but is not limited to, visual, auditory, olfactory, tactile, and other investigations; simple physical manipulation; gauging; and measurement.

Example: Visual inspection of a road to verify that drainage ditches and culverts are present.

C. Test. Test is the quantitative process whereby data is collected over a specified time period, under controlled conditions, in order to document the as-built performance of a product. A test denotes the determination of the properties or elements of items (or components thereof) by technical means, including functional operation, the application of established principles and procedures and the collection of quantitative data. The analysis of data derived from testing is an integral part of the method.

Example: Measurements to verify radiologic shielding effects. 
D. Demonstration. Demonstration is the qualitative process of exercising a product to verify its operability, where data may or may not be collected. Demonstration differs from test by directness of approach in the verification of a requirement and is accomplished without the use of instrumentation or special equipment. 1. us, operation of a representative item in or near its use environment would be defined as a Demonstration rather than a Test. Demonstration attempts to verify, qualitatively, the performance of a function, whereas Test involves verifying performance within a specific range of measurement.

Example: Deliberate cut-off of an electric power source to verify automatic operation of emergency lighting.

\subsection{CROSS-REFERENCE}

Table 4-1 correlates the requirements of Sections 3 and 5 with the method to be used to verify compliance with the requirements. Documentation of conformance will be accomplished through the use of detailed procedures developed and performed on all procured, constructed, and developed equipment, structures, and software.

\subsection{VERIFICATION}

Documentation of compliance will be accomplished through the use of detailed verification procedures developed in accordance with direction provided in test and evaluation plans and Section 5 below. These procedures will be developed and performed on all procured, constructed, and developed equipment, structures, and software. The plans will address: test program documentation; definition of developmental, acceptance, and operational testing; identification of test sites and resources; test philosophy; division of test responsibilities; and general test management. The plans will be implemented through individual test plans, test planning analysis, and test procedures.

In the following table, items marked "N/A" (not applicable) have no verification required. These items are titles or contain explanatory materials. The other columns "Analysis", "Exam", "Test", and "Demo" refer to the verification methods identified in Section 4.2. 


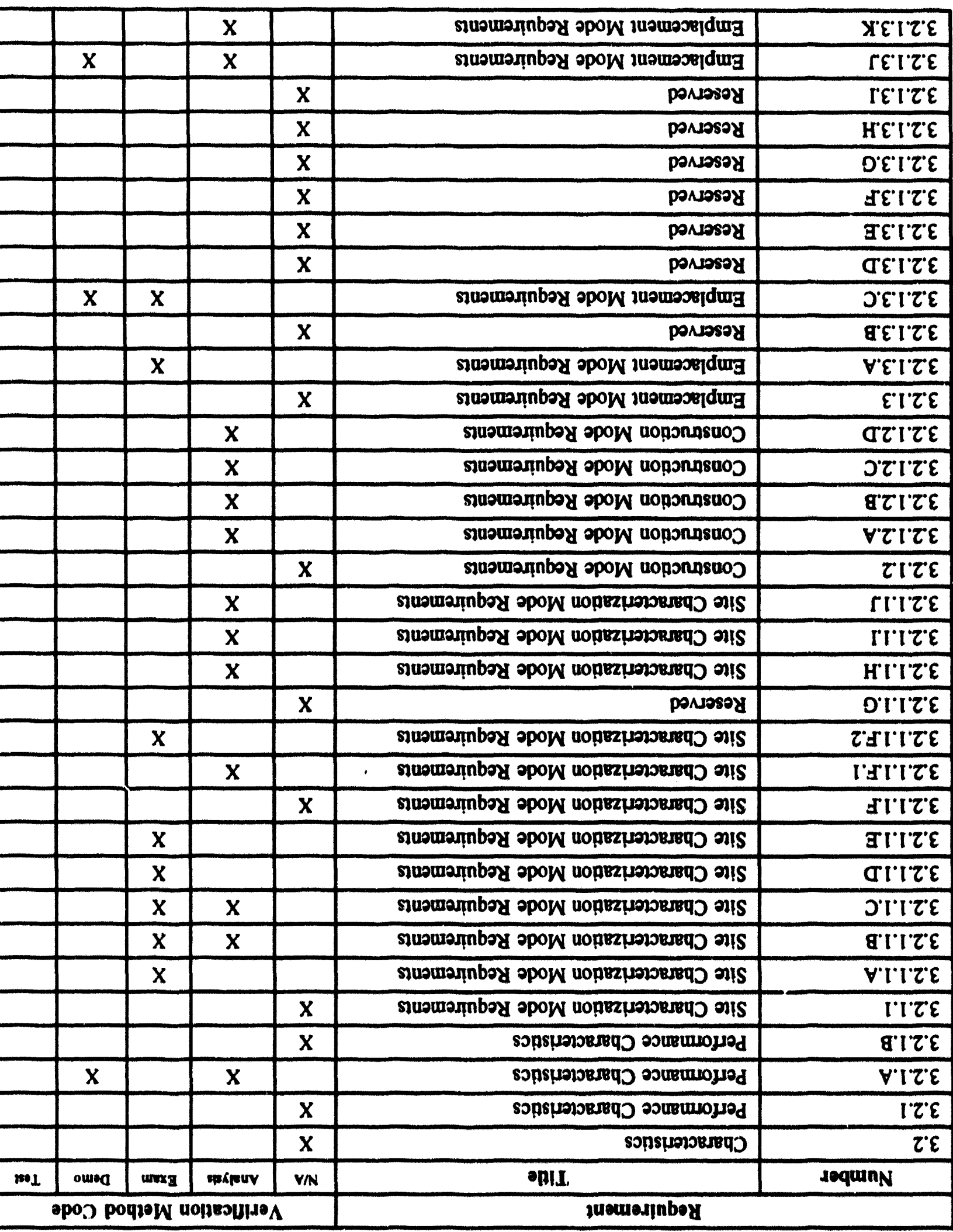

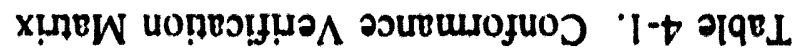


Title: Mined Geologic Disposal System Requirements Document

Table 4-1. Conformance Verification Matrix (Continued)

\begin{tabular}{|c|c|c|c|c|c|c|}
\hline \multicolumn{2}{|r|}{ Requirement } & \multicolumn{5}{|c|}{ Verification Method Code } \\
\hline Number & Title & NA & Andyds & Exam & Domo & Tout \\
\hline 3.2.1.4 & Caretaker Mode Requirements & & $\bar{x}$ & & & \\
\hline 3.2.1.5 & Retrieval Mode Requirements & $\mathbf{x}$ & & & & \\
\hline 3.2.1.5.A & Retrieval Mode Requirements & & & $\mathrm{x}$ & & \\
\hline 3.2.1.5.B & Retrieval Mode Requirements & & $\bar{x}$ & $\mathrm{x}$ & & \\
\hline 3.2.1.5.C & Retrieval Mode Requirements & & $\mathrm{x}$ & & & \\
\hline 3.2 .1 .6 & $\begin{array}{l}\text { Closure and Decommissioning Mode } \\
\text { Requirements }\end{array}$ & $\mathrm{x}$ & & & & \\
\hline 3.2.1.7 & Post-closure Mode Requirements & $\mathbf{x}$ & & & & \\
\hline 3.2.1.7.A & Post-closure Mode Requirements & & $\bar{x}$ & & & \\
\hline 3.2.1.7.B & Post-closure Mode Requirements & & & $\mathbf{x}$ & & \\
\hline 3.2.1.7.C & Post-closure Mode Requirements & & $\mathrm{x}$ & & & \\
\hline 3.2.1.8 & Off-normal Mode Requirements & $\mathbf{x}$ & & & & \\
\hline 3.2.1.8.A & Off-normal Mode Requirements & & $\mathbf{x}$ & & & \\
\hline 3.2.1.8.B & Off-normal Mode Requirements & & $\mathbf{x}$ & & & \\
\hline 3.2.1.8.C & Off-normal Mode Requirements & & $\bar{x}$ & & & \\
\hline 3.2 .2 & Radiological Protection & $\mathrm{x}$ & & & & \\
\hline 3.2.2.1 & General Requirements & $\mathrm{x}$ & & & & \\
\hline 3.2.2.1.A & Reserved & $\mathbf{x}$ & & & & \\
\hline $3.2 .2 .1 . \mathrm{B}$ & General Requirements & & $\bar{x}$ & $\mathbf{x}$ & & \\
\hline $3.2 .2 .1 . \mathrm{C}$ & General Requirements & & $\bar{x}$ & $\mathbf{x}$ & & \\
\hline 3.2.2.1. D & General Requirements & & $\bar{x}$ & & & \\
\hline $3.2 .2 .1 . \mathrm{E}$ & Reserved & $\mathbf{x}$ & & & & \\
\hline 3.2.2.1.F & General Requirements & & $\bar{x}$ & & & \\
\hline 3.2.2.1.F.1 & General Requirements & & $\bar{x}$ & & & \\
\hline 3.2.2.1.F.2 & Reserved & $\mathbf{x}$ & & & & \\
\hline $3.2 .2 .1 . \mathrm{G}$ & Individual Protection & & $\bar{x}$ & & & \\
\hline 3.2.2.2 & Reserved & $\mathrm{x}$ & & & & \\
\hline 3.2.2.3 & Public Protection & $\bar{x}$ & & & & \\
\hline 3.2.2.3.A & Public Protection & & $\bar{x}$ & $\mathrm{x}$ & & \\
\hline 3.2.2.3.B & Public Protection & & $\bar{x}$ & $\mathrm{X}$ & & \\
\hline 3.2.2.3.C & Public Protection & & $\bar{x}$ & $\bar{x}$ & & \\
\hline 3.2.2.4 & Airborne Radioactive Material Control & $\mathbf{x}$ & & & & \\
\hline 3.2.2.4.A & Airborne Radioactive Material Control & & & $\mathbf{x}$ & & \\
\hline
\end{tabular}


Title: Mined Geologic Disposal System Requirements Document

Table 4-1. Conformance Verification Matrix (Continued)

\begin{tabular}{|c|c|c|c|c|c|c|}
\hline \multicolumn{2}{|r|}{ Requirement } & \multicolumn{5}{|c|}{ Verification Method Code } \\
\hline Number & Title & NA & Andydo & Exem & Domo & Toest \\
\hline 3.2.2.4.B & Airborme Radioactive Material Control & & & $\mathbf{x}$ & & \\
\hline 3.2.2.4.C & Airborme Radioactive Material Control & & & $\mathbf{x}$ & & \\
\hline 3.2.2.5 & Radiation Monitoring & $\mathbf{x}$ & & & & \\
\hline 3.2.2.5.A & Radiation Monitoring & $\mathbf{x}$ & & & & \\
\hline 3.2.2.5.A.1 & Radiation Monitoring & & & $\mathbf{x}$ & & \\
\hline 3.2.2.5.A.2 & Radiation Monitoring & & & $\mathbf{x}$ & & \\
\hline 3.2.2.5.A.3 & Radiation Monitortng & & & $\mathbf{x}$ & & \\
\hline 3.2.2.5.B & Radiation Monitoring & $\mathbf{x}$ & & & & \\
\hline 3.2.2.5.B.1 & Radiation Monitoring & & & $\mathbf{x}$ & & \\
\hline 3.2.2.5.B.2 & Radiation Monitoring & & & $\mathbf{x}$ & & \\
\hline 3.2.2.6 & Criticality Protection & $\mathbf{x}$ & & & & \\
\hline 3.2.2.6.A & Criticality Protection & & $\mathbf{x}$ & & & \\
\hline 3.2.2.6.B & Criticality Protection & & $\mathbf{x}$ & & & \\
\hline 3.2.2.6.C & Criticality Protection & & $\mathbf{x}$ & & & \\
\hline 3.2.2.7 & Low Level Waste Disposal & $\mathbf{x}$ & & & & \\
\hline 3.2.2.7.A & Low Lovel Waste Disposal & & & $\mathbf{x}$ & & \\
\hline 3.2.2.7.B & Low Level Waste Disposal & & & $\mathbf{x}$ & & \\
\hline 3.2.2.8 & Transportation Procection & & $\mathbf{x}$ & $\mathbf{x}$ & & \\
\hline 3.2 .3 & Interface Requirements & $\mathbf{x}$ & & & & \\
\hline 3.2.3.1 & MGDS Local Interfaces & $\mathbf{x}$ & & & & \\
\hline 3.2.3.1.A & MGDS Local Interfaces & & & $\mathbf{x}$ & & \\
\hline 3.2.3.1.B & MGDS Local Interfaces & & & $\mathbf{x}$ & & \\
\hline 3.2.3.2 & Interfaces with Other CRWMS Elements & $\mathbf{x}$ & & & & \\
\hline 3.2.3.2.1 & MGDS-MRS Interface Requirements & $\mathbf{x}$ & & & & \\
\hline 3.2.3.2.1.A & MGDS-MRS Interface Requirements & & & $\bar{x}$ & & \\
\hline 3.2.3.2.1.B & Reserved & $\mathbf{x}$ & & & & \\
\hline 3.2.3.2.2 & MGDS-WA Interface Requirements & $\mathbf{x}$ & & & & \\
\hline 3.2.3.2.2.A & MGDS-WA Interface Requirements & & & $\mathbf{x}$ & & \\
\hline 3.2.3.2.2.A.1 & MGDS-WA Interface Requirements & & & $\mathbf{x}$ & & \\
\hline 3.2.3.2.2.A.2 & MGDS-WA Interface Requirements & & & $\mathbf{x}$ & & \\
\hline 3.2.3.2.2.A.3 & MGDS-WA Interface Requirements & & & $\mathbf{x}$ & & \\
\hline 3.2.3.2.2.B & MGDS-WA Interface Requirements & & $\mathbf{x}$ & $\mathbf{x}$ & & \\
\hline 3.2.3.2.2.B.1 & MGDS-WA Interface Requirements & & & $\mathbf{x}$ & & \\
\hline
\end{tabular}




\begin{tabular}{|c|c|c|c|c|c|c|}
\hline & $\mathbf{x}$ & & $\mathbf{x}$ & & wopreupunilI & $\varepsilon \tau " \downarrow \tau \varepsilon$ \\
\hline & $\mathbf{x}$ & & $\mathbf{x}$ & & 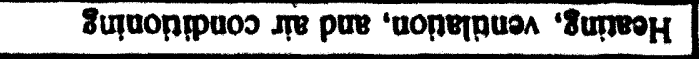 & $\tau \tau+\tau \varepsilon$ \\
\hline & & & $\mathbf{x}$ & & 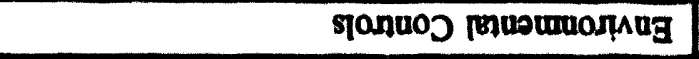 & $\Gamma \tau+\tau \varepsilon$ \\
\hline & & & & $\mathbf{x}$ & 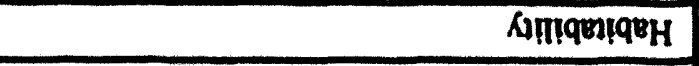 & $\tau \cdot \tau \cdot \tau$ \\
\hline & & & $\mathbf{x}$ & & 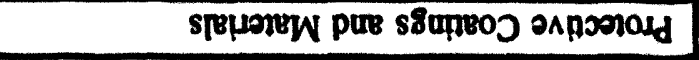 & I.t'ZE \\
\hline & & $\mathbf{x}$ & & & 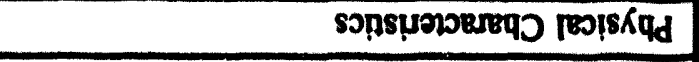 & $\nabla \tau \varepsilon$ \\
\hline & & $\mathbf{x}$ & $\mathrm{X}$ & & 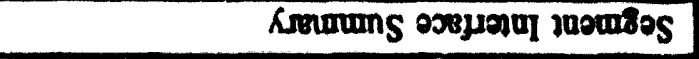 & 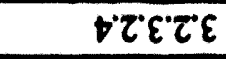 \\
\hline & $\mathbf{x}$ & $\mathbf{x}$ & $\mathbf{x}$ & & 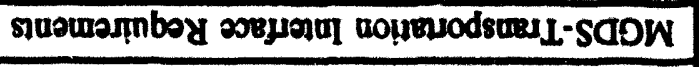 & 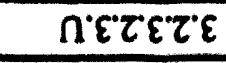 \\
\hline $\mathbf{x}$ & & $\mathbf{x}$ & $x$ & & 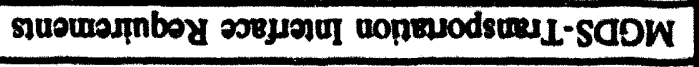 & LETEZE \\
\hline & $\mathbf{x}$ & $\mathbf{x}$ & $\mathbf{x}$ & & 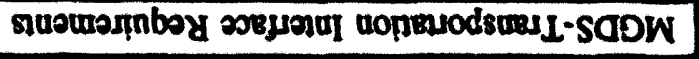 & SETETE \\
\hline $\mathrm{x}$ & & & $\bar{x}$ & & 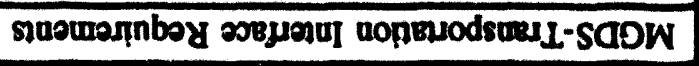 & 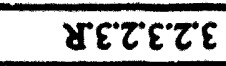 \\
\hline $\mathbf{x}$ & & & $\mathbf{x}$ & & 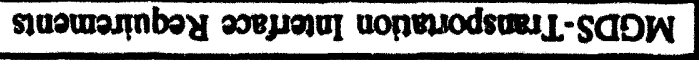 & 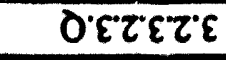 \\
\hline $\mathbf{x}$ & $\mathbf{x}$ & $\mathbf{x}$ & $\mathbf{x}$ & & 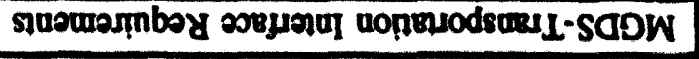 & 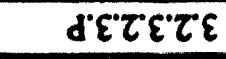 \\
\hline $\mathbf{x}$ & $\mathbf{x}$ & $\mathbf{x}$ & $\mathbf{x}$ & & 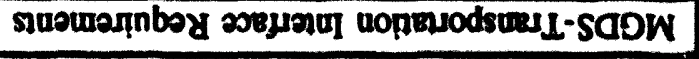 & 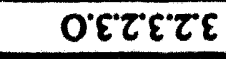 \\
\hline & $\mathbf{x}$ & $\mathbf{x}$ & & & 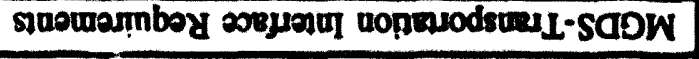 & 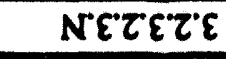 \\
\hline & & & $\mathbf{x}$ & & 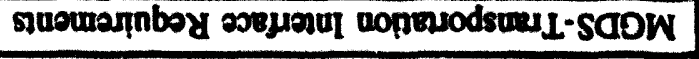 & WETETE \\
\hline & & $\mathbf{x}$ & $\mathbf{x}$ & & suomannboy aryend nopmuodsurul-saDW & 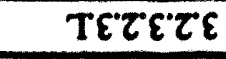 \\
\hline $\mathbf{x}$ & & $\mathbf{X}$ & $\mathbf{x}$ & & 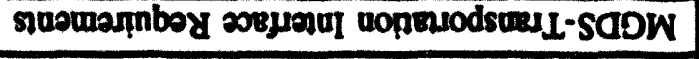 & 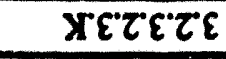 \\
\hline & & & $\mathbf{x}$ & & 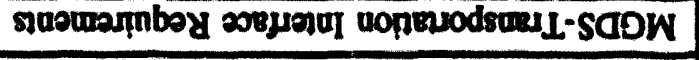 & retre'te \\
\hline & & & $\mathbf{x}$ & & 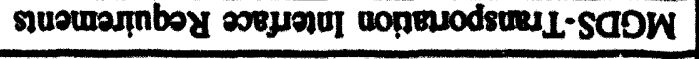 & 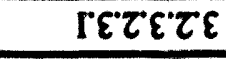 \\
\hline & & $\mathbf{x}$ & & & 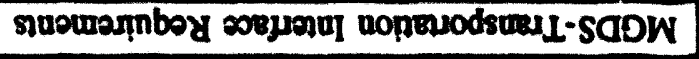 & 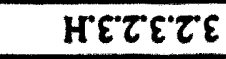 \\
\hline & & $\mathbf{x}$ & & & 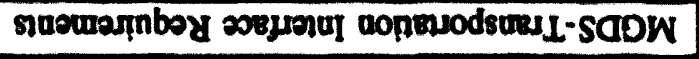 & 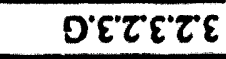 \\
\hline & & $\mathbf{x}$ & & & 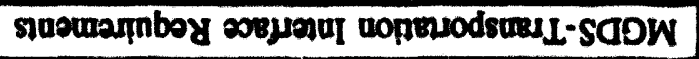 & 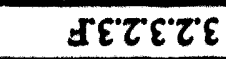 \\
\hline & & & $\mathbf{x}$ & & 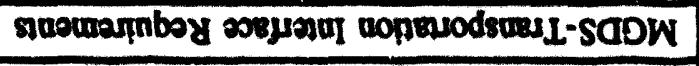 & IETEてॄ \\
\hline & & & $\mathbf{x}$ & & 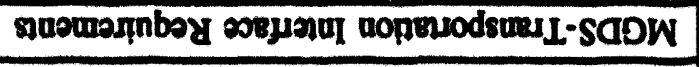 & बerete \\
\hline & & $\mathbf{x}$ & & & 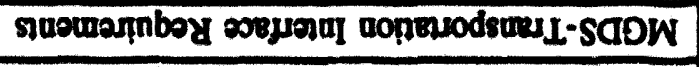 & כ. \\
\hline & & & $\mathbf{x}$ & & 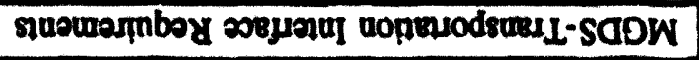 & 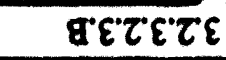 \\
\hline & & $\mathbf{x}$ & & & 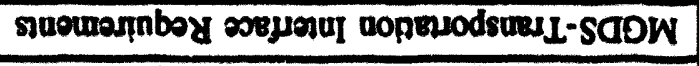 & $\forall \cdot \varepsilon \tau \varepsilon \tau \varepsilon$ \\
\hline & & & & $\mathbf{x}$ & 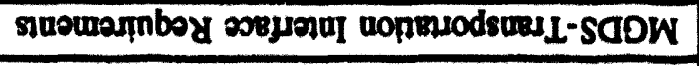 & $\varepsilon \tau \varepsilon \tau \varepsilon$ \\
\hline & & $\mathbf{x}$ & & & nuowarnboy soyumul $\forall M-S C O W$ & 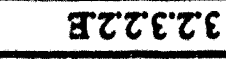 \\
\hline & & $\mathbf{x}$ & & & nuousग̣nboy sobjunu $\forall M-s a O W$ & 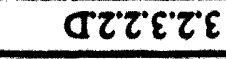 \\
\hline & & $\mathbf{x}$ & & & suowerniboy oogresul $\forall M$-SCDW & 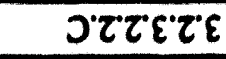 \\
\hline & & $\mathbf{x}$ & $\mathbf{x}$ & & 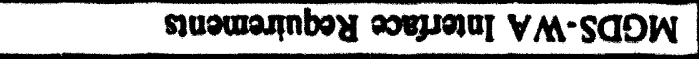 & r.grctre \\
\hline$m_{1}$ & omea & $\operatorname{ming}$ & maper & $\mathrm{VN}$ & OPIL & JequanN \\
\hline \multicolumn{5}{|c|}{ 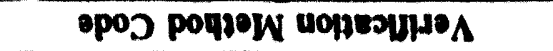 } & \multicolumn{2}{|l|}{ jucuajnbog } \\
\hline
\end{tabular}

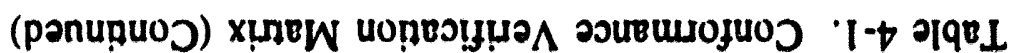




\begin{tabular}{|c|c|c|c|c|c|c|}
\hline & & $\mathbf{x}$ & $\mathrm{X}$ & & 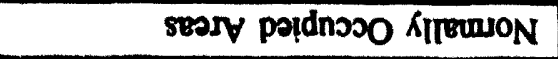 & $\forall I S S^{\circ} \tau \varepsilon$ \\
\hline & & & & $\mathbf{x}$ & u8! & I's'o'te \\
\hline & & & & $\mathbf{x}$ & 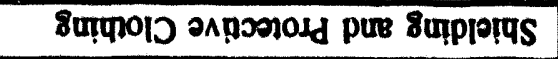 & S.t'te \\
\hline & & $\mathbf{x}$ & $\mathbf{x}$ & & 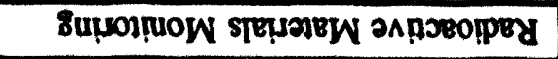 & Dotre \\
\hline & & & $\mathbf{x}$ & & stonuoj ssesor punosesepun & $\varepsilon^{\prime} \varepsilon \sigma^{\prime} \tau^{\prime} \varepsilon$ \\
\hline & & & $\mathbf{x}$ & & 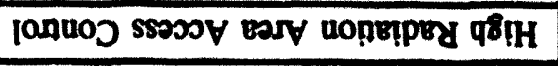 & 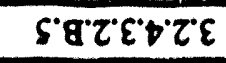 \\
\hline & & & $\mathbf{X}$ & & ןanuoj ssosoy bary uopetpty q8?!H & $\nabla^{\circ} g^{\prime} \tau \varepsilon^{\prime} \nabla^{\prime} \tau \varepsilon$ \\
\hline & & $\mathbf{x}$ & & & 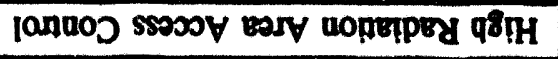 & $\varepsilon^{\circ} \operatorname{a}^{\prime} \tau \varepsilon^{\prime} b^{\prime} \tau \varepsilon$ \\
\hline & & $\bar{x}$ & & & 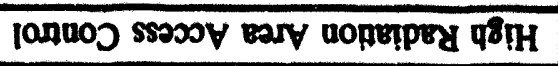 & $\tau \cdot \operatorname{cr} \tau \varepsilon^{\circ} \tau \varepsilon$ \\
\hline & & $\mathbf{x}$ & & & IanuoJ s5050 Very uopetpty q8ిth & I. \\
\hline & & & $\mathbf{x}$ & & Ianuoj ssosoy cary uop\&ipty q8!H & 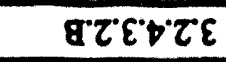 \\
\hline & & & $x$ & & 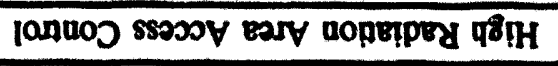 & $\forall \cdot \tau \varepsilon \triangleright r \tau \varepsilon$ \\
\hline & & & & $x$ & 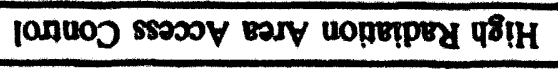 & $\tau \varepsilon \nabla \tau \varepsilon$ \\
\hline & & & $\mathbf{x}$ & & 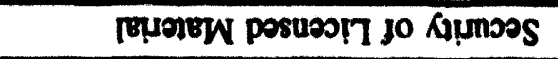 & $\nabla \Gamma \varepsilon \nabla \tau \varepsilon$ \\
\hline & & & $\mathbf{x}$ & & ION00J sseosy & 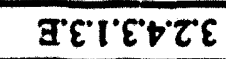 \\
\hline & & & $\mathbf{x}$ & & lanuoj ssoosy & बहाย์ \\
\hline & & & $\mathbf{x}$ & & 10nu0J 88000Y & วยโยЬてย \\
\hline & & & $\mathbf{x}$ & & januoj sseosy & 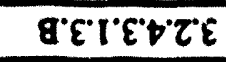 \\
\hline & & & $\mathbf{x}$ & & 10nuoj s8000\% & $\forall \varepsilon I^{\circ} \nabla^{\prime} \tau \varepsilon$ \\
\hline & & & & $\mathbf{x}$ & jonuoj ssest & $\varepsilon เ \varepsilon \nabla^{\prime} \tau \varepsilon$ \\
\hline & & & $x$ & & Shoureg reopiskTd & 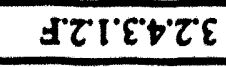 \\
\hline & & & $X$ & & supureg reotis 4 d & $\operatorname{arI\varepsilon } \bullet \tau \varepsilon$ \\
\hline & & & $x$ & & sopureg reopskqd & बrtéctre \\
\hline & & & $\mathrm{x}$ & & supureg reopjsKqd & J. TIETCE \\
\hline & & & $X$ & & sopureg leopsingd & $\mathrm{g}^{\circ} \tau I^{\prime} \varepsilon \sigma^{\circ} \tau \varepsilon$ \\
\hline & & & $\bar{x}$ & & Sopurg IEOTsKपd & VTIE'TCE \\
\hline & & & & $\mathrm{x}$ & sopureg reolsKqd & 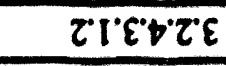 \\
\hline & & & $x$ & & uoposiald lesisk4d & 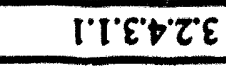 \\
\hline & & & & $\mathbf{x}$ & Rumbes leoplsk4d & 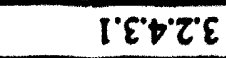 \\
\hline & & & & $\mathbf{x}$ & Aunnos & $\varepsilon \overbrace{}^{\prime} \tau \varepsilon$ \\
\hline & & $\bar{x}$ & & & sojnsopoug puuosed panorsepon & $9 \cdot 2+2 \varepsilon$ \\
\hline & $\mathbf{x}$ & & $\mathrm{X}$ & & noppesqi & $s \tau^{\prime}{ }^{\prime} \tau \varepsilon$ \\
\hline & $\mathbf{X}$ & & $\mathbf{x}$ & & oston respsnosy & $\nabla^{\prime} \tau^{\prime} \nabla^{\prime} \tau$ \\
\hline$m$ & omed & $\operatorname{monxa}$ & mpopury & $\mathbf{V N}$ & opIL & sequnN \\
\hline \multicolumn{5}{|c|}{ 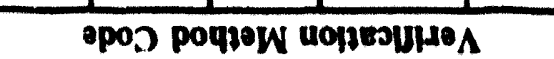 } & \multicolumn{2}{|l|}{ zucatajnbod } \\
\hline
\end{tabular}

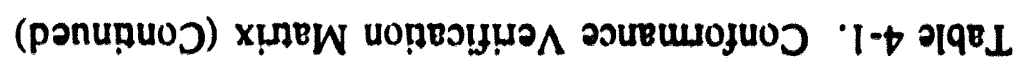


Title: Mined Geologic Disposal System Requirements Document

Table 4-1. Conformance Verification Matrix (Continued)

\begin{tabular}{|c|c|c|c|c|c|c|}
\hline \multicolumn{2}{|r|}{ Requirement } & \multicolumn{5}{|c|}{ Verification Method Code } \\
\hline Numbor & Titie & NA & Anclyou & Exw & Demo & Tom \\
\hline 3.2.4.5.1.B & Intermittently Occupied Areas & & $\mathbf{X}$ & $\mathbf{x}$ & & \\
\hline 3.2.4.5.1.C & Concrete & & $\mathbf{x}$ & $\mathbf{x}$ & & \\
\hline 3.2.4.5.1. D & Penetrations & & $\mathbf{x}$ & & & \\
\hline 3.2.4.5.2 & Remote Shielded Operation & & & $\mathbf{X}$ & & \\
\hline 3.2 .4 .6 & Design Basis Events and Accidents & $\mathbf{x}$ & & & & \\
\hline 3.2.4.6.A & Design Objective & & $\mathbf{x}$ & & & \\
\hline 3.2.4.6.B & Aircraft & & $\mathbf{x}$ & $\mathbf{x}$ & & \\
\hline 3.2.4.6.C & External Blasts and Missiles & & $\mathbf{X}$ & $\mathbf{X}$ & & \\
\hline 3.2.4.6.D & Internal Blasts and Missiles & & $\mathbf{x}$ & $\mathbf{x}$ & & \\
\hline 3.2 .5 & System Quality Factors & $\mathbf{x}$ & & & & \\
\hline 3.2.5.1 & Reliability & & $x$ & & & \\
\hline 3.2.5.1.1 & RAM Program Requirements & & & $\mathbf{x}$ & & \\
\hline 3.2.5.1.2 & Reliability of Equipment & & $\mathbf{x}$ & & & \\
\hline 3.2.5.1.3 & SSC Reliability & & $\mathbf{x}$ & & & \\
\hline 3.2.5.1.4 & Utilities Roliability & $\mathbf{x}$ & & & & \\
\hline 3.2.5.1.4.A & Utilities Reliability & & $\mathbf{x}$ & & & \\
\hline 3.2.5.1.4.B & Utillites Reliability & & $\mathbf{x}$ & & & \\
\hline 3.2.5.1.5 & System Througbput & & & $\mathbf{x}$ & & \\
\hline 3.2 .5 .2 & Maintainability/lnspectability & $\mathbf{x}$ & & & & \\
\hline 3.2.5.2.1 & Testing and Maintenance & & $\mathbf{x}$ & & & \\
\hline 3.2.5.2.2 & Physical Clearance & $\mathbf{x}$ & & & & \\
\hline 3.2.5.2.2.A & Physical Clearance & & $\mathbf{x}$ & & & \\
\hline 3.2.5.2.2.B & Physical Clearance & & $x$ & & & \\
\hline 3.2.5.2.3 & Mean Time to Repair & & & $\mathbf{x}$ & & \\
\hline 3.2.5.2.4 & Replacement Equipment & $\mathbf{x}$ & & & & \\
\hline 3.2.5.2.4.A & Replacement Equipment & & $\mathbf{x}$ & & & \\
\hline 3.2.5.2.4.B & Replacement Equipment & & $\mathbf{x}$ & & & \\
\hline 3.2.5.2.4.C & Replacement Equipment & & $\mathbf{x}$ & & & \\
\hline 3.2.5.2.5 & Fault Isolation & & $\mathbf{x}$ & $\mathbf{x}$ & & \\
\hline 3.2.5.2.6 & Maintenance in Radioactive Areas & & $\mathbf{x}$ & & & \\
\hline 3.2.5.2.7 & Important to Safety Equipment & & $x$ & & & \\
\hline 3.2.5.2.8 & Design for Maintenance & $\mathbf{X}$ & & & & \\
\hline 3.2.5.2.8.A & Design for Maintenance & & $\mathbf{x}$ & $\mathbf{x}$ & & \\
\hline
\end{tabular}


Title: Mined Gèologic Disposal System Requirements Document

Table 4-1. Conformance Verification Matrix (Continued)

\begin{tabular}{|c|c|c|c|c|c|c|}
\hline \multicolumn{2}{|r|}{ Requirement } & \multicolumn{5}{|c|}{ Verification Method Code } \\
\hline Number & Title & N/A & Analysis & Exam & Demo & Test \\
\hline 3.2.5.2.8.B & Design for Maintenance & & $\mathbf{x}$ & & & \\
\hline 3.2.5.2.8.C & Design for Maintenance & & $\mathrm{X}$ & & & \\
\hline $3.2 .5 .2 .8 . \mathrm{D}$ & Design for Maintenance & & $\bar{x}$ & & & \\
\hline 3.2.5.2.8.E & Design for Maintenance & & $\bar{x}$ & & & \\
\hline 3.2.5.2.9 & Mean Downtime & & $\mathbf{x}$ & $\mathbf{X}$ & & \\
\hline 3.2 .5 .3 & Availability & $\mathbf{X}$ & & & & \\
\hline 3.2.5.3.A & Availability & & & $\bar{x}$ & & \\
\hline 3.2.5.3.B & Reserved & $\mathrm{X}$ & & & & \\
\hline 3.2 .5 .4 & Service Life & $\mathbf{x}$ & & $\mathbf{X}$ & & \\
\hline 3.2.5.4.A & Service Life & & $\mathrm{x}$ & & & \\
\hline 3.2.5.4.B & Service Life & & & $\bar{x}$ & & \\
\hline 3.2.5.5 & Overall Utilization & $\mathbf{x}$ & & & & \\
\hline 3.2.5.5.A & Overall Utilization & & & $\bar{x}$ & & \\
\hline 3.2.5.5.B & Reserved & $\mathbf{X}$ & & & & \\
\hline 3.2 .6 & Environment Requirements & $x$ & & & & \\
\hline 3.2.6.1 & Natural Environment & & & $\mathbf{X}$ & & \\
\hline 3.2.6.1.A & Natural Conditions & & & $\bar{x}$ & & \\
\hline 3.2.6.1.B & Combinations & & $\bar{x}$ & $\bar{x}$ & & \\
\hline 3.2.6.1.C & Adverse Interaction & & $\mathbf{x}$ & $\mathbf{X}$ & & \\
\hline 3.2.6.1.D & Design Earthquake & & $\mathbf{X}$ & & & \\
\hline 3.2.6.1.E & Tornado and Exureme Wind & $\mathbf{X}$ & & & & \\
\hline 3.2.6.1 E.1 & Regulatory Guidsnce & $\mathbf{X}$ & & & & \\
\hline 3.2.6.1.E.2 & Determination of Design Basis Tornado & & $\mathbf{x}$ & $\mathrm{X}$ & & \\
\hline 3.2.6.1.E.3 & Tornado Analysis & $\mathbf{X}$ & & & & \\
\hline 3.2.6.1.E.3.a & Tornado Analysis & & & $\mathrm{X}$ & & \\
\hline 3.2.6.1.E.3.b & Tomado Analysis & & & $\mathbf{X}$ & & \\
\hline 3.2.6.1.E.3.c & Tornado Analysis & & & $\mathbf{X}$ & & \\
\hline 3.2.6.1.E.4 & Load Combination & & & $\mathrm{X}$ & & \\
\hline 3.2.6.1.F & Floods & & $\mathbf{x}$ & & & \\
\hline 3.2.6.1.G & Flood Protection & $\mathbf{X}$ & & & & \\
\hline 3.2.6.1.G.1 & Flood Protection & & $\mathbf{x}$ & & & \\
\hline 3.2.6.1.G.2 & Flood Protection & & $\mathbf{x}$ & & & \\
\hline 3.2.6.1.H & Earth and Ground Water & $\mathbf{X}$ & & & & \\
\hline
\end{tabular}


Title: Mined Geologic Disposal System Requirements Document

Table 4-1. Conformance Verification Matrix (Continued)

\begin{tabular}{|c|c|c|c|c|c|c|}
\hline \multicolumn{2}{|r|}{ Requirement } & \multicolumn{5}{|c|}{ Verification Method Code } \\
\hline Number & Title & $\mathbf{N} / \mathbf{A}$ & Andyds & Exam & Demo & Test \\
\hline 3.2.6.1.H.1 & Earth and Ground Water & & & $\mathbf{X}$ & & \\
\hline 3.2.6.1.H.2 & Earth and Ground Water & & & $\mathbf{x}$ & & \\
\hline 3.2.6.1.I & Thermal Analysis & & & $x$ & & \\
\hline $3.2 .6 .1 \mathrm{~J}$ & Rain and Snow Loads & & & $x$ & & \\
\hline 3.2 .6 .2 & Induced Environment & $\mathbf{X}$ & & & & \\
\hline 3.2.6.2.1 & Fire, Explosion and Other Disaster Protection & $\mathbf{X}$ & & & & \\
\hline 3.2.6.2.1.A & Fire, Explosion and Other Disaster Protection & & $\mathbf{x}$ & $\mathbf{x}$ & & \\
\hline 3.2.6.2.1.B & Fire, Explosion and Other Disaster Protection & & $\mathbf{X}$ & $\mathbf{X}$ & & \\
\hline 3.2.6.2.1.C & Fire, Explosion and Other Disaster Protection & & $\mathbf{x}$ & $\mathbf{X}$ & & \\
\hline 3.2.6.2.2 & Fire Resistance & $\mathbf{X}$ & & & & \\
\hline 3.2.6.2.2.A & Fire Resistance & & & $\mathbf{X}$ & & \\
\hline 3.2.6.2.2.B & Fire Resistance & & & $\mathbf{X}$ & & \\
\hline 3.2.6.2.2.C & Fire Resistance & & & $\mathbf{X}$ & & \\
\hline 3.2.6.2.2.D & Fire Resistance & & $\mathbf{x}$ & & & \\
\hline 3.2.6.2.3 & Vibration & & & $\mathbf{X}$ & & \\
\hline 3.2.6.2.4 & Creep and Shrinkage & & & $\mathbf{X}$ & & \\
\hline 3.2.6.2.5 & Underground Openings & & $\mathbf{x}$ & & & \\
\hline 3.2 .7 & Transportability/Modularity & & & $\mathbf{x}$ & & \\
\hline 3.2 .8 & Flexibility & & $\mathbf{x}$ & & & \\
\hline 3.2 .9 & Portability and Load Carrying & & $\mathbf{X}$ & & & \\
\hline 3.3 & Design and Construction & $\mathbf{X}$ & & & & \\
\hline 3.3.1 & General Design Criteria & $\mathbf{X}$ & & & & \\
\hline 3.3.1.A & General Design Criteria & & $\mathbf{x}$ & & & \\
\hline 3.3.1.B & General Design Criteria & & $\mathbf{x}$ & & & \\
\hline 3.3.1.C & General Design Criteria & & $\mathbf{X}$ & & & \\
\hline 3.3.1.D & General Design Criteria & & $\mathbf{X}$ & & & \\
\hline 3.3.1.E & General Design Criteria & & $\mathbf{X}$ & & & \\
\hline 3.3.1.F & General Design Criteria & & $\mathbf{X}$ & & & \\
\hline 3.3.1.G & General Design Criteria & & $\mathbf{x}$ & & & \\
\hline 3.3 .2 & Electromagnetic Radiation & $\mathbf{x}$ & & & & \\
\hline 3.3.2.A & Electromagnetic Radiation & & $\mathbf{x}$ & & & \\
\hline 3.3.2.B & Electromagnetic Radiation & & $\mathbf{X}$ & & & \\
\hline 3.3.2.C & Electromagnetic Radiation & & $\mathbf{X}$ & & & \\
\hline
\end{tabular}


Title: Mined Geologic Disposal System Requirements Document

Table 4-1. Conformance Verification Matrix (Continued)

\begin{tabular}{|c|c|c|c|c|c|c|}
\hline \multicolumn{2}{|r|}{ Requirement } & \multicolumn{5}{|c|}{ Verification Method Code } \\
\hline Number & Title & $\mathrm{N} / \mathrm{A}$ & Anelyds & Exam & Demo & Test \\
\hline 3.3.2.D & Electromagnetic Radiation & & $\mathbf{x}$ & & & \\
\hline 3.3.3 & Nameplares and Markings & $\mathbf{X}$ & & & & \\
\hline 3.3.3.A & Nameplates and Markings & & $x$ & & & \\
\hline 3.3.3.B & Nameplates and Markings & & $\bar{x}$ & & & \\
\hline 3.3.3.C & Nameplates and Markings & & $\mathbf{x}$ & & & \\
\hline 3.3.3.D & Nameplates and Markings & & $\mathbf{x}$ & & & \\
\hline 3.3.3.E & Nameplates and Markings & & $\mathbf{x}$ & & & \\
\hline 3.3.3.F & Nameplates and Markings & & $\mathbf{x}$ & & & \\
\hline 3.3.4 & Workmanship & $\mathbf{X}$ & & & & \\
\hline 3.3.4.A & Workmanship & & $\mathbf{x}$ & & & \\
\hline 3.3.4.B & Workmanship & & $\mathbf{x}$ & & & \\
\hline 3.3.5 & Interchangeability & & $\mathbf{x}$ & & & \\
\hline 3.3 .6 & Safety & $\mathbf{x}$ & & & & \\
\hline 3.3.6.1 & General Requirements & $\mathbf{x}$ & & & & \\
\hline 3.3.6.1.A & General Requirements & & $\mathbf{X}$ & & & \\
\hline 3.3.6.1.B & General Requirements & & $\mathbf{x}$ & & & \\
\hline 3.3.6.2 & System Safety Precedence & & $\mathbf{x}$ & & & \\
\hline 3.3.6.2.A & System Safety Precedence & & $\bar{x}$ & & & \\
\hline 3.3.6.2.B & System Safety Precedence & & $\mathbf{x}$ & & & \\
\hline 3.3.6.2.C & System Safety Precedence & & $\bar{x}$ & & & \\
\hline 3.3.6.2.D & System Safety Precedence & & $\mathbf{X}$ & & & \\
\hline 3.3.6.2.E & System Safety Precedence & $\mathbf{X}$ & & & & \\
\hline 3.3.6.2.E.1 & System Safety Precedence & & $\mathbf{x}$ & & & \\
\hline 3.3.6.2.E.2 & System Safety Precedence & & $\mathbf{x}$ & & & \\
\hline 3.3.6.3 & $\begin{array}{l}\text { Facilities, Equipment, and Materials Protective } \\
\text { Measures }\end{array}$ & $\bar{x}$ & & & & \\
\hline 3.3.6.3.A & $\begin{array}{l}\text { Facilities, Equipment, and Materials Protective } \\
\text { Measures }\end{array}$ & $x$ & & & & \\
\hline 3.3.6.3.A.1 & $\begin{array}{l}\text { Facilities, Equipment, and Materials Protective } \\
\text { Measures }\end{array}$ & & $\mathrm{x}$ & & & \\
\hline 3.3.6.3.A.2 & $\begin{array}{l}\text { Facilities, Equipment, and Materials Protective } \\
\text { Measures }\end{array}$ & & $\mathbf{x}$ & & & \\
\hline 3.3.6.3.A.3 & $\begin{array}{l}\text { Facilities, Equipment, and Materials Protective } \\
\text { Measures }\end{array}$ & & $\mathbf{X}$ & & & \\
\hline
\end{tabular}


Title: Mined Geologic Disposal System Requirements Document

Table 4-1. Conformance Verification Matrix (Continued)

\begin{tabular}{|c|c|c|c|c|c|c|}
\hline \multicolumn{2}{|r|}{ Requirement } & \multicolumn{5}{|c|}{ Verification Method Code } \\
\hline Number & Title & $\overline{N / A}$ & Anslyds & Exam & $\overline{\text { Demo }}$ & Teat \\
\hline 3.3.6.3.A.4 & $\begin{array}{l}\text { Facilities, Equipment, and Materials Protective } \\
\text { Measures }\end{array}$ & & $\mathrm{x}$ & & & \\
\hline 3.3.6.3.B & $\begin{array}{l}\text { Facilities, Equipment, and Materials Protective } \\
\text { Measures }\end{array}$ & & $\mathrm{x}$ & & & \\
\hline 3.3.6.3.C & $\begin{array}{l}\text { Facilities, Equipment, and Materials Protective } \\
\text { Measures }\end{array}$ & & $\mathbf{x}$ & & & \\
\hline 3.3.6.3.D & $\begin{array}{l}\text { Facilities, Equipment, and Materials Protective } \\
\text { Measures }\end{array}$ & & $\mathrm{x}$ & & & \\
\hline 3.3.6.3.E & $\begin{array}{l}\text { Facilities, Equipment, and Materials Protective } \\
\text { Measures }\end{array}$ & & $\mathbf{x}$ & & & \\
\hline 3.3.6.3.F & $\begin{array}{l}\text { Facilities, Equipment, and Materials Protective } \\
\text { Measures }\end{array}$ & & $\mathrm{x}$ & & & \\
\hline 3.3.6.4 & Personal Protective Equipment & $\mathbf{x}$ & & & & \\
\hline 3.3.6.4.A & Personal Protective Equipment & & $x$ & & & \\
\hline 3.3.6.4.B & Personal Protective Equipment & & $\bar{x}$ & & & \\
\hline 3.3.6.4.C & Personal Protective Equipment & & $\bar{x}$ & & & \\
\hline 3.3.6.4.D & Personal Protective Equipment & & $\mathbf{x}$ & & & \\
\hline 3.3.6.4.E & Personal Protective Equipment & & $\mathbf{x}$ & & & \\
\hline 3.3.6.5 & Underground Protective Measures & & $\mathbf{x}$ & & & \\
\hline 3.3.6.6 & Safety Labels and Placards & $\mathbf{X}$ & & & & \\
\hline 3.3.6.6.A & Safety Labels and Placards & & $\mathrm{X}$ & & & \\
\hline 3.3.6.6.B & Safety Labels and Placards & & $\bar{x}$ & & & \\
\hline 3.3.6.6.C & Safety Labels and Placards & & $\mathrm{X}$ & & & \\
\hline 3.3.6.7 & Emergency Lighting & $x$ & & & & \\
\hline 3.3.6.7.A & Emergency Lighting & & $\mathrm{X}$ & $\mathrm{x}$ & & \\
\hline 3.3.6.7.B & Emergency Lighting & & $\mathbf{X}$ & & & \\
\hline 3.3.6.7.C & Emergency Lighting & & $\mathrm{X}$ & & & \\
\hline 3.3.6.8 & Equipment Related Hazards & $\mathrm{x}$ & & & & \\
\hline 3.3.6.8.A & Equipment Related Hazards & & $\mathrm{x}$ & & & \\
\hline 3.3.6.8.B & Equipment Related Hazards & & $\mathrm{X}$ & & & \\
\hline 3.3.6.8.C & Equipment Related Hazards & & $\bar{X}$ & & & \\
\hline 3.3.6.8.D & Equipment Related Hazards & & $\mathrm{X}$ & & & \\
\hline 3.3.6.8.E & Equipment Related Hazards & & $\mathbf{x}$ & & & \\
\hline 3.3.6.8.F & Equipment Related Hazards & & $\mathrm{X}$ & & & \\
\hline 3.3.6.9 & Posting Requirements & $\mathbf{X}$ & & & & \\
\hline
\end{tabular}


Title: Mined Geologic Disposal System Requirements Document

Table 4-1. Conformance Verification Matrix (Continued)

\begin{tabular}{|c|c|c|c|c|c|c|}
\hline \multicolumn{2}{|r|}{ Requirement } & \multicolumn{5}{|c|}{ Verification Method Code } \\
\hline Number & Title & N/A & Analyads & Exam & Demo & Tost \\
\hline 3.3.6.9.A & Posting Requirements & & $\mathrm{x}$ & & & \\
\hline 3.3.6.9.B & Posting Requirements & & $\mathrm{x}$ & & & \\
\hline 3.3.6.9.C & Posting Requirements & & $\mathbf{X}$ & & & \\
\hline 3.3.6.9.D & Posting Requirements & & $\mathbf{x}$ & & & \\
\hline 3.3.6.9.E & Posting Requirements & & $\mathbf{x}$ & & & \\
\hline 3.3.6.10 & Work Platforms & $\mathbf{x}$ & & & & \\
\hline 3.3.6.10.A & Work Platforms & & $\mathbf{x}$ & & & \\
\hline 3.3.6.10.B & Work Platforms & & $\bar{x}$ & & & \\
\hline 3.3.6.11 & Electrical Safety & $\mathbf{x}$ & & & & \\
\hline 3.3.6.11.A & Electrical Safety & & $\bar{x}$ & & & \\
\hline 3.3.6.11.B & Electrical Safety & & $\mathbf{x}$ & & & \\
\hline 3.3.6.11.C & Electrical Safety & & $\mathbf{x}$ & & & \\
\hline 3.3.7 & Human Factors Engineering & $x$ & & & & \\
\hline 3.3.7.1 & Workstations and Control Rooms & & $\mathbf{x}$ & & & \\
\hline 3.3.7.2 & Voice Communications Equipment & & $\mathbf{x}$ & & & \\
\hline 3.3.7.3 & Alarms and Warning Systems & & $\mathbf{x}$ & & & \\
\hline 3.3.7.4 & Controls & & $\mathrm{x}$ & & & \\
\hline 3.3.7.5 & Visual Displays & & $\bar{x}$ & & & \\
\hline 3.3.7.6 & Control Panel Layout & & $\mathbf{X}$ & & & \\
\hline 3.3.7.7 & Control-Display Integration & & $\mathbf{x}$ & & & \\
\hline 3.3.7.8 & Labeling, Markings and Signs & & $\mathbf{x}$ & & & \\
\hline 3.3.7.9 & Visual Display Terminal Workstation & & $\mathbf{x}$ & & & \\
\hline 3.3.7.10 & Anthropometry & & $\mathbf{X}$ & & & \\
\hline 3.3.7.11 & Remote Handling and Operation & & $\mathbf{x}$ & & & \\
\hline 3.3.7.12 & Vehicles and Material Handling & & $\bar{x}$ & & & \\
\hline 3.3.7.13 & $\begin{array}{l}\text { Accessibility and Usability by the Physically } \\
\text { Handicapped }\end{array}$ & $\bar{x}$ & & & & \\
\hline 3.3.7.13.A & $\begin{array}{l}\text { Accessibility and Usability by the Physically } \\
\text { Handicapped }\end{array}$ & & $\bar{x}$ & & & \\
\hline 3.3.7.13.B & $\begin{array}{l}\text { Accessibility and Usability by the Physically } \\
\text { Handicapped }\end{array}$ & & $\bar{x}$ & & & \\
\hline 3.3.7.14 & User-Computer Software Interface & & $\bar{x}$ & & & \\
\hline 3.3 .8 & Methods and Controls & $\bar{x}$ & & & & \\
\hline 3.3.8.1 & Material Management & $\bar{x}$ & & & & \\
\hline
\end{tabular}


Title: Mined Geologic Disposal System Requirements Document

Table 4-1. Conformance Verification Matrix (Continued)

\begin{tabular}{|c|c|c|c|c|c|c|}
\hline \multicolumn{2}{|r|}{ Requirement } & \multicolumn{5}{|c|}{ Verification Method Code } \\
\hline Number & Title & N/A & Andyals & Exwm & Damo & Test \\
\hline 3.3.8.1.A & Material Management & & $x$ & & & \\
\hline 3.3.8.1.B & Material Management & & $\mathbf{x}$ & & & \\
\hline 3.3.8.1.C & Material Management & & $\mathbf{x}$ & & & \\
\hline 3.3.8.1.D & Material Management & & $\mathbf{x}$ & & & \\
\hline 3.3.8.2 & Inventory Control & $\mathbf{x}$ & & & & \\
\hline 3.3.8.2.A & Inventory Control & & $x$ & & & \\
\hline 3.3.8.2.B & Inventory Control & & $\mathbf{x}$ & & & \\
\hline 3.3.8.2.C & Inventory Control & & $\mathbf{x}$ & $\mathbf{x}$ & & \\
\hline 3.3.9 & Government Furnished Property & $\mathbf{x}$ & & & & \\
\hline 3.3.9.A & Reserved & $\mathbf{x}$ & & & & \\
\hline 3.3.9.B & Reserved & $\mathbf{x}$ & & & & \\
\hline 3.3.9.C & Government Furnished Property & & $\bar{x}$ & & & \\
\hline 3.3.10 & Computer Resources & $\mathbf{X}$ & & & & \\
\hline 3.3.10.A & Computer Resources & & & $\mathrm{x}$ & & \\
\hline 3.3.10.B & Computer Resources & & & $\mathbf{x}$ & & \\
\hline 3.3.11 & Environmental Protection Requirements & $\mathbf{X}$ & & & & \\
\hline 3.3.11.A & Environmental Protection Requirements & & $\mathbf{x}$ & & & \\
\hline 3.3.11.B & Environmental Protection Requirements & & $\mathbf{x}$ & & & \\
\hline 3.3.11.1 & Reserved & $\mathbf{x}$ & & & & \\
\hline 3.3.11.2 & Air Pollution Control & $\mathbf{x}$ & & & & \\
\hline 3.3.11.2.A & Air Pollution Control & & $\mathbf{X}$ & & & \\
\hline 3.3.11.2.B & Air Pollution Control & & $\mathbf{X}$ & & & \\
\hline 3.3.11.3 & Water Pollution Control & $\mathbf{X}$ & & & & \\
\hline 3.3.11.3.A & Water Pollution Control & & $\mathbf{x}$ & & & \\
\hline 3.3.11.3.A.1 & Water Pollution Control & & $\mathbf{x}$ & & & \\
\hline 3.3.11.3.A.2 & Water Pollution Control & & $\mathbf{x}$ & & & \\
\hline 3.3.11.3.A.3 & Water Pollution Control & & $\mathbf{x}$ & & & \\
\hline 3.3.11.3.A.4 & Water Pollution Control & & $\mathbf{x}$ & & & \\
\hline 3.3.11.3.A.5 & Water Pollution Control & & $\mathbf{x}$ & & & \\
\hline 3.3.11.3.B & Water Pollution Control & & $x$ & & & \\
\hline 3.3.11.4 & Drinking Water Protection & $\mathbf{X}$ & & & & \\
\hline 3.3.11.4.A & Drinking Water Protection & & $\mathrm{X}$ & & & \\
\hline 3.3.11.4.B & Drinking Water Protection & & $\mathbf{X}$ & & & \\
\hline
\end{tabular}


Title: Mined Géologic Disposal System Requirements Document

Table 4-I. Conformance Verification Matrix (Continued)

\begin{tabular}{|c|c|c|c|c|c|c|}
\hline \multicolumn{2}{|r|}{ Requirement } & \multicolumn{5}{|c|}{ Verification Mothod Code } \\
\hline Number & Tite & NA & Andyde & $\mathrm{Exam}$ & Damo & Teat \\
\hline 3.3.11.5 & Toxic Substance Control & & $\mathbf{x}$ & & & \\
\hline 3.3.11.6 & Pesticide Control & & $\mathbf{x}$ & & & \\
\hline 3.3.11.7 & Solid Waste Control & & $\mathbf{x}$ & & & \\
\hline 3.3.11.8 & Noise Control & & $\mathbf{x}$ & & & \\
\hline 3.3.11.9 & Endangered Species & & $\bar{x}$ & & & \\
\hline 3.4 & Documentation & $\mathbf{x}$ & & & & \\
\hline 3.4.1 & Specifications & $\mathbf{x}$ & & & & \\
\hline 3.4.1.A & Reserved & $\mathbf{X}$ & & & & \\
\hline 3.4.1.B & Specifications & & $\bar{x}$ & & & \\
\hline 3.4.1.C & Specifications & & $\mathbf{x}$ & & & \\
\hline 3.4.2 & Drawings & & $\bar{x}$ & & & \\
\hline 3.4.3 & Maintenance, Operators, and Tech Manuals & & $\mathbf{x}$ & & & \\
\hline 3.4.4 & Test Plans and Procedures & & $\mathbf{x}$ & & & \\
\hline 3.4.5 & Quality Assurance Documentation & & & $\mathbf{x}$ & & \\
\hline 3.4.6 & Construction Records & $\mathbf{x}$ & & & & \\
\hline 3.4.6.A & Corstruction Records & & & $\mathbf{x}$ & & \\
\hline 3.4.6.B & Construction Records & & $\mathbf{x}$ & & & \\
\hline 3.4.7 & Computer Documentation & $\mathbf{X}$ & & & & \\
\hline 3.4.7.A & Computer Documentation & & $\mathbf{x}$ & & & \\
\hline 3.4.7.B & Reserved & $\mathbf{x}$ & & & & \\
\hline 3.4.8 & Records Management & & $\mathbf{x}$ & & & \\
\hline 3.5 & Logistics & $\bar{x}$ & & & & \\
\hline 3.5.1 & Maintenance & & $\mathbf{x}$ & & & \\
\hline 3.5.1.1 & Equipment Maintenance & $\bar{x}$ & & & & \\
\hline 3.5.1.1.1 & On-line Maintenance & $\mathbf{x}$ & & & & \\
\hline 3.5.1.1.1.A & On-line Maintenance & & $\mathbf{x}$ & & & \\
\hline 3.5.1.1.1.B & On-line Maintenance & & $\bar{x}$ & & & \\
\hline 3.5.1.1.1.C & On-line Maintenance & & $\mathbf{x}$ & & & \\
\hline 3.5.1.1.1.D & On-line Maintenance & & $\bar{x}$ & & & \\
\hline 3.5.1.1.1.E & On-line Maintenance & & $\mathrm{x}$ & & & \\
\hline 3.5.1.1.2 & Intermediate Maintenance & $x$ & & & & \\
\hline 3.5.1.1.2.A & Intermediate Maintenance & & $\mathbf{x}$ & & & \\
\hline 3.5.1.1.2.B & Intermediate Maintenance & & $\mathbf{x}$ & & & \\
\hline
\end{tabular}


Title: Mined Geologic Disposal System Requirements Document

Table 4-1. Conformance Verification Matrix (Continued)

\begin{tabular}{|c|c|c|c|c|c|c|}
\hline \multicolumn{2}{|r|}{ Requirement } & \multicolumn{5}{|c|}{ Verification Method Code } \\
\hline Numbor & Titte & NA & Andycu & Exem & Domo & Tout \\
\hline 3.5.1.1.3 & Salyaging, Off-site Repair, and Vendor Repair & & $\bar{x}$ & & & \\
\hline 3.5 .1 .2 & Callbrition Maintenance & $\mathrm{x}$ & & & & \\
\hline 3.5.1.2.A & Calibration Maintenance & & $\bar{x}$ & & & \\
\hline 3.5.1.2.B & Calibration Maintenance & & $\bar{x}$ & & & \\
\hline 3.5.1.3 & Cask Maintenance & $\mathbf{x}$ & & & & \\
\hline 3.5.1.3.A & Cask Maintenance & & $\mathbf{x}$ & & & \\
\hline 3.5.1.3.B & Cask Maintenance & & $\bar{x}$ & & & \\
\hline 3.5.1.3.C & Cask Maintenance & & $\bar{x}$ & & & \\
\hline 3.5.1.3.D & Cask Maintenance & & $\mathbf{x}$ & & & \\
\hline 3.5.1.3.E & Cask Maintenance & & $\mathbf{x}$ & & & \\
\hline 3.5.1.4 & Standardization & $\mathrm{x}$ & & & & \\
\hline 3.5.1.4.A & Standandization & & $\mathbf{x}$ & & & \\
\hline 3.5.1.4.B & Standardizadion & & $x$ & & & \\
\hline 3.5.1.5 & Security Equipment Maintenence & & $x$ & & $\bar{x}$ & \\
\hline 3.5 .2 & Supply & & $x$ & $\bar{x}$ & & \\
\hline 3.5 .3 & Facilities & $x$ & & & & \\
\hline 3.5.3.1 & Warebouse & & $\mathbf{x}$ & & & \\
\hline 3.5.3.2 & Receiving and Shipping Facilities & $x$ & & & & \\
\hline 3.5.3.2.A & Receiving and Shipping Facilities & & $\mathbf{x}$ & & & \\
\hline 3.5.3.2.B & Receiving and Shipping Facilities & & $\mathbf{x}$ & & & \\
\hline 3.5.3.3 & Cask Maintenance Facility (TBD) & & $\mathbf{x}$ & & & \\
\hline 3.5.3.4 & Licensing Support System Facility & & $x$ & & & \\
\hline 3.5.3.5 & Other Facilities & & $\bar{x}$ & & & \\
\hline 3.5.4 & Support and Test Equipment & & $\bar{x}$ & & & \\
\hline 3.6 & Personnel and Training & $x$ & & & & \\
\hline 3.6 .1 & Personnel & & $x$ & & & \\
\hline 3.6.1.A & Personnel & & $\mathbf{x}$ & & & \\
\hline 3.6.1.B & Reserved & $x$ & & & & \\
\hline 3.6.1.C & Personnel & & $\bar{x}$ & & & \\
\hline 3.6 .2 & Training & & $\mathrm{x}$ & & & \\
\hline 3.6.2.1 & General Requirements & $\mathrm{x}$ & & & & \\
\hline 3.6.2.1.A & General Requirements & & $\mathbf{x}$ & & & \\
\hline 3.6.2.1.B & General Requirements & & $\mathbf{X}$ & & & \\
\hline
\end{tabular}


Title: Mined Geologic Disposal System Requirements Document

Table 4-1. Conformance Verification Matrix (Continued)

\begin{tabular}{|c|c|c|c|c|c|c|}
\hline \multicolumn{2}{|r|}{ Requiremont } & \multicolumn{5}{|c|}{ Verifkation Method Code } \\
\hline Number & Tiue & NA & Andyous & Exam & Domo & Toet \\
\hline 3.6.2.1.B.1 & General Requirements & & & $\mathbf{x}$ & & \\
\hline 3.6.2.1.B.2 & General Requirements & & & $\mathbf{x}$ & & \\
\hline 3.6.2.1.B.3 & General Requirements & & & $\mathbf{x}$ & & \\
\hline 3.6.2.1.B.4 & General Requirements & & & $x$ & & \\
\hline 3.6.2.1.B.5 & General Requirements & & & $\mathbf{x}$ & & \\
\hline 3.6.2.1.C & General Requirements & & $\mathbf{x}$ & & & \\
\hline 3.6.2.2 & Health Physics Training & $\mathbf{x}$ & & & & \\
\hline 3.6.2.2.A & Health Physics Training & & $\mathbf{x}$ & & & \\
\hline 3.6.2.2.B & Reserved & $\mathbf{x}$ & & & & \\
\hline 3.7 & MODS Segment Characteristics/Requirements & $\mathbf{x}$ & & & & \\
\hline 3.7 .1 & MODS Stite Segment & $x$ & & & & \\
\hline 3.7.1.1.A & Appendix A Requirements & & $x$ & & & \\
\hline 3.7.1.1.B & Appendix B Criteria & & $\mathbf{x}$ & & & \\
\hline 3.7.1.1.C & Site Segment Functions & $\mathbf{x}$ & & & & \\
\hline 3.7.1.2 & Site Segment Intertace Requirements & $\mathbf{x}$ & & & & \\
\hline 3.7 .1 .3 & Site Characterization Requirements & $\mathbf{x}$ & & & & \\
\hline 3.7.1.3.A & Limitations & & $\mathbf{x}$ & & & \\
\hline 3.7.1.3.B & Requirements & & & $\mathbf{x}$ & & \\
\hline 3.7.1.3.B.1 & Mandatory Design Requirements & & $\mathbf{x}$ & & & \\
\hline 3.7.1.3.B.2 & NRC Requirements to be Considered & & $\mathbf{x}$ & & & \\
\hline 3.7.1.3.B.3 & Additional Requirements to be Considered & & $\mathbf{x}$ & & & \\
\hline 3.7.1.3.C & Site Characterization Requirements & & $\mathbf{x}$ & & & \\
\hline 3.7 .2 & MGDS Repository Segment & $\mathbf{x}$ & & & & \\
\hline 3.7.2.1 & Description & $x$ & & & & \\
\hline 3.7.2.1.A & Reposicory Functions & & $\mathbf{x}$ & & & \\
\hline 3.7.2.1.B & Repository Subsystems & & $\mathbf{x}$ & & & \\
\hline 3.7.2.1.C & Repository Interfaces & $\mathbf{x}$ & & & & \\
\hline 3.7.2.1.C.1 & Repository Interfaces & $-x$ & & & & \\
\hline 3.7.2.1.C.2 & Repository Interfaces & $\mathbf{x}$ & & & & \\
\hline 3.7.2.2 & Geologic Setuing Requirements & $\mathbf{x}$ & & & & \\
\hline 3.7.2.2.A & Geologic Setting & & $\mathbf{x}$ & & & \\
\hline 3.7.2.2.B & Ground Water Travil Time & & $x$ & & & \\
\hline 3.7.2.2. C & Ground Water & & $\mathbf{x}$ & $\mathbf{x}$ & & \\
\hline
\end{tabular}


Table 4-1. Conformance Verification Matrix (Continued)

\begin{tabular}{|c|c|c|c|c|c|c|}
\hline \multicolumn{2}{|r|}{ Requirement } & \multicolumn{5}{|c|}{ Verification Mothod Code } \\
\hline Numbar & Tito & NA & Andyed & Exam & Domo & Tou \\
\hline 3.7.2.2.D & Adverse Effects & & $\bar{x}$ & $\bar{x}$ & & \\
\hline 3.7.2.2.E & Land Ownership & & & $\mathbf{x}$ & & \\
\hline 3.7.2.3 & Repository Site Development Requirements & $\mathbf{x}$ & & & & \\
\hline 3.7.2.3.A & Site Surveys & & $\bar{x}$ & & & \\
\hline 3.7.2.3.B & Site Grading & $\bar{x}$ & & & & \\
\hline 3.7.2.3.B.1 & Sile Grading & & $\mathbf{x}$ & & & \\
\hline 3.7.2.3.B.2 & Site Grading & & $\mathbf{x}$ & & & \\
\hline 3.7.2.3.B.3 & Site Grading & & $\bar{x}$ & & & \\
\hline 3.7.2.3.C & Roads & $\bar{x}$ & & & & \\
\hline 3.7.2.3.C.1 & Roads & & $\mathbf{x}$ & & & \\
\hline 3.7.2.3.C.2 & Roands & & $\bar{x}$ & & & \\
\hline 3.7.2.3.D & Foncing & $x$ & & & & \\
\hline 3.7.2.3.D.1 & Fencing & & $\bar{x}$ & & & \\
\hline 3.7.2.3.D.2 & Foncing & & $\mathbf{x}$ & & & \\
\hline 3.7.2.3E & Eavironmeat & & $\bar{x}$ & $\bar{x}$ & & \\
\hline 3.7.2.3. F & Storm Water & & $\bar{x}$ & & & \\
\hline 3.7.2.4 & Repository Utility and Services Requirements & & $\bar{x}$ & $\bar{x}$ & & \\
\hline 3.7.2.4.1 & Electric Power & $\mathbf{x}$ & & & & \\
\hline 3.7.2.4.1.A & Emergency Power & & $x$ & & & \\
\hline 3.7.2.4.1. B & Electric Power & & $\mathbf{x}$ & & & \\
\hline 3.7.2.4.1.C & Uninternuptible Power & & $\mathbf{x}$ & & & \\
\hline 3.7.2.4.1.D & Standby Electrical Power & & $\mathbf{x}$ & & & \\
\hline 3.7.2.4.2 & Supply and Control Water & $\mathbf{x}$ & & & & \\
\hline 3.7.2.4.2.A & Plumbing & & $x$ & & & \\
\hline 3.7.2.4.2.B & Potable Water & & $\mathbf{x}$ & & & \\
\hline 3.7.2.4.2.C & Water Supply & & $\mathbf{x}$ & & & \\
\hline 3.7.2.4.3 & Communicadions & $\mathbf{x}$ & & & & \\
\hline 3.7.2.4.3.A & Communication Systems & & $x$ & & & \\
\hline 3.7.2.4.3.B & Communication Facilities & & $\mathbf{x}$ & & & \\
\hline 3.7.2.4.3.C & Guard Commundcations & & $\mathbf{x}$ & & & \\
\hline 3.7.2.4.3. D & Telephone Communication & & & $\mathbf{x}$ & & \\
\hline 3.7.2.4.3.E & Reserved & $\mathrm{x}$ & & & & \\
\hline 3.7.2.4.3.F & Radio Communication & & $\mathbf{x}$ & & & \\
\hline
\end{tabular}


Title: Mined Geologic Disposal System Requirements Document

Table 4-1. Conformance Verification Matrix (Continued)

\begin{tabular}{|c|c|c|c|c|c|c|}
\hline \multicolumn{2}{|r|}{ Requiroment } & \multicolumn{5}{|c|}{ Verification Mothod Code } \\
\hline Numbor & Title & NA & Anslych & Exm & Dumo & Tou \\
\hline 3.7.2.4.3.G & Communications Power Supply & & $\mathbf{x}$ & $\mathbf{x}$ & $x$ & \\
\hline 3.7.2.4.4 & Illumination System & $\mathbf{x}$ & & & & \\
\hline 3.7.2.4.4.A & Lighting & & $\mathbf{x}$ & $\bar{x}$ & & \\
\hline 3.7.2.4.4.B & Security Lighting & & $x$ & $\bar{x}$ & & \\
\hline 3.7.2.4.5 & Transportation & & $\mathbf{x}$ & & & \\
\hline 3.7.2.4.6 & Monitoring & $\mathbf{x}$ & & & & \\
\hline 3.7.2.4.6.A & Reserved & $\mathbf{x}$ & & & & \\
\hline $3.7 .2 .4 .6 . \mathrm{B}$ & Monitortag & & $\mathbf{x}$ & & & \\
\hline 3.7.2.4.6.C & Monitoring & & $x$ & & & \\
\hline 3.7.2.4.7 & Senitary Sewerage & $x$ & & & & \\
\hline 3.7.2.4.7.A & Sanitary Sewerage & & $x$ & & & \\
\hline $3.7 .2 .4 .7 . \mathrm{B}$ & Sanitery Sewerage & & $x$ & & & \\
\hline 3.7 .2 .4 .8 & Site-Generated Waste Treatment & $\mathbf{x}$ & & & & \\
\hline 3.7.2.4.8.A & Site-Generated Waste Treatment & & $\bar{x}$ & & & \\
\hline 3.7.2.4.8.B & Site-Generated Waste Treatment & & & $\mathrm{x}$ & & \\
\hline 3.7 .2 .5 & Repository Surface Facility Requirements & $\mathbf{x}$ & & & & \\
\hline 3.7.2.5.1 & Waste Handling Requirements & $\bar{x}$ & & & & \\
\hline 3.7.2.5.1.A & Waste Handling & $\mathbf{x}$ & & & & \\
\hline 3.7.2.5.1.A.1 & Waste Handling & & $\bar{x}$ & & & \\
\hline 3.7.2.5.1.A.2 & Waste Handling & & $\mathbf{x}$ & $\mathbf{x}$ & & \\
\hline 3.7.2.5.1.B & Delivery Modes & & $\mathbf{X}$ & $x$ & & \\
\hline 3.7.2.5.1.C & Surface Facility Ventilation & & $\bar{x}$ & $\mathbf{x}$ & & \\
\hline 3.7.2.5.1. D & Site-Generated Waste Treatment & & $\mathbf{x}$ & $\bar{x}$ & $\bar{x}$ & \\
\hline 3.7.2.5.2 & Alarm Systems & $\mathbf{x}$ & & & & \\
\hline 3.7.2.5.2.A & Alarm Systoms & & $x$ & $\mathrm{x}$ & & \\
\hline 3.7.2.5.2.B & Alarm Systems & & $\bar{x}$ & & & \\
\hline 3.7.2.5.2.B.1 & Alarm Systems & & $\mathbf{x}$ & & & \\
\hline 3.7.2.5.2.B.2 & Alarm Systems & & $\mathbf{x}$ & & & \\
\hline 3.7.2.5.2.B.3 & Alarm Systems & & $\mathbf{x}$ & & & \\
\hline 3.7.2.5.2.C & Alarm Systems & & $\bar{x}$ & & & \\
\hline 3.7.2.5.2.D & Alarm Systems & & $x$ & & & \\
\hline $3.7 .2 .5 .2 . \mathrm{E}$ & Alarm Systems & & $\bar{x}$ & & & \\
\hline 3.7.2.5.2.E.1 & Alarm Systems & & $x$ & & & \\
\hline
\end{tabular}


Title: Mined Geologic Disposal System Requirements Document

Table 4-1. Conformance Verification Matrix (Continued)

\begin{tabular}{|c|c|c|c|c|c|c|}
\hline \multicolumn{2}{|r|}{ Requirement } & \multicolumn{5}{|c|}{ Vorincation Method Code } \\
\hline Number & Title & NA & Analyats & $\operatorname{En}$ & Demo & Trat \\
\hline 3.7.2.5.2.E.2 & Alarm Systems & & $\mathbf{x}$ & & & \\
\hline 3.7.2.5.2.E.3 & Alarm Systems & & $\mathbf{x}$ & & & \\
\hline $3.7 .2 .5 .2 \mathrm{~F}$ & Alarm Systems & & $\mathbf{x}$ & & & \\
\hline 3.7 .2 .5 .3 & Reserved & $\mathbf{x}$ & & & & \\
\hline 3.7 .2 .5 .4 & Fire Protection Requirements & $\mathbf{x}$ & & & & \\
\hline 3.7.2.5.4.A & Fire Protection Requirements & & $\mathbf{x}$ & $x$ & & \\
\hline 3.7.2.5.4.B & Fire Protection Requirements & & $\bar{x}$ & & & \\
\hline 3.7.2.5.4.C & Fire Protection Requirements & & $\mathbf{x}$ & & & \\
\hline 3.7.2.5.4.D & Fire Protection Requirements & & $\mathbf{x}$ & & & \\
\hline 3.7 .2 .5 .5 & Reserved & $\mathbf{x}$ & & & & \\
\hline 3.7.2.5.6 & Other Surface Facillities & $\mathbf{x}$ & & & & \\
\hline 3.7.2.5.6.A & Chenge Rooms & & $\mathbf{x}$ & & & \\
\hline 3.7.2.5.6.B & Industrial Health and Safety & & $x$ & & & \\
\hline 3.7.2.5.6.C & Training Facility Requirements & & $\mathbf{x}$ & & & \\
\hline 3.7.2.5.6.D & Medical Facility Requirements & & $\mathbf{x}$ & & & \\
\hline 3.7.2.5.6.E & Onice Requirements & $\mathbf{x}$ & & & & \\
\hline 3.7.2.5.6.E.1 & Omice Requiremeats & & $\mathbf{x}$ & $x$ & & \\
\hline 3.7.2.5.6.E.2 & Reserved & $\mathbf{x}$ & & & & \\
\hline 3.7.2.5.6.E.3 & Office Requirements & & $\mathbf{x}$ & & & \\
\hline 3.7.2.5.6.E.4 & Office Requirements & & $\mathbf{x}$ & & & \\
\hline 3.7.2.5.6.F & Records Management Requirements & $\mathbf{x}$ & & & & \\
\hline 3.7.2.5.6.F.1 & Records Management Requirements & & $\mathbf{x}$ & & & \\
\hline 3.7.2.5.6.F.2 & Records Management Requirements & & $\mathbf{x}$ & & & \\
\hline 3.7.2.5.6.F.3 & Records Management Requirements & & $\mathbf{x}$ & & & \\
\hline 3.7.2.5.6.F.4 & Records Management Requirements & & $\mathbf{x}$ & & & \\
\hline 3.7.2.5.6.F.5 & Records Management Requirements & & $\mathbf{x}$ & & & \\
\hline 3.7.2.5.6.G & Maintenance Facility Requirements & & $\mathbf{x}$ & & & \\
\hline 3.7.2.5.6.H & Test and Maintenance Facility Requirements & & $\mathbf{x}$ & & & \\
\hline 3.7.2.5.6.1 & Emergency Response Requirements & $\mathbf{x}$ & & & & \\
\hline 3.7.2.5.6.1.1 & Emergency Response Requirements & & $\mathbf{x}$ & & & \\
\hline 3.7.2.5.6.1.2 & Emergency Response Requirements & & $\mathbf{x}$ & & & \\
\hline 3.7.2.5.6.1.3 & Emergency Response Requirements & & $\mathbf{x}$ & & & \\
\hline 3.7.2.5.6.J & Explosives Storage & $\mathbf{x}$ & & & & \\
\hline
\end{tabular}


Title: Mined Geologic Disposal System Requirements Document

Table 4-1. Conformance Verification Matrix (Continued)

\begin{tabular}{|c|c|c|c|c|c|c|}
\hline \multicolumn{2}{|r|}{ Requilrement } & \multicolumn{5}{|c|}{ Verification Method Code } \\
\hline Number & Title & N/A & Annuydes & Exam & Domo & Tout \\
\hline 3.7 .2 .5 .0 .11 & Explosives Storage & & & $\mathbf{x}$ & & \\
\hline $3.7 .2 .5 .6 \mathrm{~J} .2$ & Explosives Storage & & $\mathrm{x}$ & $\mathbf{x}$ & & \\
\hline 3.7.2.5.6.J.2.a & Explosives Storage & & $\mathbf{x}$ & $\mathbf{x}$ & & \\
\hline 3.7.2.5.6. J.2.b & Explosives Storage & & $\mathbf{x}$ & $\mathbf{x}$ & & \\
\hline 3.7.2.5.6.K & Personnel Support & & $\mathbf{x}$ & & & \\
\hline 3.7.2.5.6. L & Decontamination and Dismantling & $\mathbf{X}$ & & & & \\
\hline 3.7.2.5.6.L.1 & Decontamination and Dismantling & & $\mathbf{x}$ & & & \\
\hline 3.7.2.5.6.L.2 & Decontamination and Dismantling & & $\bar{x}$ & & & \\
\hline 3.7.2.6 & Repository Underground Requirements & $\mathbf{X}$ & & & & \\
\hline 3.7.2.6.A & Shaft Conveyances & & & $\mathbf{x}$ & & \\
\hline 3.7.2.6.A.1 & Shaft Conveyances & & $\bar{x}$ & $\mathbf{x}$ & & \\
\hline 3.7.2.6.A.2 & Shaft Conveyances & & $\mathbf{x}$ & & & \\
\hline 3.7.2.6.A.3 & Shaft Conveyances & & $\bar{x}$ & & & \\
\hline 3.7.2.6.A.4 & Shaft Conveyances & & $\bar{x}$ & & & \\
\hline 3.7.2.6.B & Underground Facility Ventilation & & & $\bar{x}$ & & \\
\hline 3.7.2.6.B.1 & Underground Facility Ventilation & & $\mathbf{x}$ & $\mathbf{x}$ & & \\
\hline 3.7.2.6.B.2 & Underground Facility Ventilation & & $\mathbf{x}$ & & & \\
\hline 3.7.2.6.B.3 & Underground Facility Ventilation & & $\mathbf{x}$ & $\mathbf{x}$ & & \\
\hline 3.7.2.6.C & Diesel Exhaust Ventilation & & $\mathbf{x}$ & & & \\
\hline 3.7.2.6.C.1 & Diesel Exhaust Ventilation & & $\mathbf{x}$ & & & \\
\hline 3.7.2.6.C.2 & Diesel Exhaust Ventilation & & $\mathbf{x}$ & & & \\
\hline 3.7.2.6.C.3 & Diesel Exhaust Ventilation & & $\mathbf{x}$ & & & \\
\hline 3.7.2.6.D & Retrieval of Wastes & & $\mathbf{x}$ & $\mathbf{x}$ & & \\
\hline 3.7.2.6E & Underground Openings & $\mathbf{X}$ & & & & \\
\hline 3.7.2.6.E.1 & Underground Openings & & $\mathbf{x}$ & $\mathbf{x}$ & & \\
\hline 3.7.2.6.E.2 & Underground Openings & & $\mathbf{x}$ & $\mathbf{X}$ & & \\
\hline 3.7.2.6.F & Subsurface Facilities and Systems & $\mathbf{x}$ & & & & \\
\hline 3.7.2.6.F.1 & Subsurface Facilities and Systems & & $\bar{x}$ & & & \\
\hline 3.7.2.6.F.2 & Subsurface Facilities and Systems & & $\mathbf{X}$ & $\mathbf{x}$ & & \\
\hline 3.7.2.6.F.3 & Subsurface Facilities and Systems & & $\bar{x}$ & & & \\
\hline 3.7.2.6.F.4 & Subsurface Facilities and Systems & & $x$ & & & \\
\hline 3.7.2.6.5.5 & Subsurface Facilities and Systems & & $\mathrm{x}$ & & & \\
\hline 3.7.2.6.F.6 & Subsurface Facilities and Systems & & $\mathbf{x}$ & & & \\
\hline
\end{tabular}


Table 4-1. Conformance Verification Matrix (Continued)

\begin{tabular}{|c|c|c|c|c|c|c|}
\hline \multicolumn{2}{|r|}{ Requitremont } & \multicolumn{5}{|c|}{ Verification Mothod Code } \\
\hline Number & Tite & NA & Anatycus & $\mathbf{I n o m}$ & Demen & Tm \\
\hline 3.7.2.6.F.7 & Subsurface Facilities and Systems & & $x$ & & & \\
\hline 3.7.2.6.G & Rock Excavation & $\mathbf{x}$ & & & & \\
\hline 3.7.2.6.G.1 & Rock Excavation & & $x$ & $\bar{x}$ & & \\
\hline 3.7.2.6.G.2 & Rock Excavation & & $\bar{x}$ & $\bar{x}$ & & \\
\hline 3.7.2.6. H & Flexibility & & $\bar{x}$ & $\bar{x}$ & & \\
\hline 3.7 .2 .6 .1 & Water and Gas & & $\bar{x}$ & $x$ & & \\
\hline $3.7 .2 .6 \mathrm{~J}$ & Seals & $\mathbf{x}$ & & & & \\
\hline $3.7 .2 .6 \mathrm{~J} .1$ & Seals & & $\bar{x}$ & $\mathbf{x}$ & $\bar{x}$ & $\bar{x}$ \\
\hline 3.7.2.6.J.2 & Seals & & $\mathrm{x}$ & $\bar{x}$ & $\bar{x}$ & $\mathbf{x}$ \\
\hline $3.7 .2 .6 \mathrm{~J} .3$ & Seals & & $\bar{x}$ & $\bar{x}$ & $\bar{x}$ & $\bar{x}$ \\
\hline 3.7.2.6.K & Control of Fluids in Construction & & & $\bar{x}$ & & \\
\hline 3.7.2.6. L & Fire Protection & $\mathbf{x}$ & & & & \\
\hline 3.7.2.6.L.1 & Fire Protection & & $\mathbf{x}$ & & & \\
\hline 3.7.2.6.L.2 & Fire Protection & & $\mathbf{x}$ & & & \\
\hline 3.7.2.6.L.3 & Fire Protection & & $\mathbf{x}$ & & & \\
\hline 3.7.2.6.L.4 & Fire Protection & & $\mathbf{x}$ & & & \\
\hline 3.7.2.6.M & Industrial Health and Safety & & & $\bar{x}$ & & \\
\hline 3.7.2.7 & Performance Confirmation Requirements & $\mathbf{x}$ & & & & \\
\hline 3.7.2.7.A & General Requirements & $\mathbf{x}$ & & & & \\
\hline 3.7.2.7.A.1 & General Requirements & & $\mathbf{x}$ & $x$ & & \\
\hline 3.7.2.7.A.2 & General Requirements & & $\mathbf{x}$ & 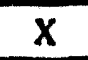 & & \\
\hline 3.7.2.7.A.3 & General Requirements & & $\mathbf{x}$ & $x$ & & \\
\hline 3.7.2.7.B & Testing & & & & $\mathbf{x}$ & \\
\hline 3.7.2.7.C & Rock Measurement & & $\mathbf{x}$ & $x$ & & \\
\hline 3.7.2.7.D & Thermomechanical Response & & $\mathbf{X}$ & $\bar{x}$ & & \\
\hline 3.7.2.7.E & Laboratory Experiments & & $\mathbf{x}$ & & & \\
\hline 3.7.2.7F & Backfill Test & & $\mathbf{x}$ & $x$ & & \\
\hline 3.7.2.7.G & Borehole and Access Seal Tests & & $\mathbf{x}$ & $\mathrm{x}$ & & \\
\hline 3.7.2.8 & Radiological Protection & $\mathbf{x}$ & & & & \\
\hline 3.7.2.8.A & Radiological Protection & $x$ & & & & \\
\hline 3.7.2.8.A.1 & Radiological Protection & & $\mathbf{x}$ & $x$ & & \\
\hline 3.7.2.8.A.2 & Radiological Protection & & $x$ & $x$ & & \\
\hline 3.7.2.8.A.3 & Radiological Protection & & $\mathbf{x}$ & $\mathrm{x}$ & & \\
\hline
\end{tabular}


Title: Mined Geologic Disposal System Requirements Document

Table 4-1. Conformance Verification Matrix (Continued)

\begin{tabular}{|c|c|c|c|c|c|c|}
\hline \multicolumn{2}{|r|}{ Requirement } & \multicolumn{5}{|c|}{ Verification Method Code } \\
\hline Number & Title & N/A & Anslyds & Exam & Demo & Test \\
\hline 3.7.2.8.A.4 & Radiological Protection & & $\mathbf{x}$ & & & \\
\hline 3.7.2.8.A.5 & Radiological Protection & & $\mathbf{x}$ & & & \\
\hline 3.7.2.8.A.6 & Radiological Protection & & $\mathbf{x}$ & & & \\
\hline 3.7.2.8.B & Radiological Protection & & $\mathbf{X}$ & & & \\
\hline 3.7.2.8.C & Radiological Protection & & $\mathbf{X}$ & $\mathbf{X}$ & & \\
\hline 3.7.2.8.D & Radiological Protection & & $\mathbf{x}$ & & & \\
\hline 3.7.2.8.E & Radiological Protection & & $\mathbf{x}$ & & & \\
\hline 3.7.2.8.F & Radiological Protection & & $\mathbf{X}$ & & & \\
\hline 3.7.2.8.G & Radiological Protection & & $\mathbf{X}$ & $\mathrm{x}$ & & \\
\hline 3.7.3 & Engineered Barrier System Segment & $\mathbf{X}$ & & & & \\
\hline 3.7.3.1 & $\begin{array}{l}\text { Engineered Barrier System Segment } \\
\text { Description }\end{array}$ & $\mathbf{x}$ & & & & \\
\hline 3.7.3.1.A & EBS Function & & $\mathbf{X}$ & $\mathbf{X}$ & & \\
\hline 3.7.3.1.B & EBS DRD & & $\mathbf{X}$ & & & \\
\hline 3.7.3.1.C & EBS Interfaces & $\mathbf{x}$ & & & & \\
\hline 3.7.3.2 & EBS General Requirements & $\mathbf{X}$ & & & & \\
\hline 3.7.3.2.A & EBS General Requirements & & $\mathbf{x}$ & $\mathbf{x}$ & $\mathbf{x}$ & $\mathbf{x}$ \\
\hline 3.7.3.2.B & EBS General Requirements & & $\mathbf{x}$ & $\mathbf{x}$ & $\mathbf{X}$ & $\mathbf{X}$ \\
\hline 3.7.3.2.C & EBS General Requirements & & $\mathbf{x}$ & $\mathbf{x}$ & $\mathbf{X}$ & $\mathbf{X}$ \\
\hline 3.7.3.2.D & EBS General Requirements & & $\mathbf{x}$ & $\mathbf{x}$ & $\mathbf{x}$ & $\mathbf{X}$ \\
\hline 3.7.3.2.E & Seals & $\mathbf{x}$ & & & & \\
\hline 3.7.3.2.E.1 & Seals & & $\mathbf{X}$ & $\mathbf{x}$ & $\mathbf{x}$ & $\mathbf{X}$ \\
\hline 3.7.3.2.E.2 & Seals & & $\mathbf{X}$ & $\mathbf{X}$ & $\mathbf{x}$ & $\mathbf{X}$ \\
\hline 3.7.3.2.E.3 & Seals & & $\mathbf{X}$ & $\mathbf{x}$ & $\mathbf{X}$ & $\mathbf{X}$ \\
\hline 3.7.3.3 & Waste Package Requirements & $\mathbf{x}$ & & & & \\
\hline 3.7.3.3.A & General & & $\mathbf{X}$ & $\mathbf{X}$ & $\mathbf{X}$ & $\mathbf{X}$ \\
\hline 3.7.3.3.B & Integrity & $\mathbf{x}$ & & & & \\
\hline 3.7.3.3.B.1 & Integrity & & $\mathbf{X}$ & $\mathbf{X}$ & $\mathbf{x}$ & $\mathbf{X}$ \\
\hline 3.7.3.3.B.2 & Integrity & & $\mathbf{X}$ & $\mathbf{X}$ & & $\mathbf{X}$ \\
\hline 3.7.3.3.B.3 & Integrity & & $\mathbf{X}$ & & & $\mathbf{x}$ \\
\hline 3.7.3.3.B.4 & Integrity & & $x$ & $\mathbf{X}$ & $\mathbf{x}$ & $\mathbf{X}$ \\
\hline 3.7.3.3.C & Package Contents & & $x$ & $X$ & $\mathbf{X}$ & $x$ \\
\hline 3.7.3.3.D & Free Liquids & & $\bar{x}$ & $\bar{x}$ & $x$ & $\bar{x}$ \\
\hline
\end{tabular}


Title: Mined Geologic Disposal System Requirements Document

Table 4-1. Conformance Verification Matrix (Continued)

\begin{tabular}{|c|c|c|c|c|c|c|}
\hline \multicolumn{2}{|r|}{ Requirement } & \multicolumn{5}{|c|}{ Verification Method Code } \\
\hline Number & Title & NA & Andyads & Exam & Demo & Test \\
\hline 3.7.3.3.E & Durability & & $\mathbf{x}$ & $\mathbf{x}$ & & \\
\hline 3.7.3.3.F & Label & & $\mathbf{x}$ & & & \\
\hline 3.7.3.3.G & Waste Form Requirements & $\mathbf{x}$ & & & & \\
\hline 3.7.3.3.G.1 & Solidification & & $\mathbf{x}$ & & & \\
\hline 3.7.3.3.G.2 & Sealed Containers & & $\mathbf{x}$ & & & $\mathbf{x}$ \\
\hline 3.7.3.3.G.3 & Consolidation & & $\mathbf{x}$ & & & $\mathbf{x}$ \\
\hline 3.7.3.3.G.4 & Combustibles & & $\mathbf{x}$ & & & $\mathbf{x}$ \\
\hline 3.7.3.4 & Underground Facility Requirements & $\mathbf{x}$ & & & & \\
\hline 3.7.3.4.A & General Criteria & & $\mathbf{x}$ & $\mathbf{x}$ & & \\
\hline 3.7.3.4 B & Reserved & $\mathbf{x}$ & & & & \\
\hline 3.7.3.4.C & Thermal Loads & & $\mathbf{x}$ & $\mathbf{x}$ & $\mathbf{x}$ & $\mathbf{x}$ \\
\hline 3.7.3.4.D & Control of Fluids in Construction & & & $\mathbf{x}$ & & \\
\hline 3.8 & Precedence & $\mathbf{X}$ & & & & \\
\hline 3.8.A & Precedence & & $\mathbf{x}$ & & & \\
\hline 3.8.B & Precedence & & $\mathbf{x}$ & & & \\
\hline 3.8.C & Precedence & & $\mathbf{x}$ & & & \\
\hline 3.9 & Qualification/Quality Assurance & & $\mathbf{x}$ & & & \\
\hline 5.1 & Key Decisions & & $\mathbf{x}$ & & & \\
\hline 5.2 & Requirements & & $\mathrm{x}$ & & & \\
\hline
\end{tabular}




\section{PREPARATION FOR OPERATIONS}

Recognizing the special nature of the ESF and SBTF systems, wherein operations (geoscientific investigations) will begin as soon as construction has started, these requirements will be adapted in the project-level Site Design and Test Requirements Document as appropriate.

\subsection{KEY DECISIONS}

Preparation for operations is governed by a series of key decision points as defined in DOE Order 4700.1. The Energy System Acquisition Advisory Board supports the DOE Acquisition Executive by providing advice and assistance at those points. The approval to commence operation is scheduled prior to transition from acquisition and construction to operation of the MGDS. Preparation of applications for the licenses, certificates, and permits which must be issued prior to commencement of operations shall be undertaken in a timely manner to ensure their review, approval and issuance prior to approval being granted for operations to begin. Transition to the operations phase is not formally made until demonstrated capability to meet technical performance goals specified in MGDS requirements documents and specifications are achieved, and required licenses, certificates, and permits have been issued. These conditions are confirmed by the Energy System Acquisition Advisory Board .

In accordance with DOE Order 4700.1 , a presentation package shall be developed to support Energy System Acquisition Advisory Board determination of the readiness of the MGDS to proceed with operations. As a minimum, the presentation packages to support the Energy System Acquisition Advisory Board in the review process shall contain: a description of the project; background data; major technical and performance requirements; licenses, certificates and permits; readiness to proceed with operations; and problems, issues, or items of concern.

\subsection{REQUIREMENTS}

In addition to satisfying the requirements of the specifications, the MGDS shall establish programs to ensure, at the commencement of operations, the availability of sufficient trained personnel to operate the elements and validated documentation to support the operations.

The MGDS shall additionally establish logistics support systems, to include ensuring the availability of sufficient spares to support the element maintenance concept and the design availability factors used in the design.

Specific plans and procedures for acceptance, operational, and integrated testing, as well as preparation of test documentation, will be governed by test and evaluation plans. 
Title: Mined Geologic Disposal System Requirements Document

Revision: 1

Page: 136

INTENTIONALLY LEFT BLANK 


\section{NOTES}

\subsection{GLOSSARY}

Accessible environment is: (1) the atmosphere, (2) the land surface, (3) surface water, (4) oceans, and (5) the portion of the lithosphere that is outside the controlled area. [10CFR60.2]

Administrative delay time is that portion of downtime during which maintenance is delayed for administrative reasons.

Anticipated processes and events are those natural processes and events that are reasonably likely to occur during the period the intended performance objective must be achieved. To the extent reasonable in the light of the geologic record, it shall be assumed that those processes operating in the geologic setting during the Quaternary Period continue to operate but with the perturbations caused by the presence of emplaced radioactive waste superimposed thereon. [10CFR60.2]

Architecture is the physical system to be built, found, or selected to perform a function subject to its stated requirements.

As low as is reasonably achievable (ALARA) means making every reasonable effort to maintain exposures to radiation as far below the dose limits in 10CFR20 as is practical consistent with the purpose for which the licensed activity is undertaken, taking into account the state of technology, the economics of improvements in relation to state of technology, the economics of improvements in relation to benefits to the public health and safety, and other societal and socioeconomic considerations, and in relation to utilization of nuclear energy and licensed materials in the public interest. [10CFR20.1003]

Barrier is any material or structure that prevents or substantially delays movement of water or radionuclides. [10CFR60.2]

Blending is (1) selecting SNF assemblies of different characteristics for inclusion in an MPC, transportation cask, storage mode, or waste package, or (2) selecting HLW of different characteristics for inclusion in a transportation cask or waste package to meet design goals.

Canister is the structure surrounding the waste form (e.g., HLW immobilized in borosilicate glass) that facilitates handling, storage, transportation, and/or disposal. A canister is a metal receptacle with the following purpose: (1) for solidified HLW, its purpose is a pour mold and (2) for SNF, it may provide structural support for intact SNF, loose rods, non-fuel components, or containment of radionuclides during preclosure operations. See definition of 'multi-purpose canister.'

Cask is a container for shipping or storing spent nuclear fuel and/or canistered high-level waste that meets all applicable regulatory requirements. 
Title: Mined Geologic Disposal System Requirements Document Revision: 1

Page: 138

I Cask maintenance facility is a facility to maintain the transportation cask subsystems. The specific mission of the cask maintenance facility is to provide for the servicing, testing, maintenance, repair, modification, storage and configuration control of transportation cask subsystems.

I Cask maintenance includes those functions necessary to keep a transportation cask in working order (i.e., keep cask in accordance with certification).

1 Cask Subsystem is defined under transportation cask subsystem

Civilian Radioactive Waste Management System (CRWMS) is the composite of sites, facilities, systems, equipment, materials, information, activities, and personnel required to perform

I those activities necessary to manage spent nuclear fuel and high-level radioactive waste disposal.

I Collocate is to place together.

I Confining means separating radioactive substances from the environment.[10CFR72]

Containment is the confinement of radioactive waste within a designated boundary. [10CFR60.2]

I Controlled area is:

(1) a surface location, to be marked by suitable monuments, extending horizontally no more than 10 kilometers in any direction from the outer boundary of the underground facility, and the underlying subsurface, which area has been committed to use as a geologic repository and from which incompatible activities would be restricted following permanent closure. [10CFR60.2];

(2) (a) a surface location, to be identified by passive institutional controls, that encompasses no more than 100 square kilometers and extends horizontally no more than 5 kilometers in any direction from the outer boundary of the original location of the radioactive wastes in a disposal system; and (b) the subsurface underlying such a surface location. [40CFR191.12(g)];

(3) an area, outside of a restricted area but inside the site boundary, access to which can be limited by the licensee for any reason. [10CFR20.1003]

Decommission means to remove safely from service and reduce residual radioactivity to a level that permits; for land or facilities, release of the property for unrestricted use and termination of license; and for casks, release of the cask for appropriate disposal.

Defense high-level radioactive waste is the high-level radioactive waste, as defined by NWPA Sec. 2(12), resulting from reprocessing spent nuclear fuel in a defense facility.

Disposal is the isolation of radioactive wastes from the accessible environment. [10CFR60.2] I Disposal is the emplacement in a repository of high-level radioactive waste, spent nuclear fuel, or other highly radioactive material with no foreseeable intent of recovery, whether or not such emplacement permits the recovery of such waste. [10CFR961.11] [NWPA Section 2(9)]

Disposal system is any combination of engineered and natural barriers that isolate spent nuclear fuel or radioactive waste after disposal. [40CFR 191.12(a)] 
Engineered barrier system is the waste packages and the underground facility.

[10CFR60.2]

Function is a primary statement of purpose; it defines what a system or subsystem must accomplish to meet the system mission.

Functional analysis is the first step in the Systems Engineering process that defines a baseline of functions and function performance requirements that must be met in order to adequately accomplish the operation, support, test, and production requirements of a system.

Functional interface is the interaction between functions, as in the flow of material or information between a sequence of activities.

Geologic repository is a system which is intended to be used for, or may be used for, the disposal of radioactive wastes in excavated geologic media. A geologic repository includes: (1) the geologic repository operations area, and (2) the portion of the geologic setting that provides isolation of the radioactive waste. [10CFR60.2]

Geologic repository operations area (GROA) is a high-level radioactive waste facility that is part of a geologic repository, including both surface and subsurface areas, where waste handling activities are conducted. [10CFR60.2]

Geologic setting is the geologic, hydrologic, and geochemical systems of the region in which a geologic repository operations area is or may be located. [10CFR60.2]

Groundwater is all water which occurs below the land surface. [10CFR60.2]

High-level radioactive waste (HLW) is (1) the highly radioactive material resulting from the reprocessing of spent nuclear fuel, including liquid waste produced directly in reprocessing and any solid material derived from such liquid waste that contains fission products in sufficient concentrations; and (2) other highly radioactive material that the Nuclear Regulatory Commission, consistent with existing law, determines by rule requires permanent isolation. The CRWMS will only accept solidified HLW. For the purposes of this document, HLW is vitrified borosilicate glass cast in a stainless steel canister. [NWPA Section 2(12)] [10CFR72.3] [10CFR960.2] [10CFR961.11] (Note that the 10CFR60 definition of HLW includes SNF.)

High radiation access area is an area, accessible to individuals, in which radiation levels could result in an individual receiving a dose equivalent in excess of $0.1 \mathrm{rem}(1 \mathrm{mSv})$ in 1 hour at 30 centimeters from the radiation source or from any surface that the radiation penetrates. [10CFR20.1003]

Important to safety with reference to structures, systems, and components means those engineered structures, systems, and components essential to the prevention or mitigation of an accident that could result in a radiation dose to the whole body, or any organ, of $0.5 \mathrm{rem}$ or greater at or beyond the nearest boundary of the unrestricted area at any time until the completion of permanent closure. [10CFR60.2] 
I (Items) Important to waste isolation are the natural and engineered barriers which are relied on for achieving the postclosure performance objectives in 10CFR60 Subpart E.

Input is anything that is acted upon by a function to produce desired outputs. Inputs can be classified as either internal or external. Inputs that originate from outside a particular system are considered to be external. Inputs that are outputs from functions within a particular system are considered to be internal.

Institutional barrier system consists of the active and passive institutional controls.

Active institutional controls include: (1) Controlling access to the MGDS by any means other than passive institutional controls; (2) Performing maintenance operations or remedial actions at a site; (3) Controlling or cleaning up releases from a site; or (4) Monitoring parameters related to disposal system performance.

Passive institutional controls include: (1) Permanent markers placed at a disposal site; (2) Public records and archives; (3) Government ownership and regulations regarding land or resource use, and (4) other means of preserving knowledge about the location, design, and contents of a disposal system. [40CFR191.02]

Intermediate maintenance is maintenance normally beyond the capability of personnel performing on-line maintenance. Intermediate maintenance activities have more tools, test equipment, and specially trained personnel to work on equipment than does on-line maintenance. Maintenance at this level is normally more complicated and time consuming, thereby requiring more highly skilled technicians.

I Interface requirement is a requirement that applies to the inputs to, or outputs from, the I function or the physical connection or dependence between architectural items.

Isolation is inhibiting the transport of radioactive material so that amounts and concentrations of this material entering the accessible environment will be kept within prescribed limits. [10CFR60.2]

Licensed material is source material, special nuclear material, or byproduct material received, possessed, used, transferred or disposed of under a general or specific license issued by the I Nuclear Regulatory Commission. [10CFR20]

Licensee is a person who is authorized to conduct activities under a license or construction permit issued by the Commission. [10CFR2.4]

I Loaded means an MPC/cask/container that (1) contains its intended complement of SNF I assemblies, (2) the contents have been verified, and (3) it has been closed and the I DOE(OCRWM)-approved tamper-indicating seal is certified. (In this configuration, the MPC I qualifies as a canistered waste form that is acceptable into the CRWMS).

I Loaded hook weight includes a transportation cask, a MPC (if included), SNF or HLW, a shield I plug, entrained water, and a lifting yoke. It may also include a cask lid. 
Title: Mined Geologic Disposal System Requirements Document

Revision: 1

Page: 141

Logistics delay time is maintenance downtime that is expanded as a result of waiting for a spare part, tool, facility, or whatever to become available in order to effect repair.

Material access area is any location which contains special nuclear material.

Mean time to repair is the mean or average elapsed time to perform scheduled and unscheduled maintenance. (Excludes Logistics Delay Time and Administrative Delay Time).

Mined Geologic Disposal System (MGDS) - See Section 1.3.4.

Motive support equipment consists of the vehicle providing motive power to the transporter and other equipment needed to support movement of a transportation cask. Examples are locomotives, rail buffer cars, barges, cranes, heavy lifthaul tractors (trucks), and legal-weight trucks.

Mult-purpose canister (MPC) refers to a sealed, metallic container maintaining multiple SNF assemblies in a dry, inert environment and overpacked separately and uniquely for the various system elements of storage, transportation, and disposal. See definition of waste form.

$\mathrm{N}$-square diagram is a type of function flow diagram. The N-Square diagram has been used extensively to develop data interfaces. The system functions are placed on the diagonal of an $\mathrm{N}$-by- $\mathrm{N}$ matrix. The remainder of the squares of the matrix represent interface inputs and outputs. Inputs to a function appear in the column above and below the function, and outputs from a functions appear in the row to the left and right of a function. Where a blank square exists there is no interface between the respective functions. N-Square diagrams are used to develop and document system and system element interfaces. The N-Square diagrams may also be used to document hardware-to-hardware interfaces where hardware items are placed on the diagonal and their interfaces shown in the remaining squares of the matrix.

Off-normal occurrences are abnormal or unplanned events or conditions that adversely affect, potentially affect, or are indicative of degradation in, the safety, security, environmental or health protection performance or operation of a facility.

On-line maintenance is maintenance performed by the using organization on its own equipment. Personnel involved in maintenance at this level are usually the operators of the equipment and have limited time available for detailed maintenance tasks.

Output is anything that leaves the system or function after it has been acted upon by that function.

Overpack is a structural component used to hold and protect an MPC so that the combination meets the NRC requirements for the application. There are several types of overpack: one for transportation, 10CFR71; one for transfer, one for storage, 10CFR72; and one for disposal, 10CFR60. An overpack is designed for its particular use in conjunction with the MPC. 
Title: Mined Geologic Disposal System Requirements Document

Revision: 1

Page: 142

Owmer is any person who has title to spent nuclear fuel or high-level radioactive waste. [10CFR961.3]

I Package is the packaging together with its radinactive contents as presented for transport. [10CFR71.4]

Packaging is the assembly of components necessary to ensure compliance with the packaging requirements of 10CFR71. It may consist of one or more receptacles, absorbent materials, spacing structures, thermal insulation, radiation shielding, and devices for cooling or absorbing mechanical shocks. The vehicle, tie-down system, and auxiliary equipment may be designated as part of the packaging. [10CFR71.4]

Performance confirmation is the program of tests, experiments, and analyses which is conducted to evaluate the accuracy and adequacy of the information used to determine with reasonable assurance that the performance objectives for the period after permanent closure will be met. [10CFR60.2]

Permanent clocure is final backfilling of the underground facility and the sealing of shafts and boreholes. [10CFR60.2]

Phydical barriers are: (1) fences constructed of No. 11 American wire gauge or heavier wire fabric, topped by three strands or more of barbed wire or similar material on brackets angled inward or outward between $30^{\circ}$ and $45^{\circ}$ from vertical, with an overall height including the barbed topping of not less than 8 feet; (2) building walls, ceilings, and floors constructed of stone, brick, cinder block, concrete, steel, or similar materials (openings in which are secured by grates, doors, or covers of construction and fastening of sufficient strength such that the integrity of the wall is not lessened by any opening), or walls of similar construction, not a part of a building, provided with barbed topping described above, of a height not less than 8 feet; (3) Any other physical obstruction constructed in a manner and of materials suitable for the purpose for which the obstruction is intended. [10CFR73.2]

Physical interface is the boundary at which physical systems interact, as in a necessary fit between elements, segments, subsystems, etc.

I Physical system is the Civilian Radioactive Waste Management System (CRWMS) consisting of the composite of the sites, and all facilities, systems, equipment, materials, information, activities, and the personnel required to perform those activities necessary to manage waste disposal.

I Producer is any generator of high-level radioactive waste resulting from atomic energy defense activities or any producer of vitrified commercial HLW.

Protected area is any area encompassed by physical barriers and to which access is controlled. [10CFR73.2] 
Title: Mined Geologic Disposal System Requirements Document

Revision: 1

Page: 143

Radioactive waste or waste is HLW and other radioactive materials other than HLW that are received for emplacement in a geologic repository. [10CFR60.2]

Repository is any system licensed by the Commission that is intended to be used for, or may be used for, the permanent deep geologic disposal of high-level radioactive waste and spent nuclear fuel, whether or not such system is designed to permit the recovery, for a limited period during initial operation, of any materials placed in such system. Such term includes both surface and subsurface areas at which high-level radioactive waste and spent nuclear fuel handling activities are conducted. [NWPA]

Restricted area is any area access to which is controlled by the licensec for purposes of protection of individuals from exposure to radiation and radioactive materials. Restricted area shall not include any areas used as residential quarters, although a separate room or rooms in a residential building may be set apart as a restricted area. [10CFR60.2]

Retrieval is the act of intentionally removing radioactive waste from the underground location at which the waste had been previously emplaced for disposal. [10CFR60.2]

Safeguards are a system of technical measures within the framework of international nonproliferation policy intrusted to the International Atomic Energy Agency in its Statute and by the Non-Proliferation Treaty ... designed to ensure that special fissionable and other materials, services, equipment, facilities, and information . . . are not used in such a way as to further any military purpose. [LAEA Glossary]

Safeguards (NRC) are (1) security measures for the physical protection of special nuclear material or (2) security measures for the physical protection and location of certain plant equipment vital to the safety of production or utilization facilities. [10CFR73]

Safety delay time is maintenance downtime imposed due to safety reasons, i.e., radiological hazard, environmental hazard, and the like.

Saturated zone is that part of the earth's crust beneath the regional water table in which all voids, large and small, are ideally filled with water under pressure greater than atmospheric. [10CFR60.2]

Segment is a distinct, top-level component of the overall architecture of each system element to which functions and requirements are allocated.

Site is the location of the controlled area. [10CFR60.2]

Site characterization is the program of exploration and research both in the laboratory and in the field, undertaken to establish the geologic conditions and the ranges of those parameters of

1 The term safeguards or international (IAEA) safeguards should not be confused with similar terms used in the context of national legislations; these sometimes cover measures for physical protection. 
a particular site relevant to the procedures under 10CFR60. Site characterization includes borings, surface excavations, excavation of exploratory shafts, limited subsurface lateral excavations and borings, and in situ testing at depth needed to determine the suitability of the site for a genlogic repository, but does not include preliminary borings and geophysical testing needed to decide whether site characterization should be undertaken. [10CFR60.2]

I Special nuclear material is (1) Plutonium, Uranium 233, Uranium enriched in the isotope 233 or in the isotope 235, and any other material which the NRC, pursuant to the provisions of section 51 of the Atomic Energy Act of 1954 as amended, determines to be special nuclear material, but does not include source material; or (2) any material artificially enriched by any of the foregoing but does not include source material. [10CFR70.4]

I Special source of ground water, as used in this document, includes those Class I ground waters identified in accordance with the EPA Ground-Water Protection Strategy published in 1984 that: (1) are within the controlled area encompassing a disposal system or are less than five kilometers beyond the controlled area; (2) are supplying drinking water for thousands of persons as of the date that the DOE chooses a location within that area for detailed characterization as a potential site for a disposal system (e. g., in accordance with section 112(b)(1)(B) of the NWPA); and (3) are irreplaceable in that no reasonable source of drinking water is available for that population. [40CFR191.12(0)]

Specialty engineering encompasses those disciplines that support the design process by applying knowledge from a specific area to ensure system operability in its operational environment. They I include reliability, availability, maintainability, human factors engineering, safeguards and security, integrated logistics support, transportability, system safety, electromagnetic compatibility, parts/materials/ processes and other specialist areas generally involved in development of systems. These specialties are integrated into the development effort through the system engineering process.

Spent nuclear fuel (SNF) is fuel that has been withdrawn from a nuclear reactor following irradiation, the constituent elements of which have not separated by reprocessing [NWPA Section 2(23)] [10CFR961.11]. [Specifically in this document, SNF includes (1) intact, nondefective fuel assemblies; (2) failed fuel assemblies in canisters; (3) fuel assemblies in canisters;

I (4) consolidated fuel rods in canisters; (5) non fuel components inserted in PWR fuel assemblies, including, but not limited to, control rod assemblies, bumable poison assemblies, thimble plug assemblies, neutron source assemblies, instrumentation assemblies; (6) fuel channels attached to BWR fuel assemblies; and (7) non fuel components and structural parts of assemblies.\}

I Subsurface, as used in this document, is the underground portions of the ESF and the Repository Segment, whether or not part of the GROA. It is used to avoid confusion with the "underground facility," which is part of the GROA/EBS. "Subsurface" does not include trenches, ditches, cellars or other similar below-grade excavations.

System element is one of the elements of the CRWMS (Waste Acceptance, Transportation, I MRS, or MGDS). This differs from the "project" that may be initiated by DOE to manage and control development of one or more system element (e.g., the Yucca Mountain Project or the 
MRS Project).

Transportable storage cask is any cask certified by the NRC for the purposes of transporting SNF, as described in 10 CFR 71, and storing SNF as described in 10 CFR 72, Subpart L.

Transportation Cask Subsystem as a minimum, includes a complete cask, an MPC (when required), truck trailer or rail car (defined as the transporter), a tiedown system, an intermodal transfer device (when required), special tools, and ancillary equipment.

Unanticipated processes and events are those processes and events affecting the geologic setting that are judged not to be reasonably likely to occur during the period the intended performance objective must be achieved, but which are nevertheless sufficiently credible to warrant consideration. Unanticipated processes and events may be either natural processes or events or processes and events initiated by human activities other than those activities licensed under 10CFR60. Processes and events initiated by human activities may only be found to be sufficiently credible to warrant consideration if it is assumed that: (1) The monuments provided for by 10CFR60 are sufficiently permanent to serve their intended purpose; (2) the value to future generations of potential resources within the site can be assessed adequately under the applicable provisions of 10CFR60; (3) an understanding of the nature of radioactivity, and an appreciation of its hazards, have been retained in some functioning institutions; (4) institutions are able to assess risk and to take remedial action at a level of social organization and technological competence equivalent to, or superior to, that which was applied in initiating the processes or events concerned; and (5) relevant records are preserved, and remain accessible, for several hundred years after permanent closure. [10CFR60.2]

Underground facility is the underground structure, including openings and backfill materials, but excluding shafts, boreholes, and their seals. [10CFR60.2]

Very high radiation access area is an area, accessible to individuals, in which radiation levels could result in an individual receiving an absorbed dose in excess of 500 rads (5 grays) in 1 hour at 1 meter from the radiation source or from any surface that the radiation penetrates.

[Note: At very high doses received at high dose rates, units of absorbed dose (e.g., rads and grays) are appropriate, rather than units of dose equivalent (e.g., rems and sieverts)].

Vital area is any area which contains vital equipment. [10CFR73.2<TBR>]

Vital equipment is any equipment, system, device, or material, the failure, destruction, or release of which could directly or indirectly endanger the public health and safety by exposure to radiation. Equipment or systems which would be required to function to protect public health and safety following such failure, destruction, or release are also considered to be vital. $[10 \mathrm{CFR} 73.2<\mathrm{TBR}>$ ]

Waste is spent nuclear fuel (SNF) and high-level waste (HLW). 
Title: Mined Geologic Disposal System Requirements Document Revision: 1

Waste form is the radioactive waste materials and any encapsulating or stabilizing matrix.

I [10CFR60.2] A loaded MPC is a canistered waste form.

I Waste handling activities include receipt of waste, preparation of waste for storage or disposal, transfer of waste from one cask to another or to its place of emplacement, emplacement of waste, and retrieval of waste.

1 Waste package is the waste form and any containers, shielding, packing and other absorbent materials immediately surrounding an individual waste container. [10CFR60.2]

\subsection{ACRONYMS AND ABBREVIATIONS}

AASHTO

ACI

ADP

AISC

AISI

ALARA

ANS

ANSI

AREA

ARI

ASCE

ASHRAE

ASME

ASTM

ATE

I Att.

AWS

BIA

BITE

BLM

BWR

CFR

CMAA

CMOCC

CRD

CRWMS

DOD

DOE

DRD

EBS

EPA

ESF

et seq.

I GWd/M7U
American Association of State Highway and Transportation Officials

American Concrete Institute

Automated Data Processing

American Institute of Steel Construction

American Iron and Steel Institute

As Low As is Reasonably Achievable

American Nuclear Society

American National Standards Institute

American Railway Engineering Association

Air Conditioning and Refrigeration Institute

American Society of Civil Engineers

American Society of Heating Refrigeration and Air-Conditioning Engineers

American Society of Mechanical Engineers

American Society for Testing and Materials

Automatic-Test-Equipment

Attachment

American Welding Society

Brick Institute of America

Built-in-Test Equipment

Bureau of Land Management

Boiling Water Reactor

Code of Federal Regulations

Crane Manufacturers Association of America

Central Management and Operations Control Center

CRWMS Requirements document

Civilian Radioactive Waste Management System

Department of Defense

Department of Energy

Design Requirements Document

Engineered Barrier System

US Environmental Protection Agency

Exploratory Studies Facility (ESF)

And following

GigaWatt days per Metric Ton of Initial Uranium 
Title: Mined Geologic Disposal System Requirements Document

Revision: 1

Page: 147

\begin{tabular}{|c|c|}
\hline GROA & Geologic Repository Operations Area \\
\hline HDBK & Handbook \\
\hline HFS & Human Factors Society \\
\hline HLW & High-Level Radioactive Waste \\
\hline IAEA & International Atomic Energy Agency \\
\hline IEEE & Institute of Electrical and Electronics Engineers \\
\hline LAR & Low Aspect Ratio \\
\hline LWT & Legal Weight Truck \\
\hline M\&O & Management and Operating Contractor \\
\hline MBMA & Metal Building Manufacturer's Association \\
\hline MGDS & Mined Geologic Disposal System \\
\hline MGDS-RD & Mined Geologic Disposal System Requirements document \\
\hline MSHA & Mine Safety and Health Administration \\
\hline MIL & Military \\
\hline MOA & Memorandum of agreement \\
\hline MOU & Memorandum of understanding \\
\hline MPC & Multi-purpose canister \\
\hline mrem & Millirem \\
\hline MRS & Monitored Retrievable Storage Installation \\
\hline MSHA & Mine Safety and Health Administration \\
\hline $\mathrm{mSv}$ & Millisievert \\
\hline MTU & Metric ton(s) of initial uranium \\
\hline NAAMM & National Association of Architectural Metal Manufacturers \\
\hline NAPHCC & National Association of Plumbing-Heating-Cooling Contractors \\
\hline NCMA & National Concrete Masonry Association \\
\hline NEMA & National Electrical Manufacturers Association \\
\hline NEPA & National Environmental Policy Act \\
\hline NFPA & National Fire Protection Association \\
\hline NIST & National Institute of Standards and Technology \\
\hline NRC & Nuclear Regulatory Commission \\
\hline NUREG & Nuclear Regulatory Guideline \\
\hline NVLAP & National Voluntary Laboratory Accreditation Program \\
\hline NWPA & Nuclear Waste Policy Act of 1982 \\
\hline NWPAA & Nuclear Waste Policy Amendments Act of 1987 \\
\hline OCRWM & Office of Civilian Radioactive Waste Management (DOE) \\
\hline OSHA & Occupational Safety and Health Administration \\
\hline OWT & Overweight Truck \\
\hline PCA & Portland Cement Association \\
\hline PCI & Prestressed Concrete Institute \\
\hline PWR & Pressurized Water Reactor \\
\hline QA & Quality Assurance \\
\hline QARD & Quality Assurance Requirements and Description Document (OCRV \\
\hline RAM & Reliability, Availability, and Maintainability \\
\hline RCRA & Pesource Conservation and Recovery Act \\
\hline RD & Requirements Document \\
\hline Rev. & Revision \\
\hline
\end{tabular}


Title: Mined Geologic Disposal System Requirements Document

RW

SAR

SBT

SBTF

SCP

SNF

SRD

SSC

STD

Sv

TBD

TBR

TDPP

UCRL

USC

WA
Office of Civilian Radioactive Waste Management (DOE)

Safety Analysis Report

Surface-Based Test

Surface-Based Testing Facilities

Site Characterization Plan

Spent Nuclear Fuel

System Requirements Document

Structure, System, and Component

Standard

Sievert

To Be Determined

To Be Resolved

Technical Document Preparation Plan

University of California Research Laboratory

United States Code

Waste Acceptance

\subsection{REQUIREMENTS CROSS-REFERENCE}

Table 6-1 provides a cross-reference between the MGDS-RD requirements, the regulatory source documents, and the sections in the CRD in which they are addressed.

Table 6-1. Requirements Cross-Reference Table

\begin{tabular}{|c|c|c|}
\hline $\begin{array}{l}\text { MGDS-RD } \\
\text { PARAGRAPH } \\
\end{array}$ & SOURCE & CRD PARAGRAPH \\
\hline 3.2.1.A & NWPA 111(a)(1), Presidential Memo 1985 & 3.2.1.A, 3.2.1.1.D \\
\hline 3.2.1.1.A & NWPA 113(c)(1) & 3.7.4.2.K.1 \\
\hline 3.2.1.1.B & 10 CFR60.15(c)(1) & 3.7.4.2.K.5 \\
\hline 3.2.1.1.C & 10 CFR $60.15(c)(2)$ & None \\
\hline 3.2.1.1.D & 10 CFR60.15(c)(3) & None \\
\hline 3.2.1.1.E & 10 CFR $60.15(c)(4)$ & None \\
\hline 3.2.1.1.F.1 & $\begin{array}{l}\text { 10CFR960.3-4, NWPAA 112(b)(1)(D)(iii), NWPA } \\
113(\mathrm{a})\end{array}$ & 3.7.4.2.K.2 \\
\hline 3.2.1.1.F.2 & $\begin{array}{l}\text { 10CFR60.17(a)(3), 10CFR960.3-4, NWPA } \\
113(\mathrm{~b})(1)(\mathrm{A})(\mathrm{iii})\end{array}$ & 3.7.4.2.K.2 \\
\hline 3.2.1.1.G & Reserved & None \\
\hline 3.2.1.1.H & $\begin{array}{l}\text { CRD, (10CFR20), (10CFR60), (40CFR191), } \\
(10 C F R 960)\end{array}$ & 3.7.4.2.K.3, 3.7.4.2.K.4 \\
\hline 3.2.1.1.I & NWPA 113(c)(2) & 3.7.4.2.K.6 \\
\hline 3.2.1.1J & 10CFR60.21(c)(1)(ii)(D) & None \\
\hline 3.2.1.2.A & 10CFR60.142(a) & 3.7.4.2. L \\
\hline 3.2.1.2.B & 10CFR60.142(b) & 3.7.4.2.L \\
\hline
\end{tabular}


Title: Mined Geologic Disposal System Requirements Document

Table 6-1. Requirements Cross-Reference Table (Continued)

\begin{tabular}{|c|c|c|}
\hline $\begin{array}{l}\text { MGDS-RD } \\
\text { PARAGRAPH }\end{array}$ & SOURCE & CRD PARAGRAPH \\
\hline 3.2.1.2.C & DOE 5480.4, Att. 2, 2.e.(8)(a) & Appendix A- DOE5480.4 \\
\hline 3.2.1.2.D & 10CFR60.111(a) & 3.2.2.2.C \\
\hline 3.2.1.3.A & NWPA 114(d) & 3.7.4.2.C \\
\hline 3.2.1.3.B & Reserved & None \\
\hline 3.2.1.3.C & 10CFR71.87f & 3.2.1.1.C \\
\hline 3.2.1.3.D & Reserved & None \\
\hline 3.2.1.3.E & Reserved & None \\
\hline 3.2.1.3.F & Reserved & None \\
\hline 3.2.1.3.G & Reserved & None \\
\hline 3.2.1.3.H & Reserved & None \\
\hline 3.2.1.3.I & Reserved & None \\
\hline 3.2.1.3.J & $\mathrm{CRD}$ & 3.2.1.B, 3.2.1.C, 3.2.1.1.E \\
\hline 3.2.1.3.K & 10CFR60.111(a), (10CFR20) & 3.2.2.2. C \\
\hline 3.2.1.4 & 10CFR60.111(a), (10CFR20) & 3.2.2.2.C \\
\hline 3.2.1.5.A & NWPA 122 & 3.7.4.2. J \\
\hline 3.2.1.5.B & 10CFR60.111(b)(1), (10CFR60.111(b)(3)) & 3.7.4.2.M \\
\hline 3.2.1.5.C & 10CFR60.111(a), (10CFR20) & $3.2 .2 .2 . \mathrm{C}$ \\
\hline 3.2.1.6 & 10 CFR60.52(c)(2) & 3.2.1.2.A \\
\hline 3.2.1.7.A & 10 CFR60.51(a)(1) & 3.7.4.2.L \\
\hline 3.2.1.7.B & $10 \mathrm{CFR} 60.51(\mathrm{a})(2)(\mathrm{i})$ & 3.7.4.2. N \\
\hline 3.2.1.7.C & 40CFR191.13(a)<TBR> & 3.7.4.2.1.2 \\
\hline 3.2.1.8.A & 10CFR60.131(b)(3)(iii) & 3.2.1.3, 3.2.6.2.A \\
\hline 3.2.1.8.B & 10CFR60.131(b)(4)(i) & 3.2.1.3 \\
\hline 3.2.1.8.C & 10 CFR60.131(b)(3)(i) & 3.2.1.3, 3.2.6.2.A \\
\hline 3.2.2.1.A & Reserved & None \\
\hline 3.2.2.1.B & $\begin{array}{l}\text { 10CFR20.1101(b), (NRC Regulatory Guides } 8.8 \text { and } \\
8.10)\end{array}$ & 3.2.2.1.C \\
\hline 3.2.2.1.C & $10 \mathrm{CFR} 20$ & \begin{tabular}{|l|}
$3.2 .2 .1 . \mathrm{D}, 3.2 .2 .2 . \mathrm{A}$, \\
3.2.2.2.B \\
\end{tabular} \\
\hline 3.2.2.1.D & $10 \mathrm{CFR} 60.111(\mathrm{a}),(10 \mathrm{CFR} 20)$ & 3.2.1.1.G, 3.2.2.2.C \\
\hline 3.2.2.1.E & Reserved & None \\
\hline 3.2.2.1.F & CRD & 3.2.2.1.E \\
\hline 3.2.2.1.F.1 & 40CFR $191.03(\mathrm{a})(1)<\mathrm{TBR}\rangle$ & 3.2.2.2.D \\
\hline 3.2.2.1.F.2 & Reserved & None \\
\hline
\end{tabular}


Title: Mined Geologic Disposal System Requirements Document

Table 6-1. Requirements Cross-Reference Table (Continued)

\begin{tabular}{|c|c|c|}
\hline $\begin{array}{l}\text { MGDS-RD } \\
\text { PARAGRAPH }\end{array}$ & SOURCE & CRD PARAGRAPH \\
\hline 3.2.2.1.G & 40CFR191.15<TBR> & Appendix A-40CFR191 \\
\hline 3.2.2.2 & Reserved & None \\
\hline 3.2.2.3.A & 10CFR20.1301(a),(10CFR20.1301(c)), (10CFR20.2003) & 3.2.2.2.B \\
\hline 3.2.2.3.B & 10CFR20.1301(b) & Appendix A- 10CFR20 \\
\hline 3.2.2.3.C & $10 \mathrm{CFR} 20.1301(\mathrm{a})(2)$ & 3.2.2.2.B \\
\hline 3.2.2.4.A & 10CFR20.1701 & 3.2.2.3 \\
\hline 3.2.2.4.B & 10CFR20.1702 & Appendix A- 10CFR20 \\
\hline 3.2.2.4.C & 10CFR20.1703(a)(3)(i) & 3.2.4.4.B \\
\hline 3.2.2.5.A.1 & 10CFR20.1502(a)(1), (10CFR20.1201(a)) & 3.2.2.4.A \\
\hline 3.2.2.5.A.2 & $\begin{array}{l}\text { 10CFR20.1502(a)(2), (10CFR20.1207), } \\
(10 C F R 20.1208)\end{array}$ & 3.2.2.4.A \\
\hline 3.2.2.5.A.3 & $10 \mathrm{CFR} 20.1502(\mathrm{a})(3)$ & 3.2.2.4.A \\
\hline 3.2.2.5.B.1 & 10 CFR20.1502(b)(1), (10CFR20.1001-20.2401), & 3.2.2.4.A \\
\hline 3.2.2.5.B.2 & 10 CFR20.1502(b)(2) & 3.2.2.4.A \\
\hline 3.2.2.6.A & 10CFR60.131(b)(7) & 3.2 .2 .5 \\
\hline 3.2.2.6.B & DOE $6430.1 \mathrm{~A}, 1300-4$ & 3.3.1.A \\
\hline 3.2.2.6.C & DOE $6430.1 \mathrm{~A}, 1324-3$ & 3.3.1.A \\
\hline 3.2.2.7.A & 10CFR20.2003 & 3.2.2.6.A \\
\hline 3.2.2.7.B & 10CFR20.2004, (10CFR20.2002), (10CFR20.2005) & 3.2.2.6.B \\
\hline 3.2 .2 .8 & CRD, (10CFR71), (49CFR173) & 3.2.2.7 \\
\hline 3.2.3.1.A & CRD & 3.2.3.1 \\
\hline 3.2.3.1.B & CRD & 3.2.3.2.B \\
\hline 3.2 .3 .2 & CRD & 3.2.3.2.B, 3.7.4.1.1 \\
\hline 3.2.3.2.1.A & NWPA 114(d) & Appendix A- NWPA \\
\hline 3.2.3.2.1.B & Reserved & None \\
\hline 3.2.3.2.2.A & 10CFR961.11 Article VI.A.1 & 3.7.4.2.H \\
\hline 3.2.3.2.2.B & 10CFR961.11 Article VI.A.1 & 3.7.4.2.H \\
\hline 3.2.3.2.2.C & Derived & None \\
\hline 3.2.3.2.2.D & Derived & None \\
\hline 3.2.3.2.2.E & 10CFR961.11 Art B.2 and B.3(b) & 3.2.1.1.A \\
\hline 3.2.3.2.3.A & Derived & None \\
\hline 3.2.3.2.3.B & Derived & None \\
\hline 3.2.3.2.3.C & Derived & None \\
\hline
\end{tabular}


Title: Mined Geologic Disposal System Requirements Document

Table 6-1. Requirements Cross-Reference Table (Continued)

\begin{tabular}{|c|c|c|}
\hline $\begin{array}{l}\text { MGDS-RD } \\
\text { PARAGRAPH }\end{array}$ & SOURCE & CRD PARAGRAPH \\
\hline 3.2.3.2.3.D & Derived & None \\
\hline 3.2.3.2.3.E & 49CFR177.842(f) & Appendix A- 49CFR 177 \\
\hline 3.2.3.2.3.F & 10CFR961.11 Article IV.B.2 & 3.2.1.1.F \\
\hline 3.2.3.2.3.G & Derived & None \\
\hline 3.2.3.2.3.H & Derived & None \\
\hline 3.2.3.2.3.I & Derived & None \\
\hline $3.2 .3 .2 .3 \mathrm{~J}$ & Ref. 2.4.2.C, RW-0199, 10CFR60.135(a)(2) & 3.2.1.1.H \\
\hline 3.2.3.2.3.K & 10CFR60.135(a)(2) & 3.2.1.1.H \\
\hline 3.2.3.2.3.L & DOE $4700.1 \mathrm{Ch}$ III B.2.c(2)(c) & 3.2.3.2.B \\
\hline 3.2.3.2.3.M & 10CFR60.131(b)(7) & 3.2 .2 .5 \\
\hline 3.2.3.2.3.N & 10CFR60.131(b) & 3.2 .1 .3 \\
\hline 3.2.3.2.3.0 & DOE $4700.1 \mathrm{Ch}$ III B.2.c(2)(c) & 3.2.3.2.B \\
\hline 3.2.3.2.3.P & DOE $4700.1 \mathrm{Ch}$ III B.2.c(2)(c) & 3.2.3.2.B \\
\hline 3.2.3.2.3.Q & 10CFR60.135(b)(3) & 3.2.1.1.H, 3.2.5.1.C \\
\hline 3.2.3.2.3.R & 10CFR60.135(b)(3) & 3.2.5.1.C \\
\hline 3.2.3.2.3.S & $10 \mathrm{CFR} 60.131(\mathrm{~b})$ & 3.2.1.3 \\
\hline 3.2.3.2.3.T & 10CFR60.131(b)(7), 10CFR60.135(b)(3) & 3.2.3.2.B \\
\hline 3.2.3.2.3.U & RW-0316 p. 101 & 3.2.1.1.I \\
\hline 3.2.3.2.4 & DOE 4700.1 Ch III B.2.c(2)(c) & 3.2.3.2.B \\
\hline 3.2 .4 & CRD & 3.2 .4 \\
\hline 3.2.4.1 & CRD, (DOE 6430.1A, 0900-99.0) & 3.2.4.1 \\
\hline 3.2.4.2.1 & 29CFR1910.141, (NUREG-0700) & 3.2.4.2.1 \\
\hline 3.2.4.2.2 & $\begin{array}{l}\text { CRD, (NUREG-0700 Section 6.1.5), (MIL-STD- } \\
\text { 1472D) }\end{array}$ & 3.2.4.2.2 \\
\hline 3.2.4.2.3 & $\begin{array}{l}\text { CRD, (Recommended Practice of the Illuminating } \\
\text { Engineering Society), (NUREG-0700) }\end{array}$ & 3.2.4.2.3 \\
\hline 3.2.4.2.4 & 29CFR1910.95, (NUREG-0700), (MIL-STD-1472D) & 3.2.4.2.4 \\
\hline 3.2.4.2.5 & CRD, (ANSI S-3.18), (MIL-STD-1472D) & 3.2.4.2.5 \\
\hline 3.2.4.2.6 & CRD & 3.2.4.2.6 \\
\hline 3.2.4.3.1.1 & CRD, (DOE 6430.1A, 1300-10) & 3.2.4.3.1.C \\
\hline 3.2.4.3.1.2.A & Derived & 3.2.4.3.1.B, 3.2.4.3.1.D \\
\hline 3.2.4.3.1.2.B & Derived & 3.2.4.3.1.B, 3.2.4.3.1.D \\
\hline 3.2.4.3.1.2.C & Derived & 3.2.4.3.1.B, 3.2.4.3.1.D \\
\hline 3.2.4.3.1.2.D & Derived & 3.2.4.3.1.B, 3.2.4.3.1.D \\
\hline
\end{tabular}


Title: Mined Geologic Disposal System Requirements Document

Table 6-1. Requirements Cross-Reference Table (Continued)

\begin{tabular}{|c|c|c|}
\hline $\begin{array}{l}\text { MGDS-RD } \\
\text { PARACRAPH }\end{array}$ & SOURCE & CRD PARAGRAPH \\
\hline 3.2.4.3.1.2.E & Derived & 3.2.4.3.1.B, 3.2.4.3.1.D \\
\hline 3.2.4.3.1.2.F & Derived & 3.2.4.3.1.B, 3.2.4.3.1.D \\
\hline 3.2.4.3.1.3.A & Derived & 3.2.4.3.1.B, 3.2.4.3.1.D \\
\hline 3.2.4.3.1.3.B & Derived & 3.2.4.3.1.B, 3.2.4.3.1.D \\
\hline 3.2.4.3.1.3.C & Derived & 3.2.4.3.1.B, 3.2.4.3.1.D \\
\hline 3.2.4.3.1.3.D & Derived & 3.2.4.3.1.B, $3.2 .4 .3 .1 . \mathrm{D}$ \\
\hline 3.2.4.3.1.3.E & Derived & 3.2.4.3.1.B, 3.2.4.3.1.D \\
\hline 3.2.4.3.1.4 & 10CFR20.1802 & 3.2.4.3.1.A \\
\hline 3.2.4.3.2.A & 10CFR20.1601, 10CFR20.1602 & 3.2.4.3.2 \\
\hline 3.2.4.3.2.B.1.a & 10CFR20.1601(a)(1) & 3.2.4.3.2 \\
\hline 3.2.4.3.2.B.1.b & 10 CFR20.1601(a)(2) & 3.2.4.3.2 \\
\hline 3.2.4.3.2.B.1.c & $10 \mathrm{CFR} 20.1601(\mathrm{a})(3)$ & 3.2 .4 .3 .2 \\
\hline 3.2.4.3.2.B.2 & 10CFR20.1601(b) & 3.2.4.3.2 \\
\hline 3.2.4.3.2.B.3 & 10CFR20.1601(c) & 3.2.4.3.2 \\
\hline 3.2.4.3.2.B.4 & $10 \mathrm{CFR} 20.1601(\mathrm{~d})$ & 3.2.4.3.2 \\
\hline 3.2.4.3.2.B.5 & 10CFR20.1601(e) & 3.2.4.3.2 \\
\hline 3.2.4.3.3 & 29CFR 1926.800 (c), 30CFR57.11058 & 3.2.4.3.3 \\
\hline 3.2.4.4 & 10CFR20.1906 & 3.2.2.4.B \\
\hline 3.2.4.5.1.A & DOE 6430.1A, 1300-6.2 & 3.2.2.1.A \\
\hline 3.2.4.5.1.B & DOE $6430.1 \mathrm{~A}, 1300-6.2$ & 3.2.2.1.A \\
\hline 3.2.4.5.1.C & $\begin{array}{l}\text { DOE 6430.1A, 1300-6.2, (ACI 318), (ACI 349), } \\
\text { (ANSUANS 6.4), (ANSIANS 6.4.2) }\end{array}$ & 3.2.2.1.A \\
\hline 3.2.4.5.1.D & DOE 6430.1A, 1300-6.2 & 3.2.2.1.A \\
\hline 3.2.4.5.2 & DOE 6430.1A, 1300-6.3 & 3.2.2.1.A \\
\hline 3.2.4.6.A & DOE 6430.1A, 1324-2.1 & 3.3.1.A \\
\hline 3.2.4.6.B & DOE 6430.1A, 0111-99.0 & 3.3.1.A \\
\hline 3.2.4.6.C & DOE $6430.1 \mathrm{~A}, 0111-99.0$ & 3.3.1.A \\
\hline 3.2.4.6. D & DOE $6430.1 \mathrm{~A}, 0111-99.0$ & 3.3.1.A \\
\hline 3.2.5.1 & CRD & 3.2.5.1.A \\
\hline 3.2.5.1.1 & CRD & 3.2.5.1.B \\
\hline 3.2 .5 .1 .2 & CRD, (10CFR20), (MIL-STD-882B) & 3.2.5.1.D \\
\hline 3.2.5.1.3 & 10CFR60.131(b)(3) & 3.2.1.3, 3.2.6.2.A \\
\hline 3.2.5.1.4.A & 10CFR $60.131(b)(5)(i)$ & 3.3.1.B \\
\hline
\end{tabular}


Title: Mined Geologic Disposal System Requirements Document

Revision: 1

Page: 153

Table 6-1. Requirements Cross-Reference Table (Continued)

\begin{tabular}{|c|c|c|}
\hline $\begin{array}{c}\text { MGDS-RD } \\
\text { PARAGRAPH }\end{array}$ & SOURCE & CRD PARAGRAPH \\
\hline 3.2.5.1.4.B & 10CFR $60.131(\mathrm{~b})(5)(\mathrm{ii})$ & 3.3.1.B \\
\hline 3.2 .5 .1 .5 & CRD & 3.2.5.1.E \\
\hline 3.2 .5 .2 .1 & 10CFR60.131(b)(6) & $3.2 .5 .2 . \mathrm{A}$ \\
\hline $3.2 .5 .2 .2 . \mathrm{A}$ & DOE $6430.1 \mathrm{~A}, 0110-99.0 .4$ & 3.3.1.A \\
\hline $3.2 .5 .2 .2 . \mathrm{B}$ & DOE $6430.1 \mathrm{~A}, 1300-3.5$ & 3.3.1.A \\
\hline 3.2.5.2.3 & Derived & None \\
\hline $3.2 .5 .2 .4 . \mathrm{A}$ & Derived & None \\
\hline 3.2.5.2.4.B & Derived & None \\
\hline 3.2.5.2.4.C & Derived & None \\
\hline 3.2 .5 .2 .5 & Derived & None \\
\hline 3.2.5.2.6 & $10 \mathrm{CFR} 60.131(\mathrm{a})(2)$ & 3.2.5.2.E \\
\hline 3.2.5.2.7 & Derived & None \\
\hline 3.2.5.2.8.A & DOE 4700.1, p.V-17, q & $\begin{array}{l}\text { Appendix A- DOE } \\
4700.1\end{array}$ \\
\hline 3.2.5.2.8. B & UCRL 15673, Section 1 & 3.2.5.2.B, D \\
\hline 3.2.5.2.8.C & UCRL 15673, Section 2 & 3.2.5.2. B, D \\
\hline 3.2.5.2.8.D & UCRL 15673, Section 3 & 3.2.5.2.B, D \\
\hline 3.2.5.2.8.E & 10CFR60.131(a)(2) & 3.2.5.2.E \\
\hline 3.2.5.2.9 & Derived & None \\
\hline 3.2.5.3.A & CRD & 3.2.5.3.A \\
\hline 3.2.5.3.B & Reserved & None \\
\hline 3.2.5.4.A & Derived, (10CFR60.3) & 3.2.5.4 \\
\hline 3.2.5.4.B & CRD & 3.2 .5 .4 \\
\hline 3.2.5.5.A & CRD & 3.2.5.5.A \\
\hline 3.2.5.5.B & Reserved & None \\
\hline 3.2.6.1 & 10 CFR60.131(b)(1)(2) & 3.2.6.1 \\
\hline 3.2.6.1.A & CRD & 3.2.6.1.A \\
\hline 3.2.6.1.B & CRD & 3.2.6.1.B \\
\hline 3.2.6.1.C & Derived & 3.2.6.1.C \\
\hline 3.2.6.1 D & Derived, (UCRL 15910) & $\begin{array}{l}\text { Appendix A- UCRL } \\
15910\end{array}$ \\
\hline 3.2.6.1.E.1 & Derived, (NRC Regulatory Guide 1.76) & $\begin{array}{l}\text { Appendix A- Reg Guide } \\
1.76\end{array}$ \\
\hline
\end{tabular}


Title: Mined Geologic Disposal System Requirements Document

Table 6-1. Requirements Cross-Reference Table (Continued)

\begin{tabular}{|c|c|c|}
\hline $\begin{array}{l}\text { MGDS-RD } \\
\text { PARAGRAPH }\end{array}$ & SOURCE & CRD PARAGRAPH \\
\hline 3.2.6.1.E.2 & $\begin{array}{l}\text { DOE 6430.1A, 0111-99.0.2, (UCRL 15910), (UCRL } \\
53526)\end{array}$ & 3.3.1.A \\
\hline 3.2.6.1.E.3.a & DOE $6430.1 \mathrm{~A}, 0111.99 .0 .2$ & 3.3.1.A \\
\hline 3.2.6.1.E.3.b & DOE 6430.1A, 0111-99.0.2, (UCRL 15910) & 3.3.1.A \\
\hline 3.2.6.1.E.3.c & DOE 6430.1A, 0111-99.0.2, (UCRL 53526) & 3.3.1.A \\
\hline 3.2.6.1.E.4 & DOE 6430.1A, 0111-99.0.2 & 3.3.1.A \\
\hline 3.2.6.1.F & DOE 6430.1A, 0111-99.0.3, (UCRL 15910) & 3.3.1.A \\
\hline 3.2.6.1.G.1 & Exec Order $11988,2(b)$ & $\begin{array}{l}\text { Appendix A- Exec Order } \\
11988\end{array}$ \\
\hline 3.2.6.1.G.2 & Exec Order $11988,2(b)$ & $\begin{array}{l}\text { Appendix A- Exec Order } \\
11988\end{array}$ \\
\hline 3.2.6.1.H.1 & DOE $6430.1 \mathrm{~A}, 0111-2.8 .2$ & 3.3.1.A \\
\hline 3.2.6.1.H.2 & DOE 6430.1A, 0111-2.8.2 & 3.3.1.A \\
\hline 3.2.6.1.I & DOE 6430.1A, 0111-2.8.4 & 3.3.1.A \\
\hline 3.2.6.1. J & DOE 6430.1A, 0111-2.3.2, (ANSVASCE 7-88) & 3.3.1.A \\
\hline 3.2.6.2.1.A & 10CFR $60.131(\mathrm{~b})(3)(\mathrm{i})$ & 3.2.6.2.A, 3.3.6.3.C \\
\hline 3.2.6.2.1.B & 10CFR60.131(b)(3)(iv) & None \\
\hline 3.2.6.2.1.C & 10 CFR60.131(b)(2) & 3.2.6.2. B \\
\hline 3.2.6.2.2.A & DOE $6430.1 \mathrm{~A}, 0110-99.0 .6$ & 3.3.1.A \\
\hline 3.2.6.2.2. B & DOE $6430.1 \mathrm{~A}, 0110-99.0 .6$ & 3.3.1.A \\
\hline 3.2.6.2.2.C & DOE $6430.1 \mathrm{~A}, 0110-99.0 .6$ & 3.3.1.A \\
\hline 3.2.6.2.2.D & 10CFR60.131(b)(3)(ii) & 3.2.6.2.A \\
\hline 3.2.6.2.3 & DOE $6430.1 \mathrm{~A}, 0111-2.8 .1$ & 3.3.1.A \\
\hline 3.2.6.2.4 & DOE 6430.1A, 0111-2.8.5 & 3.3.1.A \\
\hline 3.2.6.2.5 & 30CFR57 Subpart B & Appendix A- 30CFR57 \\
\hline 3.2 .7 & CRD & 3.2 .7 \\
\hline 3.2 .8 & CRD & 3.2 .8 \\
\hline 3.2 .9 & CRD & 3.2 .9 \\
\hline 3.3.1.A & CRD, (DOE 6430.1A) & 3.3.1.A \\
\hline 3.3.1.B & CRD, (DOE 6430.1A) & 3.3.1.A \\
\hline 3.3.1.C & Derived. (DOE 6430.1A) & 3.3.1.A \\
\hline 3.3.1.D & DOE $6430.1 \mathrm{~A}, 0101-2$ & 3.3.1.A \\
\hline 3.3.1.E & 10 CFR 60.130 & $3.7 .4 .2 . \mathrm{K} .3$ \\
\hline 3.3.1.F & CRD & 3.3.1.B \\
\hline
\end{tabular}


Title: Mined Geologic Disposal System Requirements Document

Table 6-1. Requirements Cross-Reference Table (Continued)

\begin{tabular}{|c|c|c|}
\hline $\begin{array}{l}\text { MGDS.RD } \\
\text { PARAGRAPH }\end{array}$ & SOURCE & CRD PARAGRAPH \\
\hline 3.3.1.G & CRD & 3.3.1.C \\
\hline 3.3.2.A & DOE $6430.1 \mathrm{~A}, 0200-99.8 .1$ & 3.3.2.A \\
\hline 3.3.2. B & DOE 6430.1A, 1655-99.8 & 3.3.2.B \\
\hline 3.3.2. C & DOE $6430.1 \mathrm{~A}, 0110-99.8 .3$ & 3.3.2.C \\
\hline 3.3.2.D & Derived & None \\
\hline 3.3.3.A & DOE $6430.1 \mathrm{~A}, 1300 \cdot 12.4 .11$ & 3.3.1.A \\
\hline 3.3.3.B & DOE $6430.1 \mathrm{~A}, 1300-12.4 .11$ & 3.3.1.A \\
\hline 3.3.3.C & DOE $6430.1 \mathrm{~A}, 1300-12.4 .11$ & 3.3.1.A \\
\hline 3.3.3.D & DOE $6430.1 \mathrm{~A}, 1300-12.4 .11$ & 3.3.1.A \\
\hline 3.3.3.E & DOE $6430.1 \mathrm{~A}, 1300-12.4 .11$ & 3.3.1.A \\
\hline 3.3.3. F & CRD & 3.3 .3 \\
\hline 3.3.4.A & QARD & 3.3.4.A \\
\hline 3.3.4.B & DOE $6430.1 A, 0109$ & 3.3.4.8 \\
\hline 3.3 .5 & CRD & 3.3 .5 \\
\hline $3.3 .6 .1 . \mathrm{A}$ & 29USC651 et seq. (654 (a), (b)) & 3.3.6.1.A \\
\hline 3.3.6.1.B & CRD, (30CFR57), (29CFR 1910), (29CFR1926) & 3.3.6.1.B \\
\hline $3.3 .6 .2 . \mathrm{A}$ & CRD & 3.3.6.2.A \\
\hline 3.3.6.2.B & CRD & 3.3.6.2.B \\
\hline 3.3.6.2.C & CRD & 3.3.6.2. C \\
\hline 3.3.6.2D & CRD & 3.3.6.2.D \\
\hline 3.3.6.2.E.1 & CRD, (30CFR57) & 3.3.6.2.E, 3.8.C \\
\hline 3.3.6.2.E.2 & CRD, (29CFR 1910), (29CFR 1926), (30CFR57) & 3.3.6.2.E, 3.8.C \\
\hline 3.3.6.3.A & 29 CFR $1910, D, E, G, J$ & 3.3.6.3.A \\
\hline 3.3.6.3.B & DOE 6430.1A & 3.3.6.3.B \\
\hline 3.3.6.3.C & 29CFR 1910.94 & 3.3.6.3.E \\
\hline 3.3.6.3.D & $29 \mathrm{CFR} 1910, \mathrm{H}$ & $3.3 .6 .3 . \mathrm{F}$ \\
\hline 3.3.6.3.E & 29CFR1910, H, O, (MIL-STD-1472D) & 3.3.6.3.G \\
\hline $3.3 .6 .3 . \mathrm{F}$ & 10 CFR $60.131(b)(8)$ & 3.3.6.3.D \\
\hline 3.3.6.3.G & 30CFR57, Subpart D & None \\
\hline 3.3.6.4.A & $\begin{array}{l}\text { 29CFR 1910, I, 29CFR 1926, E, 30CFR57, N, DOE } \\
6430.1 \mathrm{~A}, 1300-12.4 .5 \text {, NUREG-0700 Section 6.1.4 } \\
\end{array}$ & 3.3.6.4.A \\
\hline 3.3.6.4.B & 29CFR 1910.95(a), (b) & 3.3.6.4.B \\
\hline 3.3.6.4.C & 30CFR57.5005(a) & 3.3 .6 .5 \\
\hline
\end{tabular}


Title: Mined Geologic Disposal System Requirements Document

Table 6-1. Requirements Cross-Reference Table (Continued)

\begin{tabular}{|c|c|c|}
\hline $\begin{array}{l}\text { MGDS.RD } \\
\text { PARAGRAPH }\end{array}$ & SOURCE & CRD PARAGRAPH \\
\hline 3.3.6.4.D & 10CFR20.1703(a) & 3.2.4.4.A \\
\hline 3.3.6.4.E & 29CFR1910.132(a) & 3.3.6.4.C \\
\hline 3.3 .6 .5 & CRD, (29CFR 1910), (29CFR 1926), (30CFR57) & 3.3.6.5 \\
\hline 3.3.6.6.A & 29CFR1910, J, MIL-STD-1472D) & 3.3.6.6.A \\
\hline 3.3.6.6.B & CRD & 3.3.6.6. B \\
\hline 3.3.6.6.C & 29CFR1910, E, (MR-STD-1472D) & 3.3.6.6.C \\
\hline 3.3.6.7.A & CRD & 3.3.6.7.A \\
\hline 3.3.6.7.B & CRD & 3.3.6.7.B \\
\hline 3.3.6.7.C & Derived, NUREG-0700) & 3.3.6.7. C \\
\hline 3.3.6.8.A & 29CFR1910, 30CFR57, (MIL-STD-1472D) & 3.3.6.8.A \\
\hline 3.3.6.8.B & 29 CFR $1910.147(c)=(0,30$ CFR 57.12016 & 3.3.6.8.B \\
\hline 3.3.6.8.C & 29CFR 1910, O, 30CFR57, M & 3.3.6.8.C \\
\hline 3.3.6.8.D & 29CFR 1910, P & 3.3.6.8.D \\
\hline 3.3.6.8.E & 29 CFR $1910, Q$ & 3.3.6.8.E \\
\hline 3.3.6.8.F & 29CFR1910.151(c) & $3.3 .6 .8 . \mathrm{F}$ \\
\hline 3.3.6.9.A & 10CFR20.1902(a) & 3.2.2.1. B \\
\hline 3.3.6.9.B & 10CFR20.1902(b) & 3.2.2.1.B \\
\hline 3.3.6.9. C & 10CFR20.1902(c) & 3.2.2.1. B \\
\hline 3.3.6.9.D & 10CFR20.1902(d) & 3.2.2.1.B \\
\hline $3.3 .6 .9 . \mathrm{E}$ & 10CFR20.1902(e), (10CFR20.1001-20.2401) & $3.2 .2 .1 . \mathrm{B}$ \\
\hline 3.3.6.10.A & 29CFR 1910, F & 3.3.6.9.A \\
\hline 3.3.6.10.B & 29CFR1910, D, F, MIL-STD-1472D) & 3.3.6.9.B \\
\hline 3.3.6.11.A & 29CFR $1910, S$ & 3.3.6.10.A \\
\hline 3.3.6.11.B & 10CFR60.131(b)(5)(iii) & 3.3.6.10.C \\
\hline 3.3.6.11.C & 30CFR57, K, ANSI C2, ANSLNFPA 70 & 3.3.6.10.D \\
\hline 3.3.7.1 & CRD, NUREG-0700) & 3.3.7.1 \\
\hline 3.3.7.2 & CRD, (NUREG-0700), (MIL-STD-1472D) & 3.3.7.2 \\
\hline 3.3 .7 .3 & CRD, (NUREG-0700) & 3.3.7.3 \\
\hline 3.3.7.4 & CRD, (NUREG-0700) & 3.3.7.4 \\
\hline 3.3.7.5 & CRD, (NUREG-0700) & 3.3.7.5 \\
\hline 3.3.7.6 & CRD, (NUREG-0700) & 3.3.7.6 \\
\hline 3.3.7.7 & CRD, (NUREG-0700) & 3.3.7.7 \\
\hline 3.3.7.8 & CRD, (NUREG-0700) & 3.3.7.8 \\
\hline
\end{tabular}


Title: Mined Geologic Disposal System Requirements Document

Table 6-1. Requirements Cross-Reference Table (Continued)

\begin{tabular}{|c|c|c|}
\hline $\begin{array}{l}\text { MGDS.RD } \\
\text { PNRAGRAPH }\end{array}$ & SOURCE & CRD PARAGRAPH \\
\hline 3.3 .7 .9 & CRD, (ANSI/AFS Std. No. 100-1988) & 3.3.7.9 \\
\hline 3.3.7.10 & CRD, (MM-STD-1472D), (DOD-HDBK-743A) & 3.3 .7 .10 \\
\hline 3.3.7.11 & CRD, (Mm-STD-1472D) & 3.3.7.11 \\
\hline 3.3 .7 .12 & CRD, (MIL-STD-1472D) & 3.3.7.12 \\
\hline 3.3.7.13.A & $\begin{array}{l}\text { 41CFR 101-19.603, (GSA Uniform Accessibility } \\
\text { Standards) }\end{array}$ & 3.3.7.13 \\
\hline 3.3.7.13.B & CRD, (DOE 6430.1A Section 1300-13) & 3.3.7.13 \\
\hline 3.3.7.14 & CRD, (MTR 10090) & 3.3.7.14 \\
\hline 3.3.8.1.A & OARD & 3.3.8.1.A \\
\hline 3.3.8.1.B & CRD & 3.3.8.1.B \\
\hline 3.3.8.1.C & CRD & 3.3.8.1.C \\
\hline 3.3.8.1D & CRD & 3.3.8.1.D \\
\hline 3.3.8.2. A & CRD & 3.3.8.2.A \\
\hline 3.3.8.2.B & CRD & 3.3.8.2. B \\
\hline 3.3.8.2. C & 10CFR75.1 & 3.3.8.2. C \\
\hline 3.3.9.A & Reserved & None \\
\hline 3.3.9. B & Reserved & None \\
\hline 3.3.9.c & CRD & 3.3.9. C \\
\hline 3.3.10.A & CRD & 3.3.10.A \\
\hline $3.3 .10 . \mathrm{B}$ & CRD & 3.3.10.B \\
\hline 3.3.11.A & CRD & 3.3.11.A \\
\hline 3.3.11.B & 10CFR960.3-4 & 3.7.4.2.K.2 \\
\hline 3.3.11.1 & Reserved & None \\
\hline 3.3.11.2. A & 40CFR $50,60,61,(42$ USC7401) & 3.3.11.B \\
\hline 3.3.11.2. B & 42USC7401 & 3.3.11.B \\
\hline 3.3.11.3.A & 33USC1251, 40CFR122.41 & 3.3.11.C, 3.5.3.B \\
\hline 3.3.11.3.A.1 & 33USC1251 et seq. Section 1252(b)(1) & 3.3.11.C, 3.5.3.B \\
\hline 3.3.11.3.A.2 & 33USC1251 et seq. Section 1345 & 3.3.11.C, 3.5.3.B \\
\hline 3.3.11.3.A.3 & 33USC1251 et seq. Section 1311(a) & 3.3.11.C, 3.5.3.B \\
\hline 3.3.11.3.A.4 & 33USC1251 et seq. Section 1318(a)(1)(A) & 3.3.11.C, 3.5.3.B \\
\hline 3.3.11.3.A.5 & 33USC1251 et seq. Section 1311 & 3.3.11.C, 3.5.3.B \\
\hline 3.3.11.3.B & 33CFR323, (33USC1251 et seq.) & 3.3.11.C \\
\hline 3.3.11.4.A & 42 USC 300 f et seg. & 3.3.11.D \\
\hline
\end{tabular}


Title: Mined Geologic Disposal System Requirements Document

Revision: 1

Page: 158

Table 6-1. Requirements Cross-Reference Table (Continued)

\begin{tabular}{|c|c|c|}
\hline $\begin{array}{l}\text { MGDS-RD } \\
\text { PARIFP }\end{array}$ & SOURCE & CRD PARAGRAPH \\
\hline 3.3.11.4.B & $\begin{array}{l}\text { 42USC300f et seq. 300j, (42USC300f et seq.), } \\
(40 \mathrm{CFR} 144.31)\end{array}$ & 3.3.11.D \\
\hline 3.3 .11 .5 & 15USC2601 et seg. 29CFR1910 Subpart Z & 3.3.11.E \\
\hline 3.3 .11 .6 & TUSC136, 40CFR165 & 3.3.11.F \\
\hline 3.3 .11 .7 & 40CFR261, 262, 270, (42USC6901 et seg.) & 3.3.11.0 \\
\hline 3.3.11.8 & 40CFR204, 40CFR205, 42USC4901 et seq. & $\begin{array}{l}\text { Appendix A. 40CFR204, } \\
203,42 \text { USC } 4901\end{array}$ \\
\hline 3.3 .11 .9 & 50CFR17 & Appendix A- 50CFR 17 \\
\hline 3.4.1.A & Reserved & None \\
\hline $3.4 .1 . \mathrm{B}$ & CRD & 3.4.1.B \\
\hline $3.4 .1 . \mathrm{C}$ & OARD & 3.4.1.A \\
\hline 3.4 .2 & OARD & 3.4.2.A \\
\hline 3.4 .3 & QARD & 3.4 .3 \\
\hline $\mathbf{3 . 4 . 4}$ & CRD & 3.4 .4 \\
\hline 3.4 .5 & OARD & 3.4 .5 \\
\hline 3.4.6.A & CRD & 3.4.6.A \\
\hline $3.4 .6 . \mathrm{B}$ & 10 CFR60.72(a)(b), (10CFR60.72(b)) & 3.4.6.B \\
\hline 3.4 .7 & QARD & 3.4 .7 \\
\hline 3.4 .8 & 10CFR60.71(a), (b) & 3.4 .8 \\
\hline 3.5 .1 & 10CFR60.131(b)(6) & 3.5 .1 \\
\hline 3.5.1.1.1.A & Derived & None \\
\hline 3.5.1.1.1.B & CRD & 3.5.1.1.A \\
\hline 3.5.1.1.1.C & CRD & 3.5.1.1.B \\
\hline 3.5.1.1.1.D & DOE 4330.4A, I, 3.5 & 3.5.1.1.C \\
\hline 3.5.1.1.1. E & 30CFR57 Subpan M & Appendix A- 30CFR57 \\
\hline 3.5.1.1.2.A & Derived & None \\
\hline $3.5 .1 .1 .2 . \mathrm{B}$ & Derived & None \\
\hline 3.5.1.1.3 & Derived & None \\
\hline 3.5.1.2.A & 10 CFR60.131(a)(6) & 3.2.2.1.E, 3.5.1.2 \\
\hline 3.5.1.2.B & $10 \mathrm{CFR} 20.1501(\mathrm{~b})$ & 3.2.2.1.E, 3.5.1.2 \\
\hline 3.5 .1 .3 & 10CFR961.11, IV, B, (2)(c) & 3.5.1.4 \\
\hline 3.5.1.4.A & Derived & 3.3.8.1.D \\
\hline 3.5.1.4.B & Derived & 3.3.8.1.D \\
\hline 3.5.1.5 & Derived & 3.2.4.3.1.B, $3.2 .4 .3 .1 . \mathrm{D}$ \\
\hline
\end{tabular}


Title: Mined Geologic Disposal System Requirements Document

Table 6-1. Requirements Cross-Reference Table (Continued)

\begin{tabular}{|c|c|c|}
\hline $\begin{array}{c}\text { MGDS-RD } \\
\text { PNP ARP }\end{array}$ & SOURCE & CRD PARAGRAPH \\
\hline 3.5 .2 & CRD, (MR-STD- 1388 Series) & 3.5 .2 \\
\hline 3.5 .3 .1 & CRD & 3.5.3.C \\
\hline 3.5.3.2. A & Derived & None \\
\hline 3.5.3.2.B & Derived & None \\
\hline 3.5.3.3. & Derived & None \\
\hline 3.5.3.4 & $10 \mathrm{CFR} 2.1101(\mathrm{~b})(1)$ & 3.7.4.2.0 \\
\hline 3.5.3.5 & CRD & $3.5 .3 . \mathrm{E}$ \\
\hline 3.5.4 & CRD & 3.5.4 \\
\hline 3.6 .1 & CRD & 3.6.1 \\
\hline 3.6.1.A & 10 CFR 60.160 & 3.6.1.A \\
\hline $3.6 .1 \mathrm{~B}$ & Reserved & None \\
\hline 3.6.1.C & 10CFR60.162 & 3.6.1.C \\
\hline 3.6 .2 & CRD & 3.6 .2 \\
\hline 3.6.2.1.A & DOE $4330.4 A, l, 3.1 .4$ & 3.5.3.D, 3.6.2.1.C \\
\hline 3.6.2.1.B & CRD & 3.6.2.1.A, 3.6.2.1.D \\
\hline 3.6.2.1.C & 10CFR60.161 & 3.6.2.1.E \\
\hline 3.6.2.2. A & CRD & 3.6.2.2 \\
\hline 3.6.2.2.B & CRD & None \\
\hline 3.7.1.1.A & Derived, (10CFR60.15) & 3.7.4.2.K.1-7 \\
\hline 3.7.1.1.B & Derived & 3.7.4.2.K.1.7 \\
\hline 3.7.1.1.C & CRD & 3.7.4.1.1.B \\
\hline 3.7.1.2 & None & None \\
\hline $3.7 .1 .3 . \mathrm{A}$ & NWPA, 113(c)(1) & 3.7.4.2.K.1 \\
\hline $3.7 .1 .3 . \mathrm{B}$ & Derived & None \\
\hline 3.7.1.3.B.1 & DOE Louer 2/27/90 & None \\
\hline 3.7.1.3.B.2 & DOE Louter 2/27/90 & 3.7.4.2.A \\
\hline 3.7.1.3.B.3 & Derived & 3.7.4.2.A \\
\hline 3.7.1.3.C & CRD & 3.7.4.2.K.7 \\
\hline 3.7 .2 & 10 CFR 60.130 & 3.7.4.2.B \\
\hline 3.7.2.1.A & CRD & 3.7.4.1.1 \\
\hline 3.7.2.1.B & Derived & None \\
\hline 3.7.2.1.C & None & None \\
\hline 3.7.2.2. A & 10CFR60.112 & 3.7.4.2.F \\
\hline
\end{tabular}


Title: Mined Geologic Disposal System Requirements Document

Table 6-1. Requirements Cross-Reference Table (Continued)

\begin{tabular}{|c|c|c|}
\hline $\begin{array}{l}\text { MGDS.RD } \\
\text { PARAGR }\end{array}$ & SOURCE & CRD PARAGRAPH \\
\hline $3.7 .2 .2 . \mathrm{B}$ & 10 CFR60.113(a)(2) & 3.7.4.2.A \\
\hline 3.7.2.2. C & 40CFR191.16(a), (b) <TBR & Appendix A. 40CFR191 \\
\hline $3.7 .2 .2 . \mathrm{D}$ & 10 CFR60.122(a), (b), (c) & 3.7.4.2.A \\
\hline $3.7 .2 .2 . \mathrm{E}$ & 10CFR60.121 & 3.3.1.A \\
\hline 3.7.2.3.A & DOE $6430.1 \mathrm{~A}, 0202$ & 3.3.1.A \\
\hline $3.7 .2 .3 . \mathrm{B} .1$ & DOE 6430.1A, 0150-1 & 3.3.1.A \\
\hline $3.7 .2 .3 . \mathrm{B} .2$ & DOE $6430.1 \mathrm{~A}, 0220$ & 3.3.1.A \\
\hline $3.7 .2 .3 . \mathrm{B} .3$ & DOE $6430.1 \mathrm{~A}, 0250-4$ & 3.3.1.A \\
\hline 3.7.2.3.C.1 & BLM, 9113 & $\begin{array}{l}\text { Appendix A- BLM } \\
\text { Monual }\end{array}$ \\
\hline $3.7 .2 .3 . \mathrm{C} .2$ & DOE $6430.1 \mathrm{~A}, 0250-3,0250-5$ & 3.3.1.A \\
\hline $3.7 .2 .3 . \mathrm{D} .1$ & DOE 6430.1A, 0150-5 & 3.3.1.A \\
\hline $3.7 .2 .3 . \mathrm{D} .2$ & DOE 6430.1A, 0280-1 & 3.3.1.A \\
\hline 3.7.2.3. E & 10CFR960.3-4 & $3.7 .4 .2 . \mathrm{K} .2$ \\
\hline 3.7.2.3.F & DOE 6430.1A, 0270-2 & 3.3.1.A \\
\hline 3.7 .2 .4 & 10 CFR $60.131(\mathrm{~b})(5)(\mathrm{i})$ & 3.2 .1 .3 \\
\hline 3.7.2.4.1.A & 10CFR60.131(b)(5)(ii) & 3.3.6.10.C \\
\hline $3.7 .2 .4 .1 . \mathrm{B}$ & DOE $6430.1 \mathrm{~A}$ & 3.3.6.10.B \\
\hline 3.7.2.4.1.C & DOE $6430.1 \mathrm{~A}$ & 3.3.1.A \\
\hline 3.7.2.4.1. D & DOE $6430.1 \mathrm{~A}$ & 3.3.1.A \\
\hline 3.7.2.4.2.A & 42USC300f et seq. $300 \mathrm{~g}-6$ & $\begin{array}{l}\text { Appendix A- } 42 \text { USC } 300 \text { f } \\
\text { of seq. }\end{array}$ \\
\hline 3.7.2.4.2.B & 40CFR141, 40CFR143, 42USC300f et seq. $300 \mathrm{~g}-3$ & $\begin{array}{l}\text { Appendix A- 40CFR141, } \\
40 \mathrm{CRR} 143,42 \mathrm{USC} 300 \mathrm{f} \\
\text { et sea. } 300 \%-3\end{array}$ \\
\hline 3.7.2.4.2.C & DOE 6430.1A & 3.3.1.A \\
\hline 3.7.2.4.3.A & DOE 6430.1A & 3.3.1.A \\
\hline 3.7.2.4.3.B & DOE $6430.1 A, 1630-99.8$ & 3.3.1.A \\
\hline 3.7.2.4.3.C & Derived & 3.2.4.3.1.B, 3.2.4.3.1.D \\
\hline 3.7.2.4.3.D & Derived & 3.2.4.3.1.B, 3.2.4.3.1.D \\
\hline 3.7.2.4.3. E & Reserved & None \\
\hline 3.7.2.4.3.F & Derived & 3.2.4.3.1.B, 3.2.4.3.1.D \\
\hline 3.7.2.4.3.G & Derived & 3.2.4.3.1.B, 3.2.4.3.1.D \\
\hline 3.7.2.4.3.H & Derived & None \\
\hline 3.7.2.4.4.A & DOE 6430.1A & 3.3.1.A \\
\hline
\end{tabular}


Title: Mined Géologic Disposal System Requirements Document

Table 6-1. Requirements Cross-Reference Table (Continued)

\begin{tabular}{|c|c|c|}
\hline $\begin{array}{c}\text { MGDS-RD } \\
\text { PARAGRAPH }\end{array}$ & SOURCE & CRD PARAGRAPH \\
\hline 3.7.2.4.4.B & DOE $6430.1 \mathrm{~A}, 0278$ & 3.3.1.A \\
\hline 3.7.2.4.5 & DOE $6430.1 \mathrm{~A}, 0281$ & 3.3.1.A \\
\hline 3.7.2.4.6.A & Reserved & None \\
\hline 3.7.2.4.6.B & $10 \mathrm{CFR} 60.131(\mathrm{~b})(8)$ & 3.3.6.3.D \\
\hline 3.7.2.4.6.C & DOE 6430.1A & 3.3.1.A \\
\hline 3.7.2.4.7.A & 33USC1251 et seg. Section 1345(a) & 3.5.3.B \\
\hline 3.7.2.4.7.B & DOE 6430.1A & 3.3.1.A \\
\hline 3.7.2.4.8.A & 10 CFR60.132(d) & 3.7.4.2.B \\
\hline 3.7.2.4.8.B & 33USC1251 et.seq. & 3.5.3.B \\
\hline 3.7.2.5.1.A.1 & 10CFR60.132(a) & 3.7.4.2.B \\
\hline 3.7.2.5.1.A.2 & DOE 6430.1A, 1460, (CMAA 70) & 3.3.1.A \\
\hline 3.7.2.5.1.B & RW-0316, pp 101 & Appendix A- RW-0316 \\
\hline 3.7.2.5.1.C & 10CFR60.132(b) & 3.7.4.2.B \\
\hline 3.7.2.5.1.D & CRD & 3.2.2.8 \\
\hline 3.7.2.5.2.A & 10CFR60.131(b)(3)(iii) & 3.2.1.3 \\
\hline 3.7.2.5.2.B & Derived, (GSA-IFS-W-A- 450/1-17) & 3.2.4.3.1.B, 3.2.4.3.1.D \\
\hline 3.7.2.5.2.C & Derived & 3.2.4.3.1.B, 3.2.4.3.1.D \\
\hline 3.7.2.5.2.D & DOE 6430.1A, 1300-6.5 & 3.3.1.A \\
\hline 3.7.2.5.2.E & Derived & 3.2.4.3.1.B, 3.2.4.3.1.D \\
\hline 3.7.2.5.2.F & Derived & 3.2.4.3.1. B, 3.2.4.3.1.D \\
\hline 3.7.2.5.3 & Reserved & None \\
\hline 3.7.2.5.4.A & 10CFR60.131(b)(3)(iii) & 3.2.1.3 \\
\hline 3.7.2.5.4.B & DOE $6430.1 \mathrm{~A}, 0110-6$ & 3.3.1.A \\
\hline 3.7.2.5.4.C & DOE 5480.7, DOE 6430.1A & $\begin{array}{l}\text { Appendix A- DOE } \\
5480.7\end{array}$ \\
\hline 3.7.2.5.4.D & DOE 5480.7 & $\begin{array}{l}\text { Appendix A- DOE } \\
5480.7\end{array}$ \\
\hline 3.7.2.5.5 & Reserved & None \\
\hline 3.7.2.5.6.A & DOE $6430.1 \mathrm{~A}, 1300-6.8$ & 3.3.1.A \\
\hline 3.7.2.5.6.B & DOE 3790.1A, 1.3.a.(5) & $\begin{array}{l}\text { Appendix A- DOE } \\
3790.1 \mathrm{~A}\end{array}$ \\
\hline 3.7.2.5.6.C & $\begin{array}{l}\text { CRD, (10CFR60.161), (29CFR1926.21), (29CFR1960 } \\
\text { Subpart H), (30CFR48), (30CFR57), (49CFR172 } \\
\text { Subpart H), (QARD), (DOE 3790.1A), (DOE } \\
\text { 4330.4A), (DOE 5000.3A) }\end{array}$ & 3.6.2.1.A, 3.6.2.1.F \\
\hline
\end{tabular}


Title: Mined Géologic Disposal System Requirements Document

Table 6-1. Requirements Cross-Reference Table (Continued)

\begin{tabular}{|c|c|c|}
\hline $\begin{array}{l}\text { MGDS-RD } \\
\text { PARAGRAPA }\end{array}$ & SOURCE & CRD PARAGRAPH \\
\hline 3.7.2.5.6.D & DOE 3790.1A, Chapter VIII & $\begin{array}{l}\text { Appendix A- DOE } \\
3790.1 \mathrm{~A}\end{array}$ \\
\hline 3.7.2.5.6.E.1 & 41CFR101-17.3 & Appendix A- 41CFR101 \\
\hline 3.7.2.5.6.E.2 & Reserved & None \\
\hline 3.7.2.5.6.E.3 & $10 \mathrm{CFR} 60.75(\mathrm{c})$ & 3.3.1.B \\
\hline 3.7.2.5.6.E.4 & Derived & None \\
\hline 3.7.2.5.6.F.1 & 29USC651 et seq. Section 657 & 3.5.3.E \\
\hline 3.7.2.5.6.F.2 & $\begin{array}{l}\text { DOE 3790.1A, page VII-8, (5)(b)(2)(g)(3), (DOE } \\
1324.2 \mathrm{~A})\end{array}$ & 3.5.3.E \\
\hline 3.7.2.5.6.F.3 & RW-0194 & 3.5.3.E \\
\hline 3.7.2.5.6.F.4 & QARD & 3.5.3. $\mathrm{A}$ \\
\hline 3.7.2.5.6.F.5 & CRD & 3.5.3.E \\
\hline 3.7.2.5.6.G & DOE 4330.4A & 3.5.3.E \\
\hline 3.7.2.5.6.H & Derived, (10CFR60) & 3.2.4.3.1.D \\
\hline 3.7.2.5.6.1.1 & DOE $3790.1 \mathrm{~A}, \mathrm{VII} .5(\mathrm{l})(\mathrm{m})$ & $\begin{array}{l}\text { Appendix A -DOE } \\
\text { 3790.1A }\end{array}$ \\
\hline 3.7.2.5.6.1.2 & 10CFR60.131(b)(4)(ii) & 3.2 .1 .3 \\
\hline 3.7.2.5.6.1.3 & DOE $6430.1 \mathrm{~A}, 0110-1.3$ & 3.3.1.A \\
\hline 3.7.2.5.6J.1 & $\begin{array}{l}\text { 27CFR55.201-211, 29CFR1910.109, DOE 5480.4, } \\
\text { DOE 6430.1A }\end{array}$ & $\begin{array}{l}\text { 3.3.1.A, Appendix A- } \\
\text { 27CFR55, 29CFR1910, } \\
\text { DOE 5480.4 }\end{array}$ \\
\hline $3.7 .2 .5 .6 \mathrm{~J} .2 . \mathrm{a}$ & 27CFR55.206 & Appendix A- 27CFR55 \\
\hline $3.7 .2 .5 .6 \mathrm{~J} .2 . \mathrm{b}$ & 27CFR55.206 & Appendix A- 27CFR55 \\
\hline 3.7.2.5.6.K & Derived & None \\
\hline 3.7.2.5.6.L.1 & 10CFR60.132(e) & 3.2.1.2.A \\
\hline 3.7.2.5.6.L.2 & DOE $6430.1 \mathrm{~A}, 1300-11.2$ & 3.2.1.2.E \\
\hline 3.7.2.6.A.1 & 10 CFR60.131(b)(10)(i) & 3.3.1.B \\
\hline 3.7.2.6.A.2 & 10CFR60.131(b)(10)(ii) & 3.3.1.B \\
\hline 3.7.2.6.A.3 & 10CFR60.131(b)(10)(iii) & 3.3.1.B \\
\hline 3.7.2.6.A.4 & 10CFR60.131(b)(10)(iv) & 3.3.1.B \\
\hline 3.7.2.6.B.1 & 10CFR60.133(g)(1) & 3.3.1.B \\
\hline 3.7.2.6.B.2 & 10 CFR60.133(g)(2) & 3.3.1.B \\
\hline 3.7.2.6.B.3 & 10CFR60.133(g)(3) & 3.3.1.B \\
\hline 3.7.2.6.C.1 & $\begin{array}{l}\text { 10CFR60.131(b)(9), } \\
\text { MOU DOEDOL }\end{array}$ & $\begin{array}{l}\text { 3.3.1.B, MOU } \\
\text { DOE/DOL }\end{array}$ \\
\hline
\end{tabular}


Title: Mined Geologic Disposal System Requirements Document

Table 6-1. Requirements Cross-Reference Table (Continued)

\begin{tabular}{|c|c|c|}
\hline $\begin{array}{l}\text { MGDS-RD } \\
\text { PARAGRAPH }\end{array}$ & SOURCE & CRD PARAGRAPH \\
\hline 3.7.2.6.C.2 & $\begin{array}{l}\text { 10CFR60.131(b)(9), } \\
\text { MOU DOE/DOL }\end{array}$ & $\begin{array}{l}\text { 3.3.1.B MOU } \\
\text { DÖE/DOL }\end{array}$ \\
\hline 3.7.2.6.C.3 & $\begin{array}{l}\text { 10CFR60.131(b)(9), } \\
\text { MOU DOE/DOL }\end{array}$ & 3.3.1.B MOU DOE/DOL \\
\hline 3.7.2.6.D & $10 \mathrm{CFR} 60.133(\mathrm{c})$ & 3.7.4.2. J \\
\hline 3.7.2.6.E.1 & 10CFR60.133(e)(1) & 3.7.4.2.J \\
\hline 3.7.2.6.E.2 & 10 CFR60.133(e)(2) & 3.3.1.B \\
\hline 3.7.2.6.F.1 & Derived, (30CFR57) & 3.3.6.5 \\
\hline 3.7.2.6.F.2 & 10 CFR60.133(a)(2) & 3.3.1.B \\
\hline 3.7.2.6.F.3 & 30CFR57, E & 3.3.6.5 \\
\hline 3.7.2.6.F.4 & 10CFR60.131(b)(3)(iii) & 3.3.6.3.C \\
\hline 3.7.2.6.F.5 & 10CFR60.131(b)(9), 30CFR Chapter I & 3.3.1.B, 30CFR Chapter I \\
\hline 3.7.2.6.F.6 & DOE $6430.1 \mathrm{~A}, 1300-6.5$ & 3.2.2.1.A \\
\hline 3.7.2.6.F.7 & DOE $6430.1 \mathrm{~A}, 0110-1.3$ & 3.3.1.A \\
\hline 3.7.2.6.G.1 & 30 CFR 57.5003 & Appendix A- 30CFR57 \\
\hline 3.7.2.6.G.2 & 10CFR60.133(f) & 3.3.1.B \\
\hline 3.7.2.6.H & 10CFR60.133(b) & 3.3.1.B \\
\hline 3.7.2.6.I & 10CFR60.133(d) & 3.3.1.B \\
\hline $3.7 .2 .6 \mathrm{~J} .1$ & 10CFR60.134(a) & 3.3.1.B \\
\hline 3.7.2.6. J.2 & 10CFR60.134(b)(1)(2) & 3.3.1.B \\
\hline 3.7.2.6. J.3 & 10 CFR60.112 & 3.7.4.2.F \\
\hline 3.7.2.6.K & Derived & None \\
\hline 3.7.2.6.L.1 & 10CFR60.131(b)(3)(iii) & 3.3.6.3.C \\
\hline 3.7.2.6.L.2 & DOE $6430.1 \mathrm{~A}, 0110-6$ & 3.3.1.A \\
\hline 3.7.2.6.L.3 & DOE 5480.7, DOE 6430.1A & $\begin{array}{l}\text { Appendix A- DOE } \\
5480.7, \text { DOE 6430.1A } \\
\end{array}$ \\
\hline 3.7.2.6.L.4 & DOE 5480.7 & \begin{tabular}{|l|l} 
Appendix A- DOE \\
5480.7 \\
\end{tabular} \\
\hline 3.7.2.6.M & DOE 3790.1A, I, (3)(a)(5) & $\begin{array}{l}\text { Appendix A- DOE } \\
\text { 3790.1A } \\
\end{array}$ \\
\hline 3.7.2.7.A.1 & 10CFR60.74(a) & None \\
\hline 3.7.2.7.A.2 & 10CFR60.74(b), 60.137 & 3.7.4.2.L \\
\hline 3.7.2.7.A.3 & 10CFR60.140(a) & 3.7.4.2.L \\
\hline 3.7.2.7.A.4 & 10 CFR60.140(c) & 3.7.4.2.L \\
\hline 3.7.2.7.A.5 & 10 CFR $60.140(\mathrm{~d})$ & 3.7.4.2.K.5, 3.7.4.2.L \\
\hline
\end{tabular}


Title: Mined Géologic Disposal System Requirements Document

Table 6-1. Requirements Cross-Reference Table (Continued)

\begin{tabular}{|c|c|c|}
\hline $\begin{array}{l}\text { MGDS-RD } \\
\text { PARAGRAPH }\end{array}$ & SOURCE & CRD PARAGRAPH \\
\hline 3.7.2.7.A.6 & 10CFR60.141(b) & $3.7 .4 .2 . \mathrm{L}$ \\
\hline 3.7.2.7.B & 10CFR60.142(a) & $3.7 .4 .2 . \mathrm{L}$ \\
\hline 3.7.2.7.C & 10CFR60.141(c) & 3.7.4.2.L \\
\hline 3.7.2.7.D & 10CFR60.141(e) & 3.7.4.2.L \\
\hline 3.7.2.7. E & $10 \mathrm{CFR} 60.143(\mathrm{c})$ & $3.7 .4 .2 . \mathrm{L}$ \\
\hline 3.7.2.7.F & 10CFR60.142(c) & 3.7.4.2.L \\
\hline 3.7.2.7.G & 10CFR60.142(d) & 3.7.4.2.L \\
\hline 3.7.2.8.A.1 & 10CFR60.131(a)(1) & $3.2 .2 .2 \mathrm{E}$ \\
\hline 3.7.2.8.A.2 & 10CFR60.131(a)(2) & 3.2.2.2. E \\
\hline 3.7.2.8.A.3 & 10CFR60.131(a)(3) & 3.2.2.2.E \\
\hline 3.7.2.8.A.4 & $10 \mathrm{CFR} 60.131(\mathrm{a})(4)$ & 3.2.2.2.E \\
\hline 3.7.2.8.A.5 & 10CFR60.131(a)(5) & 3.2.2.2. E \\
\hline 3.7.2.8.A.6 & 10CFR60.131(a)(6) & 3.2.2.1.E, 3.2.2.2.E \\
\hline 3.7.2.8. B & DOE 6430.1A & 3.3.1.A \\
\hline 3.7.2.8.C & NWPA 111(b)(1) & 3.7.4.2.1.1 \\
\hline $3.7 .2 .8 \mathrm{D}$ & DOE 6430.1A, 1300-6.6 & 3.3.1.A \\
\hline 3.7.2.8.E & 10CFR20.1204 & Appendix A- 10CFR20 \\
\hline 3.7.2.8.F & 10CFR60.132(c)(1) & 3.2.2.1.E \\
\hline $3.7 .2 .8 . \mathrm{G}$ & $10 \mathrm{CFR} 60.132(\mathrm{c})(2)$ & $3.2 .2 .1 . \mathrm{E}$ \\
\hline 3.7.3.1.A & CRD & 3.7.4.1.1 \\
\hline 3.7.3.1.B & Derived & None \\
\hline 3.7.3.1.C & None & None \\
\hline 3.7.3.2. A & 10CFR60.133(h) & 3.7.4.2.B \\
\hline 3.7.3.2.B & 10CFR60.112 & 3.7.4.2.F \\
\hline 3.7.3.2. C & 10CFR $60.113(\mathrm{a})(1)(\mathrm{ii})(\mathrm{A})$ & 3.3.1.B \\
\hline 3.7.3.2.D & $10 \mathrm{CFR} 60.113(\mathrm{a})(\mathrm{l})(\mathrm{ii})(\mathrm{B})$ & 3.3.1.B \\
\hline 3.7.3.2.E.1 & 10CFR60.134(a) & 3.3.1.B \\
\hline 3.7.3.2.E.2 & 10CFR60.134(b)(1)(2) & 3.3.1.B \\
\hline 3.7.3.2.E.3 & 10CFR 60.112 & 3.7.4.2.F \\
\hline 3.7.3.3.A & 10CFR60.135(a)(1) & None \\
\hline 3.7.3.3.B.1 & 10CFR60.135(a)(2) & 3.2.1.1.H \\
\hline 3.7.3.3.B.2 & 10 CFR60.135(a)(2) & $3.2 .1 .1 . \mathrm{H}$ \\
\hline 3.7.3.3.B.3 & 10CFR60.131(b)(7) & 3.2 .2 .5 \\
\hline
\end{tabular}


Title: Mined Geologic Disposal System Requirements Document

Table 6-1. Requirements Cross-Reference Table (Continued)

\begin{tabular}{|c|c|c|}
\hline $\begin{array}{l}\text { MGDS-RD } \\
\text { PARAGRAPH }\end{array}$ & SOURCE & CRD PARAGRAPH \\
\hline 3.7.3.3.B.4 & 10CFR60.135(a)(3), NWPA 122 & $\begin{array}{l}3.2 .1 .1 . \mathrm{H}, 3.2 .1 .1 . \mathrm{J}, \\
3.2 .5 .1 . \mathrm{C}\end{array}$ \\
\hline 3.7.3.3.C & 10CFR60.135(b)(1) & 3.2.1.1. H \\
\hline 3.7.3.3.D & 10CFR60.135(b)(2) & 3.2.1.1.H \\
\hline 3.7.3.3.E & $10 \mathrm{CFR} 60.135(\mathrm{~b})(3)$ & $3.2 .5 .1 . \mathrm{C}, 3.2 .1 .1 . \mathrm{H}$ \\
\hline 3.7.3.3.F & $10 \mathrm{CFR} 60.135(\mathrm{~b})(4)$ & None \\
\hline 3.7.3.3.G.1 & $10 \mathrm{CFR} 60.135(\mathrm{c})(1)$ & 3.3.1.B \\
\hline 3.7.3.3.G.2 & 10CFR60.135(c)(1) & 3.3.1.B \\
\hline 3.7.3.3.G.3 & $10 \mathrm{CFR} 60.135(\mathrm{c})(2)$ & 3.3.1.B \\
\hline 3.7.3.3.G.4 & 10 CFR60.135(c)(3) & 3.3.1.B \\
\hline 3.7.3.4.A & 10CFR60.133(a)(1) & 3.7.4.2.B \\
\hline 3.7.3.4.B & Reserved & None \\
\hline 3.7.3.4.C & 10CFR60.133(i) & 3.7.4.2.B \\
\hline 3.7.3.4.D & Derived & None \\
\hline 3.8.A & CRD & 3.8.A \\
\hline 3.8.B & MOA, RW/NS 4/16/92 & 3.8.B \\
\hline 3.8.C & CRD, (29CFR1910), (30CFR57) & 3.8.C \\
\hline 3.9 & 10CFR60 Subpart G, QARD & 3.9.A \\
\hline 5.1 & CRD, (DOE 4700.1) & 5.1 \\
\hline 5.2 & CRD & 5.2 \\
\hline
\end{tabular}

\subsection{SOURCE DOCUMENT CROSS-REFERENCE}

Table 6- 2 provides a cross-reference between the regulatory source document requirements and the secticas of the MGDS-RD in which they are addressed.

Table 6-2. Source Document Cross-Reference

\begin{tabular}{|l|l|}
\hline \multicolumn{1}{|c|}{ SOURCE } & \multicolumn{1}{|c|}{ MGDS-RD PARAGRAPH } \\
\hline 7USC136 & 3.3 .11 .6 \\
\hline 10 CFR2.1101(b)(1) & 3.5 .3 .4 \\
\hline 10 CFR20 & $3.2 .2 .1 . \mathrm{C}$ \\
\hline$(10$ CFR20) & $3.2 .1 .1 . \mathrm{H}, 3.2 .1 .3 . \mathrm{K}, 3.2 .1 .5 . \mathrm{C}, 3.2 .5 .1 .2,3.2 .2 .1 . \mathrm{D}$ \\
\hline$(10 \mathrm{CFR} 20.1001-20.2401)$ & $3.2 .2 .5 . \mathrm{B} \cdot 1,3.3 .6 .9 . \mathrm{E}$ \\
\hline 10 CFR20.1101(b) & $3.2 .2 .1 . \mathrm{B}$ \\
\hline
\end{tabular}


Title: Mined Gèologic Disposal System Requirements Document

Table 6-2. Source Document Cross-Reference (Continued)

\begin{tabular}{|c|c|}
\hline SOURCE & MGDS-RD PARAGRAPH \\
\hline$(10$ CFR20.1201(a)) & 3.2.2.5.A.1 \\
\hline 10CFR20.1204 & 3.7.2.8.E \\
\hline (10CFR20.1207) & 3.2.2.5.A.2 \\
\hline (10CFR20.1208) & 3.2.2.5.A.2 \\
\hline 10CFR20.1301 & A-3.4.2.B \\
\hline 10CFR20.1301(a) & 3.2.2.3.A \\
\hline $10 \mathrm{CFR} 20.1301(\mathrm{a})(2)$ & 3.2.2.3.C \\
\hline 10CFR20.1301(b) & 3.2.2.3.B \\
\hline$(10 \mathrm{CFR} 20.1301(\mathrm{c}))$ & 3.2.2.3.A \\
\hline 10CFR20.1302 & A-3.4.2.C \\
\hline 10CFR20.1501(b) & 3.5.1.2.B \\
\hline $10 \mathrm{CFR} 20.1502(\mathrm{a})(1)$ & 3.2.2.5.A.1 \\
\hline $10 C F R 20.1502(\mathrm{a})(2)$ & 3.2.2.5.A.2 \\
\hline $10 \mathrm{CFR} 20.1502(\mathrm{a})(3)$ & 3.2.2.5.A.3 \\
\hline $10 \mathrm{CFR} 20.1502(\mathrm{~b})(1)$ & 3.2.2.5.B.1 \\
\hline $10 \mathrm{CFR} 20.1502(\mathrm{~b})(2)$ & 3.2.2.5.B.2 \\
\hline $10 \mathrm{CFR} 20.1601$ & 3.2.4.3.2.A \\
\hline 10CFR $20.1601(\mathrm{a})(1)$ & 3.2.4.3.2.B.1.a \\
\hline $10 \mathrm{CFR} 20.1601(\mathrm{a})(2)$ & 3.2.4.3.2.B.1.b \\
\hline $10 \mathrm{CFR} 20.1601(\mathrm{a})(3)$ & 3.2.4.3.2.B.1.c \\
\hline $10 \mathrm{Cp}: 20.1601(\mathrm{~b})$ & 3.2.4.3.2.B.2 \\
\hline $10 . \mathrm{FR20.1601( \textrm {c } )}$ & 3.2.4.3.2.B.3 \\
\hline $10 \mathrm{C} R 20.1601(\mathrm{~d})$ & 3.2.4.3.2.B.4 \\
\hline $10 \mathrm{CFR} 20.1601(\mathrm{e})$ & 3.2.4.3.2.B.5 \\
\hline 10 CFR 20.1602 & 3.2.4.3.2.A \\
\hline 10CFR20.1701 & 3.2.2.4.A \\
\hline 10CFR 20.1702 & 3.2.2.4.B \\
\hline 10CFR20.1703(a) & 3.3.6.4.D \\
\hline 10 CFR20.1703(a)(3)(i) & 3.2.2.4.C \\
\hline $10 C F R 20.1802$ & 3.2.4.3.1.4 \\
\hline 10CFR20.1902(a) & 3.3.6.9.A \\
\hline 10CFR20.1902(b) & 3.3.6.9.B \\
\hline
\end{tabular}


Title: Mined Géologic Disposal System Requirements Document

Table 6-2. Source Document Cross-Reference (Continued)

\begin{tabular}{|c|c|}
\hline SOURCE & MGDS-RD PARAGRAPH \\
\hline 10 CFR20.1902(c) & 3.3.6.9.C \\
\hline 10 CFR20.1902(d) & 3.3.6.9.D \\
\hline 10CFR20.1902(e) & 3.3.6.9.E \\
\hline 10CFR20.1906 & 3.2 .4 .4 \\
\hline (10CFR20.2002) & 3.2.2.7.B \\
\hline 10CFR20.2003 & 3.2.2.7.A \\
\hline (10CFR20.2003) & 3.2.2.3.A \\
\hline 10CFR20.2004 & $3.2 .2 .7 . \mathrm{B}$ \\
\hline (10CFR20.2005) & 3.2.2.7.B \\
\hline 10CFR60 Subpart G & 3.9 \\
\hline (10CFR60) & $3.2 .1 .1 . \mathrm{H}, 3.7 .2 .5 .6 . \mathrm{H}$ \\
\hline (10CFR60.3) & 3.2.5.4.A \\
\hline (10CFR60.15) & 3.7.1.1.A \\
\hline 10 CFR $60.15(\mathrm{c})(1)$ & 3.2.1.1.B \\
\hline 10 CFR $60.15(c)(2)$ & 3.2.1.1.C \\
\hline $10 \mathrm{CFR} 60.15(\mathrm{c})(3)$ & 3.2.1.1.D \\
\hline 10 CFR60.15(c)(4) & 3.2.1.1.E \\
\hline 10CFR60.17(a)(3) & 3.2.1.1.F.2 \\
\hline 10 CFR60.21(c)(1)(ii)(D) & $3.2 .1 .1 \mathrm{~J}$ \\
\hline 10CFR60.21(c)(7) & A-3.4.3.E \\
\hline 10CFR60.51(a)(1) & $3.2 .1 .7 . \mathrm{A}$ \\
\hline $10 \mathrm{CFR} 60.51(\mathrm{a})(2)(\mathrm{i})$ & $3.2 .1 .7 . \mathrm{B}$ \\
\hline 10 CFR60.52(c)(2) & 3.2 .1 .6 \\
\hline 10CFR60.71(a), (b) & 3.4.8 \\
\hline 10CFR60.72(a)(b) & 3.4.6.B \\
\hline$(10$ CFR60.72(b)) & 3.4.6.B \\
\hline 10CFR60.74(a) & 3.7.2.7.A.1 \\
\hline 10CFR60.74(b) & 3.7.2.7.A.2 \\
\hline $10 \mathrm{CFR} 60.75(\mathrm{c})$ & 3.7.2.5.6.E.3 \\
\hline 10CFR60.111(a) & 3.2.1.2.D, 3.2.1.3.K, 3.2.1.4, 3.2.1.5.C, 3.2.2.1.D, A-3.4.2.A, A-3.4.3.A \\
\hline 10CFR60.111(b) & A-3.4.1.B \\
\hline 10CFR60.111(b)(1) & 3.2.1.5.B \\
\hline
\end{tabular}


Title: Mined Geologic Disposal System Requirements Document

Table 6-2. Source Document Cross-Reference (Continued)

\begin{tabular}{|c|c|}
\hline SOURCE & MGDS-RD PARAGRAPH \\
\hline$(10$ CFR60.111(b))(3)) & $3 \cdot 2 \cdot 1.5 . \mathrm{F}$ \\
\hline 10CFR60.112 & 3.7.2.2.A, 3.7.2.6.J.3, 3.7.3.2.B, 3.7.3.2.E.3, A-3.2.1.A, A-3.5.4.A \\
\hline 10CFR60.113(a) & A-3.2.1.B \\
\hline 10CFR60.113(a)(1)(ii)(A) & 3.7.3.2.C, A-3.5.1 \\
\hline 10CFR60.113(a)(1)(ii)(B) & 3.7.3.2. D, A-3.5.2 \\
\hline $10 \mathrm{CFR} 60.113(\mathrm{a})(2)$ & 3.7.2.2.B, A-3.5.3 \\
\hline 10CFR60.121 & $3.7 .2 .2 \mathrm{E}$ \\
\hline 10CFR60.122(a) & 3.7.2.2.D \\
\hline 10CFR60.122(b) & 3.7.2.2. D \\
\hline 10 CFR $60.122(\mathrm{~b})(1)$ & A-3.5.8.A \\
\hline 10 CFR60.122(b)(3) & A-3.5.8.B \\
\hline 10 CFR60.122(b)(4) & A-3.5.8.C \\
\hline 10CFR60.122(b)(5) & $\mathrm{A}-3.5 .8 \mathrm{D}$ \\
\hline 10 CFR $60.122(\mathrm{~b})(6)$ & A-3.5.8.E \\
\hline 10 CFR $60.122(\mathrm{~b})(7)$ & A-3.5.8.F \\
\hline 10CFR60.122(b)(8) & A-3.5.8.G \\
\hline 10 CFR60.122(c)(1) & A-3.5.8.H \\
\hline 10 CFR60.122(c)(2) & A-3.5.8.1 \\
\hline 10 CFR $60.122(\mathrm{c})(3)$ & $A-3.5 .8 \mathrm{~J}$ \\
\hline 10 CFR60.122(c) $(4)$ & $\mathrm{A}-3.5 .8 . \mathrm{K}$ \\
\hline 10CFR60.122(c)(5) & A-3.5.8. L \\
\hline 10CFR60.122(c)(6) & $\mathrm{A}-3.5 .8 \mathrm{M}$ \\
\hline 10 CFR $60.122(\mathrm{c})(7)$ & $\mathrm{A}-3.5 .8 \mathrm{~N}$ \\
\hline $10 \mathrm{CFR} 60.122(\mathrm{c})(8)$ & A-3.5.8.0 \\
\hline 10CFR60.122(c)(9) & A-3.5.8.P \\
\hline 10CFR60.122(c)(10) & $A-3.5 .8 .0$ \\
\hline 10CFR60.122(c)(11) & $A-3.5 .8 . R$ \\
\hline 10 CFR $60.122(\mathrm{c})(12)$ & A-3.5.8.S \\
\hline 10CFR60.122(c)(13) & $\mathrm{A}-3.5 .8 . \mathrm{T}$ \\
\hline 10 CFR $60.122(\mathrm{c})(14)$ & A-3.5.8.U \\
\hline 10CFR $60.122(\mathrm{c})(15)$ & A-3.5.8.V \\
\hline 10CFR60.122(c)(16) & A-3.5.8.W \\
\hline
\end{tabular}


Title: Mined Geologic Disposal System Requirements Document

Table 6-2. Source Document Cross-Reference (Continued)

\begin{tabular}{|c|c|}
\hline SOURCE & MGDS-RD PARAGRAPH \\
\hline 10CFR60.122(c)(17) & A-3.5.8.X \\
\hline 10CFR60.122(c)(18) & A-3.5.8.Y \\
\hline 10CFR $60.122(c)(19)$ & A-3.5.8.Z \\
\hline $10 \mathrm{CFR} 60.122(\mathrm{c})(20)$ & $\mathrm{A}-3.5 .8 . \mathrm{AA}$ \\
\hline 10CFR60.122(c)(21) & $\mathrm{A}-3.5 .8 . \mathrm{AA}$ \\
\hline 10 CFR $60.122(\mathrm{c})(22)$ & $\mathrm{A}-3.5 .8 . \mathrm{BB}$ \\
\hline $10 \mathrm{CFR} 60.122(\mathrm{c})(23)$ & $\mathrm{A}-3.5 .8 . \mathrm{CC}$ \\
\hline $10 \mathrm{CFR} 60.122(\mathrm{c})(24)$ & $\mathrm{A}-3.5 .8 . \mathrm{AA}$ \\
\hline 10CFR60.130 & 3.3.1.E, 3.7.2 \\
\hline 10CFR60.131(a) & $\mathrm{A}-3.1 .2 . \mathrm{A}, \mathrm{A}-3.4 .3 . \mathrm{B}$ \\
\hline 10CFR60.131(a)(1) & 3.7.2.8.A.1, A-3.4.3.F \\
\hline 10 CFR60.131(a)(2) & 3.2.5.2.6, 3.2.5.2.8.E, 3.7.2.8.A.2, A-3.4.3.F \\
\hline 10 CFR60.131(a)(3) & 3.7.2.8.A.3, A-3.4.3.F \\
\hline 10 CFR $60.131(\mathrm{a})(4)$ & 3.7.2.8.A.4, A-3.4.3.F \\
\hline 10CFR60.131(a)(5) & 3.7.2.8.A.5, A-3.4.3.F \\
\hline 10 CFR $60.131(\mathrm{a})(6)$ & 3.5.1.2.A, 3.7.2.8.A.6, A-3.4.3.F \\
\hline 10CFR60.131(b) & 3.2.3.2.3.N, 3.2.3.2.3.S \\
\hline 10 CFR $60.131(\mathrm{~b})(1)$ & 3.2.6.1, A-3.1.2.B \\
\hline 10 CFR60.131(b)(2) & 3.2.6.2.1.C \\
\hline 10CFR60.131(b)(3) & 3.2.5.1.3 \\
\hline 10 CFR $60.131(\mathrm{~b})(3)(\mathrm{i})$ & 3.2.1.8.C, 3.2.6.2.1.A, A-3.1.2.C \\
\hline 10CFR60.131(b)(3)(ii) & 3.2.6.2.2.D \\
\hline 10CFR60.131(b)(3)(iii) & 3.2.1.8.A, 3.7.2.5.2.A, 3.7.2.5.4.A, 3.7.2.6.F.4, 3.7.2.6.L.1, A-3.1.2.C \\
\hline 10CFR60.131(b)(3)(iv) & 3.2.6.2.1.B \\
\hline 10CFR60.131(b)(4)(i) & 3.2.1.8.B \\
\hline 10 CFR60.131(b)(4)(ii) & 3.7.2.5.6.1.2 \\
\hline 10CFR60.131(b)(5)(i) & 3.2.5.1.4.A, 3.7.2.4, A-3.1.2.D \\
\hline 10CFR60.131(b)(5)(ii) & 3.2.5.1.4.B \\
\hline 10CFR60.131(b)(5)(iii) & 3.3.6.11.B, 3.7.2.4.1.A \\
\hline 10CFR60.131(b)(6) & 3.2.5.2.1, 3.5.1 \\
\hline 10 CFR $60.131(\mathrm{~b})(7)$ & 3.2.2.6.A,3.2.3.2.3.M, 3.2.3.2.3.T, 3.7.3.3.B.3, A-3.1.2.E \\
\hline 10CFR60.131(b)(8) & 3.3.6.3.F, 3.7.2.4.6.B, A-3.1.2.F \\
\hline
\end{tabular}


Title: Mined Geologic Disposal System Requirements Document

Table 6-2. Source Document Cross-Reference (Continued)

\begin{tabular}{|c|c|}
\hline SOURCE & MGDS.RD PARAGRAPH \\
\hline 10CFR60.131(b)(9) & $3.7 .2 .6 . \mathrm{C} .1,3.7 .2 .6 . \mathrm{C} .2,3.7 .2 .6 . \mathrm{C} .3,3.7 .2 .6 . \mathrm{F} . \mathrm{S}, \mathrm{A}-3.1 .2 . \mathrm{G}, \mathrm{A}-3.1 .3 . \mathrm{A}$ \\
\hline 10 CFR60.131(b)(10)(i) & 3.7.2.6.A.1 \\
\hline 10 CFR60.131(b)(10)(ii) & 3.7.2.6.A.2 \\
\hline 10CFR60.131(b)(10)(iii) & 3.7.2.6.A.3 \\
\hline 10 CFR60.131(b)(10)(iv) & 3.7.2.6.A.4 \\
\hline 10CFR60.132(a) & 3.7.2.5.1.A.1, A-3.1.2.H \\
\hline 10CFR60.132(b) & 3.7.2.5.1.C, A-3.1.2.I, A-3.4.3.G \\
\hline 10 CFR60.132(c)(1) & 3.7.2.8.F, A-3.1.2.J, A-3.4.3.C \\
\hline 10 CFR60.132(c)(2) & 3.7.2.8.G \\
\hline 10CFR60.132(d) & 3.7.2.4.8.A \\
\hline $10 \mathrm{CFR} 60.132(0)$ & 3.7.2.5.5.L.1 \\
\hline 10 CFR60.133(a)(1) & 3.7.3.4.A, A-3.1.1.A \\
\hline 10 CFR60.133(a)(2) & 3.7.2.6.F.2 \\
\hline 10CFR60.133(b) & 3.7.2.6.H, A-3.1.1.B, A-3.1.4.A \\
\hline 10 CFR60.133(c) & 3.7.2.6.D, A-3.4.1.F \\
\hline 10CFR60.133(d) & 3.7.2.6.J, A-3.1.4.C \\
\hline 10 CFR $60.133(\mathrm{e})(1)$ & 3.7.2.6.E.1, A-3.1.3.B, A-3.1.4.D, A-3.4.1.G \\
\hline 10 CFR60.133(e)(2) & 3.7.2.6.E.2, A-3.1.1.C \\
\hline $10 \mathrm{CFR} 60.133(f)$ & 3.7.2.6.G.2, A-3.1.1.D, A-3.1.4.B \\
\hline 10 CFR60.133(g)(1) & 3.7.2.6.B.1, A-3.1.2.K, A-3.4.3.D \\
\hline 10CFR60.133(g)(2) & 3.7.2.6.B.2, A-3.1.2.K, A-3.1.3.C, A-3.1.4.E \\
\hline 10 CFR60.133(g)(3) & 3.7.2.6.B.3 \\
\hline $10 \mathrm{CFR} 60.133(\mathrm{~b})$ & 3.7.3.2.A, A-3.1.1.E \\
\hline 10 CFR60.133(i) & 3.7.3.4.C, A-3.1.1.F \\
\hline 10 CFR60.134(a) & 3.7.2.6J.1, 3.7.3.2.E.1, A-3.2.1.C \\
\hline 10CFR60.134(b) & A-3.2.1.D \\
\hline 10 CFR60.134(b)(1)(2) & 3.7.2.6 J.2, 3.7.3.2. E.2 \\
\hline 10 CFR60.135(a) & A-3.3.1 \\
\hline 10 CFR60.135(a)(1) & 3.7.3.3.A \\
\hline 10 CFR60.135(a)(2) & 3.2.3.2.3.J, 3.2.3.2.3.K, 3.7.3.3.B.1, 3.7.3.3.B.2 \\
\hline 10 CFR60.135(b)(1) & 3.7.3.3.C \\
\hline 10 CFR60.135(b)(2) & 3.7.3.3.D \\
\hline
\end{tabular}


Title: Mined Geologic Disposal System Requirements Document

Table 6-2. Source Document Cross-Reference (Continued)

\begin{tabular}{|c|c|}
\hline SOURCE & MGDS-RD PARAGRAPH \\
\hline 10 CFR $60.135(b)(3)$ & $3.2 .3 .2 .3 .0,3.2 .3 .2 .3 . R$ 3.2.3.2.3.T, 3.7.3.3.B.4, 3.7.3.3.E, A-3.4.1..H \\
\hline $10 \mathrm{CFR} 60.135(\mathrm{~b})(4)$ & 3.7.3.3.F \\
\hline $10 C F R 60.135(\mathrm{c})(1)$ & $3.7 .3 .3 .0 .1,3.7 .3 .3 .9 .2$ \\
\hline $10 C F R 60.135(c)(2)$ & 3.7.3.3.0.3 \\
\hline 10 CFR $60.135(\mathrm{c})(3)$ & 3.7.3.3.0.4 \\
\hline 10 CFR 60.137 & 3.7.2.7.A.2. A-3.5.7 \\
\hline 10CFR60.140(a) & 3.7.2.7.A.3 \\
\hline 10CFR60.140(c) & 3.7.2.7.A.4 \\
\hline 10CFR60.140(d) & 3.7.2.7.A.5 \\
\hline 10CFR60.141(b) & 3.7.2.7.A.6 \\
\hline 10 CFR $60.141(\mathrm{c})$ & 3.7.2.7. C \\
\hline 10CFR60.141(0) & 3.7.2.7.D \\
\hline 10CFR60.142 & A-3.2.1.E \\
\hline 10CFR60.142(a) & 3.2.1.2.A, 3.7.2.7.B \\
\hline 10CFR60.142(b) & 3.2.1.2.B \\
\hline 10 CFR $60.142(\mathrm{c})$ & 3.7.2.7.F \\
\hline 10CFR60.142(d) & 3.7.2.7.6 \\
\hline 10CFR60.143(c) & 3.7.2.7.E \\
\hline 10 CFR 60.160 & 3.6.1.A \\
\hline 10CFR60.161 & 3.6.2.1. C \\
\hline (10CFR60.161) & 3.7.2.5.6.C \\
\hline 10CFR 60.162 & 3.6.1.C \\
\hline (10CFR71) & 3.2.2.8 \\
\hline 10 CFR71.87(f) & 3.2.1.3.C \\
\hline 10 CFR75.1 & 3.3.8.2. C \\
\hline$(10 \mathrm{CFR} 960)$ & 3.2.1.1.H \\
\hline 10CFR $960.3-4$ & 3.2.1.1.F.1, 3.2.1.1.F.2, 3.3.11.B, 3.7.2.3.E \\
\hline 10 CER $960.4-1(\mathrm{a})$ & A-3.5.9.A \\
\hline 10CFR960.4-2-1(a) & A-3.5.9.B \\
\hline 10CFR960.4-2-1(b)(1) & A-3.5.8.F \\
\hline 10 CFR960.4-2-1(b)(2) & A-3.5.8.A.1 \\
\hline 10CFR960.4-2-1(b)(3) & A-3.5.10.A.1 \\
\hline
\end{tabular}


Title: Mined Geologic Disposal System Requirements Document

Table 6-2. Source Document Cross-Reference (Continued)

\begin{tabular}{|c|c|}
\hline SOURCE & MGDS-RD PARAGRAPH \\
\hline $10 \mathrm{CFR} 960.4-2-1(\mathrm{~b})(5)$ & A-3.5.8.0 \\
\hline $10 \mathrm{CFR} 960.42-1(\mathrm{c})(1)$ & A-3.5.8. L \\
\hline $10 C F R 960.4-2-1(c)(2)$ & A-3.5.10.A.2 \\
\hline $10 \mathrm{CFR} 960.42-1(\mathrm{c})(3)$ & $\mathrm{A}-3.5 .8 . \mathrm{CC}$ \\
\hline $10 C F R 960.42-1(d)$ & A-3.5.9.C \\
\hline 10 CFR960.4-2-2(a) & A-3.5.9.D \\
\hline $10 \mathrm{CFR} 960.4-2-2(\mathrm{~b})(1)$ & A-3.5.8.A.2 \\
\hline $10 \mathrm{CFR} 960.42-2(\mathrm{~b})(2)$ & $\mathrm{A}-3.5 .8 . \mathrm{B}$ \\
\hline $10 \mathrm{CFR} 960.4-2-2(\mathrm{~b})(3)$ & A-3.5.8.C \\
\hline $10 \mathrm{CFR} 960.4-2-2(\mathrm{~b})(4)$ & A-3.5.10.B.1 \\
\hline $10 \mathrm{CFR} 960.42-2(\mathrm{~b})(5)$ & A-3.5.10.B.2 \\
\hline 10CFR960.42-2(c)(1) & A-3.5.8. N \\
\hline $10 \mathrm{CFR} 960.4-2-2(c)(2)$ & $A-3.5 .8 .0$ \\
\hline $10 \mathrm{CFR} 960.4-2-2(\mathrm{c})(3)$ & A-3.5.8.P \\
\hline 10CFR960.42-3(a) & $\mathrm{A}-3.1 .1 . \mathrm{G}, \mathrm{A}-3.5 .9 \mathrm{E}$ \\
\hline $10 \mathrm{CFR} 960.4-2-3(\mathrm{~b})(1)$ & A-3.1.1.H \\
\hline $10 C F R 960.42-3(b)(2)$ & A-3.1.1.I \\
\hline 10CFR960.4-2-3(c)(1) & A-3.5.8.AA \\
\hline $10 \mathrm{CFR} 960.4-2-3(\mathrm{c})(2)$ & $\mathrm{A}-3.1 .1 \mathrm{~J}, \mathrm{~A}-3.1 .1 \mathrm{~K}$ \\
\hline 10CFR $960.4-2-3(\mathrm{c})(3)$ & A-3.1.1.L \\
\hline 10 CFR $960.4-2-4(\mathrm{a})$ & A-3.5.9.F \\
\hline $10 \mathrm{CFR} 960.4-2-4(\mathrm{~b})(1)$ & A-3.5.10.D.1 \\
\hline 10 CFR960.4-2-4(b)(2) & A-3.5.10.D.2 \\
\hline 10CFR $960.4-2-4(c)(1)$ & A-3.5.8.BB \\
\hline 10 CFR $960.4-2-4(\mathrm{c})(2)$ & A-3.5.8.M \\
\hline 10CFR $960.4-2-5(a)$ & A-3.1.1.M, A-3.5.9.G \\
\hline $10 C F R 960.42-5(b)(1)$ & A-3.1.1.N, A-3.5.8.D \\
\hline 10 CFR $960.42-5(b)(2)$ & A-3.1.1.0, A-3.5.8.A.3 \\
\hline $10 C F R 960.4-2-5(b)(3)$ & A-3.1.1.P \\
\hline $10 C F R 960.42-5(c)(1)$ & $\mathrm{A}-3.1 .1 .0, \mathrm{~A}-3.5 .8 . \mathrm{W}$ \\
\hline $10 \mathrm{CFR} 960.4-2-5(\mathrm{c})(2)$ & $A-3.1 .1 . R$ \\
\hline 10 CFR $960.4-2-5(\mathrm{~d})$ & $\mathrm{A}-3.1 .1 . \mathrm{S}, \mathrm{A}-3.5 .9 . \mathrm{H}$ \\
\hline
\end{tabular}


Title: Mined Geologic Disposal System Requirements Document

Table 6-2. Source Document Cross-Reference (Continued)

\begin{tabular}{|c|c|}
\hline SOURCE & MGDS.RD PARAGRAPH \\
\hline 10CFR $960.4-2-6(8)$ & A-3.5.9.1 \\
\hline $10 \mathrm{CFR} 960.42-6(\mathrm{~b})$ & $\mathrm{A}-3.5 .10 . \mathrm{F}$ \\
\hline 10CFR $960.4-2.6(\mathrm{c})$ & A-3.3.8.0 \\
\hline 10 CFR960.42-6(d) & A. $3.5 .9 \mathrm{~J}$ \\
\hline 10CFR960.4-2.7(a) & A-3.3.9.K \\
\hline $10 \mathrm{CFR} 960.42 .7(\mathrm{~b})$ & A-3.5.8.A.4 \\
\hline $10 \mathrm{CFR} P 60.42-7(\mathrm{c})(1)$ & A-3.3.8.8.R \\
\hline $10 \mathrm{CFR} 960.4-2.7(\mathrm{c})(2)$ & A-3.5.8.S \\
\hline 10 CFRP60.42-7(ט)(3) & A-3.3.8.T \\
\hline $10 \mathrm{CFR} 960.42 .7(\mathrm{c})(4)$ & A-3.5.8.U \\
\hline $10 \mathrm{CFR} 960.42-7(\mathrm{c})(5)$ & $A-3.5 .8 \mathrm{~J}$ \\
\hline $10 \mathrm{CPR} 960.42-7(\mathrm{c})(6)$ & A-3.5.8.K \\
\hline $10 \mathrm{CFR} 960.4-2-7(\mathrm{~d})$ & A-3.5.9L \\
\hline 10CFRP60.4-2-8-1(a) & A. $3.5 .9 \mathrm{M}$ \\
\hline 10 CFR $60.4-2-8-1(b)(1)$ & A-3.5.10.G.1 \\
\hline $10 C F R=60.42-8-1(b)(2)$ & A-3.5.10.6.2 \\
\hline $10 C F R=60.4-2-8-1(\mathrm{c})(4)$ & A-3.5.10.6.3 \\
\hline $10 C F R=60.4-2-8-1(\mathrm{c})(5)$ & A-3.5.8.1 \\
\hline $10 C F R=60.4-2-8-1(c)(1)$ & A-3.3.8.XX \\
\hline $10 \mathrm{CFR} 960.4-2-8-1(\mathrm{c})(2)$ & A-3.5.8.Y \\
\hline $10 C F R=60.4-2-8-1(\mathrm{c})(3)$ & A-3.5.8Z Z \\
\hline 10 CFR $960.4-2-8-1(d)(1)$ & $A-3.5 .9 \mathrm{~N}$ \\
\hline $10 C F R=60.4-2-8-1(d)(2)$ & A-3.5.9.0 \\
\hline 10CFR960.5-1(a)(1) & A-3.4.5.A \\
\hline $10 \mathrm{CFR} 960.5-1(\mathrm{a})(3)$ & $\mathrm{A}-3.3 .3, \mathrm{~A}-3.4 .6 . \mathrm{A}$ \\
\hline $10 \mathrm{CFR} 960.5-2-3(\mathrm{a})$ & A-3.4.5.B \\
\hline 10CFR960.5-2-3(b) & A-3.5.10.H.1 \\
\hline 10CFR $960.5-2-3(\mathrm{c})(1)$ & A-3.5.10.H.2 \\
\hline 10CFR960.5-2-3(c)(2) & A-3.5.10.H.3 \\
\hline 10CFR960.5-2-4(a) & A-3.4.5.C \\
\hline 10CFR960.5-2-4(b) & A-3.5.10.1.1 \\
\hline 10CFR960.5-2-4(c)(1) & A-3.5.10.1.2 \\
\hline
\end{tabular}


Titlo: Mined Geologic Disposal System Requirements Document

Table 6-2. Source Document Cross-Reference (Continued)

\begin{tabular}{|c|c|}
\hline SOURCE & MGDS.RD PARAGRAPH \\
\hline 10 CFR960.5-2-4(c)(2) & A-3.5.10.1.3 \\
\hline $10 C F R 960.5-2-4(d)$ & A-3.4.5.D \\
\hline 10CFR960.5-2-8(a) & $A-3,1,4, F, A-3,4,6, B$ \\
\hline $10 \mathrm{CFR} 960.3-2-8(\mathrm{~b})(1)$ & A.3.1.4.G \\
\hline $10 C F R P 60.3-2-8(b)(2)$ & A-3.1.4.G \\
\hline 10 CFR960.5-2-8(c) & A-3.1.4.H, A-3.5.8.H \\
\hline 10CFR960.5-2-9(8) & $\mathrm{A}-3.1 .4 . \mathrm{d}, \mathrm{A}-3.4 .6 . \mathrm{C}$ \\
\hline 10CFR960.5-2-9(0)(1) & $A-3.1 .4 \mathrm{~J}$ \\
\hline 10CFR $960.5-2-9(0)(2)$ & A-3.1.4.K \\
\hline $10 \mathrm{CFR} 960.3-2-9(\mathrm{c})(1)$ & A-3.1.4.1 \\
\hline 10CFR960.5-2-9(c)(2) & A.3.1.4.M \\
\hline 10CFRP60.9-2-9(c)(3) & $A-3.1 .4 \mathrm{~N}$ \\
\hline $10 C F R 960.9-2-9(c)(4)$ & A-3.1.4.0 \\
\hline 10 CFR960.5-2-9(c)(5) & A-3.1.4.P \\
\hline 10CFR960.5-2-9(d) & $A-3.1 .4,0, A-3,4.6, D$ \\
\hline 10CFR260.5-2-10(a) & $\mathrm{A}-3.1 .4, \mathrm{R}, \mathrm{A}-3.4 .6 \mathrm{E}$ \\
\hline 10CFR960.5-2-10(b)(1) & A-3.1.4.S \\
\hline $10 C F R 960.5-2-10(b)(2)$ & A-3.1.4.T \\
\hline 10CFR960.5-2-10(b)(3) & A-3.1.4.U \\
\hline $10 C F R=00.5-2-10(c)$ & A-3.1.4.V \\
\hline 10CFR $960.5-2-10(d)$ & A-3.1.4.W, A-3,4.6.F \\
\hline $10 C F R 260.5-2-11(\mathrm{a})$ & A-3.1.4.X, A-3.4.6.G \\
\hline 10CFR $960.5-2-11(b)$ & A-3.1.4.Y \\
\hline 10 CFRP60.5-2-11(c)(1) & A-3.1.4.Z \\
\hline $10 \mathrm{CFR} 960.5-2-11(\mathrm{c})(2)$ & A-3.1.4.AA \\
\hline 10 CFR960.5-2-11(c)(3) & $\mathrm{A}-3.1 .4 . \mathrm{BB}$ \\
\hline 10CFR960.5-2-11(d) & $\mathrm{A}-3.1,4 . \mathrm{CC}, \mathrm{A}-3,4.6 . \mathrm{H}$ \\
\hline 10CFR961.11 Article VI.A.1 & $3.2 .3 .2 .2 . \mathrm{A}, 3.2 .3 .2 .2 . \mathrm{B}$ \\
\hline 10CFR961.11 Article IV.B.2 & 3.2.3.2.3.F \\
\hline 10CFR961.11 Article IV.B.2(c) & 3.5.1.3 \\
\hline 10CFR961.11 Article V1.B.2(b) & $3.2 .3 .2 .2 \mathrm{E}$ \\
\hline 10CFR961.11 Article VI.B.3 & 3.2.3.2.2.E \\
\hline
\end{tabular}


Title: Mined Geologic Disposal System Requirements Document

Table 6-2. Source Document Cross-Reference (Continued)

\begin{tabular}{|c|c|}
\hline SOURCE & MGDS-RD PARAGRAPH \\
\hline 15 USC2601 et seg. & 3.3.11.5 \\
\hline 27CFR55.201-211 & 3.7.2.5.6.J.1 \\
\hline 27CFR55.206 & 3.7.2.5.6.J.2.a \\
\hline 27CFR55.206 & $3.7 .2 .5 .6 \mathrm{~J} .2 . \mathrm{b}$ \\
\hline 29CFR 1910 & 3.3.6.8.A \\
\hline (29CFR1910) & 3.3.6.1.B, 3.3.6.2.E.2, 3.3.6.5, 3.8.C \\
\hline 29CFR1910, S & 3.3.6.11.A \\
\hline 29CFR1910, D, F & 3.3.6.10.B \\
\hline 29CFR1910, Q & 3.3.6.8.E \\
\hline 29CFR1910, F & 3.3.6.10.A \\
\hline 29CFR $1910, \mathrm{H}, \mathrm{O}$ & 3.3.6.3.E \\
\hline 29CFR1910, P & 3.3.6.8.D \\
\hline 29CFR1910, D & 3.3.6.3.A.1 \\
\hline 29CFR1910, J & 3.3.6.3.A.4, 3.3.6.6.A \\
\hline 29CFR1910, G & 3.3.6.3.A.3 \\
\hline 29CFR1910, O & 3.3.6.8.C \\
\hline 29CFR1910, H & 3.3.6.3.D \\
\hline 29CFR1910, E & 3.3.6.3.A.2, 3.3.6.6.C \\
\hline 29CFR1910, I, E & 3.3.6.4.A \\
\hline 29CFR1910, Z & 3.3.11.5 \\
\hline 29CFR1910.94 & 3.3.6.3.C \\
\hline 29CFR1910.95(a), (b) & 3.2.4.2.4, 3.3.6.4.B \\
\hline 29CFR1910.109 & 3.7.2.5.6.J.1 \\
\hline 29CFR1910.132(a) & 3.3.6.4.E \\
\hline 29CFR1910.141 & 3.2.4.2.1 \\
\hline 29CFR1910.147(c)-(f) & 3.3.6.8.B \\
\hline 29CFR1910.151(c) & 3.3.6.8.F \\
\hline 29CFR1926 & 3.3.6.4.A \\
\hline (29CFR1926) & 3.3.6.1.B, 3.3.6.2.E.2, 3.3.6.5 \\
\hline (29CFR1926.21) & 3.7.2.5.6.C \\
\hline 29CFR1926.800(c) & 3.2.4.3.3 \\
\hline (29CFR1960 Subpart H) & 3.7.2.5.6.C \\
\hline
\end{tabular}


Title: Mined Geologic Disposal System Requirements Document

Table 6-2. Source Document Cross-Reference (Continued)

\begin{tabular}{|c|c|}
\hline SOURCE & MGDS-RD PARAGRAPH \\
\hline 29USC651 et seq. Section 657 & 3.7.2.5.6.F.1 \\
\hline 29USC651 et seq., 654 (a), (b) & 3.3.6.1.A \\
\hline 30CFR Chapter I & 3.7.2.6.F.5 \\
\hline (30CFR48) & 3.7.2.5.6.C \\
\hline (30CFR57) & 3.3.6.1.B, 3.3.6.2.E.1, 3.3.6.2.E.2, 3.3.6.5, 3.7.2.5.6.C, 3.7.2.6.F.1, 3.8.C \\
\hline 30CFR57 & 3.3.6.8.A \\
\hline $30 \mathrm{CFR} 57, \mathrm{~K}$ & 3.3.6.11.C \\
\hline 30CFR57, B & 3.2.6.2.5 \\
\hline 30CFR57, D & 3.3.6.3.G \\
\hline $30 \mathrm{CFR} 57, \mathrm{~N}$ & 3.3.6.4.A \\
\hline 30CFR57, M & 3.3.6.8.C, 3.5.1.1.1.E \\
\hline 30CFR57, E & 3.7.2.6.F.3 \\
\hline 30CFR57.11058 & 3.2.4.3.3 \\
\hline 30 CFR57.12016 & 3.3.6.8.B \\
\hline 30CFR57.5003 & 3.7.2.6.G.1 \\
\hline 30CFR57.5005(a) & 3.3.6.4.C \\
\hline 33CFR323 & 3.3.11.3.B \\
\hline 33USC1251 et.seq. & 3.3.11.3.A, 3.7.2.4.8.B \\
\hline (33USC1251 et seq.) & 3.3.11.3.B \\
\hline 33USC1251 et.seq. Section 1345 & 3.3.11.3.A.2 \\
\hline $\begin{array}{l}\text { 33USC1251 et.seq. Section } \\
1318(\mathrm{a})(1)(\mathrm{A})\end{array}$ & 3.3.11.3.A.4 \\
\hline 33USC1251 et seg. Section 1311 & 3.3.11.3.A.5 \\
\hline $\begin{array}{l}\text { 33USC1251 et seq. Section } \\
1345(a)\end{array}$ & 3.7.2.4.7.A \\
\hline $\begin{array}{l}\text { 33USC1251 et seq. Section } \\
1252(b)(1)\end{array}$ & 3.3.11.3.A.1 \\
\hline $\begin{array}{l}\text { 33USC1251 et seq. Section } \\
1311 \text { (a) }\end{array}$ & 3.3.11.3.A.3 \\
\hline 40CFR50 & 3.3.11.2.A \\
\hline 40CFR60 & 3.3.11.2.A \\
\hline 40CFR61 & 3.3.11.2.A \\
\hline 40CFR122.41 & 3.3.11.3.A \\
\hline 40CFR141 & 3.7.2.4.2.B \\
\hline
\end{tabular}


Title: Mined Geologic Disposal System Requirements Documcnt

Table 6-2. Source Document Cross-Reference (Continued)

\begin{tabular}{|c|c|}
\hline SOURCE & MGDS-RD PARAGRAPH \\
\hline 40CFR 143 & 3.7.2.4.2.B \\
\hline (40CFR144.31) & 3.3.11.4.B \\
\hline 40CFR 165 & 3.3.11.6 \\
\hline (40CFR191) & 3.2.1.1.H \\
\hline 40CFR 191.03 & $\mathrm{~A}-3.4 .2 . \mathrm{D}$ \\
\hline 40CFR191.03(a)(1)(TBR) & 3.2.2.1.F.1 \\
\hline 40CFR191.13(a) (TBR) & $3.2 .1 .7 . \mathrm{C}, \mathrm{A}-3.5 .4 . \mathrm{B}$ \\
\hline 40CFR191.15 (TBR) & 3.2.2.1.G, A-3.5.5 \\
\hline 40CFR 191.16 & $\mathrm{~A}-3.5 .6$ \\
\hline 40CFR $191.16(\mathrm{a})(\mathrm{b})(\mathrm{TBR})$ & 3.7.2.2.C \\
\hline 40CFR204 & 3.3.11.8 \\
\hline 40CFR205 & 3.3.11.8 \\
\hline 40CFR261 & 3.3.11.7 \\
\hline 40CFR262 & 3.3.11.7 \\
\hline 40CFR270 & 3.3.11.7 \\
\hline 41CFR101-17.3 & 3.7.2.5.6.E.1 \\
\hline 41CFR101-19.603 & 3.3.7.13.A \\
\hline (42USC300f et seq.) & 3.3.11.4.B \\
\hline 42USC $300 \mathrm{f}$ et seg. $300 \mathrm{~g}-3$ & 3.7.2.4.2.B \\
\hline 42USC 300 f et seg. & 3.3.11.4.A \\
\hline 42USC 300 f et seq., $300 \mathrm{~g}-6$ & 3.7.2.4.2.A \\
\hline 42USC 300 f et seg., $300 j$ & 3.3.11.4.B \\
\hline 42USC 4901 et seq. & 3.3.11.8 \\
\hline (42USC6901 et seg.) & 3.3.11.7 \\
\hline 42USC7401 & 3.3.11.2.B \\
\hline (42USC7401) & 3.3.11.2.A \\
\hline (49CFR172 Subpart H) & 3.7.2.5.6.C \\
\hline (49CFR 173) & 3.2 .2 .8 \\
\hline 49CFR $177.842(\mathrm{f})$ & 3.2.3.2.3.E \\
\hline 50CFR 17 & 3.3.11.9 \\
\hline (ACI 318) & 3.2.4.5.1.C \\
\hline (ACI 349) & 3.2.4.5.1.C \\
\hline
\end{tabular}


Title: Mined Geologic Disposal System Requirements Document

Table 5-2. Source Document Cross-Feference (Continued)

\begin{tabular}{|c|c|}
\hline SOURCE & MGDS-RD PARAGRAPH \\
\hline (ANSI/ANS 6.4.2) & 3.2.4.5.1.C \\
\hline (ANSL/ANS 6.4) & 3.2.4.5.1.C \\
\hline ANSI C2 & 3.3.6.11.C \\
\hline (ANSL/HFS Std. No. 100-1988) & 3.3.7.9 \\
\hline (ANSI S-3.18) & 3.2.4.2.5 \\
\hline (ANSUASCE 7-88) & $3.2 .6 .1 \mathrm{~J}$ \\
\hline ANSINAPA-70 & 3.3.6.11.C \\
\hline BLM, 9113 & 3.7.2.3.C.1 \\
\hline (CMAA 70) & 3.7.2.5.1.A.2 \\
\hline (DOD-HDBK-743A) & 3.3.7.10 \\
\hline (DOE 1324.2A) & 3.7.2.5.6.F.2 \\
\hline (DOE 3790.1A) & 3.7.2.5.6.C \\
\hline DOE 3790.1A, I, (3)(a)(5) & 3.7.2.5.6.B, 3.7.2.6.M \\
\hline DOE $3790.1 \mathrm{~A}, \mathrm{VU} .5(\mathrm{l})(\mathrm{m})$ & 3.7.2.5.6.1.1 \\
\hline DOE 3790.1A, Chapter VIII & 3.7.2.5.6.D \\
\hline $\begin{array}{l}\text { DOE } 3790.1 \mathrm{~A} \text {, page VII-8, } \\
(5)(\mathrm{b})(2)(\mathrm{g})(3)\end{array}$ & 3.7.2.5.6.F.2 \\
\hline DOE 4330.4A & 3.7.2.5.6.G \\
\hline (DOE 4330.4A) & 3.7.2.5.6.C \\
\hline DOE 4330.4A, $1,3.5$ & 3.5.1.1.1.D \\
\hline DOE 4330.4A, $1,3.1 .4$ & 3.6.2.1.A \\
\hline (DOE 4700.1) & 5.1 \\
\hline DOE $4700.1 \mathrm{Ch}$ III 2.c(2)(c) & 3.2.3.2.3.L \\
\hline DOE 4700.1 Ch III 2.c(2)(c) & 3.2.3.2.3.0 \\
\hline DOE 4700.1 Ch III 2.c(2)(c) & 3.2.3.2.3.P \\
\hline DOE $4700.1 \mathrm{Ch}$ III $2 . \mathrm{c}(2)(\mathrm{c})$ & 3.2.3.2.4 \\
\hline DOE 4700.1, p.V-17, q & 3.2.5.2.8.A \\
\hline (DOE 5000.3A) & 3.7.2.5.6.C \\
\hline DOE 5480.4, Att. 2, 2.e.(8)(a) & 3.2.1.2.C \\
\hline DOE 5480.4 & $3.7 .2 .5 .6 \mathrm{~J} .1$ \\
\hline DOE 5480.7 & 3.7.2.5.4.C, 3.7.2.5.4.D, 3.7.2.6.L.3, 3.7.2.6.L.4 \\
\hline
\end{tabular}


Title: Mined Geologic Disposal System Requirements Document

Table 6-2. Source Document Cross-Reference (Continued)

\begin{tabular}{|c|c|}
\hline SOURCE & MGDS-RD PARAGRAPH \\
\hline DOE $6430.1 \mathrm{~A}$ & $\begin{array}{l}\text { 3.3.6.3.B, 3.7.2.4.1.B, 3.7.2.4.1.C, 3.7.2.4.1.D, 3.7.2.4.2.C, 3.7.2.4.3.A, } \\
\text { 3.7.2.4.4.A, 3.7.2.4.6.C, 3.7.2.4.7.B, 3.7.2.5.4.C, 3.7.2.5.6.J.1, } \\
\text { 3.7.2.6.4.3, 3.7.2.8.B }\end{array}$ \\
\hline (DOE 6430.1A) & 3.3.1.A, 3.3.1.B, 3.3.1.C \\
\hline DOE 6430.1A, 0111-99.0.2 & 3.2.6.1.E.2, 3.2.6.1.E.3.a, 3.2.6.1.E.3.b \\
\hline DOE $6430.1 \mathrm{~A}, 1324-3$ & 3.2.2.6.C \\
\hline (DOE 6430.1A, 1300-10) & 3.2.4.3.1.1 \\
\hline (DOE 6430.1A, 0900-99.0) & 3.2.4.1 \\
\hline (DOE 6430.1A Section 1300-13) & 3.3.7.13.B \\
\hline DOE 6430.1A, 0111-99.0 & 3.2.4.6.B, 3.2.4.6.C, 3.2.4.6.D \\
\hline DOE $6430.1 \mathrm{~A}, 1300-6.2$ & 3.2.4.5.1.A, 3.2.4.5.1.B, 3.2.4.5.1.C, 3.2.4.5.1.D \\
\hline DOE $6430.1 \mathrm{~A}, 1300-6.3$ & 3.2.4.5.2 \\
\hline DOE 6430.1A, 1324-2.1 & 3.2.4.6.A \\
\hline DOE $6430.1 \mathrm{~A}, 0110-99.0 .4$ & 3.2.5.2.2.A \\
\hline DOE 6430.1A, 1300-3.5 & 3.2.5.2.2.B \\
\hline DOE $6430.1 \mathrm{~A}, 0110-99.8 .3$ & 3.3.2.C \\
\hline DOE 6430.1A, 0111-2.8.2 & 3.2.6.1.H.1, 3.2.6.1.H.2 \\
\hline DOE $6430.1 \mathrm{~A}, 0101-2$ & 3.3.1.D \\
\hline DOE $6430.1 \mathrm{~A}, 0109$ & 3.3.4.B \\
\hline DOE 6430.1A, 0111-2.8.4 & 3.2.6.1.1 \\
\hline DOE 6430.1A, 0111-2.3.2 & $3.2 .6 .1 \mathrm{~J}$ \\
\hline DOE 6430.1A, 0111-2.8.1 & 3.2.6.2.3 \\
\hline DOE $6430.1 \mathrm{~A}, 0110-99.0 .6$ & 3.2.6.2.2.A, 3.2.6.2.2.B, 3.2.6.2.2.C \\
\hline DOE 6430.1A, 0111-2.8.5 & 3.2.6.2.4 \\
\hline DOE 6430.1A, 0200-99.8.1 & 3.3.2.A \\
\hline DOE 6430.1A, $1655-99.8$ & 3.3.2.B \\
\hline DOE 6430.1A, 1300-12.4.11 & 3.3.3.A, 3.3.3.B, 3.3.3.C, 3.3.3.D, 3.3.3.E \\
\hline DOE $6430.1 \mathrm{~A}, 1300-12.4 .5$ & 3.3.6.4.A \\
\hline DOE $6430.1 \mathrm{~A}, 0111-99.0 .2$ & 3.2.6.1.E.3.c, 3.2.6.1.E.4 \\
\hline DOE $6430.1 \mathrm{~A}, 1300-4$ & 3.2.2.6.B \\
\hline DOE 6430.1A, 0111-99.0.3 & 3.2.6.1.F \\
\hline DOE $6430.1 \mathrm{~A}, 1300-6.6$ & 3.7.2.8.D \\
\hline DOE $6430.1 \mathrm{~A}, 0110-6$ & 3.7.2.6.L.2 \\
\hline
\end{tabular}


Title: Mined Geologic Disposal System Requirements Document

Table 6-2. Source Document Cross-Reference (Continued)

\begin{tabular}{|c|c|}
\hline SOURCE & MGDS-RD PARAGRAPH \\
\hline DOE $6430.1 \mathrm{~A}, 0150-5$ & 3.7.2.3.D.1 \\
\hline DOE $6430.1 \mathrm{~A}, 0281$ & 3.7.2.4.5 \\
\hline DOE $6430.1 \mathrm{~A}, 1460$ & 3.7.2.5.1.A.2 \\
\hline DOE $6430.1 \mathrm{~A}, 0250-3,0250-5$ & 3.7.2.3.C. 2 \\
\hline DOE 6430.1A, 0220 & 3.7.2.3.B. 2 \\
\hline DOE $6430.1 \mathrm{~A}, 1300-6.5$ & 3.7.2.5.2.D \\
\hline DOE $6430.1 \mathrm{~A}, 0250-4$ & 3.7.2.3.B.3 \\
\hline DOE $6430.1 \mathrm{~A}, 0278$ & 3.7.2.4.4.B \\
\hline DOE $6430.1 \mathrm{~A}, 0270-2$ & 3.7.2.3.F \\
\hline DOE 6430.1A, 0110-1.3 & 3.7.2.5.6.1.3, 3.7.2.6.F.7 \\
\hline DOE $6430.1 \mathrm{~A}, 1630-99.8$ & 3.7.2.4.3.B \\
\hline DOE $6430.1 \mathrm{~A}, 0110-6$ & 3.7.2.5.4. B \\
\hline DOE $6430.1 \mathrm{~A}, 1300-11.2$ & 3.7.2.5.6.L.2 \\
\hline DOE $6430.1 \mathrm{~A}, 1300-6.5$ & 3.7.2.6.F.6 \\
\hline DOE $6430.1 \mathrm{~A}, 1300-6.8$ & 3.7.2.5.6.A \\
\hline DOE $6430.1 \mathrm{~A}, 0150-1$ & 3.7.2.3.B.1 \\
\hline DOE $6430.1 \mathrm{~A}, 0202$ & 3.7.2.3.A \\
\hline DOE $6430.1 \mathrm{~A}, 0280-1$ & 3.7.2.3.D.2 \\
\hline DOE Letter $2 / 27 / 90$ & 3.7.1.3.B.1, 3.7.1.3.B. 2 \\
\hline $\begin{array}{l}\text { (GSA Uniform Accessibility } \\
\text { Standards) }\end{array}$ & 3.3.7.13.A \\
\hline (GSA-IFS-W-A-00450B) & 3.7.2.5.2.B \\
\hline MOA, RW/NS 4/16/92 & 3.8. B \\
\hline MOU DOEDOL & 3.7.2.6.C.1, 3.7.2.6.C.2, 3.7.2.6.C.3 \\
\hline (MIL-STD-1388 Series) & 3.5 .2 \\
\hline (MIL-STD-1472D) & 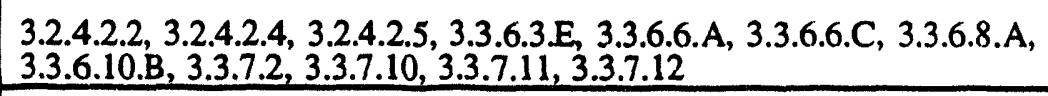 \\
\hline (MIL-STD-882B) & 3.2.5.1.2 \\
\hline (MTR 10090) & 3.3.7.14 \\
\hline (NRC Regulatory Guide 1.76) & 3.2.6.1.E.1 \\
\hline (NRC Regulatory Guide 8.8) & 3.2.2.1.B \\
\hline (NRC Regulatory Guide 8.10) & 3.2.2.1.B \\
\hline (NUREG-0700 Section 6.1.5) & 3.2.4.2.2 \\
\hline
\end{tabular}


Title: Mined Geologic Disposal System Requirements Document

Table 6-2. Source Document Cross-Reference (Continued)

\begin{tabular}{|c|c|}
\hline SOURCE & MGDS-RD PARAGRAPH \\
\hline (NUREG-0700) & $\begin{array}{l}3.2 .4 .2 .1,3.2 .4 .2 .3,3.2 .4 .2 .4,3.3 .6 .7 . C, 3.3 .7 .1,3.3 .7 .2,3.3 .7 .3,3.3 .7 .4 \text {, } \\
\text { 3.3.7.5, 3.3.7.6, 3.3.7.7, 3.3.7.8 }\end{array}$ \\
\hline NUREG-0700 Section 6.1 .4 & 3.3.6.4.A \\
\hline NWPA 111(a)(4) & 3.2.1.A \\
\hline NWPA 111(b)(1) & 3.7.2.8.C \\
\hline NWPAA 112(b)(1)(D)(iii) & 3.2.1.1.F.1 \\
\hline NWPA 113(a) & 3.2.1.1.F.1 \\
\hline NWPA $113(c)(1)$ & 3.2.1.1.A, 3.7.1.3.A \\
\hline NWPA 113(c)(2) & 3.2.1.1.1 \\
\hline NWPA 113(b)(1)(A)(iii) & 3.2.1.1.F.2 \\
\hline NWPA 114(d) & 3.2.1.3.A, 3.2.3.2.1.A \\
\hline NWPA 122 & 3.2.1.5.A \\
\hline NWPA 122 & $\mathrm{~A}-3.4 .1 . \mathrm{A}$ \\
\hline Presidential Memo 1985 & 3.2.1.A \\
\hline QARD & 3.3.4.A, 3.3.8.1.A, 3.4.1.C, 3.4.3, 3.4.5, 3.4.7, 3.7.2.5.6.F.4, 3.9 \\
\hline (QARD) & 3.7.2.5.6.C, 3.7.2.5.6.F.4 \\
\hline $\begin{array}{l}\text { (Recommended Practice of the } \\
\text { Mlluminating Engineering Society) }\end{array}$ & 3.2.4.2.3 \\
\hline $\begin{array}{l}\text { Ref 2.4.2.C, MPC-MGDS } \\
\text { Thermal Requirements }\end{array}$ & 3.2.3.2.3.J \\
\hline RW-0194P & 3.7.2.5.6.F.3 \\
\hline RW-0316P, pp 101 & 3.2.3.2.3.U, 3.7.2.5.1.B \\
\hline $\mathrm{RW}-0199,7.2 .1 .3 .3$ & 3.2.3.2.3.J \\
\hline UCRL 15673, Section 1 & 3.2.5.2.8.B \\
\hline UCRL 15673, Section 2 & 3.2.5.2.8.C \\
\hline UCRL 15673, Section 3 & 3.2.5.2.8.D \\
\hline (UCRL 15910) & 3.2.6.1.D, 3.2.6.1.E.2, 3.2.6.1.E.3.b, 3.2.6.1.F \\
\hline (UCRL 53526) & 3.2.6.1.E.2, 3.2.6.1.E.3.c \\
\hline Exec Order $11988,2(b)$ & 3.2.6.1.G.1, $\quad 3.2 .6 .1 . G .2$ \\
\hline CRD & 3.2.1.1.H \\
\hline CRD & 3.2.1.3.C \\
\hline CRD & 3.2.2.8 \\
\hline CRD & 3.2.3.1.A \\
\hline
\end{tabular}


Title: Mined Geologic Disposal System Requirements Document

Table 6-2. Source Document Cross-Reference (Continued)

\begin{tabular}{|c|c|}
\hline SOURCE & MGDS-RD PARAGRAPH \\
\hline CRD & 3.2.3.1.B \\
\hline CRD & 3.2.3.2 \\
\hline CRD & 3.2 .4 \\
\hline CRD & 3.2.4.1 \\
\hline $\mathrm{CRD}$ & 3.2.4.2.2 \\
\hline CRD & 3.2.4.2.3 \\
\hline $\mathrm{CRD}$ & 3.2.4.2.5 \\
\hline CRD & 3.2.4.2.6 \\
\hline CRD & 3.2.4.3.1.1 \\
\hline CRD & 3.2.5.1 \\
\hline CRD & 3.2.5.1.1 \\
\hline CRD & 3.2.5.1.2 \\
\hline CRD & 3.2.5.1.5 \\
\hline CRD & 3.2.5.3.A \\
\hline CRD & 3.2.5.3.B \\
\hline CRD & 3.2.5.4.B \\
\hline CRD & 3.2.5.5.A \\
\hline CRD & 3.2.5.5.B \\
\hline CRD & 3.2.6.1.A \\
\hline CRD & 3.2.6.1.B \\
\hline CRD & 3.2.6.1.C \\
\hline CRD & 3.2 .7 \\
\hline CRD & 3.2 .8 \\
\hline CRD & 3.2 .9 \\
\hline CRD & 3.3.1.A \\
\hline CRD & 3.3.1.B \\
\hline CRD & 3.3.1.F \\
\hline $\mathrm{CRD}$ & 3.3.1.G \\
\hline CRD & 3.3.10.A \\
\hline CRD & 3.3.10.B \\
\hline CRD & 3.3.11.A \\
\hline CRD & 3.3.3.F \\
\hline
\end{tabular}


Title: Mined Geologic Disposal System Requirements Document

Table 6-2. Source Document Cross-Reference (Continued)

\begin{tabular}{|c|c|}
\hline SOURCE & MGDS-RD PARAGRAPH \\
\hline CRD & 3.3.5 \\
\hline CRD & 3.3.6.1.B \\
\hline CRD & 3.3.6.2.A \\
\hline CRD & 3.3.6.2.B \\
\hline CRD & 3.3.6.2.C \\
\hline CRD & 3.3.6.2. D \\
\hline CRD & 3.3.6.2.E.1 \\
\hline CRD & 3.3.6.2.E.2 \\
\hline CRD & \begin{tabular}{|l} 
3.3.6.5 \\
\end{tabular} \\
\hline CRD & 3.3.6.6.B \\
\hline CRD & 3.3.6.7.A \\
\hline CRD & 3.3.6.7. B \\
\hline CRD & 3.3.7.1 \\
\hline CRD & 3.3.7.2 \\
\hline CRD & \begin{tabular}{|l}
3.3 .7 .3 \\
\end{tabular} \\
\hline CRD & 3.3.7.4 \\
\hline CRD & 3.3.7.5 \\
\hline CRD & 3.3.7.6 \\
\hline CRD & 3.3.7.7 \\
\hline CRD & 3.3.7.8 \\
\hline CRD & 3.3.7.9 \\
\hline CRD & 3.3.7.10 \\
\hline CRD & 3.3.7.11 \\
\hline CRD & 3.3.7.12 \\
\hline CRD & 3.3.7.13.B \\
\hline CRD & 3.3.7.14 \\
\hline CRD & 3.3.8.1.B \\
\hline CRD & 3.3.8.1.C \\
\hline CRD & 3.3.8.1.D \\
\hline CRD & 3.3.8.2.A \\
\hline CRD & 3.3.8.2. B \\
\hline CRD & 3.3.9.C \\
\hline
\end{tabular}


Title: Mined Géologic Disposal System Requirements Document

Table 6-2. Source Document Cross-Reference (Continued)

\begin{tabular}{|c|c|}
\hline SOURCE & MGDS-RD PARAGRAPH \\
\hline CRD & 3.4.1.B \\
\hline CRD & 3.4 .4 \\
\hline CRD & 3.4.6.A \\
\hline CRD & $3.5 .1 .1 .1 . \mathrm{B}$ \\
\hline CRD & 3.5.1.1.1.C \\
\hline CRD & 3.5 .2 \\
\hline CRD & 3.5.3.1 \\
\hline CRD & 3.5.3.5 \\
\hline CRD & 3.5 .4 \\
\hline CRD & 3.6 .1 \\
\hline CRD & 3.6 .2 \\
\hline CRD & $3.6 .2 .1 . \mathrm{B}$ \\
\hline CRD & 3.6.2.2.A \\
\hline CRD & 3.6.2.2.B \\
\hline CRD & 3.7.1.3.C \\
\hline CRD & $3.7 .2 .1 . \mathrm{A}$ \\
\hline CRD & 3.7.2.5.1.D \\
\hline CRD & $3.7 .2 .5 .6 . \mathrm{C}$ \\
\hline CRD & 3.7.2.5.6.F.5 \\
\hline CRD & $3.7 .3 .1 . \mathrm{A}$ \\
\hline CRD & 3.8.A \\
\hline CRD & 3.8.C \\
\hline $\mathrm{CRD}$ & 5.1 \\
\hline CRD & 5.2 \\
\hline Derived & 3.2.3.2.2.C \\
\hline Derived & 3.2.3.2.2. D \\
\hline Derived & 3.2.3.2.3.A \\
\hline Derived & $3.2 .3 .2 .3 . \mathrm{B}$ \\
\hline Derived & 3.2.3.2.3.C \\
\hline Derived & 3.2.3.2.3.D \\
\hline Derived & 3.2.3.2.3.G \\
\hline Derived & 3.2.3.2.3.H \\
\hline
\end{tabular}


Title: Mined Geologic Disposal System Requirements Document

Table 6-2. Source Document Cross-Reference (Continued)

\begin{tabular}{|c|c|}
\hline SOURCE & MGDS-RD PARAGRAPH \\
\hline Derived & 3.2.3.2.3.I \\
\hline Derived & $3.2 .4 .3 .1 .2 . \mathrm{A}$ \\
\hline Derived & 3.2.4.3.1.2.B \\
\hline Derived & 3.2.4.3.1.2.C \\
\hline Derived & 3.2.4.3.1.2.D \\
\hline Derived & 3.2.4.3.1.2.E \\
\hline Derived & 3.2.4.3.1.2.F \\
\hline Derived & 3.2.4.3.1.3.A \\
\hline Derived & 3.2.4.3.1.3.B \\
\hline Derived & 3.2.4.3.1.3.C \\
\hline Derived & 3.2.4.3.1.3.D \\
\hline Derived & 3.2.4.3.1.3.E \\
\hline Derived & 3.2.5.2.3 \\
\hline Derived & 3.2.5.2.4.A \\
\hline Derived & 3.2.5.2.4.B \\
\hline Derived & 3.2.5.2.4.C \\
\hline Derived & 3.2.5.2.5 \\
\hline Derived & 3.2.5.2.7 \\
\hline Derived & 3.2.5.2.9 \\
\hline Derived & 3.2.5.4.A \\
\hline Derived & 3.2.6.1.D \\
\hline Derived & 3.2.6.1.E.1 \\
\hline Derived & 3.3.1.C \\
\hline Derived & 3.3.2.D \\
\hline Derived & 3.3.6.7.C \\
\hline Derived & 3.5.1.1.1.A \\
\hline Derived & 3.5.1.1.2.A \\
\hline Derived & 3.5.1.1.2.B \\
\hline Derived & 3.5 .1 .1 .3 \\
\hline Derived & 3.5.1.4.A \\
\hline Derived & 3.5.1.4.B \\
\hline Derived & 3.5.1.5 \\
\hline
\end{tabular}


Title: Mined Geologic Disposal System Requirements Document

Table 6-2. Source Document Cross-Reference (Continued)

\begin{tabular}{|c|c|}
\hline SOURCE & MGDS-RD PARAGRAPH \\
\hline Derived & 3.5.3.2.A \\
\hline Derived & $3.5 .3 .2 . \mathrm{B}$ \\
\hline Derived & 3.5.3.3 \\
\hline Derived & 3.7.1.1.A \\
\hline Derived & 3.7.1.1.B \\
\hline Derived & 3.7.1.3.B \\
\hline Derived & 3.7.1.3.B.3 \\
\hline Derived & 3.7.2.1.B \\
\hline Derived & 3.7.2.4.3.C \\
\hline Derived & 3.7.2.4.3.D \\
\hline Derived & 3.7.2.4.3.F \\
\hline Derived & 3.7.2.4.3.G \\
\hline Derived & 3.7.2.4.3.H \\
\hline Derived & $3.7 .2 .5 .2 . \mathrm{B}$ \\
\hline Derived & $3.7 .2 .5 .2 . \mathrm{C}$ \\
\hline Derived & $3.7 .2 .5 .2 . \mathrm{E}$ \\
\hline Derived & 3.7.2.5.2.F \\
\hline Derived & 3.7.2.5.6.E.4 \\
\hline Derived & 3.7.2.5.6.H \\
\hline Derived & $3.7 .2 .5 .6 . \mathrm{K}$ \\
\hline Derived & 3.7.2.6.F.1 \\
\hline Derived & 3.7.2.6.K \\
\hline Derived & 3.7.3.1.B \\
\hline Derived & 3.7.3.4.D \\
\hline Reserved & 3.2.1.1.G \\
\hline Reserved & 3.2.1.3.B \\
\hline Reserved & 3.2.1.3.C \\
\hline Reserved & 3.2.1.3.D \\
\hline Reserved & 3.2.1.3.E \\
\hline Reserved & 3.2.1.3.F \\
\hline Reserved & 3.2.1.3.G \\
\hline Reserved & 3.2.1.3.H \\
\hline
\end{tabular}


Title: Mined Geologic Disposal System Requirements Document

Table 6-2. Source Document Cross-Reference (Continued)

\begin{tabular}{|c|c|}
\hline SOURCE & MGDS-RD PARAGRAPH \\
\hline Reserved & 3.2.1.3.I \\
\hline Reserved & 3.2.2.1.A \\
\hline Reserved & 3.2.2.1.E \\
\hline Reserved & 3.2.2.1.F. 2 \\
\hline Reserved & 3.2.2.2. \\
\hline Reserved & 3.3.9.A \\
\hline Reservet & 3.3.9.B \\
\hline Reserved & 3.3.11.1 \\
\hline Reserved & 3.4.1.A \\
\hline Reserved & 3.6.1. B \\
\hline Reserved & 3.7.2.4.3.E \\
\hline Reserved & 3.7.2.4.6.A \\
\hline Reserved & 3.7.2.5.3 \\
\hline Reserved & 3.7.2.5.5 \\
\hline Reserved & \begin{tabular}{|l}
$3.7 .2 .5 .6 . \mathrm{E} .2$ \\
\end{tabular} \\
\hline Reserved & 3.7.3.4.B \\
\hline Reserved & A-3.4.1.C \\
\hline Reserved & A-3.4.1.D \\
\hline Reserved & \begin{tabular}{|l|} 
A-3.4.1.E \\
\end{tabular} \\
\hline Reserved & $\mathrm{A}-3.5 .10 \mathrm{C}$ \\
\hline Reserved & $\mathrm{A}-3.5 .10 . \mathrm{E}$ \\
\hline
\end{tabular}


Title: Mined Geologic Disposal System Requirements Document

Revision: 1

Page: 188

\subsection{CRD CROSS-REFERENCE}

Table 6-3 provides a cross-reference between the requirements in the CRD and the section in the MGDS-RD in which they are addressed.

Table 6-3. CRD Cross-Reference

\begin{tabular}{|c|c|}
\hline $\begin{array}{l}\text { CRD } \\
\text { PARAGRAPH }\end{array}$ & MGDS-RD PARAGRAPH \\
\hline 3.2.1.A & 3.2.1.A \\
\hline 3.2.1.B & $3.2 .1 .3 \mathrm{~J}$ \\
\hline 3.2.1.C & 3.2.1.3. J \\
\hline 3.2.1.1.A & 3.2.3.2.2.E \\
\hline 3.2.1.1.B & N/A (Waste Acceptance) \\
\hline 3.2.1.1.C & 3.2.1.3.C \\
\hline 3.2.1.1.D & 3.2.1.A \\
\hline 3.2.1.1.E & 3.2.1.3.J \\
\hline 3.2.1.1.F & 3.2.3.2.3.F \\
\hline 3.2.1.1.G & 3.2.2.1.D \\
\hline 3.2.1.1.H & 3.2.3.2.3.J, 3.2.3.2.3.K, 3.2.3.2.3.Q, 3.7.3.3.B.1, 3.7.3.3.B.2, 3.7.3.3.B.4 \\
\hline 3.2.1.1.1 & 3.2.3.2.3.U \\
\hline 3.2.1.1. J & 3.2.3.2.3.Q, 3.7.3.3.B.4 \\
\hline 3.2.1.2.A & 3.2.1.6, 3.7.2.5.6.L.1 \\
\hline 3.2.1.2.B & N/A (MRS) \\
\hline 3.2.1.2.C & N/A (MRS) \\
\hline 3.2.1.2. D & N/A (Transportation) \\
\hline 3.2.1.2. E & 3.7.2.5.6.L.2 \\
\hline 3.2.1.3 & $\begin{array}{l}\text { 3.2.1.8.A, 3.2.1.8.B, 3.2.1.8.C, 3.2.5.1.3, 3.7.2.4, 3.7.2.5.2.A, 3.7.2.5.4.A, } \\
\text { 3.7.2.5.6.1.2, 3.2.3.2.3.N, 3.2.3.2.3.S }\end{array}$ \\
\hline 3.2.2.1.A & 3.2.4.5.1.A, 3.2.4.5.1.B, 3.2.4.5.1.C, 3.2.4.5.1.D, 3.2.4.5.2, 3.7.2.6.F.6 \\
\hline 3.2.2.1.B & 3.3.6.9.A, 3.3.6.9.B, 3.3.6.9.C, 3.3.6.9.D, 3.3.6.9.E \\
\hline 3.2.2.1.C & 3.2.2.1.B \\
\hline 3.2.2.1.D & 3.2.2.1.C \\
\hline 3.2.2.1.E & 3.2.2.1.F, 3.2.3.2.3.S, 3.5.1.2.A, 3.5.1.2.B, 3.7.2.8.A.6, 3.7.2.8.F, 3.7.2.8.G \\
\hline 3.2.2.2.A & 3.2.2.1.C \\
\hline 3.2.2.2.B & 3.2.2.1.C, 3.2.2.3.A, 3.2.2.3.C \\
\hline 3.2.2.2.C & 3.2.1.2.D, 3.2.1.3.K, 3.2.1.4, 3.2.1.5.C, 3.2.2.1.D \\
\hline 3.2.2.2.D & 3.2.2.1.F.1 \\
\hline
\end{tabular}


Title: Mined Géologic Disposal System Requirements Document

Table 6-3. CRD Cross-Reference (Continued)

\begin{tabular}{|c|c|}
\hline $\begin{array}{l}\text { CRD } \\
\text { PARAGRAPH }\end{array}$ & MGDS-RD PARAGRAPH \\
\hline 3.2.2.2.E & 3.7.2.8.A.1, 3.7.2.8.A.2, 3.7.2.8.A.3, 3.7.2.8.A.4, 3.7.2.8.A.5, 3.7.2.8.A.6 \\
\hline 3.2.2.3 & 3.2.2.4.A \\
\hline 3.2.2.4.A & 3.2.2.5.A.1, 3.2.2.5.A.2, 3.2.2.5.A.3, 3.2.2.5.B.1, 3.2.2.5.B.2 \\
\hline 3.2.2.4.B & 3.2.4.4 \\
\hline 3.2.2.5 & 3.2.3.2.3.M, 3.2.2.6.A, 3.7.3.3.B.3 \\
\hline 3.2.2.6.A & 3.2.2.7.A \\
\hline 3.2.2.6.B & 3.2.2.7.B \\
\hline 3.2 .2 .7 & 3.2.2.8 \\
\hline 3.2.2.8 & 3.7.2.5.1.D \\
\hline 3.2.3.1 & 3.2.3.1.A \\
\hline 3.2.3.2.B & 3.2.3.1.B, 3.2.3.2, 3.7.1.2, 3.7.2.1.C, 3.7.3.1.C \\
\hline 3.2.3.2.B & 3.2.3.2.3.L \\
\hline 3.2.3.2.B & 3.2.3.2.3.0 \\
\hline 3.2.3.2.B & 3.2.3.2.3.P \\
\hline 3.2.3.2.B & 3.2.3.2.3.T \\
\hline 3.2.4 & 3.2 .4 \\
\hline 3.2.4.1 & 3.2.4.1 \\
\hline 3.2 .4 .2 .1 & 3.2.4.2.1 \\
\hline 3.2.4.2.2 & 3.2.4.2.2 \\
\hline 3.2.4.2.3 & 3.2 .4 .2 .3 \\
\hline 3.2.4.2.4 & 3.2.4.2.4 \\
\hline 3.2 .4 .2 .5 & 3.2.4.2.5 \\
\hline 3.2.4.2.6 & 3.2.4.2.6 \\
\hline 3.2.4.3.1.A & 3.2 .4 .3 .1 .4 \\
\hline 3.2.4.3.1.B & $\begin{array}{l}\text { 3.2.4.3.1.2.A, 3.2.4.3.1.2.B, 3.2.4.3.1.2.C, 3.2.4.3.1.2.D, 3.2.4.3.1.2.E, 3.2.4.3.1.2.F, } \\
\text { 3.2.4.3.1.3.A, 3.2.4.3.1.3.B, 3.2.4.3.1.3.C, 3.2.4.3.1.3.D, 3.2.4.3.1.3.E, 3.5.1.5, } \\
\text { 3.7.2.4.3.C, 3.7.2.4.3.D, 3.7.2.4.3.F, 3.7.2.4.3.G, 3.7.2.5.2.B, 3.7.2.5.2.C, } \\
\text { 3.7.2.5.2.E, 3.7.2.5.2.F, 3.7.2.5.6.H }\end{array}$ \\
\hline $3.2 .4 .3 .1 . \mathrm{C}$ & 3.2 .4 .3 .1 .1 \\
\hline 3.2.4.3.1. D & $\begin{array}{l}\text { 3.2.4.3.1.2.A, 3.2.4.3.1.2.B, 3.2.4.3.1.2.C, 3.2.4.3.1.2.D, 3.2.4.3.1.2.E, 3.2.4.3.1.2.F, } \\
\text { 3.2.4.3.1.3.A, 3.2.4.3.1.3.B, 3.2.4.3.1.3.C, 3.2.4.3.1.3.D, 3.2.4.3.1.3.E, 3.5.1.5, } \\
\text { 3.7.2.4.3.C, 3.7.2.4.3.D, 3.7.2.4.3.F, 3.7.2.4.3.G, 3.7.2.5.2.B, 3.7.2.5.2.C, } \\
\text { 3.7.2.5.2.E, 3.7.2.5.2.F, 3.7.2.5.6.H }\end{array}$ \\
\hline 3.2.4.3.2 & $\begin{array}{l}\text { 3.2.4.3.2.A, 3.2.4.3.2.B.1.a, 3.2.4.3.2.B.1.b, 3.2.4.3.2.B.1.c, 3.2.4.3.2.B.2, } \\
\text { 3.2.4.3.2.B.3, 3.2.4.3.2.B.4, 3.2.4.3.2.B.5 }\end{array}$ \\
\hline
\end{tabular}


Title: Mined Geologic Disposal System Requirements Document

Revision: 1

Table 6-3. CRD Cross-Reference (Continued)

\begin{tabular}{|c|c|}
\hline $\begin{array}{c}\text { CRD } \\
\text { PARAFRAPH }\end{array}$ & MGDS-RD PARAGRAPH \\
\hline 3.2.4.3.3 & 3.2 .4 .3 .3 \\
\hline 3.2.4.4.A & 3.3.6.4.D \\
\hline 3.2.4.4.B & 3.2.2.4.C \\
\hline 3.2.5.1.A & 3.2.5.1 \\
\hline 3.2.5.1. B & 3.2.5.1.1 \\
\hline 3.2.5.1.C & 3.2.3.2.3.Q, 3.2.3.2.3.R. 3.7.3.3.E \\
\hline 3.2.5.1.D & 3.2.5.1.2 \\
\hline 3.2.5.1. E & 3.2.5.1.5 \\
\hline 3.2.5.2. A & 3.2.5.2.1 \\
\hline 3.2.5.2.B & 3.2.5.2.8.B \\
\hline 3.2.5.2.C & N/A (Reserved) \\
\hline 3.2.5.2.D & 3.2.5.2.8.B,C, D \\
\hline 3.2.5.2.E & 3.2.5.2.6 \\
\hline 3.2.5.3.A & 3.2.5.3.A \\
\hline 3.2.5.3.B & N/A (Reserved) \\
\hline 3.2.5.4 & 3.2.5.4.A, 3.2.5.4.B \\
\hline 3.2.5.5.A & 3.2.5.5.A \\
\hline 3.2.5.5.B & N/A (Reserved) \\
\hline 3.2.6.1 & 3.2 .6 .1 \\
\hline 3.2.6.1.A & 3.2.6.1.A \\
\hline 3.2.6.1.B & 3.2.6.1.B \\
\hline 3.2.6.1.C & 3.2.6.1.C \\
\hline 3.2.6.2.A & $3.2 .1 .8 . \mathrm{A}, 3.2 .1 .8 . \mathrm{C}, 3.2 .5 .1 .3,3.2 .6 .2 .1 . \mathrm{A}, 3.2 .6 .2 .2 . \mathrm{D}$ \\
\hline 3.2.6.2.B & 3.2.6.2.1.C \\
\hline 3.2.6.2.C & N/A (Transportation) \\
\hline 3.2.6.2.D & N/A (Transportation) \\
\hline 3.2 .7 & 3.2 .7 \\
\hline 3.2 .8 & 3.2.8 \\
\hline 3.2 .9 & 3.2 .9 \\
\hline
\end{tabular}


Title: Mined Geologic Disposal System Requirements Document

Table 6-3. CRD Cross-Reference (Continued)

\begin{tabular}{|c|c|}
\hline $\begin{array}{c}\text { CRD } \\
\text { PARAGRAPH }\end{array}$ & MGDS-RD PARAGRAPH \\
\hline 3.3.1.A & 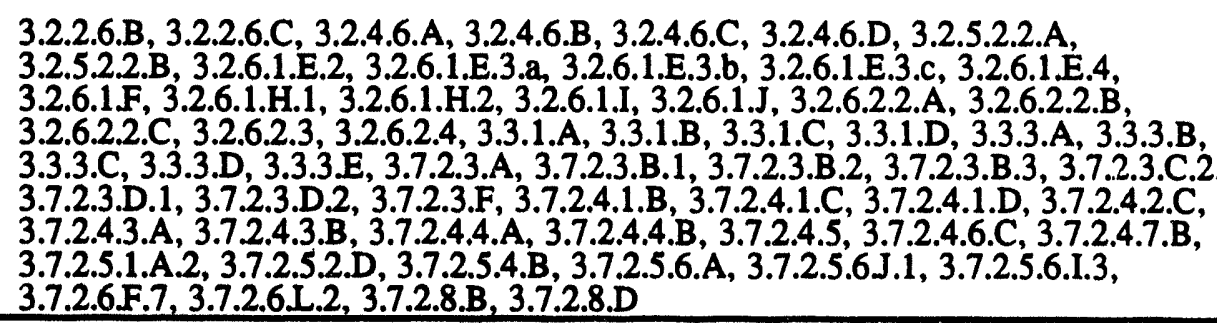 \\
\hline 3.3.1.B & 3.3.1.F \\
\hline 3.3.1.C & 3.3.1.G \\
\hline 3.3.2.A & 3.3.2.A \\
\hline 3.3.2.B & 3.3.2.B \\
\hline 3.3.2.C & 3.3.2. C \\
\hline 3.3 .3 & 3.3.3.F \\
\hline 3.3.4.A & 3.3.4.A \\
\hline 3.3.4.B & 3.3.4.B \\
\hline 3.3.5 & 3.3.5 \\
\hline 3.3.6.1.A & 3.3.6.1.A \\
\hline 3.3.6.1.B & 3.3.6.1.B \\
\hline 3.3.6.2.A & 3.3.6.2.A \\
\hline 3.3.6.2. B & 3.3.6.2.B \\
\hline 3.3.6.2. C & 3.3.6.2. C \\
\hline 3.3.6.2.D & 3.3.6.2.D \\
\hline 3.3.6.2.E.1 & 3.3.6.2.E.1 \\
\hline 3.3.6.2.E.2 & 3.3.6.2.E.2 \\
\hline 3.3.6.3.A.1 & 3.3.6.3.A.1 \\
\hline 3.3.6.3.A.2 & 3.3.6.3.A.2 \\
\hline 3.3.6.3.A.3 & 3.3.6.3.A.3 \\
\hline 3.3.6.3.A.4 & 3.3.6.3.A.4 \\
\hline 3.3.6.3.B & 3.3.6.3.B \\
\hline 3.3.6.3.C & 3.2.6.2.1.A, 3.7.2.6.F.4, 3.7.2.6.L.1. \\
\hline 3.3.6.3.D & 3.3.6.3.F, 3.7.2.4.6.B \\
\hline 3.3.6.3. $\bar{E}$ & 3.3.6.3.C \\
\hline 3.3.6.3. F & 3.3.6.3.D \\
\hline 3.3.6.3.G & 3.3.6.3.E \\
\hline
\end{tabular}


Title: Mined Geologic Disposal System Requirements Document

Table 6-3. CRD Cross-Reference (Continued)

\begin{tabular}{|c|c|}
\hline $\begin{array}{c}\text { CRD } \\
\text { PARAGRAPH }\end{array}$ & MGDS-RD PARAGRAPH \\
\hline 3.3.6.3.H & N/A (Reserved) \\
\hline 3.3.6.4.A & 3.3.6.4.A \\
\hline 3.3.6.4.B & 3.3.6.4.B \\
\hline 3.3.6.4.C & 3.3.6.4E \\
\hline 3.3.6.5 & 3.3.6.4.C, 3.3.6.5, 3.7.2.6.F.1, 3.7.2.6.F.3 \\
\hline 3.3.6.6.A & 3.3.6.6.A \\
\hline 3.3.6.6.B & 3.3.6.6.B \\
\hline 3.3.6.6.C & 3.3.6.6.C \\
\hline 3.3.6.7.A & 3.3.6.7.A \\
\hline 3.3.6.7.B & 3.3.6.7.B \\
\hline 3.3.6.7.C & 3.3.6.7.C \\
\hline 3.3.6.8.A & 3.3.6.8.A \\
\hline 3.3.6.8.B & 3.3.6.8.B \\
\hline 3.3.6.8.C & 3.3.6.8.C \\
\hline 3.3.6.8.D & 3.3.6.8.D \\
\hline 3.3.6.8.E & 3.3.6.8. E \\
\hline 3.3.6.8.F & 3.3.6.8.F \\
\hline 3.3.6.9.A & 3.3.6.10.A \\
\hline 3.3.6.9.B & 3.3.6.10.B \\
\hline 3.3.6.10.A & 3.3.6.11.A \\
\hline 3.3.6.10.B & 3.7.2.4.1. B \\
\hline 3.3.6.10.C & 3.3.6.11.B, 3.7.2.4.1.A \\
\hline 3.3.6.10.D & 3.3.6.11.C \\
\hline 3.3.7.1 & 3.3.7.1 \\
\hline 3.3.7.2 & 3.3.7.2 \\
\hline 3.3.7.3 & 3.3.7.3 \\
\hline 3.3.7.4 & 3.3.7.4 \\
\hline 3.3.7.5 & 3.3.7.5 \\
\hline 3.3.7.6 & 3.3.7.6 \\
\hline 3.3.7.7 & 3.3.7.7 \\
\hline 3.3.7.8 & 3.3.7.8 \\
\hline 3.3 .7 .9 & 3.3.7.9 \\
\hline
\end{tabular}


Title: Mined Geologic Disposal System Requirements Document

Table 6-3. CRD Cross-Reference (Continued)

\begin{tabular}{|c|c|}
\hline $\begin{array}{l}\text { CRD } \\
\text { PARAGRAPH }\end{array}$ & MGDS-RD PARAGRAPH \\
\hline 3.3 .7 .10 & 3.3 .7 .10 \\
\hline 3.3.7.11 & 3.3.7.11 \\
\hline 3.3 .7 .12 & 3.3.7.12 \\
\hline 3.3.7.13 & 3.3.7.13.A, 3.3.7.13.B \\
\hline 3.3.7.14 & 3.3.7.14 \\
\hline 3.3.8.1.A & 3.3.8.1.A \\
\hline 3.3.8.1.B & 3.3.8.1.B \\
\hline 3.3.8.1. C & 3.3.8.1.C \\
\hline 3.3.8.1.D & 3.3.8.1.D, 3.5.1.4.A, 3.5.1.4.B \\
\hline 3.3.8.2.A & 3.3.8.2.A \\
\hline 3.3.8.2.B & 3.3.8.2.B \\
\hline 3.3.8.2. C & $3.2 .3 .2 .3 \mathrm{~N}, 3.3 .8 .2 \mathrm{C}$ \\
\hline 3.3.9.A & N/A (Reserved) \\
\hline 3.3.9. B & N/A (Reserved) \\
\hline 3.3.9.C & 3.3.9.C \\
\hline 3.3.10.A & $3.3 .10 . \mathrm{A}$ \\
\hline 3.3.10.B & 3.3.10.B \\
\hline $3.3 .11 . \mathrm{A}$ & 3.3.11.A \\
\hline 3.3.11.B & 3.3.11.2.A, 3.3.11.2.B \\
\hline 3.3.11.C & 3.3.11.3.A, 3.3.11.3.A.1, 3.3.11.3.A.2, 3.3.11.3.A.3, 3.3.11.3.A.4, 3.3.11.3.A.5, \\
\hline 3.3.11.D & 3.3.11.4.A, 3.3.11.4.B, 3.7.2.4.2.B \\
\hline 3.3.11.E & 3.3.11.5 \\
\hline 3.3.11.F & 3.3.11.6 \\
\hline 3.3.11.G & 3.3.11.7 \\
\hline $3.4 .1 . \mathrm{A}$ & 3.4.1.C \\
\hline 3.4.1.B & 3.4.1.B \\
\hline 3.4.2.A & 3.4 .2 \\
\hline 3.4.2.B & N/A (Reserved) \\
\hline 3.4 .3 & 3.4 .3 \\
\hline 3.4 .4 & 3.4 .4 \\
\hline 3.4 .5 & 3.4 .5 \\
\hline
\end{tabular}


Title: Mined Geologic Disposal System Requirements Document

Table 6-3. CRD Cross-Reference (Continued)

\begin{tabular}{|c|c|}
\hline $\begin{array}{l}\text { CRD } \\
\text { PARAFRAPH }\end{array}$ & MGDS-RD PARAGRAPH \\
\hline 3.4.6.A & 3.4.6.A \\
\hline 3.4.6.B & 3.4.6. B \\
\hline 3.4 .7 & 3.4.7 \\
\hline 3.4.8 & 3.4 .8 \\
\hline 3.5.1 & 3.5.1 \\
\hline 3.5.1.1.A & 3.5.1.1.1. B \\
\hline 3.5.1.1.B & 3.5.1.1.1.C \\
\hline 3.5.1.1.C & 3.5.1.1.1.D \\
\hline 3.5 .1 .2 & 3.5.1.2.A, 3.5.1.2. B \\
\hline 3.5.1.3 & N/A Reserved) \\
\hline 3.5.1.4 & 3.5.1.3 \\
\hline 3.5 .2 & 3.5.2 \\
\hline 3.5.3.A & 3.7.2.5.6.F.4 \\
\hline 3.5.3.B & $\begin{array}{l}\text { 3.3.11.3.A, 3.3.11.3.A.1, 3.3.11.3.A.2, 3.3.11.3.A.3, 3.3.11.3.A.4, 3.3.11.3.A.5, } \\
\text { 3.7.2.4.7.A, 3.7.2.4.8.B }\end{array}$ \\
\hline 3.5.3.C & 3.5.3.1 \\
\hline 3.5.3.D & 3.6.2.1.A \\
\hline 3.5.3. E & $3.5 .3 .5,3.7 .2 .5 .6 . F .1,3.7 .2 .5 .6 . F .2,3.7 .2 .5 .6 . F .3,3.7 .2 .5 .6 . F .5,3.7 .2 .5 .6 . \mathrm{G}$ \\
\hline 3.5.4 & 3.5.4 \\
\hline 3.6 .1 & 3.6 .1 \\
\hline 3.6.1.A & 3.6.1.A \\
\hline 3.6.1.B & N/A (Transportation, MRS) \\
\hline 3.6.1.C & $3.5 .1 . \mathrm{C}$ \\
\hline 3.6 .2 & 3.6 .2 \\
\hline 3.6.2.1.A & 3.6.2.1.B, 3.7.2.5.6.C \\
\hline 3.6.2.1.B & N/A Reserved) \\
\hline 3.6.2.1.C & 3.6.2.1.A \\
\hline 3.6.2.1.D & 3.6.2.1.B \\
\hline 3.6.2.1.E & 3.6.2.1.C \\
\hline 3.6.2.1.F & 3.7.2.5.6. C \\
\hline 3.6.2.2 & 3.6.2.2.A \\
\hline 3.7.1.2 & N/A (Waste Acceptance) \\
\hline
\end{tabular}


Title: Mined Geologic Disposal System Requirements Document

Revision: 1

Page: 195

Table 6-3. CRD Cross-Reference (Continued)

\begin{tabular}{|c|c|}
\hline $\begin{array}{l}\text { CRD } \\
\text { PARAGRAPH }\end{array}$ & MGDS-RD PARAGRAPH \\
\hline 3.7.2.2 & N/A (Transportation) \\
\hline 3.7.3.2 & N/A (MRS) \\
\hline 3.7.4.1.1 & 3.7.1.1, 3.7.2.1.A, 3.7.3.1.A \\
\hline 3.7.4.2.A & $3.7 .1 .3 . B .2,3.7 .2 .2 . B, 3.7 .2 .2 . D, 3.7 .2 .2 . E$, Appendix B to MGDS-RD \\
\hline 3.7.4.2.B & $\begin{array}{l}\text { 3.2.6.2.2.D, 3.7.1.3.B.2, 3.7.1.3.B.3, 3.7.2, 3.7.2.4.8.A, 3.7.2.5.1.A.1, 3.7.2.5.1.C, } \\
\text { 3.7.3.2.A, 3.7.3.4.A, 3.7.3.4.C }\end{array}$ \\
\hline 3.7.4.2.C & 3.2.1.3.A, 3.2.3.2.1.A \\
\hline 3.7.4.2.D & N/A (Reserved) \\
\hline 3.7.4.2.E & N/A (Reserved) \\
\hline 3.7.4.2.F & 3.7.2.2.A, 7.2.6. J.3, 3.7.3.2.B, 3.7.3.2.E.3 \\
\hline 3.7.4.2.G & N/A (Reserved) \\
\hline 3.7.4.2.H & 3.2.3.2.2.A, 3.2.3.2.2.B \\
\hline 3.7.4.2.1.1 & 3.7.2.8.C \\
\hline 3.7.4.2.1.2 & 3.2.1.7.C \\
\hline $3.7 .4 .2 \mathrm{~J}$ & 3.2.1.5.A, 3.7.2.6.D, 3.7.2.6.E.1 \\
\hline $3.7 .4 .2 \mathrm{~K} .1$ & 3.2.1.1.A, 3.7.1.1.A, 3.7.1.1.B, 3.7.1.3.A \\
\hline $3.7 .4 .2 . K .2$ & 3.2.1.1.F.1, 3.2.1.1.F.2, 3.3.11.B, 3.7.1.1.A, 3.7.1.1.B, 3.7.2.3.E \\
\hline $3.7 .4 .2 . \mathrm{K} .3$ & 3.2.1.1.H, 3.3.1.E, 3.7.1.1.A, 3.7.1.1.B \\
\hline 3.7.4.2.K.4 & 3.2.1.1.H, 3.7.1.1.A, 3.7.1.1.B \\
\hline 3.7.4.2.K.5 & 3.2.1.1.B, 3.7.1.1.A, 3.7.1.1.B, 3.7.2.7.A.5 \\
\hline $3.7 .4 .2 . \mathrm{K} .6$ & 3.2.1.1. $, 3.7 .1 .1 . \mathrm{A}, 3.7 .1 .1 . \mathrm{B}$ \\
\hline $3.7 .4 .2 . \mathrm{K} .7$ & 3.7.1.1.A, 3.7.1.1.B, 3.7.1.3.C \\
\hline 3.7.4.2. L & 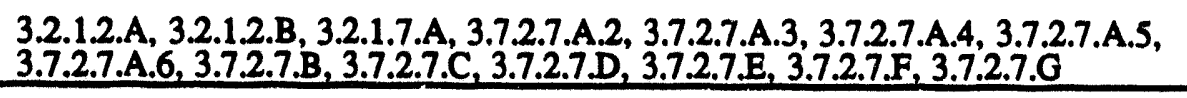 \\
\hline 3.7.4.2.M & 3.2.1.5.B \\
\hline 3.7.4.2. N & 3.2.1.7.B \\
\hline 3.7.4.2.0 & 3.5.3.4 \\
\hline 3.7.5.1.2 & Requirements to be developed \\
\hline 3.7.5.2.2 & Requirements to be developed \\
\hline 3.8.A & 3.8.A \\
\hline 3.8.B & 3.8.B \\
\hline 3.8.C & 3.3.6.2.E.1, 3.3.6.2.E.2, 3.8.C \\
\hline 3.9.A & 3.9 \\
\hline
\end{tabular}


Title: Mined Geologic Disposal System Requirements Document

Table 6-3. CRD Cross-Reference (Continued)

\begin{tabular}{|c|c|}
\hline $\begin{array}{c}\text { CRD } \\
\text { PARAGRAPH }\end{array}$ & MGDS-RD PARAGRAPH \\
\hline 3.9.B & N/A (Reserved) \\
\hline 5.1 & 5.1 \\
\hline 5.2 & 5.2 \\
\hline $\begin{array}{l}\text { Appendix A- DOE } \\
5480.4\end{array}$ & 3.2.1.2.C \\
\hline Appendix A-10CFR20 & $3.2 .2 .1 . \mathrm{B}$ \\
\hline $\begin{array}{l}\text { Appendix A- } \\
\text { 40CFR191 }\end{array}$ & 3.2.2.1.G \\
\hline Appendix A-10CFR20 & 3.2.2.3.B \\
\hline Appendix A-10CFR20 & 3.2.2.4.B \\
\hline $\begin{array}{l}\text { Appendix A- } \\
49 \text { CFR177 } \\
\end{array}$ & 3.2.3.2.3.E \\
\hline $\begin{array}{l}\text { Appendix A- } \\
\text { 10CFR60 3.3.1.B }\end{array}$ & 3.2.5.1.4.A \\
\hline $\begin{array}{l}\text { Appendix A- } \\
\text { 10CFR60 3.3.1.B }\end{array}$ & 3.2.5.1.4.B \\
\hline $\begin{array}{l}\text { Appendix A- DOE } \\
4700.1\end{array}$ & 3.2.5.2.8.A \\
\hline $\begin{array}{l}\text { Appendix A- } \\
\text { UCRL15910 } \\
\end{array}$ & 3.2.6.1.D \\
\hline $\begin{array}{l}\text { Appendix A- Reg } \\
\text { Gulde } 1.76 \\
\end{array}$ & 3.2.6.1.E.1 \\
\hline $\begin{array}{l}\text { Appendix A-Exec } \\
\text { Order } 11988 \\
\end{array}$ & 3.2.6.1.G.1 \\
\hline $\begin{array}{l}\text { Appendix A-Exec } \\
\text { Order } 11988 \\
\end{array}$ & 3.2.6.1.G.2 \\
\hline Appendix A-30CFR57 & 3.2.6.2.5 \\
\hline $\begin{array}{l}\text { Appendix A- NUREG } \\
0700\end{array}$ & 3.3.11.8 \\
\hline $\begin{array}{l}\text { Appendix A- } \\
\text { ANSIHFS 100-1988 }\end{array}$ & 3.3 .11 .9 \\
\hline Appendix A-30CFR57 & 3.5.1.1.1.E \\
\hline $\begin{array}{l}\text { Appendix A- } \\
\text { 40CFR191 }\end{array}$ & 3.7.2.2.C \\
\hline $\begin{array}{l}\text { Appendix A- BLM } \\
\text { Manual }\end{array}$ & 3.7.2.3.C.1 \\
\hline $\begin{array}{l}\text { Appendix A-DOE } \\
6430.1 \mathrm{~A}\end{array}$ & 3.7.2.4.2.A \\
\hline
\end{tabular}


Title: Mined Geologic Disposal System Requirements Document

Table 6-3. CRD Cross-Reference (Continued)

\begin{tabular}{|c|c|}
\hline $\begin{array}{c}\text { CRD } \\
\text { PARAGRAPH }\end{array}$ & MGDS-RD PARAGRAPH \\
\hline $\begin{array}{l}\text { Appendix A- DOE } \\
6430.1 \mathrm{~A}\end{array}$ & 3.7.2.4.2.B \\
\hline $\begin{array}{l}\text { Appendix A- DOE } \\
6430.1 \mathrm{~A}\end{array}$ & 3.7.2.5.1.B \\
\hline $\begin{array}{l}\text { Appendix A- DOE } \\
5480.7 \text {, DOE } 6430.1 \mathrm{~A}\end{array}$ & 3.7.2.5.4.C \\
\hline $\begin{array}{l}\text { Appendix A- DOE } \\
5480.7\end{array}$ & 3.7.2.5.4.D \\
\hline $\begin{array}{l}\text { Appendix A- DOE } \\
3790.1 \mathrm{~A}\end{array}$ & 3.7.2.5.6. B \\
\hline $\begin{array}{l}\text { Appendix A- DOE } \\
\text { 3790.1A }\end{array}$ & 3.7.2.5.6.D \\
\hline $\begin{array}{l}\text { Appendix A- } \\
4 \text { CFR101 }\end{array}$ & 3.7.2.5.6.E.1 \\
\hline 3.3.1.B & 3.7.2.5.6.E.3 \\
\hline $\begin{array}{l}\text { Appendix A- DOE } \\
4700.1\end{array}$ & 3.7.2.5.6.1.1 \\
\hline $\begin{array}{l}\text { Appendix A- } \\
\text { 29CFR1910, } \\
\text { 27CFR55, DOE } \\
\text { 5480.4, DOE 6430.1A }\end{array}$ & 3.7.2.5.6J.1 \\
\hline Appendix A-27CFR55 & 3.7.2.5.6 J.2.a \\
\hline Appendix A-27CFR55 & 3.7.2.5.6.J.2.b \\
\hline 3.3.1.B & 3.7.2.6.A.1 \\
\hline 3.3.1.B & 3.7.2.6.A.2 \\
\hline 3.3.1.B & 3.7.2.6.A.3 \\
\hline 3.3.1.B & 3.7.2.6.A.4 \\
\hline 3.3.1.B & 3.7.2.6.B.1 \\
\hline 3.3.1.B & 3.7.2.6.B.2 \\
\hline 3.3.1.B & 3.7.2.6.B.3 \\
\hline 3.3.1.B & 3.7.2.6.C. 1 \\
\hline 3.3.1.B & 3.7.2.6.C.2 \\
\hline 3.3.1.B & 3.7.2.6.C.3 \\
\hline 3.3.1.B & 3.7.2.6.E.2 \\
\hline 3.3.1.B & 3.7.2.6.F.2 \\
\hline 3.3.1.B & 3.7.2.6.F.5 \\
\hline Appendix A-30CFR57 & $3.7 .2 .6 . G .1$ \\
\hline
\end{tabular}


Title: Mined Geologic Disposal System Requirements Document Revision: 1

Table 6-3. CRD Cross-Reference (Continued)

\begin{tabular}{|c|c|}
\hline $\begin{array}{c}\text { CRD } \\
\text { PABAGRAPH }\end{array}$ & MGDS-RD PARAGRAPH \\
\hline 3.3.1. B & 3.7.2.6.G.2 \\
\hline 3.3.1.B & $3.7 .2 .6 . \mathrm{H}$ \\
\hline 3.3.1.B & 3.7.2.6.1 \\
\hline 3.3.1.B & $3.7 .2 .6 \mathrm{~J} .1$ \\
\hline 3.3.1.B & $3.7 .2 .6 \mathrm{~J} .2$ \\
\hline $\begin{array}{l}\text { Appendix A- DOE } \\
\text { 5980.7, DOE 6430.1A }\end{array}$ & 3.7.2.6.L.3 \\
\hline $\begin{array}{l}\text { Appendix A- DOE } \\
5480.7\end{array}$ & 3.7.2.6.L.4 \\
\hline $\begin{array}{l}\text { Appendix A- DOE } \\
3990.1 \mathrm{~A}\end{array}$ & 3.7.2.6.M \\
\hline 3.3.1. B & 3.7.2.8.E \\
\hline 3.3.1.B & 3.7.3.2.C \\
\hline 3.3.1.B & 3.7.3.2.D \\
\hline 3.3.1.B & 3.7.3.2.E.1 \\
\hline 3.3.1. B & 3.7.3.2.E.2 \\
\hline 3.3.1.B & 3.7.3.3.G.1 \\
\hline 3.3.1.B & \begin{tabular}{|l|}
3.7 .3 .3 .6 .2 \\
\end{tabular} \\
\hline 3.3.1.B & $\begin{array}{l}3.7 .3 .3 . G .3 \\
\end{array}$ \\
\hline 3.3.1.B & 3.7.3.3.G.4 \\
\hline
\end{tabular}


Title: Appendix A, Site Characterization System Requirements

Revision: 1

Page: $A-i$

Table of Contents

Page

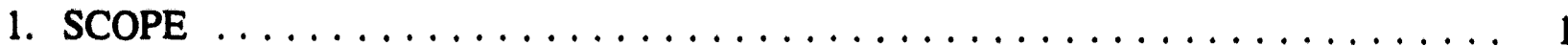

1.1 IDENTIFICATION $\ldots \ldots \ldots \ldots \ldots \ldots \ldots \ldots \ldots \ldots \ldots \ldots, 1$

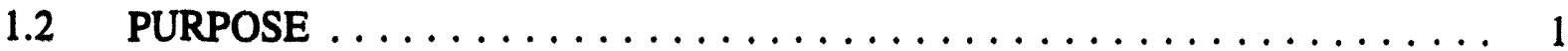

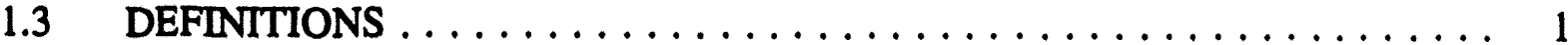

1.4 CHARACTERIZATION PROCESS $\ldots \ldots \ldots \ldots \ldots \ldots \ldots \ldots \ldots 14$

2. APPLICABLE DOCUMENTS $\ldots \ldots \ldots \ldots \ldots \ldots \ldots \ldots \ldots \ldots \ldots$

2.1 GOVERNMENT DOCUMENTS $\ldots \ldots \ldots \ldots \ldots \ldots \ldots \ldots \ldots \ldots \ldots$

2.1.1 Laws, Statutes, U.S. Codes, and Treaties .................. 19

2.1.2 Code of Federal Regulations and Executive Orders . . . . . . . . . 19

2.2 OTHER REFERENCES $\ldots \ldots \ldots \ldots \ldots \ldots \ldots \ldots \ldots \ldots \ldots \ldots$

3. SITE CHARACTERIZATION REQUIREMENTS $\ldots \ldots \ldots \ldots \ldots \ldots \ldots \ldots$

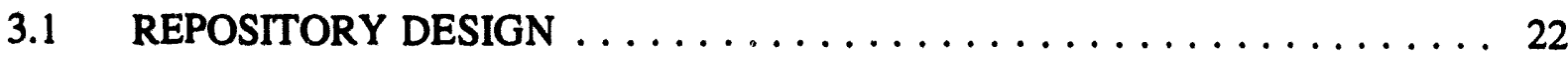

3.1.1 Configuration of Underground Facilities (Postclosure) $\ldots \ldots \ldots \ldots 23$

A. General Criteria for the Underground Facility. $\ldots \ldots \ldots \ldots \ldots \ldots 23$

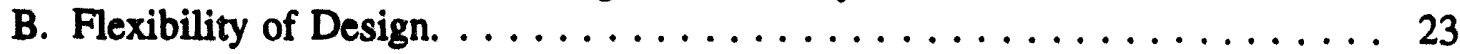

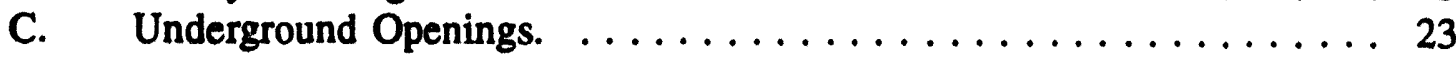

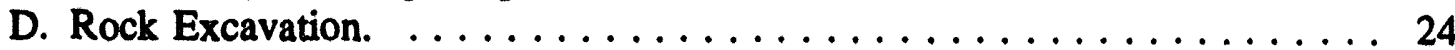

E. Engineered Barriers. $\ldots \ldots \ldots \ldots \ldots \ldots \ldots \ldots \ldots \ldots \ldots, 24$

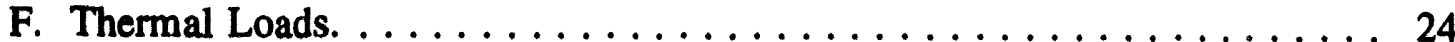

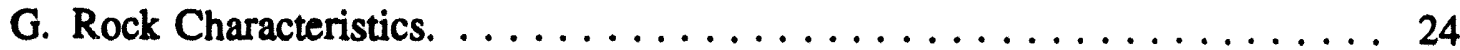

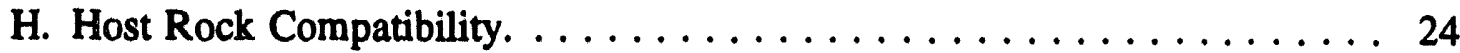

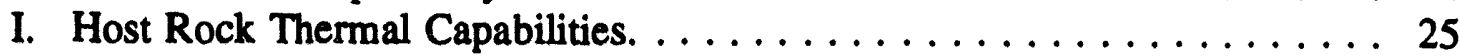

J. Reasonable Available Technologies. . . . . . . . . . . . . . 25

K. Physical, Chemical and Radiation Phenomena on Host Rock. . . . . . . . 25

L. Changes in Host Rock After Waste Emplacement. . . . . . . . . . 25

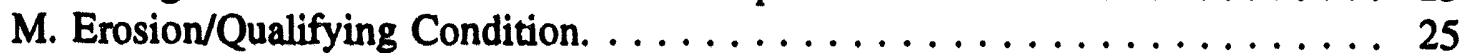

N. Waste Emplacement Depth of 300 Meters/Favorable Condition. . . . . . . 26

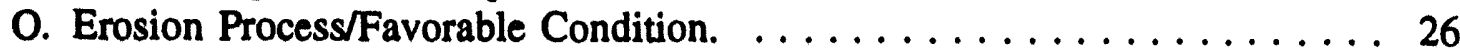

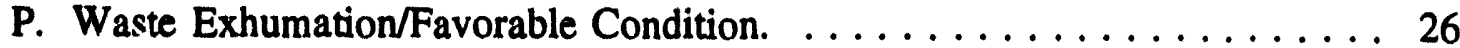

Q. Ex .eme Quatemary Period Erosion/Potentially Adverse Condition. . . . . . 26

R. Projected Quaternary Period Geomorphic Processes/Potentially Adverse

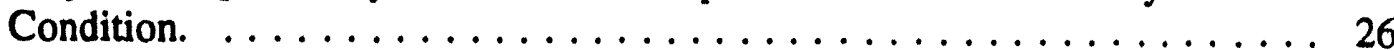

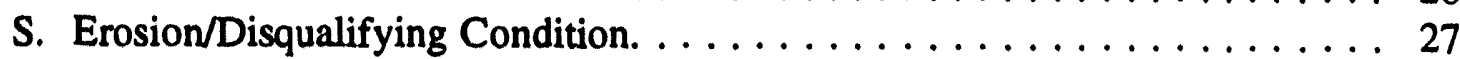


A. Radiological Protection. . . . . . . . . . . . . . . . . . 27

B. Protection Against Natural Phenomena and Environmental Conditions. . . . 28

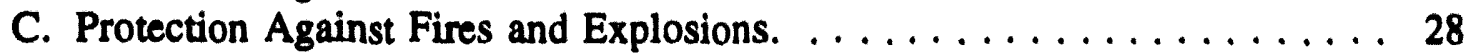

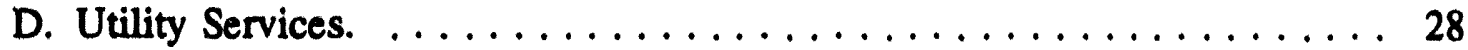

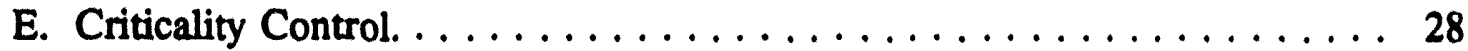

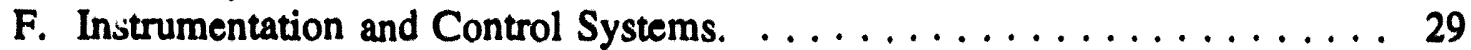

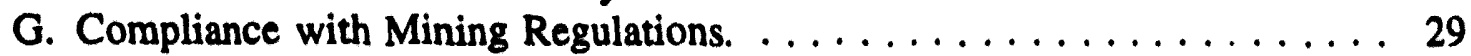

H. Facilities for Receipt and Retrieval of Waste. . . . . . . . . . . . 29

I. Surface Facility Ventilation. . . . . . . . . . . . . . . . 29

J. Radiation Control and Monitoring. $\ldots \ldots \ldots \ldots \ldots \ldots \ldots \ldots 29$

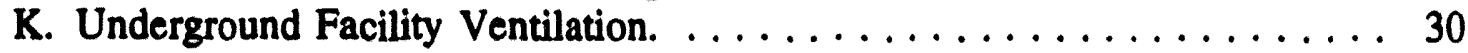

3.1.3 Worker Non-Radiological Health and Safety $\ldots \ldots \ldots \ldots \ldots \ldots$

A. Compliance with Mining Regulations. $\ldots \ldots \ldots \ldots \ldots \ldots \ldots \ldots$

B. Underground openings. $\ldots \ldots \ldots \ldots \ldots \ldots \ldots \ldots \ldots \ldots \ldots \ldots$

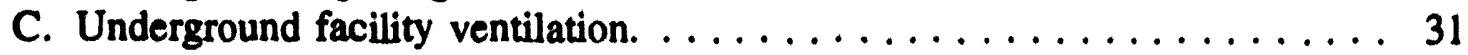

3.1.4 Preclosure Design and Technical Feasibility $\ldots \ldots \ldots \ldots \ldots \ldots \ldots$

A. Flexibility of design $\ldots \ldots \ldots \ldots \ldots \ldots \ldots \ldots \ldots \ldots \ldots \ldots \ldots$

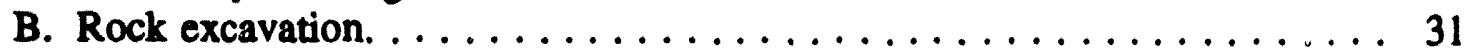

C. Water and Gas Control. ...................... 31

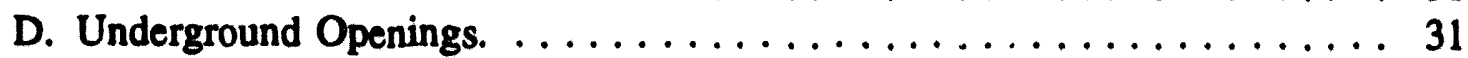

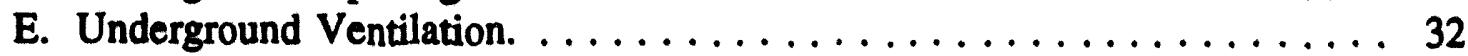

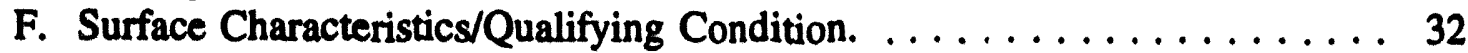

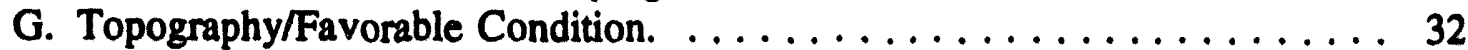

H. Flooding Due to Surface Characteristics/Potentially Adverse Condition. . . . 32

I. Pre-closure Rock Characteristics/Qualifying Condition. . . . . . . . 32

J. Host Rock Accommodation of Layout/Favorable Condition. . . . . . . 33

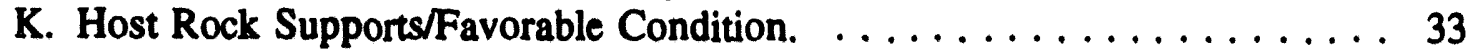

L. Minimal Flexibility of Host Rock/Potentially Adverse Condition. . . . . . 33

M. Unreasonable Technology/Potentially Adverse Condition. . . . . . . . 33

N. Excessive Maintenance/Potentially Adverse Condition. . . . . . . . 33

O. Safety Hazards/Retrieval Difficulty/Potentially Adverse Condition. . . . . . 33

P. Water Inflow/Construction Problems/Potentially Adverse Condition. . . . . 34

Q. Pre-closure Rock Characteristics/Disqualifying Condition. ........ 34

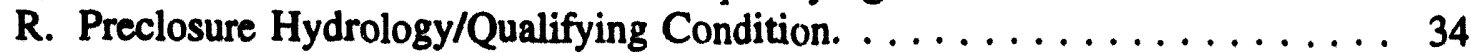

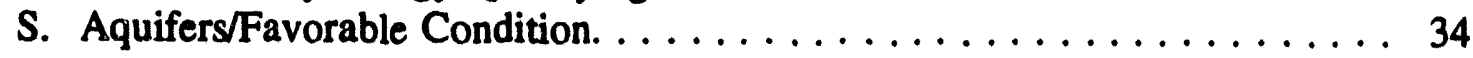

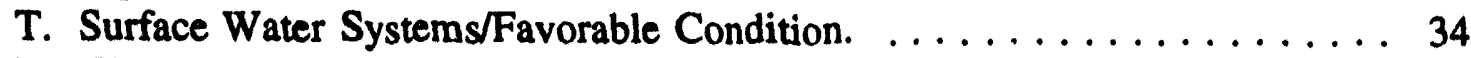

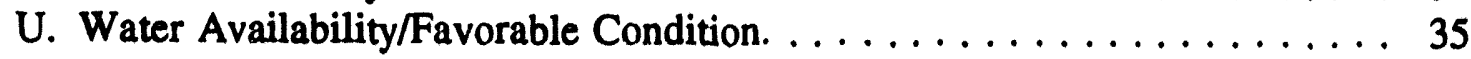

V. Unreasonable Technology/Potentially Adverse Condition. . . . . . . 35

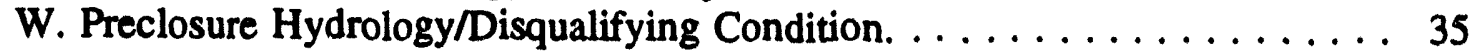

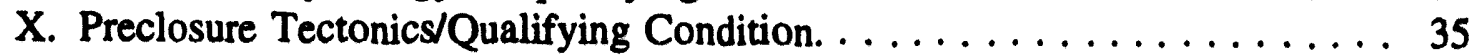


Title: Appendix A, Site Characterization System Requirements

Revision: 1

Page: A - iii

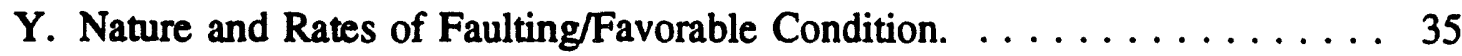

Z. Active Faulting/Potentially Adverse Condition. ............. 35

AA. Ground Motion/Potentially Adverse Condition. ............ 36

BB. Earthquake Magnitude Exceeding Historical Data/Potentially Adverse Condition. .......................... 36

CC. Preclosure Tectonics/Disqualifying Condition. ........... 36

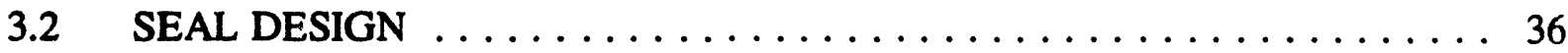

3.2.1 Seal Characteristics $\ldots \ldots \ldots \ldots \ldots \ldots \ldots \ldots \ldots \ldots \ldots \ldots, 37$

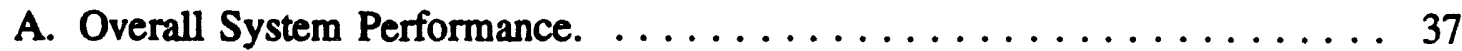

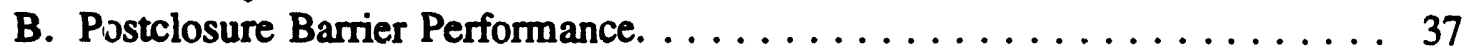

C. General Design Criterion. $\ldots \ldots \ldots \ldots \ldots \ldots \ldots \ldots \ldots \ldots \ldots$

D. Selection of Materials and Placement Methods. ............ 38

E. Design Testing. ........................ 38

$3.3 \quad$ WASTE PACKAGE $\ldots \ldots \ldots \ldots \ldots \ldots \ldots \ldots \ldots \ldots \ldots \ldots \ldots$

3.3.1 Waste Package Characteristics (Postclosure) $\ldots \ldots \ldots \ldots \ldots \ldots \ldots$

3.3.2 Waste Package Characteristics (Preclosure) $\ldots \ldots \ldots \ldots \ldots \ldots \ldots . \ldots . \ldots$

3.3.3 Waste Package Production Technologies ................ 40

Ease and Cost of Siting, Construction, Operation, and Closure. . . . . . . 40

3.4 PRECLOSURE PERFORMANCE REQUIREMENTS $\ldots \ldots \ldots \ldots \ldots .40$

3.4.1 Waste Retrievability $\ldots \ldots \ldots \ldots \ldots \ldots \ldots \ldots \ldots \ldots, 40$

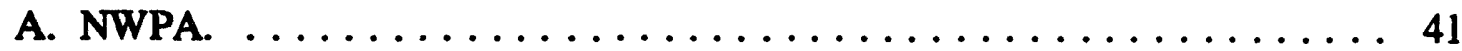

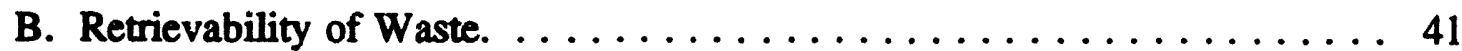

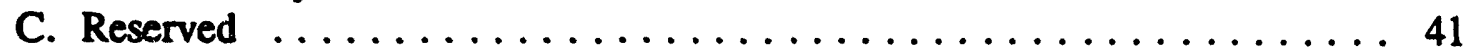

D. Reserved .......................... 41

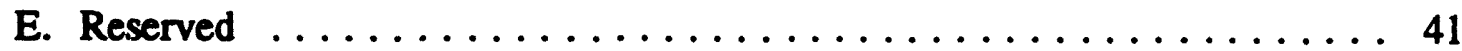

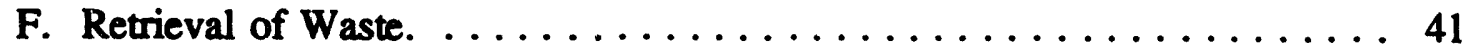

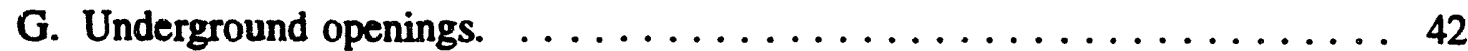

H. Handling. ..................... 42

3.4.2 Public Radiological Exposures-Normal Conditions $\ldots \ldots \ldots \ldots \ldots \ldots 4$

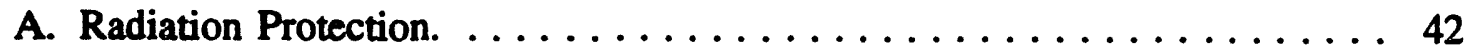

B. Public Dose Limits. . . . . . . . . . . . . . . . . . . . 42

C. Public Dose Limit Compliance. .................... 43

D. Limits on Radiation Doses to Public. ................. 44

3.4.3 Performance Objective for Preclosure Radiological Safety-Worker . . . . . 44 
A. Radiation Protection. . . . . . . . . . . . . . . . . . 44

B. Design for Radiological Protection. . . . . . . . . . . . . . . . . 45

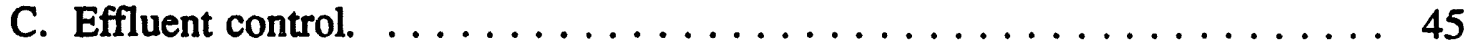

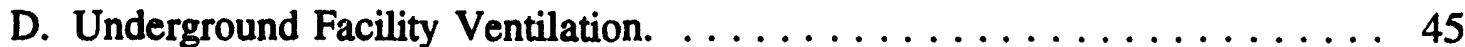

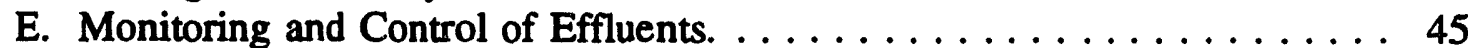

F. Radiation Protection Design Criteria. . . . . . . . . . . . . . 45

G. Surface Ventilation. . . . . . . . . . . . . . . . . . . . 46

3.4.4 Accidental Radiological Releases $\ldots \ldots \ldots \ldots \ldots \ldots \ldots \ldots \ldots$

3.4.5 Higher Level Findings-Preclosure Radiological Safety . . . . . . . . . . . . 47

A. Preclosure Radiological Safety/System Guideline . . . . . . . . . . 47

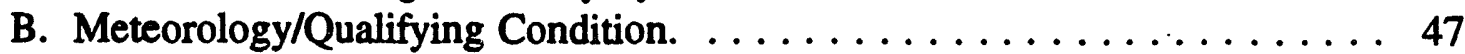

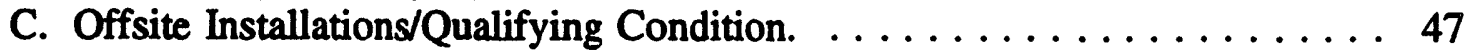

D. Offsite Installations/Disqualifying Condition. $\ldots \ldots \ldots \ldots \ldots \ldots$

3.4.6 Higher Level Findings-Ease and Cost of Construction . . . . . . . . . 48

A. Construction, Operation, and Closure/System Guideline. . . . . . . . . 48

B. Surface Characteristics/Qualifying Condition. . . . . . . . . . . . . 48

C. Pre-closure Rock Characteristics/Qualifying Condition. . . . . . . . 48

D. Pre-closure Rock Characteristics/Disqualifying Condition. . . . . . . . . . 48

E. Preclosure Hydrology/Qualifying Condition. . . . . . . . . . . . 49

F. Preclosure Hydrology/Disqualifying Condition. . . . . . . . . . . . . 49

G. Preclosure Tectonics/Qualifying Condition. . . . . . . . . . . . . . . 49

H. Preclosure Tectonics/Disqualifying Condition. . . . . . . . . . . 49

3.5 POSTCLOSURE PERFORMANCE REQUIREMENTS $\ldots \ldots \ldots \ldots \ldots 49$

3.5.1 Containment by Waste Package $\ldots \ldots \ldots \ldots \ldots \ldots \ldots \ldots \ldots \ldots$

3.5.2 Engineered Barrier System Release Rates . . . . . . . . . . . . 50

3.5.3 Groundwater Travel Time $\ldots \ldots \ldots \ldots \ldots \ldots \ldots \ldots \ldots \ldots \ldots$

3.5.4 Performance Objective for 10,000 Year Cumulative Releases ......... 51

A. Permanent Closure Performance. ................. 51

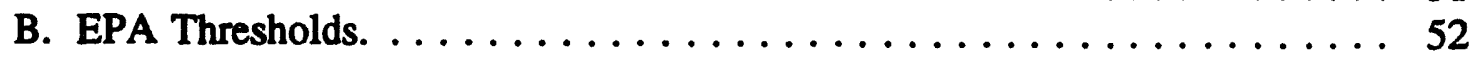

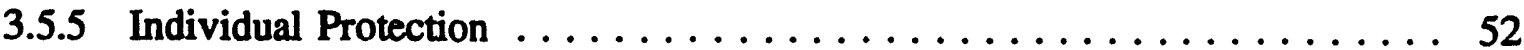

3.5.6 Protection of Special Groundwater Sources $\ldots \ldots \ldots \ldots \ldots \ldots \ldots \ldots . \ldots 53$

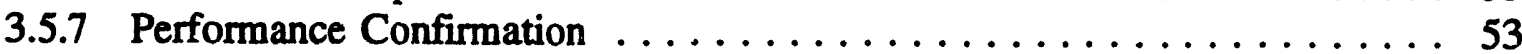

$3.5 .8 \quad$ NRC Siting Criteria $\ldots \ldots \ldots \ldots \ldots \ldots \ldots \ldots \ldots \ldots \ldots \ldots \ldots \ldots \ldots$

A. The Nature and Rates of Tectonic, Hydrogeologic, Geochemical, and Geomorphic Processes. . . . . . . . . . . . . . . . . . . . . . . 54

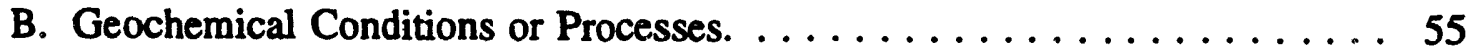


Title: Appendix A, Site Characterization System Requirements Revision: 1

Page: A - v

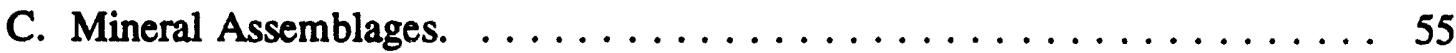

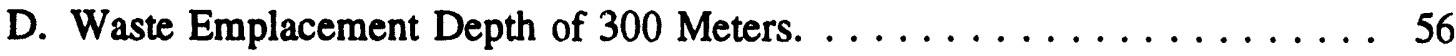

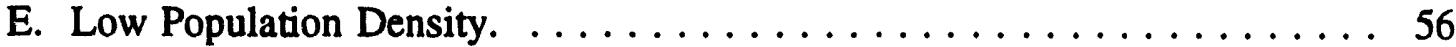

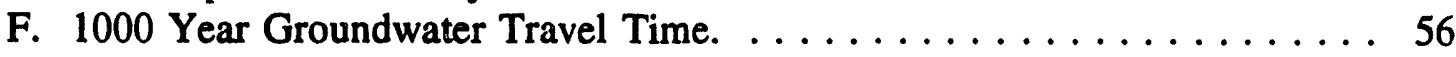

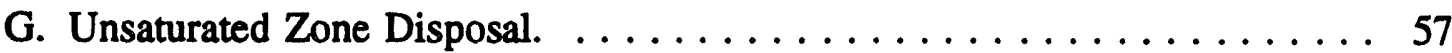

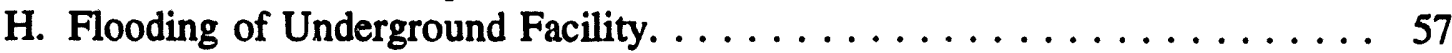

I. Human Activities. $\ldots \ldots \ldots \ldots \ldots \ldots \ldots \ldots \ldots \ldots \ldots, \ldots \ldots$

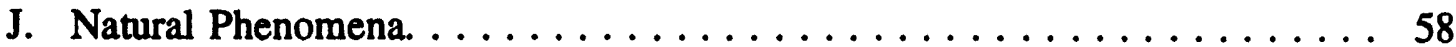

K. Tectonic Deformation. ....................... 59

L. Geohydrologic Changes. . .................... 59

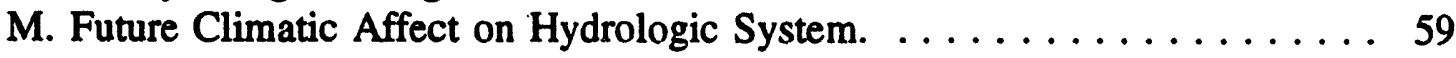

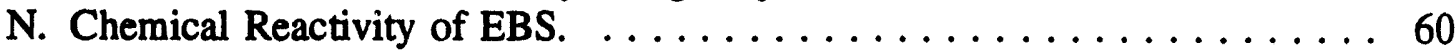

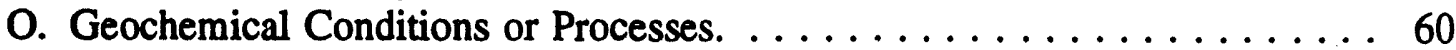

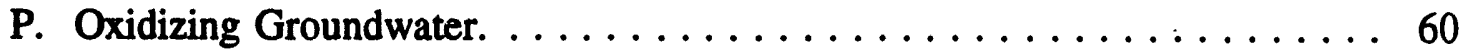

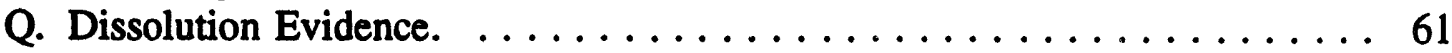

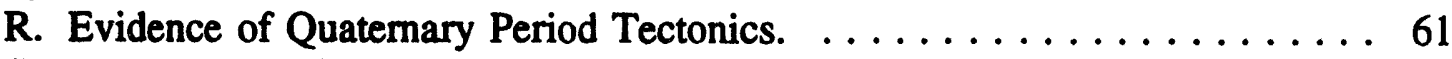

S. Historical Earthquakes. . . . . . . . . . . . . . . . . . 61

T. Increase in Frequency/Magnitude of Earthquakes. . . . . . . . 61

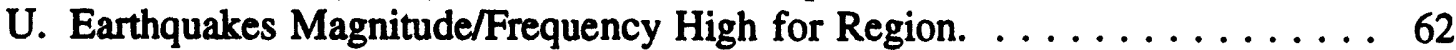

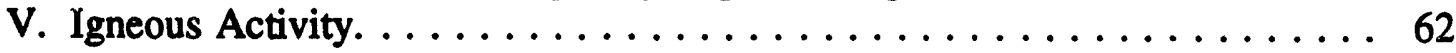

W. Extreme Quaternary Period Erosion. ................. 62

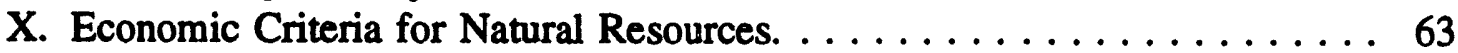

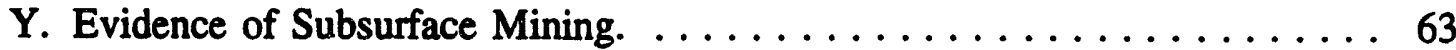

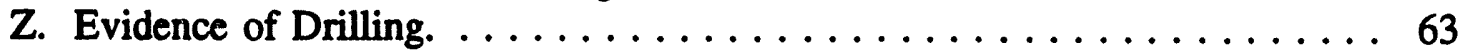

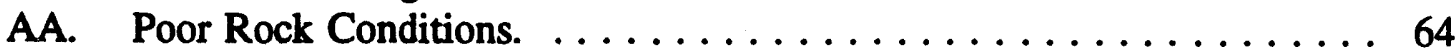

BB. Water Table Rise. ....................... 64

CC. Unpredictable Geology . . . . . . . . . . . . . . . 65

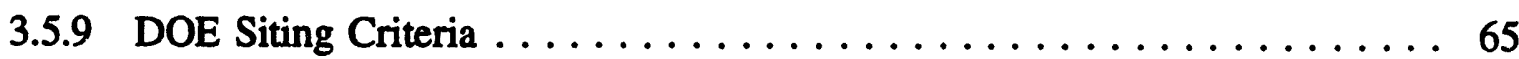

A. Postclosure System Guideline/Qualifying Condition. . . . . . . . 65

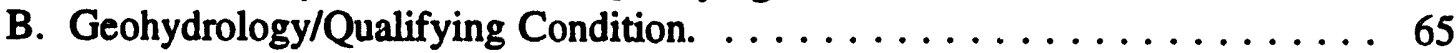

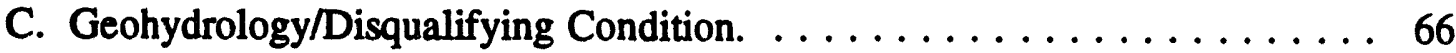

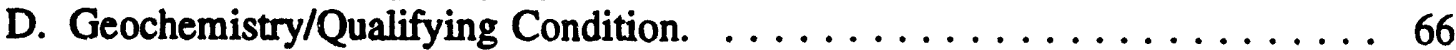

E. Rock Characteristics/Qualifying Condition. .............. 66

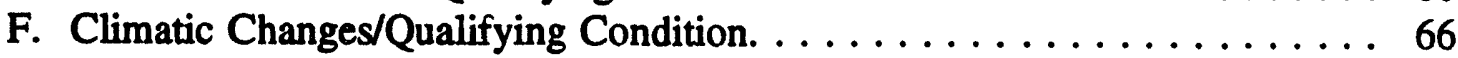

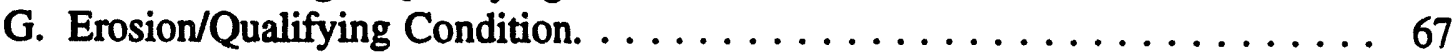

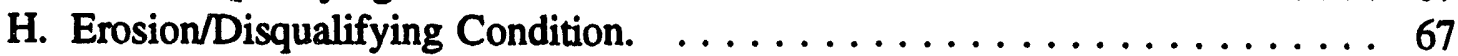

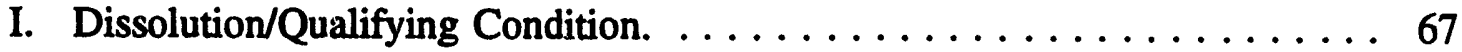

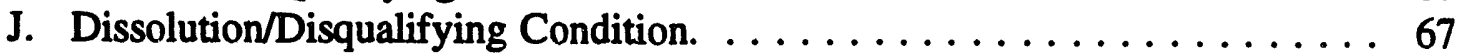

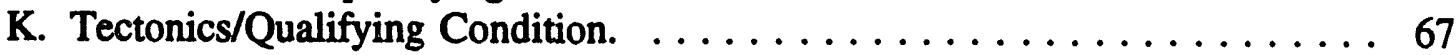

L. Tectonics/Disqualifying Condition. $\ldots \ldots \ldots \ldots \ldots \ldots \ldots \ldots 68 \ldots \ldots \ldots$

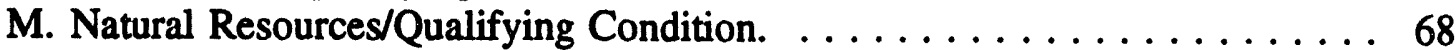

N. Natural Resources/Disqualifying Condition No $1 . \ldots \ldots \ldots \ldots \ldots 68$

O. Natural Resources/Disqualifying Condition No $2 . \ldots \ldots \ldots \ldots \ldots 68$ 
Title: Appendix A, Site Characterization System Requirements Revision: 1

Page: $A-v i$

3.5.10 Additional DOE Siting Criteria 68

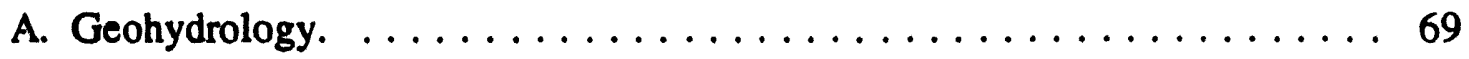

B. Geochemistry. . . . . . . . . . . . . . . . . . . . . . 69

C. Reserved. . . . . . . . . . . . . . . . . . . . . . 69

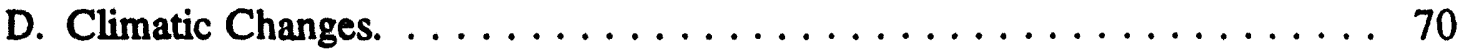

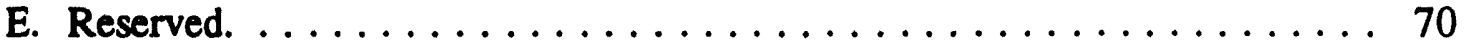

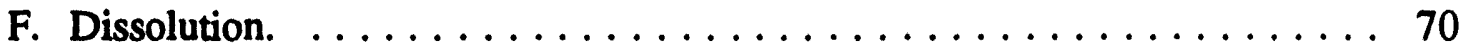

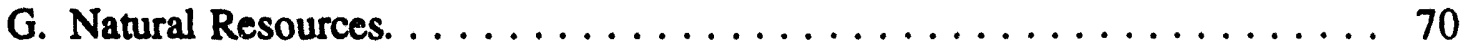

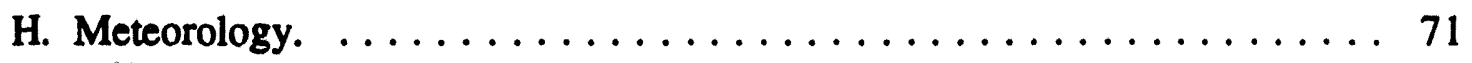

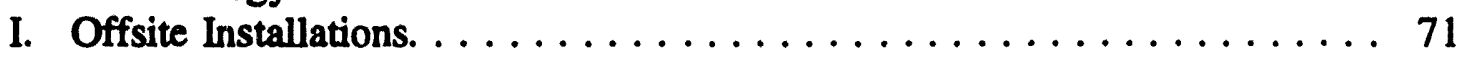




\section{SCOPE}

\subsection{IDENTIFICATION}

This appendix to the MGDS Requirements Documeat summarizes the site characterization requirements of 10 CFR Part 60, "Disposal of High-Level Radioactive Wastes in Geologic Repositories". Additionally, the Technical Guidelines of 10 CFR Part 960, "General Guidelines for the Recommendation of Sites for Nuclear Waste Repositories," are provided with the corresponding 10 CFR Part 60 requirements.

In the Nuclear Waste Policy Act 1982, the U.S. Congress directed the Department of Energy (DOE) to conduct a program for siting the nation's first geologic repository for disposal of spent fuel from commercial reactors, high level waste from defense activities, and a small quantity of commercial high level waste. One of the three sites to be reviewed as a part of DOE's geologic repository program was Yucca Mountain. In December 1987, Congress designated, in the Nuclear Waste Policy Amendments Act, Yucca Mountain as the single candidate for site characterization.

Site characterization is a comprehensive program of detailed investigations that will be conducted at Yucca Mountain in order to determine whether the site is suitable for a geologic repository. If the site is suitable, then DOE must demonstrate to the Nuclear Regulatory Commission (NRC) that the site meets regulations intended to protect the health and safety of the public. The requirements promulgated by the NRC in 10 CFR Part 60 , form the basis for the site characterization requirements that are defined within this document.

\subsection{PURPOSE}

The purpose of this appendix is to establish the requirements basis at the program level from which the project can develop the specific requirements to be addressed during site characterization, thus providing a path of traceability from the source requirement to the site characterization activities required. The project will identify the specific studies, plans, and activities in the Site Design and Test Requirements Document and in the subordinate study plans.

\subsection{DEFINITIONS}

The following words/phrases listed in this section are used in this document. The definitions of these words/phrases for both 10 CFR Part 60 and 10 CFR Part 960 are formatted in columns to allow for a ready comparison between the two different document definitions. The column title identifies the origin of the definition. The origin of the definition used shall be the same as the origin of the requirement where the word/phrase is being utilized. 


\section{CFR Part 60.2}

Accessible environment. (1) The atmosphere, (2) the land surface, (3) surface water, (4) oceans, and (5) the portion of the lithosphere that is outside the controlled area.

Active fault. No definition.

Anticipated processes and events. Those natural processes and events that are reasonably likely to occur during the period the intended performance objective must be achieved. To the extent reasonable in the light of the geologic record, it shall be assumed that those processes operating in the geologic setting during the Quaternary Period continue to operate but with the perturbations caused by the presence of emplaced radioactive waste superimposed thereon.

Aquifer. No definition listed.

Barrier. Any material or structure that prevents or substantially delays movement of water or radionuclides.

Closure. No definition listed.

Commission. The Nuclear Regulatory Commission or its duly authorized representatives.

Confining Unit. No definition listed.

\section{CFR Part 960.2}

Accessible environment. No definition.

Active fault. A fault along which there is recurrent movement, which is usually indicated by small, periodic displacements or seismic activity.

Anticipated processes and events. No definition listed.

Aquifer. A formation, a group of formations, or a part of a formation that contains sufficient saturated permeable material to yield significant quantities of water to wells and springs.

Barrier. Any material or structure that prevents or substantially delays the movement of water or radionuclides.

Closure. Synonymous with permanent closure.

Commission. No definition listed.

Confining unit. A body of impermeable or distinctly less permeable material stratigraphically adjacent to one or more aquifers. 


\section{CFR Part 60.2}

Containment. The confinement of radioactive waste within a designated boundary.

Controlled area. A surface location, to be marked by suitable monuments, extending horizontally no more than 10 kilometers in any direction from the outer boundary of the underground facility, and the underlying subsurface, which area has been committed to use as a geologic repository and from which incompatible activities would be restricted following permanent closure.

Decommissioning. No definition listed.

Disposal. The isolation of radioactive wastes from the accessible environment.

Disqualifying Condition. No definitions listed.

Disturbed zone. That portion of the controlled area the physical or chemical properties of which have changed as a result of underground facility construction or as a result of heat generated by the emplaced radioactive wastes such that the resultant change of properties may have a significant effect on the performance of the geologic repository.

\section{CFR Part 960.2}

Containment. The continement of radioactive waste within a designated boundary.

Controlled area. A surface location, to be marked by suitable monuments, extending horizontally no more than 10 kilometers in any direction from the outer boundary of the underground facility, and the underlying subsurface, which area has been committed to use as a geologic repository and from which incompatible activities would be prohibited before and after permanent closure.

Decommissioning. The permanent removal from service of surface facilities and components necessary for preclosure operations only, after repository closure, in accordance with regulatory requirements and environmental policies.

Disposal. The emplacement in a repository of high-level radioactive waste, spent nuclear fuel, or other highly radioactive material with no foreseeable intent of recovery, whether or not such emplacement permits the recovery of such waste, and the isolation of such waste from the accessible environment.

Disqualifying condition. A condition that, if present at a site, would eliminate that site from further consideration.

Disturbed zone. That portion of the controlled area, excluding shafts, whose physical or chemical properties are predicted to change as a result of underground facility construction or heat generated by the emplaced radioactive waste such that the resultant change of properties could have a significant effect on the performance of the geologic repository. 


\section{CFR Part 60.2}

DOE. The U.S. Department of Energy or its duly authorized representatives.

Effective porosity. No definition listed.

Engineered barrier system. The waste packages and the underground facility.

Expected repository performance. No definition listed.

Facility. No definition listed.

Fault. No definition listed

Faulting. No definition listed.

\section{CFR Part 960.2}

DOE. The U.S. Department of Energy or its duly authorized representatives.

Effective porosity. The amount of interconnected pore space and fracture openings available for the transmission of fluids, expressed as the ratio of the volume of interconnected pores and openings to the volume of rock.

Engineered-barrier system. The manmade components of a disposal system designed to prevent the release of radionuclides from the underground facility or into the geohydrologic setting. Such term includes the radioactive-waste form, radioactive-waste canisters, materials placed over and around such canisters, any other components of the waste package, and barriers used to seal penetrations in and into the underground facility.

Expected repoeitory performance. The manner in which the repository is predicted to function, considering those conditions, processes, and events that are likely to prevail or may occur during the time period of interest.

Facility. Any structure, system, or system component, including engineered barriers, created by the DOE to meet repository-performance or functional objectives.

Fault. A fracture or a zone of fractures along which there has been displacement of the side relative to one another parallel to the fracture or zone of fractures.

Faulting. The process of fracturing and displacement that produces a fault. 


\section{CFR Part 60.2}

Favorable condition. No definition listed.

Geohydrologic setting. No definition listed.

Geohydrologic system. No definition listed.

Geohydrologic unit. No definition listed.

Geologic repository. A system which is intended to be used for, or may be used for, the disposal of radioactive wastes in excavated geologic media. A geologic repository includes: (1) The geologic repository operations area, and (2) the portion of the geologic setting that provides isolation of the radioactive waste.

Geologic repository operations area. A high-level radioactive waste facility that is part of a geologic repository, including both surface and subsurface areas, where waste handling activities are conducted.

Geologic setting. The geologic, hydrologic, and geochemical systems of the region in which a geologic repository operations area is or may be located.

\section{CFR Part 960.2}

Favorable condition. A condition that, though not necessary to qualify a site, is presumed, if present, to enhance confidence that the qualifying condition of a particular guideline can be met.

Geohydrologic setting. The system of geohydrologic units that is located within a given geologic setting.

Geohydrologic system. The geohydrologic units within a geologic setting, including any recharge, discharge, interconnections between units, and any natural or man-induced processes or events that could affect ground-water flow within or among those units.

Geohydrologic unit. An aquifer, a confining unit, or a combination of aquifers and confining units comprising a framework for a reasonably distinct geohydrologic system.

Geologic repository. A system, requiring licensing by the NRC, that is intended to be used, or may be used, for the disposal of radioactive waste in excavated geologic media. A geologic repository includes (1) the geologic-repository operations area and (2) the portion of the geologic setting that provides isolation of the radioactive waste and is located within the controlled area.

Geologic-repository operations area. A radioactive-waste facility that is part of the geologic repository, including both surface and subsurface areas and facilities where waste-handling activities are conducted.

Geologic setting. The geologic, hydrologic, and geochemical systems of the region in which a geologic-repository operations area is or may be located. 


\section{CFR Part 60.2}

Geomorphic Processes. No definitions listed.

Groundwater. All water which oscurs below the land surface.

Ground-water flux. No definition listed.

Ground-water sources. No definition listed.

Ground-water travel time. No definition listed.

\section{CFR Part 960.2}

Geomorphic processes. Geologic processes that are responsible for the general configuration of the Earth's surface, including the development of present landforms and their relationships to underlying structures, and are responsible for the geologic changes recorded by these surface features.

Ground water. All subsurface water as distinct from surface water.

Ground-water flux. The rate of ground-water flow per unit area of porous or fractured media measured perpendicular to the direction of flow.

Ground-water sources. Aquifers that have been or could be economically and technologically developed as sources of water in the foresecable future.

Ground-water travel time. The time required for a unit volume of ground water to travel between two locations. The travel time is the length of the flow path divided by the velocity, where velocity is the average ground-water flux passing through the cross-sectional area of the geologic medium through which flow occurs, perpendicular to the flow direction, divided by the effective porosity along the flow path. If discrete segments of the flow path have different hydrologic properties, the total travel time will be the sum of the travel times for each discrete segment. 


\section{CFR Part 60.2}

High-level radioactive waste (HLW). Irradiated reactor fuel, (2) liquid wastes resulting from the operation of the first cycle solvent extraction system, or equivalent, and the concentrated wastes from subsequent extraction cycles, or equivalent, in a facility for reprocessing irradiated reactor fuel, and (3) solids into which such liquid wastes have been converted.

HLW facility. A facility subject to the licensing and related regulatory authority of the Commission pursuant to Sections 202(3) and 202(4) of the Energy Reorganization Act of 1974 (88 Stat 1244).

Host rock. The geologic medium in which the waste is emplaced.

Hydraulic conductivity. No definition listed.

Hydraulic gradient. No definition listed.

Hydrologic process. No definition listed.

Igneous activity. No definition listed.

\section{CFR Part 960.2}

High-level radioactive waste. (1) the highly radioactive material resulting from the reprocessing of spent nuclear fuel, including liquid waste produced directly in reprocessing and any solid material derived from such liquid waste that contains fission products in sufficient concentrations and (2) other highly radioactive material that the NRC, consistent with existing law, determines by rule requires permanent isolation.

HLW facillty. No definition listed.

Host rock. The geologic medium in which the waste is emplaced, specifically the geologic materials that directly encompass and are in close proximity to the underground facility.

Hydraulic conductivity. The volume of water that will move through a medium in a unit of time under a unit hydraulic gradient through a unit area measured perpendicular to the direction of flow.

Hydraulic gradient. A change in the static pressure of ground water, expressed in terms of the height of water above a datum, per unit of distance in a given direction.

Hydrologic process. Any hydrologic phenomenon that exhibits a continuous change in time, whether slow or rapid.

Igneous activity. The emplacement (intrusion) of molten rock material (magma) into material in the Earth's crust or the expulsion (extrusion) of such material onto the Earth's surface or into its atmosphere or surface water. 


\section{CFR Part 60.2}

Important to safety. With reference to structures, systems, and components means those engineered structures, systems, and components essential to the prevention or mitigation of an accident that could result in a radiation dose to the whole body, or any organ, of $0.5 \mathrm{rem}$ or greater at or beyond the nearest boundary of the unrestricted area at any time until the completion of permanent closure.

Isolation. Inhibiting the transport of radioactive material so that amounts and concentrations of this material entering the accessible environment will be kept within prescribed limits.

Likely. No definition listed.

Lithouphere. No definition listed.

Member of the Public. No definition listed.

\section{CFR Part 960.2}

Important to safety. No definition listed.

Ieolation. Inhibiting the transport of radioactive material so that the amounts and concentrations of this material entering the accessible environment will be kept within prescribed limits.

Likely. Processing or displaying the qualities, characteristics, or attributes that provide a reasonable basis for confidence that what is expected indeed exists or will occur.

Lithosphere. The solid part of the Earth, including any ground water contained within it.

Member of the public. Any individual who is not engaged in operations involving the management, storage, and disposal of radioactive waste. A worker so engaged is a member of the public except when on duty at the geologic-repository operations area. 


\section{CFR Part 60.2}

Mitigation. No definition listed.

Model. No definition listed.

NRC. No definition listed.

Perched ground-water. No definition listed.

Permanent closure. Final backfilling of the underground facility and the sealing of shafts and boreholes.

Pootclosure. No definition listed.

\section{CFR Part 960.2}

Mitigation. (1) avoiding the impact altogether by not taking a certain action or parts of an action; (2) minimizing impacts by limiting the degree or magnitude of the action and its implementation; (3) rectifying the impact by repairing, rehabilitating, or restoring the affected environment; (4) reducing or eliminating the impact over time by preservation and maintenance operations during the life of the action; or (5) compensating for the impact by replacing or providing substitute resources or environments.

Model. A conceptual description and the associated mathematical representation of a system, subsystem, component, or condition that is used to predict changes from a baseline state as a function of internal and/or external stimuli and as a function of time and space.

NRC. The U.S. Nuclear Regulatory

Commission or its duly authorized representatives.

Perched ground water. Unconfined ground water separated from an underlying body of ground water by an unsaturated zone. Its water table is a perched water table. Perched ground water is held up by a perching bed whose permeability is so low that water percolating downward through it is not able to bring water in the underlying unsaturated zone above atmospheric pressure.

Permanent Closure. (Synonymous w/closure) Final backfilling of the remaining open operational areas of the underground facility and boreholes after the termination of waste emplacement, culminating in the sealing of shafts.

Postclosure. The period of time after the closure of the geologic repository. 


\section{CFR Part 60.2}

Preclosure. No definition listed.

Pre-waste emplacement. No definition listed.

Potentially adverse condition. No definition listed.

Qualinying condition. No definition listed.

Quaternary period. No definition listed.

Radioactive waste or waste. HLW and other radioactive materials other than HLW that are received for emplacement in a geologic repository.

Radioactive waste facility. No definition listed.

Radionuclide retardation. No definition listed.

\section{CFR Part 960.2}

Preclosure. The period of time before and during the closure of the geologic repository.

Pre-waste-emplacement. Before the authorization of repository construction by the NRC.

Potentially adverse condition. A condition that is presumed to detract from expected system performance, but further evaluation, additional data, or the identification of compensating or mitigating factors may indicate that its effect on the expected system performance is acceptable.

Qualinying condition. A condition that must be satisfied for a site to be considered acceptable with respect to a specific guideline.

Quaternary Period. The second period of the Cenozoic Era, following the Tertiary, beginning 2 to 3 million years ago and extending to the present.

Radioactive waste or waste. High-level radioactive waste and other radioactive materials, including spent nuclear fuel, that are received for emplacement in a geologic repository.

Radioactive-waste facility. A facility subject to the licensing and related regulatory authority of the NRC pursuant to Sections 202(3) and 202(4) of the Energy Reorganization Act of 1974 (88 Stat. 1244).

Radionuclide retardation. The process or processes that cause the time required for a given radionuclide to move between two locations to be greater than the ground-water travel time, because of physical and chemical interactions between the radionuclide and the geohydrologic unit through which the radionuclide travels. 
10 CFR Part 60.2

Reasonably available technology. No definition listed.

Repository. No definition listed.

Repository construction. No definition listed.

Repository operation. No definition listed.

Restricted area. Any area access to which is controlled by the licensee for purposes of protection of individuals from exposure to radiation and radioactive materials.

"Restricted area" shall not include any areas used as residential quarters, although a separate room or rooms in a residential building may be set apart as a restricted area.

Retrieval. The act of intentionally removing radioactive waste from the underground location at which the waste had been previously emplaced for disposal.
10 CFR Part 960.2

Reasonably available technology. Technology which exists and has been demonstrated or for which the results of any requisite development, demonstration, or confirmatory testing efforts before application will be available within the required time period.

Repository. Synonymous with "geologic repository."

Repository construction. All excavation and mining activities associated with the construction of shafts, shaft stations, rooms, and necessary openings in the underground facility, preparatory to radioactive-waste emplacement, as well as the construction of necessary surface facilities, but excluding site-characterization activities.

Repository operation. All of the functions at the site leading to and involving radioactive-waste emplacement in the underground facility, including receiving, transportation, handling, emplacement, and, if necessary, retrieval.

Restricted area. Any area access to which is controlled by the DOE for purposes of protecting individuals from exposure to radiation and radioactive materials before repository closure, but not including any areas used as residential quarters, although a separate room or rooms in a residential building may be set apart as a restricted area.

Retrieval. The act of intentionally removing radioactive waste before repository closure from the underground location at which the waste had been previously emplaced for disposal. 


\section{CFR Part 60.2}

Saturated zone. That part of the earth's crust beneath the regional water table in which all voids, large and small, are ideally filled with water under pressure greater than atmospheric.

Site. The location of the controlled area.

Site characterization. The program of exploration and research, both in the laboratory and in the field, undertaken to establish the geologic conditions and the ranges of those parameters of a particular site relevant to the procedures under this part. Site characterization includes borings, surface excavations, excavation of exploratory shafts, limited subsurface lateral excavations and borings, and in situ testing at depth needed to determine the suitability of the site for a geologic repository, but does not include preliminary borings and geophysical testing needed to decide whether site characterization should be undertaken.

Siting. No definition listed.

Source term. No definition listed.

Spent nuclear fuel. No definition listed.

\section{CFR Part 960.2}

Saturated zone. That part of the Earth's crust beneath the water table in which all voids, large and small, are ideally filled with water under pressure greater than atmospheric.

Site. A potentially acceptable site or a candidate site, as appropriate, until such time as the controlled area has been established, at which time the site and the controlled area are the same.

Site characterization. Activities, whether in the laboratory or in the field, undertaken to establish the geologic conditions and the ranges of the parameters of a candidate site relevant to the location of a repository, including borings, surface excavations, excavations of exploratory shafts, limited subsurface lateral excavations and borings, and in situ testing needed to evaluate the suitability of a candidate site for the location of a repository, but not including preliminary borings and geophysical testing needed to assess whether site characterization should be undertaken.

Siting. The collection of exploration, testing, evaluation, and decision-making activities associated with the process of site screening, site nomination, site recommendation, and site approval for characterization or repository development.

Source term. The kinds and amounts of radionuclides that make up the source of a potential release of radioactivity.

Spent nuclear fuel. Fuel that has been withdrawn from a nuclear reactor following irradiation, the constituent elements of which have not been separated by reprocessing. 


\section{CFR Part 60.2}

Surface facilities. No definition listed.

Surface water. No definition listed.

System. No definition listed.

Unanticipated processes and events. Those processes and events affecting the geologic setting that are judged not to be reasonably likely to occur during the period the intended performance objective must be achieved, but which are nevertheless sufficiently credible to warrant consideration. Unanticipated processes and events may be either natural processes or events or processes and events initiated by human activities other than those activities licensed under this part. Processes and events initiated by human activities may only be found to be sufficiently credible to warrant consideration if it is assumed that:

(1) The monuments provided for by this part are sufficiently permanent to serve their intended purpose; (2) the value to future generations of potential resources within the site can be assessed adequately under the applicable provisions of this part; (3) an understanding of the nature of radioactivity, and an appreciation of its hazards, have been retained in some functioning institutions; (4) institutions are able to assess risk and to take remedial action at a level of social organization and technological competence equivalent to, or superior to, that which was applied in initiating the processes or events concerned; and (5) relevant records are preserved, and remain accessible, for several hundred years after permanent closure.

\section{CFR Part 960.2}

Surface facilities. Repository support facilities within the restricted area.

Surface water. Any waters on the surface of the Earth, including fresh and salt water, ice, and snow.

System. The geologic setting at the site, the waste package, and the repository, all acting together to contain and isolate the waste.

Unanticipated processes and events. No definition listed. 


\section{CFR Part 60.2}

Underground facility. The underground structure, including openings and backfill materials, but excluding shafts, boreholes, and their seals.

Unrestricted area. Any area, access to which is not controlled by the licensee for purposes of protection of individuals from exposure to radiation and radioactive materials, and any area used for residential quarters.

Unsaturated zone. The zone between the land surface and the regional water table. Generally, fluid pressure in this zone is less than atmospheric pressure, and some of the voids may contain air or other gases at atmospheric pressure. Beneath flooded areas or in perched water bodies the fluid pressure locally may be greater than atmospheric.

Waste form. No definition listed.

Waste package. The waste form and any containers, shielding, packing and other absorbent materials immediately surrounding an individual waste container.

Water table. That surface in a groundwater body at which the water pressure is atmospheric.

\section{CFR Part 960.2}

Underground facility. The underground structure and the rock required for support, including mined openings and backfill materials, but excluding shafts, boreholes, and their seals.

Unrestricted area. No definition listed.

Unsaturated zone. The zone between the land surface and the water table. Generally, water in this zone is under less than atmospheric pressure, and some of the voids may contain air or other gases at atmospheric pressure. Beneath flooded areas or in perched water bodies, the water pressure locally may be greater than atmospheric.

Waste form. The radioactive waste materials and any encapsulating or stabilizing matrix.

Waste package. The waste form and any containers, shielding, packing, and other sorbent materials immediately surrounding an individual waste container.

Water table. That surface in a body of ground water at which the water pressure is atmospheric.

\subsection{CHARACTERIZATION PROCESS}

Site-characterization is intended to provide information needed to address the requirements of the general guidelines for the recommendation of suitable sites as issued by DOE in 10 CFR Part 960 and of the regulations promulgated for the licensing of geologic repositories by the NRC in 10 CFR Part 60.

Site characterization is an element of the site-characterization program which comprises a detailed program of investigations which will determine whether the "candidate site" at Yucca Mountain is suitable for a repository and, if it is suitable, to demonstrate to the NRC that the site meets 
regulations intended to protect the health and safety of the public both during repository operations (preclosure) and after the repository has been closed (postclosure). To demonstrate to the NRC that the Mined Geologic Disposal System (MGDS) - the site, the repository, and the engineered barrier system (EBS) - will perform as required, the DOE must also develop designs for the repository and the EBS and conduct scientific assessments to determine that the performance of the repository system will meet all regulations.

The site-characterization program has been documented by DOE in the Site Characterization Plan, or SCP. The Nuclear Waste Policy Act, as amended, specifies that the SCP include a description of the Yucca Mountain site, a description of the planned site-characterization activities, a description of the packaging to be used for the waste, a conceptual design of the repository, and any other information that the NRC may specify. The requirements of the Act are repeated by the NRC in its regulations (10 CFR Part 60), which include some additional specifications (e.g., requirements for a quality assurance program).

The site-characterization program is defined in Part B of the SCP, which is Chapter 8 of the document.

As defined in the SCP, DOE's approach to the site-characterization program is based on a strategy which is related to the role that the features of the Yucca Mountain site are expected to play in achieving the general objectives of the system. The strategy is based on:

- The assumption that the major potential release of radionuclides will be from the transport of waste material by water moving down through the unsaturated zone, interacting with failures in the EBS, continuing movement down to the saturated zone and horizontal movement to the accessible environment. The strategy is to use the characteristics of the mountain to retard this motion and to design the EBS to prevent release. This requires a thorough understanding of the unsaturated zone (to include geochemical conditions), the saturated zone and the EBS.

- A second mechanism for transport would be through the release of gaseous radionuclides from breached disposal containers and movement up through the air spaces of the unsaturated rock. Because there is not current evidence to indicate whether the rock will be effective in retarding this movement, the strategy is to focus on the ability of the EBS to limit the release of gaseous radionuclides.

- Because the features described above are relied upon to achieve the objectives of the system, it is additionally important that site characterization investigates the disruptive events and processes that could significantly alter the features.

- Finally, it is necessary to emphasize preclosure radiation safety, both in the surface and underground facilities. Although standard techniques are expected to apply, some site investigations will be performed to support them. 
To establish its approach to site-characterization, the SCP defines two organizing principles - an issues hierarchy and a general strategy for issue resolution. The issues hierarchy is a three-tiered framework of questions which lays out what must be known before the site can be found suitable and licensed. It states four key issues, which are derived from the system guidelines of 10 CFR Part 960, with consideration to the strategy defined above. The system guidelines of 10 CFR Part 960 address the major performance objectives of 10 CFR Part 60 for radiological safety. The second tier of issues address the performance and design requirements of 10 CFR Part 60 , while the third tier consists of information needs. Because of this derivation, the information needs are expected to correlate to the site characterization requirements stated in section 3.0 of this document.

The derivation of these issues represents the first stage of the issue resolution strategy. The second stage is the performance allocation stage which represents the planning for the tests. It is initiated with the development of a site licensing strategy which is a statement of the site features, engineering features, conceptual models, and analyses that DOE expects to use in resolving the issues (i.e. meeting the requirements). These are the features that will be investigated. The next step is to define performance measures for these features, to include a tentative goal for the measure and a statement of needed confidence in the measure. This leads to the development of specific information needs which are the basis for the development of a testing strategy.

The testing strategy is followed by a cyclical or iterative process stage of test, analysis, evaluation and feedback to retesting as required.

As planned, the tests to be conducted are incorporated into a set of investigations which are known as the site program. This consists of sixteen characterization programs developed to address appropriately related investigations. These are:

Geohydrology

Geochemistry

Rock Characteristics

Climate

Erosion

Rock Dissolution

Postclosure Tectonics

Human Interference

Population Density and Distribution

Land Ownership and Mineral Rights

Meteorology

Offsite Installations

Surface Characteristics

Thermal and Mechanical Rock Properties

Preclosure Hydrology

Preclosure Tectonics 
As the tests and analyses are completed, information is used to resolve the issues and the resolution is documented.

As currently planned, site data will be iteratively incorporated into conceptual and numerical models for use in performance assessment. Performance assessment for the MODS includes predictions of preclosure radiological releases as well as long-term predictions of repository system performance. Initially, the inputs will be based primarily on data from surface-based testing and laboratory studies, then combining some early ESF testing and finally incorporating ESF testing in the ESF facility. The results of performance assessments and conceptual model development will be fed back into the testing program, as required, or will support determinations of test completion. Site data will also feed into the repository and waste package designs and into the Site Characterization Semi-Annual Progress Reports that are provided to the NRC every six months.

It is essential that the site characterization program be focused to support the site evaluation, the Environmental Impact Statement, and the License Application. The results of testing will be continually fed into the preparation of these reports to assure their needs are being met.

The test and assessment program described above has been documented in the Site Characterization Plan. The requirements for the program are further defined in the Site Design and Test Requirements document and the subordinate study plans. The general process of site characterization is discussed in the program and project test documentation. The licensing process is defined in the Regulatory Guidance Document and supported by the process of developing the license application through an Annotated Outline. These documents will evolve as the process of iterative characterization testing and performance assessment continues. 


\section{APPLICABLE DOCUMENTS}

This section identifies documents which have been referenced as sources of requirements or guidance for the Appendix A. The documents are included to provide traceability to the source documents and are not to be incorporated as requirements themselves.

The following documents, of the issue in effect on the date of the approval of this document form a part of the MGDS requirements to the degree specified herein.

\subsection{GOVERNMENT DOCUMENTS}

\subsubsection{Laws, Statutes, U.S. Codes, and Treaties}

Identifier Title or Deacrintion

A. 42 USC 10101 et seq. Nuclear Waste Policy Act of 1982 (NWPA, P.L. 97-425) and Nuclear Waste Policy Amendments Act of 1987 (NWPAA, P.L. 100-203)

\subsection{Code of Federal Regulations and Executive Orders}

Identifier

A. 10 CFR 20

B. 10 CFR 60

C. 10 CFR 960

D. 40 CFR 191

\section{Title or Decrintion}

Standards for Protection Against Radiation

Disposal of High-Level Radioactive Wastes in Geologic Repositories

General Guidelines for the Recommendation of Sites for Nuclear Waste Repositories

Environmental Radiation Protection Standards for Management and Disposal of Spent Nuclear Fuel, High-Level and Transuranic Radioactive Wastes.'

1 The Energy Act of 1992 nullified the effectiveness of 40 CFR 191 on the MODS. To provide a basis for design to proceed, requitements have been derived /rom the 14: veraion of 40 CFR 191 and are subject to review until replaced. 
Title: Appendix A, Site Characterization System Requirements

\subsection{OTHER REFERENCES}

This section identifies documents that have not been used as sources of requirements, but are provided here for reference.

\section{Identifier Title or Deacriotion}

A. DOE/RW-DRAFT Physical Systems Requirements - Exploratory Studies Facility (DRAFT)

B. SAIC-91/8000 Report of Early Site Suitability Evaluation of the Potential Repository Site at Yucca Mountain, Nevada, dated January 1992.

C. YMP/91-25 Testing Priorities at Yucca Mountain: Recommended Early Tests to Detect Potentially Unsuitable Conditions for a Nuclear Waste Repository

D DOE/RW-0199 Site Characterization Plan 


\section{STTE CHARACTERIZATION REQUIREMENTS}

This section states those requirements of 10 CFR Part 60 and 10 CFR Part 960 for which site characterization information must be obtained in support of the Site Characterization Program and by extension, in support of the development of the Site Evaluation Report and the License Application. In order to provide a recognizable connection to the Site Characterization Plan (SCP) the site characterization requirements have been organized to parallel SCP sections 8.3.2 through 8.3.5 as shown in Table 3-1. (Note that, as a result of patterning this appendix after the SCP it is different in its organization than the main body, and some of the terminology is also different.)

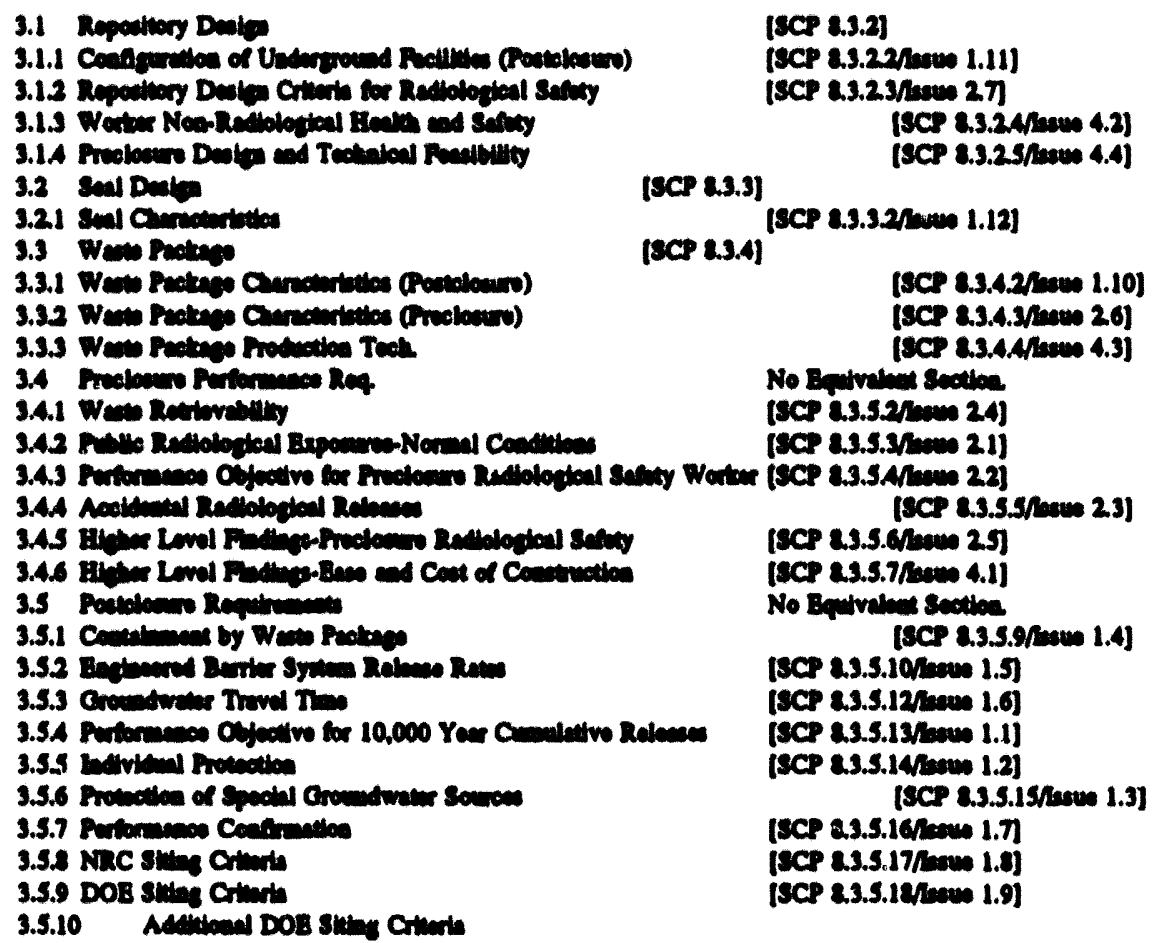

[EC 0.3 .2$]$

[scP 2.3.22/ane 1.11]

ISCP 2.3.23/ave 27]

[sCe 8.3.24/nan 4.2]

(sCP 8.3.25/Anum 4.4)

[SCP 8.3.3]

[sce 8.3.4]

[SCP 8.3.3.21mum 1.12]

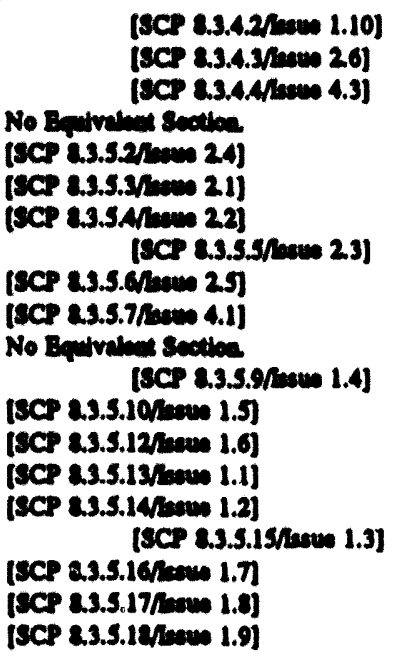

[SCP 8.3.4.2/mew 1.10]

[SCP 8.3.4.3/mem 2.6]

[SCP 8.3.4.4/men 4.3]

(1) 22

[scP 8.3.5.650un 25$]$

[SCP 23.5.7nsam 4.1]

[SCP 8.3.5.9/20w 1.4]

[SCP 8.3.5.15/hewe 1.3]

1.8

[SCP 8.3.5.12/5ew 1.9]

Table 3-1

The NRC established in 10 CFR 60 a list of Favorable Conditions (FCs) and Potentially Adverse Conditions (PACs), which must be addressed in the license application of the MGDS. The DOE in 10 CFR 960 established guidelines with corresponding Qualifying Conditions (QCs), Disqualifying Conditions (DCs), FCs, and PACs for the evaluation and comparison of multiple sites for a nuclear waste repository. The FCs and PACs were originally only being used to predict the suitability of a site for characterization and provide a preliminary indication of system performance before start of detailed site characterization studies. Further, the PACs and FCs were being considered and used in the identification and comparison of potentially acceptable sites, and in the nomination and recommendation of sites as suitable for characterization. Although, the FCs and PACs are not requirements for determining the suitability of the site for development, they are, nonetheless, included in this appendix as requiring information to support the evaluation of QCs and DCs in support of the recommendation for site development which 
is addressed in Appendix B, Site Suitability Evaluation Criteria.

Section 3.5.8 lists the 10 CFR 60.122 FCs and PACs. If a corresponding 10 CFR 960 condition exists it has been listed directly below the 10 CFR 60 condition. The grouping of the 10 CFR 60 requirements and the 10 CFR 960 requirements has been done to ensure that the subtle differences between the similar conditions are addressed when the required exploration and research are being identified. The 10 CFR 960 FCs and PACs which do not have a corresponding 10 CFR 60 FC or PAC are listed in Section 3.5.10.

The requirements listed in this section are the source requirements for all the regulatory needs for the Site Characterization Program. Currently, the exploration and research requirements are direct quotes; however, as the Repository Program matures and subsequently as the Site Characterization Program matures, decisions will be made which will allow for clarification/elaboration of the site characterization requirements listed in this appendix. These decisions and their effect on the site characterization source requirements will be documented in this Appendix and in Appendix B as appropriate.

The traceability matrix which shows a correlation between sections in this Appendix and the corresponding source requirement is included in Table 6.2 in the main body of this document.

\subsection{REPOSTTORY DESIGN}

The repository design requirements detailed in 10 CFR 60.131 to 10 CFR 60.133 that require exploration and research are quoted within this section in the one or more of the following subsections:

\subsubsection{Configuration of Underground Facilities (Postclosure)}

3.1.2 Repository Design Criteria for Radiological Safety

3.1.3 Worker Non-Radiological Health and Safety

3.1.4 Preclosure Design and Technical Feasibility

The design requirements previously mentioned (10 CFR 60.131 to 10 CFR 60.133) do not all require exploration and research. The requirements that do not require exploration and research are listed as follows:

10 CFR 60.131(a)(2)

10 CFR 60.131(a)(5)

10 CFR 60.131(b)(2)

10 CFR 60.131(b)(3)(ii)

10 CFR 60.131(b)(3)(iv)

10 CFR 60.131(b)(4)(i)

10 CFR 60.131(b)(4)(ii)

10 CFR 60.131(b)(5)(ii)

10 CFR 60.131(b)(5)(iii) 
10 CFR 60.131(b)(6)

10 CFR 60.131(b)(10)(i)

10 CFR 60.131(b)(10)(ii)

10 CFR 60.131(b)(10)(iii)

10 CFR 60.131(b)(10)(iv)

10 CFR 60.132(c)(2)

10 CFR 60.132(d)

10 CFR 60.132(e)

10 CFR 60.133(a)(2)

10 CFR 60.133(g)(3)

\subsubsection{Configuration of Underground Facilities (Postclosure)} [SCP 8.3.2.2/1ssue 1.11]

Exploration and research are required in response to the regulation(s) listed in this section. The information required is needed to support repository characteristics and configurations such as repository depth, dip, orientation, geometry, layout, access location, thermal loading, drainage or moisture control, construction materials, backfill, excavation techniques, and opening stability.

A. General Criteria for the Underground Facility. Provide the exploration and research that are required in order to design for the following requirement(s):

"The orientation, geometry, layout, and depth of the underground facility, and the design of any engineered barriers that are part of the underground facility shall contribute to the containment and isolation of radionuclides."

[10 CFR 60.133(a)(1)]

B. Flexibility of Dedign. Provide the exploration and research that are required in order to design for the following requirement(s):

"The underground facility shall be designed with sufficient flexibility to allow adjustments where necessary to accommodate specific site conditions identified through in situ monitoring, testing, or excavation."

[10 CFR 60.133(b)]

C. Underground Openings. Provide the exploration and research that are required in order to design for the following requirement(s):

"Openings in the underground facility shall be designed to reduce the potential for deleterious rock movement or fracturing of overlying or surrounding rock."

[10 CFR 60.133(e)(2)] 
D. Rock Excavation. Provide the exploration and research that are required in order to design for the following requirement(s):

"The design of the underground facility shall incorporate excavation methods that will limit the potential for creating a preferential pathway for groundwater to contact the waste packages or radionuclide migration to the accessible environment."

[10 CFR 60.133(f)]

E. Engineered Barriers. Provide the exploration and research that are required in order to design for the following requirement(s):

"Engineered barriers shall be designed to assist the geologic setting in meeting the performance objectives for the period following permanent closure."

[10 CFR 60.133(h)]

F. Thermal Loads. Provide the exploration and research that are required in order to design for the following requirement(s):

"The underground facility shall be designed so that the performance objectives will be met taking into account the predicted thermal and thermomechanical response of the host rock, and surrounding strata, groundwater system."

[10 CFR 60.133(i)]

G. Rock Characteristics. Provide the exploration and research that are required to determine if the following condition exists at the site:

"The present and expected characteristics of the host rock and surrounding units shall be capable of accommodating the thermal, chemical, mechanical, and radiation stresses expected to be induced by repository construction, operation, and closure and by expected interactions among the waste, host rock, ground water, and engineered components. The characteristics of and the processes operating within the geologic setting shall permit compliance with (1) the requirements specified in 10 CFR 960.4-1 for radionuclide releases to the accessible environment and (2) the requirements set forth in 10 CFR 60.113 for radionuclide releases from the engineered-barrier system using reasonably available technology."

[10 CFR 960.4-2-3(a)/Qualifying Condition]

H. Host Rock Compatibility. Provide the exploration and research that are required to determine if the following condition exists at the site:

"A host rock that is sufficiently thick and laterally extensive to allow significant flexibility in selecting the depth, configuration, and location of the underground facility to ensure isolation."

[10 CFR 960.4-2-3(b)(1)/Favorable Condition] 
I. Host Rock Thermal Capabilities. Provide the exploration and research that are required to determine if the following condition exists at the site:

"A host rock with a high thermal conductivity, a low coefficient of thermal expansion, or sufficient ductility to seal fractures induced by repository construction, operation, or closure or by interactions among the waste, host rock, ground water, and engineered components."

[10 CFR 960.4-2-3(b)(2)/Favorable Condition]

J. Reasonable Available Technologies. Provide the exploration and research that are required to determine if the following condition exists at the site:

"Rock conditions that could require engineering measures beyond reasonably available technology for the construction, operation, and closure of the repository, if such measures are necessary to ensure waste containment or isolation."

[10 CFR 960.4-2-3(c)(2)/Potentially Adverse Condition]

K. Physical, Chemical and Radiation Phenomena on Host Rock. Provide the exploration and research that are required to determine if the following condition exists at the site:

"Potential for such phenomena as thermally induced fractures, the hydration or dehydration of mineral components, brine migration, or other physical, chemical, or radiation-related phenomena that could be expected to affect waste containment or isolation."

[10 CFR 960.4-2-3(c)(2)/Potentially Adverse Condition]

L. Changes in Host Rock After Waste Emplacement. Provide the exploration and research that are required to determine if the following condition exists at the site:

"A combination of geologic structure, geochemical and thermal properties, and hydrologic conditions exist in the host rock and surrounding units such that the heat generated by the waste could significantly decrease the isolation provided by the host rock as compared with pre-waste-emplacement conditions."

[10 CFR 960.4-2-3(c)(3)/Potentially Adverse Condition]

M. Erosion/Qualifying Condition. Provide the exploration and research that are required to determine if the following condition exists at the site:

"The site shall allow the underground facility to be placed at a depth such that erosional processes acting upon the surface will not be likely to lead to radionuclide releases greater than those allowable under the requirements specified in 10 CFR 960.4-1. In predicting the likelihood of potentially disruptive erosional processes, the DOE will consider the 
climatic, tectonic, and geomorphic evidence of rates and patterns of erosion in the geologic setting during the Quaternary Period."

[10 CFR 960.4-2-5(a)]

N. Waste Emplacement Depth of 300 Meters/Favorable Condition. Provide the exploration and research that are required to determine if the following condition exists at the site:

"Site conditions that permit the emplacement of waste at a depth of at least 300 meters below the directly overlying ground surface."

[10 CFR 960.4-2-5(b)(1)]

O. Erosion Process/Favorable Condition. Provide the exploration and research that are required to determine if the following condition exists at the site:

"A geologic setting where the nature and rates of the erosional processes, that have been operating during the Quaternary Period, are predicted to have less than one chance in 10,000 over the next 10,000 years of leading to releases of radionuclides to the accessible environment."

[10 CFR 960.4-2-5(b)(2)]

P. Waste Exhumation/Favorable Condition. Provide the exploration and research that are required to determine if the following conditions exist at the site:

"Site conditions such that waste exhumation would not be expected to occur during the first one million years after repository closure."

[10 CFR 960.4-2-5(b)(3)]

Q. Extreme Quatemary Period Erosion/Potentially Adverse Condition. Provide the exploration and research that are required to determine if following condition exists at the site:

"A geologic setting that shows evidence of extreme erosion during the Quaternary Period."

[10 CFR 960.4-2-5(c)(1)]

R. Projected Quaternary Period Geomorphic Processes/Potentially Adverse Condition. Provide the exploration and research that are required to determine if the following condition exists at the site:

"A geologic setting where the nature and rates of geomorphic processes that have been operating during the Quaternary Period could, during the first 10,000 years after closure, 
Title: Appendix A, Site Characterization System Requirements

adversely affect the ability of the geologic repository to isolate the waste."

[10 CFR 960.4-2-5(c)(2)]

S. Erosion/Disqualifying Condition. Provide the exploration and research that are required to determine if the following conditions exist at the site:

"...site conditions do not allow all portions of the underground facility to be situated at least 200 meters below the directly overlying ground surface."

[10 CFR 960.4-2-5(d)]

\subsubsection{Repository Design Criteria for Radiological Safety}

[SCP 8.3.2.3/Issue 2.7]

Exploration and research are required in response to the regulation(s) listed in this section. The information required is needed to address the characteristics and configurations of the repository that relate to radiological safety. The characteristics and configurations consist of a set of engineered systems and components that make up the repository which address some aspects of the natural setting (i.e., the site) by accounting for the impact of these aspects on the engineered system and components. For example, the shielding properties of the host rock, naturally occurring radon, and the dispersal of airborne radioactive contamination and their effect on radiation and contamination levels in areas occupied by workers.

A. Radiological Protection. Provide the exploration and research that are required in order to design for the following requirement(s):

"The geologic repository operations area shall be designed to maintain radiation doses, levels, and concentrations of radioactive material in air in restricted areas within the limits specified in Part 20 of this chapter. Design shall include:

(1) Means to limit concentrations of radioactive material in air;

(2) Does not require site characterization information.

(3) Suitable shielding;

(4) Means to monitor and control the dispersal of radioactive contamination;

(5) Does not require site characterization information.

(6) A radiation alarm system to warn of significant increases in radiation levels, concentrations of radioactive material in air, and of increased radioactivity released in 
effluents. The alarm system shall be designed with provisions for calibration and for testing its operability."

[10 CFR 60.131(a)]

B. Protection Against Natural Phenomena and Environmental Conditions. Provide the exploration and research that are required in order to design for the following requirement(s):

"The structures, systems, and components important to safety shall be designed so that natural phenomena and environmental conditions anticipated at the geologic repository operations area will not interfere with necessary safety functions."

[10 CFR 60.131(b)(1)]

C. Protection Against Fires and Explosions. Provide the exploration and research that are required in order to design for the following requirement(s):

"(i) The structures, systems, and components important to safety shall be designed to perform their safety functions during and after credible fires or explosions in the geologic repository operations area.

(iii) The geologic repository operations shall be designed to include explosion and fire detection alarm systems and appropriate suppression systems with sufficient capacity and capability to reduce the adverse effects of fires and explosions on structures, systems, and components important to safety. "

[10 CFR 60.131(b)(3)(i)\&(iii)]

D. Utility Services. Provide the exploration and research that are required in order to design for the following requirement(s):

"Each utility service system that is important to safety shall be designed so that essential safety functions can be performed under both normal and accident conditions."

[10 CFR 60.131(b)(5)(i)]

E. Criticality Control. Provide the exploration and research that are required in order to design for the following requirement(s):

"All systems for processing, transporting, handling, storage, retrieval, emplacement, and isolation of radioactive waste shall be designed to ensure that a nuclear criticality accident is not possible unless at least two unlikely, independent, and concurrent or sequential changes have occurred in the conditions essential to nuclear criticality safety. Each system shall be designed for criticality safety under normal and accident conditions. The calculated effective multiplication factor (k[eff]) must be sufficiently below unity to show at least a 5\% margin, after allowance for the bias in the method of calculation and the uncertainty in the experiments used to validate the method of calculation." 
[10 CFR 60.131(b)(7)]

F. Instrumentation and Control Systems. Provide the exploration and research that are required in order to design for the following requirement(s):

"The design shall include provisions for instrumentation and control systems to monitor and control the behavior of systems important to safety over anticipated ranges for normal operation and for accident conditions."

[10 CFR 60.131(b)(8)]

G. Compliance with Mining Regulations. Provide the exploration and research that are required in order to design for the following requirement(s):

"To the extent that DOE is not subject to the Federal Mine Safety and Health Act of 1977 , as to the construction and operation of the geologic repository operations area, the design of the geologic repository operations area shall nevertheless include such provisions for worker protection as may be necessary to provide reasonable assurance that all structures, systems, and components important to safety can perform their intended functions. Any deviation from relevant design requirements in $30 \mathrm{CFR}$, Chapter I, Subchapters $\mathrm{D}, \mathrm{E}$, and $\mathrm{N}$ will give rise to a rebuttable presumption that this requirement has not been met."

[10 CFR 60.131(b)(9)]

H. Facilities for Receipt and Retrieval of Waste. Provide the exploration and research that are required in order to design for the following requirement(s):

"Surface facilities in the geologic repository operations area shall be designed to allow safe handling and storage of wastes at the geologic repository operations area, whether these wastes are on the surface before emplacement or as a result of retrieval from the underground facility."

[10 CFR 60.132(a)]

I. Surface Facility Ventilation. Provide the exploration and research that are required in order to design for the following requirement(s):

"Surface facility ventilation systems supporting waste transfer, inspection, decontamination, processing, or packaging shall be designed to provide protection against radiation exposures and offsite releases as provided 10 CFR Part 60.111(a)."

[10 CFR 60.132(b)]

J. Radiation Control and Monitoring. Provide the exploration and research that are required in order to design for the following requirement(s):

"Effluent control. The surface facilities shall be designed to control the release of 
radioactive materials in effluents during normal operations so as to meet the performance objectives of 10 CFR Part 60.111(a)."

[10 CFR 60.132(c)(1)]

K. Underground Facility Ventliation. Provide the exploration and research that are required in order to design for the following requirement(s):

"The ventilation system shall be designed to:

(1) Control the transport of radioactive particulates and gases within and releases from the underground facility in accordance with the performance objectives of 10 CFR Part 60.111(a).

(2) Assure continued function during normal operations and under accident conditions;" [10 CFR 60.133(g)(1)\&(2)]

\subsubsection{Worker Non-Radiological Health and Safety [SCP 8.3.2.4/Issue 4.2]}

Exploration and research are required in response to the regulation(s) listed in this section. The information required, such as the identification of marginal areas of ground, effects of thermally induced fracturing, and air quality (i.e., methane), is needed to support nonradiological health and safety concerns.

A. Compliance with Mining Regulations. Provide the exploration and research that are required in order to design for the following requirement(s):

"To the extent that DOE is not subject to the Federal Mine Safety and Health Act of 1977 , as to the construction and operation of the geologic repository operations area, the design of the geologic repository operations area shall nevertheless include such provisions for worker protection as may be necessary to provide reasonable assurance that all structures, systems, and components important to safety can perform their intended functions. Any deviation from relevant design requirements in 30 CFR, Chapter I, Subchapters $\mathbf{D}, \mathbf{E}$, and $\mathbf{N}$ will give rise to a rebuttable presumption that this requirement has not been met."

[10 CFR 60.131(b)(9)]

B. Underground openings. Provide the exploration and research that are required in order to design for the following requirement(s):

"Openings in the underground facility shall be designed so that operations can be carried out safely and the retrievability option maintained."

[10 CFR 60.133(e)(1)] 
C. Underground farility ventilation. Provide the exploration and research that are required in order to design for the following requirement(s):

"The ventilation system shall be designed to:

Assure continued function during normal operations and under accident conditions;" [10 CFR 60.133(g)(2)]

\subsubsection{Preclosure Design and Technical Feasibility [SCP 8.3.2.5/1ssue 4.4]}

Exploration and research are required in response to the regulation(s) listed in this section. The information required is needed to determine whether the repository can be designed, constructed, operated, and closed using reasonably available or proven technology or if it will be necessary to extrapolate beyond current technologies in order to meet the requirements listed in this section.

A. Flexibility of design. Provide the exploration and research that are required in order to design for the following requirement(s):

"The underground facility shall be designed with sufficient flexibility to allow adjustments where necessary to accommodate specific site conditions identified through in situ monitoring, testing, or excavation."

[10 CFR 60.133(b)]

B. Rock excavation. Provide the exploration and research that are required in order to design for the following requirement(s):

"The design of the underground facility shall incorporate excavation methods that will limit the potential for creating a preferential pathway for groundwater to contact the waste packages or radionuclide migration to the accessible environment."

[10 CFR 60.133(f)]

C. Water and Gas Control. Provide the exploration and research that are required in order to design for the following requirement(s):

"The design of the underground facility shall provide for control of water or gas intrusion. [10 CFR 60.133(d)]

D. Underground Openings. Provide the exploration and research that are required in order to design for the following requirement(s):

"Openings in the underground facility shall be designed so that operations can be carried out safely and the retrievability option maintained.

[10 CFR 60.133(e)(1)] 
E. Underground Ventilation. Provide the exploration and research that are required in order to design for the following requirement(s):

"The ventilation system shall be designed to-

Assure continued function during normal operations and under accident conditions." [10 CFR 60.133(g)(2)]

F. Surface Characteristica/Qualinying Condition. Provide the exploration and research that are required to determine if the following condition exists at the site:

"The site shall be located such that, considering the surface characteristics and conditions of the site and surrounding area, including surface-water systems and the terrain, the requirements specified in 10 CFR $960.5-1(a)(3)$ can be met during repository siting, construction, operation, and closure."

[10 CFR 960.5-2-8(a)]

G. Topography/Favorable Condition. Provide the exploration and research that are required to determine if the following conditions exist at the site:

i) "Generally flat terrain."

[10 CFR 960.5-2-8(b)(1)]

ii) "Generally well-drained"

[10 CFR 960.5-2-8(b)(2)]

H. Flooding Due to Surface Characteristics/Potentially Adverse Condition. Provide the exploration and research that are required to determine if the following conditions exist at the site:

"Surface characteristics that could lead to the flooding of surface or underground facilities by the occupancy and modification of flood plains, the failure of existing or planned manmade surface water impoundments, or the failure of engineered components of the repository."

[10 CFR 960.5-2-8(c)]

I. Pre-closure Rock Characteristica/Qualifying Condition. Provide the exploration and research that are required to determine if the following condition exists at the site:

"The site shall be located such that (1) the thickness and lateral extent and the characteristics and composition of the host rock will be suitable for accommodation of the underground facility; (2) repository construction, operation, and closure will not cause 
undue hazard to personnel; and (3) the requirements specified in 10 CFR 960.5-1(a)(3) can be met."

[10 CFR 960.5-2-9(a)]

J. Host Rock Accommodation of Layout/Favorable Condition. Provide the exploration and research that are required to determine if the following condition exists at the site:

"A host rock that is sufficiently thick and laterally extensive to allow significant flexibility in selecting the depth, configuration, and location of the underground facility."

[10 CFR 960.5-2-9(b)(1)]

K. Host Rock Supporta/Favorable Condition. Provide the exploration and research that are required to determine if the following condition exists at the site:

"A host rock with characteristics that would require minimal or no artificial support for underground openings to ensure safe repository construction, operation, and closure." [10 CFR 960.5-2-9(b)(2)]

L. Minimal Fexibility of Host Rock/Potentially Adverwe Condition. Provide the exploration and research that are required to determine if the following condition exists at the site:

"A host rock that is suitable for repository construction, operation, and closure, but is so thin or laterally restricted that little flexibility is available for selecting the depth, configuration, or location of an underground facility."

[10 CFR 960.5-2-9(c)(1)]

M. Unreasonable Technology/Potentially Adverse Condition. Provide the exploration and research that are required to determine if the following condition exists at the site:

"In situ characteristics and conditions that could require engineering measures beyond reasonably available technology in the construction of the shafts and underground facility."

[10 CFR 960.5-2-9(c)(2)]

N. Excesive Maintenance/Potentially Adverse Condition. Provide the exploration and research that are required to determine if the following condition exists at the site:

"Geomechanical properties that could necessitate extensive maintenance of the underground openings during repository operation and closure."

[10 CFR 960.5-2-9(c)(3)]

0. Safety Hazards/Retrieval Difficulty/Potentially Adverse Condition. Provide the exploration and research that are required to determine if the following condition exists 
at the site:

"The potential for such phenomena as thermally induced fracturing, the hydration and dehydration of mineral components, or other physical, chemical, or radiation-related phenomena that could lead to safety hazards or difficulty in retrieval during repository operation."

[10 CFR 960.5-2-9(c)(4)]

P. Water Inflow/Conotruction Problema/Potentially Adverse Condition. Provide the exploration and research that are required to determine if the following condition exists at the site:

"Existing faults, shear 20nes, pressurized brine pockets, dissolution effects, or other stratigraphic or structural features that could compromise the safety of repository personnel because of water inflow or construction problems."

[10 CFR 960.5-2-9(c)(5)]

Q. Pre-cloware Rock Charncteristica/Diequallihing Condition. Provide the exploration and research that are required to determine if the following condition exists at the site:

"...rock characteristics are such that the activities associated with repository construction, operation, or closure are predicted to cause significant risk to the health and safety of personnel, taking into account mitigating measures that use reasonably available technology."

[10 CFR 960.5-2-9(d)]

R. Preclosure Hydrology/Qualifying Condition. Provide the exploration and research required to determine if the following condition exists at the site:

"The site shall be located such that the geohydrologic setting of the site will (1) be compatible with the activities required for repository construction, operation, and closure; (2) not compromise the intended functions of the shaft liners and seals; and (3) permit the requirements specified in 10 CFR 960.5-1(a)(3) to be met."

[10 CFR 960.5-2-10(a)]

S. Aquifera/Favorable Condition. Provide the exploration and research that are required to determine if the following condition exists at the site:

"Absence of aquifers between the host rock and the land surface."

[10 CFR 960.5-2-10(b)(1)]

T. Surface Water Systems/Favorable Condition. Provide the exploration and research that are required to determine if the following condition exists at the site: 
"Absence of surface-water systems that could potentially cause flooding of the repository."

[10 CFR 960.5-2-10(b)(2)]

U. Water Avallability/Favorable Condition. Provide the exploration and research that are required to determine if the following condition exists at the site:

"Availability of the water required for repository construction, operation, and closure." [10 CFR 960.5-2-10(b)(3)]

V. Unreasonable Technology/Potentially Adverse Condition. Provide the exploration and research that are required to determine if the following conditions exist at the site:

"Ground-water conditions that could require complex engineering measures that are beyond reasonably available technology for repository construction, operation, and closure."

[10 CFR 960.5-2-10(c)]

W. Precloeure Hydrologo/Disqualifying Condition. Provide the exploration and research required to determine if the following condition exists at the site:

"... if, based on expected ground-water conditions, it is likely that engineering measures that are beyond reasonably available technology will be required for exploratory-shaft construction or for repository construction, operation, or closure."

[10 CFR 960.5-2-10(d)]

X. Precloeure Tectonica/Qualinging Condition. Provide the exploration and research that are required to determine if the following condition exists at the site:

"The site shall be located in a geologic setting in which any projected effects of expected tectonic phenomena or igneous activity on repository construction, operation, or closure will be such that the requirements specified in 10 CFR 960.5-1(a)(3) can be met."

[10 CFR 960.5-2-11(a)]

Y. Nature and Rates of Faulting/Favorable Condition. Provide the exploration and research that are required to determine if the following condition exists at the site:

"The nature and rates of faulting, if any, within the geologic setting are such that the magnitude and intensity of the associated seismicity are significantly less than those generally allowable for the construction and operation of nuclear facilities."

[10 CFR 960.5-2-11(b)]

Z. Active Faulting/Potentially Adverse Condition. Provide the exploration and research that are required to determine if the following condition exists at the site: 
Title: Appendix A, Site Characterization System Requirements

"Evidence of active faulting within the geologic setting."

[10 CFR 960.5-2-11(c)(1)]

AA. Ground Motion/Potentially Adverse Condition. Provide the exploration and research that are required to determine if the following condition exists at the site:

"Historical earthquakes or past man-induced seismicity, if either were to recur, could produce ground motion at the site in excess of reasonable design limits."

[10 CFR 960.5-2-11(c)(2)]

BB. Earthquake Magnitude Exceeding Hibtorical Data/Potentially Adverse Condition. Provide the exploration and research that are required to determine if the following condition exists at the site:

"Evidence exists, based on correlations of earthquakes with tectonic processes and features, (0.8., faulis) within the geologic setting, that the magnitude of earthquakes at the site during repository construction, operation, and closure may be larger than predicted from historical seismicity."

[10 CFR 960.5-2-11(c)(3)]

CC. Preclosure Tectonica/Diaqualihying Condition. Provide the exploration and research that are required to determine if the following condition exists at the site:

"...based on the expected nature and rates of fault movement or other ground motion, it is likely that engineering measures that are beyond reasonably available technology will be required for exploratory-shaft construction or for repository construction, operation, or closure."

[10 CFR 960.5-2-11(d)]

\subsection{SEAL DESIGN}

The seal performance requirements (10 CFR 60.112 and 113) and design requirements (10 CFR 134) that require exploration and research for the seal design are listed within this section.

The design and performance requirements previously mentioned do not all require exploration and research. The requirements that do not require site exploration and research are listed as follows:

10 CFR 60.113(b)

10 CFR 60.113(b)(1)

10 CFR 60.113(b)(2)

10 CFR 60.113(b)(3)

10 CFR 60.113(b)(4)

10 CFR 60.113(c) 


\subsubsection{Seal Characteriatics}

[SCP 8.3.3.2/1ssue 1.12]

Exploration and research are required in response to the regulation(s) listed in this section. The information required, such as groundwater chemistry, drainage capacity of Topopah Springs welded unit (TSw2), determination of water drainage patterns, and the thermal expansion characteristics of TSW2, is needed to address the effects of site characteristics on the proposed seals.

A. Overall System Performance. Provide the exploration and research that are required in order to design for the following requirement(s):

"The geologic setting shall be selected and the engineered barrier system and the shafts, boreholes and their seals shall be designed to assure that releases of radioactive materials to the accessible environment following permanent closure conform to such generally applicable environmental standards for radioactivity as may have been established by the Environmental Protection Agency with respect to both anticipated processes and events and unanticipated processes and events."

[10 CFR 60.112]

B. Poutcloeure Barrier Performance. Provide the exploration and research that are required in order to design for the following requirement(s):

"(a) General Provisions - (1) Engineered barrier system. (i) The engineered barrier system shall be designed so that assuming anticipated processes and events: (A) Containment of HLW will be substantially complete during the period when radiation and thermal conditions in the engineered barrier system are dominated by fission product decay; and (B) any release of radionuclides from the engineered barrier system shall be a gradual process which results in small fractional releases to the geologic setting over long times. For disposal in the saturated zone, both the partial and complete filling with groundwater of available void spaces in the underground facility shall be appropriately considered and analyzed among the anticipated processes and events in designing the engineered barrier system.

(ii) In satisfying the preceding requirement, the engineered barrier system shall be designed, assuming anticipated processes and events, so that:

(A) Containment of HLW within the waste packages will be substantially complete for a period to be determined by the Commission taking into account the factors specified in 10 CFR Part 60.113(b) provided, that such period shall be not less than 300 years nor more than 1,000 years after permanent closure of the geologic repository; and 
(B) The release rate of any radionuclide from the engineered barrier system following the containment period shall not exceed one part in 100,000 per year of the inventory of that radionuclide calculated to be present at 1,000 years following permanent closure, or such other fraction of the inventory as may be approved or specified by the Commission; provided, that this requirement does not apply to any radionuclide which is released at a rate less than $0.1 \%$ of the calculated total release rate limit. The calculated total release rate limit shall be taken to be one part in 100,000 per year of the inventory of radioactive waste, originally emplaced in the underground facility, that remains after 1,000 years of radioactive decay. [10 CFR 60.113(a)]

C. Genern Dealen Criterion. Provide the exploration and research that are required in order to design for the following requirement(s):

"Seals for shafts and boreholes shall be designed so that following permanent closure they do not become pathways that compromise the geologic repository's ability to meet the performance objectives or the period following permanent closure."

[10 CFR 60.134(a)]

D. Selection of Materials and Placement Methods. Provide the exploration and research that are required in order to design for the following requirement(s):

"Materials and placement methods for seals shall be selected to reduce, to the extent practicable:

(1) The potential for creating a preferential pathway for groundwater to contact the waste packages or

(2) For radionuclide migration through existing pathways."

[10 CFR 60.134(b)]

E. Deaign Teating. Provide the exploration and research that are required in order to design for the following requirement(s):

"(a) During the early or developmental stages of construction, a program for in situ testing of such features as borehole and shaft seals, backfill, and the thermal interaction effects of the waste packages, backfill, rock, and groundwater shall be conducted.

(b) The testing shall be initiated as early as is practicable.

(c) A backfill test section shall be constructed to test the effectiveness of backfill placement and compaction procedures against design requirements before permanent backfill placement is begun.

(d) Test sections shall be established to test the effectiveness of borehole and shaft seals 
before full-scale operation proceeds to seal boreholes and shafts." [10 CFR 60.142]

\subsection{WASTE PACKAGE}

The waste package design (10 CFR 60.135(a)), and production technologies requirements (10 CFR 960.5-1(a)(3)) that require exploration and research for the waste package design are listed within this section in one of the following subsections except as noted:

3.3.1 Waste Package Characteristics (Postclosure)

3.3.2 Waste Package Characteristics (Preclosure)*

3.3.3 Waste Package Production Technologies

* No site characterization requirements

\subsubsection{Waste Package Characteristics (Postclosure)}

[SCP 8.3.4.2/Issue 1.10]

Exploration and research are required in response to the regulation(s) listed in this section. The information required, such as the in situ chemical, physical, and nuclear properties of the waste package and its interaction with the emplacement environment, is needed to address the required waste package characteristics.

Provide the exploration and research that are required in order to design for the following requirement(s):

"(1) Packages for HLW shall be designed so that the in situ chemical, physical, and nuclear properties of the waste package and its interactions with the emplacement environment do not compromise the function of the waste packages or the performance of the underground facility or the geologic setting.

(2) The design shall include but not be limited to consideration of the following factors: solubility, oxidation/reduction reactions, corrosion, hydriding, gas generation, thermal effects, mechanical strength, mechanical stress, radiolysis, radiation damage, radionuclide retardation, leaching, fire and explosion hazards, thermal loads, and synergistic interactions."

[10 CFR 60.135(a)]

\subsubsection{Waste Package Characteristics (Preclosure)}

[SCP 8.3.4.3/Issue 2.6]

No site characterization requirements. 


\subsubsection{Waste Package Production Technologies}

[SCP 8.3.4.4/Issue 4.3]

Exploration and research are required in response to the regulation(s) listed in this section. The information required is needed to determine the technical feasibility of the waste package as it relates to the anticipated service environment.

Ease and Cost of Siting, Construction, Operation, and Closure. Provide the exploration and research that are required in order to design for the following requirement(s):

"... operation, and closure shall be demonstrated to be technically feasible on the basis of reasonably available technology, and the associated costs shall be demonstrated to be reasonable relative to other available and comparable siting options."

[10 CFR 960.5-1(a)(3)]

\subsection{PRECLOSURE PERFORMANCE REQUIREMENTS}

The preclosure performance requirements for Waste Retrievability (NWPA, 10 CFR 60.111(b)), Public Radiological Exposures-Normal Conditions (10 CFR 60.111(a), 10 CFR 20.1301 \&.1302, 40 CFR 191.03), Radiological Safety-Worker (10 CFR 20 invoked by 10 CFR 60), Preclosure Radiological Safety (Portions of 10 CFR 960.5) and Ease and Cost of Construction (Portions of 10 CFR 960.5) that require exploration and research are quoted within this section in one or more of the following subsections except as noted.

\subsubsection{Waste Retrievability}

3.4.2 Public Radiological Exposures-Normal Conditions

3.4.3 Performance Objective for Preclosure Radiological Safety-Worker

3.4.4 Accidental Radiological Releases*

3.4.5 Higher Level Findings-Preclosure Radiological Safety

3.4.6 Higher Level Findings-Ease and Cost of Construction

* Awaiting NRC ruling. No site characterization requirements at this time.

\subsubsection{Waste Retrievability}

[SCP 8.3.5.2/Issue 2.4]

Exploration and research are required in response to the regulation(s) listed in this section. The information required, such as the identification of both normal and credible abnormal retrieval conditions, is needed to support waste retrievability.

2 The 10 CFR 960 regulation mentioned above is applicable to the waste package production technologies because the waste packages are a "product" of the repository operation and therefore must be technically feasible on the same basis. 
A. NWPA. Provide the exploration and research that are required in order to design for the following requirement(s):

"Notwithstanding any other provision of this subtitle, any repository constructed on a site approved under this subtitle shall be designed and constructed to permit the retrieval of any spent nuclear fuel placed in such repository, during an appropriate period of operation of the facility, for any reason pertaining to the public health and safety, or the environment, or for the purpose of permitting the recovery of the economically valuable contents of such spent fuel. The Secretary shall specify the appropriate period of retrievability with respect to any repository at the time of design of such repository, and such aspect of such repository shall be subject to approval or disapproval by the Commission as part of the construction authorization process under subsections (b) through (d) of Section 114."[NWPA Section 122]

B. Retrievability of Waste. Provide the exploration and research that are required in order to design for the following requirement(s):

"(1) The geologic repository operations area shall be designed to preserve the option of waste retrieval throughout the period during which wastes are being emplaced and, thereafter, until the completion of a performance confirmation program and Commission review of the information obtained from such a program. To satisfy this objective, the geologic repository operations area shall be designed so that any or all of the emplaced waste could be retrieved on a reasonable schedule starting at any time up to 50 years after waste emplacement operations are initiated, unless a different time period is approved or specified by the Commission. This different time period may be established on a case-by-case basis consistent with the emplacement schedule and the planned performance confirmation program.

(2) This requirement shall not preclude decisions by the Commission to allow backfilling part or all of, or permanent closure of, the geologic repository operations area prior to the end of the period of design for retrievability.

(3) For purposes of this paragraph, a reasonable schedule for retrieval is one that would permit retrieval in about the same time as that devoted to construction of the geologic repository operations area and the emplacement of wastes.

[10 CFR 60.111(b)]

\section{Reserved \\ D. Reserved \\ E. Reserved}

F. Retrieval of Waste. Provide the exploration and research that are required in order to 
design for the following requirement(s):

The underground facility shall be designed to permit retrieval of waste in accordance with the performance objectives of 10 CFR Part 60.111.

[10 CFR 60.133(c)]

G. Underground openings. Provide the exploration and research that are required in order to design for the following requirement(s):

"Openings in the underground facility shall be designed so that operations can be carried out safely and the retrievability option maintained."

[10 CFR 60.133(e)(1)]

H. Handling. Provide the exploration and research that are required in order to design for the following requirement(s):

"Waste packages shall be designed to maintain waste containment during transportation, emplacement, and retrieval."

[10 CFR 60.135(b)(3)]

\subsubsection{Public Radiological Exposures-Normal Conditions}

[SCP 8.3.5.3/Issue 2.1]

Exploration and research are required in response to the regulation(s) listed in this section. The information required, such as (1) locations of release points, (2) exposure pathways, and (3) meteorologic and hydrologic parameters, is needed to address radiological exposures to the public.

A. Radiation Protection. Provide the exploration and research that are required in order to design for the following requirement(s):

"Protection against radiation exposures and releases of radioactive material. The geologic repository operations area shall be designed so that until permanent closure has been completed, radiation exposures and radiation levels, and releases of radioactive materials to unrestricted areas, will at all times be maintained within the limits specified in Part 20 of this chapter and such generally applicable environmental standards for radioactivity as may have been established by the Environmental Protection Agency."

[10 CFR 60.111(a)]

B. Public Dose Limits. Provide the exploration and research that are required in order to design for the following requirement(s):

"(a) Each licensee shall conduct operations so that -- 
1) The total effective dose equivalent to individual members of the public from the licensed operation does not exceed $0.1 \mathrm{rem}(1 \mathrm{mSv})$ in a year, exclusive of the dose contribution from the licensee's disposal of radioactive material into sanitary sewerage in accordance with 10 CFR Part 20.2003, and

(2) The dose in any unrestricted area from external sources does not exceed $0.002 \mathrm{rem}$ $(0.02 \mathrm{mSv})$ in any one hour.

(b) If the licensee permits members of the public to have access to controlled areas, the limits for members of the public continue to apply to those individuals.

(c) A licensee or license applicant may apply for prior NRC authorization to operate up to an annual dose limit for an individual member of the public of $0.5 \mathrm{rem}(5 \mathrm{mSv})$. The licensee or license applicant shall include the following information in this application:

(1) Demonstration of the need for and the expected duration of operations in excess of the limit in paragraph (a) of this section;

(2) The licensee's program to assess and control dose within the $0.5 \mathrm{rem}(5 \mathrm{mSv})$ annual limit; and

(3) The procedures to be followed to maintain the dose as low as is reasonably achievable.

(d) In addition to the requirements of this part, a licensee subject to the provisions of EPA's generally applicable environmental radiation standards in 40 CFR Part 190 shall comply with those standards.

(e) The Commission may impose additional restrictions on radiation levels in unrestricted areas and on the total quantity of radionuclides that a licensee may release in effluents in order to restrict the collective dose.

[10 CFR 20.1301]

C. Public Dose Limit Compliance. Provide the exploration and research that are required in order to design for the following requirement(s):

"(a) The licensee shall make or cause to be made, as appropriate, surveys of radiation levels in unrestricted and controlled areas and radioactive materials in effluents released to unrestricted and controlled areas to demonstrate compliance with the dose limits for individual members of the public in 10 CFR Part 20.1301.

(b) A licensee shall show compliance with the annual dose limit in 10 CFR Part 20.1301 by -- 
(1) Demonstrating by measurement or calculation that the total effective dose equivalent to the individual likely to receive the highest dose from the licensed operation does not exceed the annual dose limit; or

(2) Demonstrating that --

(i) The annual average concentrations of radioactive material released in gaseous and liquid effluents at the boundary of the unrestricted area do not exceed the values specified in table 2 of appendix B to 10 CFR Part 20.1001-20.2401; and

(ii) If an individual were continually present in an unrestricted area, the dose from external sources would not exceed $0.002 \mathrm{rem}(0.02 \mathrm{mSv})$ in an hour and $0.05 \mathrm{rem}(0.5$ $\mathrm{mSv}$ ) in a year.

(c) Upon approval from the Commission, the licensee may adjust the effluent concentration values in appendix B to 10 CFR Part 20.1001-20.2401, table 2, for members of the public, to take into account the actual physical and chemical characteristics of the effluents (e.g., aerosol size distribution, solubility, density, radioactive decay equilibrium, chemical form)."

[10 CFR 20.1302]

D. Limits on Radiation Doses to Public. Provide the exploration and research that are required in order to design for the following requirement(s):

(a) Management and storage of spent nuclear fuel or high-level or transuranic radioactive wastes at all facilities regulated by the Commission or by Agreement States shall be conducted in such a manner as to provide reasonable assurance that the combined annual dose equivalent to any member of the public in the general environment resulting from: (1) Discharges of radioactive material and direct radiation from such management and storage and (2) all operations covered by Part 190; shall not exceed 25 millirems to the whole body, 75 millirems to the thyroid, and 25 millirems to any other critical organ. [40 CFR 191.03]

\subsubsection{Performance Objective for Preclosure Radiological Safety-Worker} [SCP 8.3.5.4/Issue 2.2]

Exploration and research are required in response to the regulation(s) listed in this section. The information required, such as (1) an analysis of the transport, dispersion, and diffusions of routine airborne radioactive effluents within the site boundary, (2) an analysis of the natural underground radiation released, and (3) analysis of the ventilation and filtration of repository airstreams, is needed to address preclosure radiological safety.

A. Radiation Protection. Provide the exploration and research that are required in order to design for the following requirement(s): 
"Protection against radiation exposures and releases of radioactive material. The geologic repository operations area shall be designed so that until permanent closure has been completed, radiation exposures and radiation levels, and releases of radioactive materials to unrestricted areas, will at all times be maintained within the limits specified in Part 20 of this chapter and such generally applicable environmental standards for radioactivity as may have been established by the Environmental Protection Agency." [10 CFR 60.111(a)]

B. Design for Radiological Protection. Provide the exploration and research that are required in order to design for the following requirement(s):

"The geologic repository operations area shall be designed to maintain radiation doses, levels, and concentrations of radioactive material in air in restricted areas within the limits specified in Part 20 of this chapter."

[10 CFR 60.131(a)]

C. Emuent control. Provide the exploration and research that are required in order to design for the following requirement(s):

"The surface facilities shall be designed to control the release of radioactive materials in effluents during normal operations so as to meet the performance objectives of 10 CFR Part 60.111(a)." [10 CFR 60.132(c)(1)]

D. Underground Facility Ventilation. Provide the exploration and research that are required in order to design for the following requirement(s):

"The ventilation system shall be designed to:

(1) Control the transport of radioactive particulates and gases within and releases from the underground facility in accordance with the performance objectives of 10 CFR Part 60.111(a)." [10 CFR 60.133(g)(1)]

E. Monitoring and Control of Emuents. Provide the exploration and research that are required in order to design for the following requirement(s):

"A description of the program for control and monitoring of radioactive effluents and occupational radiation exposures to maintain such effluents and exposures in accordance with the requirements of Part 20 of this chapter.

[10 CFR 60.21(c)(7)]

F. Radiation Protection Design Criteria. Provide the exploration and research that are required in order to design for the following requirement(s):

"Radiological protection. The geologic repository operations area shall be designed to 
maintain radiation doses, levels, and concentrations of radioactive material in air in restricted areas within the limits specified in Part 20 of this chapter. Design shall include:

(1) Means to limit concentrations of radioactive material in air;

(2) Does not require site characterization information.

(3) Suitable shielding;

(4) Means to monitor and control the dispersal of radioactive contamination;

(5) Does not require site characterization information.

(6) A radiation alarm system to warn of significant increases in radiation levels, concentrations of radioactive material in air, and of increased radioactivity released in effluents. The alarm system shall be designed with provisions for calibration and for testing its operability."

[10 CFR 60.131(a)(1-6)]

G. Surface Ventilation. Provide the exploration and research that are required in order to design for the following requirement(s):

"Surface facility ventilation. Surface facility ventilation systems supporting waste transfer, inspection, decontamination, processing, or packaging shall be designed to provide protection against radiation exposures and offsite releases as provided in 10 CFR 60.111(a)."

[10 CFR 60.132(b)]

\subsubsection{Accidental Radiological Releases}

[SCP 8.3.5.5/1ssue 2.3]

Currently there are no regulatory limits for radiation exposures to either members of the public or repository workers from accidents at a repository. 10 CFR Part 60 does not specify an accident dose guideline to the public. The DOE has initiated steps to petition the NRC to amend the rule so as to include an accident dose guideline in Part 60 . When such guideline is promulgated, it will be addressed in the repository design. Regulatory criteria pertaining to worker exposure during accidents for other situations and facilities will considered. 


\subsubsection{Higher Level Findings-Preclosure Radiological Safety [SCP 8.3.5.6/1ssue 2.5]}

Exploration and research are required in response to the 10 CFR 960 conditions listed in this section. The information required by the conditions in this section will be used for site suitability evaluation in junction with the information that is generated by the conditions in Sections 3.4.6, 3.5.8, 3.5.9 and 3.5.10.

A. Preclosure Radiological Safety/System Guideline. Provide the exploration and research that are required to determine if the following condition exists at the site:

"Any projected radiological exposures of the general public and any projected releases of radioactive materials to restricted and unrestricted areas during repository operation and closure shall meet the applicable safety requirements set forth in 10 CFR Part 20, 10 CFR Part 60, and 40 CFR 191, Subpart A (see Appendix II of this part)." [10 CFR 960.5-1(a)(1)]

B. Meteorology/Qualifying Condition. Provide the exploration and research that are required to determine if the following condition exists at the site:

"The site shall be located such that expected meteorological conditions during repository operation and closure will not be likely to lead to radionuclide releases to an unrestricted area greater than those allowable under the requirements specified in 10 CFR 960.5-1(a)(1)."

[10 CFR 960.5-2-3(a)]

C. Oftsite Installations/Qualifying Condition. Provide the exploration and research that are required to determine if the following condition exists at the site:

"The site shall be located such that present projected effects from nearby industrial, transportation, and military installations and operations, including atomic energy defense activities, (1) will not significantly affect repository siting, construction, operation, closure, or decommissioning or can be accommodated by engineering measures and (2), when considered together with emissions from repository operation and closure, will not be likely to lead to radionuclide releases to an unrestricted area greater than those allowable under the requirements specified in 10 CFR 960.5-1(a)(1)."

[10 CFR 960.5-2-4(a)]

D. Offsite Installations/Disqualifying Condition. Provide the exploration and research that are required to determine if the following condition exists at the site:

"...atomic energy defense activities in proximity to the site are expected to conflict irreconcilably with repository siting, construction, operation, closure, or decommissioning." 
[10 CFR 960.5-2-4(d)]

\subsubsection{Higher Level Findings-Ease and Cost of Construction [SCP 8.3.5.7/1ssue 4.1]}

Exploration and research are required in response to the 10 CFR 960 conditions listed in this section. The information required by the conditions in this section will be used for site suitability evaluation in junction with the information that is generated by the conditions in Sections 3.4.5, 3.5.8, 3.5.9 and 3.5.10.

A. Construction, Operation, and Closure/System Guideline. Provide the exploration and research that are required to determine if the following condition exists at the site:

"...construction, operation, and closure* shall be demonstrated to be technically feasible on the basis of reasonably available technology, and the associated costs shall be demonstrated to be reasonable relative to other available and comparable siting options." ${ }^{3}$ [10 CFR 960.5-1(a)(3)]

B. Surface Characteristica/Qualifying Condition. Provide the exploration and research that are required to determine if the following condition exists at the site:

"The site shall be located such that, considering the surface characteristics and conditions of the site and surrounding area, including surface-water systems and the terrain, the requirements specified in 10 CFR $960.5-1(a)(3)$ can be met during repository siting, construction, operation, and closure." [10 CFR 960.5-2-8(a)]

C. Pre-closure Rock Characteristica/Qualifying Condition. Provide the exploration and research that are required to determine if the following condition exists at the site:

"The site shall be located such that (1) the thickness and lateral extent and the characteristics and composition of the host rock will be suitable for accommodation of the underground facility; (2) repository construction, operation, and closure will not cause undue hazard to personnel; and (3) the requirements specified in 10 CFR 960.5-1(a)(3) can be met. [10 CFR 960.5-2-9(a)]

D. Pre-closure Rock Characteristics/Disqualifying Condition. Provide the exploration and research that are required to determine if the following condition exists at the site:

"...rock characteristics are such that the activities associated with repository construction, operation, or closure are predicted to cause significant risk to the health and safety of

\footnotetext{
3 Due to the NWPAA siting is no longer applicable; therefore, it has been removed from the quote.
} 
personnel, tuking into account mitigating measures that use reasonably available technology."

[10 CFR 960.5-2-9(d)]

E. Preclosure Hydrology/Quallifing Condition. Provide the exploration and research required to determine if the following condition exists at the site:

"The site shall be located such that the geohydrologic setting of the site will (1) be compatible with the activities required for repository construction, operation, and closure; (2) not compromise the intended functions of the shaft liners and seals; and (3) permit the requirements specified in 10 CFR 960.5-1(a)(3) to be met."

[10 CFR 960.5-2-10(a)]

F. Preclosure Hydrolog/Disqualifying Condition. Provide the exploration and research required to determine if the following condition exists at the site:

"... if, based on expected ground-water conditions, it is likely that engineering measures that are beyond reasonably available technology will be required for exploratory-shaft construction or for repository construction, operation, or closure." [10 CFR 960.5-210(d)]

G. Preclosure Tectonica/Qualifying Condition. Provide the exploration and research that are required to determine if the following condition exists at the site:

"The site shall be located in a geologic setting in which any projected effects of expected tectonic phenomena or igneous activity on repository construction, operation, or closure will be such that the requirements specified in 10 CFR 960.5-1(a)(3) can be met." [10 CFR 960.5-2-11(a)]

H. Preclosure Tectonica/Disqualifying Condition. Provide the exploration and researsh that are required to determine if the following condition exists at the site:

"...based on the expected nature and rates of fault movement or other ground motion, it is likely that enginearing measures that are beyond reasonably available technology will be required for exploratory-shaft construction or for repository construction, operation, or closure."

[10 CFR 960.5-2-11(d)]

\subsection{POSTCLOSURE PERFORMANCE REQUIREMENTS}

The postclosure performance requirements for Containment by Waste Package [10 CFR 60.113(a)(1)(ii)(A)], Engineered Barrier System Release Rates [10 CFR 60.113(a)(ii)(B)], Groundwater Travel Time [10 CFR 60.113(a)(2)], Performance Objective for 10,000 Year Cumulative Releases [10 CFR 60.112 \& 40 CFR 191.13(a)], Individual Protection [40 CFR 191.15], Protection of Special Groundwater Sources [40 CFR 191.16], Performance Confirmation 
[10 CFR 60.137], NRC Siting Criteria [10 CFR 60.122], DOE Siting Criweria [Portions of 10 CFR 960], and additional DOE Siting Criteria [Portions of 10 CFR 960] that require exploration and research are quoted within this section in one or more of the following subsections:

3.5.1 Contuinment by Waste Package

3.5.2 Engineered Barrier System Release Rates

3.5.3 Groundwater Travel Time

3.5.4 Performance Objective for 10,000 Year Cumulative Releases

3.5.5 Individual Protection

3.5.6 Protection of Special Groundwater Sources

3.5.7 Performance Confirmation

3.5.8 NRC Siting Criteria

3.5.9 DOE Siting Criteria

3.5.10 Additional DOE Siting Criteria

\subsubsection{Containment by Waate Package}

[SCP 8.3.5.9/1ssue 1.4]

Exploration and research are required in response to the regulation(s) listed in this section. The information required is needed to address the in situ chemical, physical, and nuclear properties of the waste package and its interaction with the emplacement environment.

Provide the exploration and research that are required to demonstrate, with reasonable assurance, compliance with the following requirement:

"(ii) In satisfying the preceding requirement, the engineered barrier system shall be designed, assuming anticipated processes and events, so that:

(A) Containment of HLW within the waste packages will be substantially complete for a period to be determined by the Commission taking into account the factors specified in 60.113(b) provided, that such period shall be not less than 300 years nor more than 1,000 years after permanent closure of the geologic repository; and"

[10 CFR 60.113(a)(1)(ii)]

\subsubsection{Engineered Barrier Syetem Release Rates}

[SCP 8.3.5.10/1ssue 1.5]

Exploration and research are required in response to the regulation(s) listed in this section. The information required, such as (1) hydrologic and geochemical conditions, (2) mechanical stress model, (3) heat transfer model and (4) waste package performance model, is needed to address the release rates for the engineered barrier.

Provide the exploration and research that are required to demonstrate, with reasonable assurance, compliance with the following requirement: 
"...the engineered barrier system shall be designed, assuming anticipated processes and events, so that.."

"(B) The release rate of any radionuclide from the engineered barrier system following the containment period shall not exceed one part in 100,000 per year of the inventory of that radionuclide calculated to be present at 1,000 years following permanent closure, or such other fraction of the inventory as may be approved or specified by the Commission; provided, that this requirement does not apply to any radionuclide which is released at a rate less than $0.1 \%$ of the calculated total release rate limit. The calculated total release rate limit shall be taken to be one part in 100,000 per year of the inventory of radioactive waste, originally emplaced in the underground facility, that remains after 1,000 years of radioactive decay." [10 CFR 60.113(a)(1)(ii)]

\subsubsection{Groundwater Travel Time} [SCP 8.3.5.12/1ssue 1.6]

Exploration and research are required in response to the regulation(s) listed in this section. The information required, such as (1) identification of all hydrogeologic units along potential flow paths to the accessible environment, (2) classification of hydrogeologic units and flow processes, and (3) establishment of measures of performance that allow comparisons of the flow behavior in each unit to the 1000-yr flow time requirement, is needed to address the groundwater travel time.

Provide the exploration and research that are required to demonstrate, with reasonable assurance, compliance with the following requirement:

"(2) Geologic setting. The geologic repository shall be located so that pre-waste-emplacement ground water travel time along the fastest path of likely radionuclide travel from the disturbed zone to the accessible environment shall be at least 1,000 years or such other travel time as may be approved or specified by the Commission."

[10 CFR 60.113(a)(2)]

\subsubsection{Performance Objective for 10,000 Year Cumulative Releases} [SCP 8.3.5.13/1ssue 1.1]

Exploration and research are required in response to the regulation(s) listed in this section. The information required, such as (1) identification of all significant processes and events, (2) evaluation of the effects of these processes and events on the release of radionuclides to the accessible environment, (3) estimation of these effects to the extent practicable into a complementary cumulative distribution function (CCDF), and (4) a comparison of the numerical predictions with the performance objective, is needed to address the groundwater travel time.

A. Permanent Closure Performance. Provide the exploration and research that are required to demonstrate, with reasonable assurance, compliance with the following requirement: 
"The geologic setting shall be selected and the engineered barrier system and the shafts, boreholes and their seals shall be designed to assure that releases of radioactive materials to the accessible environment following permanent closure conform to such generally applicable environmental standards for radioactivity as may have been established by the Environmental Protection Agency with respect to both anticipated processes and events and unanticipated processes and events."

[10 CFR 60.112]

B. EPA Thresholds. Provide the exploration and research that are required to demonstrate, with reasonable assurance, compliance with the following requirement:

"(a) Disposal systems for spent nuclear fuel or high-level or transuranic radioactive wastes shall be designed to provide a reasonable expectation, based upon performance assessments, that the cumulative releases of radionuclides to the accessible environment for 10,000 years after disposal from all significant processes and events that may affect the disposal system shall:

(1) Have a likelihood of less than one chance in 10 of exceeding the quantities calculated according to Table 1 (Appendix A);

(2) Have a likelihood of less than one chance in 1,000 of exceeding ten times the quantities calculated according to Table 1 (Appendix A)."

[40 CFR 191.13(a)]

\subsubsection{Individual Protection}

[SCP 8.3.5.14/1ssue 1.2]

Exploration and research are required in response to the regulation(s) listed in this section. The information required, such as (1) flux through the unsaturated 20ne, (2) retardation through the unsaturated zone, and (3) determination of significant groundwater source, is needed to address the groundwater travel time.

Provide the exploration and research that are required to demonstrate, with reasonable assurance, compliance with the following requirement:

"Disposal systems for spent nuclear fuel or high-level or transwanic radioactive wastes shall be designed to provide a reasonable expectation that, for 1,000 years after disposal, undisturbed performance of the disposal system shall not cause the annual dose equivalent from the disposal system to any member of the public in the accessible environment to exceed 25 millirems to the whole body or 75 millirems to any critical organ. All potential pathways (associated with undisturbed performance) from the disposal system to people shall be considered, including the assumption that individuals consume 2 liters per day of drinking water from any significant source of ground water outside of the controlled area."

[40 CFR 191.15] 


\subsubsection{Protection of Special Groundwater Sources} [SCP 8.3.5.15/Issue 1.3]

Exploration and research are required in response to the regulation(s) listed in this section. The information required, such as (1) a determination if any Class I or special sources of ground water exist, and (2) a determination for all special sources whether concentrations of waste products in the groundwater during the first 1000 years after disposal could exceed limits in $\mathbf{4 0}$ CFR 191.16, is needed to address the groundwater travel time.

Provide the exploration and research that are required to demonstrate, with reasonable assurance, compliance with the following requirement:

"Ground water protection requirements:

(a) Disposal systems for spent nuclear fuel or high-level or transuranic radioactive wastes shall be designed to provide a reasonable expectation that, for 1,000 years after disposal, undisturbed performance of the disposal system shall not cause the radionuclide concentrations averaged over any year in water withdrawn from any portion of a special source of ground water to exceed:

(1) 5 picocuries per liter of radium-226 and radium-228;

(2) 15 picocuries per liter of alpha-emitting radionuclides (including radium-226 and radium-228 but excluding radon); or

(3) The combined concentrations of radionuclides that emit either beta or gamma radiation that would produce an annual dose equivalent to the total body or any internal organ greater than 4 millirems per year if an individual consumed 2 liters per day of drinking water from such a source of ground water.

(b) If any of the average annual radionuclide concentrations existing in a special source of ground water before construction of the disposal system already exceed the limits in 40 CFR Part 191.16(a), the disposal system shall be designed to provide a reasonable expectation that, for 1,000 years after disposal, undisturbed performance of the disposal system shall not increase the existing average annual radionuclide concentrations in water withdrawn from that special source of ground water by more than the limits established in 40 CFR Part 191.16(a)." [40 CFR 191.16]

\subsubsection{Performance Confirmation}

[SCP 8.3.5.16/Issue 1.7]

Exploration and research are required in response to the regulation(s) listed in this section. The information required, such as (1) annual precipitation, (2) wind speed, (3) seismic data, and water table elevation, is needed to support performance confirmation. 
Provide the exploration and research that are required to demonstrate, with reasonable assurance, compliance with the following requirement:

"The geologic repository operations area shall be designed so as to permit implementation of a performance confirmation program that meets the requirements of Subpart F of this part." [10 CFR 60.137]

\subsubsection{NRC Siting Criteria}

[SCP 8.3.5.17//ssue 1.8]

The conditions listed in this section require exploration and research to be obtained for the License Application (LA) and the site suitability decision. The 10 CFR 960 Favorable Conditions (FCs) and Potentially Adverse Conditions (PACs) are included to ensure that subtle differences are recognized and responded to in the development of the subordinate Site Design and Test Requirements Document and associated study plans. The association of the 10 CFR 60 PACs and FCs with the similar 10 CFR 960 PACs and FCs is done to place emphasis on the fact that the information obtained for the LA need to be consistent with the information collected for site suitability evaluation (See Appendix B for Site Suitability Evaluation Criteria).

As discussed in Section 3., the FCs and PACs are not requirements for determining the suitability of the site for development; they are nonetheless, included in this appendix as requiring information to support the evaluation of QCs and DCs.

A. The Nature and Rates of Tectonic, Hydrogeologic, Geochemical, and Geomorphic Processes. Provide the exploration and research that are required to determine if either of the following conditions exist at the site:

"The nature and rates of tectonic, hydrogeologic, geochemical, and geomorphic processes (or any of such processes) operating within the geologic setting during the Quaternary Period, when projected, would not affect or would favorably affect the ability of the geologic repository to isolate the waste." [10 CFR 60.122(b)(1)/Favorable Condition]

\section{Corresponding 10 CFR 960 Conditions:}

1. Hydrologic Processes. "The nature and rates of hydrologic processes operating within the geologic setting during the Quaternary Period would, if continued into the future, not affect or would favorably affect the ability of the geologic repository to isolate the waste during the next 100,000 years."

[10 CFR 960.4-2-1(b)(2)/Favorable Condition]

2. Geochemical Processes. "The nature and rates of geochemical processes operating within the geologic setting during the Quaternary Period would, if continued into the future, not affect or would favorably affect the ability of the geologic repository to 
isolate the waste during the next 100,000 years."

[10 CFR 960.4-2-2(b)(1)/Favorable Condition]

3. Erosion Process. "A geologic setting where the nature and rates of the erosional processes, that have been operating during the Quaternary Period, are predicted to have less than one chance in 10,000 over the next 10,000 years of leading to releases of radionuclides to the accessible environment."

[10 CFR 960.4-2-5(b)(2)/Favorable Condition]

4. Nature and Rates of Igneous and Tectonic Activity. "The nature and rates of igneous activity and tectonic processes (such as uplift, subsidence, faulting, or folding), if any, operating within the geologic setting during the Quaternary Period would, if continued into the future, have less than one chance in 10,000 over the first 10,000 years after closure of leading to releases of radionuclides to the accessible environment."

[10 CFR 960.4-2-7(b)/Favorable Condition]

B. Geochemical Conditions or Processes. Provide the exploration and research that are required to determine if either of the following conditions exist at the site:

"Geochemical conditions that:

(i) Promote precipitation or sorption of radionuclides;

(ii) Inhibit the formation of particulates, colloids, and inorganic and organic complexes that increase the mobility of radionuclides; or

(iii) Inhibit the transport of radionuclides by particulates, colloids, and complexes."

[10 CFR 60.122(b)(3)/Favorable Condition]

\section{Corresponding 10 CFR 960 Condition:}

"Geochemical conditions that promote the precipitation, diffusion into the rock matrix, or sorption of radionuclides; inhibit the formation of particulates, colloids, inorganic complexes, or organic complexes that increase the mobility of radionuclides; or inhibit the transport of radionuclides by particulates, colloids, or complexes."

[10 CFR 960.4-2-2(b)(2)/Favorable Condition]

C. Mineral Assemblages. Provide the exploration and research that are required to determine if either of the following conditions exist at the site:

"Mineral assemblages that, when subjected to anticipated thermal loading, will remain unaltered or alter to mineral assemblages having equal or increased capacity to inhibit radionuclide migration." 
[10 CFR 60.122(b)(4)/Favorable Condition]

\section{Corresponding 10 CFR 960 Condition:}

"Mineral assemblages that, when subjected to expected repository conditions, would remain unaltered or would alter mineral assemblages with equal or increased capability to retard radionuclide transport."

[10 CFR 960.4-2-2(b)(3)/Favorable Condition]

D. Waste Emplacement Depth of 300 Meters. Provide the exploration and research that are required to determine if either of the following conditions exist at the site:

"Conditions that permit the emplacement of waste at a minimum depth of 300 meters from the ground surface. (The ground surface shall be deemed to be the elevation of the lowest point on the surface above the disturbed zone.)"

[10 CFR 60.122(b)(5)/Favorable Condition]

\section{Corresponding 10 CFR 960 Condition:}

"Site conditions that permit the emplacement of waste at a depth of at least 300 meters below the directly overlying ground surface."

[10 CFR 960.4-2-5(b)(1)/Favorable Condition]

E. Low Population Density. Provide the exploration and research that are required to determine if either of the following conditions exist at the site:

"A low population density within the geologic setting and a controlled area that is remote from population centers."

[10 CFR 60.122(b)(6)/Favorable Condition]

F. 1000 Year Groundwater Travel Time. Provide the exploration and research that are required to determine if either of the following conditions exist at the site:

"Pre-waste-emplacement groundwater travel time along the fastest path of likely radionuclide travel from the disturbed zone to the accessible environment that substantially exceeds 1,000 years."

[10 CFR 60.122(b)(7)/Favorable Condition]

\section{Corresponding 10 CFR 960 Condition:}

"Site conditions such that the pre-waste-emplacement ground-water travel time along any path of likely radionuclide travel from the disturbed zone to the accessible environment would be more than 10,000 years."

[10 CFR 960.4-2-1(b)(1)/Favorable Condition] 
G. Unsaturated Zone Disposal. Provide the exploration and research that are required to determine if either of the following conditions exist at the site:

Unsaturated Zone Criteria (10 CFR 60)

"(i) Low moisture flux in the host rock and in the overlying and underlying hydrogeologic units;

(ii) A water table sufficiently below the underground facility such that fully saturated voids contiguous with the water table do not encounter the underground facility;

(iii) A laterally extensive low-permeability hydrogeologic unit above the host rock that would inhibit the downward movement of water or divert downward moving water to a location beyond the limits of the underground facility;

(iv) A host rock that provides for free drainage; or

(v) A climatic regime in which the average annual historic precipitation is a small percentage of the average annual potential evapotranspiration."

[10 CFR 60.122(b)(8)/Favorable Condition]

\section{Corresponding 10 CFR 960 Condition:}

Unsaturated Zone Criteria (The following 10 CFR 960 criteria apply to the pre-waste emplacement condition.)

"(i) A low and nearly constant degree of saturation in the host rock and in the immediately surrounding geohydrologic units.

(ii) A water table sufficiently below the underground facility such that the fully saturated voids contiguous with the water table do not encounter the host rock.

(iii) A geohydrologic unit above the host rock that would divert the downward infiltration of water beyond the limits of the emplaced waste.

(iv) A host rock that provides for free drainage.

(v) A climatic regime in which the average annual historical precipitation is a small fraction of the average annual potential evapotranspiration."

[10 CFR 960.4-2-1(b)(5)/Favorable Condition]

H. Flooding of Underground Facility. Provide the exploration and research that are required to determine if either of the following conditions exist at the site: 
"Potential for flooding of the underground facility, whether resulting from the occupancy and modification of floodplains or from the failure of existing or planned man-made surface water impoundments."

[10 CFR 60.122(c)(1)/Potentially Adverse Condition]

\section{Corresponding 10 CFR 960 Condition:}

"Surface characteristics that could lead to the flooding of surface or underground facilities by the occupancy and modification of flood plains, the failure of existing or planned man-made surface-water impoundments, or the failure of engineered components of the repository."

[10 CFR 960.5-2-8(c)/Potentially Adverse Condition]

I. Human Activities. Provide the exploration and research that are required to determine if either of the following conditions exist at the site:

"Potential for foreseeable human activity to adversely affect the groundwater flow system, such as groundwater withdrawal, extensive irrigation, subsurface injection of fluids, underground pumped storage, military activity or construction of large scale surface water impoundments."

[10 CFR 60.122(c)(2)/Potentially Adverse Condition]

\section{Corresponding 10 CFR 960 Condition:}

"Potential for foresecable human activities-such as ground-water withdrawal, extensive irrigation, subsurface injection of fluids, underground pumped storage, military activities, or the construction of large-scale surface water impoundments-that could adversely change portions of the groundwater flow system important to waste isolation."

[10 CFR 960.4-2-8-1(c)(5)/Potentially Adverse Condition]

J. Natural Phenomena. Provide the exploration and research that are required to determine if the following condition exists at the site:

"Potential for natural phenomena such as landslides, subsidence, or volcanic activity of such a magnitude that large-scale surface water impoundments could be created that could change the regional groundwater flow system and thereby adversely affect the performance of the geologic repository."

[10 CFR 60.122(c)(3)/Potentially Adverse Condition]

\section{Corresponding 10 CFR 960 Condition:}

"Potential for natural phenomena such as landslides, subsidence, or volcanic activity of such magnitudes that they could create large-scale surface-water impoundments that could change the regional ground-water flow system." 
[10 CFR 960.4-2-7(c)(5)/Potentially Adverse Condition]

K. Tectonic Deformation. Provide the exploration and research that are required to determine if either of the following conditions exist at the site:

"Structural deformation, such as uplift, subsidence, folding, or faulting that may adversely affect the regional groundwater flow system."

[10 CFR 60.122(c)(4)/Potentially Adverse Condition]

\section{Corresponding 10 CFR 960 Condition:}

"Potential for tectonic deformation-such as uplift, subsidence, folding, or faulting-that could adversely affect the regional ground-water flow system."

[10 CFR 960.4-2-7(c)(6)/Potentially Adverse Condition]

L. Geohydrologic Changes. Provide the exploration and research that are required to determine if either of the following conditions exist at the site:

"Potential for changes in hydrologic conditions that would affect the migration of radionuclides to the accessible environment, such as changes in hydraulic gradient, average interstitial velocity, storage coefficient, hydraulic conductivity, natural recharge, potentiometric levels, and discharge points."

[10 CFR 60.122(c)(5)/Potentially Adverse Condition]

\section{Corresponding 10 CFR 960 Condition:}

"Expected changes in the geohydrologic conditions-such as changes in the hydraulic gradient, the hydraulic conductivity, the effective porosity, and the ground-water flux through the host rock and the surrounding geohydrologic units-sufficient to significantly increase the transport of radionuclides to the accessible environment as compared with pre-waste-emplacement conditions."

[10 CFR 960.4-2-1(c)(1)/Potentially Advcrse Condition]

M. Future Climatic Affect on Hydrologic System. Provide the exploration and research that are required to determine if either of the following conditions exist at the site:

"Potential for changes in hydrologic conditions resulting from reasonably foreseeable climatic changes."

[10 CFR 60.122(c)(6)/Potentially Adverse Condition]

\section{Corresponding 10 CFR 960 Condition:}

"Evidence that climatic changes over the next 10,000 years could cause perturbations in the hydraulic gradient, the hydraulic conductivity, the effective porosity, or the 
ground-water flux through the host rock and the surrounding geohydrologic units, sufficient to significantly increase the transport of radionuclides to the accessible environment."

[10 CFR 960.4-2-4(c)(2)/Potentially Adverse Condition]

N. Chemical Reactivity of EBS. Provide the exploration and research that are required to determine if either of the following conditions exist at the site:

"Groundwater conditions in the host rock, including chemical composition, high ionic strength or ranges of Eh-ph, that could increase the solubility or chemical reactivity of the engineered barrier system."

[10 CFR 60.122(c)(7)/Potentially Adverse Condition]

\section{Corresponding 10 CFR 960 Condition:}

"Ground-water conditions in the host rock that could affect the solubility or the chemical reactivity of the engineered-barrier system to the extent that the expected repository performance could be compromised."

[10 CFR 960.4-2-2(c)(1)/Potentially Adverse Condition]

O. Geochemical Conditions or Processes. Provide the exploration and research that are required to determine if either of the following conditions exist at the site:

"Geochemical processes that would reduce sorption of radionuclides, result in degradation of the rock strength, or adversely affect the performance of the engineered barrier system."

[10 CFR 60.122(c)(8)/Potentially Adverse Condition]

\section{Corresponding 10 CFR 960 Condition:}

"Geochemical processes or conditions that could reduce the sorption of radionuclides or degrade the rock strength."

[10 CFR 960.4-2-2(c)(2)/Potentially Adverse Condition]

P. Oxidizing Groundwater. Provide the exploration and research that are required to determine if either of the following conditions exist at the site:

"Groundwater conditions in the host rock that are not reducing."

[10 CFR 60.122(c)(9)/Potentially Adverse Condition]

\section{Corresponding 10 CFR 960 Condition:}

"Pre-waste-emplacement ground-water conditions in the host rock that are chemically oxidizing." 
[10 CFR 960.4-2-2(c)(3)/Potentially Adverse Condition]

Q. Dissolution Evidence. Provide the exploration and research that are required to determine if either of the following conditions exist at the site:

2) "Evidence of dissolutioning such as breccia pipes, dissolution cavities, or brine pockets."

[10 CFR 60.122(c)(10)/Potentially Adverse Condition]

\section{Corresponding 10 CFR 960 Condition:}

"Evidence of dissolution within the geologic setting-such as breccia pipes, dissolution cavities, significant volumetric reduction of the host rock or surrounding strata, or any structural collapse-such that a hydraulic interconnection leading to a loss of waste isolation could occur."

[10 CFR 960.4-2-6(c)/Potentially Adverse Condition]

R. Evidence of Quaternary Period Tectonics. Provide the exploration and research that are required to determine if either of the following conditions exist at the site:

"Structural deformation such as uplift, subsidence, folding, and faulting during the Quaternary Period."

[10 CFR 60.122(c)(11)/Potentially Adverse Condition]

\section{Corresponding 10 CFR 960 Condition:}

"Evidence exists of active folding, faulting, diapirism, uplift, subsidence, or other tectonic processes or igneous activity within the geologic setting during the Quaternary Period." [10 CFR 960.4-2-7(c)(1)/Potentially Adverse Condition]

S. Historical Earthquakes. Provide the exploration and research that are required to determine if either of the following conditions exist at the site:

"Earthquakes which have occurred historically that if they were to be repeated could affect the site significantly."

[10 CFR 60.122(c)(12)/Potentially Adverse Condition]

\section{Corresponding 10 CFR 960 Condition:}

"Historical earthquakes within the geologic setting of such magnitude and intensity that, if they recurred, could affect waste containment or isolation."

[10 CFR 960.4-2-7(c)(2)/Potentially Adverse Condition]

T. Increase in Frequency/Magnitude of Earthquakes. Provide the exploration and research that are required to determine if either of the following conditions exist at the 
site:

"Indications, based on correlations of earthquakes with tectonic processes and features, that either the frequency of occurrence or magnitude of earthquakes may increase."

[10 CFR 60.122(c)(13)/Potentially Adverse Condition]

\section{Corresponding 10 CFR 960 Condition:}

"Indications, based on correlations of earthquakes with tectonic processes and features, that either the frequency of occurrence or the magnitude of earthquakes within the geologic setting may increase."

[10 CFR 960.4-2-7(c)(3)/Potentially Adverse Condition]

U. Earthquakes Magnitude/Frequency High for Region. Provide the exploration and research that are required to determine if either of the following conditions exist at the site:

"More frequent occurrence of earthquakes or earthquakes of higher magnitude than is typical of the area in which the geologic setting is located."

[10 CFR 60.122(c)(14)/Potentially Adverse Condition]

\section{Corresponding 10 CFR 960 Condition:}

"More-frequent occurrences of earthquakes or earthquakes of higher magnitude than are representative of the region in which the geologic setting is located."

[10 CFR 960.4-2-7(c)(4)/Potentially Adverse Condition]

V. Igneous Activity. Provide the exploration and research that are required to determine if the following condition exists at the site:

"Evidence of igneous activity since the start of the Quatemary Period.

[10 CFR 60.122(c)(15)/Potentially Adverse Condition]

W. Extreme Quatemary Period Erosion. Provide the exploration and research that are required to determine if either of the following conditions exist at the site:

"Evidence of extreme erosion during the Quaternary Period."

[10 CFR 60.122(c)(16)/Potentially Adverse Condition]

Corresponding 10 CFR 960 Condition:

"A geologic setting that shows evidence of extreme erosion during the Quaternary Period."

[10 CFR 960.4-2-5(c)(1)/Potentially Adverse Condition] 
X. Economic Criteria for Natural Resources. Provide the exploration and research that are required to determine if either of the following conditions exist at the site:

"The presence of naturally occurring materials, whether identified or undiscovered, within the site, in such form that:

(i) Economic extraction is currently feasible or potentially feasible during the foresceable future; or

(ii) Such materials have greater gross value or net value than the average for other areas of similar size that are representative of and located within the geologic setting." [10 CFR 60.122(c)(17)/Potentially Adverse Condition]

\section{Corresponding 10 CFR 960 Condition:}

"Indications that the site contains naturally occurring materials, whether or not actually identified in such form that:

(i) economic extraction is potentially feasible during the foreseeable future, or

(ii) such materials have a greater gross value, net value, or commercial potential than the average for other areas of similar size that are representative of, and located in, the geologic setting."

[10 CFR 960.4-2-8-1(c)(1)/Potentially Adverse Condition]

Y. Evidence of Subsurface Mining. Provide the exploration and research that are required to determine if either of the following conditions exist at the site:

"Evidence of subsurface mining for resources within the site." [10 CFR 60.122(c)(18)/Potentially Adverse Condition]

\section{Corresponding 10 CFR 960 Condition:}

"Evidence of subsurface mining or extraction for resources within the site if it could affect waste containment or isolation." [10 CFR 960.4-2-8-1(c)(2)/Potentially Adverse Condition]

Z. Evidence of Drilling. Provide the exploration and research that are required to determine if either of the following conditions exist at the site:

"Evidence of drilling for any purpose within the site." [10 CFR 60.122(c)(19)/Potentially Adverse Condition] 


\section{Corresponding 10 CFR 960 Condition:}

"Evidence of drilling within the site for any purpose other than repository-site evaluation to a depth sufficient to affect waste containment and isolation."

[10 CFR 960.4-2-8-1(c)(3)/Potentially Adverse Condition]

AA. Poor Rock Conditions. Provide the exploration and research that are required to determine if any of the following conditions exist at the site:

1) "Geomechanical properties that do not permit design of underground opening that will remain stable through permanent closure."

[10 CFR 60.122(c)(21)/Potentially Adverse Condition]

2) "Rock or groundwater conditions that would require complex engineering measures in the design and construction of the underground facility or in the sealing of boreholes and shafts."

[10 CFR 60.122(c)(20)/Potentially Adverse Condition]

3) "Potential for the movement of rudionuclides in a gaseous state through air-filled pore spaces of an unsaturated geologic medium to the accessible environment."

[10 CFR 60.122(c)(24)/Potentially Adverse Condition]

\section{Corresponding 10 CFR 960 Condition:}

"Rock conditions that could require engineering measures beyond reasonably available technology for the construction, operation, and closure of the repository, if such measures are necessary to ensure waste containment or isolation."

[10 CFR 960.4-2-3(c)(1)/Potentially Adverse Condition]

BB. Water Table Rise. Provide the exploration and research that are required to determine if either of the following conditions exist at the site:

"Potential for the water table to rise sufficiently so as to cause saturation of an underground facility located in the unsaturated zone."

[10 CFR 60.122(c)(22)/Potentially Adverse Condition]

\section{Corresponding 10 CFR 960 Condition:}

"Evidence that the water table couid rise sufficiently over the next 10,000 years to saturate the underground facility in a previously unsaturated host rock."

[10 CFR 960.4-2-4(c)(1)/Potentially Adverse Condition] 
CC. Unpredictable Geology. Provide the exploration and research that are required to determine if either of the following conditions exist at the site:

"Potential for existing or future perched water bodies that may saturate portions of the underground facility or provide a faster flow path from an underground facility located in the unsaturated zone to the accessible environment."

[10 CFR 60.122(c)(23)]

\section{Corresponding 10 CFR 960 Condition:}

"The presence in the geologic setting of stratigraphic or structural features- such as dikes, sills, faults, shear zones, folds, dissolution effects, or brine pockets-if their presence could significantly contribute to the difficulty of characterizing or modeling the geohydrologic system."

[10 CFR 960.4-2-1(c)(3)/Potentially Adverse Condition]

\subsubsection{DOE Siting Criteria}

[SCP 8.3.5.18/1ssue 1.9]

Exploration and research are required in response to the regulations/conditions listed in this section. The conditions listed in this section are from 10 CFR 960, and the information required by the conditions in this section will be used for site suitability evaluation in conjunction with the information that is generated by the conditions in Section 3.4.5, 3.4.6, 3.5.8 and 3.5.1C.

A. Postclosure System Guideline/Qualifying Condition. Provide the exploration and research that are required to determine if the following condition exists at the site:

"The geologic setting at the site shall allow for the physical separation of radioactive waste from the accessible environment after closure in accordance with the requirements of 40 CFR Part 191, Subpart B, as implemented by the provisions of 10 CFR Part 60. The geologic setting at the site will allow for the use of engineered barriers to ensure compliance with the requirements of 40 CFR Part 191 and 10 CFR Part 60 (see Appendix I of this Part)."

[10 CFR 960.4-1(a)]

B. Geohydrology/Qualifying Condition. Provide the exploration and research that are required to determine if the following condition exists at the site:

"The present and expected geohydrologic setting of a site shall be compatible with waste containment and isolation. The geohydrologic setting, considering the characteristics of and the processes operating within the geologic setting, shall permit compliance with (1) the requirements specifiel in 10 CFR Part 960.4-1 for radionuclide releases to the accessible environment and (2) the requirements specified in 10 CFR 60.113 for radionuclide releases from the engineered-barrier system using reasonably available 
technology."

[10 CFR 960.4-2-1(a)]

C. Geohydrology/Disqualifying Condition. Provide the exploration and research that are required to determine if the following condition exists at the site:

"... pre-waste-emplacement ground-water travel time from the disturbed zone to the accessible environment is expected to be less than 1,000 years along any pathway of likely and significant radionuclide travel."

[10 CFR 960.4-2-1(d)]

D. Geochemistry/Qualifying Condition. Provide the exploration and research that are required to determine if the following condition exists at the site:

"The present and expected geochemical characteristics of a site shall be compatible with waste containment and isolation. Considering the likely chemical interactions among radionuclides, the host rock, and the ground water, the characteristics of and the processes operating within the geologic setting shall permit compliance with (1) the requirements specified in 10 CFR 960.4-1 for radionuclide releases to the accessible environment and (2) the requirements specified in 10 CFR 60.113 for radionuclide releases from the engineered-barrier system using reasonably available technology."

[10 CFR 960.4-2-2(a)]

E. Rock Characteriatica/Qualifying Condition. Provide the exploration and research that are required to determine if the following condition exists at the site:

"The present and expected characteristics of the host rock and surrounding units shall be capable of accommodating the thermal, chemical, mechanical, and radiation stresses expected to be induced by repository construction, operation, and ' 'osure and by expected interactions among the waste, host rock, ground water, and engineered components. The characteristics of and the processes operating within the geologic setting shall permit compliance with (1) the requirements specified in 10 CFR 960.4-1 for radionuclide releases to the accessible environment and (2) the requirements set forth in 10 CFR 60.113 for radionuclide releases from the engincered-barrier system using reasonably available technology."

[10 CFR 960.4-2-3(a)/Qualifying Condition]

F. Climatic Changes/Qualifying Condition. Provide the exploration and research that are required to determine if the following condition exists at the site:

"In predicting the likely future climatic conditions at a site, the DOE will consider the global, regional, and site climatic patterns during the Quatemary Period, considering the geomorphic evidence of the climatic conditions in the geologic setting."

[10 CFR 960.4-2-4(a)] 
Title: Appendix A, Site Characterization System Requirements

G. Erosion/Qualifying Condition. Provide the exploration and research that are required to determine if the following condition exists at the site:

"The site shall allow the underground facility to be placed at a depth such that erosional processes acting upon the surface will not be likely to lead to radionuclide releases greater than those allowable under the requirements specified in 10 CFR 960.4-1. In predicting the likelihood of potentially disruptive erosional processes, the DOE will consider the climatic, tectonic, and geomorphic evidence of rates and patterns of erosion in the geologic setting during the Quaternary Period."

[10 CFR 960.4-2-5(a)/Qualifying Condition]

H. Erosion/Disqualifying Condition. Provide the exploration and research that are required to determine if the following condition exists at the site:

"...site conditions do not allow all portions of the underground facility to be situated at least 200 meters below the directly overlying ground surface."

[10 CFR 960.4-2-5(d)/Disqualifying Condition]

I. Dissolution/Qualifying Condition. Provide the exploration and research that are required to determine if the following condition exists at the site:

"The site shall be located such that any subsurface rock dissolution will not be likely to lead to radionuclide releases greater than those allowable under the requirements specified in 10 CFR 960.4-1. In predicting the likelihood of dissolution within the geologic setting at a site, the DOE will consider the evidence of dissolution within that setting during the Quaternary Period, including the locations and characteristics of dissolution fronts or other dissolution features, if identified."

[10 CFR 960.4-2-6(a)]

J. Dissolution/Disqualifying Condition. Provide the exploration and research that are required to determine if the following condition exists at the site:

"...it is likely that, during the first 10,000 years after closure, active dissolution, as predicted on the basis of the geologic record, would result in a loss of waste isolation." [10 CFR 960.4-2-6(d)]

K. Tectonics/Qualifying Condition. Provide the exploration and research that are required to determine if the following condition exists at the site:

"The site shall be located in a geologic setting where future tectonic processes or events will not be likely to lead to radionuclide releases greater than those allowable under the requirements specified in 10 CFR 960.4-1. In predicting the likelihood of potentially disruptive tectonic processes or events, the DOE will consider the structural, stratigraphic, geophysical, and seismic evidence for the nature and rates of tectonic processes and 
events in the geologic setting during the Quatemary Period."

[10 CFR 960.4-2-7(a)]

L. Tectonics/Disqualifying Condition. Provide the exploration and research that are required to determine:

"...if based on the geologic record during the Quaternary Period, the nature and rates of fault movement or other ground motion are expected to be such that a loss of waste isolation is likely to occur."

[10 CFR 960.4-2-7(d)]

M. Natural Resources/Qualifying Condition. Provide the exploration and research that are required to determine if the following condition exists at the site:

"This site shall be located such that -- considering permanent markers and records and reasonable projections of value, scarcity, and technology -- the natural resources, including ground water suitable for crop irrigation or human consumption without treatment, present at or near the site will not be likely to give rise to interference activities that would lead to radionuclide releases greater than those allowable under the requirements specified in 10 CFR 960.4-1."

[10 CFR 960.4-2-8-1(a)]

N. Natural Resources/Disqualifying Condition No 1. Provide the exploration and research that are required to determine if the following condition exists at the site:

"Previous exploration, mining, or extraction activities for resources of commercial importance at the site have created significant pathways between the projected underground facility and the accessible environment."

[10 CFR 960.4-2-8-1(d)(1)]

0. Natural Resources/Disqualifying Condition No 2. Provide the exploration and research that are required to determine if the following condition exists at the site:

"Ongoing or likely future activities to recover presently valuable natural mineral resources outside the controlled area would be expected to lead to an inadvertent loss of waste isolation."

[10 CFR 960.4-2-8-1(d)(2)]

\subsubsection{Additional DOE Siting Criteria}

Exploration and research are required in response to the regulations/conditions listed in this section. The conditions listed in this section are from 10 CFR 960, and the information required by the conditions in this section will be used for site suitability evaluation in junction with the information that is generated by the conditions in Sections 3.4.5, 3.4.6, 3.5.8 and 3.5.9. 
As discussed in Section 3., the FCs and PACs are not requirements for determining the suitability of the site for development, they are nonetheless, included in this appendix as requiring information to support the evaluation of QCs and DCs.

\section{A. Geohydrology.}

1. Ease of Characterization. Provide the exploration and research that are required to determine if the following condition exists at the site:

"Sites that have stratigraphic, structural, and hydrologic features such that the geohydrologic system can be readily characterized and modeled with reasonable certainty."

[10 CFR 960.4-2-1(b)(3)/Favorable Condition]

2. Groundwater Sources. Provide the exploration and research that are required to determine if the following condition exists at the site:

"The presence of groundwater sources, suitable for crop irrigation or human consumption without treatment, along ground-water flow paths from the host rock to the accessible environment."

[10 CFR 960.4-2-1(c)(2)/Potentially Adverse Condition]

\section{B. Geochemistry.}

1. Dissolving of Radionuclides. Provide the data, exploration and research that are required to determine if the following condition exists at the site:

"A combination of expected geochemical conditions and a volumetric flow rate of water in the host rock that would allow less than 0.001 percent per year of the total radionuclide inventory in the repository at 1000 years to be dissolved."

[10 CFR 960.4-2-2(b)(4)/Favorable Condition]

2. Radionuclide Release Reduction. Provide the data, exploration and research that are required to determine if the following condition exists at the site:

"Any combination of geochemical and physical retardation processes that would decrease the predicted peak cumulative releases of radionuclides to the accessible environment by a factor of 10 as compared to those predicted on the basis of groundwater travel time without such retardation."

[10 CFR 960.4-2-2(b)(5)/Favorable Condition]

\section{Reserved.}




\section{Climatic Changes.}

1. Climatic Cycles. Provide the exploration and research that are required to determine if the following wndition exists at the site:

"A surface-water system such that expected climatic cycles over the next 100,000 years would not adversely affect waste isolation."

[10 CFR 960.4-2-4(b)(1)/Favorable Condition]

2. Past Climatic Affect on Hydrologic System. Provide the exploration and research that are required to determine if the following condition exists at the site:

"A geologic setting in which climatic changes have had little effect on the hydrologic system throughout the Quaternary Period."

[10 CFR 960.4-2-4(b)(2)/Favorable Condition]

\section{E. Reserved.}

\section{F. Dissolution.}

Quaternary Period Dissolution. Provide the exploration and research that are required to determine if the following condition exists at the site:

"No evidence that the host rock within the site was subject to significant dissolution during the Quaternary Period."

[10 CFR 960.4-2-6(b)/Favorable Condition]

\section{G. Natural Resources.}

1. Natural Resources. Provide the exploration and research that are required to determine if the following condition exists at the site:

"No known natural resources that have or are projected to have in the foreseeable future a value great enough to be considered a commercially extractable resource." [10 CFR 960.4-2-8-1(b)(1)/Favorable Condition]

2. Total Dissolved Solids. Provide the exploration and research that are required to determine if the following condition exists at the site:

"Ground water with 10,000 parts per million or more of total dissolved solids along any path of likely radionuclide travel from the host rock to the accessible environment."

[10 CFR 960.4-2-8-1(b)(2)/Favorable Condition] 
3. Significant Concentration of Naturally Occurring Material. Provide the exploration and research that are required to determine if the following condition exists at the site:

"Evidence of a significant concentration of any naturally occurring material that is not widely available from other sources."

[10 CFR 960.4-2-8-1(c)(4)/Potentially Adverse Condition]

\section{H. Meteorology.}

1. Prevailing Meteorclogical Conditions. Provide the exploration and research that are required to determine if the following condition exists at the site:

"Prevailing meteorological conditions such that any radioactive. releases to the atmosphere during repository operation and closure would be effectively dispersed, hereby reducing significantly the likelihood of unacceptable exposure to any member of the public in the vicinity of the repository."

[10 CFR 960.5-2-3(b)/Favorable Condition]

2. Prevailing Meteorological Conditions. Provide the exploration and research that are required to determine if the following condition exists at the site:

"Prevailing meteorological conditions such that radioactive emissions from repository operation and closure could be preferentially transported toward localities in the vicinity of the repository with higher population densities than are the average for the region."

[10 CFR 960.5-2-3(c)(1)/Potentially Adverse Condition]

3. Weather History. Provide the exploration and research that are required to determine if the following condition exists at the site:

"History of extreme weather phenomena-such as hurricanes, tornadoes, severe floods, or severe and frequent winter storms-that could significantly affect repository operation or closure."

[10 CFR 960.5-2-3(c)(2)/Potentially Adverse Condition]

\section{Offsite Installations.}

1. Contributing Radioactive Releases. Provide the exploration and research that are required to determine if the following condition exists at the site:

"Absence of contributing radioactive releases from other nuclear installations and operations that must be considered under the requirements of 40 CER 191, Subpart A." 
Title: Appendix A, Site Characterization System Requirements

[10 CFR 960.5-2-4(b)/Favorable Condition]

2. Potentially Hazardous Installations. Provide the exploration and research that are required to determine if the following condition exists at the site:

"The presence of nearby potentially hazardous installations or operations that could adversely affect repository operation or closure."

[10 CFR 960.5-2-4(c)(1)/Potentially Adverse Condition]

3. Presence of other Nuclear Facilities. Provide the exploration and research that are required to determine if the following condition exists at the site:

"Presence of other nuclear installations and operations, subject to the requirements of 40 CFR Part 190 or 40 CFR 191, Subpart A, with actual or projected releases near the maximum value permissible under those standards."

[10 CFR 960.5-2-4(c)(2)/Potentially Adverse Condition] 
Title: Appendix B, Site Suitability Evaluation Criteria

\section{Table of Contents}

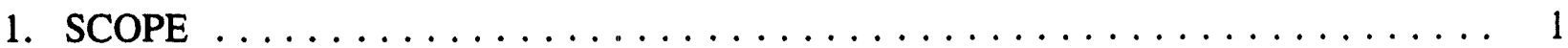

1.1 IDENTIFICATION $\ldots \ldots \ldots \ldots \ldots \ldots \ldots \ldots \ldots \ldots \ldots \ldots \ldots \ldots$

1.2 DOCUMENT DEVELOPMENT $\ldots \ldots \ldots \ldots \ldots \ldots \ldots \ldots \ldots \ldots, 1$

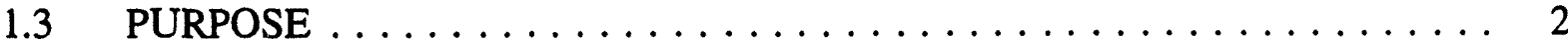

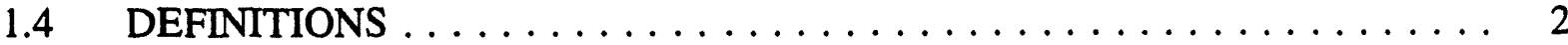

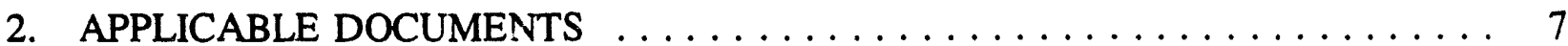

2.1 GOVERNMENT DOCUMENTS $\ldots \ldots \ldots \ldots \ldots \ldots \ldots \ldots \ldots$

2.1.1 Laws, Statutes, U.S. Codes, and Treaties ............... 7

2.1.2 Code of Federal Regulations and Executive Orders $\ldots \ldots \ldots \ldots \ldots, 7$

2.1.3 Other References .......................... 7

3. GUIDELINES $\ldots \ldots \ldots \ldots \ldots \ldots \ldots \ldots \ldots \ldots \ldots \ldots \ldots \ldots \ldots \ldots \ldots$

3.1 GENERAL GUIDELINES $\ldots \ldots \ldots \ldots \ldots \ldots \ldots \ldots \ldots \ldots, 9$

3.2 SYSTEM GUIDELINES $\ldots \ldots \ldots \ldots \ldots \ldots \ldots \ldots \ldots \ldots, 9$

3.2.1 Postclosure: Physical Separation of Radioactive Waste from Environment . 9

3.2.2 Preclosure: Radiological Safety . . . . . . . . . . . . . . . . 9

3.2.3 Preclosure: Environment, Socioeconomics, and Transportation ....... 9

3.2.4 Preclosure: Ease and Cost of Siting, Construction, Operation, and Closure . 10

3.3 TECHNICAL GUIDELINES $\ldots \ldots \ldots \ldots \ldots \ldots \ldots \ldots \ldots \ldots \ldots$

3.3.1 Postclosure: Physical Separation of Radioactive Waste from Environment . 10

3.3.1.1 Geohydrology $\ldots \ldots \ldots \ldots \ldots \ldots \ldots \ldots \ldots \ldots \ldots$

3.3.1.2 Geochemistry ....................... 11

3.3.1.3 Rock Characteristics ...................... 11

3.3.1.4 Climatic Changes $\ldots \ldots \ldots \ldots \ldots \ldots \ldots \ldots \ldots \ldots \ldots \ldots \ldots$

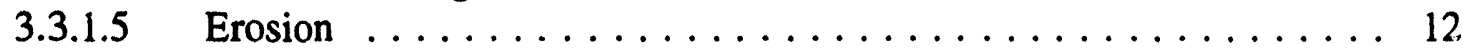

3.3.1.6 Dissolution .......................... 12

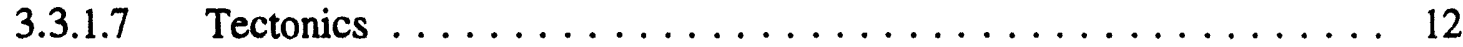

3.3.1.8 Human Interference. . . . . . . . . . . . . . . . 13

3.3.2 Preclosure: Radiological Safety $\ldots \ldots \ldots \ldots \ldots \ldots \ldots \ldots \ldots$

3.3.2.1 Population Density and Distribution. .............. 14

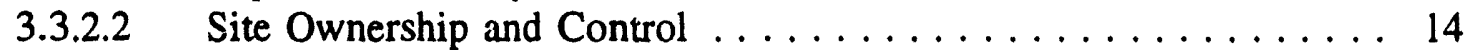


Title: Appendix B, Site Suitability Evaluation Criteria

3.3.2.3 Meteorology .................... 15

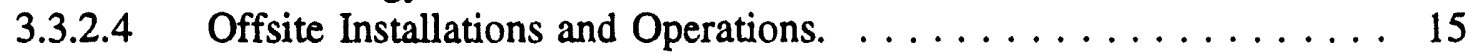

3.3.3 Preclosure: Environment, Socioeconomics, and Transportation $\ldots \ldots \ldots 15$

3.3.3.1 Environmental Quality $\ldots \ldots \ldots \ldots \ldots \ldots \ldots \ldots \ldots \ldots$

3.3.3.2 Socioeconomic Impacts $\ldots \ldots \ldots \ldots \ldots \ldots \ldots \ldots \ldots \ldots$

3.3.3.3 Transportation. ..................... 17

3.3.4 Preclosure: Ease and Cost of Siting, Construction, Operation, and Closure . 17

3.3.4.1 Surface Characteristics ................... 17

3.3.4.2 Rock Characteristics ................... 18

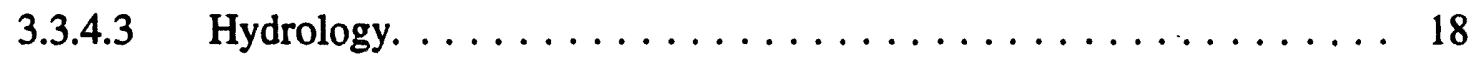

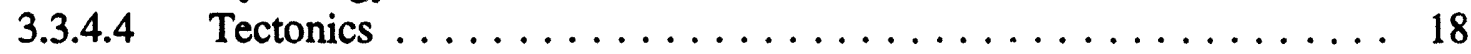


Title: Appendix $\cdot$ B, Site Suitability Evaluation Criteria

Revision: 1

Page: B -1

\section{SCOPE}

\subsection{IDENTIFICATION}

This appendix to the MGDS Requirements Document summarizes those guidelines of 10 CFR 960, "Nuclear Waste Policy Act; General Guidelines for the Recommendation of Sites for the Nuclear Waste Repositories," which must be met in order for the Secretary of Energy to recommend to the President a site for development as a repository.

10 CFR 960 was developed in accordance with the requirements of the Nuclear Waste Policy Act of 1982 to be used by the Secretary of Energy in the evaluation and comparison of multiple repository sites. In 1987, the Nuclear Waste Policy Amendments Act was issued and designated the Yucca Mountain site as the only site that would be characterized until site suitability of the site has been determined. Once the suitability of the site has been determined, then either a new site would be chosen to be characterized or the development of Yucca Mountain would proceed.

The criteria in 10 CFR 960 serve as the bases for suitability of the Yucca Mountain site. The process of developing and assessing data to support this determination is described in section 1 of Appendix A of the MGDS Requirements Document.

The development and control of this appendix is quality affecting and subject to the same QARD and Configuration Management Controls as is the basic document.

\subsection{DOCUMENT DEVELOPMENT}

The framework for the development of site suitability criteria is established in this appendix through guidelines derived from the Qualifying Conditions (QCs) and Disqualifying Conditions (DCs) of 10 CFR 960. The favorable conditions (FCs) and potentially adverse conditions (PACs) are not specifically utilized in this document because they are not evaluation criteria that must be met; however, as this document matures, some of the PACs and the FCs could conceivably be the source/origin for some of the criteria that are listed under the QCs.

Initially, the QCs and DCs in this document are verbatim quotes from 10 CFR 960 . It is recognized that these statements contain wording which must be defined in order to determine what data must be gathered and what analysis must be accomplished to evaluate the guidelines. As definitive answers are developed, this document will be updated to document the cumulative results of analyses and agreements. The evolved, definitive product will provide the following:

A. A list of the criteria required for site suitability evaluation.

B. Criteria for determining when enough information has been collected. 


\subsection{PURPOSE}

The purpose of this appendix is to provide the following:

A. Criteria for program management to review project activities and evaluate project recommendations of site suitability.

B. A basis for the project to develop site characterization activities and facilities to gather data and conduct evaluations and analyses.

C. Criteria to enable the project to develop recommendations for suitability.

Development of this appendix will be an iterative process which will eventually evolve into a definitive product which will meet the purpose of the document stated above.

\subsection{DEFINITIONS}

The following definitions that relate to this document have been taken from 10 CFR 960.2:

Accessible Environment. The atmosphere, the land surface, surface water, oceans, and the portion of the lithosphere that is outside the controlled area.

Barrier. Any material or structure that prevents or substantially delays the movement of water or radionuclides.

Closure. Final backfilling of the remaining open operational areas of the underground facility and boreholes after the termination of waste emplacement, culminating in the sealing of shafts.

Disqualifying Condition. A condition that, if present at a site, would eliminate that site from further consideration.

Disturbed Zone. That portion of the controlled area, excluding shafts, whose physical or chemical properties are predicted to change as a result of underground facility construction or heat generated by the emplaced radioactive waste such that the resultant change of properties could have a significant effect on the performance of the geologic repository.

DOE. The U.S. Department of Energy or its duly authorized representatives.

Effective Porosity. The amount of interconnected pore space and fracture openings available for the transmission of fluids, expressed as the ratio of the volume of interconnected pores and openings to the volume of rock.

Engineered-Barrier System. The manmade components of a disposal system designed to prevent the release of radionuclides from the underground facility or into the geohydrologic setting. Such term includes the radioactive-waste form, radioactive-waste canisters, materials placed over and around such canisters, any other components of the waste package, and barriers used to seal 
penetrations in and into the underground facility.

Fault. A fracture or a zone of fractures along which there has been displacement of the side relative to one another parallel to the fracture or zone of fractures.

Favorable Condition. A condition that, though not necessary to qualify a site, is presumed, if present, to enhance confidence that the qualifying condition of a particular guideline can be met.

Geohydrologic Setting. The system of geohydrologic units that is located within a given geologic setting.

Geologic Setting. The geologic, hydrologic, and geochemical systems of the region in which a geologic repository operations area is or may be located.

Ground water. All subsurface water as distinct from surface water.

Ground-Water Travel Time. The time required for a unit volume of ground water to travel between two locations. The travel time is the length of the flow path divided by the velocity, where velocity is the average ground-water flux passing through the cross-sectional area of the geologic medium through which flow occurs, perpendicular to the flow direction, divided by the effective porosity along the flow path. If discrete segments of the flow path have different hydrologic properties, the total travel time will be the sum of the travel times for each discrete segment.

Host rock. The geologic medium in which the waste is emplaced, specifically the geologic materials that directly encompass and are in close proximity to the underground facility.

High-level radicactive waste. (1) The highly radioactive material resulting from the reprocessing of spent nuclear fuel, including liquid waste produced directly in reprocessing and any solid material derived from such liquid waste that contains fission products in sufficient concentrations and (2) other highly radioactive material that the NRC, consistent with existing law, determines by rule requires permanent isolation.

Isolation. Inhibiting the transport of radioactive material so that the amounts and concentrations of this material entering the accessible environment will be kept within prescribed limits.

Likely. Processing or displaying the qualities, characteristics, or attributes that provide a reasonable basis for confidence that what is expected indeed exists or will occur.

Member of the public. Any individual who is not engaged in operations involving the management, storage, and disposal of radioactive waste. A worker so engaged is a member of the public except when on duty at the geologic-repository operations area.

Mitigation. (1) Avoiding the impact altogether by not taking a certain action or parts of an action; (2) minimizing impacts by limiting the degree or magnitude of the action and its 
implementation; (3) rectifying the impact by repairing, rehabilitating, or restoring the affected environment; (4) reducing or eliminating the impact over time by preservation and maintenance operations during the life of the action; or (5) compensating for the impact by replacing or providing substitute resources or environments.

NRC. The U.S. Nuclear Regulatory Commission or its duly authorized representatives.

Postclosure. The period of time after the closure of the geologic repository.

Preclosure. The period of time before and during the closure of the geologic repository.

Pre-waste-emplacement. Before the authorization of repository construction by the NRC.

Qualifying Condition. A condition that must be satisfied for a site to be considered acceptable with respect to a specific guideline.

Quaternary Period. The second period of the Cenozoic Era, following the Tertiary, beginning 2 to 3 million years ago and extending to the present.

Radioactive Waste or Waste. High-level radioactive waste and other radioactive materials, including spent nuclear fuel, that are received for emplacement in a geologic repository.

Reasonably Available Technology. Technology which exists and has been demonstrated or for which the results of any requisite development, demonstration, or confirmatory testing efforts before application will be available within the required time period.

Repository. Synonymous with "geologic repository."

Repository Closure. Synonymous with "closure."

Repository Operation. All of the functions at the site leading to and involving radioactive-waste emplacement in the underground facility, including receiving, transportation, handling, emplacement, and, if necessary, retrieval.

Site. A potentially acceptable site or a candidate site, as appropriate, until such time as the controlled area has been established, at which time the site and the controlled area are the same.

Site characterization. Activities, whether in the laboratory or in the field, undertaken to establish the geologic conditions and the ranges of the parameters of a candidate site relevant to the location of a repository, including borings, surface excavations, excavations of exploratory shafts, limited subsurface lateral excavations and borings, and in situ testing needed to evaluate the suitability of a candidate site for the location of a repository, but not including preliminary borings and geophysical testing needed to assess whether site characterization should be undertaken.

Surface water. Any waters on the surface of the Earth, including fresh and salt water, ice, and 
snow.

Tectonics. The branch of geology dealing with the broad architecture of the outer part of the Earth, that is, the regional assembling of structural or deformational features and the study of their mutual relations, origin, and historical evolution.

Underground Facility. The underground structure and the rock required for support, including mined openings and backfill materials, but excluding shafts, boreholes, and their seals. 
Title: Appendix.B, Site Suitability Evaluation Criteria

Revision: 1

Page: $B-7$

\section{APPLICABLE DOCUMENTS}

This section identifies documents which have been references as sources of requirements or guidance for this Appendix. The documents are included to provide traceability to the source documents and are not to be incorporated as requirements themselves.

The following documents, of the issue in effect on the date of the approval of design requirements documents form a part of the MGDS requirements to the degree specified herein.

\subsection{GOVERNMENT DOCUMENTS}

\subsubsection{Laws, Statutes, U.S. Codes, and Treaties}

Identifier

Title or Description

A. 42 USC 10101 et seq. Nuclear Waste Policy Act of 1982 (NV/PA, P.L. 97-425) and Nuclear Waste Policy Amendments Act of 1987 (NWPAA, P.L. 100-203)

\subsubsection{Code of Federal Regulations and Executive Orders}

Identifier

A. 10 CFR 960
Title or Description

General Guidelines for the Recommendation of Sites for Nuclear Waste Repositories

\subsubsection{Other References}

This section identifies documents that have not been used as sources of requirements, but are provided here for reference.

\section{Identifier}

A. 10 CFR 20

B. 10 CFR 60

\section{Title or Description}

Standards for Protection Against Radiation

Disposal of High-Level Radioactive Wastes in Geologic Repositories 
Title: Appendix B, Site Suitability Evaluation Criteria

Revision: 1

Page: $B-8$

C. 40 CFR 191

Environmental Radiation Protection Standards for Management and Disposal of Spent Nuclear Fuel, High-Level and Transuranic Radioactive Wastes ${ }^{1}$

1 The Energy Act of 1992 nullified the effectiveness of 40 CFR 191 on the MGDS. To provide a basis for design to proceed, requirements have been derived from the 1985 version of 40 CFR 191 and are subject to review until replaced. 


\section{GUIDELINES}

\subsection{GENERAL GUIDELINES}

The site may be recommended as acceptable for geologic repository development only if all the System Guidelines (see below) are met.

[10 CFR 960.4-2]

\subsection{SYSTEM GUIDELINES}

This section summarizes the System Guidelines of 10 CFR Part 960 which must be met to support a recommendation that a site be developed as a repository. It will incorporate clarifications and extensions of the regulatory guidelines statements as they are evolved.

\subsubsection{Postclosure: Physical Separation of Radioactive Waste from Environment}

The geologic setting at the site shall allow for the physical separation of radioactive waste from the accessible environment after closure in accordance with the requirements of 40 CFR 191, Subpart B. The geologic setting at the site will allow for the use of engineered barriers to ensure compliance with the requirements of 40 CFR 191 and 10 CFR 60.

[10 CFR 960.4-1(a)]

\subsubsection{Preclosure: Radiological Safety}

Any projected radiological exposures of the general public and any projected releases of radioactive materials to restricted and unrestricted areas during repository operation and closure shall meet the applicable safety requirements set forth in 10 CFR 20,10 CFR 60, and 40 CFR 191, Subpart A.

[10 CFR 960.5-1(a)(1)]

\subsubsection{Preclosure: Environment, Socioeconomics, and Transportation}

During repository siting ${ }^{2}$, construction, operation, closure, and decommissioning the public and the environment shall be adequately protected from the hazards posed by the disposal of radioactive waste.

[10 CFR 960.5-1(a)(2)] 


\subsubsection{Preclosure: Ease and Cost of Siting, Construction, Operation, and Closure}

Repository siting ${ }^{3}$, construction, operation, and closure shall be demonstrated to be technically feasible on the basis of reasonably available technology, and the associated costs shall be demonstrated to be reasonable relative to other available and comparable siting options.

[10 CFR 960.5-1(a)(3)]

\subsection{TECHNICAL GUIDELINES}

The Technical Guidelines establish conditions that shall be considered in determining compliance with the System Guidelines.

[10 CFR 960.4-2]

\subsubsection{Postclosure: Physical Separation of Radioactive Waste from Environment}

The following conditions relate to the System Guideline 3.2.1.

\subsubsection{Geohydrology}

\subsection{Qualifying Condition}

Compatible with Waste Isolation/Containment. The present and expected geohydrologic setting of the site shall be compatible with waste containment and isolation. The geohydrologic setting, considering the characteristics of and the processes operating within the geologic setting shall permit compliance with:

(1) the System Guideline specified in 3.2.1 for radionuclide releases to the accessible environment; and

(2) the requirements specified in 10 CFR 60.113 for radionuclide releases from the engineeredbarrier system using reasonably available technology.

[10 CFR 960.4-2-1(a)]

\subsection{Disqualifying Condition}

Groundwater Travel Time. The site shall be disqualified if the pre-waste emplacement groundwater travel time from the disturbed zone to the accessible environment is expected to be less than 1,000 years along any pathway of likely and significant radionuclide travel.

[10 CFR 960.4-2-1(d)]

\footnotetext{
3 The activity of siting is no longer applicable due to the NWPAA precluding other siting options.
} 
Title: Appendix B, Site Suitability Evaluation Criteria

\subsubsection{Geochemistry}

\subsection{Qualifying Condition}

Compatible with Waste Isolation/Containment. The present and expected geochemical characteristics of the site shall be compatible with waste containment and isolation. Considering the likely chemical interactions among radionuclides, the host rock, and the ground water, the characteristics of and the processes operating within the geologic setting shall permit compliance with:

(1) the System Guideline specified in 3.2.1 for radionuclide releases to the accessible environment; and

(2) the requirements specified in 10 CFR 60.113 for radionuclide releases from the engineeredbarrier system using reasonably available technology.

[10 CFR 960.4-2-2(a)]

\subsubsection{Rock Characteristics}

\subsection{Qualifying Condition}

The present and expected characteristics of the host rock and surrounding units shall be capable of accommodating the thermal, chemical, mechanical, and radiation stresses expected to be induced by repository construction, operation, and closure and by expected interactions among the waste, host rock, ground water, and engineered components. The characteristics of and the processes operating within the geologic setting shall permit compliance with:

(1) the System Guideline specified in 3.2.1 for radionuclide releases to the accessible environment; and

(2) the requirements specified in 10 CFR 60.113 for radionuclide releases from the engineeredbarrier system using reasonably available technology.

[10 CFR 960.4-2-3(a)]

\subsubsection{Climatic Changes}

\subsection{Qualifying Condition}

The site shall be located where future climatic conditions will not be likely to lead to radionuclide releases greater than those allowable under the System Guideline specified in 3.2.1. In predicting the likely future climatic conditions at the site, the global, regional, and site climatic patterns during the Quaternary Period, considering the geomorphic evidence of the climatic conditions in the geologic setting will be considered.

[10 CFR 960.4-2-4(a)] 


\subsubsection{Erosion}

\subsection{Qualifying Condition}

The site shall allow the underground facility to be placed at a depth such that erosional processes acting upon the surface will not be likely to lead to radionuclide releases greater than those allowable under the System Guideline specified in 3.2.1. In predicting the likelihood of potentially disruptive erosional processes, the climatic, tectonic, and geomorphic evidence of rates and patterns of erosion in the geologic setting during the Quaternary Period will be considered. [10 CFR 960.4-2-5(a)]

\subsection{Disqualifying Condition}

The site shall be disqualified if site conditions do not allow all portions of the underground facility to be situated at least 200 meters below the directly overlying ground surface.

[10 CFR 960.4-2-5(d)]

\subsubsection{Dissolution}

\subsection{Qualifying Condition}

The site shall be located such that any subsurface rock dissolution will not be likely to lead to radionuclide releases greater than those allowable under the System Guideline specified in 3.2.1. In predicting the likelihood of dissolution within the geologic setting at the site, the evidence of dissolution within that setting during the Quaternary Period, including the locations and characteristics of dissolution fronts or other dissolution features, if identified, will be considered. [10 CFR 960.4-2-6(a)]

\subsection{Disqualifying Condition}

The site stall be disqualified if it is likely that, during the first 10,000 years after closure, active dissolution, as predicted on the basis of the geologic record, would result in a loss of waste isolation.

[10 CFR 960.4-2-6(d)]

\subsubsection{Tectonics}

\subsection{Qualifying Condition}

The site shall be located in geologic setting where future tectonic processes or events will not be likely to lead to radionuclide releases greater than those allowable under the System Guideline specified in 3.2.1. In predicting the likelihood of potentially distuptive tectonic processes or events, the structural, stratigraphic, geophysical, and seismic evidence for the nature and rates of tectonic processes and events in the geologic setting during the Quaternary Period, will be considered. [10 CFR 960.4-2-7(a)] 
Title: Appendix B, Site Suitability Evaluation Criteria

\subsection{Disqualifying Condition}

The site shall be disqualified if, based on the geologic record during the Quaternary Period, the nature and rates of fault movement or other ground motion are expected to be such that a loss of waste isolation is likely to occur.

[10 CFR 960.4-2-7(d)]

\subsubsection{Human Interference.}

The site shall be located such that activities by future generations at or near the site will not be likely to affect waste containment and isolation. In assessing the likelihood of such activities the estimated effectiveness of the permanent markers and records required by 10 CFR Part 60 , taking into account site specific factors as stated in 3.3.1.8.1 and 3.3.1.8.2 that could compromise their continued effectiveness, will be considered.

[10 CFR 960.4-2-8]

\subsection{Natural Resources}

\subsection{Qualifying Condition}

The site shall be located such that-considering permanent markers and records and reasonable projections of value, scarcity, and technology-the natural resources, including ground water suitable for crop irrigation or human consumption without treatment, present at or near the site will not be likely to give rise to interference activities that would lead to radionuclide releases greater than those allowable under the System Guideline specified in 3.2.1.

[10 CFR 960.4-2-8-1(a)]

\subsection{Disqualifying Condition}

A site shall be disqualified if:

(1) Previous exploration, mining, or extraction activities for resources of commercial importance at the site have created significant pathways between the projected underground facility and the accessible environment; or

(2) Ongoing or likely future activities to recover presently valuable natural mineral resources outside the controlled area would be expected to lead to an inadvertent loss of waste isolation. [10 CFR 960.4-2-8-1(d)]

\subsection{Site Ownership and Control}

\subsection{Qualifying Condition}

The site shall be located on land that can be obtained in accordance with the requirements of 10 CFR Part 60, ownership, surface and subsurface rights, and control of access that are required in order that potential surface and subsurface activities at the site will not be likely to lead to a 
Title: Appendix.B, Site Suitability Evaluation Criteria

Revision: 1

Page: $\mathrm{B}-14$

radionuclide release greater than those allowable under the System Guideline specified in 3.2.1. [10 CFR 960.4-2-8-2(a)]

\subsubsection{Preclosure: Radiological Safety}

The following conditions relate to the System Guideline 3.2.2.

\subsubsection{Population Density and Distribution.}

\subsection{Qualifying Condition}

The site shall be located such that, during repository operation and closure:

(1) the expected average radiation dose to members of the public within any highly populated area will not be likely to exceed a small fraction of the limits allowable under the System Guideline specified in 3.2.2; and

(2) the expected radiation dose to any member of the public in an unrestricted area will not be likely to exceed the limits allowable under the System Guideline specified in 3.2.2.

[10 CFR 960.5-2-1(a)]

\subsection{Disqualifying Condition}

A site shall be disqualified if:

(1) any surface facility of a repository would be located in a highly populated area; or

(2) any surface facility of a repository would be located adjacent to an area 1 mile by 1 mile having a population of not less than 1,000 individuals as enumerated by the most recent U.S. census; or

(3) an emergency preparedness program which meets the requirements specified in DOE Order 5500.3 (Reactor and Non-Reactor Facility Emergency Planning, Preparedness, and Response Program for Department of Energy Operations) and related guides, or when issued by the NRC, in 10 CFR Part 60, Subpart I, "Emergency Planning Criteria" can not be provided.

[10 CFR 960.5-2-1(d)]

\subsubsection{Site Ownership and Control}

\subsection{Qualifying Condition}

The site shall be located on land which can be obtained in accordance with the requirements of 10 CFR 60.121, ownership, surface and subsurface rights, and control of access that are required in order that surface and subsurface activities during repository operation and closure will not be likely to lead to radionuclide releases to an unrestricted area greater than those allowable under the System Guideline specified in 3.2.2. 
[10 CFR 960.5-2-2(a)]

\subsubsection{Meteorology}

\subsection{Qualifying Condition}

The site shall be located such that expected meteorological conditions during repository operation and closure will not be likely to lead to radionuclide releases to an unrestricted area greater than those allowable under the System Guideline specified in 3.2.2.

[10 CFR 960.5-2-3(a)]

\subsubsection{Offsite Installations and Operations.}

\subsection{Qualifying Condition}

The site shall be located such that present projected effects from nearby industrial, transportation, and military installations and operations, including atomic energy defense activities:

(1) will not significantly affect repository siting, construction, operation, closure, or decommissioning or can be accommodated by engineering measures; and

(2) when considered together with emissions from repository operation and closure, will not be likely to lead to radionuclide releases to an unrestricted area greater than those allowable under the System Guideline specified in 3.2.2.

[10 CFR 960.5-2-4(a)]

\subsection{Disqualifying Condition}

The site shall be disqualified if atomic energy defense activities in proximity to the site are expected to conflict irreconcilably with repository siting, construction, operation, closure, or decommissioning.

[10 CFR 960.5-2-4(d)]

\subsubsection{Preclosure: Environment, Socioeconomics, and Transportation}

The following conditions relate to the System Guideline 3.2.3.

\subsubsection{Environmental Quality}

\subsection{Qualifying Condition}

The site shall be located such that:

(1) the quality of the environment in the affected area during this and future generations will be adequately protected during repository siting, construction, operation, closure, and decommissioning, and projected environmental impacts in the affected area can be mitigated to 
an acceptable degree, taking into account programmatic, technical, social, economic, and environmental factors; and

(2) the Guidelines specified in the System Guideline 3.2 .3 can be met [10 CFR 960.5-2-5(a)]

\subsection{Disqualifying Condition}

Any of the following conditions shall disqualify the site:

(1) During repository siting, construction, operation, closure, or decommissioning the quality of the environment in the affected area could not be adequately protected or projected environmental impacts in the affected area could not be mitigated to an acceptable degree, taking into account programmatic, technical, social, economic, and environmental factors.

(2) Any part of the restricted area or repository support facilities would be located within the boundaries of a component of the National Park System, the National Wildlife Refuge System, the National Wilderness Preservation System, or the National Wild and Scenic Rivers System.

(3) The presence of the restricted area or the repository support facilities would conflict irreconcilably vith the previously designated resource preservation use of a component of the National Park System, the National Wildlife Refuge System, the National Wilderness Preservation System, the National Wild and Scenic Rivers System, or National Forest Lands, or any comparably significant State protected resource that was dedicated to resource preservation at the time of the enactment of the Act.

[10 CFR 960.5-2-5(d)]

\subsubsection{Socioeconomic Impacts}

\subsection{Qualifying Condition}

The site shall be located such that:

(1) any significant adverse social and/or economic impacts induced in communities and surrounding regions by repository siting, construction, operation, closure, and decommissioning can be offset by reasonable mitigation or compensation, as determined by a process of analysis, planning, and consultation among the DOE, affected State and local government jurisdictions, and affected Indian tribes; and

(2) the System Guideline specified in 3.2.3 can be met.

[10 CFR 960.5-2-6(a)] 


\subsection{Disqualifying Condition}

The site shall be disqualified if repository construction, operation, or closure would significantly degrade the quality, or significantly reduce the quantity, of water from major sources of offsite supplies presently suitable for human consumption or crop irrigation and such impacts cannot be compensated for, or mitigated by, reasonable measures.

[10 CFR 960.5-2-6(d)]

\subsubsection{Transportation.}

\subsection{Qualifying Condition}

The site shall be located such that:

(1) the access routes constructed from existing local highways and railroads to the site:

(i) will not conflict irreconcilably with the previously designated use of any resource listed in Section 3.3.3.1.2(2) and (3);

(ii) can be designed and constructed using reasonably available technology;

(iii) will not require transportation system components to meet performance standards more stringent than those specified in the applicable DOT and NRC regulations, nor require the development of new packaging containment technology;

(iv) will allow transportation operations to be conducted without causing an unacceptable risk to the public or unacceptable environmental impacts, taking into account programmatic, technical, social, economic, and environmental factors; and

(2) the System Guideline specified in 3.2.3 can be met.

[10 CFR 960.5-2-7(a)]

\subsubsection{Preclosure: Ease and Cost of Siting, Construction, Operation, and Closure}

The following conditions relate to the System Guideline 3.2.4.

\subsubsection{Surface Characteristics}

\subsection{Qualifying Condition}

The site shall be located such that, considering the surface characteristics and conditions of the site and surrounding area, including surface-water systems and the terrain, the Guidelines specified in the System Guideline 3.2.4 can be met during repository siting, construction, operation, and closure.

[10 CFR 960.5-2-8(a)] 


\subsubsection{Rock Characteristics}

\subsection{Qualifying Condition}

The site shall be located such that:

(1) the thickness and lateral extent and the characteristics and composition of the host rock will be suitable for accommodation of the underground facility;

(2) repository construction, operation, and closure will not cause undue hazard to personnel; and

(3) the System Guideline specified in Section 3.2.4 can be met.

[10 CFR 960.5-2-9(a)]

\subsection{Disqualifying Condition}

The site shall be disqualified if the rock characteristics are such that the activities associated with repository construction, operation, or closure are predicted to cause significant risk to the health and safety of personnel, taking into account mitigating measures that use reasonably available technology.

[10 CFR 960.5-2-9(d)]

\subsubsection{Hydrology.}

\subsection{Qualifying Condition}

The site shall be located such that the geohydrologic setting of the site will:

(1) be compatible with the activities required for repository construction, operation, and closure;

(2) not compromise the intended functions of the shaft liners and seals; and

(3) permit the System Guideline specified in 3.2.4 to be met.

[10 CFR 960.5-2-10(a)]

\subsection{Disqualifying Condition}

A site shall be disqualified if, based on expected ground-water conditions, it is likely that engineering measures that are beyond reasonably available technology will be required for exploratory-shaft construction or for repository construction, operation, or closure.

[10 CFR 960.5-2-10(d)] 


\subsubsection{Tectonics}

\subsection{Qualifying Condition}

The site shall be located in a geologic setting in which any projected effects of expected tectonic phenomena or igneous activity on repository construction, operation, or closure will be such that the guidelines specified in System Guideline 3.2.4 can be met.

[10 CFR 960.5-2-11(a)]

\subsection{Disqualifying Condition}

A site shall be disqualified if, based on the expected nature and rates of fault movement or other ground motion, it is likely that engineering measures that are beyond reasonably available technology will be required for exploratory-shaft construction or for repository construction, operation, or closure.

[10 CFR 960.5-2-11(d)] 
Title: Appendix B, Site Suitability Evaluation Criteria

Revision: 1

Page: $\mathrm{B}-20$

INTENTIONALLY LEFT BLANK 
Title: Mined Geologic Disposal System Requirements Document, Appendix C Revision: 1

Page: $\mathrm{C}-\mathrm{i}$

\section{TABLE OF CONTENTS}

Function Page

1.4 Dispose of Waste $\ldots \ldots \ldots \ldots \ldots \ldots \ldots \ldots \ldots \ldots \ldots \ldots \ldots \ldots \ldots \ldots \ldots \ldots, 1$

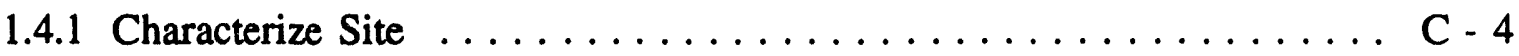

1.4.1.1 Conduct Surface Investigations $\ldots \ldots \ldots \ldots \ldots \ldots \ldots \ldots$ C -7

1.4.1.2 Conduct Subsurface Investigations $\ldots \ldots \ldots \ldots \ldots \ldots \ldots, \mathrm{C}-7$

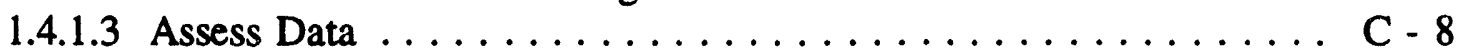

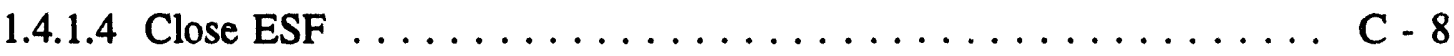

1.4.2 Operate MGDS $\ldots \ldots \ldots \ldots \ldots \ldots \ldots \ldots \ldots \ldots \ldots \ldots \ldots \ldots \ldots \ldots$

1.4.2.1 Handle Waste ........................ -12

1.4.2.2 Support MGDS Operations $\ldots \ldots \ldots \ldots \ldots \ldots \ldots \ldots \ldots, C-15$

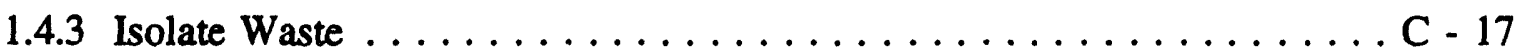

1.4.4 Evaluate System Performance $\ldots \ldots \ldots \ldots \ldots \ldots \ldots \ldots \ldots \ldots \ldots \ldots$

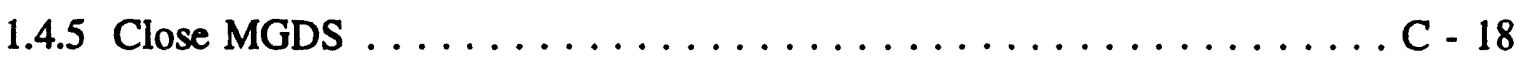

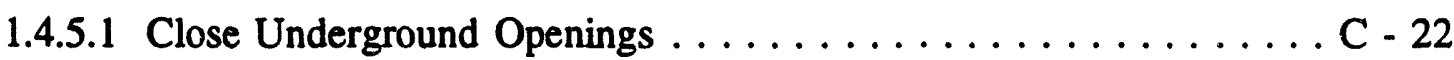

1.4.5.2 Decommission Surface Facilities $\ldots \ldots \ldots \ldots \ldots \ldots \ldots \ldots, C-22$

1.4.5.3 Establish Institutional Barriers $\ldots \ldots \ldots \ldots \ldots \ldots \ldots \ldots \ldots, 23$

1.4.5.4 Reclaim Site . . . . . . . . . . . . . . . . . . . . - 24 
Title: Mined Geologic Disposal System Requirements Document, Appendix C Revision: 1

Page: C-ii

\section{LIST OF FIGURES}

C-1. Function 1.4 Dispose of Waste $\ldots \ldots \ldots \ldots \ldots \ldots \ldots \ldots \ldots \ldots \ldots$ C 2

C-2. N-Square Chart for Function 1.4 Dispose of Waste $\ldots \ldots \ldots \ldots \ldots \ldots$ C - 3

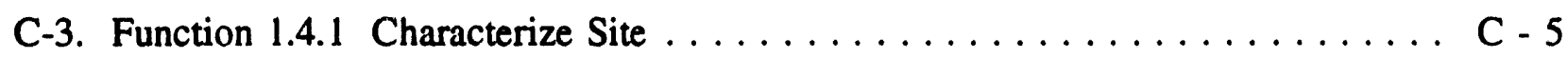

C-4. N-Square Chart for Function 1.4.1 Characterize Site $\ldots \ldots \ldots \ldots \ldots \ldots$ C - 6

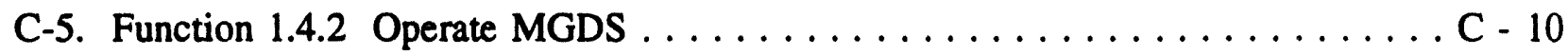

C-6. N-Square Chart for Function 1.4.2 Operate MGDS $\ldots \ldots \ldots \ldots \ldots \ldots \ldots$ C 11

C-7. Function 1.4.2.1 Handle Waste $\ldots \ldots \ldots \ldots \ldots \ldots \ldots \ldots \ldots \ldots \ldots \ldots$

C-8. N-square Chart for Function 1.4.2.1 Handle Waste $\ldots \ldots \ldots \ldots \ldots \ldots \ldots$ C 14

C-9. Function 1.4 .4 Evaluate System Performance ................ C 19

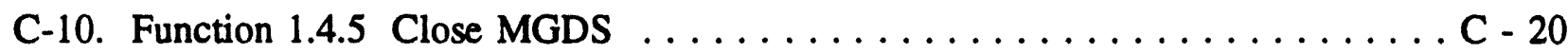

| C-11. N-Square Chart for Function 1.4.5 Close MGDS $\ldots \ldots \ldots \ldots \ldots \ldots$. -21 
Title: Mined Geologic Disposal System Requirements Document, Appendix C Revision: 1

\section{APPENDIX C MGDS FUNCTION DESCRIPTIONS}

This appendix includes descriptive statements for each of the functions and subfunctions assigned to the Mined Geologic Disposal System (MGDS) by the MGDS Requirements Document. Each function statement includes a list of inputs and outputs, with an indication of the interfacing functions or if the interface is external to the MGDS.

\subsection{Dispose of Waste}

This function includes emplacing spent fuel and high-level radioactive waste in a geologic medium and isolating such wastes from the accessible environment. Figures $\mathrm{C}-1$ and $\mathrm{C}-2$ show the functional decomposition and interfaces associated with the Dispose of Waste function.

\section{Inputs:}

- Documentation, procedures, and data $\ldots \ldots \ldots \ldots \ldots \ldots \ldots$ Outside 1.4

- Legal/Regulatory (and licensing) . ................... Outside 1.4

- Site ............................... Outside 1.4

- Loaded transportation cask subsystems $\ldots \ldots \ldots \ldots \ldots \ldots \ldots \ldots \ldots .2$

- Loaded or empty multi-purpose canisters (MPCs) $\ldots \ldots \ldots \ldots \ldots \ldots \ldots . .2$

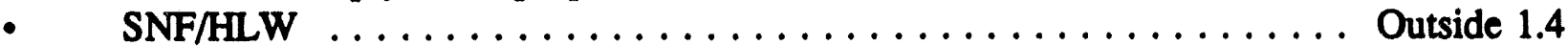

- Shipping documentation $\ldots \ldots \ldots \ldots \ldots \ldots \ldots \ldots \ldots \ldots \ldots \ldots \ldots \ldots, 1.2$

- Utilities . ............................. Outside 1.4

- $\quad$ Equipment, parts, and supplies $\ldots \ldots \ldots \ldots \ldots \ldots \ldots \ldots$ Outside 1.4

- Vehicles (highway and rail) $\ldots \ldots \ldots \ldots \ldots \ldots \ldots \ldots$ Outside 1.4

- Emergency response $\ldots \ldots \ldots \ldots \ldots \ldots \ldots \ldots \ldots$ Outside 1.4

- Services .............................. Outside 1.4

- Intake air $\ldots \ldots \ldots \ldots \ldots \ldots \ldots \ldots \ldots \ldots \ldots \ldots \ldots \ldots$ Outside 1.4

- Human activity ......................... Outside 1.4

- Natural transport media (for radionuclide migration) $\ldots \ldots \ldots \ldots \ldots$ Outside 1.4

- Models . . ............................... Outside 1.4

- Waste containers ........................... Outside 1.4

- Site Characterization Plan ....................... Outside 1.4

- Vehicles ............................... Outside 1.4

- License amendments to construct and operate $\ldots \ldots \ldots \ldots \ldots \ldots$ Outside 1.4

- License amendment to terminate $\ldots \ldots \ldots \ldots \ldots \ldots \ldots$ Outside 1.4

- Potential site $\ldots \ldots \ldots \ldots \ldots \ldots \ldots \ldots \ldots \ldots$ Outside 1.4

\section{Outputs:}

- Information ........................... Outside 1.4

- Retrieved waste packages (if required) $\ldots \ldots \ldots \ldots \ldots \ldots \ldots \ldots \ldots \ldots \ldots \ldots .2$

- Retrieved loaded MPCs (if required) $\ldots \ldots \ldots \ldots \ldots \ldots \ldots \ldots \ldots \ldots .2$

- Loaded (if required) or unloaded transportation cask subsystems $\ldots \ldots \ldots \ldots 1.2$

- Dust . . . . . . . . . . . . . . . . . . . . . . . . . . Outside 1.4

- $\quad$ Noise . . . . . . . . . . . . . . . . . . . . . . . . Outside 1.4

- Site-generated waste $\ldots \ldots \ldots \ldots \ldots \ldots \ldots \ldots$ Outside 1.4 

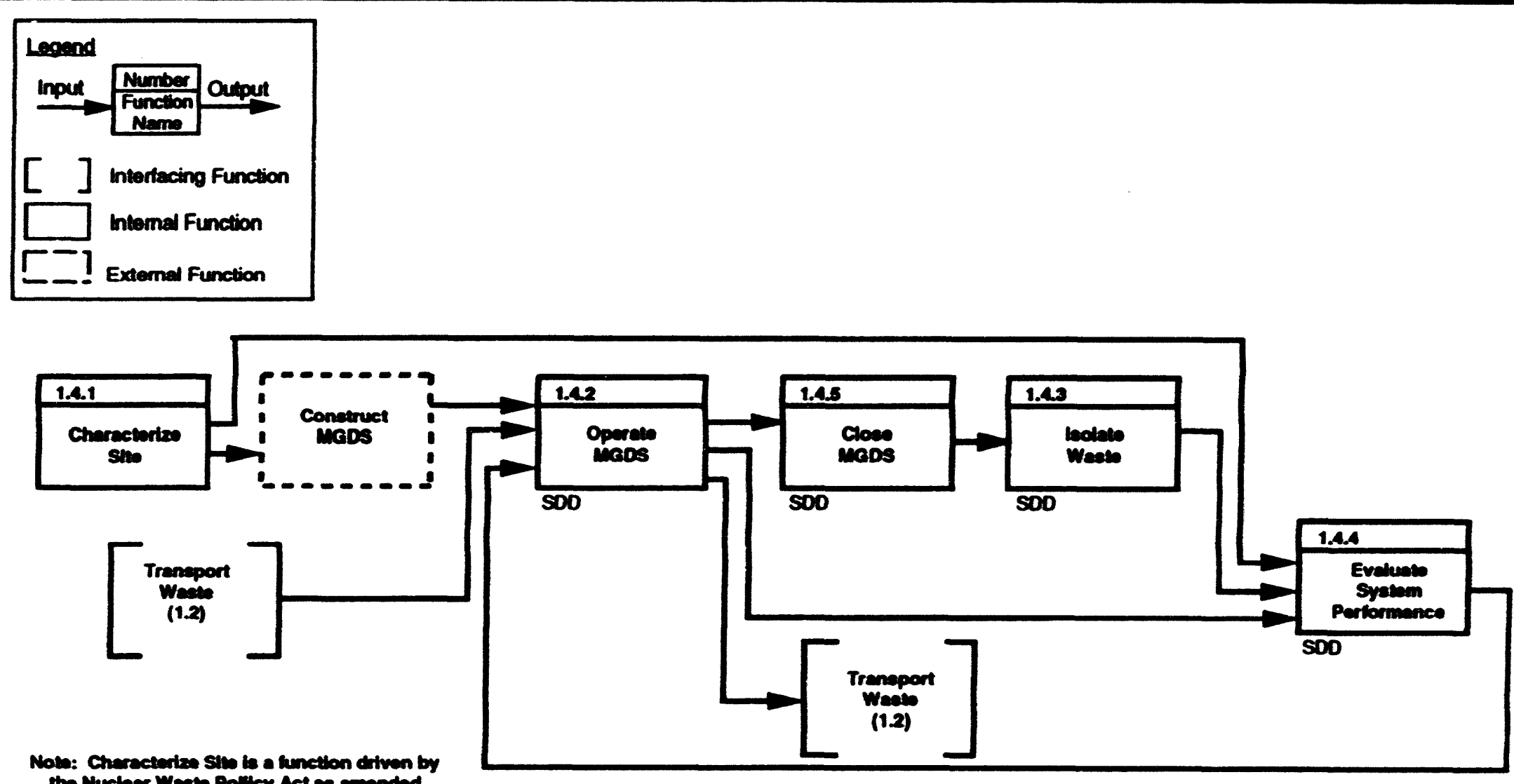

the Nucheer Weato Pollicy Met es anionded

SDD: See Decompositton Diegram

Figure C-1. Function 1.4 Dispose of Waste 
Title: Mined Geologic Disposal System Requirements Document, Appendix C Revision: 1

Page: C-3

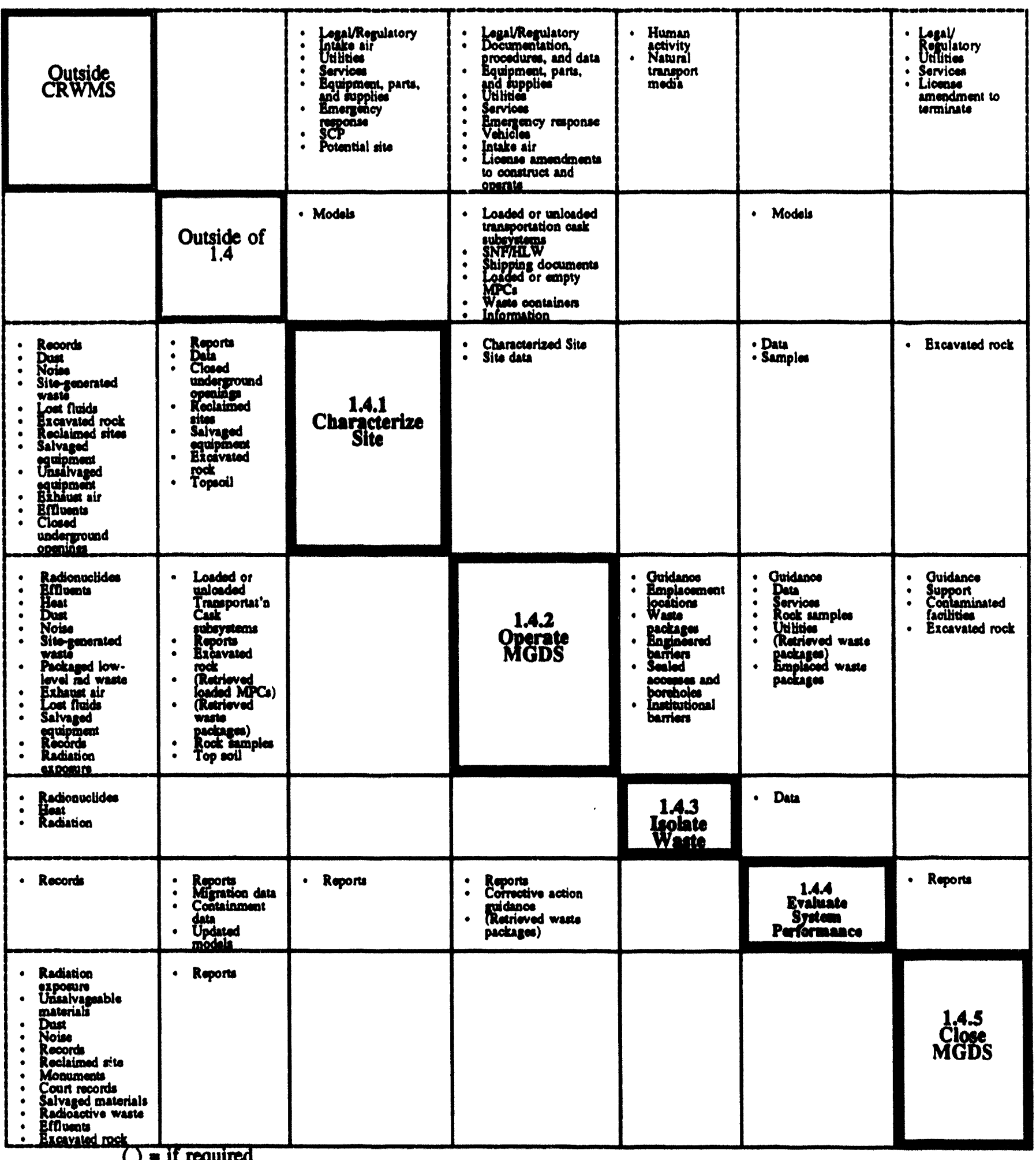

Figure C-2. N-Square Chart for Function 1.4 Dispose of Waste 
Title: Mined Geologic Disposal System Requirements Document, Appendix C Revision: 1

Page: C-4

Effluents $\ldots \ldots \ldots \ldots \ldots \ldots \ldots \ldots \ldots \ldots \ldots \ldots \ldots$ Outside 1.4

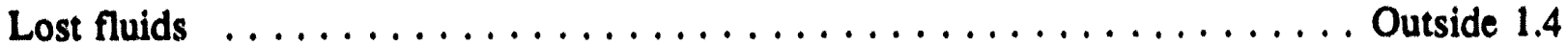

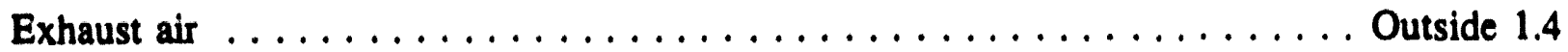

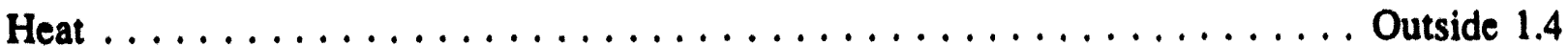

Salvaged equipment $\ldots \ldots \ldots \ldots \ldots \ldots \ldots \ldots \ldots \ldots \ldots \ldots \ldots \ldots$ Outside 1.4

Salvaged materials $\ldots \ldots \ldots \ldots \ldots \ldots \ldots \ldots \ldots \ldots \ldots$ Outside 1.4

Unsalvageable materials $\ldots \ldots \ldots \ldots \ldots \ldots \ldots \ldots \ldots \ldots$ Outside 1.4

Radionuclides $\ldots \ldots \ldots \ldots \ldots \ldots \ldots \ldots \ldots \ldots \ldots \ldots$ Outside 1.4

Monuments .............................. Outside 1.4

Court records $\ldots \ldots \ldots \ldots \ldots \ldots \ldots \ldots \ldots \ldots \ldots$ Outside 1.4

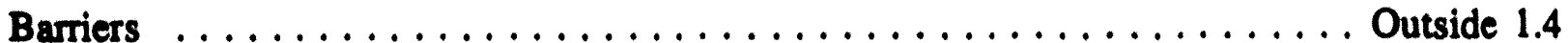

Reclaimed sites $\ldots \ldots \ldots \ldots \ldots \ldots \ldots \ldots \ldots \ldots \ldots \ldots$ Outside 1.4

Data ................................. Outside 1.4

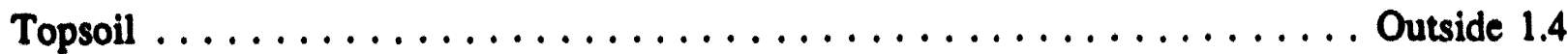

Excavated rock $\ldots \ldots \ldots \ldots \ldots \ldots \ldots \ldots \ldots \ldots \ldots$ Outside 1.4

Closed underground openings $\ldots \ldots \ldots \ldots \ldots \ldots \ldots \ldots \ldots$ Outside 1.4

Radiation exposure $\ldots \ldots \ldots \ldots \ldots \ldots \ldots \ldots \ldots \ldots \ldots$ Outside 1.4

Packaged low-level radioactive waste $\ldots \ldots \ldots \ldots \ldots \ldots \ldots \ldots \ldots$ Outside 1.4

Rock samples $\ldots \ldots \ldots \ldots \ldots \ldots \ldots \ldots \ldots \ldots \ldots \ldots$ Outside 1.4

Migration data $\ldots \ldots \ldots \ldots \ldots \ldots \ldots \ldots \ldots \ldots \ldots$ Outside 1.4

Containment data $\ldots \ldots \ldots \ldots \ldots \ldots \ldots \ldots \ldots \ldots \ldots$ Outside 1.4

Updated models $\ldots \ldots \ldots \ldots \ldots \ldots \ldots \ldots \ldots \ldots \ldots \ldots \ldots$ Outside 1.4

\subsubsection{Characterize Site}

This function includes determining the suitability of the potential site for a licensed repository. This includes providing and supporting an Exploratory Studies Facility (ESF) and Surface Based Testing Facilities; and performing a coordinated series of surface and subsurface based tests and geoscientific investigations. Site characterization means the program of exploration and research, both in the laboratory and in the field, undertaken to establish the geologic conditions and the ranges of those parameters of a particular site relevant to the procedures under 10CFR6C. Site characterization includes borings, surface excavations, excavation of exploratory shafts, limited subsurface lateral excavations and borings, and in situ testing at depth needed to determine the suitability of the site for a geologic repository, but does not include preliminary borings and geophysical testing needed to decide whether site characterization should be undertaken. It also includes either closing the ESF or preparing to incorporate it into the MGDS. Figures C-3 and C-4 show the functional decomposition and interfaces associated with the Characterize Site function.

Inputs:

Legal, regulatory, and licensing constraints $\ldots \ldots \ldots \ldots \ldots \ldots \ldots$ Outside 1.4 .1

- Site characterization plan $\ldots \ldots \ldots \ldots \ldots \ldots \ldots \ldots \ldots \ldots$ Outside 1.4 .1

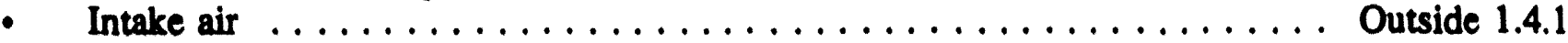

- Potential site $\ldots \ldots \ldots \ldots \ldots \ldots \ldots \ldots \ldots \ldots \ldots \ldots \ldots \ldots$ Outside 1.4 .1

- Utilities $\ldots \ldots \ldots \ldots \ldots \ldots \ldots \ldots \ldots \ldots \ldots \ldots \ldots \ldots$ Outside 1.4 .1

- Services ................................. Outside 1.4 .1

- Models .................................... Outside 1.4.1 
Title: Mined Geologic Disposal System Requirements Document, Appendix C Revision: 1

Page: C.5

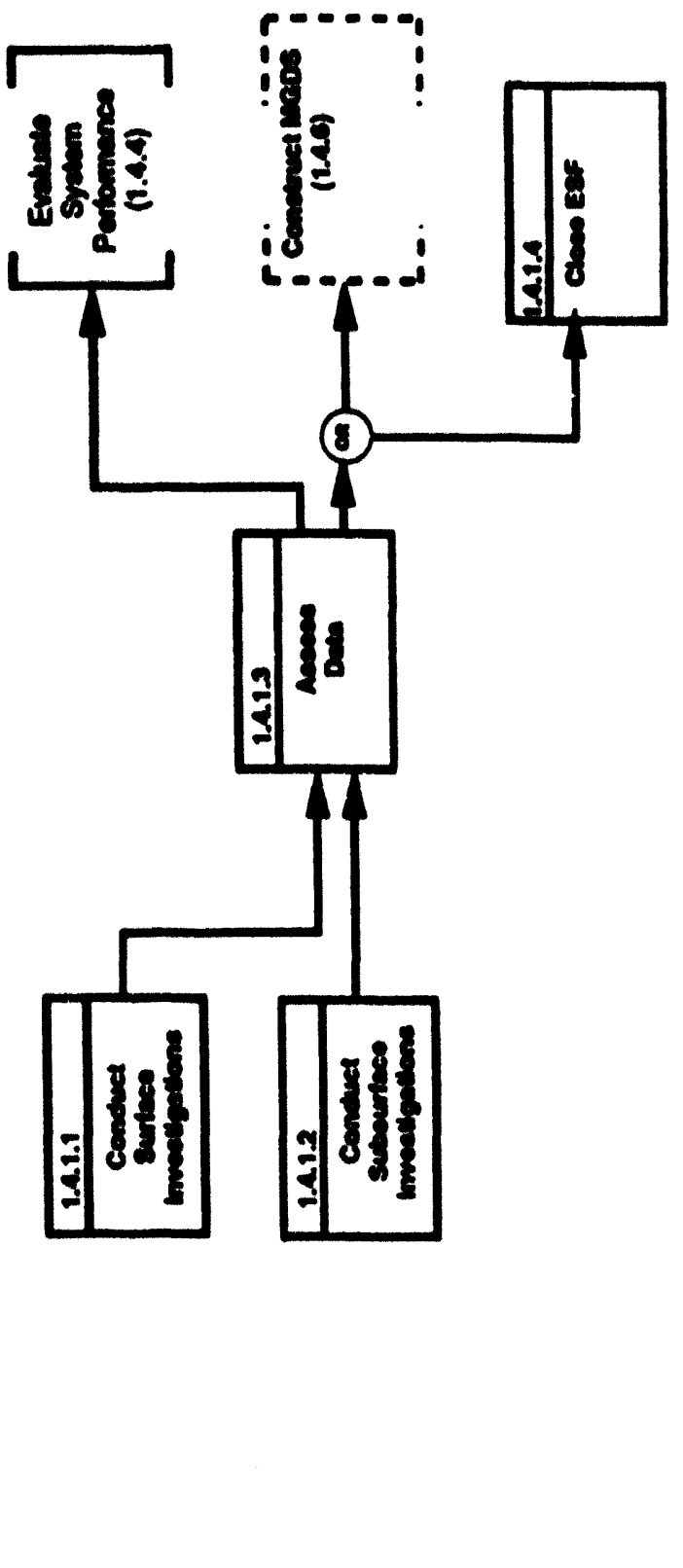

के

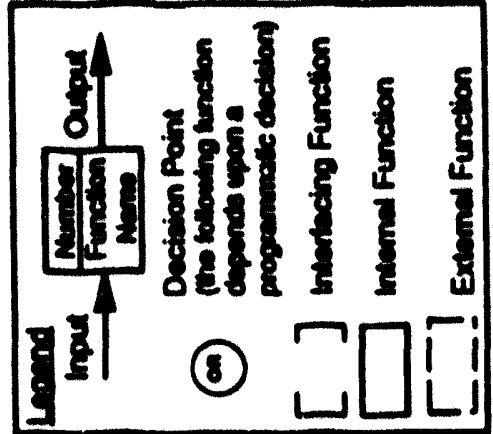


Title: Mined Geologic Disposal System Requirements Document, Appendix C Revision: 1

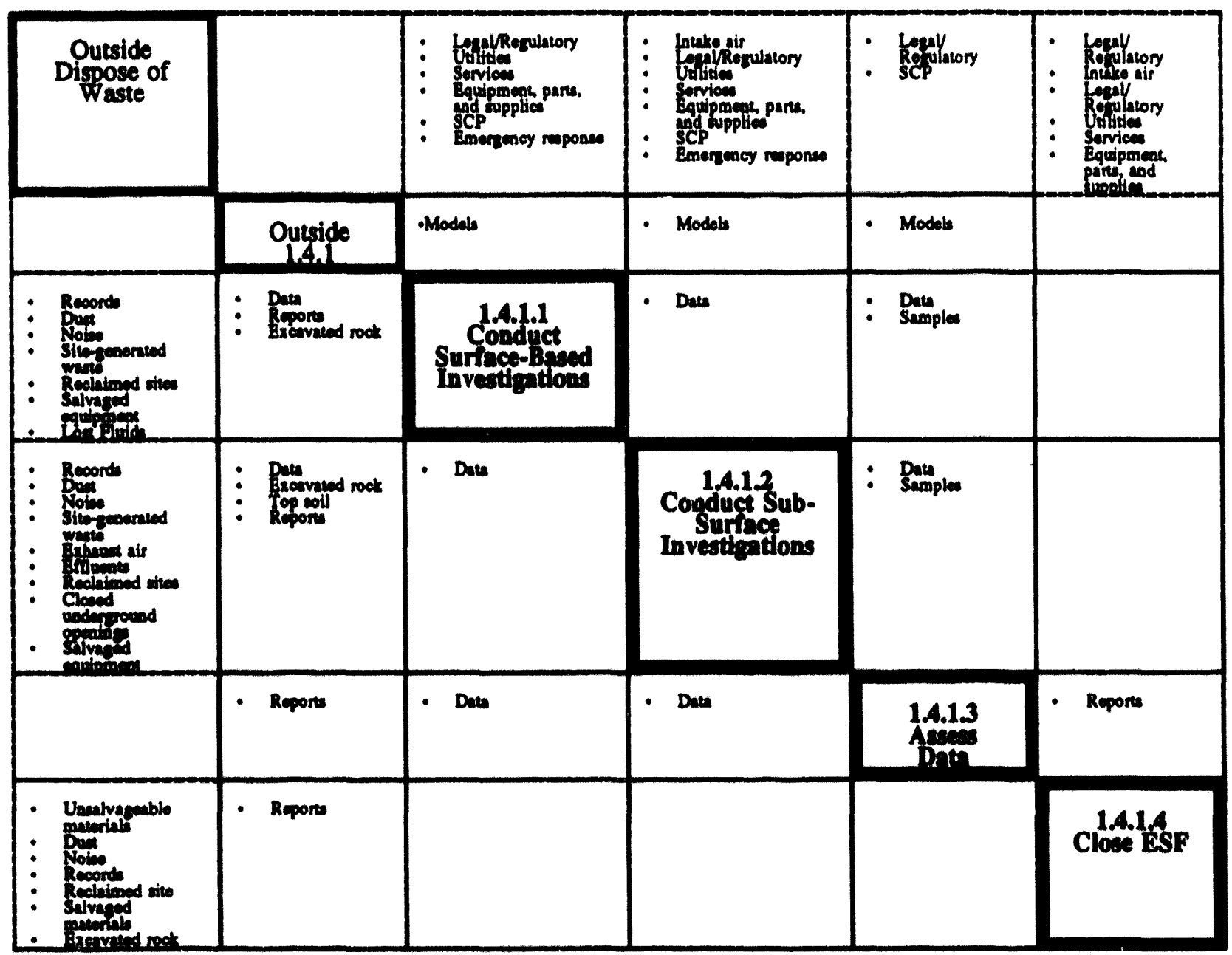

Figure C-4. N-Square Chart for Function 1.4.1 Characterize Site

\section{Outputs:}

\section{- Site}

Site . . . . . . . . . . . . . . . . . . . . . . . . Outside 1.4 .1

- Reports and records ......................... Outside 1.4 .1

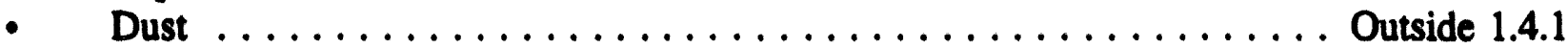

- Noise ................................ Outside 1.4 .1

- Site-generated waste $\ldots . . . \ldots \ldots \ldots \ldots \ldots \ldots$. . . . . . . . . . . Outside 1.4.1

. Lost fluids . . . . . . . . . . . . . . . . . . . . . . . . . . . . Outside 1.4 .1

. Exhaust air . . . . . . . . . . . . . . . . . . . . . . . . Outside 1.4.1

. Data . . . . . . . . . . . . . . . . . . . . . . . . . . . Outside 1.4 .1

- Samples ................................. Outside 1.4 .1

. Excavated rock . . . . . . . . . . . . . . . . . . . . . . . . . . . Outside 1.4.1

- Closed underground openings . . . . . . . . . . . . . . . . . . . Outside 1.4 .1

. Reclaimed site ... . . . . . . . . . . . . . . . . . . . . . . Outside 1.4 .1

- Salvaged equipment $\ldots \ldots \ldots \ldots \ldots \ldots \ldots \ldots \ldots \ldots$. . . . . . . . . . . . . . . . . 1.1

- Salvaged materials .......................... Outside 1.4 .1

. Unsalvageable materials . . . . . . . . . . . . . . . . . . . . . . . . Outside 1.4.1 
Title: Mined Geologic Disposal System Requirements Document, Appendix C Revision: 1

Page: C-7

\subsubsection{Conduct Surface Investigations}

This function includes performing surface based geoscientific investigations in support of site characterization, site suitability determination, and license application. These investigations include surface testing, trenching, and drilling activities directed at obtaining geological samples and data.

Inputs:

- Site characterization plan ........................ Outside 1.4 .1

- Legal, regulatory, and licensing constraints ............... Outside 1.4 .1

- Utilities .................................... Outside 1.4 .1

- Services $\ldots \ldots \ldots \ldots \ldots \ldots \ldots \ldots \ldots \ldots \ldots \ldots \ldots \ldots$. . . . . . . . . . . . . . . . . . . .

\section{Outputs:}

- Reports and records $\ldots \ldots \ldots \ldots \ldots \ldots \ldots \ldots \ldots \ldots \ldots \ldots \ldots . \ldots \ldots .1 .4$

- Dust ................................ Outside 1.4 .1

- $\quad$ Noise $\ldots \ldots \ldots \ldots \ldots \ldots \ldots \ldots \ldots \ldots \ldots \ldots \ldots \ldots \ldots$ Outside 1.4 .1

- Site-generated waste $\ldots \ldots \ldots \ldots \ldots \ldots \ldots \ldots \ldots \ldots \ldots$ Outside 1.4 .1

- Data ................................... 1.4.1.4

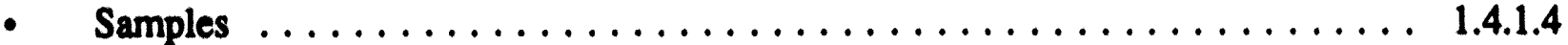

- Reclaimed test sites $\ldots \ldots \ldots \ldots \ldots \ldots \ldots \ldots \ldots \ldots \ldots \ldots$. . . . . . . . . . . . . 1.4 .1

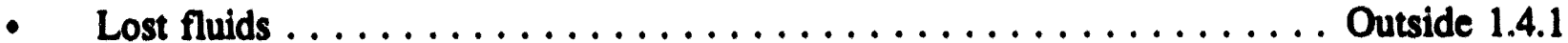

- Exhaust air ............................. Outside 1.4 .1

- Salvaged equipment $\ldots \ldots \ldots \ldots \ldots \ldots \ldots \ldots \ldots \ldots$ Outside 1.4 .1

- Excavated rock $\ldots \ldots \ldots \ldots \ldots \ldots \ldots \ldots \ldots \ldots$ Outside 1.4 .1

\subsubsection{Conduct Subsurface Investigations}

This function includes subsurface exploration and testing at depth in support of site suitability determination and license application in a manner that protects the environment and radioactive waste isolation capabilities of the site. The function provides personnel access at the planned waste emplacement depth and planned underground facility locations. The function also provides for utility and administrative support of subsurface testing and for closing and decommissioning the ESF site.

\section{Inputs:}

- Site characterization plan $\ldots \ldots \ldots \ldots \ldots \ldots \ldots \ldots \ldots \ldots \ldots$ Outside 1.4 .1

- Legal, regulatory, and licensing constraints $\ldots \ldots \ldots \ldots \ldots \ldots \ldots$ Outside 1.4 .1

- Intake air $\ldots \ldots \ldots \ldots \ldots \ldots \ldots \ldots \ldots \ldots \ldots \ldots \ldots$ Outside 1.4 .1

- Utilities . . . . . . . . . . . . . . . . . . . . . . . . . . . . Outside 1.4 .1

- Services $\ldots \ldots \ldots \ldots \ldots \ldots \ldots \ldots \ldots \ldots \ldots \ldots \ldots \ldots$ Outside 1.4 .1

- Models ................................ Outside 1.4 .1

\section{Outputs:}

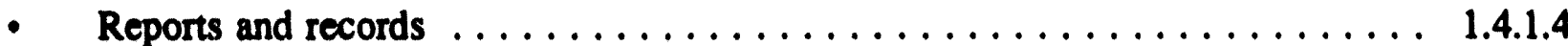

- Dust ................................. Outside 1.4 .1

- Noise ............................... Outside 1.4.1 
Title: Mined Geologic Disposal System Requirements Document, Appendix C Revision: 1

- $\quad$ Site-generated waste

\subsubsection{Assess Data}

This programmatic function includes assessing the data and samples provided from the surfacebased and subsurface-based investigations and other site characterization activities.

\section{Inputs:}

- Site characterization plan $\ldots \ldots \ldots \ldots \ldots \ldots \ldots \ldots \ldots$. . . . . . . . . . 1.4 .1

- Legal, regulatory, and licensing constraints .............. Outside 1.4 .1

- Data .............................. 1.4.1.1, 1.4.1.2, 1.4.1.3

- Samples $\ldots \ldots \ldots \ldots \ldots \ldots \ldots \ldots \ldots \ldots \ldots \ldots . \ldots \ldots .4 .1 .1,1.4 .1 .2,1.4 .1 .3$

\section{Outputs:}

- Reports ................................. Outside 1.4 .1

- Characterized site .............................. 1.4 .1

\subsubsection{Close ESF}

This function includes closing the underground openings; dismantling and disposing of surface facilities; and regrading and reclaiming the site in the event that the site is determined unsuitable for a repository. If the site is determined to be suitable, only those portions not to be incorporated into the MGDS design will be closed, dismantled, disposed, and reclaimed.

\section{Inputs:}

- Legal/Regulatory ............................ Outside 1.4 .1

- Intake air $\ldots \ldots \ldots \ldots \ldots \ldots \ldots \ldots \ldots \ldots \ldots \ldots$ Outside 1.4 .1

- Legal/Regulatory $\ldots \ldots \ldots \ldots \ldots \ldots \ldots \ldots \ldots \ldots$ Outside 1.4 .1

- Utilities ............................... Outside 1.4 .1

- Services .............................. Outside 1.4 .1

- Equipment, parts, and supplies $\ldots \ldots \ldots \ldots \ldots \ldots \ldots \ldots \ldots$ Outside 1.4 .1

- Reports ............................. Outside 1.4 .1

\section{Outputs:}

- Unsalvageable materials $\ldots \ldots \ldots \ldots \ldots \ldots \ldots \ldots \ldots \ldots$ Outside 1.4 .1

- Dust $\ldots \ldots \ldots \ldots \ldots \ldots \ldots \ldots \ldots \ldots \ldots \ldots \ldots$ Outside 1.4 .1

- $\quad$ Noise $\ldots \ldots \ldots \ldots \ldots \ldots \ldots \ldots \ldots \ldots \ldots \ldots \ldots$ Outside 1.4 .1

- Records ............................... Outside 1.4 .1

- Reclaimed site ............................ Outside 1.4 .1

- Salvaged materials $\ldots \ldots \ldots \ldots \ldots \ldots \ldots \ldots \ldots \ldots \ldots$ Outside 1.4 .1

- Excavated rock $\ldots \ldots \ldots \ldots \ldots \ldots \ldots \ldots \ldots \ldots \ldots$ Outside 1.4 .1 
Title: Mined Geologic Disposal System Requirements Document, Appendix C Revision: 1

Page: C-9

\subsubsection{Operate MGDS}

This function includes operating surface and underground facilities to handle radioactive wastes (including receiving, preparing, transferring, emplacing, and retrieving [if required] radioactive wastes), and supporting MGDS operations (including, but not limited to, development of underground openings, and supplying utilities and services, QA, and administration). This function begins at the time the waste is received at the repository and ends when NRC terminates the license. Figures C-5 and C-6 show the functional decomposition and interfaces associated with the Operate MGDS function.

Inputs:

- Documentation, procedures, and data . . . . . . . . . . . . . Outside 1.4 .2

- Legal/Regulatory (and licensing constraints) $\ldots \ldots \ldots \ldots \ldots \ldots$. . . . Outside 1.4 .2

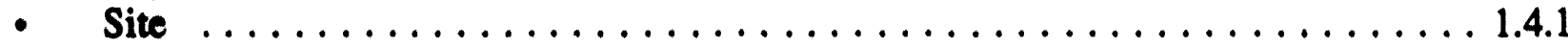

- Loaded or unloaded transportation cask subsystems $\ldots \ldots \ldots \ldots \ldots \ldots \ldots \ldots$

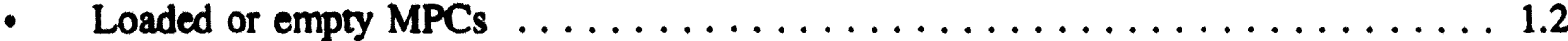

SNF/HLW . . . . . . . . . . . . . . . . . . . . . . . . Outside 1.4 .2

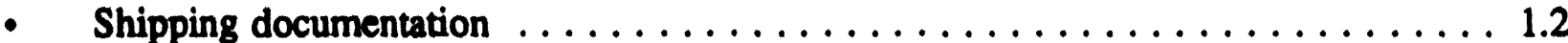

- Utilities . . . . . . . . . . . . . . . . . . . . . . . . Outside 1.4 .2

- Equipment parts, and supplies . . . . . . . . . . . . . . . Outside 1.4 .2

- Vehicles (highway and rail) . . . . . . . . . . . . . . . . . Outside 1.4 .2

- Emergency response . . . . . . . . . . . . . . . . . . . . . . . Outside 1.4 .2

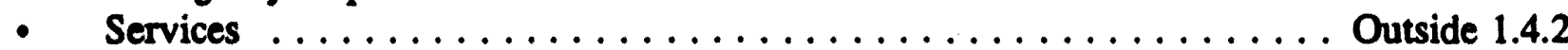

- Intake air . . . . . . . . . . . . . . . . . . . . . . Outside 1.4 .2

- License amendments to construct and operate MGDS . . . . . . . . . . . O Outside 1.4 .2

. Waste containers . . . . . . . . . . . . . . . . . . . . Outside 1.4 .2

\section{Outputs:}

- Reports

Outside 1.4 .2

- Records

Outside 1.4 .2

Loaded and unloaded transportation cask subsystems $\ldots \ldots \ldots \ldots \ldots \ldots \ldots$

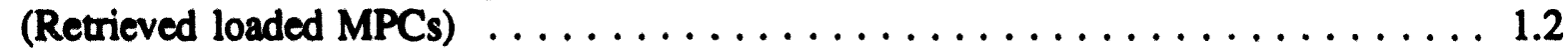

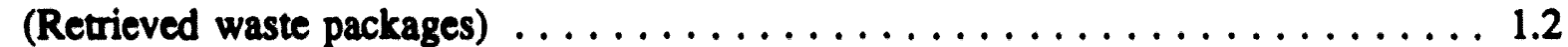

Dust.

Outside 1.4.2

Noise

Outside 1.4.2

Site-generated waste $\ldots \ldots \ldots \ldots \ldots \ldots \ldots$ Outside 1.4 .2

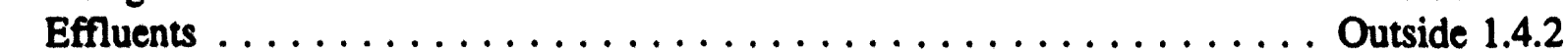

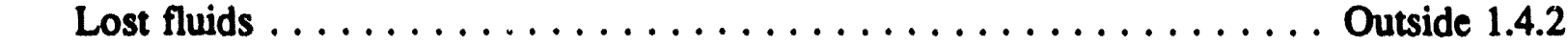

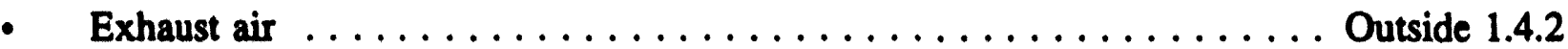

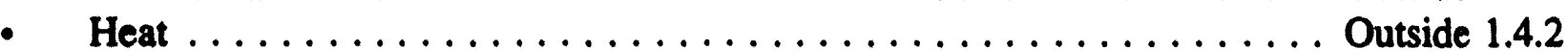

- Unsalvageable materials . . . . . . . . . . . . . . . . . . Outside 1.4 .2

- Packaged radioactive waste (low level) . . . . . . . . . . . . . . Outside 1.4 .2

- Radiation exposure . . . . . . . . . . . . . . . . . . . . Outside 1.4 .2

. Radionuclides .............................. Outside 1.4 .2 


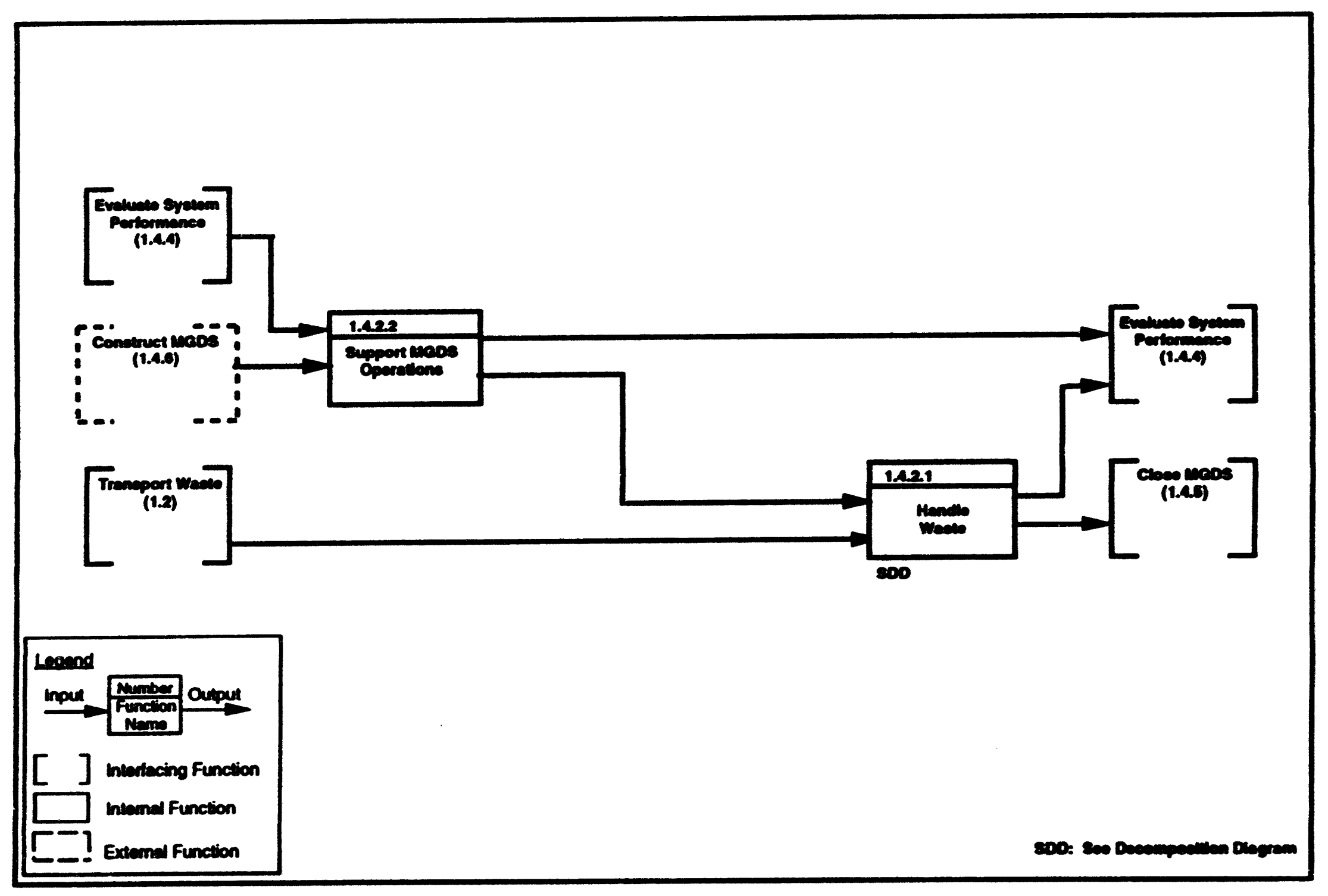

Figure C-5. Function 1.4.2 Operale MGDS

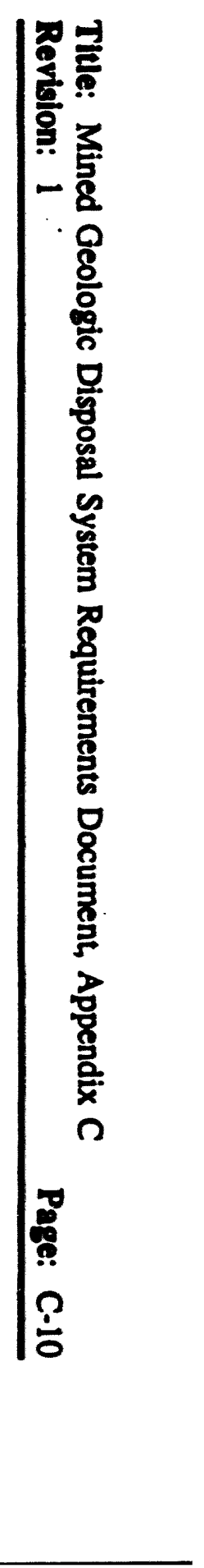


Title: Mined Geologic Disposal System Requirements Document, Appendix C Revision: 1

Page: C-11

\begin{tabular}{|c|c|c|c|}
\hline Outside Dispose of Waste & & $\begin{array}{l}\text { Documentation, } \\
\text { procedures, and data } \\
\text { Loaded or Unloaded } \\
\text { Transportation Cask } \\
\text { Subsystems } \\
\text { Legal/Regulatory } \\
\text { Equipment, parts, and } \\
\text { supplies } \\
\text { Utilities } \\
\text { Services } \\
\text { Emergency response } \\
\text { Waste containers } \\
\text { Vehicles } \\
\text { Intake air } \\
\text { License and amendments } \\
\text { SNF/HLW } \\
\text { Shipping Documentation } \\
\text { Loaded or empty MPCs }\end{array}$ & $\begin{array}{l}\text { Legal/Regulatory } \\
\text { Equipment, parts, and } \\
\text { supplies } \\
\text { Utilities } \\
\text { Services } \\
\text { Emergency response } \\
\text { Waste containers } \\
\text { Vehicles } \\
\text { Intake air }\end{array}$ \\
\hline & Outside 1.4 .2 & $\begin{array}{l}\text { Site } \\
\text { Reports } \\
\text { Corrective action guidance }\end{array}$ & Site \\
\hline $\begin{array}{l}\text { Radiation exposure } \\
\text { Unloaded casks } \\
\text { Effluents } \\
\text { Site-generated waste } \\
\text { Packaged rad waste } \\
\text { (low level) } \\
\text { Records } \\
\text { Reports } \\
\text { Noise } \\
\text { Exhaust air } \\
\text { Heat } \\
\text { (Retrieved waste) } \\
\end{array}$ & $\begin{array}{l}\text { Emplaced waste } \\
\text { packages } \\
\text { Engineered barriers } \\
\text { Loaded or unloaded } \\
\text { transportation cask } \\
\text { subsystems } \\
\text { (Retrieved waste } \\
\text { packages) } \\
\text { (Retrieved loaded } \\
\text { MPCs) }\end{array}$ & $\begin{array}{l}\text { 1.4.2.1 } \\
\text { Handle Waste }\end{array}$ & \\
\hline $\begin{array}{l}\text { Lost fluids } \\
\text { Dust } \\
\text { Noise } \\
\text { Effluents } \\
\text { Site-generated waste } \\
\text { Heat } \\
\text { Reconds } \\
\text { Exhaust air } \\
\text { Noise } \\
\text { Radiation exposure }\end{array}$ & $\begin{array}{l}\text { Reports } \\
\text { Excavated rock } \\
\text { Rock samples } \\
\text { Top soil } \\
\text { Guidance } \\
\text { Utilities } \\
\text { Services } \\
\text { Support } \\
\text { Data }\end{array}$ & $\begin{array}{l}\text { Utilities } \\
\text { Support } \\
\text { Emplacement locations } \\
\text { Guidance } \\
\text { Waste containers }\end{array}$ & $\begin{array}{c}1.4 .2 .2 \\
\text { Support MGDS Operations }\end{array}$ \\
\hline
\end{tabular}

( ) = if required

Figure C-6. N-Square Chart for Function 1.4.2 Operate MGDS 
Title: Mined Geologic Disposal System Requirements Document, Appendix C Revision: 1

Page: C-12

- $\quad$ Engineered barriers

1 - Emplaced waste packages

- Data ........................................4.4.

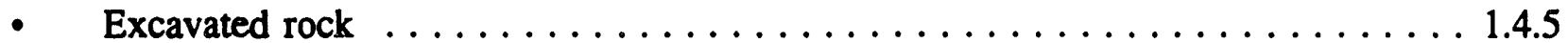

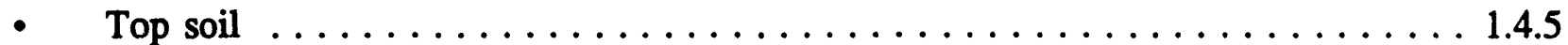

- Rock Samples .............................. 1.4 .4

\subsubsection{Handle Waste}

This function includes receiving, preparing, transferring (within the MGDS), emplacing, and, if required, retrieving radioactive wastes. The capability for performing this function is necessary from the start of waste receipt at the MGDS. Each shipment requires this capability from the time of transfer of the shipment to the repository until completion of emplacement to satisfy the possibility of retrieval. The capability must remain available through the start of permanent closure. This function depends upon function 1.4.2.2 for utilities and other support, and assumes underground emplacement locations are prepared. Figures C-7 and C-8 show the functional decomposition and interfaces associated with the Handle Waste function.

\section{Inputs:}

- Documentation, procedures, and data

Outside 1.4

Guidance .............................. 1.4.2.2

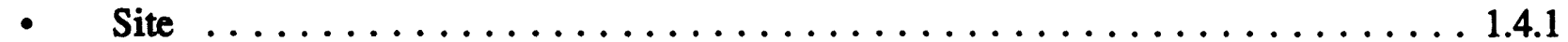

I $\quad$ Loaded or unloaded transportation cask subsystems $\ldots \ldots \ldots \ldots \ldots \ldots \ldots \ldots$

- SNF/HLW ............................... Outside 1.4 .2

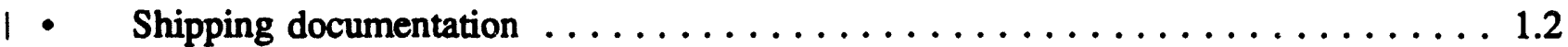

. Utilities . . . . . . . . . . . . . . . . . . . . . . . . . . . 1.4.2.2

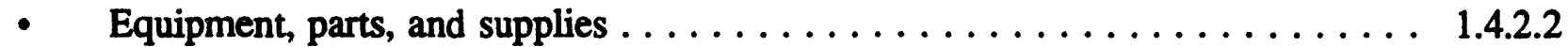

- Vehicles ................................. 1.4 .2 .2

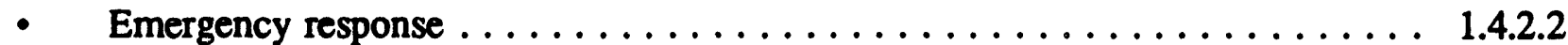

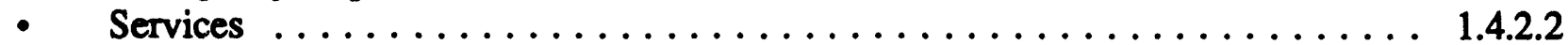

- Intake air ............................. Outside 1.4 .2

- Legal/Regulatory . . . . . . . . . . . . . . . . . . . Outside 1.4 .2

- Waste containers . . . . . . . . . . . . . . . . . Outside 1.4 .2

I $\quad$ Loaded or empty MPCs . . . . . . . . . . . . . . . . . . Outside 1.4 .2

\section{Outputs:}

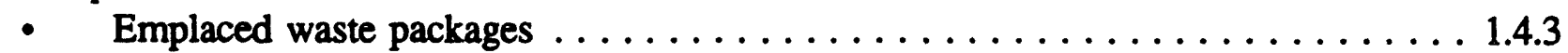

. Requirements ................................ 1.4.2.2

- Radiation exposure . . . . . . . . . . . . . . . . . . Outside 1.4 .2

- Heat . . . . . . . . . . . . . . . . . . . . . . . Outside 1.4 .2

I $\quad$ Loaded or unloaded transportation cask subsystems $\ldots \ldots \ldots \ldots \ldots \ldots \ldots \ldots$

I $\quad$ Retrieved waste packages, if required . . . . . . . . . . . . . . . . TBD

. Effluents . . . . . . . . . . . . . . . . . . . . . . . . . Outside 1.4 .2

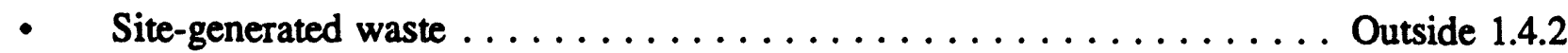

- Records ................................ Outside 1.4 .2

- Exhaust air ........................... Outside 1.4 .2

. Noise ................................ Outside 1.4 .2 


\begin{tabular}{|c|c|c|c|c|c|c|}
\hline Outside 1.4 & & 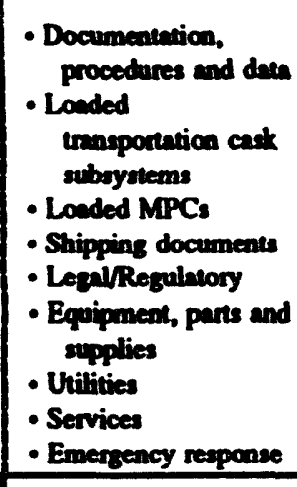 & $\begin{array}{l}\text { - Equipmenta, paras and } \\
\text { - supplies } \\
\text { - Utilities } \\
\text { - Servioes } \\
\text { - Emergency response } \\
\text { - Warle conchiners } \\
\text { - Emply MPCs }\end{array}$ & 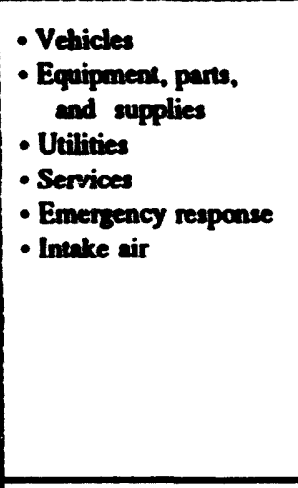 & $\begin{array}{l}\text { - Vechicles } \\
\text { - Equipanentepers and } \\
\text { - Unpplies } \\
\text { - Uilities } \\
\text { - Services } \\
\text { - Emergency response } \\
\text { - Intake air }\end{array}$ & 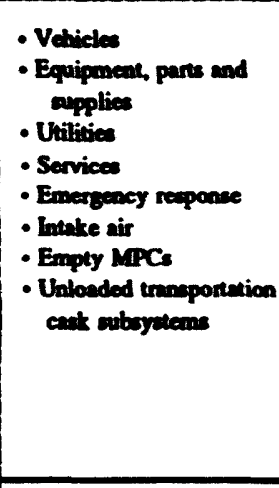 \\
\hline & Outside 1.4.2.1 & $\begin{array}{l}\text { - Guidenoce } \\
\text { - Sire }\end{array}$ & \begin{tabular}{|l} 
- Guidenoe \\
- Site \\
\end{tabular} & $\begin{array}{l}\text { - Guidenoce } \\
\text { - Sire } \\
\end{array}$ & $\begin{array}{l}\text { - Guidenoce } \\
\text { - Silte } \\
\end{array}$ & \begin{tabular}{|l} 
- Guidence \\
- Sile \\
\end{tabular} \\
\hline 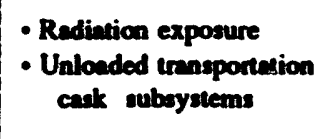 & & $\begin{array}{c}\text { 1.4.2.1.1.1 } \\
\text { Receive Waste }\end{array}$ & - Requirements & & & \\
\hline 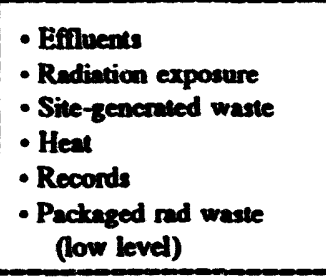 & & & $\begin{array}{l}\text { 1.4.2.1.2 } \\
\text { Prepare Waste }\end{array}$ & - Waste packinges & & \\
\hline $\begin{array}{l}\text { - Exhause air } \\
\text { - Rediation exposure } \\
\text { - Noive } \\
\text { - Heat }\end{array}$ & & & & $\begin{array}{c}1.4 .2 .1 .3 \\
\text { Transfer } \\
\text { Contuintertized } \\
\text { Waste to } \\
\text { Underground }\end{array}$ & - Waste prockenges & \\
\hline $\begin{array}{l}\text { - Rediation exposure } \\
\text { - Sire-genernted waste } \\
\text { - Heat } \\
\text { - Exheust air } \\
\text { - Records } \\
\end{array}$ & $\begin{array}{l}\text { - Emploced waste } \\
\text { pactinges }\end{array}$ & & & & $\begin{array}{c}\text { 1.4.2.2.4.4 } \\
\text { Emplace Waste }\end{array}$ & $\begin{array}{l}\text { - Emplaced wasere } \\
\text { pactiges }\end{array}$ \\
\hline $\begin{array}{l}\text { - Packaged nd waste } \\
\text { (low level) }\end{array}$ & $\begin{array}{l}\text { - Retrieved waste) } \\
\text { - (Retrieved looded } \\
\text { MPCs) }\end{array}$ & & & & & $\begin{array}{c}1.4 .2 .1 .5 \\
\text { Retrieve Waste }\end{array}$ \\
\hline
\end{tabular}

Figure C-8 N-Square Chart for 1.4.2.1 Handle Waste 
Title: Mined Geologic Disposal System Requirements Document, Appendix C Revision: 1

Page: C-15

\subsubsection{Support MGDS Operations}

This function includes operational and administrative support for operating and maintaining the MGDS, including continuing development of the underground waste emplacement areas.

\section{Inputs:}

*1 Documentation, procedures, and data $\ldots \ldots \ldots \ldots \ldots \ldots \ldots$ Outside 1.4 .2

* Legal, regulatory, and licensing constraints $\ldots \ldots \ldots \ldots \ldots \ldots$ Outside 1.4 .2

* $\quad$ Site . . . . . . . . . . . . . . . . . . . . . . . . . . . 1.4 .1

- Waste containers ......................... Outside 1.4 .2

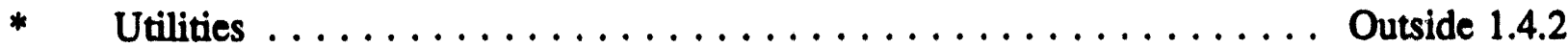

* Equipment, parts, and supplies $\ldots \ldots \ldots \ldots \ldots \ldots \ldots \ldots \ldots$ Outside 1.4 .2

* Vehicles ............................... Outside 1.4 .2

* Emergency response $\ldots \ldots \ldots \ldots \ldots \ldots \ldots \ldots \ldots \ldots$ Outside 1.4 .2

* Services $\ldots \ldots \ldots \ldots \ldots \ldots \ldots \ldots \ldots \ldots \ldots \ldots \ldots$ Outside 1.4 .2

- Intake air ............................. Outside 1.4 .2

* Requirements $\ldots \ldots \ldots \ldots \ldots \ldots \ldots \ldots \ldots \ldots \ldots \ldots \ldots . . .4 .2 .1,1.4 .4$

\section{Outputs:}

* Reports and records $\ldots \ldots \ldots \ldots \ldots \ldots \ldots \ldots \ldots$ Outside 1.4 .2

- Dust ................................ Outside 1.4 .2

* Noise $\ldots \ldots \ldots \ldots \ldots \ldots \ldots \ldots \ldots \ldots \ldots \ldots \ldots$ Outside 1.4 .2

* Site-generated waste $\ldots \ldots \ldots \ldots \ldots \ldots \ldots \ldots \ldots \ldots$ Outside 1.4 .2

* Effluents ............................. Outside 1.4 .2

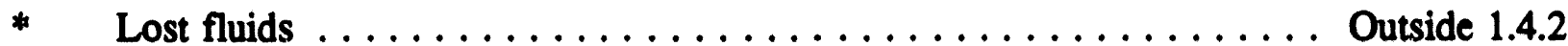

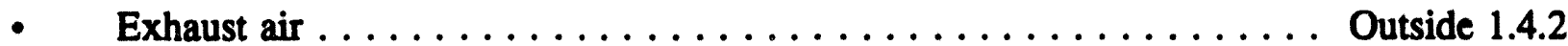

- Heat ............................... Outside 1.4 .2

- Radiation exposure $\ldots \ldots \ldots \ldots \ldots \ldots \ldots \ldots \ldots \ldots \ldots$ Outside 1.4 .2

- Barriers ....................................... 1.4

- Utilities $\ldots \ldots \ldots \ldots \ldots \ldots \ldots \ldots \ldots \ldots \ldots \ldots \ldots . . .4 .2 .1,1.4 .4,1.4 .5$

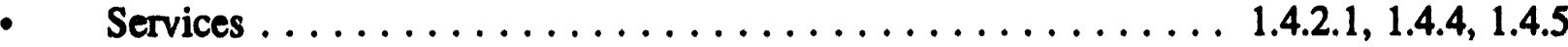

- Emplacement locations . . . . . . . . . . . . . . . . . . 1.4.2.1, 1.4.3

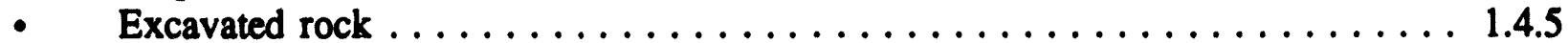

\subsection{Provide Utilities and Services}

This function includes providing utilities and services, including ventilation, communication, water, power, illumination, and on-site transportation in support of MGDS operations.

\section{Outputs:}

- Ventilation .............................. Outside 1.4 .2

- Electric power .......................... Outside 1.4 .2

- Internal and external communications $\ldots \ldots \ldots \ldots \ldots \ldots \ldots$ Outside 1.4 .2

1 Asterisks indicate inputs and outputs that are common to all Support MGDS subfunctions and are not repeated below. 
Titte: Mined Geologic Disposal System Requirements Document, Appendix C Revision: 1

Page: C-16

- Water distribution $\ldots \ldots \ldots \ldots \ldots \ldots \ldots \ldots \ldots \ldots$ Outside 1.4 .2

- Illumination $\ldots \ldots \ldots \ldots \ldots \ldots \ldots \ldots \ldots \ldots \ldots \ldots$ Outside 1.4 .2

- Site $\ldots \ldots \ldots \ldots \ldots \ldots \ldots \ldots \ldots \ldots \ldots \ldots \ldots \ldots$ Outside 1.4 .2

- Transportation $\ldots \ldots \ldots \ldots \ldots \ldots \ldots \ldots \ldots \ldots \ldots \ldots$ Outside 1.4 .2

- Effluents $\ldots \ldots \ldots \ldots \ldots \ldots \ldots \ldots \ldots \ldots \ldots \ldots$ O . . . . . . . . . . 1.2

\subsection{Provide Protective Services}

This function includes providing general protective services and ensuring the safety and security of men, materials, and operations at the MGDS under both normal and off-normal conditions.

\subsection{Administer General Support Services}

This function includes general administrative support at the MGDS, including records maintenance, engineering, human resources, training, procurement, public relations, and financial accounting.

Outputs:$$
\text { - }
$$

Guidance $\ldots \ldots \ldots \ldots \ldots \ldots \ldots \ldots \ldots \ldots$ Outside 1.4 .2

\subsection{Process Site-Generated Waste}

This function includes preparation and disposal of wastes that are generated at the MGDS site. Site-generated waste includes all forms of waste, including radioactive, hazardous, and non-hazardous wastes. This function includes collecting, storing, sorting, treating, packaging, and disposing of the wastes.

\section{Outputs:}

- Non-hazardous wastes ........................ Outside 1.4 .2

- Non-radioactive hazardous wastes .................. Outside 1.4 .2

- Radioactive (low-level) wastes . ................... Outside 1.4 .2

- Effluents ............................ Outside 1.4 .2

\subsection{Maintain Operating Facilities}

This function includes maintaining MGDS operating facilities, including operating equipment, buildings, and utilities, and preparing casks for return to service.

\subsection{Administer Quality Assurance}

This function includes facilities and equipment to support a QA program which is required for all MGDS quality affecting work.

\subsection{Develop Underground Openings}

This function includes continuing and completing development of underground openings required for MGDS operations and to backfill openings, if required, prior to the start of closure of the repository. This includes performing all operations needed to construct the underground 
openings, to handle excavated rock and backfill materials, and (if required) to backfill underground openings. The time period covered under this function is from the start of waste receipt at the MGDS to the beginning of permanent closure.

\section{Inputs:}

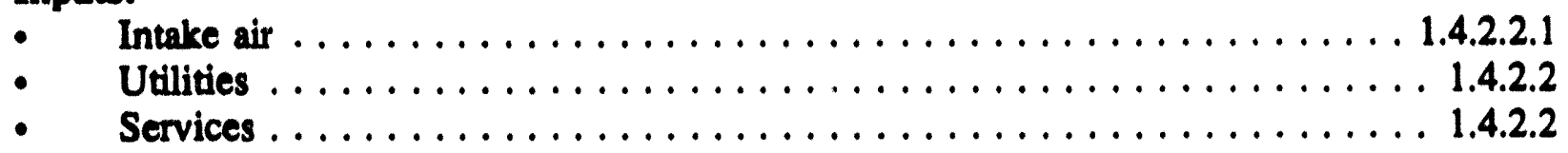

Outputs:

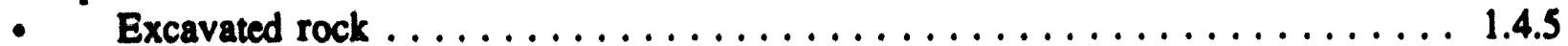

- Heat $\ldots \ldots \ldots \ldots \ldots \ldots \ldots \ldots \ldots \ldots \ldots$ Outside 1.4 .2

- Dust $\ldots \ldots \ldots \ldots \ldots \ldots \ldots \ldots \ldots \ldots \ldots \ldots \ldots$ Outside 1.4 .2

- $\quad$ Noise $\ldots \ldots \ldots \ldots \ldots \ldots \ldots \ldots \ldots \ldots \ldots \ldots \ldots$ Outside 1.4 .2

- Effluents .............................. Outside 1.4 .2

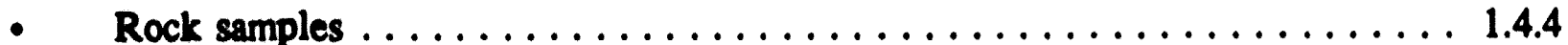

- $\quad$ Exhaust air $\ldots \ldots \ldots \ldots \ldots \ldots \ldots \ldots \ldots \ldots \ldots \ldots \ldots \ldots . \ldots \ldots . \ldots \ldots .2 .1$

\subsubsection{Isolate Waste}

This function includes inhibiting the transport of radionuclides so that amounts and concentrations of this material entering the accessible environment are kept within prescribed limits. It includes initial containment of waste within a waste package, and then, by means of the other engineered and natural barriers, retardation of the movement of any uncontained radionuclides within the geologic setting.

\section{Inputs:}

- Guidance $\ldots \ldots \ldots \ldots \ldots \ldots \ldots \ldots \ldots \ldots \ldots \ldots \ldots \ldots \ldots \ldots . . \ldots \ldots .2 .2$

- Emplacement locations . . . . . . . . . . . . . . . . . . . . . . . .

- Human activity ........................... Outside 1.4 .3

- Natural transport media for radionuclide migration ............ Outside 1.4 .3

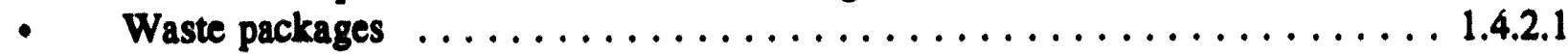

- Engineered barriers $\ldots \ldots \ldots \ldots \ldots \ldots \ldots \ldots \ldots \ldots \ldots \ldots \ldots . .4 .2 .2$

\section{Outputs:}

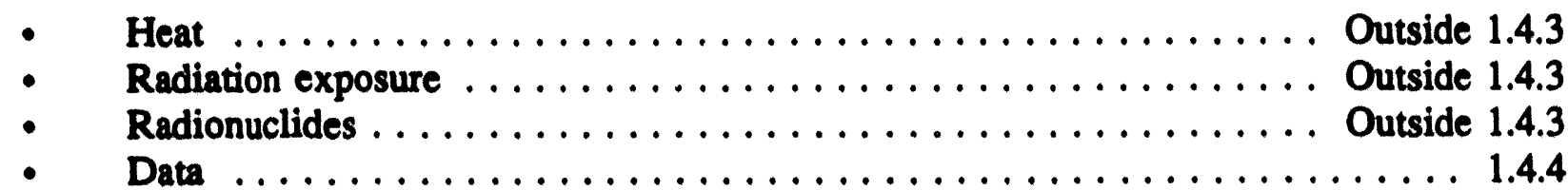

\subsubsection{Evaluate System Performance}

This function includes: estimating the ability of the repository system to comply with regulations governing its preclosure and postclosure performance objectives and its effects on the environment; using the estimates in updates to compliance documents and in support of the continuing development of the system; conducting the performance confirmation and 
environmental monitoring programs needed to supply data for the estimates; and planning for postclosure monitoring of the system. The function starts during site characterization and continues until permanent closure. [10CFR60.140(b)] Provision may be added for post-closure monitoring. Figure C-9 shows the functional decomposition and interfaces associated with the Evaluate System Performance function.

\section{Inputs:}

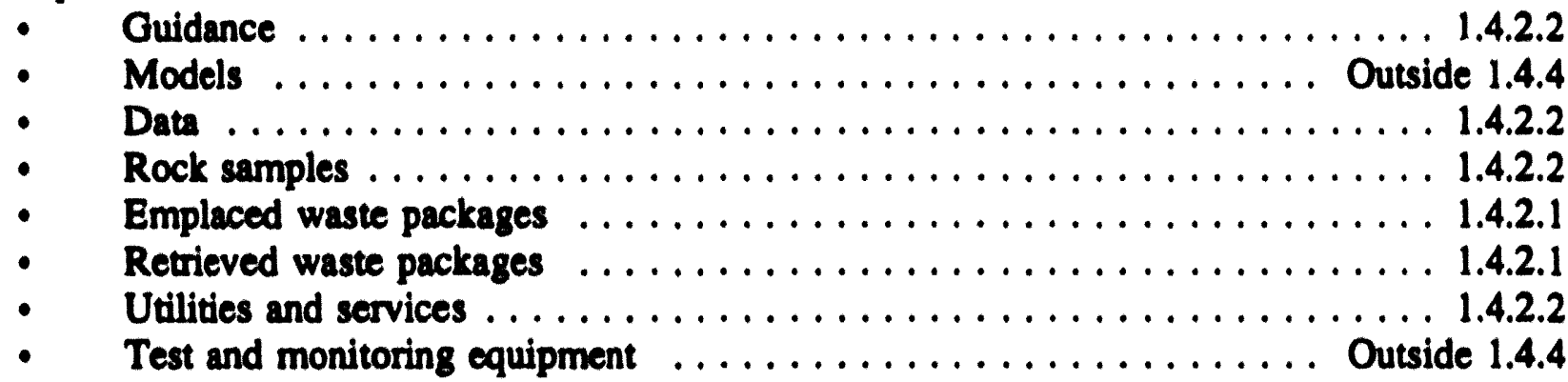

\section{Outputs:}

- Reports and records $\ldots \ldots \ldots \ldots \ldots \ldots \ldots \ldots \ldots$ Outside 1.4 .4

- Migration data $\ldots \ldots \ldots \ldots \ldots \ldots \ldots \ldots \ldots \ldots \ldots$ Outside 1.4 .4

- Containment data $\ldots \ldots \ldots \ldots \ldots \ldots \ldots \ldots \ldots \ldots \ldots$ Outside 1.4 .4

- Updated models ............................. Outside 1.4 .4

- Corrective action guidance $\ldots \ldots \ldots \ldots \ldots \ldots \ldots \ldots \ldots \ldots \ldots \ldots . \ldots \ldots .2 .2$

- Retrieved waste packages $\ldots \ldots \ldots \ldots \ldots \ldots \ldots \ldots \ldots \ldots \ldots . . \ldots \ldots .2 .1$

\subsubsection{Close MGDS}

This function includes permanent closure of the MGDS to human access. This may include final backfilling of all or part of the underground facility (if deemed necessary by analysis and authorized by the license), closing and sealing openings (ramps, shafts, and boreholes), decommissioning surface facilities, reclaiming the site, and establishing institutional barriers. This does not preclude partial backfilling before permanent closure. This function begins upon approval of the license amendment for permanent closure and continues until the last institutional barrier is established and the license is terminated. Figures C-10 and C-11 show the functional decomposition and interfaces associated with the Close MGDS.

\section{Inputs:}

Guidance $\ldots \ldots \ldots \ldots \ldots \ldots \ldots \ldots \ldots \ldots \ldots \ldots \ldots \ldots \ldots \ldots \ldots \ldots \ldots . .2 .2$

- License to terminate ......................... Outside 1.4 .5

- Contaminated facilities $\ldots \ldots \ldots \ldots \ldots \ldots \ldots \ldots \ldots \ldots \ldots \ldots . \ldots \ldots .2 .1$

- Backfill material $\ldots \ldots \ldots \ldots \ldots \ldots \ldots \ldots \ldots \ldots \ldots \ldots \ldots \ldots \ldots . \ldots \ldots .2 .2$

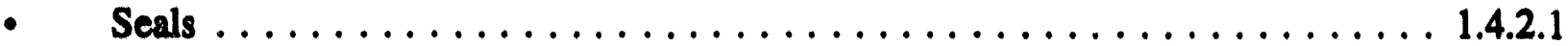

- Utilities and services $\ldots \ldots \ldots \ldots \ldots \ldots \ldots \ldots \ldots \ldots$ Outside 1.4 .5 


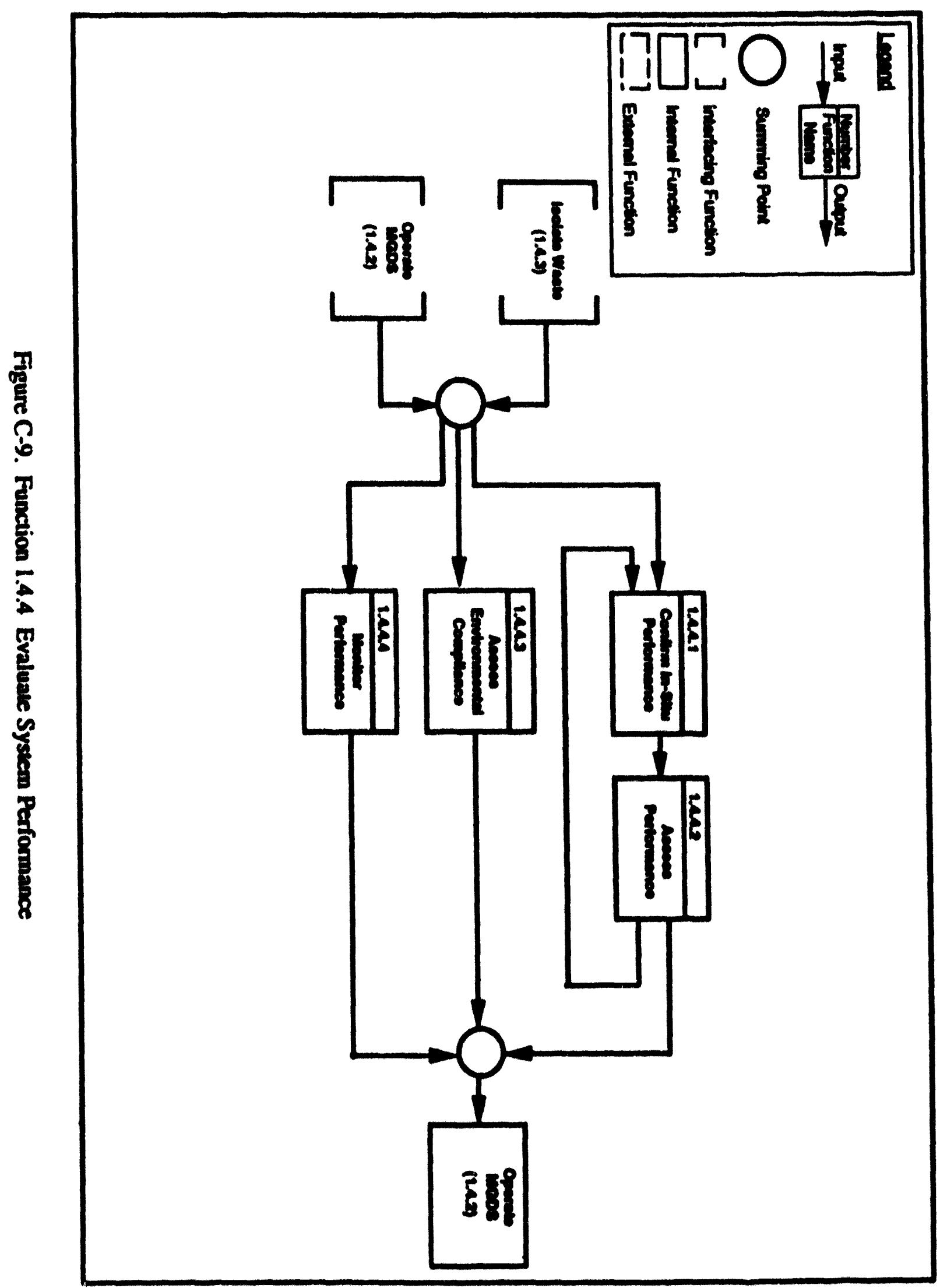

$61-5: 085 d$ 


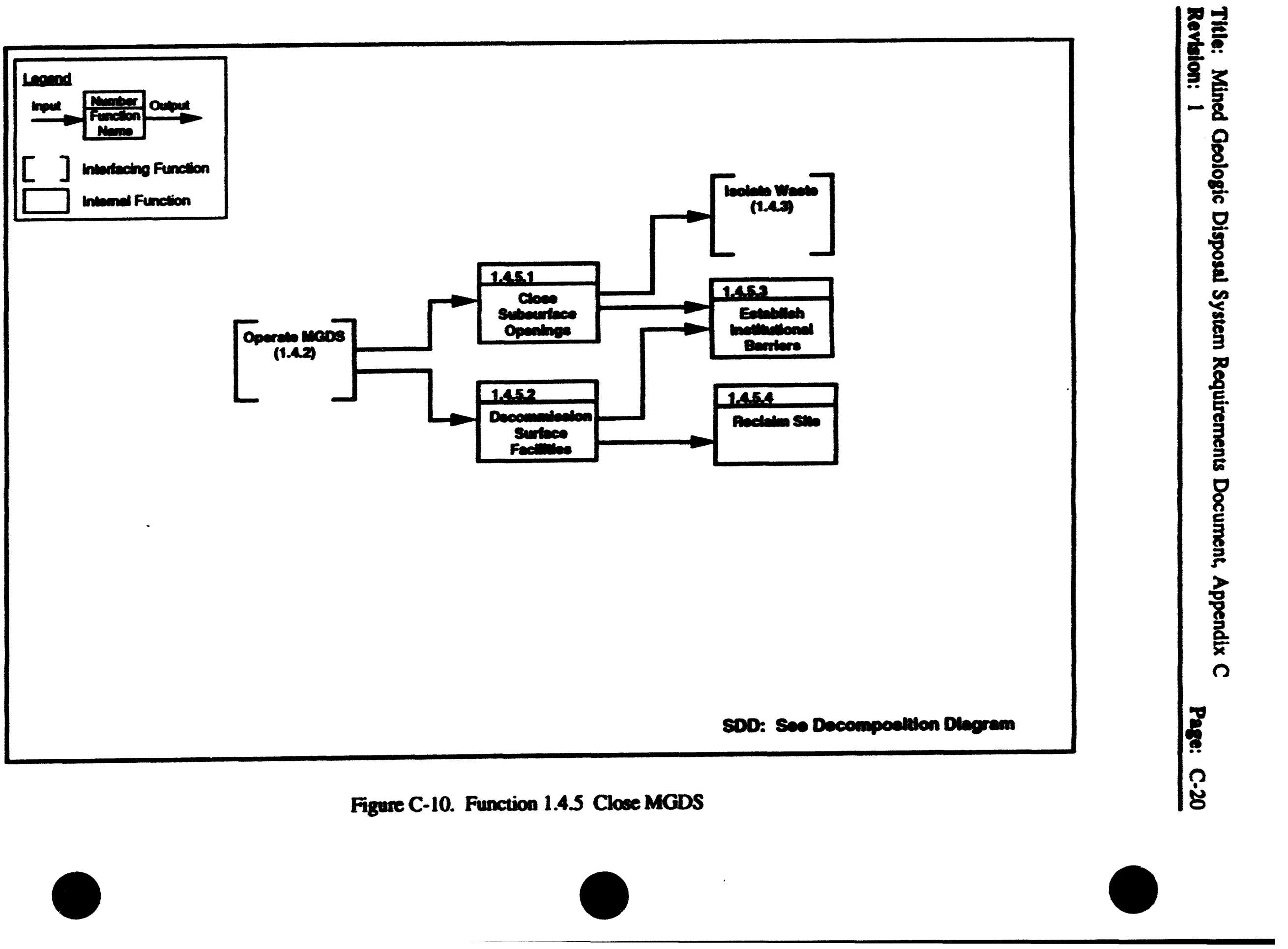


Title: Mined Geologic Disposal System Requirements Document, Appendix C Revision: 1

\begin{tabular}{|c|c|c|c|c|c|}
\hline $\begin{array}{l}\text { Outalde } \\
\text { Dippose of } \\
\text { Waste }\end{array}$ & $\begin{array}{l}\text { - Legal/ } \\
\text { Regulatory }\end{array}$ & $\begin{array}{l}\text { - License } \\
\text { amendment to } \\
\text { terminate } \\
\text { - Utilidies } \\
\text { - Services } \\
\end{array}$ & & & \\
\hline & $\begin{array}{c}\text { Outelde } \\
1.4 .5\end{array}$ & $\begin{array}{l}\text { - Underground } \\
\text { facility with } \\
\text { emplaced } \\
\text { - Baste } \\
\text { - Baclefill } \\
\text { masterial } \\
\text { - Soals } \\
\text { - Guidance }\end{array}$ & $\begin{array}{l}\text { - Contaminared } \\
\text { facilities } \\
\text { - Guidance }\end{array}$ & - Guidance & - Guidance \\
\hline $\begin{array}{l}\text { - Radiation } \\
\text { exposure } \\
\text { - Unsalvago- } \\
\text { able } \\
\text { materials } \\
\text { - Duat } \\
\text { - Noise } \\
\text { - Records }\end{array}$ & -Reports & $\begin{array}{c}\text { 1A.S.1 } \\
\text { Cloce } \\
\text { Underground }\end{array}$ & $\begin{array}{l}\text { - Cloced } \\
\text { underground } \\
\text { openings } \\
\text { - Unneoded } \\
\text { surface } \\
\text { structures }\end{array}$ & & \\
\hline $\begin{array}{l}\text { - Salvaged } \\
\text { marterials } \\
\text { - Unsalvage- } \\
\text { able } \\
\text { materials } \\
\text { - Radiouctive } \\
\text { - Raste } \\
\text { - Radiation } \\
\text { exposure } \\
\text { E Eftuents } \\
\text { : Dust } \\
\text { - Noise } \\
\text { - Records } \\
\end{array}$ & - Reporss & & 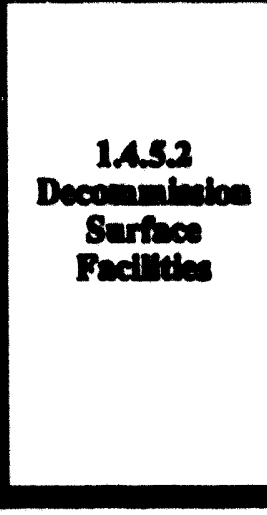 & - Clean sitre & - Clean sice \\
\hline $\begin{array}{l}\text { - Courr } \\
\text { records } \\
\text { - Monuments }\end{array}$ & - Repors & & & 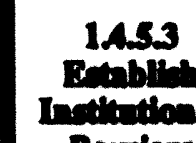 & - Marked site \\
\hline $\begin{array}{l}\text { - Dust } \\
\text { - Noise } \\
\text { - Reclaimed } \\
\text { sibe } \\
\end{array}$ & - Reports & & & & $\begin{array}{l}\text { 1.4.5.4.4 } \\
\text { Reclatum } \\
\text { Site }\end{array}$ \\
\hline
\end{tabular}

Figure C-11. N-Square Chart for Function 1.4.5 Close MGDS

\section{Outputs:}

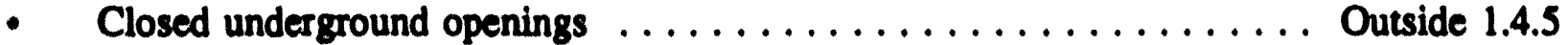

- Clean, reclaimed, monumented site .................. Outside 1.4 .5

- Reports and records ........................ Outside 1.4 .5

- Dust ............................... Outside 1.4 .5

- Noise $\ldots \ldots \ldots \ldots \ldots \ldots \ldots \ldots \ldots \ldots \ldots \ldots \ldots$ Outside 1.4 .5

- Effluents .............................. Outside 1.4 .5

- Salvaged equipment $\ldots \ldots \ldots \ldots \ldots \ldots \ldots \ldots \ldots$ Outside 1.4 .5 
- Salvage materials

Outside 1.4 .5

- Unsalvageable materials

Outside 1.4 .5

- Radioactive waste

Outside 1.4 .5

- Radiation exposure

Outside 1.4 .5

- Court records

Outside 1.4.5

\subsubsection{Close Underground Openings}

This function includes final backfilling of the remaining open operational areas of the underground facility and boreholes after the termination of waste emplacement. It includes removing underground equipment, backfilling underground openings, and the sealing of shafts and ramps.

\section{Inputs:}

- Guidance . . . . . . . . . . . . . . . . . . . . . . . . . . . 1.4.2

- License to terminate .......................... Outside 1.4 .5

- Underground facility with emplaced waste $\ldots \ldots \ldots \ldots \ldots \ldots \ldots \ldots$. $\ldots .2 .1$

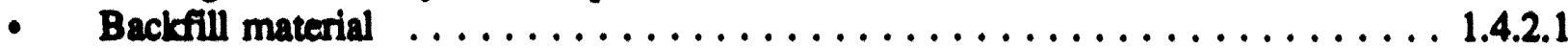

- Seals ............................... Outside 1.4 .5

\section{Outputs:}

- Closed underground openings $\ldots \ldots \ldots \ldots \ldots \ldots \ldots \ldots$ Outside 1.4 .5

- Unneeded surface structures $\ldots \ldots \ldots \ldots \ldots \ldots \ldots \ldots \ldots \ldots \ldots \ldots . . \ldots \ldots .5 . \ldots \ldots$

- Reports and records $\ldots \ldots \ldots \ldots \ldots \ldots \ldots \ldots \ldots \ldots$ Outside 1.4 .5

- Dust ............................... Outside 1.4 .5

- Noise ............................... Outside 1.4 .5

- Radiation exposure ........................ Outside 1.4 .5

\subsubsection{Decommission Surface Facilities}

This function includes the permanent removal from service of surface facilities and components (necessary for preclosure operations only) after repository closure, in accordance with regulatory requirements and environment policies. It includes decontaminating, dismantling, and removing facilities and reclaiming the site.

Inputs:

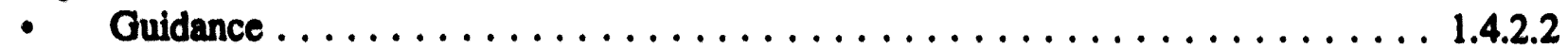

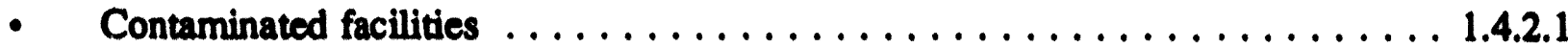

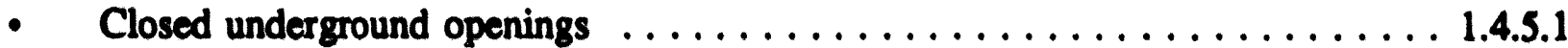

- Unneeded surface structures $\ldots \ldots \ldots \ldots \ldots \ldots \ldots \ldots \ldots \ldots$ 1.4.2.1, 1.4.2.2

\section{Outputs:}

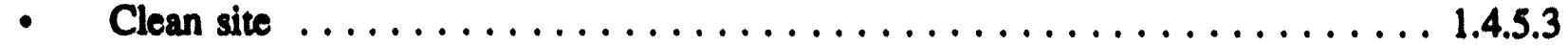

- Reports and records $\ldots \ldots \ldots \ldots \ldots \ldots \ldots \ldots \ldots$ Outside 1.4 .5

- Dust ................................ Outside 1.4 .5

- Noise ............................... Outside 1.4 .5

- Effluents .............................. Outside 1.4 .5

- Salvage materials $\ldots \ldots \ldots \ldots \ldots \ldots \ldots \ldots \ldots \ldots \ldots$ Outside 1.4 .5 
Title: Mined Geologic Disposal System Requirements Document, Appendix C Revision: 1

Page: C-23

- Unsalvageable materials $\ldots \ldots \ldots \ldots \ldots \ldots \ldots \ldots \ldots \ldots$ Outside 1.4 .5

- Radioactive waste $\ldots \ldots \ldots \ldots \ldots \ldots \ldots \ldots \ldots \ldots$ Outside 1.4 .5

- Radiation exposure ........................ Outside 1.4 .5

\subsubsection{Establish Institutional Barriers}

This function includes establishing active and passive institutional controls for restricting access and avoiding disturbance in the MGDS controlled area and minimize or prevent intentional and unintentional activities in and around the MODS that could breach the barrier systems for at least 1,000 years.

Inputs:

- Guidance $\ldots \ldots \ldots \ldots \ldots \ldots \ldots \ldots \ldots \ldots \ldots \ldots \ldots \ldots \ldots \ldots \ldots . \ldots \ldots .2 .2$

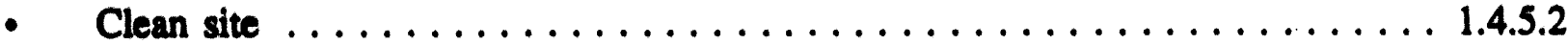

- Monuments ............................. Outside 1.4 .5

\section{Outputs:}

- Clean, monumented site $\ldots \ldots \ldots \ldots \ldots \ldots \ldots \ldots \ldots \ldots \ldots . \ldots \ldots . \ldots \ldots . . \ldots \ldots$

- Reports and records ......................... Outside 1.4 .5

- Court records ............................ Outside 1.4 .5

\subsubsection{Reclaim Site}

This function includes actions taken to restore the MGDS site to as close as practicable to its original undisturbed condition.

\section{Inputs:}

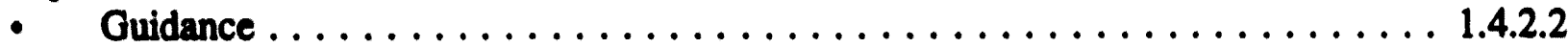

- Clean, monumented site $\ldots \ldots \ldots \ldots \ldots \ldots \ldots \ldots \ldots \ldots \ldots \ldots . .4 .5 .5 .3$

\section{Outputs:}

- Clean, reclaimed, monumented site $\ldots \ldots \ldots \ldots \ldots \ldots \ldots$ Outside 1.4 .5

- Reports and records $\ldots \ldots \ldots \ldots \ldots \ldots \ldots \ldots \ldots$ Outside 1.4 .5

- Dust $\ldots \ldots \ldots \ldots \ldots \ldots \ldots \ldots \ldots \ldots \ldots \ldots$ Outside 1.4 .5

- Noise $\ldots \ldots \ldots \ldots \ldots \ldots \ldots \ldots \ldots \ldots \ldots \ldots \ldots$ Outside 1.4 .5 
Title: Mined Geologic Disposal System Requirements Document, Appendix C Revision: 1

Page: C-24

INTENTIONALLY LEFT BLANK 


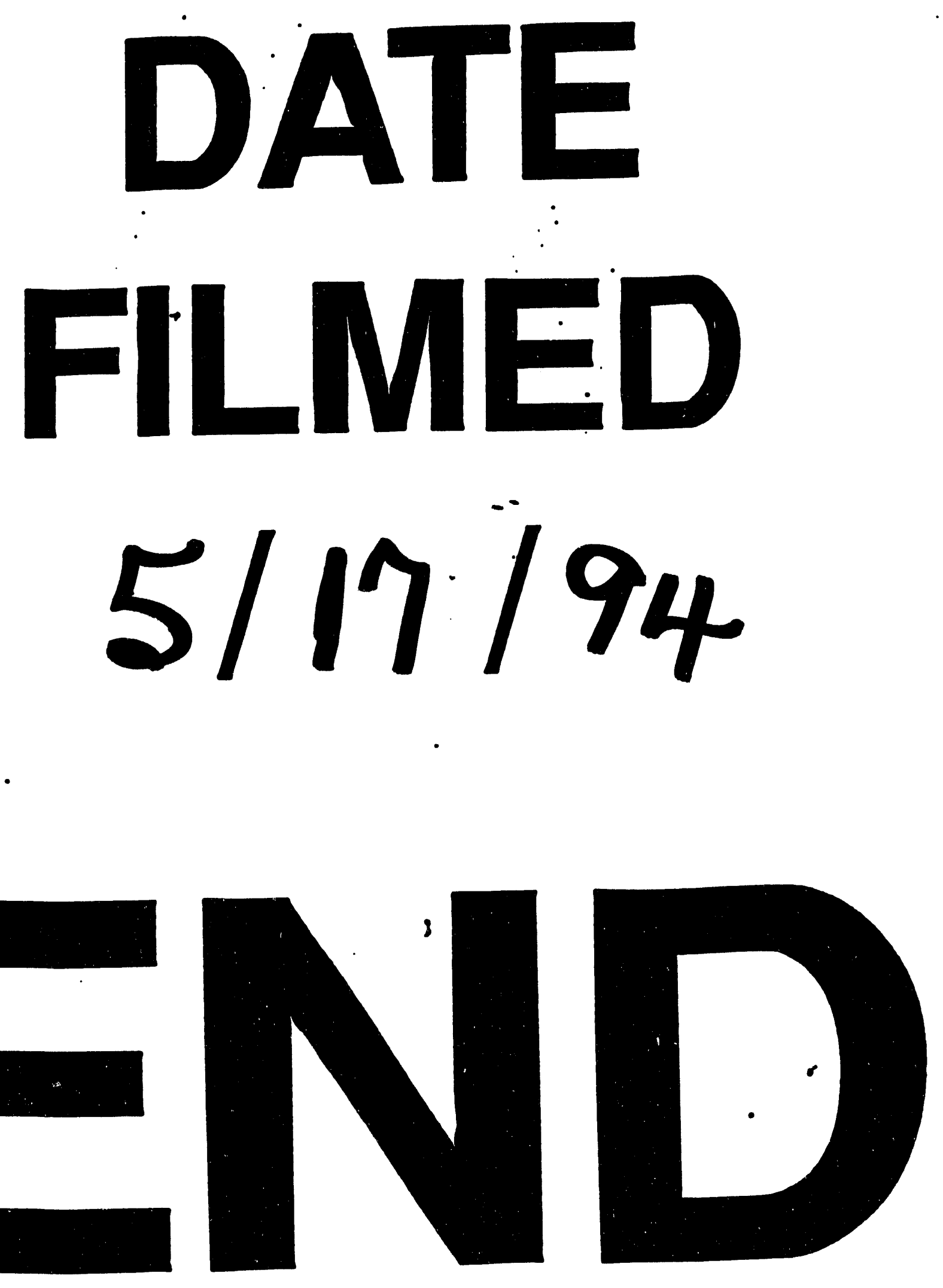


